THE CENTURY OF THE CHILD: THE MENTAL HYGIENE MOVEMENT AND SOCIAL POLICY IN THE UNITED STATES AND CANADA

\author{
by \\ THERESA MARIANNE RUPKE RICHARDSON \\ B.F.A. Univeraity of California Berkeley, 1967
}

\begin{abstract}
A THESIS SUBMITTED IN PARTIAL FULFILMENT OF THE REQUIREMENTS FOR THE DEGREE OF DOCTOR OF PHILOSOPHY
\end{abstract}

in

THE FACULTY OF GRADUATE STUDIES

Social and Educational Studiea

We accept thie theele as conforming

to the required etenderd

THE UNIVERSITY OF BRITISH COLUMBIA

Novomber 1987

a Therese Merianne Rupke R1chardson, 1987 
In presenting this thesis in partial fulfilment of the requirements for an advanced degree at the University of British Columbia, I agree that the Library shall make it freely available for reference and study. I further agree that permission for extensive copying of this thesis for scholarly purposes may be granted by the head of my department or by his or her representatives. It is understood that copying or publication of this thesis for financial gain shall not be allowed without my written permission.

Department of Social and Educational Studies

The University of British Columbia

1956 Main Mall

Vancouver, Canada

V6T 1 Y 3

Date 7 eleraen 1987 


\section{Abstract}

The purpose of this study is to examine the dynamios between professional knowledge and the power to construct sacial realities. The focus la on the institutions which contributed to mental hygiene as a protocol for public policies directed toward children. The social history of the child in the twentieth century is juxtaposed with shifts in the configurations of private and public institutions in a sociology of mental illness.

The mental hygiene movement created one of the twentieth century's major paradigms. Mental hygiene was conceptualized as the development of a science of promoting mental health and preventing mental illness. The working premise of the movement was that early life experiences determined adult competence and constituted the root cause of major social problems from crime and dependency to labour unrest and war. The National Committee for Mental Hygiene was established in the United States in 1909 and a second National Committee was established in Canada in 1918. Mental hygienists developed an ideology of child oriented prevention in public health, welfare and educational policies which legitimated public intervention into the private spheres of family relations and child rearing.

The idea of mental hygiene was based on a medical model and as such it was part of the new paychiatry and public health movements of the Progressive Era. As a paradigm mental hygiene fostered the identification of children according to scientific standards. Mental hyglene contributed to the transformation of 
juvenile delinquency into a psychiatry of maladjustment in childhood. As a positivistic approach to public health, mental hygiene research elaborated criteria to determine age related stages of normal psychological and biological progress.

Mental hygiene was a product of professional researchers and policy makers. The knowledge base of mental hygiene grew with the expansion of higher education in the United States especially In regard to sclentific medicine. The medical model was subsequently applied to research in the behavioural and social sciences. Scientific philanthropy provided funds for research, professional education, and the distribution of knowledge. The accumulation of monetary resources by nineteenth century entrepreneurial capitalists, who applied these funds to further the growth of scientific models, were a sustaining factor in twentieth century mental hygiene.

The agents of power described as part of the mental hygiene movement include: 1) the National Committees for Mental Hygiene in the United States and Canada: and, 2) general purpose foundations in Rockefeller related philanthropy and the Commonwealth Fund. By mid-century, the federal, atate/provincial and local governments of the United States and Canada had assumed major aspects of the former role of the National Committees and philanthropy in mental health advocacy.

The theoretical foundation of mental hygiene evolved in conjunction with the development of the scientific method as applied to preventive medicine, especially in fields related to 
poychlatry. Mental hygiene was a primary carrier of the medical model into applied disciplines in the social and health sciences. The professionalization of education, social welfare and psychology, as imbued with mental hygiene, translated technological change into revised concepts of public and private spheres in relationship to family and child life.

The medicalization of human differences limited the potential for radical revisions in social organization. It justified unequal access to political and economic power on the basis of psychological and biological characteristics. The mental hygiene paradigm served to maintain established social configurations in the face of social change. The function of justifying inequalities was especially important in the United states but lese so in Canada for reasons of the timing of nationbuilding, national history, character, and culture. 
TABLE OF CONTENTS

INTRODUCTION: CENTURY OF THE CHILD.............

PART I

THE BODY: Science And The Medical Model

Chapter

I. THE CHILDHOOD GAZE And The spirit of JOHNS HOPKINS..................... 20

II. THE MIDAS TOUCH: Philanthropy And The Power of science..................... 55

III. MENTAL HYGIENE: A Biography of The

National Committees................ 106

PART II

THE MIND: Paradigms of Childhood

IV. THE DEVIANT CHILD AND PSYCHIATRY: The Invention of A Mental Hygiene of Childhood........................ 165

v. U.S. CHILD GUIDANCE DEMONSTRATIONS:

Hedicalizing Maladjustment........... 207

VI. MENTAL HYGIENE IN CONTEXT: Eugenics And Preventive Psychiatry In Canada...... 268

VII. TRANSITIONS TO A MENTAL HYGIENE OF NORMAL DEVELOPMENT: From Monmouth County To Toronto........................... 301

VIII. INFANCY TO ADOLESCENCE: Rockefeller Philanthropy And The Paradigm of Normality...................... 356

\section{PART III}

THE ESTATE: The Legacy of The Paradigm

IX. INSTITUTIONALIZING THE MENTAL HYGIENE

X. PR CHILDHOOD .... . . . . . . . . . .

XI. CONSERVATISM AND PROGRESS............ 493 


\section{ACKNOWLEDGEMENTS}

I wish to express my gratitude to Donald Fisher, chair of my supervisory committee, for his guidance, oritical commentary, and unwavering support. I would like to thank Neil sutherland for his insightful critiques and encouragement. I am also indebted to Maryin Lazerson for his constructive comments at every stage of this dissertation. His contribution to my intellectual growth has been substantial. A special remembrance and tribute is also due to the late historian of Canadian curriculum, George S. Tomkins (1920-1985). His encouragement at an early stage of this research was timely, and his wise counsel proved timeless. I would like to thank R.S. Ratner, A.C.L. Smith, R.H. Rodgers and C.E. Strickland for their careful reading of the manuseript and provocative questions. The Department of Social and Educational studies provided a forum for learning of the highest quality. I would especially like to thank Professor J. Donald Wilson.

This research owes much to the expert assistance of the staffs of the U.B.C. and University of Toronto Libraries, the Rockefeller Archive Center, Cornell Medical Center Archives, Public Archives of Canada, and the Griffin-Greenland Archives.

My family provided the sustenance which gives birth to scholarship. To my husband, John, as friend, critic, editor, and teacher unparalleled, a word of special appreciation for his uncompromising love and support. Most important, my daughters, Genevieve, Anne and Nicole taught me lessons of the heart beyond words. 


\section{INTRODUCTION}

\section{Century of the Child}

Now along comes science, which has illuminated so many things in this age of efficiency, and throws light into the dark places of age-long customs. We may expect that many errors will be disclosed and as they are and the faulty practices which grew out of them corrected there will result a better society. 1

The twentieth century was ushered in as the century of the child. 2 The mental hygiene movement combined nineteenth century child saving and preventive medicine with the idea of the scientific promotion of mental health in children. This prescription for solving social problems became one of the major paradigms of this century. 3 The paradigm originated with the premise that fundamental aspects of soclal disorder such as war, crime, poverty, adult dependency, social unrest and insanity could be eliminated if adult problems were prevented by perfecting the physical and mental well being of children. Mental hygiene became the ideological momentum behind the transformation

1. William A. White. The_Mental_Hygienge_of Chilidhogod (Boston: Litt19 Brown and Co.. 1919, reprint 1923), p. 190.

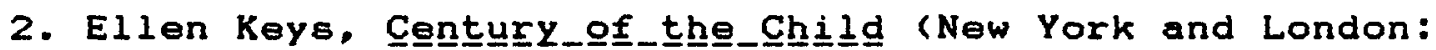
G.P. Putnam's Sons, 1909), seven English editions and twenty European editions appeared by 1912; Peter B. Neubauer, "The Century of the Child," in Charles Rolo. PEyghiatryy_in_Ameriegan Lifie (Freeport, N.Y: Books for Libraries Press, 1971), pp. 133-41.

3. Thomas S. Kuhn defined paradigms as "universally recognized scientific achievements that for a time provide model problems and solutions to a community of practitioneers," The

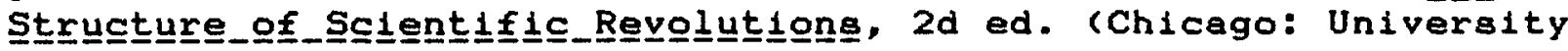
of Chicago, 1962,1970 ), p. vi11. 
and medicalization of child life in this century. 4 It was one of the underlying rationales that defined the parameters between public and private spheres which structured growing up in the United States or Canada.

The subjects of this study are the interrelated National Committees for Mental Hygiene in the United States and Canada and the American general purpose philanthropies which supported the mental hygiene movement in the twentieth century. It is an historical and sociological inquiry into the relationship between the accumulation of authority to legitimate ideas on normality and abnormality, and, the process of institutionalizing these ideas in public practices. As a paradigm which defined normal and abnormal childhood, mental hygiene served as a mechanism for structuring social change which shaped the transformation of child life. Mental hygienists developed a working hypothesis for advancing social progress by scientifically studying the young. Needless to say, mental hygiene was not successful in fulfilling its original objectiver in eliminating social disorders by way of perfecting mental health. Poverty. crime, mental illness and adult dependency did not disappear with the advent of preventive child psychiatry or modern child rearing practices. In spite of this fact, as an ideology, mental hygiene was enormously succeseful in spreading a conceptual framewark as a protocol for social policy directed at children. The ideology

4. Sol Cohen, "The Mental Hygiene Movement: The Development of Personality and the School, The Medicalization of Education."

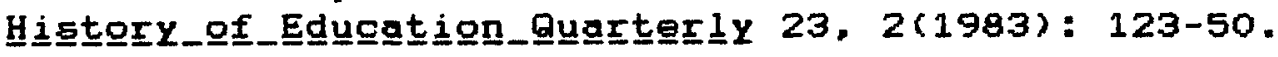


was most successful in contexts where it complemented existing systems of social values. Partly for this reason, the movement had a greater impact in the United States than in Canada.

The origins of mental hygiene, as a set of related ideas, coincided in the United States and Canada. Yet, the outcomes and policies differed. The relatively more conservative canadian perspective found the psychiatric orientation inherent in mental hygiene less compatible with its own traditional values than did the United States. 5 However, the interaction between preventive psychiatry. public health and children's policy was equally complex.

The relationship between power and knowledge in mental hygiene in the United States can be seen as a process involving the rationalization of preexistent social configurations. Mental hygiene served to unify and justify the contradictory nature of liberal reform in U.S. society. As an optimistic, deterministic and individualistic ideology, mental hygiene wedded the two sides of progressivism: social engineering and humanism. Mental hygiene restructured these issues into a prescription for intervention into child and family 1 ife which continues to contribute to the rationale justifying contemporary social policy.

This study is grounded in the questions and dilemmas of revisionist social historians of the past two decades. The

5. See Seymour Martin Lipset's discussion of Canadian and American values: "Historical Traditions and National Characteristics: A Comparative Analysis of Canada and the United

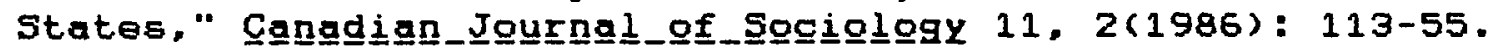




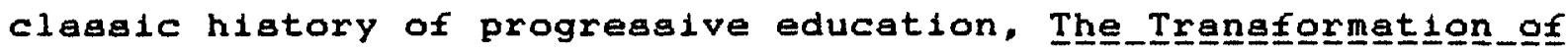

The_schogl, by Lawrence Cremin, documents the recasting of

American schooling in the twentieth century. 6 Mental hygiene was

an important aspect of progressive education. 7 There were

staggering changes in American and Canadian societies between

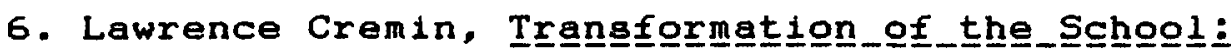

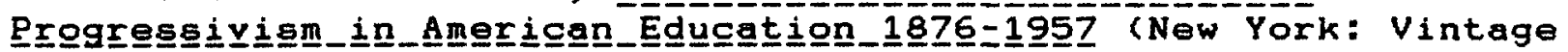

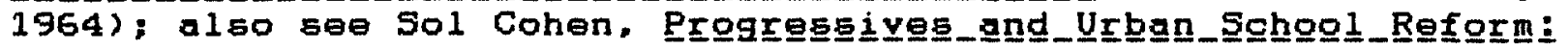

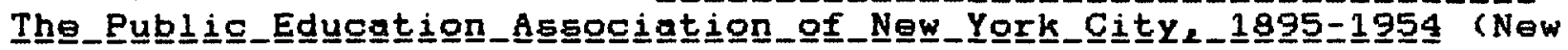
York: Teachers College Columbia Univ. 1964); Geraldine Joncich

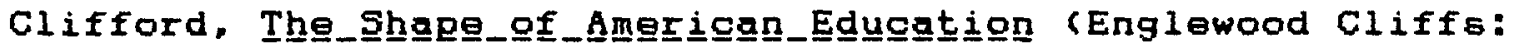

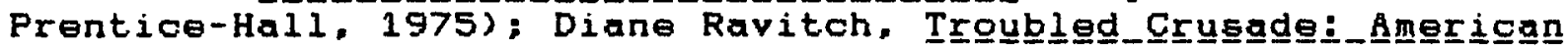

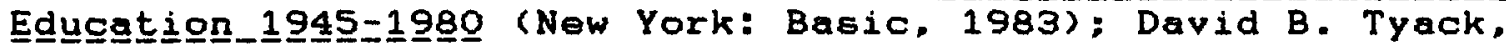

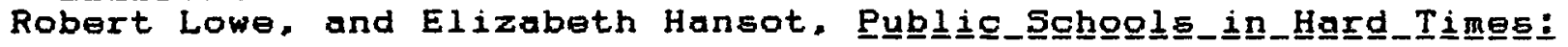

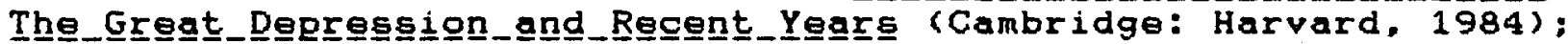
David B. Tyack and Elizabeth Hansot, Manggers_of_Virtúteg_Public

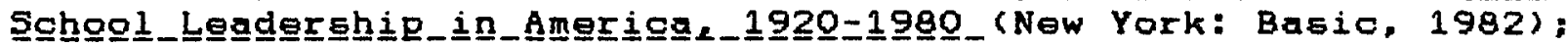
on Canada see: $J$. Donald Wilson. Robert $M$. Stamp and Louis-

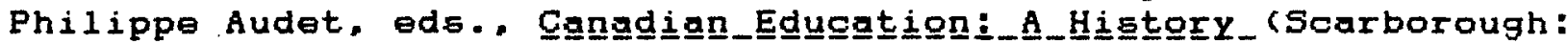

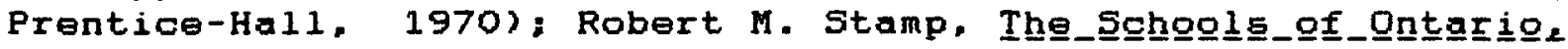
1므므느그 (Toronto: Univ. of Toronto. 1981); George S. Tomkins,

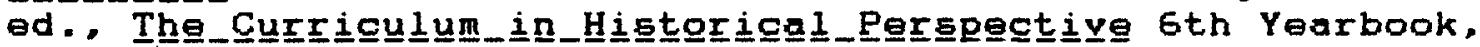
Vancouver: Canadian Society for the Study of Education, 1979; David/C. Jones, Nancy M. Sheehan, and Robert M. Stamp, eds..

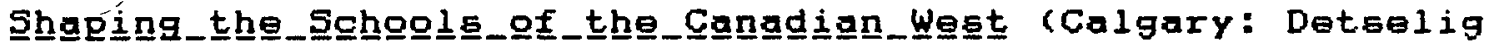
Enterprises Ltd.. 1980): J. D. Wilson and David C. Jones, eds.,

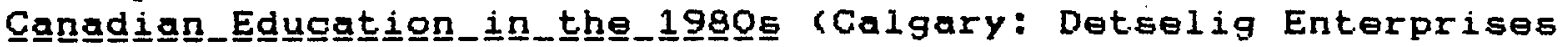
Ltd., 1981); J. Donald Wilson. An_Imperfect_Pagti_Education_and

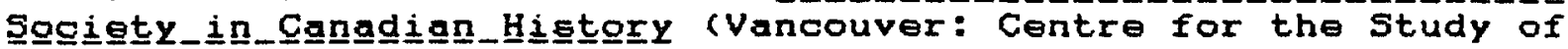
Curriculum and Instruction, Univ. of British Columbia, 1984); Nancy M. Sheehan, J. Donald Wilson, and David C. Jones, eds.,

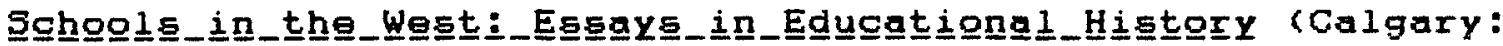
Detselig, 1986 ).

7. Sol Cohen. "The School and Personality Development:

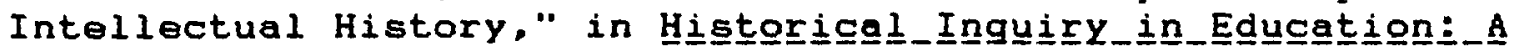
Reseeㅡㄷㅡ. Agende, ed. John Best (washington D.C.: AERA, 1983), pp. 109-37; "The Mental Hygiene Movement: The Development of Personality and the School. The Medicalization of American

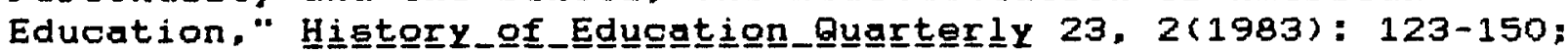

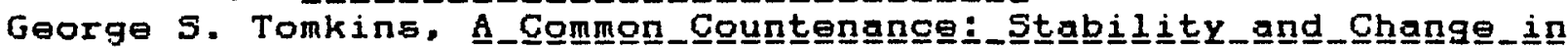

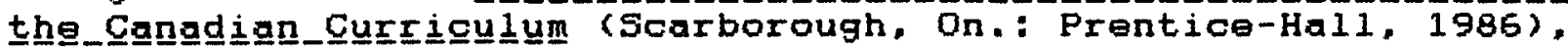
pp. 177-88; also two earlier manuscripts by Tomkins, "Medicalizing the Curriculum: The Heyday of Experimentalism," and "Early Experimentalism in the Schools," 1983, (typescript). 
1880 and 1950. Schools and courts flgured prominently in changea effecting children's lives. As schooling became universal, curriculum was diversified, children were screened for mental and physical defects, specialists were trained to guide children toward the best possible future. This time frame also encompassed the proclamation of child protective legislation, the creation and expansion of juvenile court systems and child guidance clinics. 8 Scholars have offered various interpretations on the motives behind and outcome of social reformism directed toward children. The reconceptualization of public responsibility toward

8. See for example: Marvin Lazerson. "Urban Reform and the Schools: Kindergartens in Massachusetts, 1870-1915," Hisstorgy_of

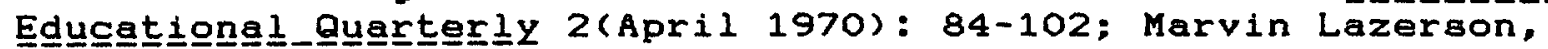

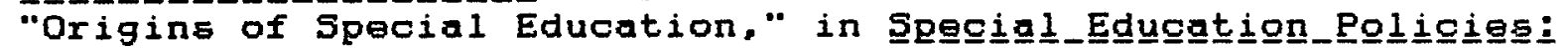

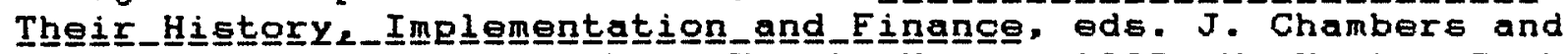
W. T. Hartman (Philadelphia: Temple Univ., 1983; W. Norton Grubb

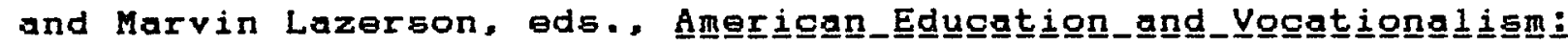

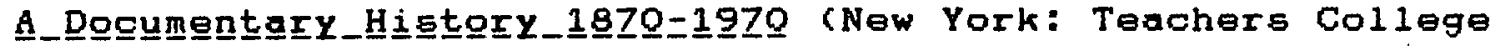
1974); W. Norton Grubb and Marvin Lazerson, "Rally 'Round the Workplace: Continuities and Fallacies in Career Education,"

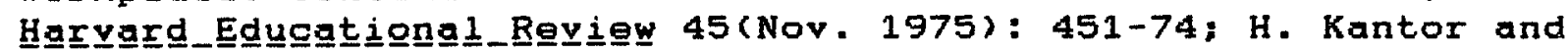

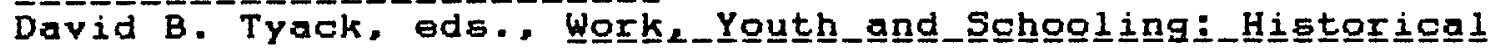

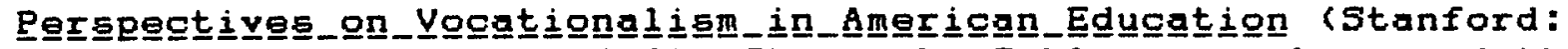
Stanford Univ. Pres5, 1982): Steven L. Schlossman, Love_angetthe

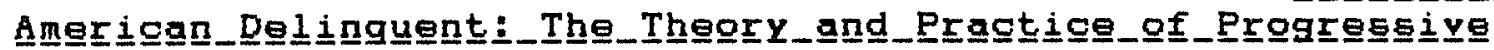

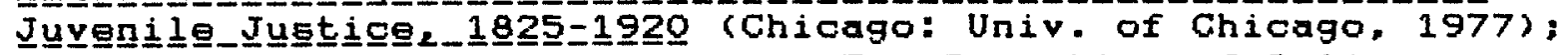

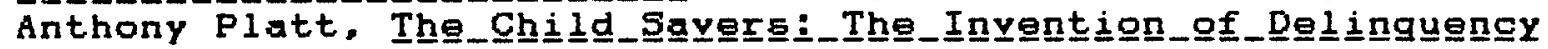

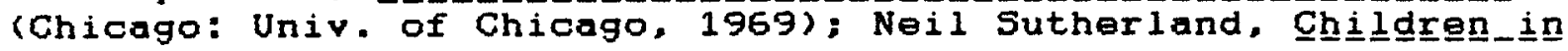

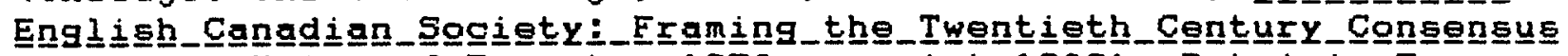
(Toronto: Univ. of Toronto: 1976, reprint 1982); Patricia T.

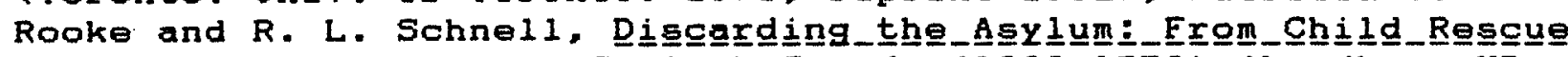

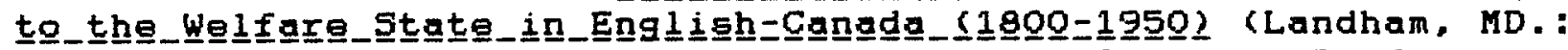
Univ. Press of America. 1983); Norah Lewis. "Physical Perfection for Spiritual Welfare: Health Care for the Urban Child, 1900-

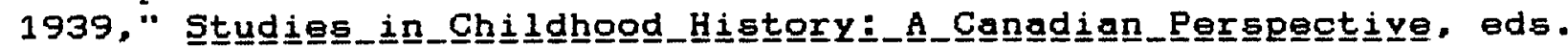
Patricia T. Rooke and R.L. Schnell (Calgary: Deteelig, 1982), pp. 135-66; Veronica Strong-Boag, "Intruders in the Nursery:

Childcare Professionals Reshape the Years One to Five, 1920-

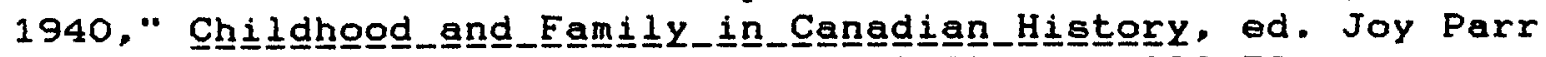
(Toronto: MeCleliand and Stewart, 1982), pp. 160-78. 
children in this century has resulted in an equivocal record. 9 The character of Progressive Era child saving is not agreed upon by historians. Anthony Platt called into question the juvenile court movement on the basis of its negative effect on children. Platt also pointed out the class based motives of supposedly benevolent reformers. Other interpretations have viewed the early decades of the twentieth century as reaching a consensus based on a genuine concern over child welfare which largely succeeded in improving the life chances of poor and disadvantaged children. 10 Public health activities are generally seen as more successful and less complicated by motivational issues or unintended consequences than other aspects of Progressive Era social

9. See W. Norton Grubb and Marvin Lazerson, Broken_P Promiseg

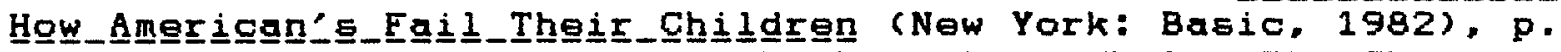
97: Viviana Zelizer. Prí

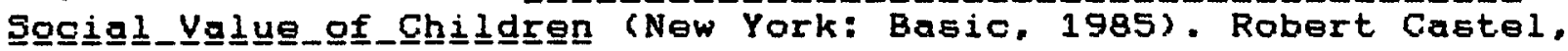
Francoise Castel and Anne Lovell have observed that "childhood has attracted the attention of all the professions that specialize in suspicion." The_PEyghigtarig_sogiety trans. Arthur Goldhammer (New York: Columbia, 1982), p. 202; Joseph Goldstein. Anna Freud, Albert J. Solnit and Sonja Goldstein. In__thhe_BEgest

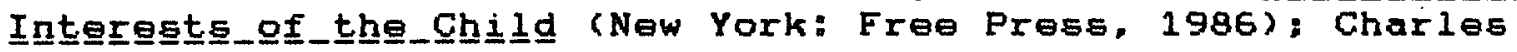
Strickland, "The Rise and Fall of Childhood in the Twentieth

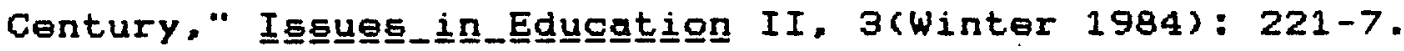

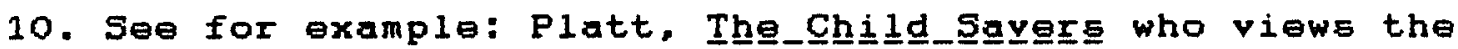
child savers as self-motivated and largely concerned with social

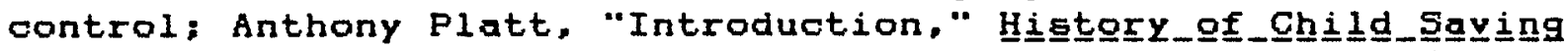

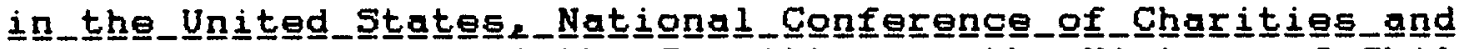

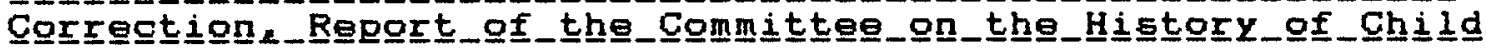

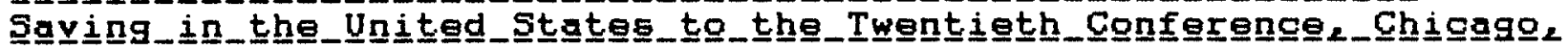
Junnes 1893 (Montclaire, N.J.: Patterson Sith, 1892, reprint

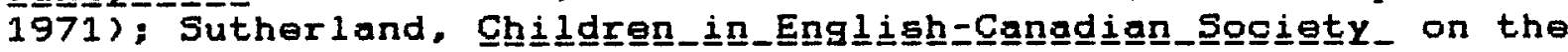
other hand places mental hygiene with its eugenical overtone as an exception to the generally positive nature of child oriented reforms, see ch. 5; Rooke and Schnell, Dígearding also tend toward this latter view; R.L. Schnell, "Childhood Rescued and

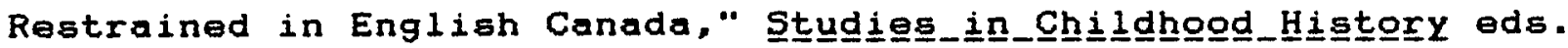
Rooke and Schnell, pp. 204-12. 
reforms. 11 This perception is generally grounded in a narrow definition of public health primarily as concerned with outbreaks of communicable diseases and reducing mortality rates. Broadly defined public health not only includes "maternal and child health and welfare," but "nursing, social work, the social sciences, and paychiatry." 12 Mental hyglene 1a inseparable from public health reform. As George Rosen points out, public health and psychiatry are closely interwoven both historicaliy and in terms of the more recent trend toward community-oriented services. 13

Since 1960, there has been an increased interest in the history of the mentally 111. This corresponds to research in related areas of revisionist history which has looked at the development of modern institutions. Social historians have turned to topics previously considered mundane in family studies, childhood history, education, public health and social welfare. Historical research into mental hygiene tended to focus on the

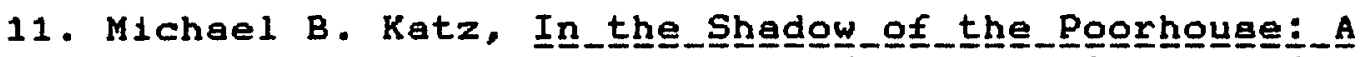

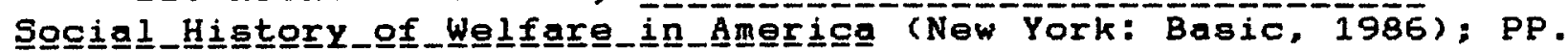
137-45; Walter I. Trattner, Ergom_Egor_Law_to_weltagre_statei_A

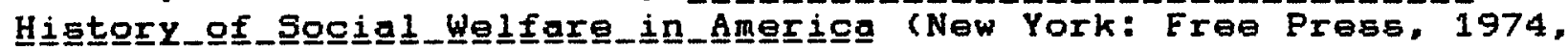

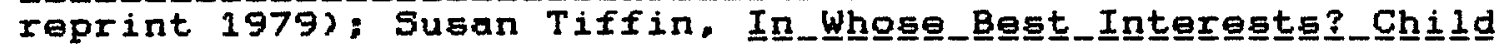

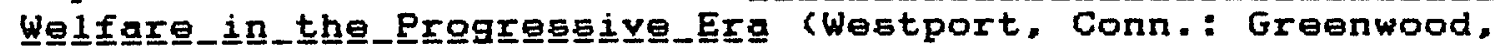
1982): Lela B. Costin. Two_sígters_for_Sogial_Justigei_A

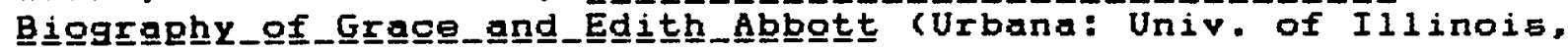
1983): S. Josephine Baker, Fighting_fol_Lifé (New York: Mackilian, 1939).

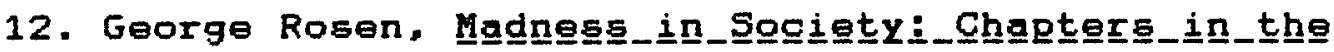

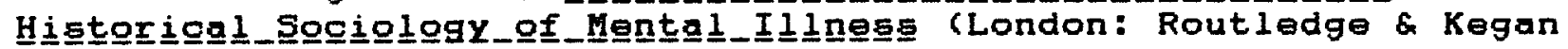
Paul, 1968), pp. 263-3.

13. Rosen, pp. 263-328. 
insane. Up to 1960 the history of madness was largely without

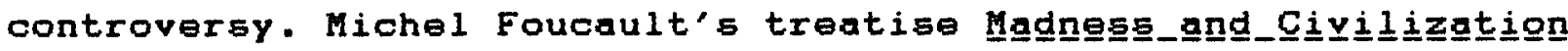
contributed to a rethinking of earliex sequential models of progress and the treatment of mental illness as a part of that progress. 14 Foucault juxtaposed the development of modern concepts on the identification and treatment of mental illness with the rise of modern medical ideologieg and relationahipg of power in social configurations. 15

Public pexceptions of what is normal and abnormal have shaped psychiatry and psychiatric practice. Madness, as a form of social deviance, takes various forms in different societies. Abberant behaviour or thought is a matter of accepted concepts of normative behaviour. Mental illness is more of a social construct and less vertfiable on an empirical or biological level than physical illness. Early peychiatrists, called alienists, were keepers of institutions, not doctors. The superintendency of an asylum was a political appointment whose prestige was allocated. These alienists-superintendents had higher prestige than medical doctors in the nineteenth century. By the end of the century, redicine was in the process of achieving professional status on the grounds that doctors possessed unique access to specialized

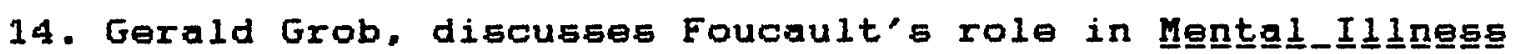

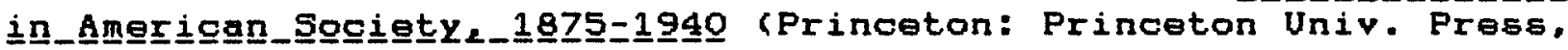
$1983)$, p. 412 .

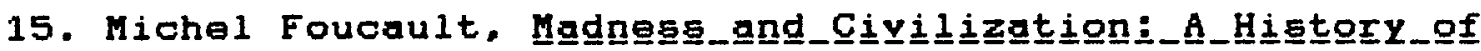
Inssanity_in_thㅡ_Age_of_Regeson trans. Richard Howard (New York:

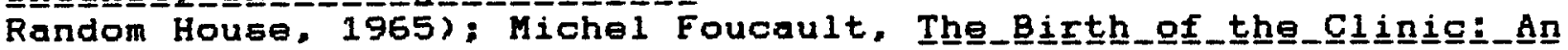
A드트이이﹎of_Medi York: Random House, 1975). 
scientific knowledge. The success of the new medical model

reversed the traditional status order. Asylum psychiatrists began to look to medical science as a model for their own

discipline. 16 The mental hygiene movement coincided with the professional transition of paychiatry from politica to medicine, and from asylums, to general hospitals.

Mental hyglene had a broad-based and multidisciplinary influence. 17 In spite of the concentration by social historians on social movements, the mental hygiene movement has received relatively little scholarly attention in the United States. It has received even less attention in Canada. 18 Jacques M. Quen

16. Sander L. Gilman, "The Struggle of Psychiatry with

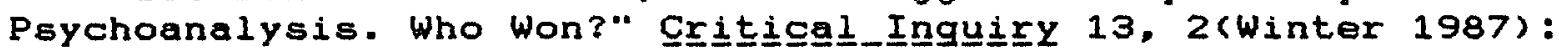
293-313.

17. Sol Cohen, "The Mental Hygiene Movement and the Development of Personality: Changing Conceptions of the American College and University," Hi 2(1982): 65-101; Jacques M. Quen, "Asylum Psychiatry, Neurology

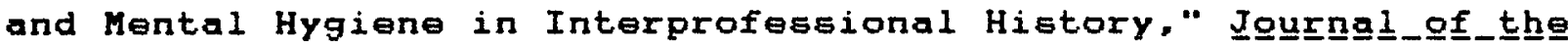

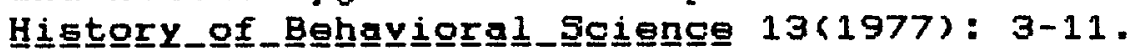

18. The main work is the autobiography which kicked of the

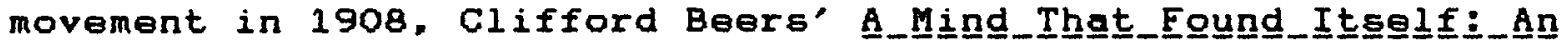

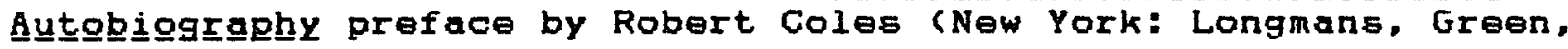
1907, reprint Pittsburgh: University of Pittsburgh Press for the American Foundation for Mental Hygiene, 1981); also. Earl D.

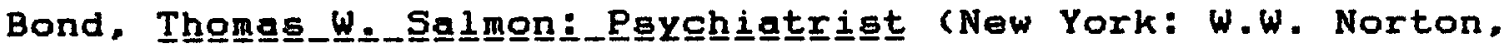

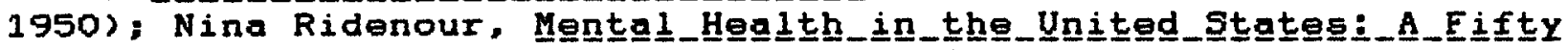
Year Hiㅌtorg (Cambridge: Harvard Univ. Press for Commonwealth

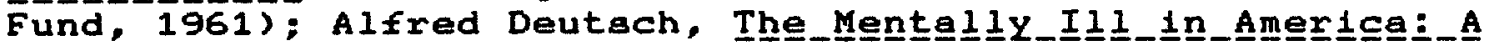

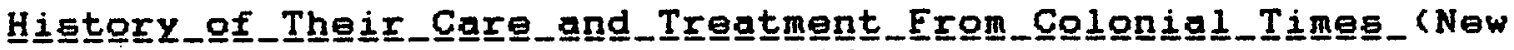
York: Doubleday, Doran 6 Co.. 1937). All of the above are more or less in-house histories with the exceptions. Norman Dain's

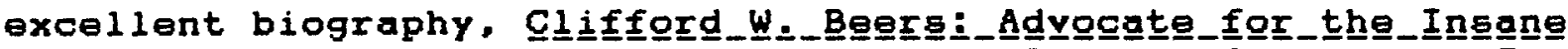
(Pittsburgh: Univ. of Pittsburgh, 1980); Barbara Sickerman, The

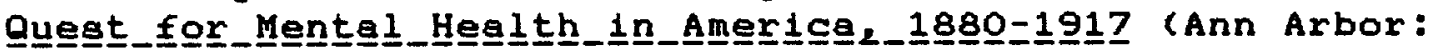
Michigan, 1967; Fred Matthews, "In Defense of Common Sense: Mental Hygiene $A s$ Ideology and Mentality in Twentieth-Century America," ProgsgegtEg 2(Winter 1979): 459-516; Kathleen 
has argued that mental hyglene was an interdisciplinary phenomena and should be examined from an integrated perspective in order to capture the interdependency of its disciplinary statuses. 19

The social perception of children has been altered along with changes in the structure of family life. 20 The seminal work

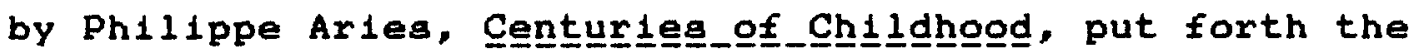
proposition that childhood is a social category of relatively modern origin. 21 American sociologist, W.I. Thomas, in one of the first sociological works on childhood, stressed what he called "the definition of the situation" which shaped the

McConnachie, "The Mental Hygiene and Eugenics Movement in the Inter-War Years." paper presented at the History of Education Association Meetings, Vancouver, B.C., October 1983.

19. Quen, "Asylum Paychlatry."

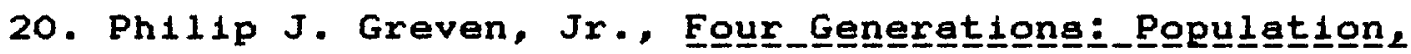

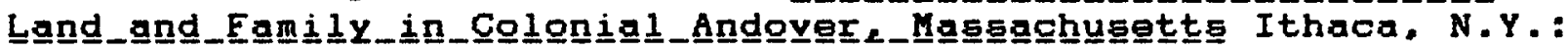

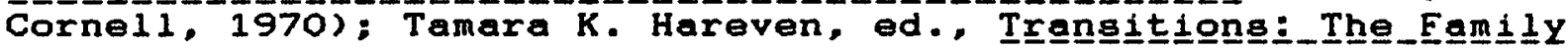

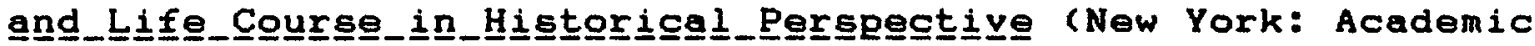
Press, 1978); Tamara K. Hareven, "Modernization and Family History: Perspectives on Social Change," Signe 2(Autumn 1976):

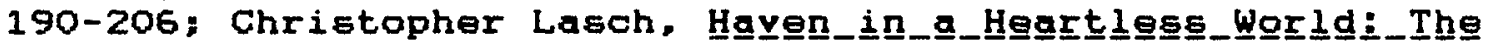
Eamilily_Begsiegged (New York: Basic. 1977); Michael B. Katz, Pegogle

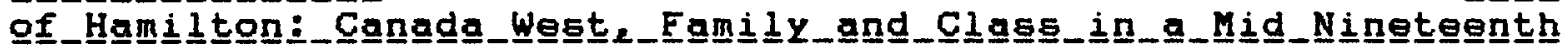
Centuryy_City (Cambridge: Harvard Univ. Press. 1975); for a contrary view see Linda Pollook. Forgotten__Ghildgren:_Parent_tghild

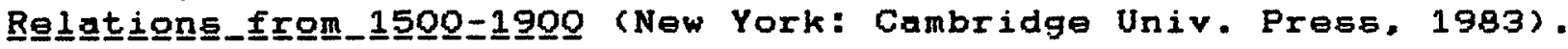

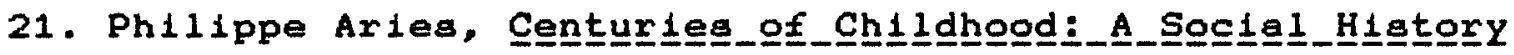
gf_Family_Life trans. Robert Baldrick (New York: Random House,

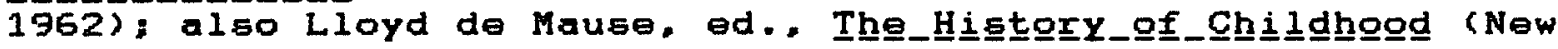
York: Peychohistory Press, 1974); R.L. Schnell, "Childhood as

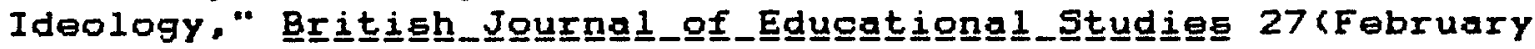
1979): 7-28; J.H. Plumb. "The Great Change in Children," Hor 13, 1(Winter 1971); Arlene Skolnick, ed., Rethinking_Childhogó:

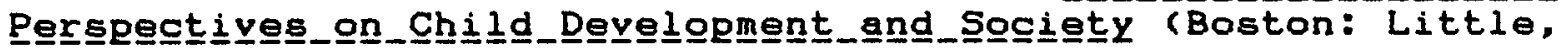

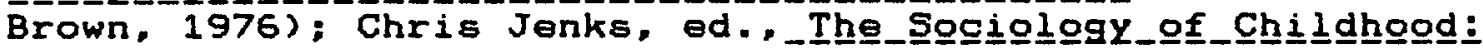

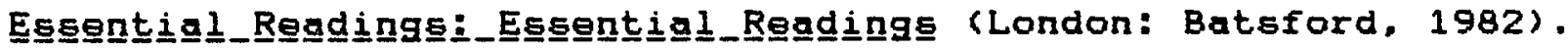


socialization process. 22 The study presented here focusaes on how situations determining life courses came to be redefined in this century. Since the 1920 s scientific research expanded cognitive and biological categories which have in turn elaborated multiple statuses between birth and the age of majority.

The perception of infancy, childhood, and adolescence as socially constructed categories, rather than universal and immutable trutha, is essential to a critical analysis of the mental hygiene movement. The strategy of mental hygienists was to conceptualize social problems as scientific and technical as opposed to cultural, political, or economic. 23 It 18 this strategy and its outcome which is the object of study. The fallure of mental hyglene to produce a science of human behaviour which resulted in conclueive evidence on the nature of social problems and their solution, was a persiatent source of frustration for mental hygienists and their philanthropic supporters. The structure of their questions shaped both their

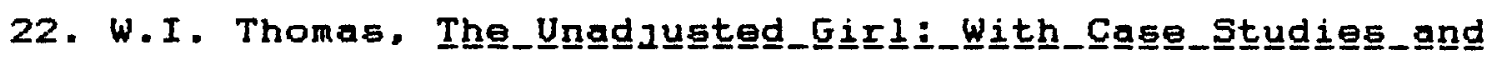
Standgoint_for_Behayior_Anglysig (Boston: Little, Brown, 1923), pp. 41-44; Robert K. Merton's concept of the self-fulfiling prophecy is based on Thomas"work, see "The Self-Fulfilling Prophecy," in Lewis A. Coser, ed." The_Plegagurege_of_Sogiology (New York: New American Library, 1980), pp. 29-44; also see excerpt from Thomas above. pp. 26-28 in Coser; also the classio, w.I. Thomas and Dorothy Swaine Thomas, The_Chilild_in_ A A

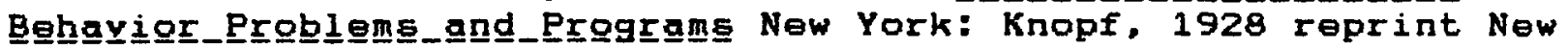
York: Johnson Reprint Corp., 1970; and, Peter Berger and Thomas

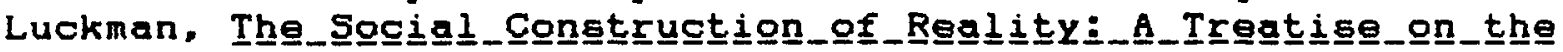

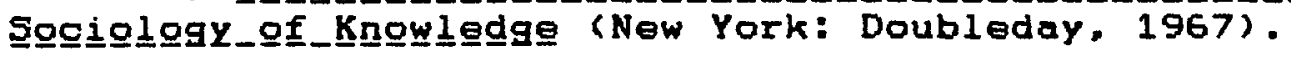

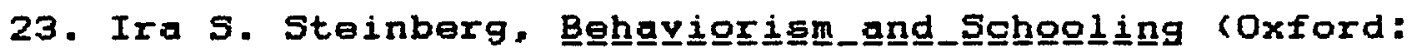
Martin Robertson, 1980) for his discussion on the distinction between science and scientism, p. 116. 
successes and fallures.

This same dilemma, in applying science to social policy, is a current issue of some importance, in that, the social and behavioural sciences continue to fail to match the oriteria for scientific validity characteristic of the natural sciences.

Social and behavioural science has failed to make obsolete old theories before moving on to secondary conclusions. They have not demonstrated cumulativeness in their findings or agreement on the finer points of their paradigms. 24 Regardless, the social Importance of ldeas which are legitimated and put into social practices, institutionalized, and formalized are, in and of themselves, culturally powerful in thelr asaumed sclentific status. 25

The purpose of this atudy ia not to review or question the scientific validity of human biological or cognitive development but to explore the cultural impact of interpretations of scientific findings on children. The focus is on the relationship

24. Robert N. Bellah, Richard Madsen, William M. Sullivan, Ann Swidler, and Steven M. Tipton, "Appendix: Social Science as

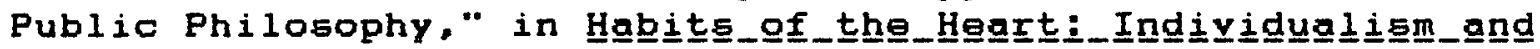

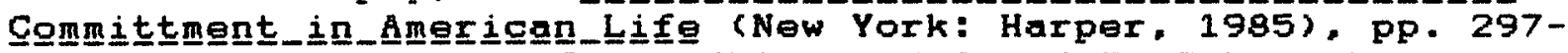
307; also see Charles E. Lindblom and David K. Cohen, Usable

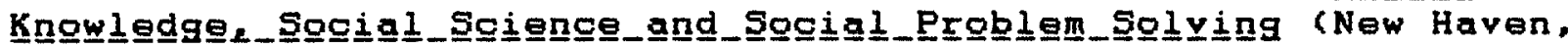
Conn.: Yale University Press. 1979).

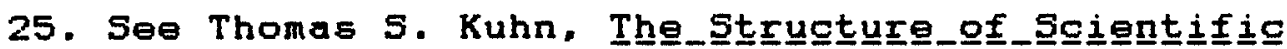
Revolutiong (Chicago: Univ. of Chicago, 1970) as a counter to the immutability of science; Robert K. Merton, The_Sogiolggy_gf Sgiengeg (Chicago: Univ. of Chicago, 1974); also Berger and

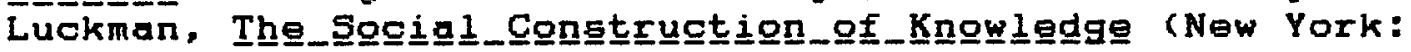
Doubleday, 1967); and Karl Mannheim, IgeglogY_and_Utopian_An

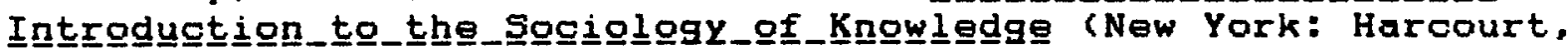
Brace and Jovanovich, 1936). 
between the origins of the belief structure of mental hygiene and its social outcomes. The answer to this question must be sought in the contextual relationship between ideas and social practices. As Sol Cohen has pointed out, the study of mental hygiene necessarily is concerned with "the problem of how and in what form ideag become influential and of how to estimate their Influence." 26

The study of the institutionalization of mental hygiene necessarily involves the examination of philanthropies and their impact on social policy in this century. 27 There is a substantial body of literature on the origins and work of twentieth century foundations but we have only just begun to critically evaluate their impact on social organization. 28

26. Sol Cohen. "The Mental Hygiene Movement, the Development of Personality and the School: The Medicalization of Education of

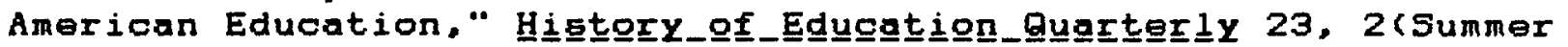
1983): 123-50, p. 125: also see Wayne Urban. "Some Historiographical Issues in Revisionist Educational History."

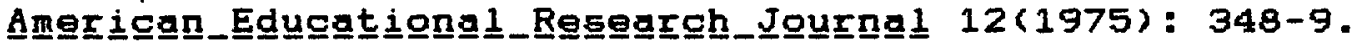

27. Sol Cohen, "The School and Personality Development:

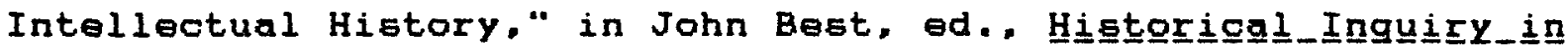

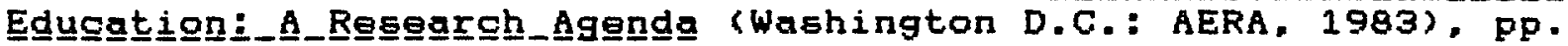
109-37; Cohen, "The Mental Hygiene Movement, the Commonwealth Fund and Public Education, 1921-1933," In Gerald Benjamin, ed..

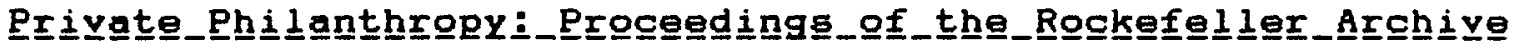

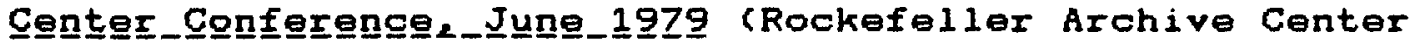
Publication, 1980), Pp. 33-46; in the same volume see: Steven L. schlossman, "Philanthropy and the Gospel of Child Development," pp. 15-32; and Robert J. Havighurst, "Foundations and Public Education in the Twentieth Century," pp. 5-14; also. Elizabeth Lomax, "The Laura Spelman Rockefeller Memorial, Some of its

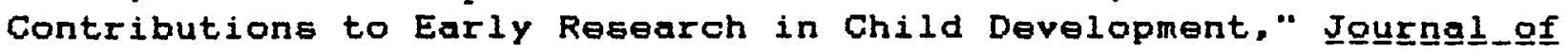

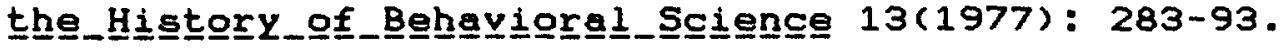

28. See recent contributions in this area: Ellen Condliffe Lagemann, "The Politics of Knowledge: The Carnegie Corporation

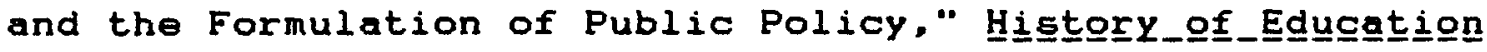


Philanthropies have had a significant impact on social policies in health, education and social welfare. 29 The influence on children's policy related to mental hygiene was dominated in the $1920 \mathrm{~s}$ and $1930 \mathrm{~s}$ by Rockefeller related philanthropy in child study research and the Harkness family philanthropy, the Commonwealth Fund, in child guidance. 30 The structure of power in legitimating ideas is an important aspect of the institutionalization of some ideas over othera. Mental hyglene,

Quarterly 27, 2(Summer 1987): 205-220; and W1111am R. Johnson, "Empowering Practioners: Holms, Carnegie, and the Lessons of

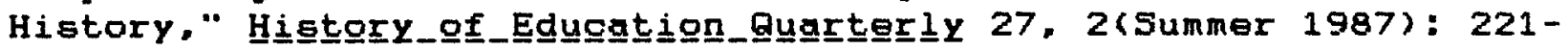
245 .

29. Donald Fisher, "American Philanthropy and the Social Sciences: The Reproduction of a Conservative Ideology," In Robert

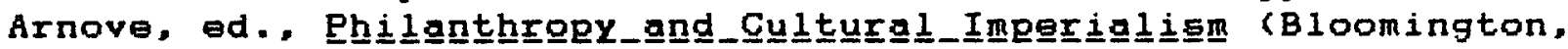
Indiana: Univ. of Indiana, 1982), pp. 233-68; Doriald Fisher, "The Role of Philanthropic Foundations in the Reproduction and Production of Hegemony: Rockefeller Foundations and the Social

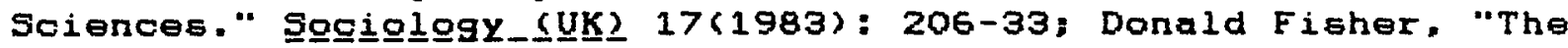
Impact of American Foundations on the Development of British University Education, 1900-1939," (Ph.D. Dissertation, University of California, 1977), and "American Philanthropy and the Social Sciences in Britain." Sociglogicgal_Review 28 (1980): 277-315; Ellen Condliffe Lagemañ. Pri ivate日e_Powwer (Middletown Conn.: Wesleyan University Press. 1983); Edward

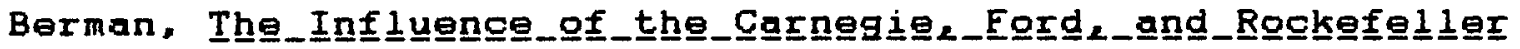

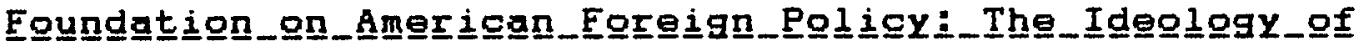
Philanthropy (Albany, N.Y.: State Univ. of New York Pres5, 1983);

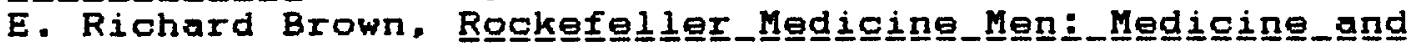

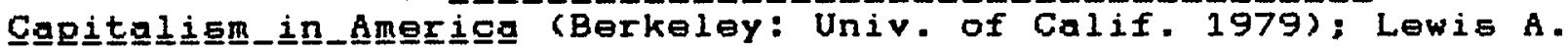
Coser, "Foundations as Gatekeepers of Contemporary Intellectual

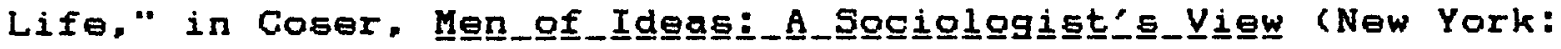
Free Prese. 1970), pp. 337-48.

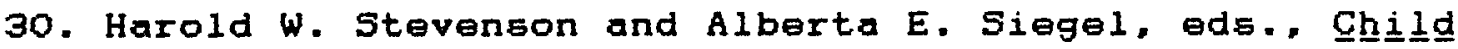

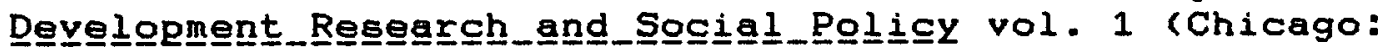

University of Chicago Press for the Society for Research in Child Development, 1984), pp. 1x-xii1; Orville G. Brim Jr., Éduchatílon for_Ghilld_Re日ering (New York: Free Press, 1959 reprint 1965), pp.

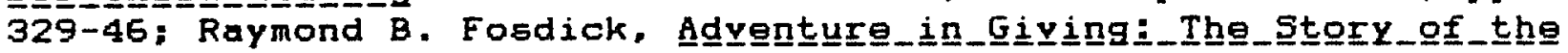

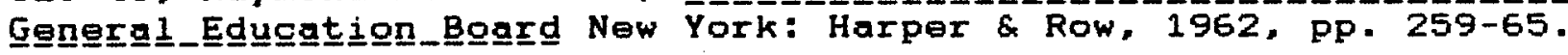


in its relationship to philanthropies, is an excelient arena in which to study this relationship.

This study is divided into three parts which are arranged chronologically in terms of time and the ideological emphasis in mental hygiene. The three parts: The_Body, The Mind, and The Estatete also define parta of a whole. They are mutually complementary functiona in conceptualizing the origin of ldea, their organization, and practical application. 31

The field of inquiry in this study encompasses the changing relationship between private and public aspects of social 11fe. 32 The tripartite model helpa ldentify value laden conceptual emphases as psychiatric theories evolved in what can be seen as thre日 stages. First, the emphasis was on physical well being; secondly, on psychological processes in normal and abnormal development; third, on an expanded public role in atandardizing the physical, mental, and social conditions sheping child life. The tripartite model also makes evident the contextual differences in divergent orientations toward mental hygiene as expressed in U.S. and Canadian societieg.

The body-mind continuum was one of the major underlying philosophical iasues debated by mental hygieniats. Trying to

31. The idea of the body, the mind and the estate was conceptualized out of George Duby's study of the three orders or estates general of France, the clergy, the Nobility, and the Third Estate, [estat meaning both estate and state], The﹎. Thr

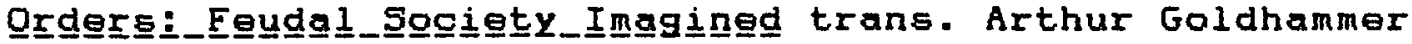
(Chicago: Univ. of Chicago, 1980 reprint 1982), p. 1-9.

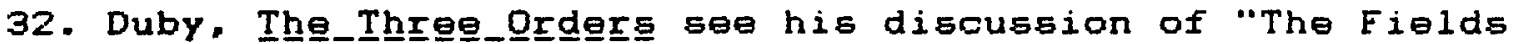
of Inquiry." pp. 1-9. 
comprehend the relationship between physical and mental health was a major preoccupation of the late nineteenth century. The focus on child growth reflects the conceptualization that psychological and biological growth were interdependent and that the integration of the mind-body was a key to adult health. 33 Controveraies over the relationship between the body, the mind and the estate contributed to the professional development of paychology as separate from philogophy. Paychoblology also contributed to the movement of psychiatry into the general hospital and with an emphasia on private practice within a medical discipline as distinguished from asylum administration. The nature-nurture controversies, over the dominance of innate genetic traita or environmental conditions es determinants of behaviour, were fostered by mental hygiene research as practioners attempted to sort out the relationship between these thre日 spheres. 34

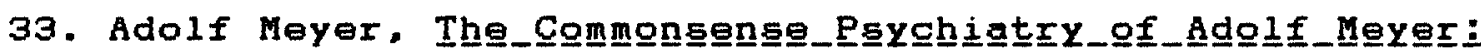

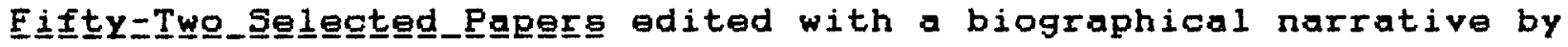
Alfred Lief (New York: MeGraw-Hi11, 1948); Adolf Meyer,

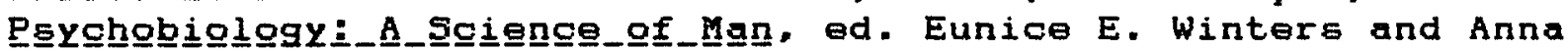
Mae Bowers (Springfield. Ill.: Charles G. Thomas, 1957).

34. Mary J. Wright and C. Roger Meyer, eds., Histgorgy_of

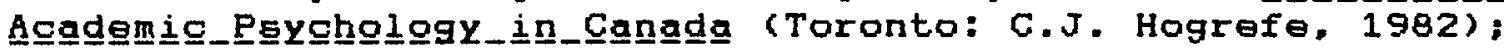

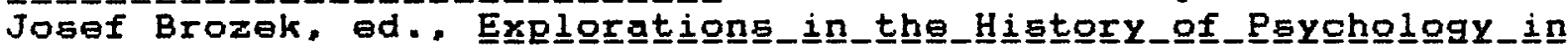

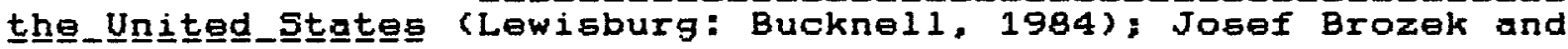

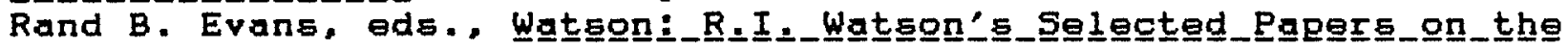
Histgry_of Psychology (Hanover, N.H.: Univ. of New Hampshire, 1977); Gerald Grob, The_Inner_Wor 1d_of_Amerigan_Psychiatr. $1890=$

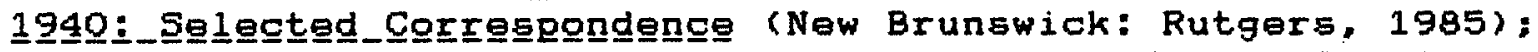

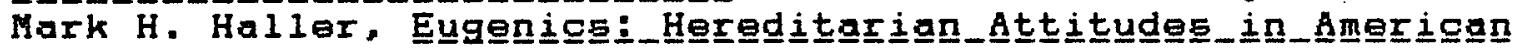
Thought (New Brunswick: Rutgers, 1963): N.J. Block and G. Dworkin, The_I.Q._Contrgoyersy (New York: Pantheon Books, 1974);

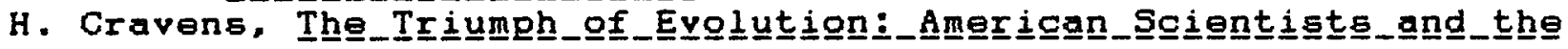

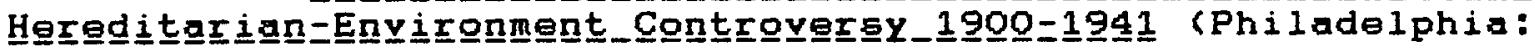


The ideas supporting mental hyglene in the twentieth century originated in the ascendancy of science over metaphysics in the Enlightenment. The long term effects of thie revolution in intellectual and political thought fostered a new way of looking at social and natural phenomenon. A phrase, "the childhood gaze,". borrowed from Michel Foucault's study on the birth of medical knowledge in the clinics and mental asylums of France, captures the essence of the relationship between science and mental health. The childhood gaze is used in this study to refer to the convergence of medical and scientific perspectives into the mental hyglene paradigm. 35 The chlldhood gaze as a method of inquiry, a focus of attention, and a belief system, transformed modern concepts of the body, mind, and estate of childhood.

The first three chapters trace the derivation of the ideological and organizational aspects of mental hygiene as a medical model closely allied to the development of scientific philanthropy at the turn of the twentieth century. This inoludes the professionalization of modern medical science, the origins of Rockefeller philanthropy, and the role of philanthropy in the promotion of modern scientific perepeotives. The interplay of personal blography and external dynamics are juxtaposed in the

Univ. of Pennsylvania, 1978); Twenty-seventh Yearbook, National

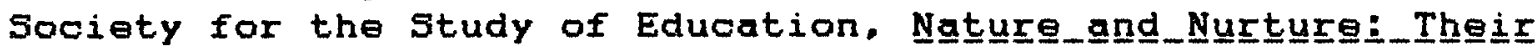

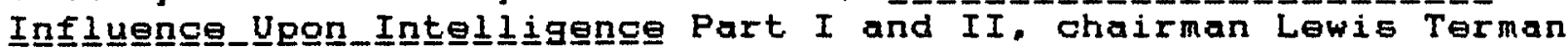
(Chicago: Univ. of Chicago for NSSE, 1928), Thirty-ninth Yearbook, National Society for the Study of Education,

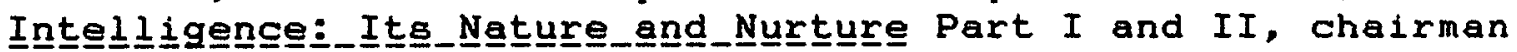
George Stoddard (Chicago: Univ. of Chicago for NSSE, 1940).

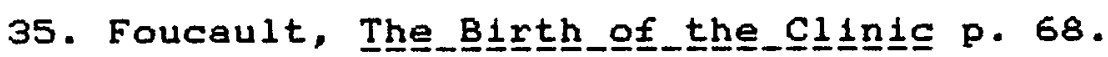


origins of the Canadian and U.S. National Committees for Mental Hygiene.

Part II elaborates the most dynamic period of mental hygiene in the 1920 s and 1930 . Mental hygiene had dual outcomes in terms of developing childhood paradigms. The emphasis on maladjustment and abnormality contributed to the legitimation of a paychiatry of childhood. The focus on adjustment, and the preservation of normality, fostered scientific child study research and contributed to the institutionalization of standardized versions of normal cognitive and age related stages. The origins and progress of the development of the mental hygiene paradigms on normality and abnormality in childhood are discussed in the chapters on child guidance and scientific child study.

The conoluding chapters address mental hygiene policy on children as it was incorporated into government agencies in the 19405 and immediate post war period. The legitimation of a medicalized version of childhood reflects the configurations of power and authority relationships in different contexts. The concept of the estate is used to explore the legacy of mental hygiene in two related dimeneions of social contexts: one the nation-state represented by the United States and Canada; and secondly, the condition of private life in the larger public order. 


\section{PART I}

THE BODY: SCIENCE AND THE MEDICAL MODEL

The child is more precious than the problem. The only field in which experiment on the human being is recognized, or rather practices without recognition, is medicine, where the material is already threatened with destruction through sickness, and the physician introduces an experimental change... which gives a chance of preserving life and

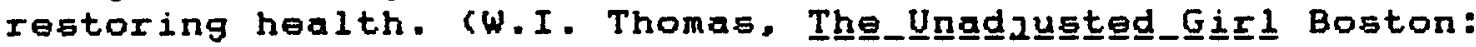
Little and Brown, 1923, pp. 244-5.) 


\section{CHAPTER ONE}

\section{THE CHILDHOOD GAZE AND THE SPIRIT OF JOHNS HOPKINS}

\section{The Theme of the Childhood Gaze:}

\section{Intellectual and Social Origins of A Paradigm}

Child and family life in the twentieth century have been dominated by bureaucratic institutions. One of the underlying principles which has organized these institutions, concerned with family welfare, education and mental and physical well being, is a particular sense of order. The bureaucratic framework for institutional organization was derived from the nineteenth century. 1 This sense of order originated in the eighteenth century. The development of seientific knowledge as the legitimate basis for understanding the natural and social world is fundamental to the modern sense of social cohesion. 2 This

1. See Michael Katz, "Origins of the Institutional State,"

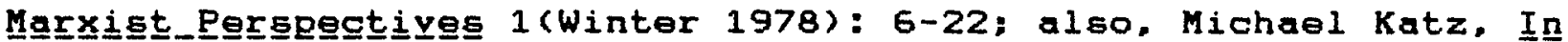

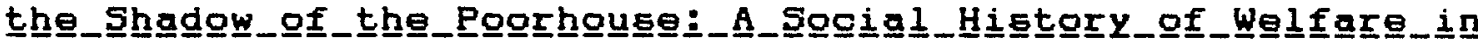
Ameriia (New York: Basic, 1986); Patricia T. Rooke and R.L

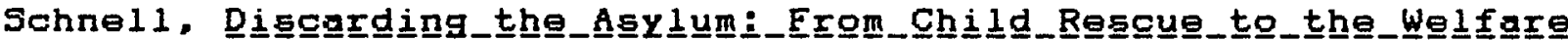

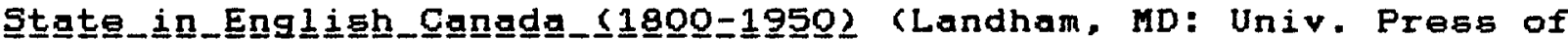
America, 1983).

2. Robert Weibe, The_Searrgh_for_order__18ZZ=1920_ (New York: Hill and Wang, 1967); See Karl Mannheim, Ideology_and_utgogiag:_An

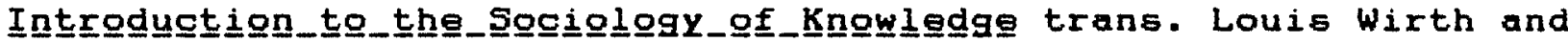
Edward Shile (New York: Harcourt, Brace and Jovanovich, 1936). pp. 54, 59-70, Mannheim traces the origin of ideological and utopian thought from the 18th century. His problem. similar to the one in this thesis, is concerned with the development of methods of understanding the forms of ideas and forms of social and political organization. Social concepts of order are evaluated as context specific. Concepts of order reflect and maintain the external social order. Mannheim points out that differences in concepts between different groups reflect different positions in the social structure. Also see Louis Wirth's "Preface," to Mannheim, pp. xii-xiii; and George

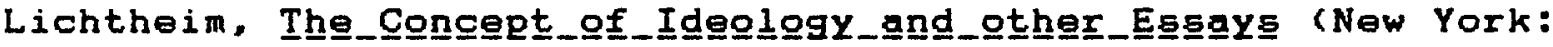


work is about the sclentific structuring of knowledge concerning children in the mental hygiene movement in the United States and Canada. The study of childhood through science has informed our views of children and has shaped the contemporary institutions that have been created to serve them.

The mental hygiene movement in this century cohered a way of looking at childhood that was grounded in the natural sciences. The gaze of soience as directed toward children was the theme of preventive social psychiatry. Children became objects of research. They were systematically classified by age and their growth was described and quantified. Experimental investigations were carried out on how children behaved and what they learned at various ages. Theoretical explanations for human growth and development were based on the findings of systematic observations. The mental hygiene movement and its influence on social policy affecting children was part of the more general theme of the childhood gaze. 3

The childhood gaze was a theoretical perspective, a method of inquiry and a prescription for action. This chapter discusses two interrelated parts of the origins and dynamice of the medicalization of social policy as a derivative of the childhood gaze. The childhood gaze was implicated in the development of scientific curriculum in the modern university and especially in

Vintage, 1967), pp. 4-5, 30-46; Michel Foucault, The__orgler_of Thinggㅗ (New York: Vintage, 1973), pp. 344-87.

3. Michel Foucault, The_Bírth_of__the_clingig (New York: Pantheon), p. 68 . 
medical education. This is illustrated in the establishment of Johns Hopkins University and its graduate medical school. The men who were instrumental in making Johns Hopkins the model for American higher education and especially graduate education in medicine and psychiatry were also instrumental in establishing the National Committee for Mental Hygiene. They played central roles in directing philanthropic funds toward the support of research in the medical sciences. Johns Hopkins epitomized the institutionalization of the childhood gaze in the twentieth century.

The childhood gaze sought to understand events by way of secular observation rather than metaphysical or sacred inspiration. This revised way of legitimating knowledge evolved out of the intellectual revolution of the Enlightenment. It encouraged emergent sciences in medicine in the hospitals and clinics of the late 18 th century. 4 The childhood gaze has increasingly come to represent an ordering of ideas based on systematic primary or clinical research sanctioned by professionals in a particular field.

The rise of professionalism in this century increased the

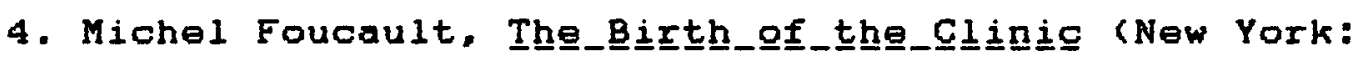
Pantheon, 1973), p. 64. The reference is to the origins of what

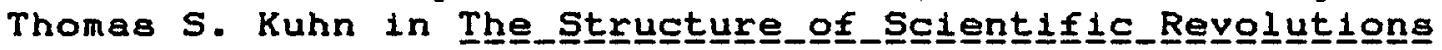
(Chicago, Illinois: University of Chicago Press, 1970), defines as a paradigm. Also see: Mannheim, Idegology_and__utgopia ; and Lichtheim, The_Concept_of__Idegloggy. 
value of education. 5 The need for specialized knowledge had a reciprocal effect on the value of training. The more widespread, advanced educational institutions became, the more generally accepted and legitimate was the validation of expert knowledge. Knowledge based in science, as a form of understanding obtained by experience, implied a certain kind of credentialing process. soientific objectivity in its exclusiveness created, in a sense, its own form of sacred or inspirational reality. Through the childhood gaze the mental hygiene of childhood was conceived as a path to social salvation. Systematic investigation as a way of uncovering the truth of nature assumed the role of an ultimate order based on objective principles. 6

Mental hygiene as it developed in the twentieth century was grounded in scientific medicine and peychiatry as well as public health reformism. The search for a sense of order based in science tended to ignore or deny alternate explanations

5. Magali Sarfatti Larson. The_Rige_of_Profegesiongalígmi_A Sogiologicgal_Anglysis (Berkeley: Univ. of Calif. Press, 1977), pp. 14-17, makes this point where "the production of knowledge and the production of producers are unified into the same structure," namely, "modern systems of education... as the central hinge" in professionalization. p. 17. Larson discusses the monopolization and standardization of the production of knowledge by experts as a market system. Control over that market, it is argued, requires a reoiprocal relationship between professionals and knowledge producing centres.

6. Similarly, Ernest Gellner, The_PEychognglytíg_Mogyement__or

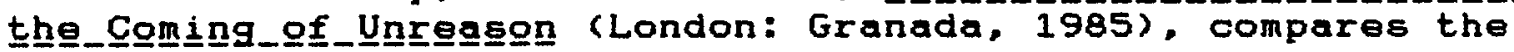
psychoanalytic movement with Christianity as a belief system, p. 5. Gellner also notes that in the examination of peychoanalysis as a method of systematically revealing truth we must also examine the anatomy of the faith which supports it as an 1deology, pp. 163, 205. 
concerning the causation or possible remediation of social

problems involving political, cultural or economic accommodation. Mental hygiene as an appraach to problem solving is an inherently conservative framework. The medical and behavioural sciences which make up mental hygiene mediate the natural sciences and social sciences. The attempt to achieve the status of a natural science proved to be a major problem for the mental hygiene paradigm. The goal of the mental hygiene movement was to perfect knowledge about human behaviour based on objective truths. The childhood gaze created and supported the positivistic perspectives inherent in the mental hygiene movement's search for empirical validation. 7

Efforts to identify the early period of life as having

7. For a general synthesis of the era see Wiebe. Theneseagrach for (Chicago: University of Chicago. 1957). For the structuring of this period in relationship to the structuring of knowledge, se日 Charles E. Rosenberg, "An Ecology of Knowledge," in A. Oleson and

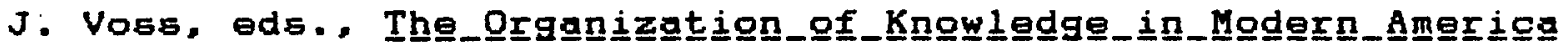
$196 \underline{6}=1920$ (Baltimore and London: The Johns Hopkins University Press. 1979), pp. 440-55. On the importance of science in relation to popular ideology. see Charles E. Rosenberg. №_othher Gods: On_Sgi London: The Johns Hopkins University Press. 1976). See Anthony

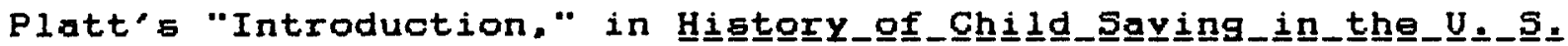

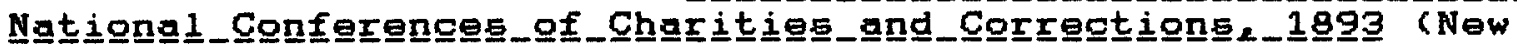
Jersey: Patterson Smith, reprint 1971), p. ix. This view point is

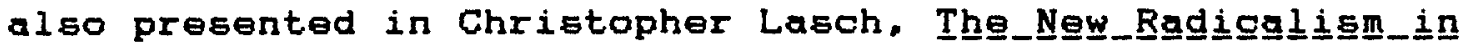

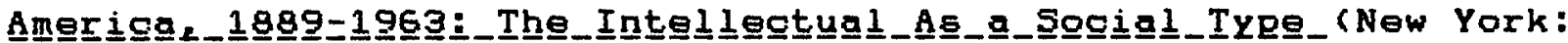
Alfred A. Knoph, 1965); Gabriel Kolko, The_Triumph_of

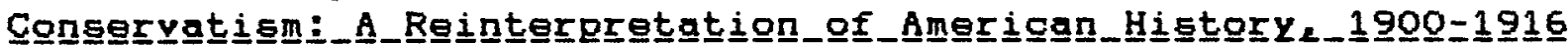
(New York: Free Press, 1963); and James Weinstein. The_Egrgorate

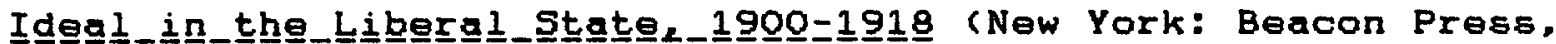
1968 ). 
special needs are a relatively recent phenomenon. 8 Jacques Rousseau's eighteenth century Emile, idealized a philosophy for training children which fed into Pestalozzi's pedagogy and Froebel's concept of the kindergarten. The earliest approach to the study of defective children was also grounded in epistemology. For example, in the early 19 th century the Physician to the School for Deaf Mutes in Paris, Dr. Jean-MarcGaspard Itard, tried to see if the human psyche was indeed a blank slate, a state of innocence, upon which it was possible to insoribe civilization. To explore this philosophical question he took on the education of Victor, a feral child, the so-called "Sauvage d'Aveyron." 9

Itard's more practical student, Edward Seguin, saw in what Itard thought was disappointing results the possibility for elaborating a method of studying mentally handicapped children. sequin's motive turned away from philosophical inquiry toward scientific investigation and practical application. Seguin went

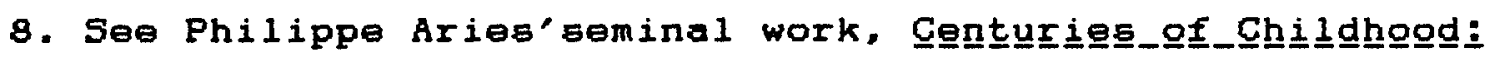

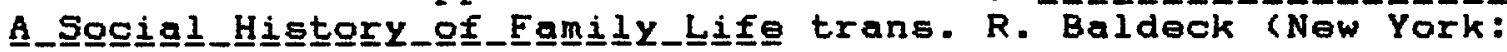
Knopf, 1962), on the origins of the concept of childhood. Aries contends that there was no notion of childhood, as we know it today, in the Middle Ages. Also se日: H. Plumb, "The Great Change in Children," Horiżon, 13, 1 (Winter 1971); Arlene skolnick.

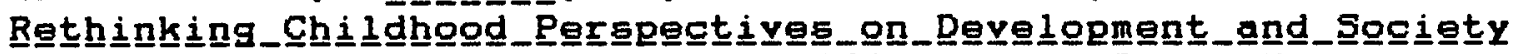
(Boston: Little, Brown and Co. 1976). Also, Frank Musgrove, Youth

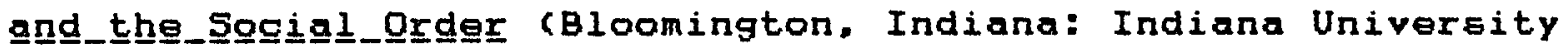
Press. 1965), for his disoussion on the invention of adolescence.

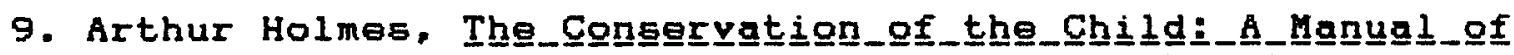

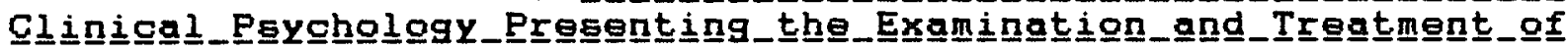

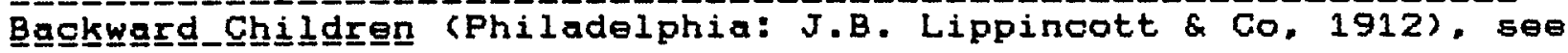
the "Historical Sketch," pp. 15-31, especially p. 18. 
on to pioneer in France and in the United States the study, education, and, institutional care. of retarded children. 10

The government of France was impressed with the possibility of identifying and treating abnormality. Systematic methods of classification were required. In 1904 a Commission was set up to evaluate the status of subnormal children in the schools of Paris. Alfred Binet, Director of a laboratory and school for studying defective children at the Sorbonne, was asked to devise a means of screening the school population. The mental tests Binet and his student Theodore Simon devised became the foundation for twentieth century intelligence scales popularized in the United States by Henry Goddard and Lewis Terman and in Canada by Peter Sandiford. 11

As the application of scientific principles gained status over philosophical conoerns, intervention became more common.

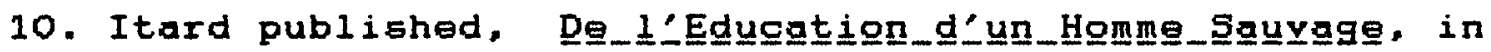
Paris in 1801. Edward Sequin published, Thegerie_ęt_pragtiquue_de

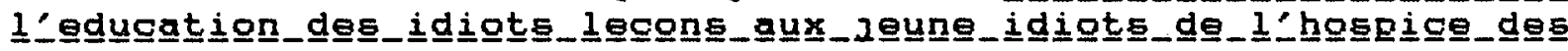
Inguㅡ므느토. in Paris in 1842 .

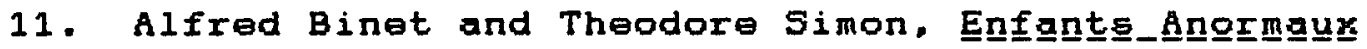

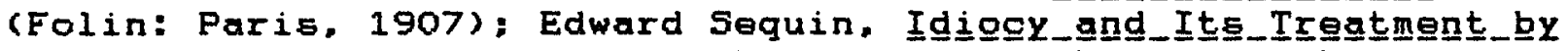

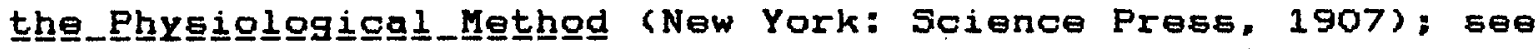
Arthur MacDonald, "Abnormal Man," reports and bibliographies in

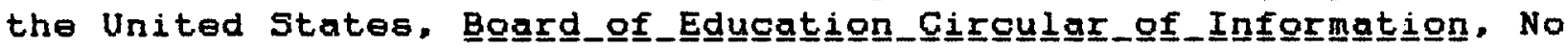

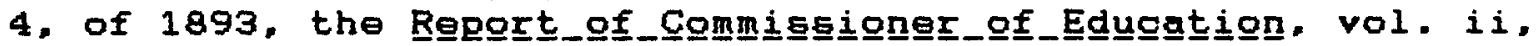

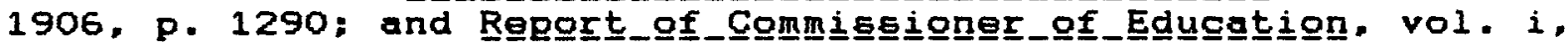
1909, p. 30; George Sidney Brett, A_Higtory_of_Peychology, Volume 3. Modern Peychology. (London: George Allen and Unwin, New York: MacMillan Co., 1921), pp. 252-3; Mark Haller, Eugengiges:

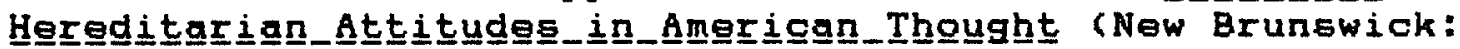
Rutgers Univ. Press, 1963), has a good discussion on this topic. see ch.7, pp. 95-110. 
Intervening in developmental and evolutionary processes to prevent, identify, and control abnormal populations was made possible by science. Over the nineteenth century not only the rationale for an interest in different children changed from philasophy to science but the practices of intervention into child life became more insistent and widespread. 12 The themes of the childhood gaze set up and were incorporated into the golden age of preventive medicine from the 18805 to the first world War.

\section{The Spirit of Johns Hopkins}

No previous historical periods so concentrated the spirit of science with benevolent social action as in the late nineteenth and early twentieth century Progressive Era. Few men have so engaged in the self-conscious reflection of their own contributions to social life as did the reformists of this period who dedicated themselves to medical progress and social change. Nowhere was this reformist spirit more visible or viable as a model for ather institutions than at the newly established Johns Hopkins University Medical School. This model was carried far afield to influence the course of medical education and leadership training in both the United States and Canada.

Johns Hopkins University was originally endowed by the Baltimore Quaker merchant of the same name. Hopkins was

12. John A. Popplestone and Marion White McPherson, "Pioneer

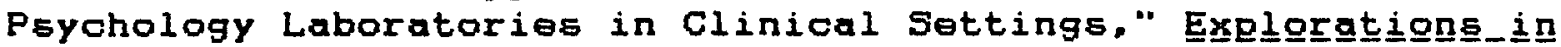

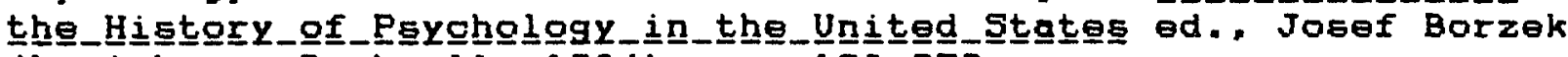
(Lewisburg: Bucknell, 1984), pp. 196-272. 
influenced by his fellow townsman, George Peabody, who had been instrumental in the southern states in pioneering educational philanthropy. Hopkins had come to believe that the most enduring needs were "a university, for there will always be youth to train: and a hospital, for there will always be suffering to relieve." 13 On his death in 1873, two overlapping Boards of Truste日s were set up to establish two institutions with seven million dollars divided between them. The Boards, with a sow and unhurried pace, set about finding and securing the finest men available to pursue the work of these two precedent setting orgenizations.

The result was unique: the first true university in America and the first organically connected medical facility with post graduate medical education. Johns Hopkins combined the most advanced scientific medical research with olinical hospital experience in a university setting. Clinics were established for both medical and psychiatric disorders. The role of the university was defined according to European and especially Germanic tradition, as providing the insights of true enlightenment and scientific discovery. Johns Hopkins helped redefine doctors as social leaders possessing the necessary knowledge and qualifications to solve fundamental social problems. The alliance with large scale donors in the newly formed general purpose American Philanthropies and their

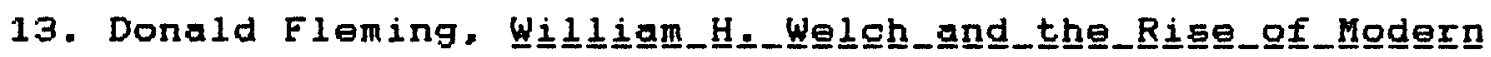
Meg íginge (Boston: Little, Brown and Co. 1954), p. 153. 
precursorg allowed for the institutionalization of massive policy changes and intervention in traditional social practices. The sucoess of this endeavour rested heavily on the quality of leadership training in higher education. The movement toward scientific curriculum and university reform had been initiated by President of Harvard, Charles Eliot, in his inaugural address in 1869, but nowhere was the new spirit so concentrated as at Johns Hopking. 14

The vision of Johns Hopkins University was largely shaped by its first President, Daniel Coit Gilman. Gilman was a contemporary of other great university presidents of the times: Charles W. Eliat of Harvard, Andrew W. White of Cornell, and James B. Angell of Michigan. These men strongly supported the introduction of scientific curriculum in addition to the traditional classic curriculum. Gilman was unusual in that he supported the introduction of post graduate work in science at a time when most others were deeply concerned with upgrading and differentiating the undergraduate university traditions from secondary and college curriculums. Gilman like his contemporaries, was concerned with the upgrading of science and medical science, especially as an integral part of the university in connection with clinical facilities in a hospital.

14. Charles William Eliot, "Inaugural Address as President of Harvard, 1869," In Richard Hofstadter and Wilson Smith.

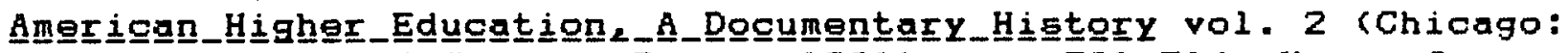
The University of Chicago Pres5, 1961), pp. 701-714: Henry James,

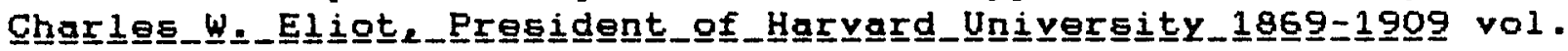
2 (London: Constable and Co. 1930), see ch 9. 
Gilman was heavily influenced by his personal experience of graduate education in Germany. After graduating from Yale he had sought further study in these more scientifically oriented academic environments. German universities had reached their peak of productivity by 1870 and they had become a mecca for Americans and Canadians seeking advanced work. 15 Instruction in Theology. Law and Philosophy excelled, as did the Medical Soiences. Basic research was pursued with diligence, and the scholar, and researcher, was looked upon with high prestige. The goal of university education was interpreted as the furtherance of the horizons of human knowledge rather than the mundane pursuit of practical certificates. The pursuit of pure understanding in clinical and laboratory studies revolutionized the basic sciences upon which modern technologies with practical application were founded. Part of the impact of the childhood gaze was a millennial belief in a future shaped by advanced scientific knowledge. The premonition of a better world was not grounded in the abstractions of metaphysios but in the readily apparent

15. Thomas Neville Bonner. Amer

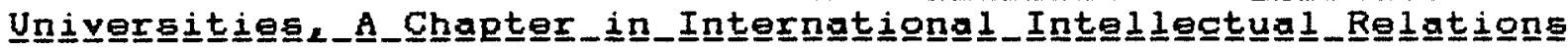
(Lincoln: The University of Nebraska Press, 1963). Bonner. "Frantpiece," cites a quate from osler dated 1890: "The Universities of Germany are her chief glory, and the greatest boon she can give us in the New world is to return our young men infected with the spirit of earnestness and with the love of thoroughness which characterizes the work done in them." It was the spirit of which Osler spoke that infected Johns Hopkins. Also see Daniel Coit Gilman, The_Laungching_of_a_ungivergitey (New York: Dodd \& Mead Co., 1906); also, Richard Hofstadter and Walter P.

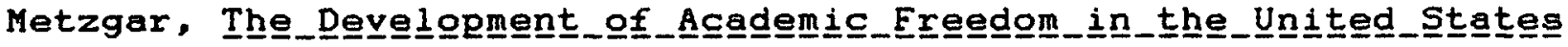
(New York: Columbia University Press, 1955), see ch. 8, "The German Influence," pp. 369-377. 
advances being made through sclentific research. Gliman and his contemporaries were profoundly impressed by the intense and exciting intellectual atmosphere which prevailed in the laboratories of Europe. 16 Gilman was determined to bring home what he felt was a dynamic new spirit with great potenital.

Upon his return from Germany. Gilman helped organize the Sheffield Scientific Sohool of Yale. 17 In 1872 he was inaugurated President of the University of California. Gilman's work in Berkeley was hampered by recalcitrant trustees and political conflicts. In 1874, Gilman's fine reputation and many publications on higher education led to the offer by the trustees of Johns Hopkins University which "involved nothing less than creating a new institution without restriction of precedent ar the interference of political manipulation." 18 This offer, which

16. See excerpts from: James Morgan Hart, Germanan

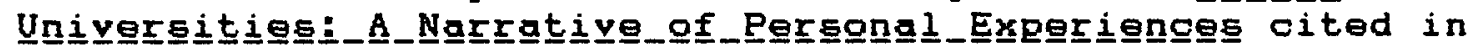
Hof stadter and Smith, Ameri

17. "The Governors of the Board and Faculty of the Sheffield Scientific School of Yale College, Statemenent_Presented_tótthe

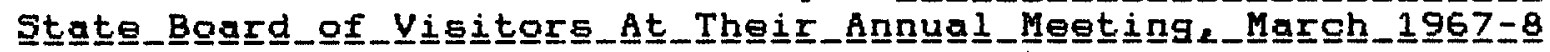
(New Haven, Connecticut, 1968), p. 10-17, in Hofstadter and

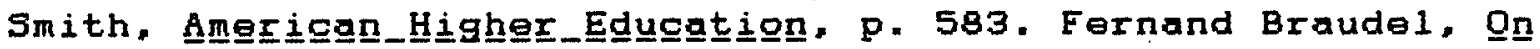
Histetory (Chicago: Univ. of Chicago Press, 1980) in his discussion of "History and the Social Sciences: The Longue Duree," pp 25-54, especially see p. 41.

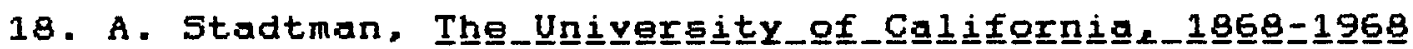
(New York: MCGraw-Hili Book Co. 1970), pp. 61-80; Harvey

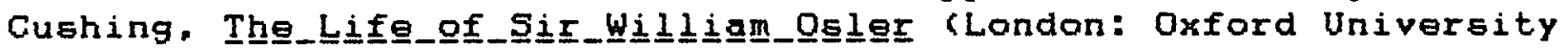

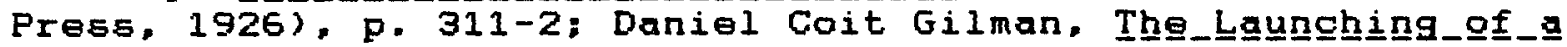
Uni commented that Gilman's special talent was his ability to please all and offend none. "doing the absolutely necessary ungentle things in a gentle way." William Osler in one of his addresses. the "Fixed Period Address," stated that he had learned much from Gilman, "I had never before been brought into close contact with 
clearly suited Gilman's temperament and vision, was accepted. In this event, a particular man in a particular time came together to form an institution which was capable of coalescing the tenor and direction of the childhood gaze in a prescriptive model for social action.

The years 1876 to 1890 were the adolescent years of American Universities. Before 1876 and the opening of Johns Hopkins there had been only immature beginnings of higher education in the United States. In the fifteen years after its establishment, Johns Hopkins along with Harvard University approached maturity in so far as they were able to provide training and opportunities previously available only in Europe. After 1890 other universities in the United States and Canada began to experiment with the "university idea." Notable schools which made this effort included: Cornel1, Columbia. Stanford, Michigan. California, Yale, Toronto, and MoGill. Fifteen major graduate schools or departments, inspired by the model provided at Johns Hopkins, were established by the end of the nineteenth century. 19 The university was distinguished from a college in this model by offering a diversified curriculum and graduate level opportunities. Harvard at first evolved along the lines that there should be no arbitrary differentiation between graduate and undergraduate studies. Harvard President Charles

a man who loved difficulties just for the pleasure of making them

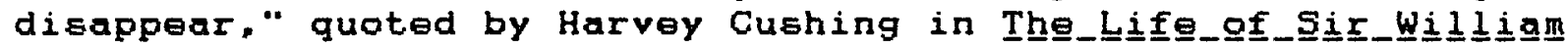
Q트톨 2 vols (Oxford: Oxford Univ. Press, 1925). I: 312, fn 1 .

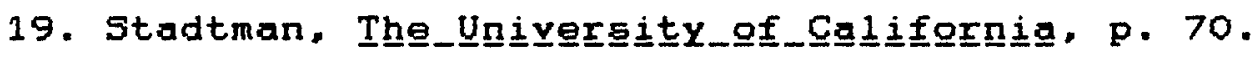


El lot advocated the development of the undergraduate level before advancing into the graduate level. "The single most brilliant experiment in the development of graduate education and research was the one made at Johns Hopkins. It influenced all the others." 20 Eliot wrote to Gilman on his retirement:

There is not a university in the country that has not benefited by what you have done at Baltimore. I am well aware that it would have been much more difficult, if not impossible, for us at Harvard to have developed our graduate school, which was but a feeble infant in 1872-76, if you had not built up your University so wisely and effectively on the graduate side. Then your Medical School has been a real inspiration in the reform of medical education in the United States. 21

The spirit of Johns Hopkins has been described as thriling and exhilarating. An early description of the heady atmosphere appeared in Scribner's Magazine, in 1891, written by Josiah Royce, one of the early fellows:

Here at last, so we felt, the American university had been founded. The beginning ... was a dawn wherein 'twas blessed to be alive. Freedom and wise counsel one enjoyed together... One longed to be a doer of the word, and not a hearer only, a creator of his own infinitesimal fraction of a product. 22

The spirit of the Medical School at Johns Hopking was the spirit of activist social and medical reformism. William Henry Welch, the first Dean of Medicine at Johns Hopkins, epitomized the combination of reform and scientific medicine which

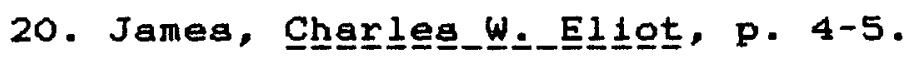

21. Charles W. Eliot to Daniel Goit Gilman, dated January

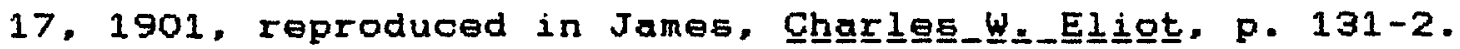

22. James, Gharleeㅌw._Eliot, p. 8; Josiah Rayce, in

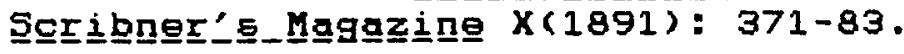


prevalled:

We are only upon the threahold of deeper inaight into the nature of the class of diseases which have been more devastating to the human race than any upheavals of nature or any wars. They have left their imprint upon the political, social and intellectual history of the world. 23

Wiliam Osler, as first Head of the Department of Medicine,

declared in regard to one of his public health campaigns:

The outlook for the world represented by Mary and John, and Jennie and Joan, has never been so hopeful. There is no place for despondency or despair. As for dour dyseptios in mind and in morals who sit idly croaking like ravene-let them come into the arena. let them wrestle for their flesh and blood against the principalities and powers represented by bad air and worse houses, by drink and disease, by needless pain, and by the 1055 annually to the state of thousands of valuable lives-let them fight for the day when a man's life shall be more precious than gold. Now, alas! the cheapness of life is every day's tragedy. 24

The men who gathered to embody the Medical School were immortalized by John Singer Sargent's famous oil painting, "The Four Doctors." 25 First, William Welch, halled as the dean of

23. William Henry Welch, "Opening Remarks by the Prealdent of the Section of Pathology and Bacteriology of Tuberculosis,"

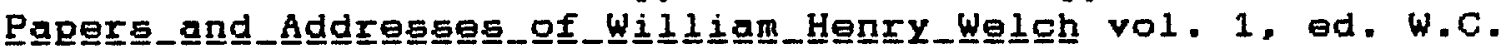
Burket (Baltimore and London: The Johns Hopkins University Press, 1920), 3 vols.

24. Sir William Oaler, Coungelg.and_Idealg ed. C.N.B. Camac (New York, 1921), p. 7, quoted in Lloyd C. Taylor Jr.. The

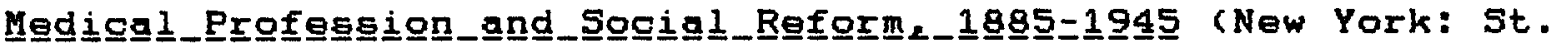
Martins, 1974), p. 5, fn. 21 p. 13 .

25. The often reproduced painting by the well known American portrait painter John Singer Sargent. "The Four Doctors," hangs in the William Henry Welch Medical Library at Johns Hopkins Medical School in Baltimore. It is reproduced in Simon Flexner and James Thomas Flexner, willi

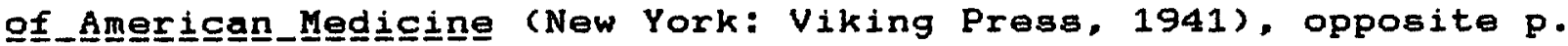
246 . 
American Medicine, was perhaps the most critical both at Johns Hopkins and as a liaison between science, medical reform and funding agencies. Welch became one of the influential founders of the mental hygiene movement. Welch served as Vice President (1909-1923). President (1923) and Honorary President (1924-1934) of the National Committee as well as President of the American Foundation for Mental Hygiene (1928-1934) and the International Comittee for Mental Hygiene (1923-1934). 26 He helped eecure support for the mental hygiene movement as well as funds by way of his contacts which were numerous. He served in executive positions in Rockefeller related philanthropies in the Sanitary Commission. International Health Board and Rockefeller Institute among others. He colncidentally served on the Board of Trustees of the Carnegie Institution of Washington and the Milbank Memorial Fund. His biographers give a partial list of aver eighty scientific and civic organizations, largely dealing with public health, and the medical, and social sciences where welch was most active. 27

Mental hygiene was a coordinated part of Welch's more general activism in public health, pathology and medical education. All of these areas were linked in Welch's mind with social reform. To Welch, medical science was a practical means of social intervention which included eliminating diseases, such as tuberculosis along with urban renewal and public welfare. Welch

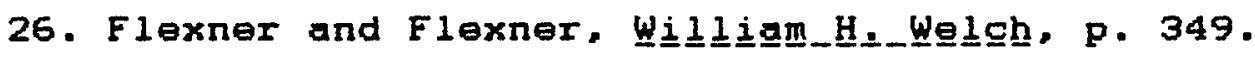

27. Ibid, Appendix B, pp. 462-5. 
saw poor housing, sewage problems and industrial conditions as part of the etiology of physical, mental and moral disease. Weak character, alcoholism and pauperism were essentially problems of sanitation curable by way of medical intervention. 28

Another figure of great influence depicted in Sargent's portralt was Canadian born William Osler. Osler was one of the most internationally celebrated clinical teachers of medicine of his day. Osler was also an eloquent spokesman for the application of the medical model in solving social problems. He was known for his kesn wit and charismatic discourses on the nobility of the cause of preventive medicine. He viewed scientific medicine and pathology as a practical extension of a democratic social conscience properly directed toward uplifting the common man. He was a world leader in public health and mental hygiene in canada. the United States and England. He resigned from Johns Hopkins to

28. Lloyd $C$. Taylor, Jr.. The_Medicg1_Profession_and_sogigl Ref으는 18 $85=1945$ (New York: St. Martin's Press, 1974), pp. 2-3; Welch was nicknamed "Popsy" by his studente. See Flexner and

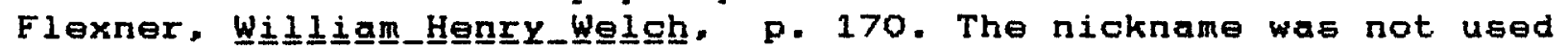
in Welch's presence but does indicate that while his relationship with his students was professional and not personal, he was revered as a father figure in the developmental stages of modern American medicine. Also on Welch see. Fleming, willili

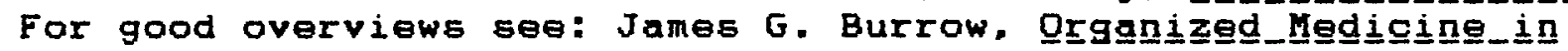

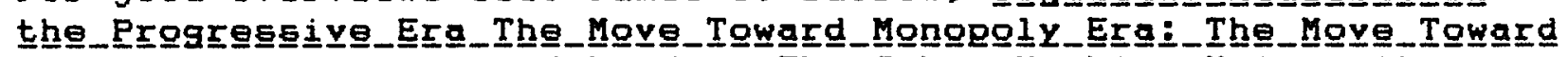
Mongegly (Baltimore and London: The Johns Hopkins University

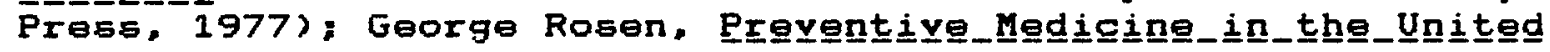

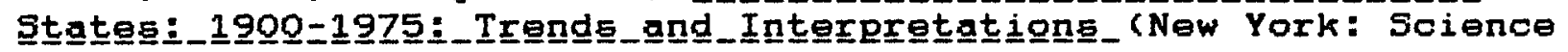
History Publications, 1975); for overviews on the importance of Johns Hopkins' original faculty to medical history. A fictional work by James G. Mumford, A_Dggtgí's_Table﹎.Talk (Boston: Houghton, Mifflin and Co.. 1912), depicts Dsler as "Superbus" and William 5. Thayer as "Blair." the fictional setting "Liverpool" is actually Baltimore. 
become Regius Professor of Medicine at Oxford in 1905 and was knighted in 1910. 29 His published works and addresses greatly influenced the orientation toward science of major figures in the history of general purpose philanthropy, such as Frederick $T$. Gates, advisor to John D. Rockefeller Sr. 30

The final two figures in Sargent's portrait advanced the medical fields of Eurgery and gynecology at Johns Hopkins. William S. Halated, was a major figure in the development of modern surgery. He created a medical technology which contributed to the legitimacy of the new medicine. Hia wife, Caroline Hampton Halsted, pioneered in the field of surgical nursing. 31 Howard A. Kelly. Professor of Gynecology, was an activist in progressive political issues such as women's sufferage. He argued for the inclusion of women in medicine and in public health and social welfare. 32

29. Charles G. Rolend, "W1lliam Oeler, 1849-1919,

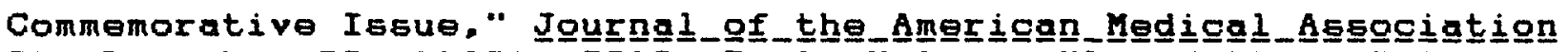
210(December 22, 1969): 2213; Emile Holman. "Sir William Osler. Teacher and Bibliophile," Journngl_of_the_American_Mediggl Assogiatiㅇㅁ 210 ( December 22, 1969): 2223; See Taylor. The

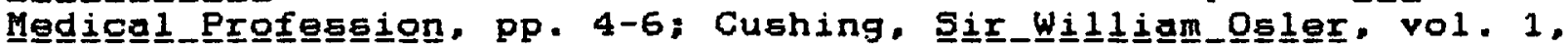
part 2 on Baltimore; also. Fleming. The_Hergeíg_Age, ch. 7 to 12.

30. Frederick T. Gates, "Recollections of Frederick T. Gates on the Origins of the Institute," in George $W$. Corner, A_Higtggry of York: Rockefeller Institute Press, 1965), Appendix I, 576-84.

31. Wilder Penfield, "Halsted of the Johns Hopkins," Jourrangl

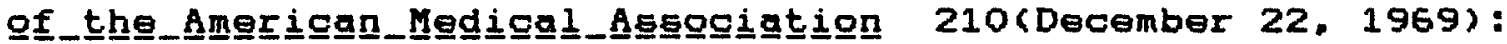
2216; J.M.J. Finney, "An Appreciation of Dr. Halsted," Johnng

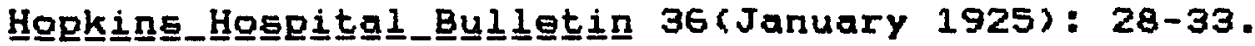

32. Thomas S. Cullen, "Dr. Howerd Atwood Kelly," Johang

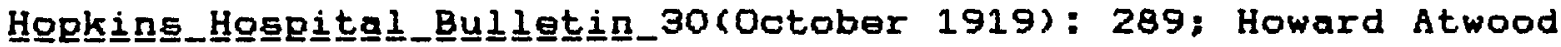

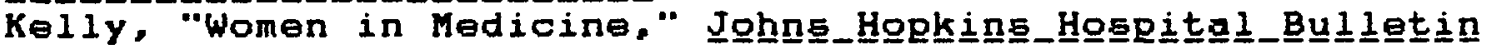


The atudents of these men are equally illustrlous, for among them are included Simon Flexner of the Rockefeller Institute of Medicine (Rockefeller Univeraity), and his brother, Abraham Flexner who wrote the influential 1910 Carnegie study of Megiggal

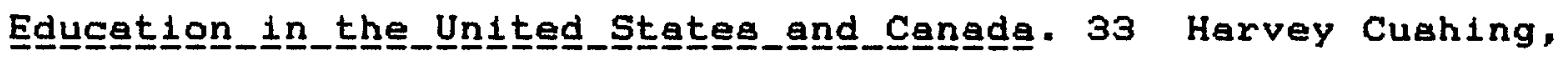
became a renowned medical educator and researcher at Harvard University and biographer of osler. 34 One of the first of many Canadian students to come to Johns Hopkins, Lewellya F. Barker, was also active in public health and medical reform. He became the first President of the National Committer for Mental

7 (Feb./Mar. 1896): 52; Curtis F. Burnam, "Howard Atwood Kelly,"

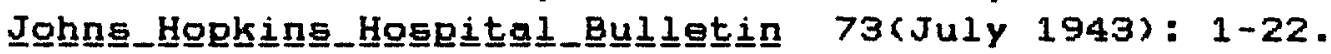

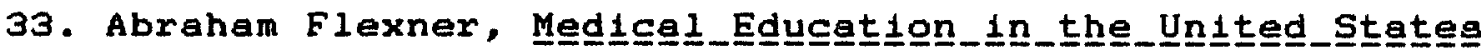
and Cangada Carnegie Foundation for the Advancement of Teaching Bulletin No. 4 (1910); "touched off a great movement of reform that in a decade or so made the departures of the Hopkins experiment standard all over the continent," Flexner and Flexner.

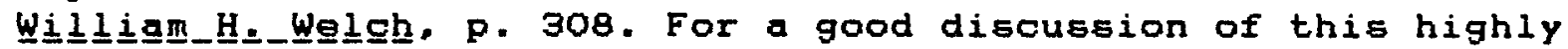
influential report see Ellen Condliffe Lagemann. Pri

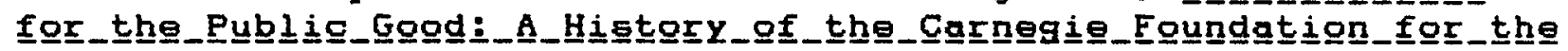
Advanncement_of Teagching (Middletown. Connecticut: Wesleyan

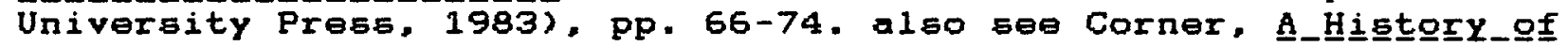

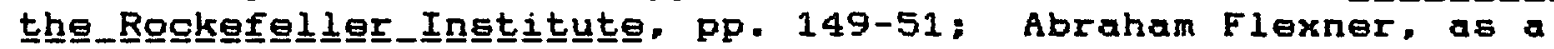
student at Johns Hopkins was greatly impressed with Gilman as a role model and with Johns Hopkins as a model university and medical school. See Abraham Flexner, Abra

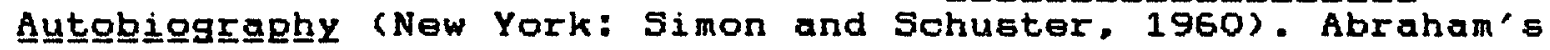
brother. Simon Flexner, a medical student at Hopkins went on to become Director of the Rockefeller Institute for Medical

Research. See James Thomas Flexner, An_American_Sagn: The_Storgy

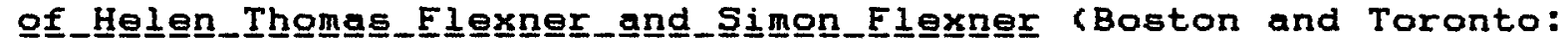
Little, Brown and Co.. 1984). Also se日 Barker, Tịme_ang-

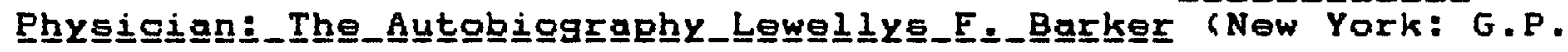
Putnam's Sons, 1942 ).

34. John F. Fulton, Haryvey_Cughhing:_A_B1ography (Springfield, Illinois: Charles C. Thomas Publisher, 1946). 
Hygiene. 35 Illustrating the intimate connection between

Canadians and American medical institutions from 1890:

Barker was the first of a succession of Canadians, Toronto Graduates, the picked men of their time, who after finishing a service at the Toronto General hospital gravitated to Baltimore on the recommendation of Osler's friend Jas. E. Graham, the Profeseor of Medicine at Toronto. Succeeding Barker during the 1890's were Cullen, Parsons, Fletcher, and the MoCrae brothers. Their firet summer before going to the Hopkins was usually spent at Garrett Hospital for Children at Mt. Airy, Frederick County, Maryland. 36

In addition to pioneering scientific medicine, laboratory research in pathology, and a reformed and upgraded medical education, Johns Hopkins also served as a model for the advancement of paychiatry and paychology. Johns Hopkins legitimated clinical research in a university setting and placed the support of medical science behind paychiatry, neurology, and their related fielde in preventive public health. Johns Hopkins was also at the forefront of the advancement of psychology which at other universities at the turn of the century was undistinguished from philosophy. Three major figures of influence in theae fielda include: G. Stanley Ha11, Adolf Meyer, and John B. Watson.

\section{G. Stanloy Hall and Ch1ld Study}

G. Stanley Hall, was one of the dominant figurea in peychology and education in the Progressive era. Hall was educated at Harvard with renowned Amerlcan paychologist Wil11am James and in Europe at Leipzig in Wilhem Wundt's pioneer clinical

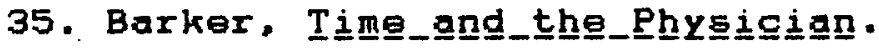

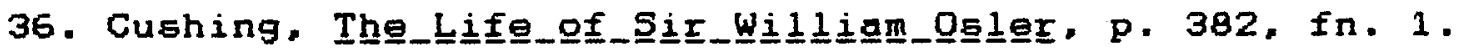


laboratory in paychology. President Gilman, with James'

recommendation, offered Hall a professorship in psychology and pedagogics at Johns Hopkins in 1882. In 1883, Hall published The

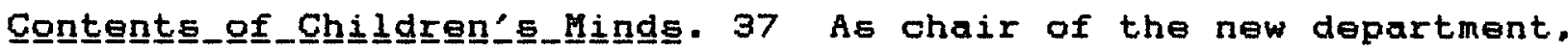
Hall initiated a model paychological laboratory grounded in hia experiences in experimental peychology in Europe. While William James had previously established a "psycho-physics" laboratory at Harvard, Hall'a laboratory at Johns Hopkins is considered the first true example in the United States. $38 \mathrm{Hall,} \mathrm{as} \mathrm{others} \mathrm{were}$ prone to do at Johns Hopkins, gathered around him men who later went on to make aignificant independent contributions to the development of science. Among Hall's students at Johns Hopkins can be counted: James McKeen Cattel1, John Dewey, Joseph Jastrow, and Edmund Clark Stanford. 39

Hall's influence was eclectic and widespread. His influence,

37. G. Stanley Hall, "The Contents of Children'a Minds,"

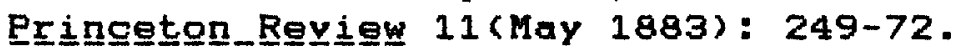

38. James M. Baldwin, "Psychology, Past and Present, "

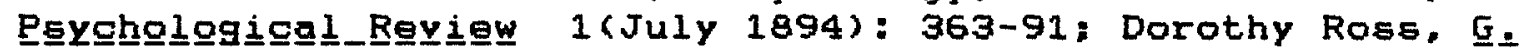

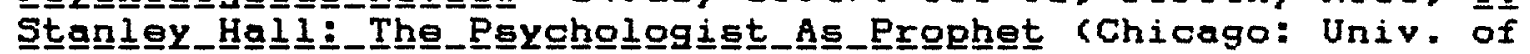
Chicago, 1972), pp. 154-5, 180, 246-7.

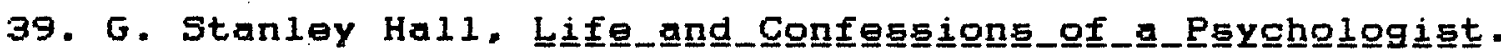
(New York: Appleton-Century-Crofts, Ino.. 1923). Also see two other contemporary accounts of Hall's life: E.L. Thorndike, pioneer in behavioral psychology. learning theory and intelligence testing, wrote a Biggraghical_Mengín_of_G._stanlanley Hall 1 published in New York, in 1923; and, Lorine Pruette's G.

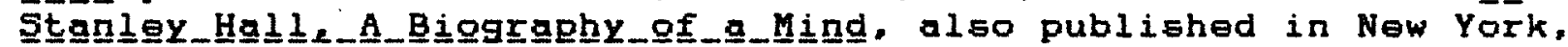
1926. For a more contemporary biography of Hall, see Ross, $G$.

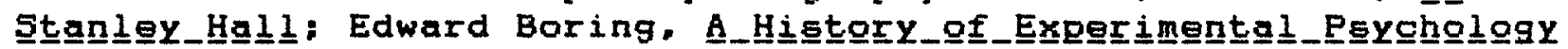
(New York: Appleton-Century-Crofts, second edition, 1950, first edition 1929), pp. 532-5. 
by way of students such as Lewis Terman, continued through to the second World War. He was the founder and first president of the American Paychological Association. Hall was also the founder and first editor of two journals, the Pegagogigaㅛ_semingary.

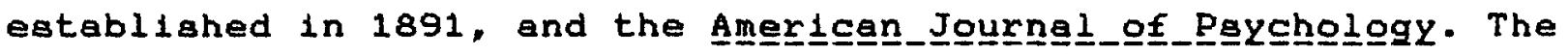
object of this latter journal, as Hall atated in the firat volume in 1887 was: "to record the psychological work of a scientific as distinct from a speculative character, which has been so widely scattered as to be largely unacceasible save to a very few and aften to be overlooked by them." The journal was directed at "teachers of psychology, blology, physlology, and anthropology who are interested in the primitive manifestations of psyohic laws, and physicians who give special attention to mental and nervous diseases." 40

By 1888 Hall had become the foremost critic of secondary and higher education in the United States. Hall became President of Clark University in 1889. Clark University, as conceived by Hall, was modeled on the principles embodied by Johns Hopkins under Gilman. Hall's vision was modified even more sharply toward the German model of post graduate acientiflc research. Hall's interest in and advocacy of child study had long term consequences. Hall, as an activist educational reformer, sought the attention of educators and incipient paychologists through

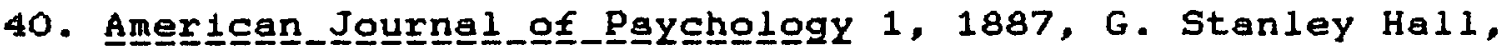
Editor. Title Page. Hall also edited the Pedagogigal_semingry. founded in 1891 which became the mouthpiece for Hall's work in child study. 
hia journals and lectures based at Clark and through his professional leadership in other organizations. 41

Hall'a perception of children was in part a refinement of the conceptualization of Rousseau's noble savage. Hall added to this 1dea, however, Charleg Darwin's notion of the aurvival of the fittest. Hall found the stages of childhood and adolescence in human development to be a reflection of natural processes in a recapitulation of the hiatory of the race. Hall explained adolescent behaviour in terms of storm and strese:

The adolescent is neo-ataviatic, and in this the later acquisitions of the race slowly become prepotent. Development [in this life stage] is less gradual and more salutatory, suggestive of some ancient period of storm and stress when old moorings were broken and a higher level attained. 42

The Child Study Movement grew in the $1880^{\prime} \mathrm{g}$ and $1890^{\circ} \mathrm{g}$. However, Child Study as an independently organized movement was

41. On Hall and Clark Un1versity see: Ross, G._Stannley_Hal Ch. 11; on the place of Clark University in American higher education see: Lawrence Russ Veysey, The_Emergenge日_of American_uniygereitey (Chicago: The Univereity of Chicago Press, 1965); Merle Curti and Roderick Nash. Phi

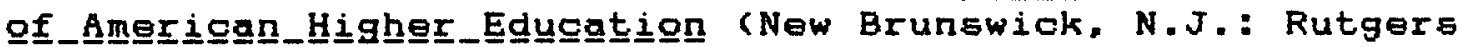
University Press, 1965); $W$. Carson Ryan, Stuudiege_in_Eax

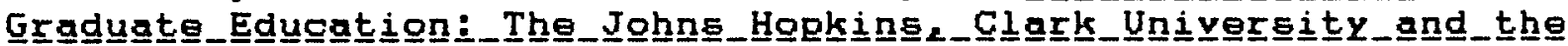
univereity of Chicago (New York: Carnegie Foundation for the Advancement of Teaching, 1939). The failure of Clark University to match its early potential even under the able leadership of Hall was due in part to its under endowment. Clark had much less money than originally supposed and financial crisis left Hall's small but talented faculty a prime target for other more well endowed universities, see Hall, Liffe_and_Gonfegesigons. pp. 295-7.

42. Granville Stanley Hall, Adolesgence:_Itg__Psycholgogy_and

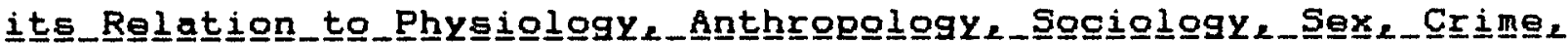
Reliiion_and_Education von vol 1 (New York: D. Appleton, 1904), $p$.

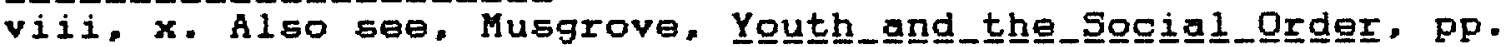
56-7, on Hall. 
relatively short lived even though it boasted study groups in a number of states and was counted among the two or three most vital topica in educational circlea up to World War I. Hall attempted to permanently establish child study in the National Education Association. His first attempt was in 1891 at the Annual Convention of the NEA held in Toronto. Hall was more successful at the 1894 NEA me日tings partly due to having popularized his ideas at the World Columbian Congreas held in conjunction with the 1893 Exposition in Chicago. The formal aspects of the movement were in decline, however, by 1904 when Hall's treatise on child study. Agglegg日enge, was published. Nevertheless, the impact of child study was more pervasive than its official organization or temporal existence might imply. Hall'a ideas on chlld study filtered into other organizations such as the Mother's Congress. precursor to the contemporary Parent Teacher Associations. It became a part of the developing academic disciplines which were to become the official guides for child life in the twentieth century. 43 One of the long term

43. A review of the child study movement in the states can be found in Pedggogicgal_Semingry 3(1895): 189-212; 4 (1896): 111-25. The Procegedings of the National Education Association in 1895. pp. 893-906, also contain survey data of the garly movement. G. Stanley Hall's most important work. Adglescenge. is a digest of his views on child study published in 2 vols. in 1904. It sold over 25,000 copies in the United states. Two years later the publisher came out with Youthh:_Its_Eguggatione_Regimen and_Hygiene, which was an abridgement of Adolegsgenge directed at an audience of teachers and parents. Hall's other works include:

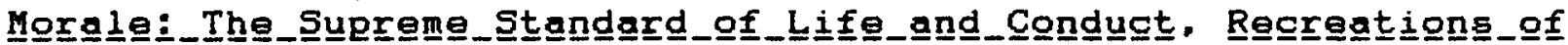

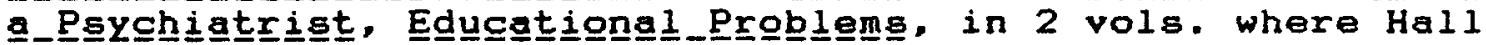
describes the essential problem of education to be "the pupil."

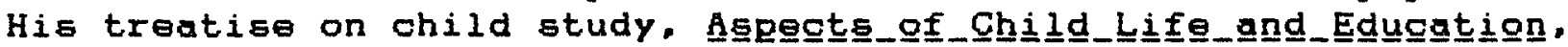
appropriately contains essays by his students as well as his own. 
contributions of the child study movement, as concelved by hall, was the great forward thrust that it gave to the theme of the childhood gaze in the legitimation of a scientific perspective which bolstered the medical model.

Hall'a concentration on the mental life and development of children combined with his publicly visible position did much to legitimize research on children on an international level. One author speculates that Alfred Binet's early experimental work on individual differences in children was spurred by Hall's early publications on the atudy of children. 44 Hall was also instrumental in introducing Freudian theory to the United states. Freud's only visit to the United States was hosted by Hall at the twentieth anniversary of the opening of Clark University In 1909. 45

Hall's influence was furthered by the fact that his students at Clark became highly influential leaders. For example, Lewis Terman, professor of educational psychology at Stanford

On the initiation of the child atudy movement see Ross, G. Stanley_Hall, p. 282 on the programme of the World's Congresses of 1893; al5o, Wilber Harvey Dutton, "The Child study Movement in American from its Origin (1880) to the Organization of the Progressive Education Association, (1920)." Ph.D Thesis, Stanford University, 1945. See Robert E. Grinder and Charles E. Strickland, "G. Stanley Hall and the Social Significance of

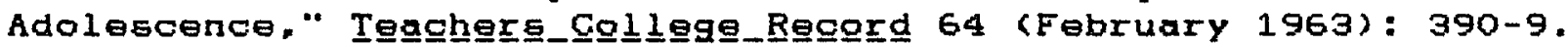

44. Theta H. Wolf, "Intuition and Experiment: Alfred Binet"s First Efforts in Child Psychology," Journal_of_the_his

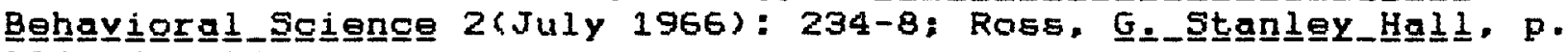
284, fn. 24 .

45. Ross, G._Stanley_Hel1 pp. 284, 352, 391-4; Nathan Hale,

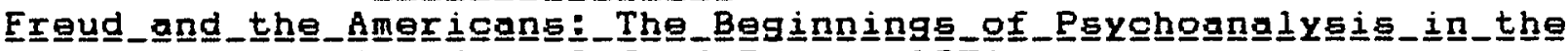

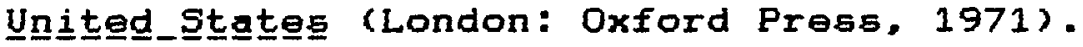


University, dominated the American Paychological Association in the inter-War years and greatly furthered the professionalization of school psychology and the dissemination of standardized testing and tracking in public schools. He was co-author of the Stanford Binet intelligence scale. Henry H. Goddard introduced Binet's tests to the United States. 46 He was Scientific Director at Vineland Training School for Defectives in Vineland, New Jersey where the Army Intelilgence acales were developed during the first World War. Goddard was a strong advocate of the eugenics and testing movements. Arnold Gesell was the founder of the Child Development Clinic at Yale in 1911. His work in early childhood development helped to establish this field. These figures, among other students of Hall at Clark, did much to shape educational psychology, special education, and early childhood education in the twentieth century. 47 If Hall helped to structure the times and was a product of $1 t$, he also participated in the development and diffusion of the spirit of Johns Hopkins

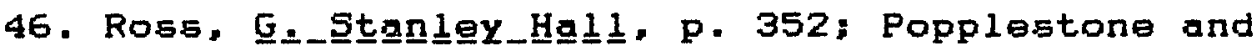
Mopherson. "Pioneer Psychology Laboratories," pp. 238-43.

47. Lawrence A. Cremin, The Trang formatison of

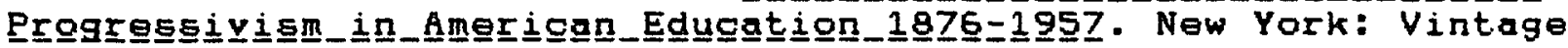
Book, 1964, p. 115, also p. 101 on Hall and pp. $110-1$ on Thorndike. Cremin ties in the influence of science in the psychology of William James and Social Darwinism as they shaped the ideological perspective of Progressive thought as it was directed toward education. The 1932 Distiongryy_of_Amerigan Bigggraphy Vol. VIII, ed. Malone Dumas (New York: Charles Scribner). pp. 127-9, cites Hall as second only to william $T$. Harris and John Dewey in his influence in education. His extended international impact is noted "especially recently in England." Wolf. "Intuition and Experiment." pp. 234-8. 
medical model.

\section{Adolf Moyer and Peychoblology}

Adolf Meyer was a Swlag born neuropathologlat who had come to the United States to work at Kankakee State Hospital in Worchester, Massachusetts in 1893. Meyer had in part been attracted to Worchester because of the presence of Hall and his work at Clark. Hall used Meyer and the state Hospital for lectures and clinical experience for his students. 48

Meyer's arrival in the United states also signaled a drive on the part of asylum paychiatriats to improve the scientific aspects of asylum peychiatry. Meyer was a respected and established laboratory worker in Europe. He introduced methods of laboratory science to the care and study of paychiatric patients as well as the collection of clinical records at Worchester. His efforts were recognized widely in the burgeoning medical field of the era. The influence of his experiences in the asylum and Hall's influential emphasis on biology and behaviour led Meyer toward a holiatic approach to mental 11 iness based on a theory which emphasized the interplay between mental and physical

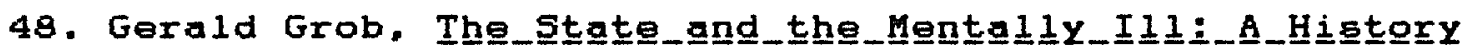

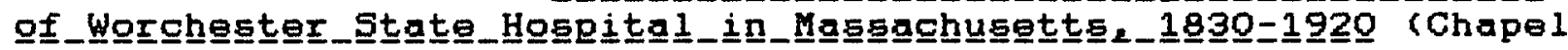
Hill: University of North Carolina Press, 1966); on Hall's influence in reforming psychiatry see New York Évenning_Pogst 6

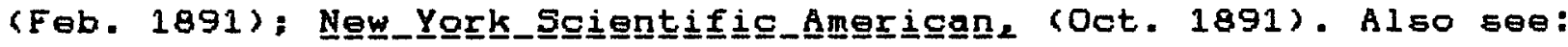
Adolf Meyer. "A Functional Appraach to Dementia Praecox," in

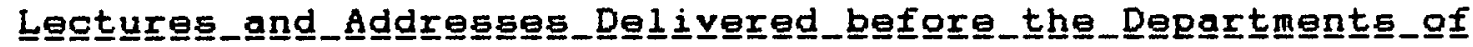

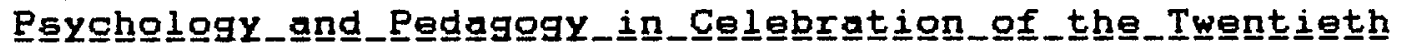

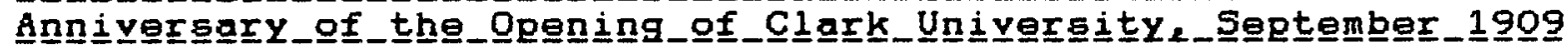
(Worchester. Mass.: Clark University, 1910), pp. 156-157. 
states. 49 By 1898 Meyer's purely neuro-anatomical orientation evolyed into the peychobiological approach which became a central premise in mental hyglene.

Meyer was called to Johns Hopkins by William Welch, where he was Director of the Phipps Paychiatric Clinic. The clinic had a social service department and served both adults and children. In this period Meyer was also an influential figure in the mental hygiene movement. 50 Meyer also provided an early scientific legitimation of peychiatrio interest which became fundamental to interventions into child life. Meyer's interests were reinforced by the theories of Freudian peychoanalysis, as well as by his medical colleagues at Johns Hopkins with their public health orientation. Meyer's paychobiology had affiliations with the developing environmental or behaviourist approach to psychiatric iliness. This is evidenced by his support for John B. Watson who conducted laboratory work in the Phipps Psychiatric Clinic at Johns Hopkins in the years just prior to and just after the first World War.

\section{John B. Watson and Bohaviourism}

John Broadus Watson took a position at Johns Hopkins in 1908. Watson had studied functional peychology at the University

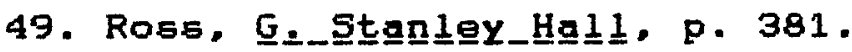

50. See Louis Hausman's "Introduction," in Eunice E.

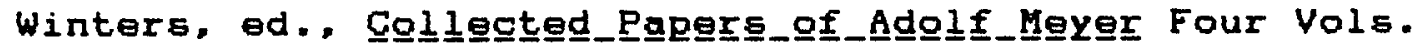
(Baltimore and London: The Johns Hopkins University Press, 1951-2), see especially Volumes I and II. Also see Clifford W. Beers, A Mind_That_Found_ItEe日le (New York: Longmans, Green and Co.. 1909 reprint Garden Gity. New York: Doubleday, 1965). 
of Chicago under psychologist James R. Angell. 51 Functional psychology as espoused at the University of Chicago tied together what were concelved as divergent perapectives. Angell described functional psychology at Chicago in these terms:

Functionalism as a psychophysical psychology is...constantly recognizing and insisting upon the mind-body relation - not as existential but as functional - as illustrated in the process of habit formation, with the end state one where consciousness has substantially given place to psychological automatism. The dominance of the social situation as stimuli, as objects toward which reaction is directed, is always stressed in this point of view. 52

This view was compatible with John Dewey's evolving environmentalism and Adolf Meyer's psychobiology as well as the behaviourism later identified with John B. Watson and B.F. Skinner. Watson's work was concerned with comparative psychology and laboratory research. H1s dissertation was on the growth of medullation in the central nervous system of white rats. Watson is known as the father of behaviourism stemming from his behaviouriat manifesto published in 1913. 53 However, it geems evident that these ideas and even the terminology had evolved in a larger context and in light of the advance of ayatematic

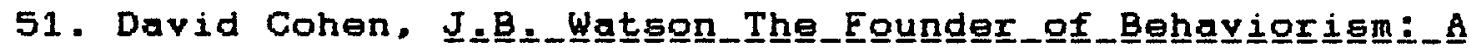
Biggraphy (London: Routledge \& Kegan Paul, 1979); James R. Angel1 was the son of James B. Angell. President of the University of Michigan. James R. later became President of Yale University.

52. James Rowland Angel1, "James Rowland Ange11," in HígtgrIy

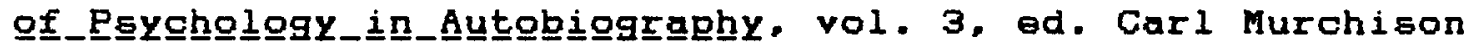

(Worchester, Mass.: Clark University Press, 1936), pp. 28-29.

53. John B. Watson, "Psychology as the Behavioriat Viewa

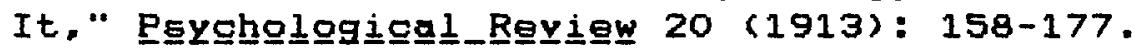


scientific inquiry. 54 watson, nevertheless, greatly contributed to behaviourism by establishing its basic premises in uncompromiaing terms. After world war I he did laboratory work with infants supported in his own words by "Dr. Adolf Meyer, Dr. John Howland, and Dr. J. Whitridge Williams," of Johns Hopkins.

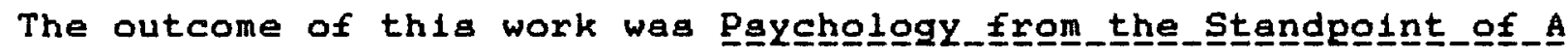

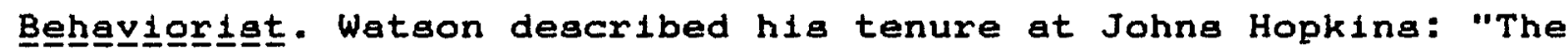
whole tenor of my life was changed. I taated freedom in work without supervision. I was lost in and happy in my work ... money and apparatus were provided amply." 55

\section{Medical Seience and Children}

The rising international concern over the physical and mental well beling of children and youth at the turn of the century accumulated a perspective grounded in the principles of preventive medical science. The impetus behind the direction of reformism was borrowed from the enormous impact of technical and scientific advances made in the first half of the nineternth century which had contributed to the rise of scientific medicine. The sharing of this knowledge was greatly facilitated by an International exchange of both leadership and technology.

54. Robert $M$. Yerkes and James $R$. Angell had apparently independently used the term "behaviorist" in 1912. Yerkes had given an earlier address. "Study of Human Behavior" at a Eugenics conference in June 1913. See Franz Samuelson, "Struggle for Soientific Authority: The Reception of Watson's Behaviorism,

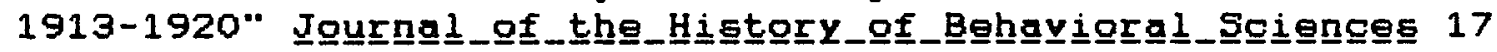
(1981): $399-425,401$.

55. John Broadus Watson, "John Broadus Watson," in The

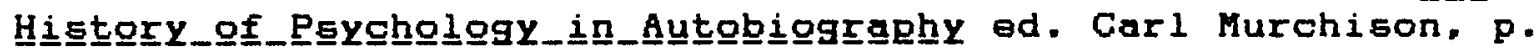
276. 
The invention of the microscope in 1830 led to the discovery of the medical origin of diseases. In the last two decades of the nineteenth century bacterlology made use of the fundamental discoveries of microscopic organisms in the $1860 s$ and 18705 and attempted to apply them. In the 18805 and 18905 the microbial causes of typhoid, malaria, tuberculosis, diphtheria, dysentery, tetanus, and cholera were uncovered. 56 On March 4, 1882, Robert Koch announced his discovery of the tubercle bacllius. The same year, Louis Pasteur discovered the principles of vaccination in the effectiveness of immunization against anthrax in sheep. The posaibility arose of vaccinating human populations against deadly diseases. Pathology became the central focus of advanced medical knowledge with ita most potent practical application termed "hygiene." Hygiene was later designated as "state medicine, public health or preventive medicine." 57

The school age population made accessible by the auccessful nineteenth century establishment of common schools and the legislation of compulsory school laws, offered an unprecedented opportunity for large scale public intervention into child health. European and British reform predated efforts in the

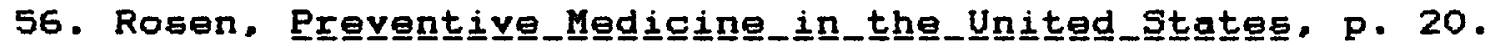

57. Flexner and Flexner, Wil1im HenIy_Welgh, p. 341 . fn. p. 234. Welch delivered two addresses on the subject of state medicine before the American Medical Association, one in 1889 and again in 1903. See Fleming, Willigm_H. Welgh, ch. 10, "The Birth of an Influential," pp. 131-151. 
United States and Canada. 58 So-called school hyglene was an

early battleground in the campaign for public health.

Medical inspection of schools was legislated in Brussels in

1874, in Sweden in 1878, and Paris in 1879. In England, advocates

first attempted to uplift the physical health of children in the

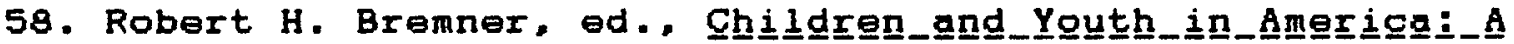

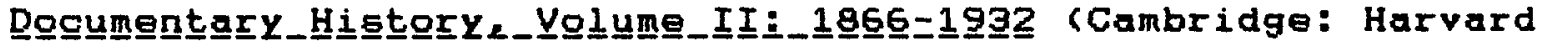
University. 1971), has an excellent overview of child health, pp. 811-15, and documentary coverage on the development of pediatrio thought, pp. 817-831, especially relevant: Section II, School Health. Organized medical inspections began in the United states in Boston, conducted by Dr. Samuel H. Durgin of the Boston Board of Health in 1894. The appointment of School physicians occurred in Chicago and Philadelphia in 1895. In 1897, New York established a model school health programme which was influential in Canada. Dr. Herman Biggs of the New York Gity Department of Health spoke to a meeting of the British Medical Association in Montreal, explaining the work in New York. Children with contagious diseases were to be sent home and examined by part time school medical doctors. Biggs expanded this madel to include the use of school nurses in 1902. Dr. Peter Bryce. first secretary of the Ontario Board of Health, supported the idea of following the procedures outlined by Bigge. See, Canada Commission of Conservation, Report, 1910, p. 132; also, Sutherland. Chilild포르. oh. 3 "Qur Whole Aim is Prevention:" Public Health in the Schools," for a discussion. Early concerns in the United States and Canada for school inspections initially focused on sanitary school environments. Augustus $V i e l e$ and W.H.B. Post, "Report on School-Buildings," This

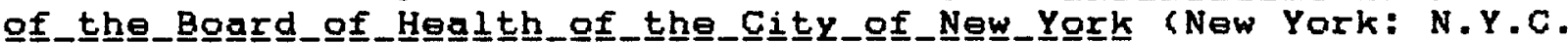

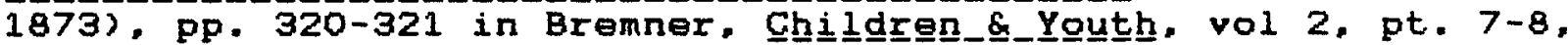
pp. 895-6. The concern with sanitation extended to the collection of physical data on the children. Information on the number of physical defects and diseases prevalent in school children was extended to include mental defects. See for example. Taliaferro Clark, George L. Collins, and W.L. Treadway, "Rural School Sanitation." in U.S. Public Health Service, Publlic

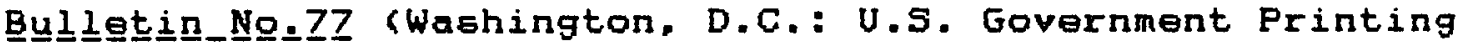
Office, 1916), pp. 107-113. Early sanitary inspections began in Ganada in 1883. Ontario Board of Health Regort, 1883, p.xivi. In British Columbia the first attempt to regulate health in the schools occurred in 1911. See the British Columbia Board of Health, Medical Inspection of Schools, Regorte. 1911. Comprehensive legislation allowing municipalities to make By-laws for the protection of children's health and welfare was enacted

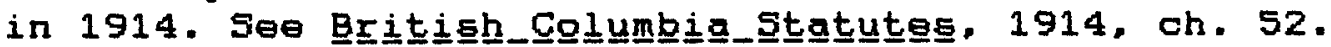


schools in the 1880s. Efforts in the United States and Canada

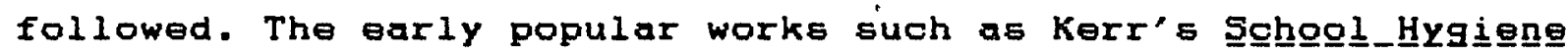
sold thousands of copies on an international market and were continuously reissued and updated. The connection between phyalcal health and environmentel conditions led to efforts for sanitary school buildings. Open air classrooms, and nursing and dental services were included as a part of schooling. By the early twentieth century direct arguments were made for the preservation of physical health in order to preserve mental health. By 1913, works on school hygiene included chapters on mental testing and detailed scientific descriptions of the brain and discussions of emotions and emotional development in children. 59

\section{The Formalization of Progress:}

The Spirit of Johns Hopkins as an Institutional Model The revolution in public health necessarily began in the restructuring of medical education and the building of a new medical leaderghip. Medicine was used as a guide for the reconstruction of profeseional schools at the graduate level and

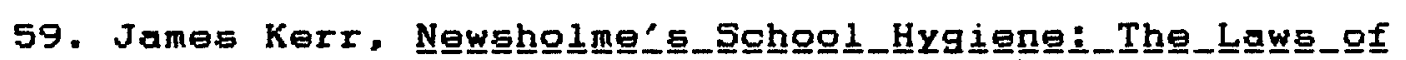

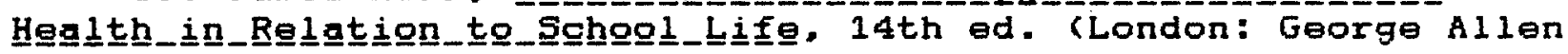
\& Unwin. LTD. 1887, 1916). By 1916 twenty-two thousand copies were sold. Kerr's (1916) revision of Newsholme's original included sections on "mental excercise and fatigue," the Binet-Simon Measuring Scale for Intelligence,' the physically defective,' and 'psychology.'Also se日 A.H. Hogarth, Medíg $\underline{\text { al }}$

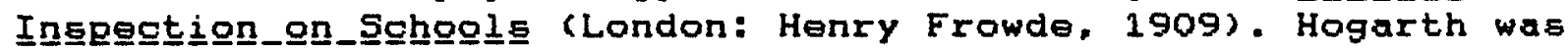
the Medical Officer for the Mansion House Committee on the Dwellings of the Poor, County Medical Officer for Buckinghamshire and Assistant Medical officer (for Education) on the London County Council. The book is dedicated to "Dr. Kerr, the first School Doctor." 
the creation of a base of social leaderghip as well. Standards were established for medical education which became the model for the American university system and for post graduate professional education in particular. These innovations depended on the legitimation of knowledge in systematic scientific research. Johns Hopkins served as a template for the application of science to the study of childhood. The Johns Hopkins model is especially relevant to the hiatorical convergence of the theme of the childhood gaze, medical reformism, mental hygiene, and scientific philanthropy in the twentieth century.

By the beginning of the twentieth century, the childhood gaze had taken shape in the form of graduate professional education. A concentration on scientific research pursued the advance of the medical and social sciences. The new knowledge base in medicine was conceived as a part of social reform in public health. The language of reform was a part of the childhood gaze as well. The men who first came to Johns Hopkins University were already convinced of the social value of the application of scientific knowledge. They did not get the idea of using science to protect human welfaxe from Johns Hopkins but from the ethos and ethic of the childhood gaze which gave Johns Hopkins its "spirit." The men and women in higher education who came after the clinical pioneers at Johns Hopkins had the benefita of their early theories, techniques and organizational models. The National Committee for Mental Hygiene and the Rockefeller Foundation also inherited the intellectual climate which Johns 
Hopking had carried with vigoux into the twentieth century. Practitioners in the new science of medicine sought to establiah social practices that would improve the quality of human life. The medical image of progress captured the Imagination of the formulatora of scientific philanthropy. The combination of philanthropy and science created one of the great alliances of modern times. It made it finanoially feasible to establish institutions which supported and made powerful a medical paradigm in the name of human pragress. In this period, medicine, bolstered by philanthropy, was established as a dominant profession in the United States. 60

The years between 1880 and the firat world war have been called the "herolc age of medicine." 61 There was a reciprocal relationship between public health reformism and the philanthropies which took shape in the first decadea of the new century. The geniuses of early entrepreneurial capitalism applied their resources and talents to philanthropy in this period. The outcome was an attempt to apply science to human welfare in the same sense as technology and industrialization had rationalized the economic aphere.

60. See Paul Starr. The_Socíl Trang

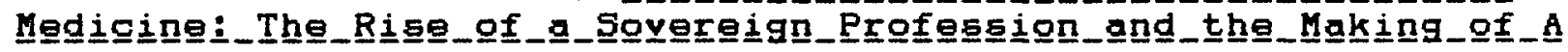
vasst_Industry (New York: Basic, 1982).

61. This is the title of Welch's biography. Flexner and

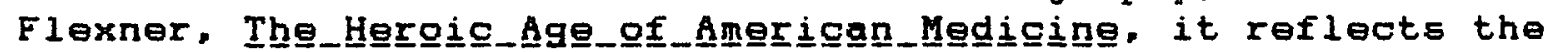
perception of the age by the medical establishment and the philanthropies which supported medical research and higher education. 


\section{CHAPTER TWO}

\section{THE MIDAS TOUCH: PHILANTHROPY AND THE POWER OF SCIENCE}

The diffusion of the medical reform as pionerred at Johns Hopkins and its formal establishment in institutional practices on a broader scale required vast sums of money = Benevolent donations to education and welfare are an established tradition in western societies. This tradition was pursued on a relatively large but unsystematic scale in the United States in the nineteenth century by men such as George Peabody and Henry Phippe. The character of economic expansion in the nineteenth century created a situation, however, which was unprecedented. Modern American philanthropic foundations directed resources in the twentieth century which were larger than any private pool of wealth the world had previously experienced in charitable organization. The rationale for private donations of large contributions for public purposes was perfected in the modern era by men such as Andrew Carnegie. The concentration of large scale philanthropic interventions in public health and the expansion of the scale of this work on an international basis was advanced by John D. Rockefeller Sr. and the Rockefeller family of philanthropies. Our concern with the elaboration of the childhood gaze in sacial policy directed toward children intersects with the role of philanthropy in modern social life. 1

1. On the origins of the Charity Organization Movement see, Frank Dexter watson. The_Gharityy_organization Moyement_in_the

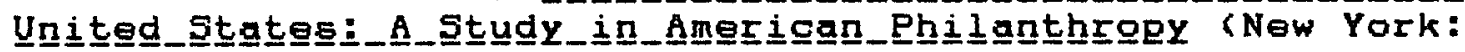

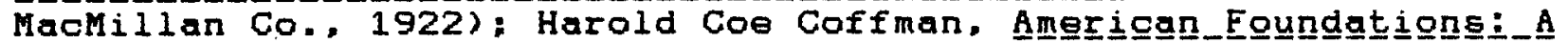

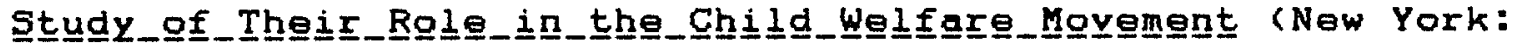




\section{The Rise of Twentieth Century American Philanthropy}

In the three and a half decades after the Civil war the United States reached unprecedented levels of industrial power. The accumulated national wealth approached sloo billion. The population stood at seventy-six million with city dwellers rapidly outpacing the rural population. The urban population grew from 15 per cent in 1850 to 40 per cent by the turn of the century. 2 The Jacksonian Democratio ideal of unencumbered individualism encouraged entrepreneurial capitalism and the accumulation of personal fortunes. The British observer, James Bryce, ended the first edition of The_Amerigaㅛ Commonweglth in

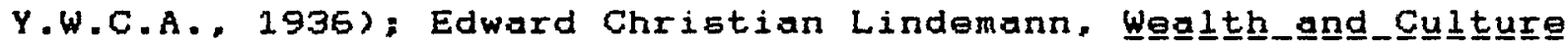
(New York: Harcourt Brace, 1936); Ernest Victor Hollis,

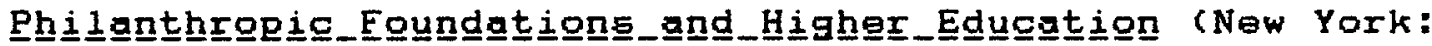
Columbia, 1938); more recently, Merle Curti and Roderick Nash,

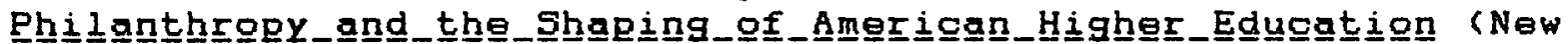
Brunswick: Rutgers University Press, 1965); on medical research, George Corner. A_Hi (New York: Rockefeller University Pres5, 1965); E. Richard Brown,

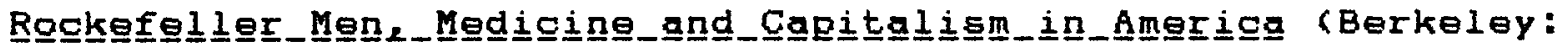
University of California Press, 1960); general overviews include:

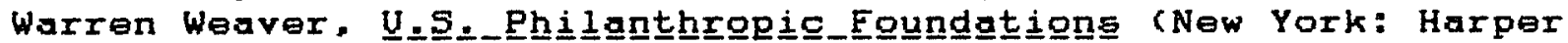
and Row, 1967); Waldemar A. Nielsen, The_Big_Equngantiㅡ믈 (New York: Columbia Univereity Press, 1972); Ben Whitaker, The

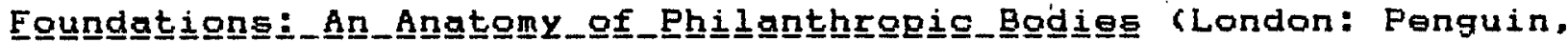

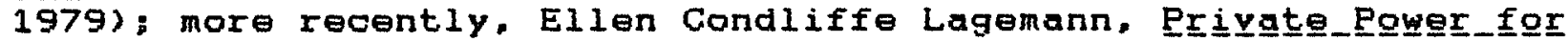

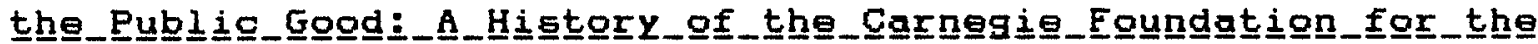
Agvannge日ment_of Tegeching (Middletown. Cann.: Wesleyan Univereity

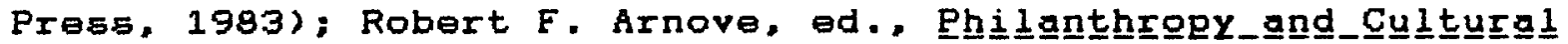

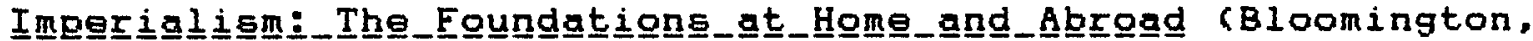
Indiana: Indiana University Press, 1982); and, Edward Berman, The

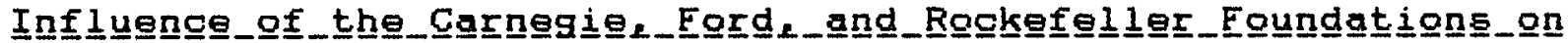

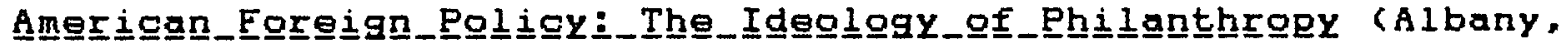
New York: State University of New York Press. 1983).

2. U.S. Department of Commerce, Bureau of the Census, "U.S.

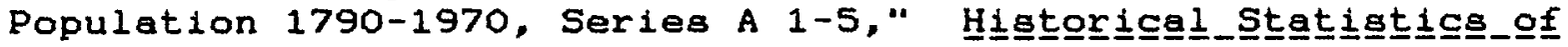

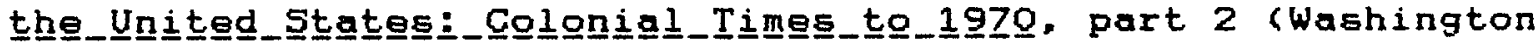
D.C.: U.S. Government Publications, 1975), p. 8. 
1888, with the statement that "America marks the highest level, not only of material well-being, but of intelligence and happiness, that the race has yet attained." 3 Not everyone concurred with the enthusiasm of this description. The discrepancies that de Tocqueville had observed as the contradictions of unrelenting individualism had bypassed the problems of equality to encompaes its opposite. Vast differences emerged in the distribution of financial and material resources. 4 "In the land of plenty there was never enough food. clothing and shelter for the underprivileged, and cyclical depressions... plunged millions into actual want. In the great cities slums grew apace and from the slums spread dirt and disease, crime and vice." 5

A U.S. Senate Committe日 on Social Betterment in 1909. reported on the poor health of women and children in the glass, textile, and clothing industries. The cause was attributed to the long hours of work, heat, noise, and poor ventilation. President Theodore Roosevelt called the first white House

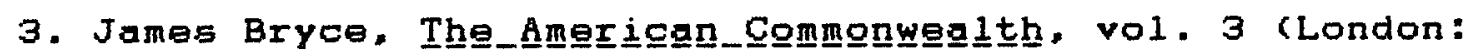
Mackillan and Co., 1888), p. 431 .

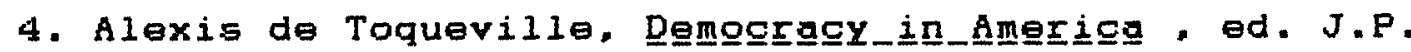
Mayer, trans. George Lawrence (Garden City. N.Y.: Doubleday, 1969), see pp. 503 on equality, p. 525 on democracy, and pp. 671-674 on individualism. also pp. 690-691.

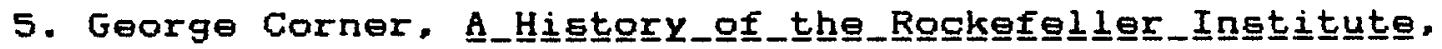
uses this quate by $E$. Morrison and Henry $S$. Commanger, The_G

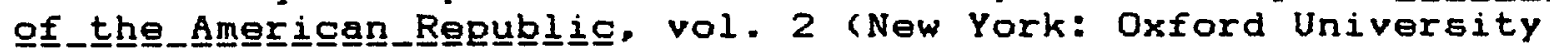
Press, 1950), p. 355, as a reason why the Institute for scientific medical research was founded. Charles A. Beard and

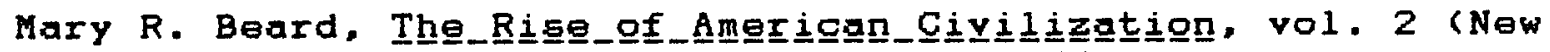
York: The Mackilian Co.. 1927), pp. 175-177. 
Conference on the Care of Dependent Chlldren on January 25-26, 1909. This conference was eventually to result in the establishment of the Federal Children's Bureau in 1912. Roosevelt's Commission on Country Life looked at the figures on rural populations. Rural areas lagged behind the urban centers in the technological advantages of educational facilities and lacked the prosperity to implement reforms. These problems were exacerbated in the poorer regions of the rural South. Efficient water quality control, sewage treatment, garbage collection and rudimentary health care, were a thing of the future. Industrial growth, urban expansion and high rates of immigration produced unhealthy living conditions. 6

The rising public awareness of health and other social problems associated with social and economic change were themselves by-products of the advances in technological innovation and in the elaboration of communication and transportation networks. A rising middle class was matched by an expanded lower class. Urban poverty supplied by immigration and low wages produced slums while at the same time the degraded conditions served as a reservoir of cheap labour for new

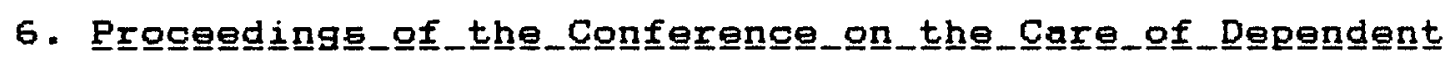

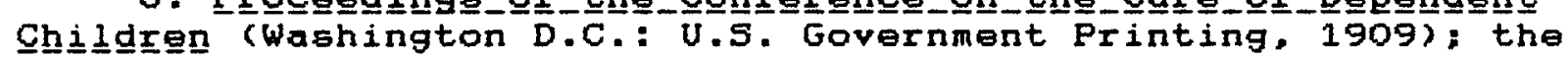
Commission on Country Life was appointed by Theodore Roosevelt in 1907, the report came out in 1909, on rural health see paul

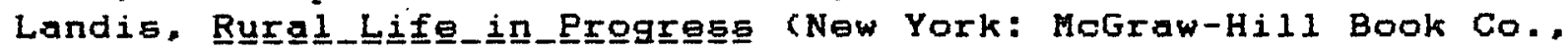
1940), oh. 28. p. 544, also. $59 \theta$ his appendix on the role of this Commission on the development of rural sociology and the professionalization of sociology as an academic discipline;

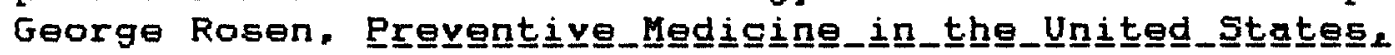

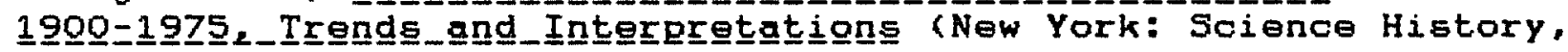
$1975), \mathrm{pp} \cdot \mathrm{6}-7$. 
industries. Cheap lebour contributed directly to the success of the entrepreneurial economy.

The 1890 census calculated that 71 per cent of the national wealth in the United States was held by 9 per cent of the population. The presence of the unequal distribution of the advantages of the growing economy did not escape the popular press. The muckrakers of the first decade of the century derided the corruption of power and wealth. For example, Claud W. Wetmore

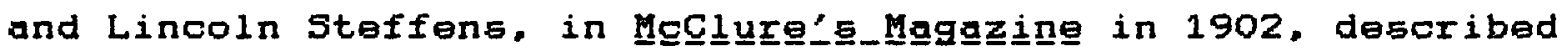
unscrupulous city officials to middle class readers. Similarly, Ida Tarbell singled out the injustices committed by monopolistic business practices in the Rockefeller controlled standard Dil Company. Frank Norris critiqued speculators in the railroad and grain industries. Upton sinclair illustrated abuses in the meatpacking industry and Hopkins Adams targeted medical quackery. 7 Middle class reformers in child welfare and public health did not incorporate the muckraker's arguments into their prescriptions for social problem solving. The character of the economic system and the nature of business practices as contributing to social problems were more often addressed as a matter of inefficiency. The consequences of extremes in the distribution of income and its effect on the degradation of the quality of life of a significant portion of the population'was

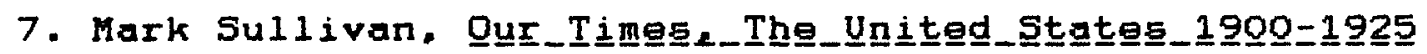
(New York: Charles Scribner"s Sons, 1926); Richard Hofstadter, ed. . The_Proggregs Prentice Hall, 1963), contains excerpts from many of these works. 
explained in other waya. Political liberaliam in ita concern for social issues was also a product of technological and scientific advance. There was a reciprocal relationship between laissezfaire economics and politioal liberalism. In combination they gave great impetus to the search for progress through positivistic inquiry. The search for progress stimulated all forms of scientific research in the same way that laissez-faire capitalism gave positive feedback to the development of scientific medicine. It was largely the advances of technology and scientific inguiry which brought about the possibility for a successful attack on public health related social issues. 8

Solutions to social disorder based in medioal and biological terms were elevated as viable while economic and political alternatives were less likely to even be raised as possibilities. 9 The approach to social problems adapted by scientific philanthropy sought explanations for poverty which leaned away from structural features of the economic system. Unequal income distribution was the source of middle and upper class financial status and its accompanying social and political benefits. In

8. See Marvin Harris. The_Rise_of_Anthrgogologicgl_Thegry:_A

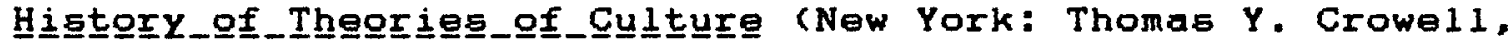
1968). p. 108; Charles E. Rosenberg. №_othrer_Godg:_on_Sgignge日

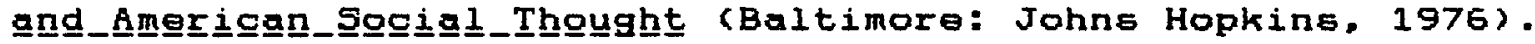

9. The intimation here is that economic systems predispose or favour certain types of information as legitimate knowledge. Social institutions accordingly use specific frames of reference which support their organization, see Basil Bernstein. Elass

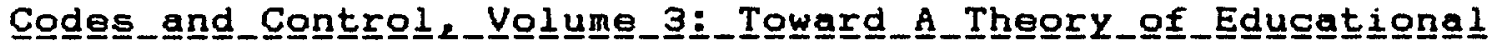
Trannsㅛㅛ톹욭 (London: Routledge \& Kegan Paul, 1975, reprint 1980), where he discusses the classification and framing of educational knowledge. 
seeking reforms the effort noticeably avoided upsetting what was becoming an established system of rewards accrued by relative positions of capital and labour.

This environment of economic and industrial growth, combined with the potential for social disruption, fostered the application of ecience to public problem solving. Charity in western, and especially British, culture was traditionally directed toward public issues. The benevolent society and charitable organization tradition became formalized and diversified in the course of the nineteenth century. The modern general purpose foundation with its unique scientific orientation, however, was a twentieth century phenomenon with specific historical roots in the United States. 10 Scientific philanthropy has been enormously influential in shaping twentiøth century U.S. institutions. It has been noted that "very few important cultural projects of any size are consummated .. Without having experienced either the direct or indirect impact of foundation philosophy or influence." 11

F. Emerson Andrews, first Director of the Foundation Library Center, defines foundations as non-governmental, nonprofit organizations which are established to maintain and further sooial, educational, charitable or religious activities for the

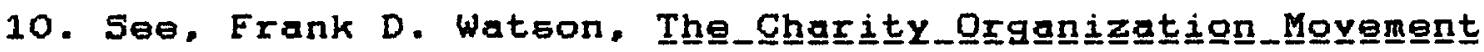

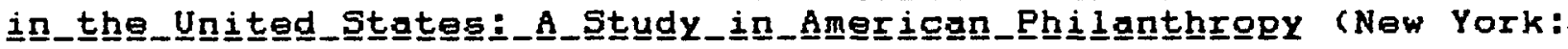
MacMillan, 1922). 1936.

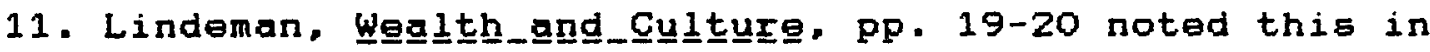


common welfare. They are supported by a prinoipal fund and governed by trustees or directors. 12 General philanthropic foundations evolved in the past one hundred years and their major development has been in the shorter time period since 1917.13 The Encyclopedia Britannica in 1910 did not deem them important enough for an entry. Fifty years later, 45,000 tax-exempt organizations were listed at the Foundation Library Center. Of these eleven per cent were endowed with one million dollars, 1855 than two percent had access to one to ten million dollars, and less than one half of one percent had over ten million dollars at their disposal. 14 while the absolute numbers of philanthropies have increased, the number of large powerful foundations is sma1l.

The large twentieth century foundations were a product of the unique circumstances of nineteenth century economic growth

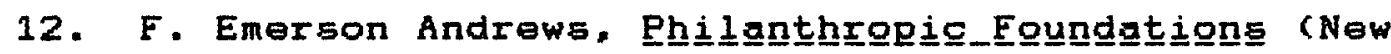

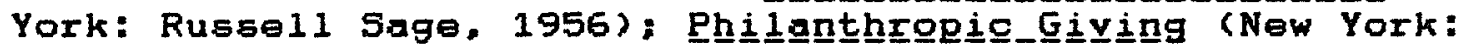

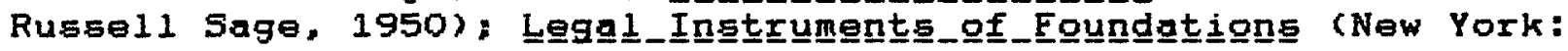
Russel1 Sage, 1958).

13. Milton Katz, "Intraduction," in u.s.

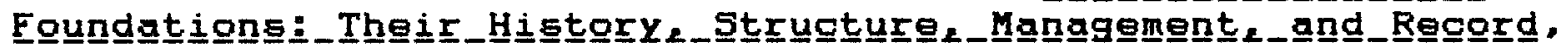
ed. Warren Weaver (New York: Harper and Row, 1967), p. ix: Barbara Howe, "The Emergence of Scientific Philanthropy, 1900-1920, Origins, Issues, and Outcomes," pp. 52-54; also Sheila Slaughter and Edward T. Sliva, "Looking Backward: How Foundations Formulated Ideology in the Progressive Period," pp. 55-87, both

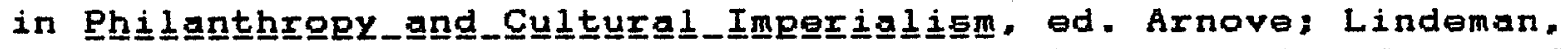

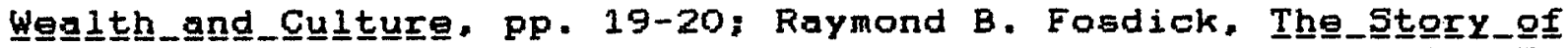

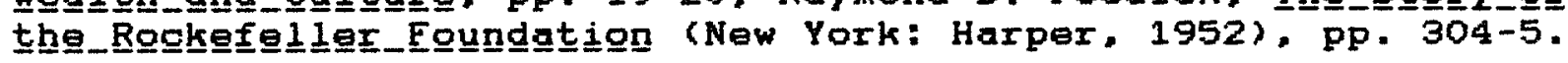

14. The Rockefeller Foundation is one of the most prestigious of the foundations in the latter category. Foundation Library Center data, 1960. Government tax Form 990-A, cited in Weaver, U. 
and social changes. The U.S. in the nineteenth century was witness to the establishment of a group of elites who acquired great wealth and power independent of their family of origin. The characterization of the self-made man fits sterl magnate. Andrew Carnegie: oil baron. John D. Rockefeller Sr. and automobile empire builder, Henry Ford. 15 The careers of these entrepreneurs validated the ideology of individual competition and laissezfaire capitalism where honest work and talent were rewarded by access to a good life and material comfort. Financial success was used to justify, by way of hindsight, the authority of men of wealth to exercise control over the lives of others. High social prestige and access to power in political as well as economic circles was argued to be a natural outcome of superior talent demonstrated in acquired wealth. 16

This perepective postulated that the wealthy, and, therefore

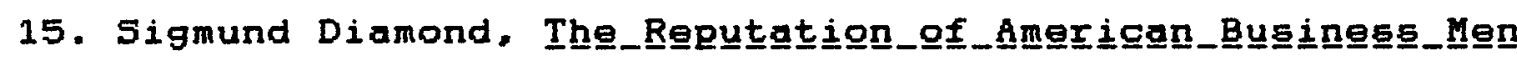
(Cambridge, Mass.: Harvard University Press, 1955), was interested in public perceptions of men who had accumulated great wealth during the nineteenth century; R.M. Galois and Alan Mabin, "Canada, the United States and the World-System." in Hearrtilang

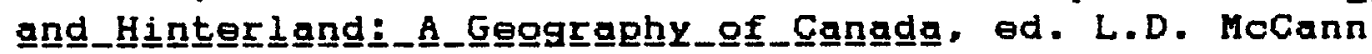
(Scarborough, On.: Prentice-Hall, 1982), pp. 37-62, point out, from a world system perspective. the conditions which made the accumulation of great wealth possible. The deceleration of the world-economy between 1875 and 1895 occurred after the initial thrust of the industrial revolution. The economic growth of the United States began to challenge British dominance of world economic relations. Competition increased over the accumulation of markets, raw materials, outlets for profit and investment. These conditions fostered the growth of "large corporations with monopolistic powers such as Standard $D_{i l}$ of New Jersey in the United States and the Canadian Pacific Railway of Canada." p. 41.

16. C. Wright Mil1s, The_Power_Elitge (London: Oxford. 1956. reprint 1969), pp. 271-4. 
the competent, had a responsibility to the less competent to provide leadership for the benefit of all. Andrew Carnegie's 1899 essay. "The Gospel of Wealth" stated the case of the philanthropist in these terms. To Andrew Carnegie, the problem of the twentieth century was the "proper administration of wealth" and that this endeavour "bound the rich and the poor." 17 The responsibility of the wealthy to advance society justified economic inequality on the basis of competence. The way to social progress should be led by a competent elite vanguard represented by men of power and welth. Carnegie favoured the development of a science of philanthropy in order to guide this elite in the distribution of funds in the public interest.

The major philanthropies of the twentieth century were formalized in the midst of a controversy over the validity of these views. Carnegie incorporated the Carnegie Institution of Washington on January 4, 1902. On January 28 he gave the newly formed Board of Trustees ten million dollars "to encourage, in its broadest and most liberal manner, investigation, research, and discovery and the application of knowledge to the improvement of mankind." 18 Carnegie's act, in its scope and breadth, was to

17. Andrew Carnegie, "The Gospel of Wealth," in Thhe_Goggel

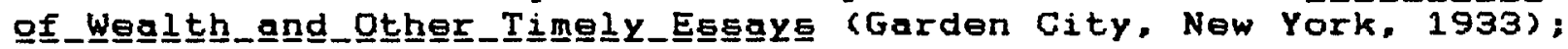
this essay first appeared in the Northb_omerisean_Review (June 1889) with a supplement in December 1889; Howard J. Savage, Er gf_an_Impulise (New York: Harcourt Brace, 1953).

18. "Charter Carnegie Institution of Washington," in George

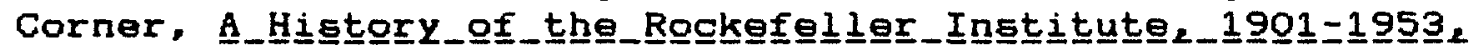

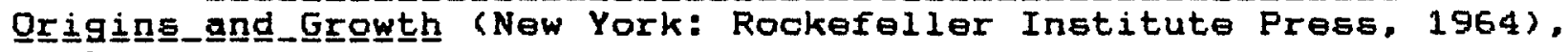
p. 51 . 
stimulate the development of the other philanthropies such as those of John D. Rockefeller Sr.

The identification of the private interests of entrepreneurial capitalist with the public good was a common and pervasive belief of the originators of scientific philanthropy. This strategy seems to have worked at least in influencing popular rhetorical descriptions of industrialists and their practices. One scholar found that public media in magazines and journals advanced the reputation of the entrepreneur based less on "the business activities or of the methods by which his fortune was made than on consideration of the destination of his wealth." 19 The early industrial philanthropists, both in rhetoric and practice, used a similar argument in justifying their accumulation of resources on the grounds that they redistributed benefits to noble causes. 20

One student of the American financiers John D. Rockefeller, Pierpont Morgan, Andrew Garnegie, George Peabody, Henry Ford, and John Astor was impressed with what he perceived as a "double

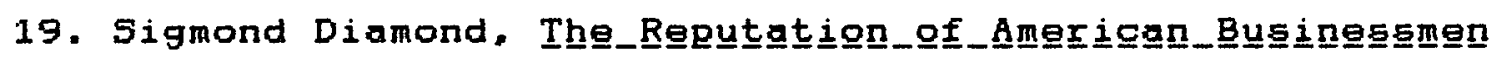
(Cambridge, Mass.: Harvard Univ. Press, 1955).

20. John D. Rockefeller Sr. is quoted as saying: "A man should make all he can and give all he can," in Allan Nevins, John_p_-Rogkkefelliex (New York: Charles Soribner's Sons), 1940. vol II, p. 191: Ellen Condliffe Lagemann, Privatépopower_for

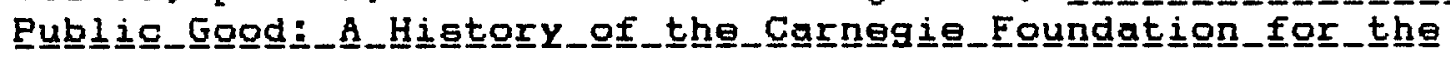
Advancegment_of_Tenching (Middletown, Conn.: Wesleyan Univ. Press, 1983). similarly notes that Andrew Carnegie gave away much of the fortune which threatened to make him the "richest man in the world,." p. 3 . 
language." 21 The f1rst, Internal to their mutual class and status interests, and, the second language directed toward public consumption. "This last truth to tell, was a brand of special pleading with public opinion to whom success of the financier is presented as the typical triumph of the self-made man. the condition necessary for the nation's prosperity." 22 This double language of rationalization can be seen as a personal and human reaction. Secondly, it can be interpreted as the "customary reaction of any dominant olass which fe日s its prestige waning and its privileges threatened. In order to camouflage itself it is necessary for it to confuse its own fate with that of the city, of the nation, its own private interests with the public interest." 23

The rationalization of philanthropy in the twentieth century turned the issues of social justice away from solutions based in economic or political considerations. It tended toward scientific explanations of personal and interpersonal failures. The tone, however, was optimistic in that these failures could be reversed or prevented by concerted eyetematic effort. Mary O. Furner notes that the American Social Science Association, (established in

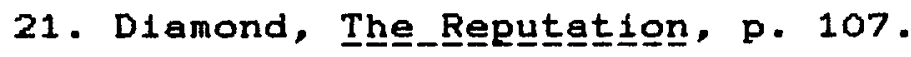

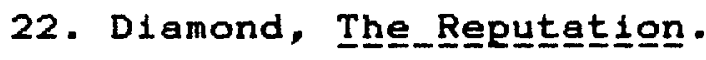

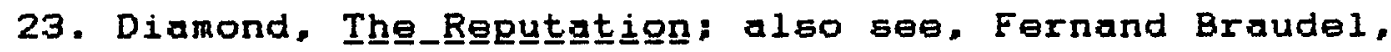
"History and the social Sciences: The Longue Duree," In On History (Chicago: Univereity of Chicago Press, 1980), pp. 25-47, p. 41, fn. 27; note, Raymond D. Fosdick, President of the Rockefeller Foundation, 1936-1948, expresely denies the interpretation of philanthropy as a "shield against public

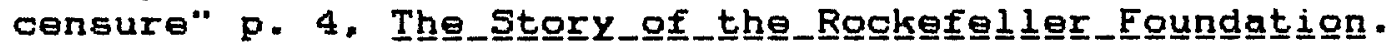


1865), which crossed between charity organizations and the eventual professionalization of social science, interpreted "iliness, crime, and social pathology as curable by measures that promoted physical and moral health; voluntary, collective efforts to reduce the economic insecurities of the industrial system were vastly preferred by reformers in almost every case to basic changes in the system." 24 Thase who were outspoken in their critique of capitalism in academic circles found themselves ostracized by the outraged industrial patrons of higher education. 25

Social problems were often reinterpreted and only partly seen, even by more radical contingencies, in terms of the unequal distribution of rewards and income. There was an ambivalence even in the populist rhetoric between respect for the successful self-made man no matter how he earned his mobility, and ideas of individual freedom, fair play, and democracy. The 1880 witnessed the popularity of Edward Bellamy's utopian socialist novel

Lgoking_Bgagkwaㅁㅁ․ Bellamy's world was based on a vision of well being for all in a planned social order which maintained high

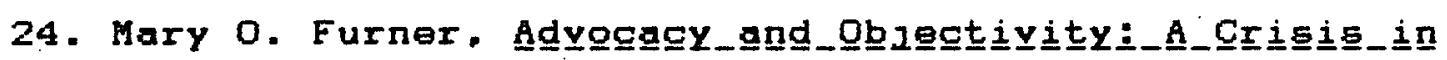

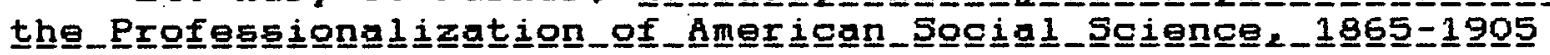
(Lexington, Kentucky: University of Kentucky, 1975), pp. 33 \& 38;

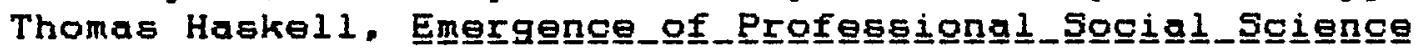
(Chicago: University of Chicago. 1977).

25. Richard Hofstader and walter P. Metzger. The日e-Dẹelolopment

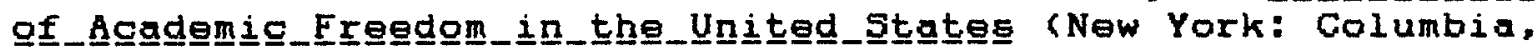

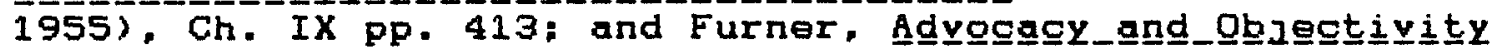
illustrate this point. 
atandarda in an atmosphere of rationalized inequalitiea. 26 The syndicalist movement in labour organizations such as the International Workers of the World (the I.W.W.) attempted to organize a better world based on the opposite premise of a brotherhood of equals. 27

None of the more extreme perspectives on class related inequalities were to gain general credence by the larger contingents of moderate middle class reformers. Reform efforts in education, public health, and welfare were not concerned with the underlying political causes of economic or social discrepancies. The objective was to establish efficient social leadership which was capable of solving public disorders such as disease and ignorance. This ideological emphasis was articulated and encouraged by industrial leaders turned philanthropists. John D. Rockefeller Sr. and his advisors were caught up in this rhetoric. A model for the organization of scientific

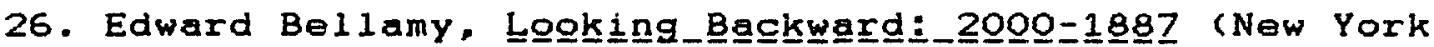
Modern Library, 1893, reprint 1917); Arthur Lipow, Authoritaㅗien

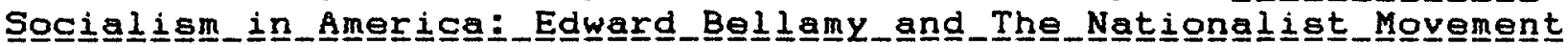
(Berkeley: University of California. 1982); Robert Weibe, The

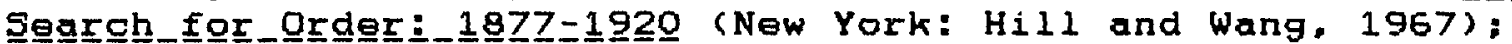

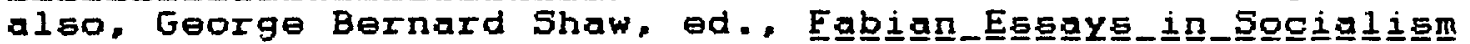
(Boston: Ball, 1911).

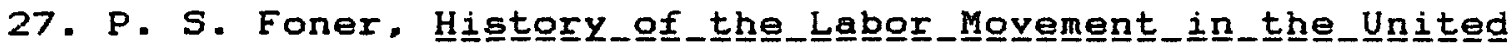

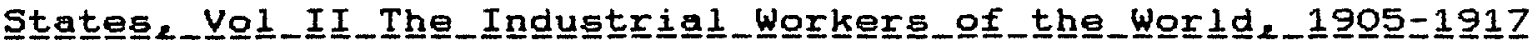
(New York: International Publishers, 1965); Patrick Renshaw, The

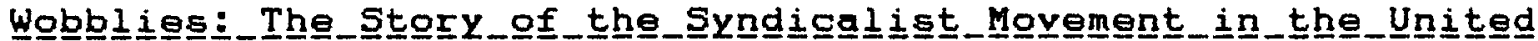
Statee (Garden C1ty, New York: Anchor, 1968); on Canada see

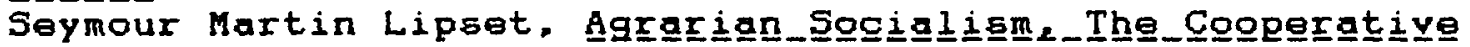

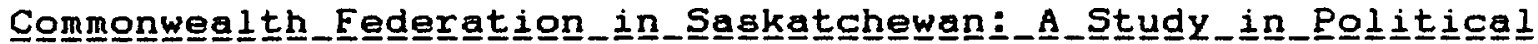
So으으의ogy (Berkeley: Univ. of California Press, 1950); and, David

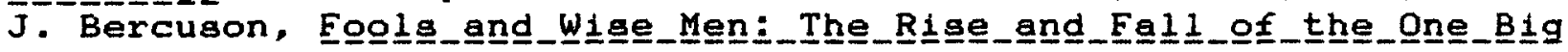
Uniㅡㅁㅡ (Toronto: McGraw-Hill, 1978). 
philanthropy emerged. 28 Certain general principles or practices guided Rockefeller philanthropy and contributed to the organization of other foundations as well. Foundations were conceived as affecting public interest and were consequently considered to be a public trust in private hands. Rockefeller made the innovation in charity that the donation of capital funds were to be chartered. Full responsibility for the execution of the charter was to be placed in the hands of trustees and officers of the organization rather than the donor. Neither the mandate for the use of funds nor the organization of the foundation itself was to be restricted to rigid or unchangeable purposes. Control over projects was to be exercised in the original grant or approval for continuing allocation. Once a responsible agency and project was deemed worthy of support, it was to be given independent responsibility to carry out the work. The purpose of grants were to "prime the pump" for social reforms rather than be considered a "permanent reservoir" for long term efforts. No one fund or philanthropic board was to be considered permanent. Broad topics and issues were to be pursued for specified periods of time. The concern was to avoid "frittering away" funds on diverse unrelated small projects. The general criteria for the worthiness of a topic as a focus for the creation of a foundation or board with capital funds to disperse was the importance of national or international impact of an

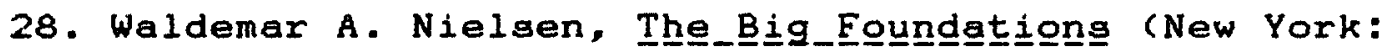
Columbia, 1971), p. 47, Ch. 4. 
issue. According to Rockefeller Foundation officials one of the "useful functions" of foundations, with their "wide and intimate contacts," was their projected ability to act as an "unofficial clearing house for ideas." 29

Rockefeller philanthropy which was the major patron of medical science and philosophy in the first half of the twentieth century, evolved through several different organizational forms during this period. In 1901 John D. Rockefeller Sr. established the Rockefeller Institute for Medical Research with a total gift of $\$ 60,673,409$ figured on the market price of eecurities of the day. Two years later in 1903 the General Education Board was established for the promation of education in the United States with a gift of $\$ 129,209,167$. The Rockefeller Foundation itself was established in 1913 with a gift of $\$ 182,851,480$. In 1918 , the Laura Spelman Rockefeller Memorial (LSRM) was created to further the humanities and social sciences with a gift of $\$ 73,985,313$. In 1923 the General Education Board's work was carried to other countries with the creation by John D. Rockefeller Jr. of the International Education Board (IEB) with a gift of $\$ 20,050,947$. When the IEB spent its funds in five years it was liquidated. That same year, the LSRM was consolidated with the Rockefeller Foundation but certain epecial programs were continued under the Spelman Fund of New York with a gift of $\$ 10,000,000$ until it too was consolidated with the Rockefeller Foundation. The expenditures of these Boards to 1950 were $\$ 451.5$

29. Fosdlck, The_Story, pp. 289-300. 
million for the Rockefeller Foundation, $\$ 296.7$ million for the General Education Board, $\$ 55.3$ million for the Laura Spelman Rockefeller Memorial, and $\$ 18.3$ million for the International Education Board. Between 1917 and 1928 alone, \$10 million was spent on schools of hygiene and public health, \$3.7 million was spent on research fellowships in math, science, and medicine in the United States, Ganada and Europe. 30

Although monopoly capitalism and its offspring in scientific philanthropy have periodically come under serious political and legislative attack in the United States, no other country has so favoured the development of large scale philanthropies. The principle of private giving survived the early vicious controversies such as the thres year deadlock of the U.S. Congress over the incorporation of the Rockefeller Foundation. While the foundations have periodically come under review their existence has never been seriously in danger. 31 The philanthropies have assumed a major role not only in the United States but have impacted the institutions of other nations.

30. Rockefeller Foundation, Annugl-Reports; Fosdick, The Story, "introduction" p. ix-x, also see, Appendix III, p. 313-314 where areas of Rockefeller Foundation activities are listed for the 1913-1950 period, including: 28 European countries, 5 African, 33 in "The East," 5 in North America, 12 in South America, and 10 in the Caribbean, totaling 93 in all.

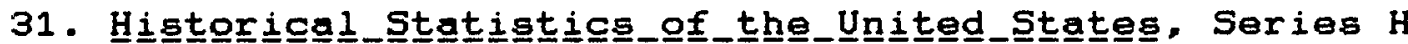
398-411, p. 354; There have been four major Congressional Investigations of Foundations in the United States lead by Frank P Walsh, Montana, 1915; E. Eugene Cox, Georgia, 1952; B. Carroll Reece, Tennessee, 1954; and Wright Patman, Texas, 1962-1964; see

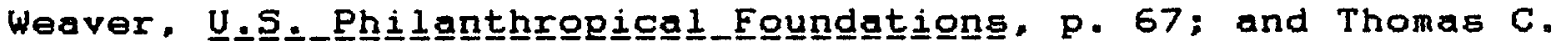

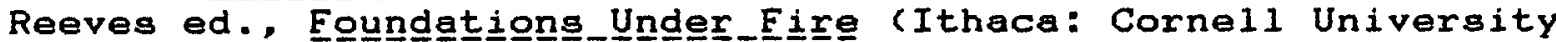
Press, 1970). 
Canadian inatitutions have both benefited from, and upon occasion, seriously resented both publicly and privately, the Invasion of resources and precedents from the south.

\section{The Canadian Perspective}

The Canadian late nineteenth and early twentieth century experience, in spite of similarities with the United states, also differed significantly. A transcontinental economy was barely achieved in Canada at the turn of the century and a nationally integrated urban system was not achieved until the early 1920s. 32 By the twenties most of the productive agricultural land was occupied and a strong manufacturing industry had emerged. Prior to World War I the United Kingdom was the major source of foreign capital. After world War I the United States increasingly displaced the United Kingdom. By 1926, the U.S. was the dominant foreign investor in Canada. 33 The bulk of Canadian

32. George A. Nader describes an urban system as: "territorial units of human organization which become specialized and therefore more interdependent, and in which the whole social

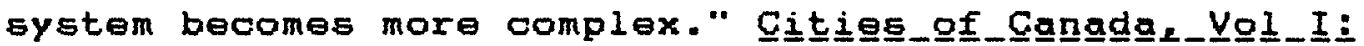

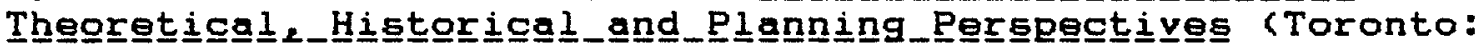
MacMilian, 1975): p. 2; Gilbert A Stelter and Alan F.J. Artibise,

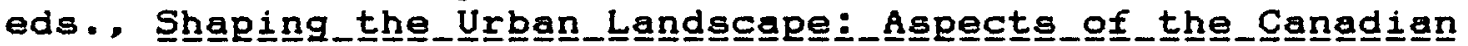
City-Building Progese (Ottawa: Carleton University Press, 1982), L. D. McCann "Heartland and Hinterland: A Framework for Regional

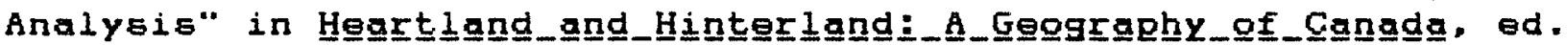
L.D. McCann (Scarborough, On.: Prentice Hall, 1982), pp. 2-34; also, in the same volume, R. M. Galois and Alan Mabin "Canada, the United States and World System: The Metropolitan Hinterland Paradox" pp. 37-62; see figure 2.3 which describes the patterns of economic core and periphery in North America in $1911, p .53$.

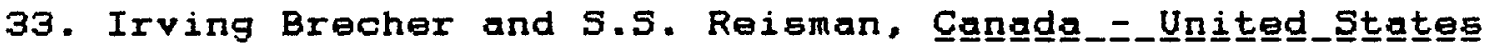

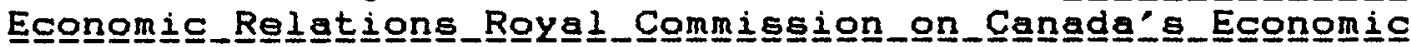
Prospects (w.L. Gordon, Chairman, July 1957), see pp. 18-24, and pp. 112-115 on the determinants of foreign investment in Canada in general, and 116-129 on the interdependence of the canadian 
development occurred at $a$ later date than in the United States for numerous reasons. No national urban system based on an industrial economy existed at the time of the Confederation of modern Canada in 1867. The British North American colonies tended not to rely on each other but instead shared a common external orientation to Great Britain or the United States. The rate of population growth actually declined in the $1880 \mathrm{~s}$ and 18908 attributable to out-migration exceeding natural growth. 34 In 1891 the Canadian total population stood at 5 million in comparison with 63 million Americans. A vigorous prairie settlement policy established in 1896 brought 3 million immigrante to Canada between 1896 and 1914 with 400,000 arriving in 1913 alone. 35 The wheat boom on the prairies stimulated the interregional movement of goods and people helping to forge a transcontinental economy and a national Canadian urban system. The population had increased to $7 \mathrm{million}$ in the 1911 Census and to nearly 9 million in 1921. These figures are still appreciably less than the $106 \mathrm{million}$ American census figure for the same

and U.S. economies: Nader, Gittieg_of_Eangda p.210; Michael 5 . Cross and Gregory 5 . Kealey, eds.. The Congolidgation_of

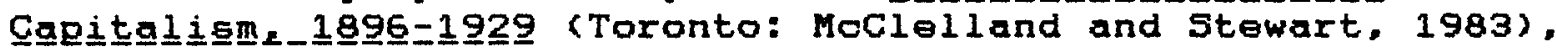
ses especially John $C$. Weaver, "Elitism and the Corporate Ideal: Businessmen and Boosters in Canadian Civil Reform, 1890-1920" pp. 143-168; Galois and Mabin, "Canada, the United States, and the world-system" see Table 2.3 on direct foreign investments in Canada, p.49.

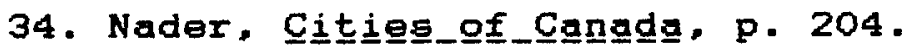

35. Nader, pp. 204-205; on the wheat economy, pp. 206-207. 
period. 36

Canadian nation-building occurred after the United States. The nation-building process in Canada also differed significantly in political and sconomic character and especially in its elaboration of the relationship between the individual and the state. Part of the ideology of the nation-building process in the United states was based on a Republican version of the "agrarian myth." Republican and democratic beliefs were intertwined with the image of the yeoman farmer as the embodiment of political and social values. The right of the individual to ownership and exploitation of land and resources was a central aspect of the American version of this ideology. With land ownership went the privileges of citizenship, political independence, economic status and social and self-respect. The advance of the individual in a Darwinian struggle for survival assured the advance of the nation. The land policy which incorporated these beliefs encouraged the dispersion of the publio domain to private hands in 160 acre plots for either cash or equivalent labour. The principles of the reservation of land from private ownership. the practice of crown ownership and lease-hold tenure, which characterizes Ganadian land policies and distribution of natural resources, are in stark contrast to nineteenth century American

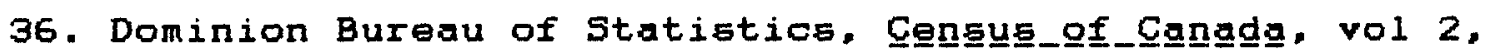

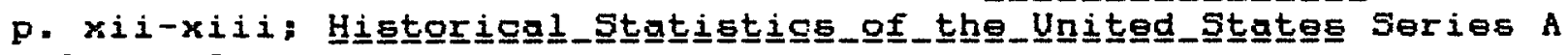
1-5, p. 8 . 
counterparts. 37

The Canadian conception of the state and the retention of state ownership expressed in "crown lands" was a product of Canada's colonial heritage and unique social and economic history. In the early nineteenth century two-sevenths of all public land was tied up in Grown and Clergy Reserves. Of the 4.5 million acres which were transferred to individuals or groups. the distribution was characterized by extreme favoritism. Loyalists received 200 acres, ex-officers could claim up to 5,000 acres, Legislative Councillors got 6,000 apiece, and entire townshipe were granted to "entrepreneurs" for speculative purposes. 38 The oligarchy of upper Canada acquired the name of "The Family Compact." Versions of the "Family Compacts" or "Ghateau Cliques" of Halifax. Fredericton, Guebec and Toronto, did not go without criticism and opposition. 39 Nevertheless, as John Porter has pointed out, modern Canadian society retained families of ascribed wealth and prominence over the generations. These families have taken on the traditional philanthropic role of overseeing the common good which is the accepted "duty" of

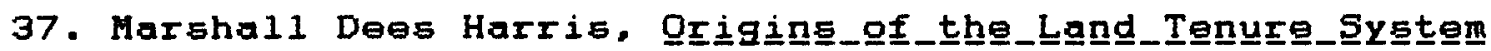

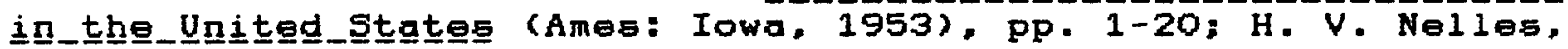

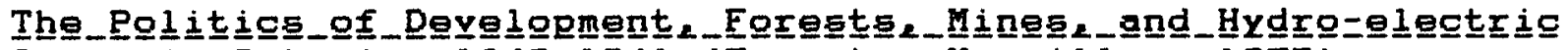

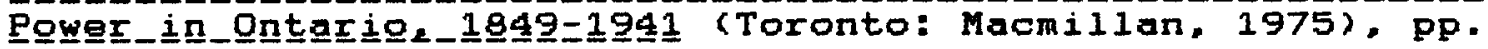
30-41.

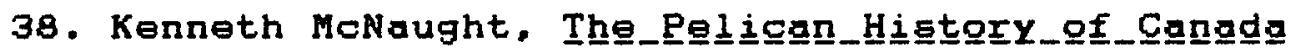
(Middlesex, England: Penguin, 1982), pp. 66.

39. Donald Creighton, The_storgy_gf_Eangda (Toronto: Macmillan, 1978), pp. 118-9; J.M.S. Careless, Union_of_the

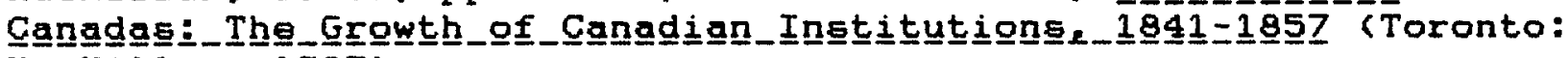
MacMillan, 1967). 
those of high status. It is not surprising that the families of traditional rank, largely of British Protestant origin, have contributed more than their disproportionate share to an emergent corporate elite in the twentieth century. These precedente have extended into the post world war II era, indicated by the fact that at mid century, the upper one per cent income recipients in Canada received 40 per cent of their income from stocks. 40 While there ie little reason to believe that the United States and Canada have different levels of material inequalitiee, it has been postulated that "Canada is more elitist, ascriptively oriented and particularistic than the United States." 41 The possessive individualism of an agrarian frontier made inroads upon monarchical traditions in Canada but did not eliminate them. As A.R.M Lower commented, "The perpetration of monarchical forms, even though the life has long since gone out of them, doubtless serves to act as a curb upon the fulleat expression of

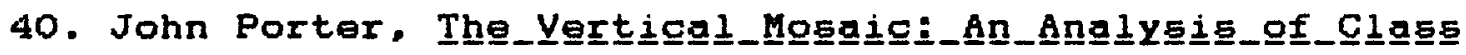
and_Power_in_Cangda (Toronto: University of Toronto, 1981), 4-5; Peter Newman, The_Cangdian_Egtablis

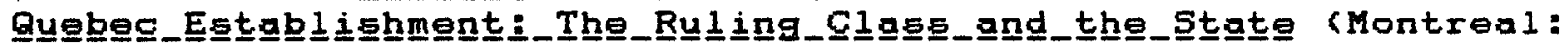

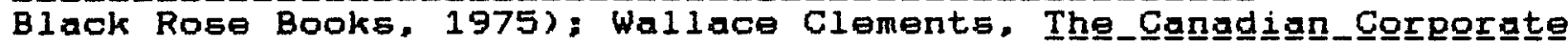

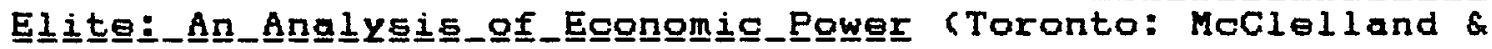

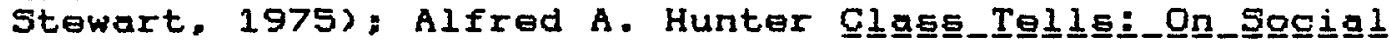

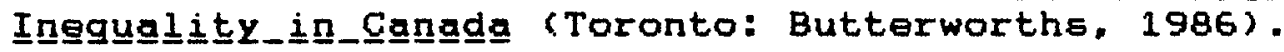

41. S. Gilbert, "The Selection of Educational Aspirations." in R. A. Garlton. I A. Colley and N.J. Mackinnon, øds.,

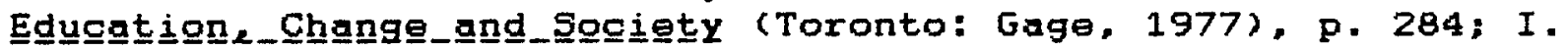
Gillespie, "On the Redistribution of Income in Canada." In J.

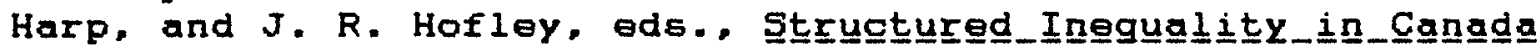
(Scarborough: Prentice-Hall of Canada. 1980). 
democracy." 42 The monarchical tradition encompasses an

ideological perspective as well as a set of institutions. It presents an organio view of sooiety where the erown, and leading classes, in conjunction with government institutions, are responsible for molding the character of individual members of society. The role of established leadership is to measure "wealth against commonwealth" in the preservation of a just society and to assure orderly social change. American conservative intellectuals at the turn of the century relied on individualistic values justified by Darwinian and Spencerian models as the basis for progreseive reformism. Canadian counterparts owing more to Burke than to Darwin looked to the state for moral direction as a legitimate basis for collective reformism. Canadian organic conservatism has shaped Canadian individualism, materialism, and democratic values. Similarly, Canadian liberal traditions emphasized the role of the state in exercising authority in the collective interest. The tendency has been to champion unencumbered provincial rights and jurisdiction over individual property and civil rights. This has been a significant constitutional and ideological difference between the United States and Canada. 43

42. A.R.M. Lower, "The Origins of Democracy in Canada,"

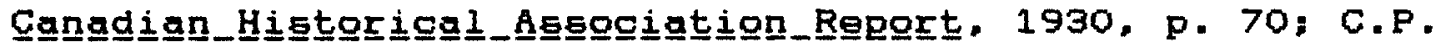
MacPherson, The_Egli York: Oxford, 1979).

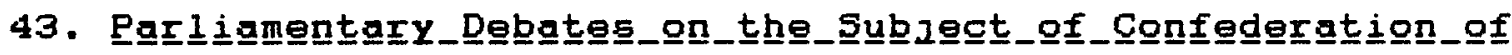

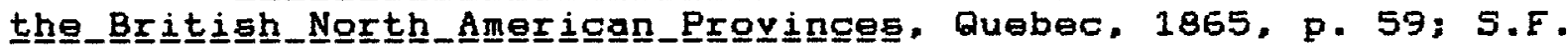
Wise. "Upper Canada and the Conservative tradition," in Ontario

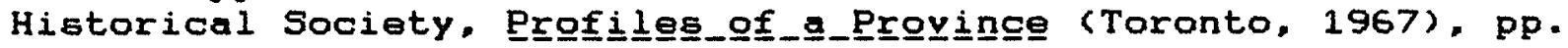


There 1s ample literature to explain the differences in Canadian and U.S. by the comparative strength of conservative values in each of the societies. 44 However, as H.V.Nelles points out in his study of Ontario, conervative values are also retained because to some extent they are funotional. We need to offer explanations for the maintenance of traditions on this basis. Nelles submits that the origin of provincial land policy in Ontario has a more satisfying explanation. He postulates that the:

maintenance of the old, imperial habit of authority into the industrial age stemmed primarily from the interaction of interest groups and moderately conservative ideology, within an agriculturally barren environment. The lumbermen, the [Canadian] Shield, and the threat of direct taxation

20-33; Gad Horowitz, "Conservatism, Liberalism and Socialism in

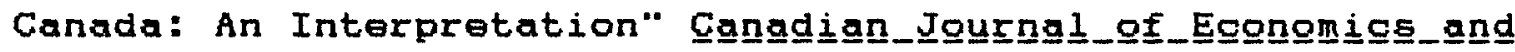

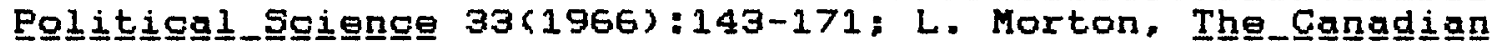
Identity (Toronto, Univ. of Toronto Press, 1961, 1972), pp.

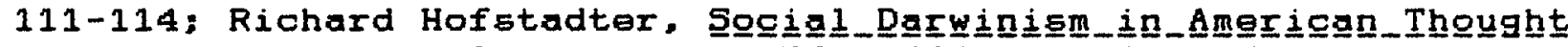
rev. ed (New York: Braziller, 1955, 1969), p. 8; H.V.Nelies, The

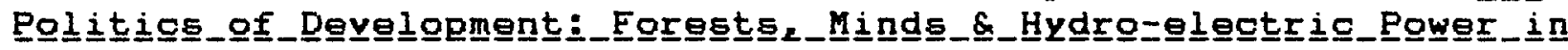
Ontaㅗ은 1949=1941 (Toronto: MacMilian, 1975), p. 41; Richard

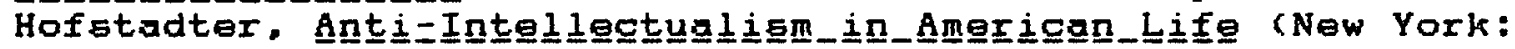

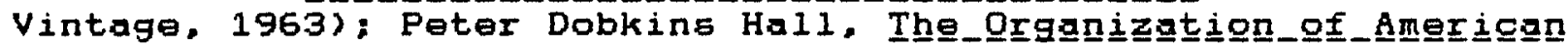

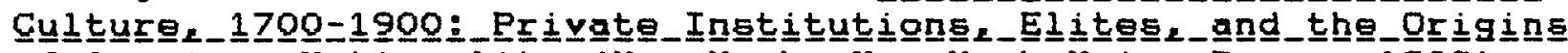

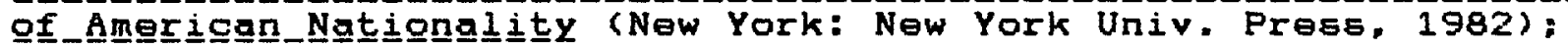

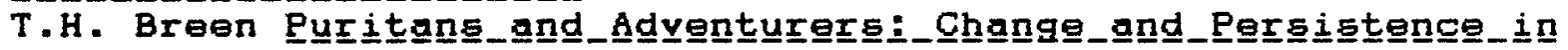
Egerly_Amegriga (New York: Oxford Univ. Pres5. 1980).

44. D. G. Creighton. The_Roga_tg__Egnfederatign (Toronto, 1964), see p. 142; W.L. Morton, The Cangdian-Identity (Madison: Univ. of Wisconsin, 1962, reprint 1972), pp. 111-114; Richard

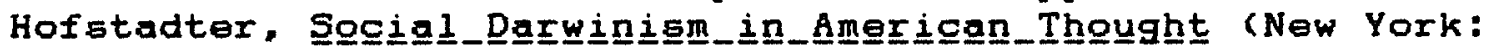
Braziller, 1944, reprint 1969), pp. 8-9; C. Berger. The_senge_of

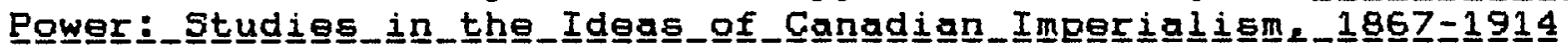
(Toronto: Univ. of Toronto, 1970). pp.187-188; Seymour M. Lipset, "Canada and the U.S.: A Comparative View," Cangagiann_Reyiew_of

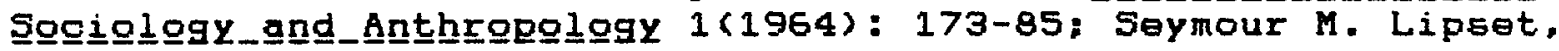
"Historical Traditions and National Characteristics: A Comparative Analysis of Canada and the United States, " Gangagian

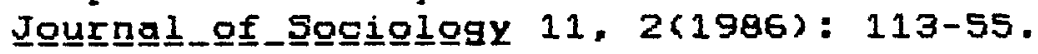


sanctioned a set of resource laws that preserved the germ of an earlier collectivist, conservative conception of the state. The interaction of these ideological and material forces blunted the individualistic, appropriative, liberal qualities-in short the "American-ness" of the northern Ontario frontier. 45

In Canada the interaction between diverse political values stemming from its dual French-English heritage, and its diverse geographic environment did not allow a single conception of land use during the period of its agrarian transformation. "Like democracy itself, Canadian agrarianism was more a condition and less of a theory than in the United States." 46

Mutual Perepectives: Children, Poverty and Public Health It is instructive that Canadian nation building took place precisely during the period when the medical model and the primacy of the scientific method in the childhood gaze was established. If the transcontinental development of Canada differed in its timing, value orientations, and policies from the United States, it differed less in the physical conditions which faced the urban dwellers of the late nineteenth century. Urbanization followed a pattern similar to that of the U.S. which rose from 13.1 per cent in 1851 to 34.9 per cent in 1901.47 However, discrepancies between provinces varied widely with Ontario (40.3x), Quebec ( $36.1 x)$, and British Columbia (56.4x), leading. Saskatchewan, by comparison, was as yet undeveloped with

45. Nelles, The_Pgli

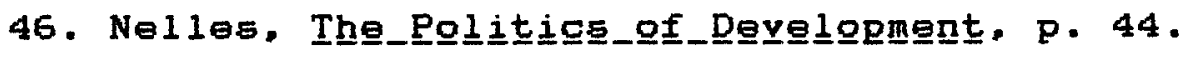

47. M.C. Urquhart and K.A.H. Buckley. Hístorigigal_stgatistíges of _Canado (Toronto: MacMillan, 1965), p. 119. 
6.1 per cent urban. The British Columbia statistica are alao misleading in that they reflect the rapid growth of the city of Vancouver after the arrival of the transcontinental railway in 1885. Vast territories in the province remained untapped until the 19305. Canadian urbanization increased to 47.4 per cent in 1921 and over 50 per cent in 1931. 48 The language describing urban conditions paralleled that used in the United States.

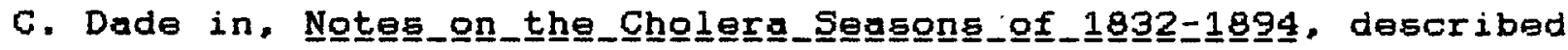
the conditiong in York a followa:

The genius of filth, if such there be, reigned predominant both in public and private. Crowded and loathsome hovels. cellars putrid and stagnant water, dunghills with animal and vegetable garbage reeking in the scorching rays of the summer's sum, these deadly agents everywhere spread their contaminating influence. 49

These conditions brought active reform movements in Canada as they did in the United States. The fight against civic corruption and vested interests can be seen in the social programmes of English and French-Canadian nationalists, in the struggles of organized labour, as well as in the concerted efforts of social organizations to uplift the lives and welfare

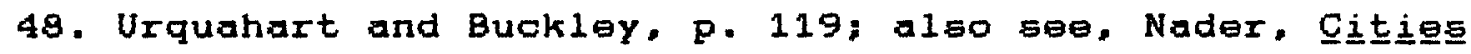
qf Eangaga, pp. 206-207: John Bradbury, "British Columbia: Metropolis and Hinterland in Microcosm," in Heartland_and Hintegrland, ed. L.D. McCann, pp. 339-370.

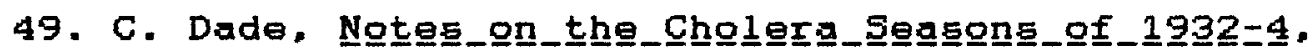
Pamphlet \#1428, P.A.C. Catalogue of Pamphlets, vol. 1, p. 18.

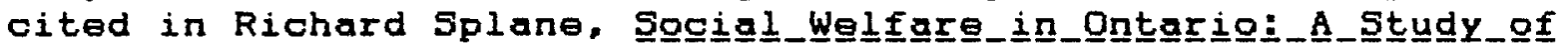

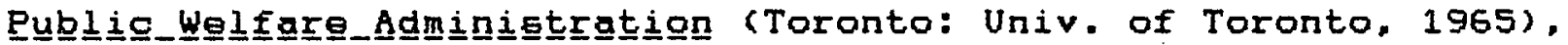
p. 197 fn. 18; also 589: T.J. Copp. The_Anatgmy_of_Royerty:_The

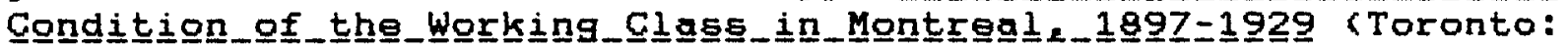
MCClelland \& stewart, 1974). 
of children. 50 of the social conditions which reformers sought to cure, public health was a major issue in both the United States and Canada. In Massachusetts of 1000 live births in 1855-1859, 123 babies died. This figure rose to 170 per 10001 ive births in 1870-1874. It was not until the turn of the century that this trend was seriously reversed, dropping to 116.7 in 1910 and 78.7 in 1920 . 51 In winnipeg there were 207 deaths per 1000 live births in 1912, 106 deaths in 1915, and 78 per 1000 births in 1921. 52 Life expectancy in 1900 was 48.2 years. By 1970 this figure was 71.7 years with the increase mainly between birth and

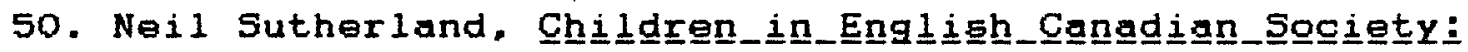

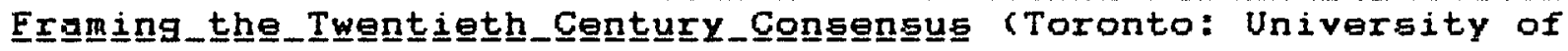
Toronto. 1977): P.T. Rooke and R.L. Schnel1, Disgarding thre

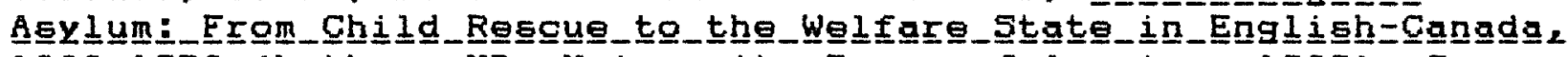
1음1ㅗㅇㅇ (Lathan, MD: University Press of America, 1983); Susan Houston. "The Waifs and Strays of a Late Victorian City." in

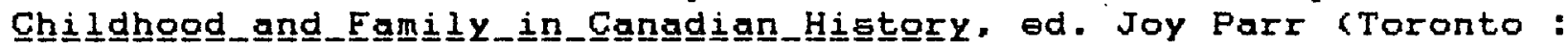
Mocleliand and Stewart, 1982), pp. 129-142; also Veronica Strong-Boag. "Intruders in the Nursery," in the same volume;

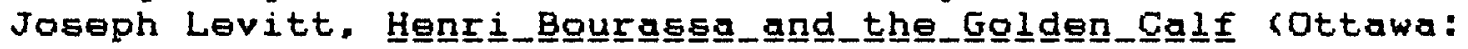
University of ottawa. 1972); for a look at the more recent

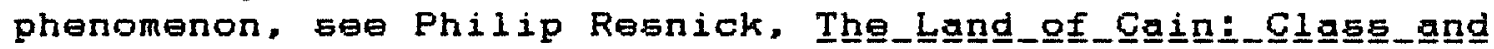

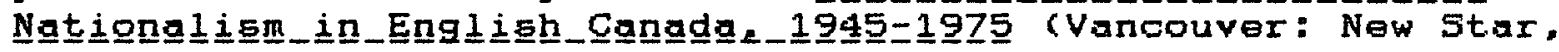
1977); on labour se日, David J. Bercuson, Egols_and_wisemeng The

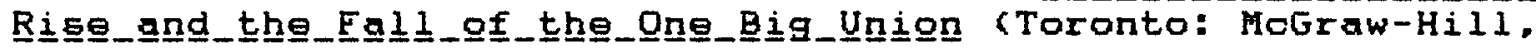
1978); James Struthers. №_Egult﹎of Their_own:_Unemgloyment_ang

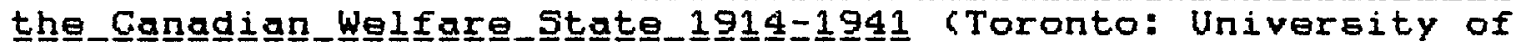
Toronto, 1983); Desmond Morton with Terry Copp. Working Pegple:

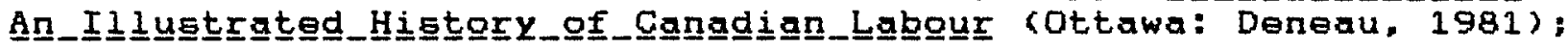
on the influence of religion. Richard Allen, The_sogeigl_Pasㅡ믐 (Toronto: Univ. of Toronto, 1973); John C. Weaver. "Elitism and the Corporate Ideal: Businessmen and Boosters in Canadian Civic

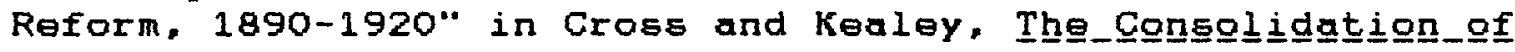
G므므므토툐 p. 143 . p. 57 .

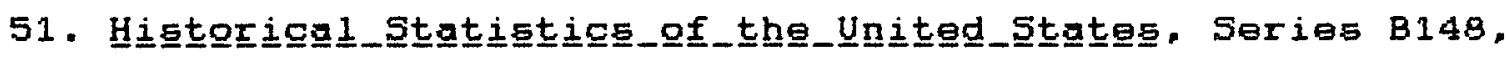

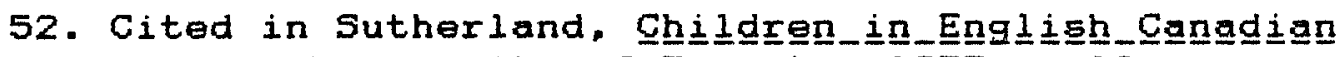
Sggietey Toronto: University of Toronto, 1977 , p $6 \overline{8}$. 
15 years of age. 53 foreign born mothers and those in rural communities were likely to give birth without medical attention. Their infanta were unlikely to ever see a doctor. 54

The major killers of children were diarrhoea and dysentery and communicable diseases like dyptheria, scarlet fever, small pox, typhoid fever, malaria, whooping cough, and measles. 55 Children in institutions had the least expectation of survival. 56 William Osler in his Pringeiples_and_Prgetgige_of Negdiginge (1892) noted that 50 to 80 per cent of the children in European cities had diseases of malnutrition such as rickets. Children in the U.S. and Canada were similarly afflicted. Rickets affected both mental and physical health and was a part of the larger problem of malnutrition. Children with rickets often died

53. These figures soared in the first year of life, diminishing substantially in the 1 to 4 year old bracket and again in the 5 to 14 year old range. U.S._Historicgal_statistigs.

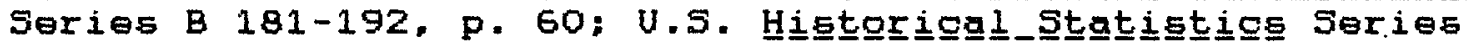
B107-115, p. 55: Series B116-125, p. 56 .

54. Emma Duke, "Infant Mortality: Results of a Field Study

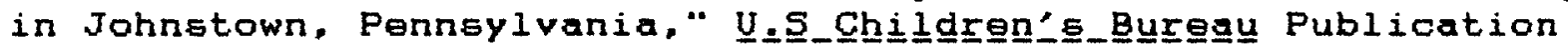
No. 9. (Washington D.C. 1915); Ontario Board of Health Regerte 1889, p. 16 .

55. Grover Powers, "Developments in Pediatrics in the Past

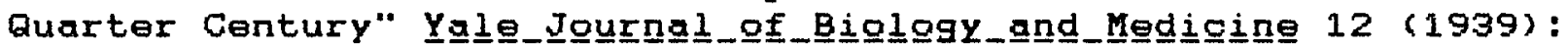
1-22, p. 9, cites that the majority of admissions to children's wards prior to 1925 were due to diarrhoea or vitamin D deficiencies; Robert wodehouse, "Vital Statistics Pertaining to

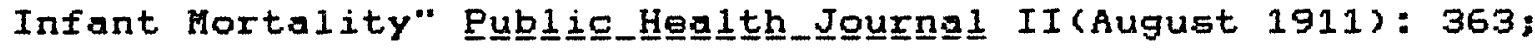
Albert J. Mayer. "Life Expectancy in the City of Chicago.

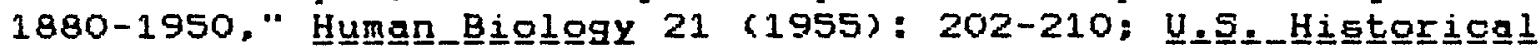
Stat트ti토 Series B 193-200, p. 63; Sutherland, Ghilidgren. ch. 4, pp. 56-69.

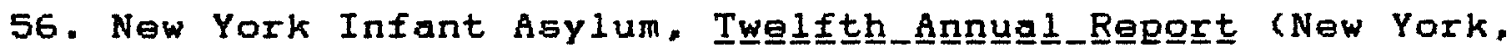

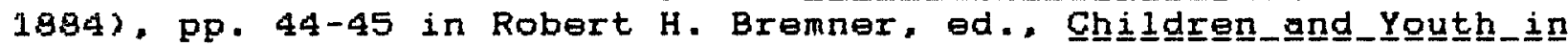
Ame토드 3 vols. (Cambridge, Mass.: Harvard, 1971), II: 937. 
of secondary complications such as pneumonia exacerbated by thoracic deformities caused by the disease. Others died of spasms of the larynx. Pelvic deformities in female children contributed to illness and death in their childbearing years. 57 John Spargo

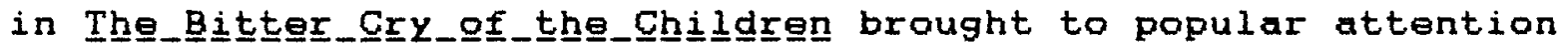
the high rates not only of rickets and malnutrition, but of tuberculosis as well. Hunger, disease, and poverty became social problems of widespread notoriety. 58

Philanthropy and the New Secular Religion of Science: Value in the Sphere of Investment as well as in

\section{The Sphere of Bestowal}

In placing wealth in the "service of mankind" both John D. Rockefeller Sr. and his advisor Frederick T. Gates were concerned with the value of the "sphere of investment as well as the sphere of bestowal." Gates, in particular, was interested in applying the principles of science to philanthropic endeavours. 59 John D. Rockefeller Sr. did not accumulate his fortune by acting hastily

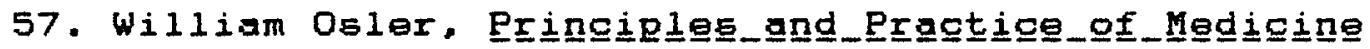
(London: Young J. Pentland, 4th edition 1901); Harvey Cushing,

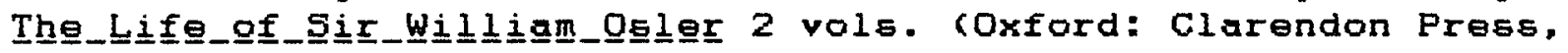
1926), se日 vol. 1 .

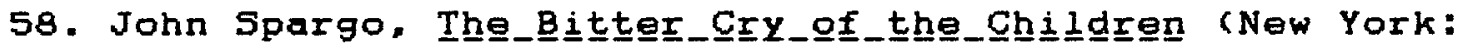
The Mackillan Co., 1906); Ernest Poole, "Waifs of the Street,"

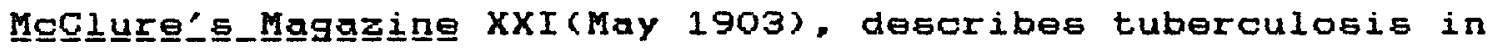
tenements and attacked the notion that newsboys grew up to be wealthy capitalists.

59. Selections from Frederick Gates" manuscript

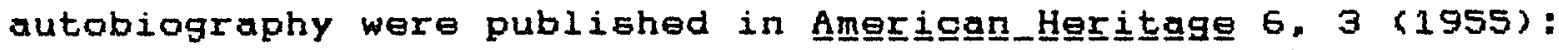
65-86; Gates manuscript, is also cited in Fosdick, The_story_of

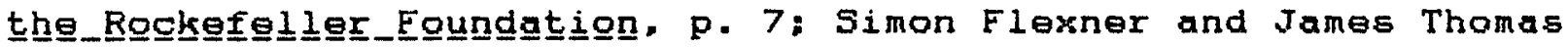

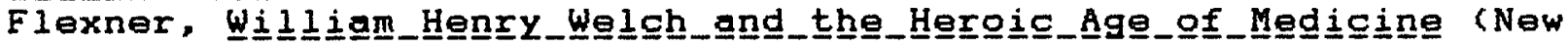
York: Viking, 1941), ch. 13, p. 269. 
or without forethought. As he turned to seriously consider the organizational imperatives his philanthropic enterprises should follow, he was similarly of cautious and prudent disposition. Rockefeller's forte was building empires which were capable of adapting themselves to various social and economic pressures over time. Rockefeller looked to precedents and suggestive openings in areas which had a ready made clientele that begged for the vision of large scale development.

Gates, a Baptist minister and former head of the American Baptist Education Society, had become principal aide to John D. Rockefeller Sr. in 1892. His role was to direct Rockefeller's increasing forays into philanthropy. In 1896 the senior Rockefellex retired from the management of Standard 0 il to devote his time to his philanthropic activities. A year later his son, John D. Rockefeller Jr., graduated from Brown University and essentially began a life career in philanthropy. The Rockefellere and their collaborator, Gates, agreed that charitable work was an enterprise as serious as business which ought to be based on rational principlea.

Gates' own business acumen is witnessed by the fact that he initially helped to "thin out bad investmente." In one instance, he added 50 million dollars to Rockefeller's philanthropic fund of surplus wealth through his handling of Rockefeller interests in the Mesabi iron range (1893-1901). 60 Gates' personality was

60. Frederick Gates' manuscript autabiography, Amen

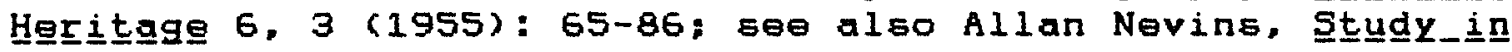

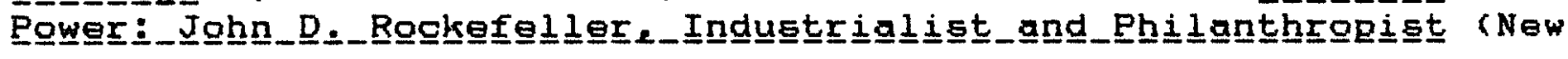


forthright and independent, even in hig relationghip with John D. Rockefeller Jr. and Sr., he preferred to bolster his argument against opposition rather than back down. Fosdick describes Gates as, "fearless, often fiery in his words, powerful in exhortation, with a mind that was too precipitous to be always tolerant, and with a voice that thundered from Sinai." 61 Gates viewed the Foundation as more than a commonplace responsibility. In his final speech before the Board on his retirement he reminded the truste日s. "When you die and come to approach the judgement of Almighty God, what do you think He will demand of you? Do you for an instant presume to believe that He will enquire into your petty failures or your trivial virtues? No: He will ask just one question, "What did you do as a Trustee of the Rockefeller Foundation?"* 62

Gates was an important link in directing the Rockefeller fortune toward scientific medicine. In 1897, a young medical student Gates had known as a child, and, whom he had befriended in New York, suggested that he read Osler's Príngígle日__and

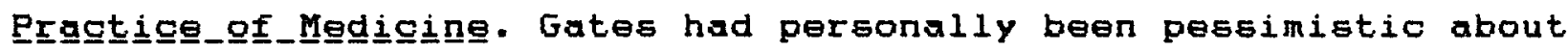
the state of medicine and his fears were confirmed by osler. However, Osler also argued strongly for the reform of medicine along the lines of scientific research and he described the

York: Charles Scribner's Sons, 1953), p. 166; George Corner, The

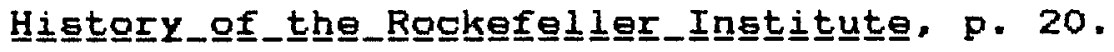

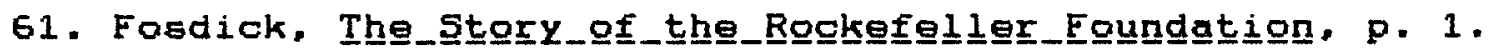

62. Recollections of Raymond Fasdick, Alan Gregs, quoted in Fosdiok, The_stgrgy, p. 1, p. 325, fn. 2. 
potential benefits of large scale public health intervention. Gates was profoundly moved:

When I laid down this book. I had begun to realize how woefully neglected in all civilized countries and perhaps most of all in this country, had been the scientific study of medicine... It became clear that medicine could hardly hope to become a science until medicine could be endowed and qualified men could give themeelves to uninterrupted study and investigation, on ample salary, entirely independent of practice. To his end, it seemed to me an Institute of medical research ought to be established in the United States. Here was an opportunity, to me the greatest, which the world could afford, for Mr. Rockefeller to become a pioneer. 63

Filled with these thoughts Gates brought his case before $\mathrm{Mr}$. Rockefeller.

I remember insisting...that the mere fact that he, Mr. Rockefeller, had established such an institute of research.. . would result in other institutes of research in a similar kind, or at least other funds for research being established, until research in this country would be conducted on a great scale and that out of the multitudes of workers, we might be sure in the end of abundant rewards even though those rewards did not come directly from the institute which he might found. 64

\section{The Rockefeller Institute}

Rockefeller Institute, the end product of Gates' ineight from reading Osler, was formed in 1901. Gates saw in the Institute "a kind of theological researoh." Addressing a group of scientists, Gates is quoted as having described the Institute as a "theological seminary." This comment was greeted with laughter. "Why do you laugh?" Gates countered. "I am now talking of the

63. Frederick T. Gates, "Recollections of Frederick T. Gates on the Origin of the Institute" Appendix I, pp. 575-584 in George

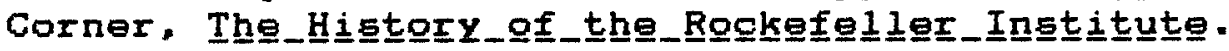

64. Gates, "Recollections" p. 576. 
religion, not of the past but of the future, and I tell you that as this medical research goes on you will ... promulgate... new moral laws and new social laws, new definitions of what is right and wrong in our social relations." 65 If the medical doctors and researchers at Johns Hopkins and the Rockefeller Institute were "therapeutic nihilists." Gates" "accommodation of religion to science on the terms of science" added a dimension and a destiny to the theme of the ohildhood gaze which was to be furthered by Rockefeller philanthropy. 66

The first Board of Directors of the Institute included: Simon Flexner, of the University of Penneylvania and Johns Hopkins, who became Director: William Welch of Johns Hopkins: L. Emmett Holt, the New York pediatrician and fellow parishioner of John D. Rockefeller Sr. at the Fifth Avenue Baptist Church; $T$. Mitchell Prudden, Chair of Pathology at College of Physicians and Surgeons since 1892; Hermann M. Biggs, of the Division of Bacteriology and Inspection of the New York City Department of Health: Theobald Smith, Chair of Comparative Pathology at Harvard; and, Christian A. Herter, Professor of Pathological Chemistry at Bellevue Hospital Medical Center who was also Professor of Pharmacology at the College of Physicians and Surgeons in New York City. This was an amazingly homogeneous group in age, background, experience and interests. Only Smith

65. Donald Fleming. Willi Megigine (Boston: Little and Brown, 1954), p. 106 .

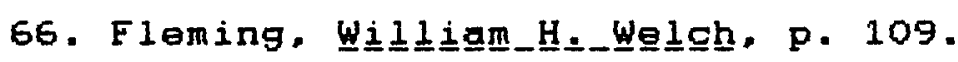


had not studied in Germany. Nonetheless, he among othera could boast of their shared experiences at Johns Hopkins. 67

Two thinge stand out about the Institute. First, the institute was important in furthering and establishing the philanthropic use of the theme of the chlldhood gaze in scientific medicine and public health research. Secondly, it furthered the scientific orientation of Johns Hopkins university as a role-model for other philanthropic projects designed to further the advance of scientific knowledge for the public good. In the first year of the Institute, the Directors allocated funds toward a study of New York Gity's milk supply. Philanthropist Nathan Strauss had previously set up milk stations to distribute pasteurized milk at a low cost to poor families. 68 However, no scientifically verified facts had been collected, and, no pathological studies had be日n conducted. Institute Directors, L. Emmett Holt, Hermann M. Biggs and Christian Herter had long been involved in child related public health initiatives. The sum of $\$ 7000$ was allocated for the salary of a bacteriologist, a biochemist, laboratory supplies and animals for research as well as personnel to inspect dairies, tenements, and children's hospitals. Holt presented a report of the study to the City Health Department which was also widely publicized in the 6. 62 .

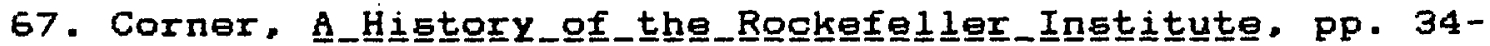

68. Lina Gutherz Straus, Disegase_in Milk_thhe_Remedy

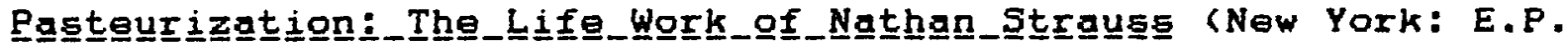
Dutton, second edition revised 1917). 


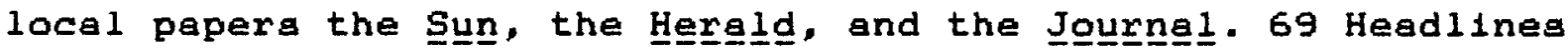
in the newspapers were alarmist. The Hergld_broadcast in multiple headlines: "Germs Swarming in City"s Purest Milk...Rockefeller experts report appalling uncleanliness prevaile in most of the dairies which supply New York...Trace 330 epidemics to this cause...Much more rigorous inspection is urged." 70 The problem of contaminated milk was found to be widespread even in the better grades. It was suggested that babies fed on commercial bottled milk were healthier than babies fed from other sources. Babies whose mothers had gone to the milk stations, it was surmised, were healthier not so much because the milk was so much lower in bacteriological counts but because of the more hygienic practices of these mothers as a result of the baby care advice which they received along with milk.

A concern with nutrition and health was consistent in the milk study and to the interests of Holt, Biggs, and Herter. Christian Herter's research specifically focussed on malnutrition in infants. After his death in 1910 this research was conducted by Angela M. Courtney until she took a position at the University of Toronto. She was only one of many exchanges between the

69. Board of Health of the City of New York. Annuugl_Regort for. 19일 (New York: Board of Health, 1902).

70. Hergald, January 19, 1902, p. 1; also se日, United states Public Health and Marine Hospital Service, Hygienic Laboratory.

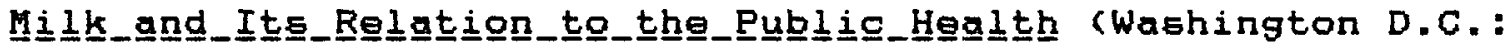

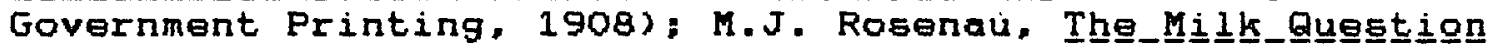
(Boston: Houghton Mifflin Co., 1912); Philip Van Ingen and Paul

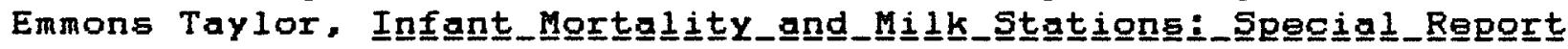

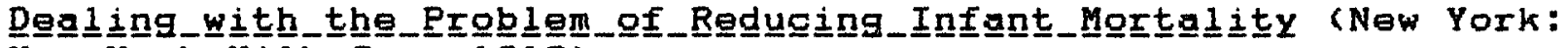
New York Milk Co., 1912). 
Institute and Canadien institutions. Canadiang were included in the original conceptualization of the Institute. 71 Canadians were consulted from the planning stage as to the advisability of establishing the Institute. Some physicians were reticent. For example, J. G. Adami of MoGill University was concerned about the proliferation of scientific medicine which would potentially end up in a glut of men in research who could not be placed in universities. Yet, fellow Canadian, G.W. Ross of Toronto participated gladly. When returning from research and study in London in 1906, Ross was sidetracked to New York by Simon Flexner to give a short course at the Institute to relay his work. 72 Osler maintained contact with his old colleagues even as he took on his responsibilities as Regius Professor of Medicine at Oxford. The Institute's clientele was conceived to be international. 73 Life and death and the intervention of science were understood within the German tradition as transgressing political boundaries for the gaod of mankind.

Much of the routine work and significant discoveries at The Institute contributed both to general health and to infant and child health in the twentieth century. The laboratories organized in 1910 worked on the prevention of epidemics, contagious diseases and on the advancement of a basic understanding of human 65.

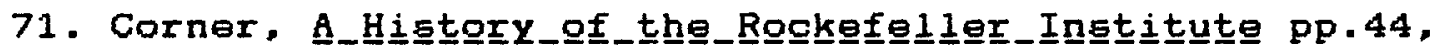

72. Cited in Corner, "Flexner memorandum" in welch papers, p. 551, fn. 27.

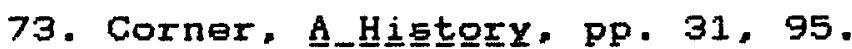


blology critical to normal growth and development. The milk study in New York had contributed an understanding of bacillary dysentery especially as it contributed to infant mortality. Early work on venereal disease, cancer and polio were conducted. 74

The Rockefeller Institute and the Spirit of Johns Hopkins If the epirit of The Rockefeller Institute and The Rockefeller University is reminiscent of Johns Hopkins, the convergence was not accidental. The Institute's relationship to Johns Hopkins was direct and acknowledged. Detlev w. Bronk, who took over the Institute as it was restructured as a graduate university in the 1950s, was called from the Presidency of Johns Hopkins. Bronk comments in his introduction to George Corner's official history of the Institute:

It is warthy of comment that there have been many remarkable relations between The Rockefeller Institute and The Johns Hopkins University. Both have pioneered in graduate education. Many of the most influential members of the Institute staff were Hopkins men: the first and last presidents of the Board of Directors, all the Directors of the Institute and of the Institute Hospital. scores of its most distinguished Members - Welch, Longcope, Simon Flexner, Gasser, Cole. Rivers, Rous, Opie are but a few of many who brought the ideas of Gilman and Hopkins traditions to the Rockefeller. It is less well known that the new character of the Institute as a graduate university owns much to another Hopkins man: Abraham, the brother of Simon Flexner...He was for thirty years my wise mentor in the ideals and traditions of Gilman whom he greatly revered as his teacher. At the age of 90. Abraham Elexner urged that the functions of the Institute first directed by his brother be changed and broadened to meet new needs. By happy chance, two brothers were able to influence the character of the Institute at the

74. Fritz Schaudinn Discovered the parasite of syphilis Spirochaeta Palleda June 17, 1905: Corner, A_HiEtgory, p. 95. 
beginning of two eras. 75

The offspring of the Institute. The Rockefeller University, was endowed with 100 million dollars in 1952. Looking back, the notion of a graduate university was first suggested in 1885 by Daniel Coit Gilman and William Henry Welch during the formative stages of the Institute. 76 The Rockefeller Institute had come full circle.

Scientific Knowledge for the Public Good

If the Rockefeller Institute became the ideal type of research organization designed to develop and test advanced scientific knowledge, other early Rockefeller philanthropic endeavours evolved models for the large scale application of elite knowledge for the general good. The General Education Board, and, Sanitary Commission for the Eradication of Hookworm Disease in the southern states, were notable projects of this nature.

The General Education Board officially began its work in 1903. The General Education Baard became in essence a steering committee for the earlier non-Rockefeller philanthropies in the South. Its success was in adapting and coordinating the work which had been initiated by others on a much grander scale than would have otherwise been possible. The G.E.B. also served as a

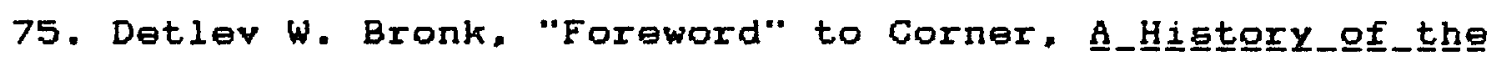

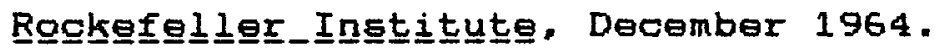

76. Bronk, "Foreword;" The General Education Board, An AgCount_of Board, 1915. 
precursor for what was to become important international

endeavours on the part of Rockefeller related philanthropy in both education and public health. 77

The first model for public health work was established in 1909 in the Sanitary Commission for the Eradication of Hookworm Disease in the Southern States. The widespread existence of Hookworm disease among the rural southern poor was presented dramatically to Rockefeller's advisors. The fact that people so infected were drained of energy and ambition by the illness seemed to directly counter work started by the General Education Board. Hookworm disease se日med to underlie many of the basic social problems of the South. The northern press played up the fact that the symptom of the anaemic disease was low energy or laziness. 78 Efficient and productive workers first had to be healthy. As Frederick Gates had atated:

If science and education are the brain and nervous system of civilization, health is its heart. It is the organ that pushes vital fluid into every part of the social organism, enabling each organ to function and measuring and limiting its effective life... Disease is the supreme ill of 1 ife and in its main source of almost all other human ills - poverty, crime, ignorance, vice, inefficiency, hereditary taint, and many other evils. 79

Hookworm disease was indeed a widespread health hazard which

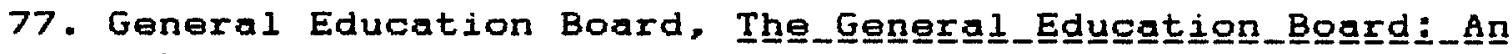

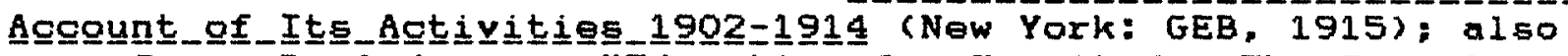
ser, James D. Anderson, "Education for Servitude: The Social Purposes of Schooling in the Black South, 1870-1930," Ph.D Thesis University of Illinois, 1973.

78. Mark Sullivan, Qux Times vol. 3 (New York: Charles Scribner and Sons, 1926-1932), p. 327 .

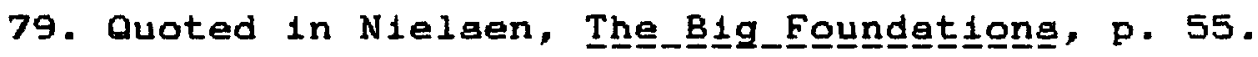


contributed to the phyaical and mental disabilities of those effected. The Sanitary Commission became the world's largest full scale campaign for the eradication of a single public health problem. The Sanitary Commission for the Eradication of Hookworm Disease in the Southern States had its precursors in William Osler's Laennec Society in the battle against Tuberculosis, Welch's public health campaigns in Baltimore, and in even earlier work in fighting epidemics with clinical research in New York City. None of the predeceseors undertook the eradication of a pervasive health problem within a defined geographioal unit of such large scale, nor did any of the others have the financial support represented in the Sanitary Commision. The project included public education, laboratory studies and clinical treatment.

The eradication of this disease served as an influential demonstration project for other international Rockefeller related work in public health. Thla model developed under the enthusiastic direction of Wiokliffe Rose. Rose was trained as a philosopher prior to the time when peychology and philosophy were distinguished from one another in academic departments. 80 Rase shared with Frederick Gates what one author has noted as "an

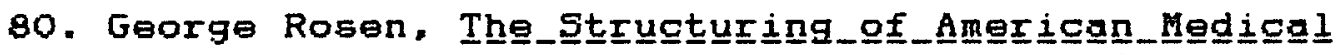

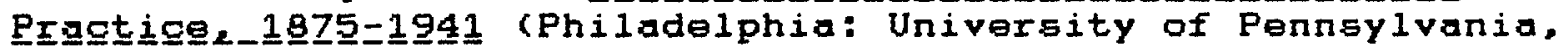
1983); Rosen, Pxeqyentive_Medicinge: Lloyd Taylor, The_Medical

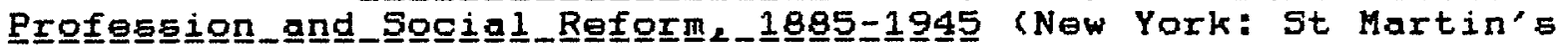

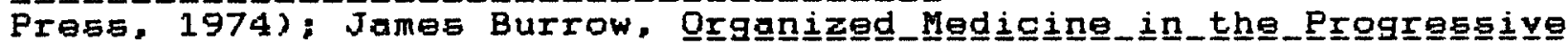
Eraㅡ_The_Moye_Towar Press, 1977). 
amateur's fervour in his belief that science held primacy over all other forms of human activity." 81 In a sense it is less a question of being amateurish than a measure of Rose's belief in the power of science to solve public problems. Rase's conviction reflected the childhood gaze:

Science is the method of knowledge. It is the key to such dominion as man may ever acquire over his physical environment. Appreciation of its spirit and technique. moreover, determines the mental attitude of a people, affects the entire system of education and carries with it the shaping of a civilization. 82

The International Health Board was created in 1913 to absorb the Sanitary Commission and to elaborate its mission to solve other pervasive public health problems on an international scale. Eventually the IHB's programmes were involved in 62 countries on aix continents. 83

81. Note that the academic department which had been headed by G. Stanley Hall at Jahns Hopkins was unusual in that Hall was professor of psychology and pedagogic. When Hall left for clark University the department was taken over by John Baldwin and subsequently by John B. Watson, who insisted on a separate Peychology Department, a move supported by Adolf Meyer. This was accomplished in 1910; Josef Brozek and Rand B. Evans, eds.. R. $I_{-}$

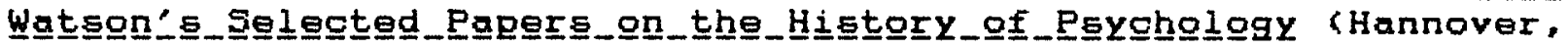
New Hampshire: University of New Hampshire, 1977); George Sidney Brett. A_Histogry_of_Psychology vol. 3 (London: George Alien $G_{x}$

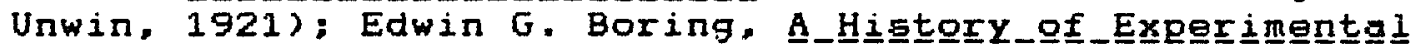
PEychology (New York: Appleton-Century-Crofts, 1950); Carl

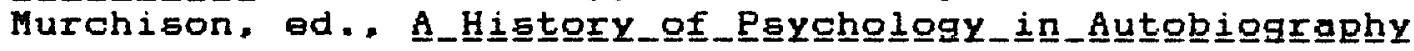
(Worchester, Mass.: Clark University Press, 1936); Richard J.

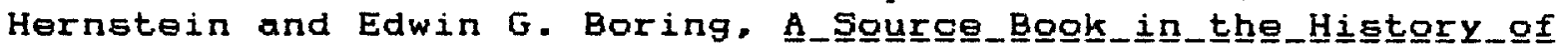
Psychology (Cambridge, Mass.: Harvard University Press, 1965).

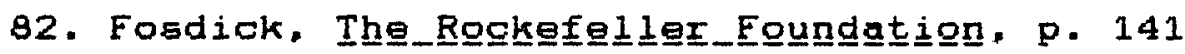

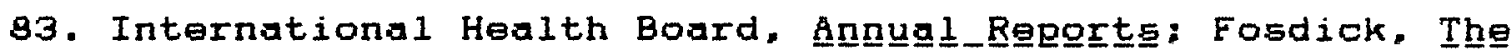

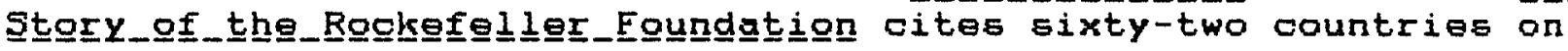
six continents, "Areas of Rockefeller Foundation Aotivities (1913-1950)," Appendix III, pp. 313-314. 


\section{The Rockefeller Foundation}

In light of Gates admonition that the accumulation of assets continued to outpace Rockefeller's charitable outlays, on the 29th of July 1909, John D. Rockefeller set aside \$50 million dollars worth of shares in Standard Oil Company of New Jersey to be used for the endowment of a philanthropic organization to be known as the Rockefeller Foundation. 94 This sum is in contrast to the \$10 milion with which Carnegie had initiated the Carnegie Institution of Washington D. C. in 1902. In March 1910, a bill was put before the United States Senate requesting incorporation of the Rockefeller Foundation. Rockefeller could have initiated the Foundation with a simple deed of trust but he wanted to set an example for the establishment of a corporate structure in scientific philanthropy which was based on a business model.

It is ironic that if the early attempts to charter the foundation at the federal level had been successful they would have led to a coneiderably greater degreg of public intervention inta the organizational functioning of the foundations. It was not to be. The attempt to incorporate the Foundation was met with considerable opposition. The William H. Taft Administration and the Congress were suspicious. They were not alone in feeling that Rockefeller's request for a charter amounted to an "indefinite scheme for perpetuating vast wealth." 85 This feeling was exacerbated by bad publicity and imposing court cases. Judge

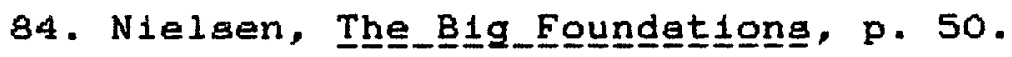

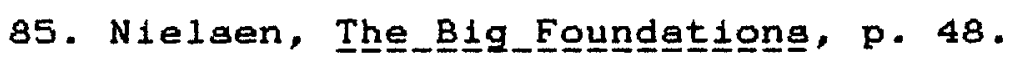


Kenesaw Mountain Landis had fined the standard oll Company of Indiana 29.2 million dollars in 1908 for monopolistic practices and the corruption of public officials. Appeals were still pending in this case. Serious questions were raised concerning the public's right to oversee and have a measure of control over private charitable expenditures which were directed at the public interest. Congress added numerous amendments of dubious effectiveness to the proposed bill which were accepted by Rockefeller at the time. These included: the limitation of the total asaeta to $100 \mathrm{million}$ dollars; that there be no accumulation of Foundation income; that Congress could dissolve the Foundation in 100 years; and, that the election of trustees be subject to veto within 60 days by the President of the United States, the President of the Senate, the speaker of the House of Representatives or the Presidents of Harvard, Yale, Columbia, Johns Hopkins, or Chicago universities. After three years, Congress still could not confirm the charter and it was withdrawn by Rockefeller and placed in the state legislature of New York where it was passed without further arguments and without the limits of the amendments. Two of the amendments have nominally been used in the organization of Rockefeller philanthropy. namely, the nonaccumulation of assets and the dissolvability of any one Foundation.

Gates argued that maximum benefits would be derived from providing prototypical programmes for others to follow. This rationale became a policy imperative which served as a guideline 
for Rockefellex philanthropy. A new viaion of the role of charity evalved where philanthropy was conceived as responsible for creating new ideas, institutional models, and social programmes in the same way commercial products are privately developed, tested, and marketed. Demonstration projects and model institutions were to be funded just long enaugh to eerve this larger purpose. Secretary of the Rockefeller Foundation, Jerome Greene, later explained in a speech before the Commercial Glub of Cincinnati:

So far as the Rockefeller Foundation is concerned, it strenuously avoids the creation of a relationship of continuing dependence upon the favour of the foundation for the perpetration of any of the charitable or educational currents to which it contributes, and its greatest satisfaction is derived from those lines where after a preliminary period of experiment or demonstration entire responsibility is assumed by governmental or other permanent agencies. 86

Scientific philanthropy in this sense differed from traditional charity whose individual contributions served to bolster the short term needs of specific populations. Rather than set up funds for one purpose in perpetuity Rockefeller preferred a dynamic model which was not locked into any one time period.

In the same way that the funde were not inderinitely tied to specific projects they were also freed from the personal control of the donor. In 1917 John D. Rockefeller Sr. relinquished the right to make personal designations of the Foundation's funds. Up to that time he had made contributions of one hundred to one

96. Jerome Greene. "Abetract of Addrese before the Commercial Club of Cincinnati" 18 March 1916, 900 Hist 1, 6. pp. 1518-1519, RAC, N. Tarrytown, N.Y. 
hundred thousand dollars to various Charity Organization

Societies and Baptist missionary organizations largely based in New York City or state. Many of the donations went to child related causes including the: Children's Aid Society of New York, Girls' Branch of the Public Schools Athletic League in New York City, New York Milk Committee, New York Child Labor Commitee, Parks and Playgrounds Association of the City of New York, Public Education Association of the City of New York, Public Schools Athletic League of the City of New York. Superintendent of New York Schoola, and the state and four local Y.M.C.A'B. Additionally, Rockefeller supported the Eugenice Record Office at Cold Springs Harbor, Long Island, and the United Hospital Fund of New York. 87 After, 1917 the Board of Trustegs was responsible for policy and the distribution of foundation funds: however, the Rockefeller family remained active in the Faundation's wark. In 1917. John D. Rockefeller Jr. stepped down from the Presidency of the Foundation, taking instead, the position of Chairman of the Board, a position which he held until 1939. He retired April 3 , 1940, having spent a lifetime devoted to philanthropic work. Rockefellex philanthropy during this period was characteristically braadened from John D. Rockefeller Senior's personal charitable interests which were often local and specific. A scientific approach to philanthropy differed from the

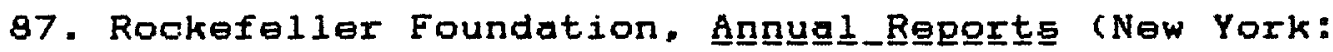
Rockefeller Foundation, 1917), pp. 302-303; 1913-1914, pp. 201-206: 1915, pp. 323-325; 1916, pp. 356-358; 1917; al60 900 Hist-1, 6, pp. 1531-1532, RAC, N. Tarrytown, N.Y. 
earlier charity primarily on the basia of the universality of its outcome.

The purpose of the Foundation was written into its charter in 1913, "to promote the well-being of mankind throughout the world." In the pursuit of "policies and lines of work which were likely to present the largest possibility of permanent and farreaching usefulness, there was general agreement that the advancement of public health through medical research and education... afforded the surest prospect of such usefulness." The International Health Commission was set up with a zeal learned from the Sanitary Commission that "diagnosis of disease can be made with certainty and that it can be cured and easily prevented:...people, physicians, state boards of health, county and municipal officers [are] all eager to cooperate... [when] an intelligent public interest is awakened in hygiene and in modern scientific medicine and in practical measures for permanent public sanitation." Mental hygiene was cited as "one of the important subjects" to be undertaken. 88

\section{Selentific Philanthropy}

and the Eradication of the Evils of Society

The subsequent problems and tensions in the mental hygiene movement as it contributed to child health, stem in part, from its relationship to the organizational struoture of philanthropy, and, to scientific philanthropy's particular vision of the

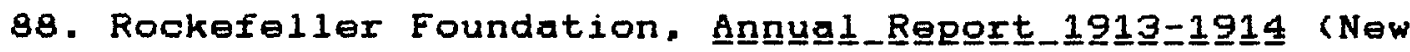
York: Rockefeller Foundation, 1914), pp. 1, 11, 21, 18. 
childhood gaze. The majority of the work of the Rockefeller Foundation in its early years focussed on issues in public health and medicine, which were peripherally if not directly related to mental hygiene. The Foundation's mandate in the field of mental health was broad both in rhetoric and practice. It was conceived as the fundamental link between the "natural and social sciences." 89 Psychiatry and the medical model served as an underlying theme determining the general value of projects as contributing to human welfare as much as it contributed to the methodological approach to problem solving favoured by the Foundation.

The method and theme of medicalization and mental hygiene are evident in the development of Foundation policy from an early date. At a meeting of the trustees on October 27, 1915, Secretary Jerome Greene addressed the "close interrelation of many of the familiar evile of society." which were of central importance to the work of the philanthropy. Included among the evils of which Greene spoke were: insanity, feeblemindednes5, alcoholism, drug habit, prostitution, orime, venereal disease, infant mortality, child labor, illegitimacy, pauperism, divorce, bad milk and other food, bad housing, tuberculosis, and typhoid fever. The

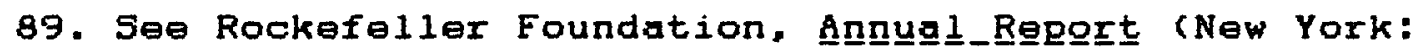
Rockefeller Foundation, 1921), p 21: also 1935, p. 69: 1940, p.

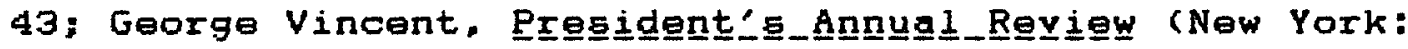
Rockefeller Foundation), 1922, p. 8; also 1925, pp. 22, 39; 1926,

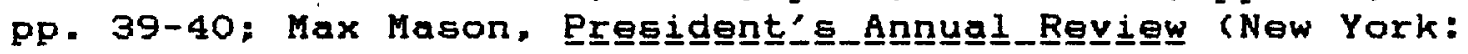
Rockefeller Foundation, 1933), p. xviii: Raymond B. Fosdick,

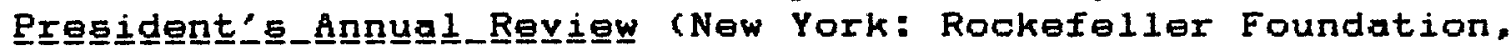
1936), pp. 9. 22; 1938, pp. 22-3; Fosdick, The_Stgory, pp. 123-34, see extended quate by Alan Gregg, p. 133. 
interrelationship between insanity and the other evila were expla1ned:

It was certainly linked with alcoholism and the drug habit. Venereal disease was responsible for a large percentage of all cases of insanity, and was a large factor in divorce. Mental deficiency was olosely connected with prostitution and crime, and the same was true of drug habits. Alcoholism accounted for a large proportion of crime, pauperism and divorce. Venereal disease was the cause of a large percentage of blindness and of infant mortality, including premature birth. Bad housing had a large responsibility for infant mortality, for tuberculosis and for typhoid; also for the spread of venereal disease. Child labor was a large factor in infant mortality and to some extent in insanity and mental deficiency. Divorce was frequently the fruit of insanity, alcoholism, drug habit, venereal disease. 90

A committee was formed to investigate and report on the "actual and desirable activity in these fields with a view to their proper correlation." 91 This correlation remained an underlying focus of Rockefeller related philanthropy which was to preserve the resources inherent in the minds of the nation's and the world'a young.

Greene wrote to Harvard President Charles W. Eliot underscoring the importance of making sound recommendations to the Trustees on the coordination of "social health and welfare"

90. Jerome Greene, "statement to RF Board of Trustees, Oct. 27. 1915," cited in Rockefeller Foundation. "Minutes Oetober 27. 1915," pp. 3108-3109; J.D. Greene to J. Koren, 29 October 1915. RF 1.1, 200 A, 1913-1916, RFA; also se日 900 Hist-1, 6, 1589-1590, RAC, N. Tarrytown, N.Y.

91. The Committee consisted of Starr J. Murphy, Harry Pratt Judson, Wickliffe Rose, John D. Rockefeller Jr., and Jerome Greene. The conference was held December 7, 1915, present: Murphy, Rose, Gre日ne, Fosdick, with John Koren, Thomas Salmon and Abraham Flexner attending: see, Report_of_thhe_Conférerence. 7 December 1915. Johns Hopkine School of Hygiene and Public Health, RF 1.1, 200 A, RFA, RAC, N. Tarrytown, N.Y: 
activities. He emphasized "that contributions to health through medical research and preventive medicine are the surest means of doing an unqualified good to the human race, but it seems to me that there can be no better application of philanthropy than in efforts to promate the intellectual and epiritual life of the human animal made healthy by medical research and preventative medicine." 92

A conference was held on December 7, 1915, which reiterated the importance of the work and its interconnections. Participants Thomas Salmon and Wickliffe Rose emphasized that combined work in areas such as mental hygiene and venereal disease should be taken up under the International Health Commission. An unofficial report unanimously conourred with this conclusion. 93 In January 1916. Green wrote to John D. Rockefeller Jx. that national committe日s as diverse as the American Society for the Control of Cancer, the National Committe日 for the Prevention of Blindness, the National Committee for Mental Hygiene, and the American Social Hygiene Association should perhaps carry on all of their

92. J.D. Greene to C.W. Eliot, 11 November 1915, Johns Hopkins School of Public Health. RF 1.1. 200 A. RFA: also se日 900 Hist-1,6, pp. 1590-1591, RAC, N. Tarrytown, N.Y; this letter goes on to address the uplifting of cultural and moral values as an important role of philanthropy.

93. J.D. Greene, "letters of invitation," 4 December 1915, John Hopkins School of Public Health and Hygiene, RF 1.1, 200 A RFA; the committee apparently made no $f$ inal report to the Board of Trustees, Rockefeller Foundation, "Minutes," 26 January 1916.

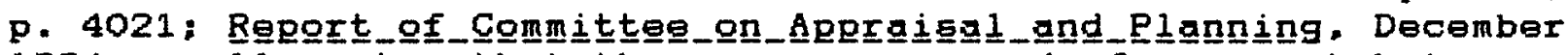
1934, p. 11, notes that there was no record of a report but an unsigned carbon of a draft was cited: also se日 $900 \mathrm{Hist-1,6.} \mathrm{p.}$ 1597, RAC, N. Tarrytown, N.Y. 
activities under some auch name as [the] Public Health

Association. Se日ming to back away from a directly coordinated effort on the part of the Foundation, Greene stated:

I am inolined to think that the solution of this problem will be that specialized national committees to procure and disseminate reliable information and advice will be needed for some time to come, and that such specialized committers will enlist more interest and support than would one organization combining them all. On the other hand. I believe the time is coming when the residents of the town or city may properly organize a layman's public health association whose business it will be to guide local effort along the several lines of health activity suggested by the various specialized national committees. 94

For abscure reasons, an official report from the December conference was not submitted to the January meeting of the truste日s. Subsequently, a combined attack on "social evils" remained an undergirding rather than a formal policy of the Foundation. 95

In the year of its creation, the Rockefeller Foundation entered into a cooperative relationship with the National Committee for Mental Hygiene. The origins of the Foundation's interest in mental hygiene predate the formal establishment of Rockefeller philanthropy. In a sense, the creation of scientific philanthropy, the rise of modern medical science, and the formalization of the mental hygiene movement were mutually supportive events which helped to lend this century its

94. J.D. Greene to J.D. Rockefeller Jr., 4 January 1916, RF 1.1. $200 \mathrm{~A}$ (old RF dr 1) cited in 900 Hist-1, 6, pp. 1600-1601, RAC, N.Tarrytown, N.Y.

95. Rockefeller Foundation, Annugl_Report (New York: Rockefeller Foundation, 1916), p. 32 . 
character. Aa Raymond Foadick pointa out, "The Foundation was a child of the era in which it was born, and it has been shaped by its environment." 96 Mental hygiene was a part of the original era, and a mutual contributor to the ongoing environment. Mental hygiene was written into the original mandate of the Rockefelier Foundation as set out in its 1913 charter. Rockefeller Foundation interest in mental health was expressed in independent projects and in support for the National Committees for Mental Hygiene. Inter-War mental hygiene projects were largely funded through the Rockefeller Foundation, General Education Board and the Laura Spelman Rockefeller Memorial. Rockefeller support was supplemented by other philanthropies such as the Harkness family Commonwealth Fund. The Sanitary Commission and the GEB's work in the Southern states served as models for public health intervention. Early mental hygiene studies and surveys were elaborated in the 1920 s into research and training programmes designed to establish psychiatry, peychiatric social work, and psychology in public policy and in institutions of higher learning. In 1933, under Alan Gregg. Director of the Division of Medical Sciences, psychiatry broadly interpreted was formalized as the major thrust of the Foundation's work. 97

96. Fosdick, The_Storgy, p. 300 .

97. Rockefeller Foundation. Annugl_Report (New York: Rackefeller Foundation, 1933), p. xviii; Raymond Fosdick. The

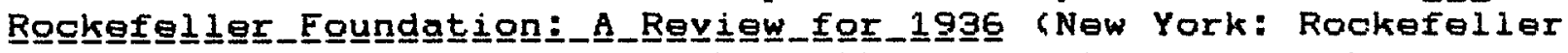
Foundation, 1937), p. 8, "work in the medical sciences has chiefly to do with psychiatry, broadly interpreted." 
CHAPTER THREE

MENTAL HYGIENE: A BIOGRAPHY OF THE NATIONAL COMMITTEES

The convergence of three events made it possible for the initiation of the mental hygiene movement in the firet decade of this century: the development of large scale general purpose scientific philanthropy, the rise of modern medicine and the medicalization of psychiatry. The mental hygiene movement was a direct extension of the transformation of psychiatric thought and practice which accurred in the latter part of the nineteenth century. The conflicts and inconsistencies in the professionalization of psychiatry shaped the National Committees for Mental Hygiene. 1 This chapter discusses the convergence of these events in the internal dynamics of the establishment of the two national committe日s for mental hygiene in 1909 and 1918 in the U.S. and Canada respectively.

The transition of psyohiatry out of the asylum was slower in Canada than in the United States. The rise of medicine as an influential discipline was less rapid and its ultimate prestige value never solidified at such a high level as in the U.S. There was no Canadian counterpart to general purpose scientific philanthropy even though U.S. foundations and wealthy Canadians contributed to the Canadian movement.

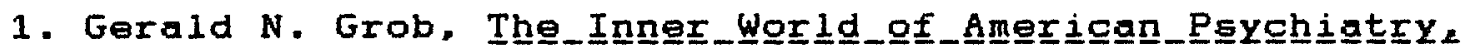

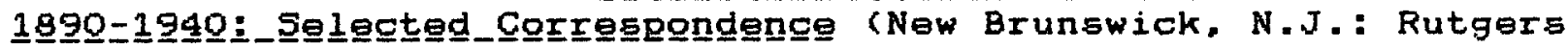
Univ. Press, 1985), see pp. 1-18; Barbara Sicherman, "The Quest for Mental Health in America 1880-1917." Ph.D. Thesis, Columbia University, 1967, reprint New York, 1980); Alfred Deutsch. The

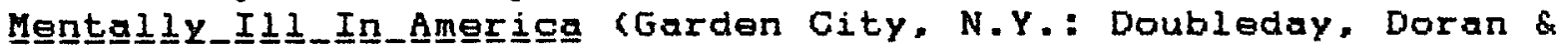
Co.. 1937, 2 edition 1949). 
Advocate for the Insane: Clifford W. Beers (1876-1943)

In the United States, public health reform followed clasely on the advances of medical science in the Progressive Era. Leaders in the movement for medical reform such as William Welch and William Osler also led campaigns to provide public standards for physical health. Reforms in asylum psychiatry were in the process of evolving but had not yet moved toward a public campaign. Instead, a former psychiatric patient, Clifford W. Beers, advanced the first steps toward a campaign for preventive paychiatry.

The founding of the first two national mental hygiene committees was stamped with the personality and work of Clifford Beers. Beers' role in mental hygiene was complex. On one hand, it was characterized by the tenacity of his dedication to psychiatric reform. On the other hand, Beers compromised his vision and was swept along by events beyond his control. Beers" personal history evolves from his status as a mental patient, to a "persuasive chronicler, to [an] ardent, entrepreneurial, sophisticated, pragmatio organizer and reformer." Beers was also a "shrewd tactician, [and] sensitive observer of the wealthy and powerful." 2 From the publication of his book to his last illness, Beers' primary role was as a propagandist and fund raiser for the cause of mental hygiene.

Beers wanted to reform psychiatric practices in the

2. Robert Coles. "Introduction." in Clifford Whittingham

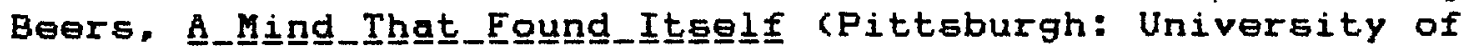
Pitteburgh, original 1907, reprint 1981), p. xvi. 
custodial care of institutionalized adults. He hoped to alter these practices by creating a public body which would overse日 psychiatric policy. In spite of Beers' vision of a lay organization with control over psychiatry, the direction of the incipient mental hygiene movement was dominated by medical professionals. In the process of organization, Beers' advocacy programme for the insane was translated into conformity with an evolving new leadership in medicine and psychiatry.

Born in 1876. Beers was from a relatively well connected middle class Connecticut family. He became mentally ill while a student at Sheffield Scientific School at Yale University, which he entered in 1894. 3 Beers experienced increased episodes of psychological distress which became a life long problem with varied periods of depression and elation. During the onset of his psychiatric illness. Beere managed to edit and serve as business manager for the Yale_erẹgord. He received his diploma on schedule in 1897. He was also able to successfully hold a job for a short time after graduation.

Beers had become obsessed with the idea that he was an epileptic, a delusion derived from the death of a favaured older brother of a seizure disorder caused by a brain tumour. Feeling he could not live as an epileptic and die as his brother, he attempted suicide by jumping from an upper story window at his family home. A last minute decision to jump feet-first probably

3. See Norman Dain's excellent biography of Be日rs. Sliffígrd W._Bgers._Adyggate_ffor_the_Insgng (Pitteburgh, Pa.: University of Pittsburgh Press, 1980); on Be日rs early life se日 pp. 6-21. 
saved his ilfe. Beers was admitted to a mental institution by his parents in 1900 . He was then 24 years of age. Beers was eventually treated in both private and public hospitals for the insane over a period of several years.

Begrs remained cognizant of his treatment while institutionalized. He resented his personal loss of freedom and degraded position. He vocally protested the brutalizing and insensitive practices including physical restraint, which he experienced as a routine part of institutional procedure. He began his protest over these policies during his first hospltalization.

He decided to write a book designed to arouse sympathy for, and interest in, "that class of unfortunates," who had undergone similar experiences. 4 Beers' conception was to create a lay advocacy organization to protect the insane against brutal institutional practices. He was concerned with arousing public Eupport for nonrestraint policies. individualized treatment, open door or freedom of movement within the hospital, uncensored communication outside the haspital, and more highly trained professional attendants and medical staff. 5

Beers" autobiographical account of his institutionalization

4. CWB fragment from an original draft of A_Mind_That_Eoung Ittselé, [after Jan. 1905], 5 typed pages; A_Mind, draft 1, Yale. pp. 266-68; 16t edition, p. 263; Beers Papers 2, AFMH Archives, GMC, NYC; Beers had been influenced by reading Hugo's noyel Les

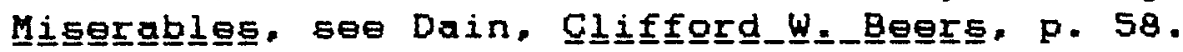

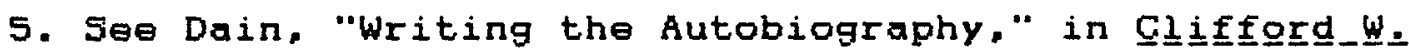
B日e돝. ch. 6, pp. 61-86. 
for mental 1 liness was written with the express purpose of creating a reform movement in psychiatric reform. He called it $A$ Mingl_That__Foung fegling about the contribution of institutional psychiatry to the remediation of his illness. An early draft read:

This book is dedicated to Humanity in its own behalf, by one whose rare privilege it has been, and is, to epeak for those afflicted thousands of human beings least able to speak for themselves. 6

The autobiography was begun at the Yale Club on January 1 , 1905 and continued after a relapse and commitment as a valuntary patient at the Hartford Retreat. A 176 page document was drafted along with a 14 page plan to establish a national organization to be funded by philanthropic donations. Beers felt assured that he could acquire funds for such an organization. He noted in his diary that John D. Rookefeller Sr. was providing large donations in public health medicine, apparently a reference to the founding of the Rockefeller Institute. Beers pondered that "the death of a favorite grandson led him to do this. Is it unreasonable to suppose that some rich man or men would become interested in my scheme because of the death or recovery of some relative afflicted with mental disease? I think not." 7

During the writing and rewriting of the first manuscripts, Beers continually solicited the opinion of influential figures in

8. Beers notebook, January, 1907. Beers Papers 2, AFMH Archives, CMC, NYC.

7. CWB "Notebook \#1, Hartford, Jan. 1905,"6-10 January 1905, pp. 4-5. 18, Beers Papers 2, AFMH Archives, CMC, NYC; also

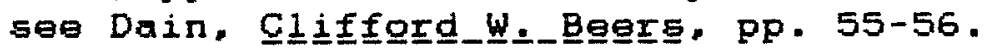


medical and psychiatric circles. 8 Beers' business sense and organizational ability made it olear to him that in order to get his manuscript published he had to avoid being discredited as a former psychiatric patient. Beers sought prior sanction from the medical and psychiatric profession to gain legitimacy for his movement. He hoped to balance this support with powerful leaders in political, gconomic and social circles. 9 His early lists of potential members ranged from the President of the United States to the presidents of universities. He inoluded top business leaders. religious leaders and reformers. First drafts went, hawever, to superintendents whose institutions he wished to reform.

Beers sent early draft copies of the monograph to the superintendent and doctors of the Connecticut Hoepital for the Insane, where he had been a patient. $10 \mathrm{He}$ also sent copies to Charles Page, Superintendent of the Danvers Insane Hospital at Hathorne. Massachusetts. Page suggested that Beers omit the names of specific institutions. Beers began to alter the manuscript to conform to the sensibilities of his potential critios. In so doing Beers set the precedent for a transformation away from his original intention to create a lay advocacy organization. The

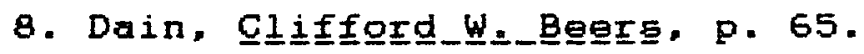

9. CWB to Herbert Wescott Fisher, 20 June 1907. Beers Papers 2. AFMH Archives CMC, NYC.

10. Henry S. Noble to CWB, 15 March 1907; A.R. Diefendorf to CWB, 13 September 1905; Albert A. Thomas to CWB 24 November 1905. Beers Papers 2, AFMH Archives, CMC. NYC. 
incipient movement was increasingly influenced by professionala. 11

Beers Justified his willingness to compromise with the excuse that it facilitated his own ends. One particularly hostile critic of the manuscript was Dr. William MoDonald of Butler Hospital in Rhode Island. Beers noted to a friend, Herbert Fisher, who was helping him with the editing: "He [MeDonald] has proved himself an invaluable friend. These points he raises are the very ones a hostile critic would have singled out for the purposes of discrediting my story... Only an unfair oritic oan attack me-and such an attack will, of course, be nothing but an advertisement for the book." 12

One of the more positive and fruitful responses to Begrs" early inquiries came from renowned Harvard psychologist, William James, to whom he sent a manuscript in June of 1906. To Beers" projection that "the reading of [the manuscript] ...will lead to your complete enlightenment as to my experience." James replied, it is a "olassic account 'from within' of an insane person's psychology." 13 James became a staunch friend and personal advocate until his death in 1910. James was also one of the few individuals who did not seek to alter or direct Beers'

11. Charles W. Page to CWB, 8 March 1906, and 14 March 1906; CWB to CWP 18 September 1906. Beers Papers 2. AFMH Archives. CMC, NYC.

12. CWB to H.W. Fisher, 20 June 1907. Beers Papers 2. AFMH Archives, CMC, NYC.

13. CWB to William James, 9 June 1906: GWB to WJ, 27 January 1907; CWB to WJ, 17 April 1907; WJ to CWB, 12 March 1907, Begrs Papers 2, AFMH Archives, CMC, NYC. 
description of his experiences even though he was uncertain about the wisdom of forming a national advacacy organization. James served as an eariy mediator between Beers and those professional leaders in medical and psychiatric circles who eventually came to provide direction for the movement.

It was oritical that Begre find financial backing. From an early stage he looked to the trend in scientific philanthropy for support to carry out his work. Beers was predisposed to ask Andrew Carnegie for support before John D. Rockefeller Sr. However, in June 1907 he introduced himself to Anson Phelps Stokes, Jr., Secretary of Yale University. Stokes, in Be日rs' words, "suggested that Mr. Rockefeller, rather than Mr. Carnegie, would be the more likely to give pecuniary assistance to the projected National Society...With a view to enlisting Mr. Rockefeller's support, Mr. Stokes offered to place my story, then in page proof form, before Mr. Gates." 14

Beers' attempt to attract the support of John D. Rockefeller Sr. through Gates was not succeseful. Beers concluded that his project was still viewed as illegitimate. Beers noted that the delay in Gates" response might prove to be beneficial, "if I can in the meantime secure the support of certain doctors not yet approached. Among them, Dr. Welch of Johns Hopkins who, I am informed, is the most influential member of the medical

14. CWB, personal notes (typed, no heading), [probably June 19071, Beers Papers 2, AFMH Archives, CMC, NYC. 
profession." 15 Stewart Paton, a well known progregsive psychiatrist who was also a Truster of the Carnegie Institution of Washington suggested that Adolf Meyer was the most influential psychiatrist in America. 16 Beers decided that if he could enlist Meyer "all the other psychiatrists would follow." 17

Adolf Meyer and the Establishment of the National Committer By the fall of 1907 . Beers had successfully courted the interest of both Adolf Meyer and William Welch. 18 Welch proved to be an invaluable advocate. He helped solicit contributions from Henry Phipps and the Rockefeller Foundation. He agreed to serve in executive positions on the Committe日, a fact which did much to legitimize the organization in medical circles.

Adolf Meyer's early presence on the Committee was as critical to its character and organization as Beers'. Meyer suggested the name "mental hygiene" and established the preventive format for the movement in social poychiatry rather than institutional reform. One of Meyer's main interests was in

15. CWB to Anson P. Stokes, Falls Village, Conn., 9 September 1909. (handwritten and typescript copies), Beers Papers 2. AFMH Archives, CMC. NYC.

16. Stewart Paton to CWB, 9 January 1907; CWB to SP, 20 May 1907; SP to CWB, 20 May 1909. The Chapter to be included was an essay on "The Modern Hospital for the Insane." Beers Papers 2 , AFMH Archives, CMC, NYC.

17. CWB, "Address Delivered at the 70th Birthday of Dr. Adalf Meyer," (typescript), pp. 174, 215, 228 Beers Papers 3, AFMH Archives, CMC, NYC.

19. CWB to Adolf Meyer, 24 September 1907, hand written copy of a letter transmitting a manuecript of A Hind; CWB, "Notebook," 22-25 September 1907: and 2, 6, 8, 9 Octaber 1907, Beers Papers 2. CHC, NYC. 
the advencement of profeasionel peychiatry through scientific research. 19 Beers' and Meyer's interests were in direct conflict. Meyer's reading of Beere' draft of the autobiagraphy was highly critical. He opposed Beers' notion of a publicly oriented national organization. He saw Beers' version of public eritiques of psychiatry as dangerous propagandizing. 20

After some thought, Meyer agreed to collaborate with Beers in editing the manuscript into a platform which he would support. Meyer's revisions altered the work both in form and content. Meyer envisioned a professional organization oriented toward scientific and clinical research controlled by physicians and psychiatrists. Meyer directed Beers' work away from what he thought of as his "hypercritical" and unbalanced views. 21

Beers was anrioyed by Meyer's changes but he went along with them. He wrote James: "I am securing the support of the medical profession...before long. I shall have the medical jury fixed." 22 Beers even conceded to Meyer's proposed position on leadership. He agreed to have the incipient association organized in such a way as to exhibit the "desired medical color." This was to be in Beers" words: "secured by selecting as officers of the

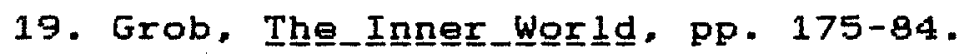

20. Eunice Winters. "Adolf Meyer and Clifford Beers, 1907-

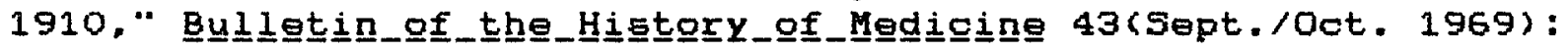
414-43.

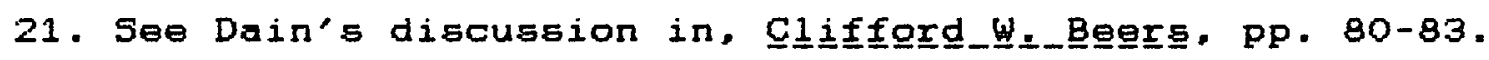
22. CWB to William James, 29 October 1907. Beers Papers 2. AFMH Archives, CMC, NYC. 
association members of the medical profession itself as to seem, at least in the eyes of the members of that profession, to be a medical movement." still, Beers thought of the organization as one which offeet the power of psychiatrists by way of the support of powerful nonmedical members. A "Well balanced medical-layman control of the National Association for Mental Hygiene will render what might be called megaphonic eervice for the medical profession by giving voice to authoritative opinion and advice which heretofore has not even succeeded in reaching all members of the medical profession itself, let alone the public at large." 23 Meyer was aware of Beers' conflict in needing his apprabation but resenting his input. Meyer wrote him. "If you don't want medical staff directing the organization then I might also become an obstacle to your own aims and those of your society." 24

Beers fully intended to pursue his own goals after he had successfully acquired the necessary backing. After making changes in the final manuecript prior to publication. Beers asked Meyer to contribute a letter of support in the autobiography. Penciled on his copy of the request he sent Meyer, Beers smugly noted to himself: "Perhape this letter will strike you as being flippant.

23. CWB to Adolf Meyer, 27 October 1908, enclosed with a draft of a "Keynote Address" for the proposed National Association for Mental Hygiene. Beers Papers 2, AFMH Archives, CMC, NYC.

24. Adolf Meyer to CWB, 18 October 1908; CWB to AM, 19 October 1905, Beers Papers 2, AFMH Archives, CMC, NYC. 
nevertheless, it brought forth what I needed." 25 Beers' book was finally published amid praise and publicity.

The autobiography, whatever else its literary or olinical value, is also a deliberately written piece of inspirational literature for what Beers considered as 'his movement.' Written as a persuasive argument it contained introductory letters from Adolf Meyer, William James and Stewart Paton. 26 The large appendix included supplementary material designed to attract support for the National Committe日 for Mental Hygiene.

After the publication of A_Mind_That_Found_Itgegelf the conflicting views of Meyer and Beers over the objectives and organization of the movement came to a head. Beers' interest was in expansion, publicity and the pursuit of funds. He wanted to immediately establish a national association. Meyer openly disagreed. He favoured a small profeseional committee which would avoid public statements. Meyer had every intention of keeping control of the movement in professional circles. He hoped to minimize Begrs' in-put. The immediate lack of funds for expansion tended to favour Meyer's view. However, the attention and support Beers had already attracted had set up a momentum which was difficult to offaet.

A compromise was worked out which allowed Beers a forum yet limited the organization's public scope. Beers was persuaded to

25. CWB to Adolf Meyer, 26 Dctober 2 1907; a return letter from Meyer is dated 27 Detober 1907. CMC CWB Papers 2.

26. Beers, A_Ming (1909); also drafts, A_Ming, Beers Papers 2, AFMH Archives. CMC, NYC. 
begin with a state society in Connecticut rather than a national association as he had envisioned. Meyer argued that a state level society should provide a practical demonstration of the functioning of an organization to promote mental hygiene before expansion was sexiously considered. Meyer insisted that "not depending on a large association [was] bound to be the only correct policy." 27 Meyer emphasizing this point wrate Beers: "I hope very much that the Connecticut Society will get into working order on essentials autside of legislative propaganda." 28

Meyer also paternalistically felt that he was helping Beers. "I wanted him to learn something of what he wanted to get the money for... I felt the work should be on a foundation of knowledge and not merely of dreaming." 29 Meyer was concerned about the still primitive state of psychiatric knowledge. He noted that the high expectations and enthusiasm of nonprofessionals could do more harm than good. He stressed the point that "I feel very keenly that people who give money without knowing very clearly what it is for are rather dangerous

27. CWB to Adolf Meyer. 22 December 1908; AM to CWB, 16 January 1909, Beers Papers 2, AFMH Archives, CMC, NYC.

28. Adolf Meyer to CWB, 16 January 1909, Beers Papers 2. AFMH Archives, CMC, NYC.

29. "A Visit with Dr. Meyer in Baltimore." Interview transcript with Paul 0. Komora, (typescript). Salmon Papers 1, 3. AFMH Archives. Payne Whitney Clinic Library, CMC, NYC. 
helpers." 30 Meyer felt that Beers with his limited knowledge and grandiose schemes was a rather dangerous helper.

Over the few months preceding the founding of the

Connecticut Society Beers was more successful in expanding mental hygiene than Meyer was in limiting its impact. Two months after the acclaimed publication of A_Mind_That__Egung founding members of the Connecticut Society for Mental Hygiene gathered in New Haven at the home of Anson Phelps stokes to launch the movement. 31 Beers wrote William James on the Committe日's first stationery describing the second meeting which listed 105 members enrolled. 32 Plans were made over Meyer's objection to establish a national association. In a last minute compromise the title of the national organization was changed from an association to the less formal connotation of a committer. 33 Membership was to include both medical professionals and influential political, social and economic leaders in the style of a voluntary association.

The first meeting of the National committer was held on

30. Adolf Meyer to CWB, November 1908, Beers Papers 2, AFMH Archives, CMC, NYC.

31. CWB to Anson Phelps Stokes, 1 May 1908, Beers Papers 2, AFMH Archives, CMC, NYC: Everitt G. Hill "Editorial: A Great Work Begun," New_Hayeng_Eyenging_Regi

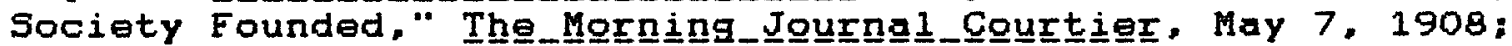
"Friends of the Insane Meet," New_Haven_Eyening_Regiseter. 7 May 1908.

32. CWB to William James, 16 June 1908, cont. 18 June 1908 , Beers Papers 2, AFMH Archives, CMC, NYC.

33. CWB to Adolf Meyer, 22 December 1908; AM to CWB, 16 January 1909, Beers Papers 2, AFMH Archives, CMC, NYC. 
February 19, 1909. Among those present were Harvard paychologist William James; Russell H. Chittenden, Head of Yale University Sheffield Scientific School: President Jacob G. Schurman of Cornell University; Anson Phelps Stokes, Secretary of Yale University: Johns Hopkins University physician, Lewellys F. Barker; neurologist, August Hoch; first women on the Illinois Board of State Commissioners of Public Charities, Julia Lathrop: Chicago physician, Henry B. Favill; psychiatrift, Adolf Meyer; Charles P. Bancroft, Head of New Hampehire State Hospital and William Welch. Meyer became Chairman of the Executive Committe日 with Bancroft, Chittenden, James, and Lathrop. Favill became President with Bancroft and Welch, Vice Presidents. 34

Beers began to campaign for the position of secretary of the National Committee. Meyer opposed strengthening Beers" position in the Committee leadership. However. Beers' successfully appealed to James to influence Meyer in his favour. Beers was appointed secretary pro tem. Meyer was persuaded to make the appointment by the fact that Beers had borne the financial costs of organization in its early stages. James had on occasion provided Beers with living expenses. 35

34. Minutes, "Meeting for the Founding of the National Committee For Mental Hygiene." 19 February 1909, Beere Papers 2. AFMH Archives, CMC, NYC.

35. Meyer explained his change of heart "on account of the financial advantages that should come your way as the natural and well deserved reward for your labors. "Dain, Cllíf壬or 130, fn. 58; William James to Adolf Meyer, 24 February 1909; AM to WJ. 26 February 1909; AM to CWB, 27 February 1909, Beers Papers 2, AFMH Archives, CMC, NYC. 
Upon being made secretary pro tem, Beers proceeded with an ambitious publicity plan for the Committer. This action went directly against Meyer's adamant position on avaiding publicity. Meyer responded angrily. $36 \mathrm{James}$ attempted to intervene as mediator but the two positions were not reconcilable. James greatly respected Meyer and valued Beers' potential contribution to the cause of mental hygiene. James finally concluded, "I can see both sides-it is a case of the ox and the wild ass, not working well in double harness." 37

The continuing and most persistent problem which superseded the bickering over policy was the imperative need for funding. This too created policy problems. James had made a personal appeal to John D. Rockefeller Sr. Which had not been succeseful. 38 It was determined after the founding of the committee that a formal appeal should be drafted. Meyer and Beers olashed on the drafting of the document. Meyer disliked the unprofessional use of statistics, the exaggerated length, and the emotionalism. "With me the appeal leaves an impression as if I had gone through a troublesome dream-that is not the most favorable attitude on

36. Meyer wrote Beexs, 2 March 1909: "No sooner do I mention the arrangement for the secretaryship preliminary of the Executive Committer, than I se日 you sitting on the fence flapping your wings. The part I have most at heart se日ms quite secondary." Beers Papers 2, AFMH Archives, CMC, NYC.

37. William James postcard to CWB, 22 September 1909; WJ to CWB 22 May 1910, Beers Papers 2, AFMH Archives. CMC, NYC.

38. WJ to John D. Rockefeller Sr.. 31 January 1909, (copy, Beers Papers 2, AFMH Archives, CMC, NYC. 
which to plan action of a somewhat optimiatic character." 39

A revised appeal was finally delivered by Anson Phelps Stokes. June 2, 1909. It contained letters from William James and Adolf Meyer requesting $\$ 13$ million. John D. Rockefeller Sr. and his advisors declined the request. Even though funds were not granted, the proposal was influential by way of its timing in the formative period of the Rockefeller Foundation. It contributed to the Foundation's eventual orientation toward mental hygiene as an important and legitimate area in need of research and support. 40 The inability of the Committe日 to secure solid research funding increased Meyer's disillusionment with the bilateral laymedical voluntary society which was coming into being as initiated by Beers. Meyer decided to resign and to contribute to the advance of extramural psychiatry in his own professional capacities. 41

Heyer had substantially influenced the formal structure and orientation of the movement. Meyer's orientation toward a professional leadership on the committe日 was never thereafter seriously questioned, even though his resignation appeared to make Beers the victor in their disagreements. Meyer had, along with the active work of Welch and James, greatly facilitated the

39. Adolf Meyer to CWB, 12 April 1909; AM to CWB, 13 April 1909. Papexs 2, AFMH Archives, CMC, NYC.

40. Anson Phelps Stokes to CWB, 19 June 1909, Beers Papers 2. AFMH Archives, CMC, NYG.

41. George Blumer to Charles P. Emerson, April 1910; Adolf Meyer to Henry B. Favill, 8 May 1910; AM to CWB, 14 August 1910: Beers Papers 2, AFMH Archives, CMC, NYC. 
legitimation of the natianal committea in the Fyes af professional organizations such as the American MedicoPsychological Aseociation fforerunner to the American Peychiatrio Association). Meyer's resignation took effect in 1911 just as he moved to Johns Hopkins University as Director of The Henry Phipps Psychiatric Clinic which opened in 1912. Personally, Meyer continued to influence the Committee and to help direct and provide a rationale for the mental hygiene movement without the burdensame and time consuming arguments with Beers. 42

Thomas W. Salmon and the Rockefeller Foundation

Finanoing was a continuing and critical problem if the National Committee was to survive. It was imperative to attract respectable leaderehip for the Committee as well as to replace Meyer. Thomas w. Salmon (1876-1927) stepped in to fill this gap. He was the influential voice which carried the opinion of Rockefeller interests in favour of the NCMH. Salmon and Meyer agreed on many key issues. Both men sought to circumseribe Beers" orientation as potentially of negative impact or unworkable and to channel the movement into what they considered to be a more fruitful and scientifically accurate direction. It was this latter orlentation toward acience which interested the Rockefeller Foundation officials. By arguing for the development of a scientific approach to psychiatry, Salmon secured Rockefeller support for mental hygiene. Both the National

42. Paul O. Komora Interview, "Visit with Dr. Meyer in Baltimore," Thomas Salmon Papers 1, 3, AFMH Archives, Payne Whitney Clinic Library, GMC, NYC. 
Committee for Mental Hyglene and the Rockefeller Foundation can be said to have been influenced by "the Salmon years." Gerge Vincent, President of the Rockefeller Foundation (1917-1929), is reputed to have attributed the Foundation's commitment to mental hygiene and psychiatry to the influence of Thomas Salmon. 43

Adolf Meyer credited Salmon as "an advisor and helper.. who really was the mental hygienist in peychiatry. I don't know if he had a very keen interest in the theory of psychiatry or in research-pathological anatomy and matters of that sort. He was in it for the mental hygiene that was contained in poychiatry." 44 He was largely responsible for moving mental hygiene toward a working hypothesis, namely, that mental illness arises out of harmful experiences in childhood. He became a leader in establishing psychiatry in medical education. Salmon reshaped Beers' vague notion of a lay controlled advocacy association into a large scale public health effort coordinated by top level government officials with the influential backing of powerful philanthropic leadership.

Salmon was a highly respected, politically effective advocate for the use of applied psychiatry to social problems. As first Medical Director of the NCMH, Salmon formulated and shaped

43. Paul 0. Komora, Interview, "Visit with Dr. Duggan," (typescript), p. 1, Thomas Salmon Papers 1. 1, AFMH Archives, Payne Whitney Clinic Library, CMC, NYC; Raymond B. Fosdick, The

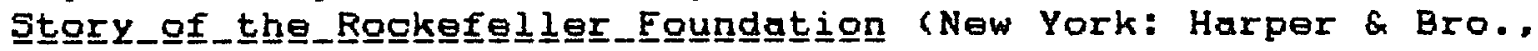
1952): pp. 26, 127-8.

44. Paul 0. Komora Interview, "Visit With Dr. Meyer in Baltimore." p. 2, Thomas Salmon Papers 1, 3, AFMH Archives, Payne Whitney Clinic, CMC, NYC. 
the public health orientation of the policiea and practices of the Committer. He set up protocols which were influential in mental hygiene circles over the next two decades. Salmon also influenced the Rockefeller Foundation as a consultant on the Board of Trustees. He received a salary from the Foundation from 1915 to 1922. 45 He was appointed Chief of Psychiatry in the U.S. Army during world war $I$. On his resignation from the NCMH, he became the first professor of psychiatry at Columbia University Medical School where he helped establish a state funded Psychiatric Institute. Salmon worked diligently to secure the support of Rockefeller and other philanthropies for medical training in psychiatry which he foresaw as the single most critical long term issue in the success of the mental hygiene movement. 46 Salmon's activities in other organizations in addition to the National Committer, including the American Psychopathic Association, the National Institute of Social Science, and the American Psychiatrio Association furthered the

45. NCMH, "How and by whom the work of the National Committee for Mental Hygiene has been financed, covering the organizing period, 1907-1911 and the period of its active work. 1912 to date 1918," 29 January, 1918, RG 1.1, 200, 33, 373; NCMH, "Bureau of Uniform Statistics," 1919, RG 1.1, 200, 33, 375, RFA, RAC, N. Tarrytown, N.Y.

46. Paul 0. Komora Notes. "Psychiatry in Medical Education," typescript. Thomas Salmon Papers 1, 3; George H. Kirby "The New York Psychiatric Institute and Hospital: A Sketch of Its Development from 1895-1929;" George H.Kirby. "Opening Address: Dedication of New York's New Psychiatric Institute and Hospital." 3 December 1929; with George H. Kirby to William Darrach, 20 May 1930. Thomas Salmon Papers 4. 11; New York State Hospital Commiesion, "Released for Morning and Evening Papers. Friday Dec. 31," 30 December 1926. Thomas Papers 4, 7, AFMH Archives, Payne Whitney Clinie Library, CMC, NYC. 
work of mental hygiene. 47

Salmon acquired a reputation as a man of science. His ideas were acquired more by the accidents of his personal biography than his educational training. After completing medical school Salmon tried private medical practice in the footsteps of his father, a country doctor. It was financial disaster. His disinterest and lack of talent for coordinating the business aspect of an entrepreneurial medical practice encouraged him to take a position with the New York State Health Department to afford some security for his growing family. He was sent as a bacteriologist to investigate an epidemic of diphtheria at Willard State Hospital for the Insane. He so impressed officials that he was subsequently put in charge of bacteriology in all of New York state mental hospitals. It was at Willard that he first met Adolf Meyer and became close friends with Dr. William L. Russell, another early pioneer in psychiatry. Meyer later noted that "Russell was the one who put a great deal of stock in Salmon. I learned to do the same thing." 48 It was the active and vocal eupport that Salmon evaked from men such as William Russell and Adolf Meyer, later Stewart Paton and Charles Eliot among others, that placed him in positions of authority in the NCMH, RF, in the U.S. Public Health and Military Services, and later at

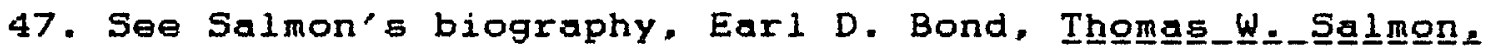

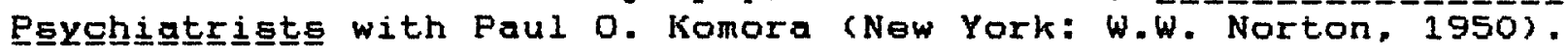

48. Paul 0. Komora Interview "Visit with Dr. Meyer in Baltimore," p. 2, Thomas Salmon Papers 1, 3, AFMH Archives, Payne Whitney Clinic Library, CMC, NYC.. 
Columbia Univeraity. 49

Central to Salmon's conceptual perspectives was his experience as an officer in the Public Health Service which he joined in 1903 as an Assistant Surgeon. He was assigned to the Immigration Service on Ellis Island during the height of the European exodus from the Old to the New World. Salmon was directed to prepare and carry out psychiatric examinations. Salmon came to the Service with a heightened awareness of mental illness from his personal observation of the insane in mental hospitals. He became convinced of the reality of a serious and widespread epidemic of insanity in the general public. To Salmon, this quite clearly indicated the urgent need for remedial and preventive measures. Salmon characteristically developed a plan for action in the early identification in children and youth, the examination and deportation of defective aliens, and the collection of accurate statistics on the incidence of insanity or inoipient insanity in other institutions such as hospitals. Jails, almshouses, and schools. His ideas on prevention focussed on the eradication of contagious diseases, the application of eugenical principles in social policy, the upgrading of profeseionals and the development of active field work in mental hygiene. 50

49. Komora, "Visit,"; also se日 Charles W. Eliot to CWB, 5 February 14 Thomas Salmon Papers 1, 9, AFMH Archives, Payne Whitney Clinic Library, CMC, NYC.

50. Thomas $w$. Salmon, "The Prevention of Mental Diseases," Paper read at the 15th International Congress of Hygiene and Demography, Washingtón D.C.. 26 September 1912, (typescript). 
Salmon'a atance ag an advocate for the restriction of alieng and more efficient examination and deportation procedures, contributed to the making of his reputation in psychiatry. Even his suspension from his position at Ellis Island served his cause we11. Salmon was relieved of duty due to insubordination when he refused one particularly busy day with over 5000 arrivals, to carry out routine inspection duties which detracted from what he considered to be his more urgent peychiatric work. The suspension attracted the attention of Surgeon General Rupert Blue and President Theodore Roosevelt.

Additionally, the immigration issue fostered a close working relationship with Homer Folks, Director of the State Charities Aid Association. Under Folk's direction the Charities Aid Saciety took up an interest in immigration in 1904. 51 After joining the NCMH in 1912-1914. Salmon successfully lobbied for legislation aimed at restricting the "admission of insane and mentally defective immigrants." Salmon managed to engage benevolent and charity societies to work on improving conditions at Ellis Island. A major concern was the development of services for detained women and children. When he left the Public Health

Thomas Salmon Papers 1, 6, AFMH Archives, Payne whitney Clinic Library, CMC, NYC.

51. See the quote from Folks cited in Bond, Thom Salmon, p. 40-41. Folks later recommended Salmon for positions on the NCMH and Rockefeller Foundation: Homer Folks. The_Cange_of

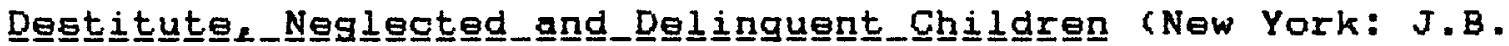
Lyon, 1900 reprint New York: Arno. 1971); Walter I. Trattner,

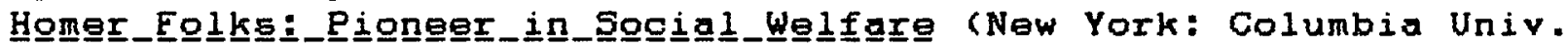
Pres5, 1968). 
Service, Salmon offered plans for the establiahment of a permanent psychiatric division in the Public Health Service to the Surgeon General. Theae plane contributed to the institutionalization of psychiatry in the immigration service and the legitimation of mental health issues as within the proper sphere of interest of the Public Health Service. 52

In 1911, the New York State Commission in Lunacy asked that Salmon be given leave of absence to serve as Chief Medical Examiner of the Board of Alienists. He became the "provisional statistician," in charge of determining the number of foreign born in New York hospitals. A talented graphic artist Salmon produced the first viaual charts available to hospital administrators illustrating the over representation of foreign born in public hospitals. He also helped to develop at this time the first uniform system of reporting admissions and discharges from a state hospital system in the United States. As Salmon moved up in power and position, this system was adopted first by the National Committee for Mental Hygiene, and; by the American Psychiatric Association in the 1920s. The surveys of New York

52. TWS to Lewellys F. Barker, 27 January 1913; TWS to The Surgeon General, 27 January 1913; "Minutes of Committee on Mental Hygiene." 21 February 1913, 16 May 1913, 15 May 1913; Tws to Mrs. Caraline B. Alexander, 12 December 1913; (with a copy of a letter of intraduction from Stewart Paton. 7 August 1913); TWS to Rupert Blue, 18 February 1914; "Alien Insane Bil1," Albany_Medígal Annals, 35, 228, (April 1914); and numerous typescript of papers presented to meeting or published by Salmon with regard to the immigration question. Thomas salmon Papers 1, 8; CWB to stewart Paton, 29 October 1912, regarding a meeting to foster legiblation between the NCMH and the Eugenics Section of the American Breeders Association and the American Medico-Psychological Association, AFMH Archives, Payne Whitney Clinic Library, CHC, NYC. 
Hospitala provided a stepping atone to the RF and the NCMH.

Salmon's transfer to the NCMH was precipitated by the gift from Henry Phipps to the National Committee. In 1911, Phipps sent 550,000 to William Welch, then President. Half of this sum was to be spent for the purpose of creating a "Special Committee on Survey and Improvement of Conditions" among the insane. It was generally agreed that Salmon "esemed to be the man best fitted to serve as Special Inveatigator." 53

Salmon drew up a master plan of action for the Committee which included a series of surveye. Salmon emphasized two prerogatives: the elimination of defective populations and the preservation of health in normal children. He insisted that the Committee provide leadership for preventive action concerning social problems related to increases in insanity due to syphilis. alcohol, immigration, heredity, and marriage of the feebleminded. On the other hand, he favoured earlier recognition of psychiatric problems by way of establishing "dispensaries, mental examination of school children, [and] teaching medical psychology to teachers." 54 The substance of these ideas reflected a combination of the public health reformist models. Salmon borrowed from ideas pioneered by William Welch and William Osler, the psychobiology of Adolf Meyer, and the clinical emphasis on

53. NCMH, "Joint Meeting lof the Executive and Finance Committees]," 9 December 1911. Thomas Salmon Papers 1. 5. AFMH Archives, Payne Whitney Clinic Library, CMC, NYC.

54. NCMH, "Firat joint meeting of Exec. \& Finance Committers." 25 April 1911. Thomas Salmon Papers 1, 5. AFMH Archives, Payne Whitney Clinic Library, CMC, NYG. 
dynamic paychology favoured by G. Stanley Hall and his studenta. The impetus for the mental hygiene movement was also encouraged by the popular rise of eugenics. Eugenical views underscored the authority of scientific and statistical knowledge which strongly supported a medical approach to sooial problem solving. Biology and evolutionary theory placed an emphasis on heredity family and racial factors in abnormality. 55

Unlike Meyer, Salmon was not opposed to making mental hygiene a public issue. He favoured the legislative propagandizing Meyer had opposed. Salmon initiated the preparation of a summary of legislation related to mental hygiene in order to determine the changes which needed to be made. He then set about educating the public on the changes in laws which he desmed important. In keeping with the forms of popular education of the day a mental hygiene exhibit was made to be presented at the International Congress on Hygiene and Demography

55. Immigration issues were a major concern in the early 1900s. Salmon's concern over immigration made it an intimate aspect of the campaign for mental hygiene. The application of evolutionary theory to human populations popularized public fears over the status of immigrants and the role of the underolasses in perpetrating social and health problems. This became a major issue in both the National Committee for Mental Hygiene and the Canadian National Committee. The effort to control immigration served as a crude model for preventive social action. While seemingly divorced from ohildren, the issue of immigrant status was grounded in the childhood gaze with its scientism and concern over the future. Undetected degenerate individuals were viewed as undermining national vitality by reducing the potential of the young and unborn and therefore the promise of the nation's heritage.TWS to Frederick Peterson (of the New York Psychiatrical Society regarding the Conference on Immigration) 14 November 1912. Thomas Salmon Papers 1, 6, AFMH Archives, Payne Whitney Clinic Library, CMC, NYC. 
held in Washington D.C. In November of 1912. This Exhibit, which Salmon and Paton prepared, became an important tool of mental hygiene propaganda for many years to come. It emphasized mental hygiene work with children in parent education, child rearing, and the prevention of delinquency. The dangers to the general public of the uncontrolled proliferation of defective gene pools by way of uncontrolled immigration or uncontrolled marriages of defective or diseased persons were compared to an epidemic. Henry Goddard's work at Vineland and the need to control feebleminded children was a prominent portion of the dieplay. 56

Salmon also sought to legitimize mental hygiene in professional circles. During this first year, Salmon instigated the formal recognition of the National Committee by the American Medico-Psychological Association in a resolution adopted in Atlantic City, May 30, 1912: and by the American Medical Association, also in Atlantic City, June 6, 1912. The Committer sent delegates to the Fourth International Congrese on Sohool Hygiene held in Buffalo, New York. The Congress, chaired by Charles Eliot, attracted prominent figures from the United States and Canada. 57 Topics included child study, sex hygiene, the need

56. National Committee for Mental Hygiene and the Committer on Mental Hygiene of the New York State Charities Aid Association, "Hental Hygiene Conference and Exhibit, held at the College of the City of New York, 8-15 November 1912;" J.D. Greene, Memo, 15 November 1912; CWB to John D. Rockefeller Sr. 7 November 1912, RG 1.1, 200, 32, 363, RFA, RAC, N. Tarrytown, NY.

57. NCMH, "Minutes Annual Meeting," 5 April 1913, pp. 82143, AFMH Archives, GMC, NYC; Clarence Hinoks and Helen Machurchy who became prominent in the Canadian mental hygiene movement were among the Canadian delegates. Clarence Hincks, "International 
for special facilities for defective and delinquent children, school inspection and peychiatric clinics. 58

As Salmon became increasingly instrumental in the functioning of the National Committee it was essential to consolidate the power structure of the committee and to secure a permanent salary for the chief officer. Salmon took on an increasingly important role in negotiating with John D. Rockefeller Sr and his advisors with the ever present hopes of acquiring a permanent endowment.

At the annual meeting of the National Committer for Mental Hygiene in 1913 the problem of the leadership was resolved. The position of medical director was created as chief officer. This placed Beers' position as Executive Secretary as subordinate to Salmon as Medical Director. The issue of scientific leadership was essential to Rockefeller support. Beers did not fully understand this condition. He was infuriated at what he felt was the usurpation of his movement by medical professionals. He contacted Charles Eliot, Vice President of the NCMH, as one of the mast influential figures in the nonmedical field. Eliot was also familiar with the Rockefeller Foundation having served as a

Conference on School Hygiene in Buffalo," Torontonto_star (26 August 1913): John D. Griffin, "Mental Health - Canada: The Chronicle of a National Voluntary Movement, The Canadian Mental Health Association, 1918-1980," vol. 1 (May 1981), p. 13, GreenlandGriffin Archives. Toronto.

58. "Report of the Permanent International Committe日." Meeting of the Permanent International Committer. Fourth International Congress on School Hygiene, "Proceedings," (New York, 1913), pp. 113-63. 
member of the General Education Board since 1908. 59 Beers asked Eliot to intervene in preventing "a small group of men, more or less withdrawn from the public eye, as the principal agent for promoting improvements in the care of the insane." Beers had underestimated Eliot's support for the scientific side of the mental hygiene movement which Salmon had come to represent. Eliot reminded Beers that "the Rockefeller Foundation will always be glad to hear any proposals of the National Committee which may have the endorsement of Dr. Thomas Salmon for I know that the gentlemen who manage most of the Rockfeller trusts have a high regard for [his] Judgement and efficiency." 60 This was Beers" last attempt to eliminate the soientific and professional orientation of the NCMH.

In December, August Hoch and Salmon approached Jerome Greene, Secretary of the Rockefeller Foundation, with a proposal for funding mental hygiene surveys. 61 The Rockefeller Foundation agreed to support the surveys as a way of initiating its own mental hygiene program as well as in support of the NCMH. The Board of Trustees in a unique action on ite part, appointed Thomas salmon to a position on the Board as "its advisor in

59. General Education Board. The_General_Edugation_Boardi_An

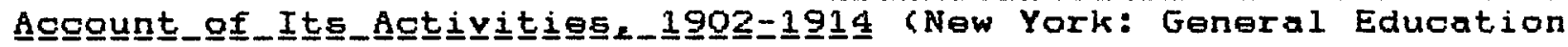
Board, 1915), pp. xiii-xiv.

60. Charles W. Eliot to CWB, 5 February 1914. Beers Papers 3. AFMH Archives, CMC, NYC.

61. August Hoch to Lewellys $F$. Barker (President of the NCMH), 30 December 1914, Thomas Salmon Papers 1, 6, AFMH Archives, Payne whitney Clinic Library, CMC, NYC. 
matters relating to mental hygiene," and "lent" him to the National Comitter. 62 Salmon served this dual function for the next seven years.

The Foundation appropriated $\$ 205.800$ for the Committee between 1915 and 1918 . The appropriations were for epecific demonstration projects initiated by Salmon. Salmon's salary (\$28,000) for the period is ineluded in the total figure. The survey work (for which $\$ 45,800$ was appropriated) collected data on the quality of child life. A study, between 1916 and 1918 , funded for a total of $\$ 47,500$ was conducted on the psychopathology of crime at the Penitentiary at Sing Sing in connection with the Children's Court in New York City. The NCMH's work with state Commissions concerned with the mentally defective (supported for $\$ 39.250$ ) was an area where the major cause for alarm was in the identification of school age children. The creation of a Bureau within the NCMH to keep uniform statistics on mental disease (initiated with a grant of $\$ 2.750$ ) was modeled on the procedures developed during Salmon's New York study of hospitals. This work was taken over by the U.S. Gensus Bureau in the 1920s. 63

62. August Hoch to L.F. Barker, 31 December 1914; Jerome D. Greene to AH 4 January 1915: J.D. Greene to TWS, 4 January 1915; "Summary of the negotiations with the Rockefeller Foundation," typescript, 5 January 1915, Thomas Salmon Papers 1, 6, AFMH Archives, Payne Whitney Clinic Library, CMC, NYC.

63. National Committe日 for Mental Hygiene. "How and By Whom the work of the National Committee for Mental Hygiene has been financed, covering the organizing period 1907-1911 and the period of its active work, 1912 to date: 1918," 29 January 1918, pp. 16. RG 1.1, 200, 33, 373; NCMH "Bureau of Uniform Statistics." 
In addition to Rockefeller funds, Beers was able to produce close to $\$ 207,500$ in matching contributions from other sources. 64 The requirement of matching funda became a characteristic of Rockefeller appropriations for mental hygiene in the years to come. Beers prided himself on his fund raising ability. Nonetheless, it was Salmon's dual role with the Rockefeller Foundation Board of Trusters and the Committee which made the work of the Committer possible in the early years. As the budget of the National Committe日 soared in the inter-war period it was the Foundation which continued to supply the financial aid which sustained the movement.

\section{War Work}

The first World war played a significant role in the mental hygiene movement even though the initial response appeared to deter the advance of the idea. No state societies were added during the War years. Canada entered the war in 1914 and the United States in the spring of 1917. The Rockefeller Foundation placed increased priority in War relief work in Europe during this period. This accounts in part for the Foundation's reluctance to engage in large soale funding of the NCMH survey work. In 1917 most of the medical leadership of the National Committee entered the war including Thomas Salmon. The long term effect of the War was to legitimize and publicize the need for

1919, RG 1.1, 200, 33, 375, REA, RAC, N. Tarrytown, N.Y.

64. National Committee for Mental Hygiene, "How and By Whom." Nearly half of this amount was from a single pledge from Mrs. Elizabeth Milbank Anderson. 
preventive mental health in the post war period.

In February of 1917, Stewart Paton, Pierce Bailey, and Salmon appraached the Surgeon General, then William C. Gorgas. concerning the need for peychiatric screening and clinical work in the military service. Salmon was sent to survey the mental status of the Canadian army. He was to report back to Gorgas on the need for psychiatric scre日ning amang soldiers during wartime. The idea of clinical screening of recruits was not original: Lewis Terman, Edward Thorndike, Robert Yerkes and Henry Goddard, devised intelligence screening tests for the Army in Goddard's laboratory at Vineland Training school. The two versions became known as the Army Alpha and Beta tests. These teste pioneered massive testing programmes which were to become common place research and diagnostic tools with children. Yerkes" supervision of testing in the Army did not include peychiatric screening or clinical services. In the United States Army, clinical psychology and psychiatry as concerned with the mental status of soldiers, occurred independently. The proposal presented to Gorgas for a psychiatric division in the U.S. Army in Europe was aceepted. Salmon was subsequently asked to direct the program as Chief of Peychiatry for the U.S. Expeditionary Forces in France. 65 In this official capacity salmon devised programs for peychiatric care in the army and initiated a professional

65. Stewart Paton to CWB, 8 October 1923 discusses the origins of neuropsychiatric work in the army in 1917. Thomas Salmon Papers 3, 6; TWS to C.W. Gorgas, 12 May 1917, reports the management of mental cases in the Canadian Army. Thomas Salmon papers 2, 3, AFMH Archives, Payne Whitney Clinic Library, CMC, NYC. 
training course for poychiatric aidg at Smith college. These programmes served as models for post War pragrammes many of which were directly concerned with children. The special course work in peychiatry at Smith College had direct post War connections with the permanent establishment of a professional course in psychiatric social work. After the war Salmon reported his conclusions on psychiatry and war experiences to both canadian and U.S. audiences. Salmon through the official position as Director of the National Committee brought the organization into active war work as well. The National Committee contributed to the war effort by recruiting psychiatrists and neurologists, organizing records, printing medical examinations, and arranging after care facilitieg. 66

\section{Canadian Psychiatric Reformism}

One other consequence of the war was the freedom it afforded Clifford Beers to reaffirm his position of influence in the Committe日's work. Beers was disgruntled by the fact that the building of an international organization as well as the growth of local and state societies had ceased during the war.

66. Stewart Paton to CWB, 8 October 1923. Thomas Salmon Papers 3, 6, AFMH Archives, Payne Whitney Clinic, CMC, NYC: Norman Fenton and Thomas Salmon, eds.. "Neuropsychiatry,. U..S.

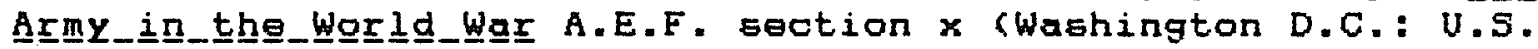
Government Printing Office. 1950); Thomas W. Salmon "Recommendations for the Treatment of Mental and Nervaus Diseases

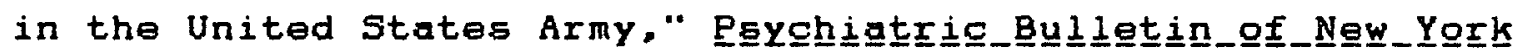
Stat트_Hospitale 2 (July 1917): 353-376; Thomas W. Salmon. "Psychiatric Lessons of the war." Progegedings_of the_canadian

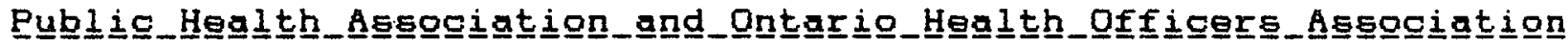
(May 6-8, 1919), also abstracted in the New_Yoㅡㅌ_kedi 110 (July 12, 1919): 84 . 
Unencumbered by opponents to the expansion of the Committee, Beers organized a coup in helping to establish an affiliated Canadian National Committe日. This was the first step toward his dream of an international organization. The organizing meetings of the Canadian National Committee for Mental Hygiene took place in the spring of 1918 . The official organization of the mental hygiene movement was extended beyond the national boundary of the United states. While mental hygiene societies extended around the world by 1930, the majority of the actual work continued to be conducted in the United States and canada. 67

A mavement for the reform of medicine and asylum peychiatry in the nineteenth century had been present in canada as well as in the United States. From the early years of the twentieth century, reformist were concerned with public policies on mental deficiency, immigration, public health and schooling. However, the movement did not come together prior to world war I as it had in the United States under Beers' tutelage. The Canadian National Comittee was postponed until after world war I. 68

Psychiatrist Charles K. Glarke and physician Clarence M. Hincks became the principle figures in the formal organization of the Canadian National Committer for Mental Hygiene at the clase of the War. Clarke became the firet Medical Director with Hincks

67. CWB to Clarence M. Hincke, 23 November 1918, Clarence Hincks Papers 4, 3, Greenland Griffin Archives. Taronto; NCMH, "How and By whom the work of the National Committee has Been Financed," RG 1.1, 200, 33, 373, RFA, RAC, N. Tarrytown, N.Y. 1 and 13 .

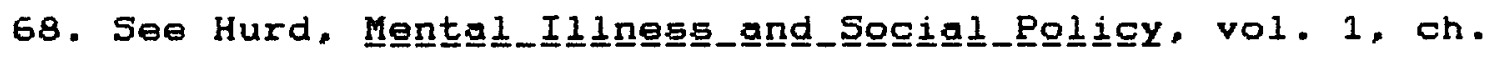


as Secretary and Assistant Director. The composition of the Canadian National Committer reflected the advance of public health medicine and the transition of psychiatry from nineteenth century asylums to twentieth century universities, hospitals and clinics.

Charles K. Clarke was the Canadian counterpart to Adolf Meyer. The Canadian movement was shaped by Clarke's personal perspective and experiences. Clarke combined the seemingly contradictory tendencies of his time more than Meyer. Meyer was devoutly scientific in his orientation, whereas, Clarke's science was more a veneer. He was a medical reformer of institutional psychiatric practice who opposed using physical restraint to control mental patients. Yet, he staunchly argued for increased detection and institutionalization of the mentally ill. His beliefs were based on a combination of eugenics, and, a personal fear of mental disorders and mental defects. Clarke was considerably less interested in prevention or social psychology than Adolf Meyer. He emphasized biology over psychiatry in opposition to Meyer's psychabiology. Clarke became inereasingly hostile to psychoanalytic perspectives. Clarke's interests were more compatible with Beers in that he was concerned with institutional reform. He also encouraged publicity and strongly supported fund raising among the wealthy and influential.

Clarke became the first Medical Director of the Canadian National Committee. He began his psychiatric training under two early activists in the international reform movement in 
paychiatry. Clarke'a mentorg are importent a they shaped hia perspective and subsequently the outlook of the canadian mental hygiene movement. The position of the asylum superintendent was a political position of respect and importance in nineternth century Canada. Clarke had varied experience at the major institutions in Ontario. Clarke trained at the Toronto Asylum, in 1874, under a Canadian pioneer in psychiatry. Joseph Workman. Joseph Workman was an early spokesman for the application of medical science to psychiatric problems. He was an early pioneer in arguing for nonrestraint polioies in mental hospitals. $69 \mathrm{C} . \mathrm{K}$. Clarke worked with Daniel Clark at Toronto Asylum up to 1880. Daniel Clark was also a reformer in international asylum psychiatry. An immigrant from Scotland, Daniel Clark received his early education in Canada with post graduate work in Europe. He served as a voluntary surgeon in the American Civil war. He was twice President of the Ontario College of Physicians and Surgeons and served as Vice President of the Medico-Legal Society of New York. In 1891 he was President of the American MedicoPsychological Association. 70 Clarke returned to the Toronto Asylum in 1905 to serve as superintendent after having gained experience as Assistant and then Superintendent at Rockwood Hospital for the Insane at Kingston.

Upon the completion of his apprenticeship at Toronto Asylum.

69. Joseph Workman, "Discussion on Dr. Ray's Paper on Mental

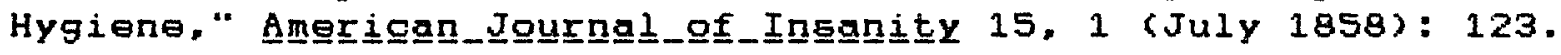

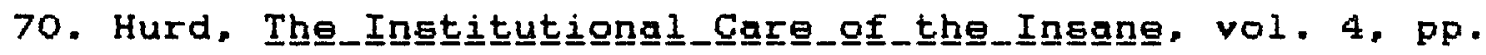
$559-61,143,146-7,153-5$. 
C.K. Clarke joined the ataff at Rockwood Hospital which was astablished in 1856 for "insane criminals and dangerous lunatics only." 71 clarke became Aseistant Superintendent under william G. Metcalf who was his brother-in-law and a close personal friend. Metcalf was an avid reformer who experimented with innovative policies including a programme of abolishing physical restraint of patients.

Nonrestraint, in this case, led to an event which greatly influenced C.K. Clarke"s version of psychiatric reformism. One morning Metcalf and Clarke were attacked by a patient while touring the hospital ward. Clarke was wounded and Metcalf was fatally injured. Clarke became preoccupied with psychiatric patients as homicidal or suicidal. He did not give up the idea of nonrestraint but tried to find other means of control. He adopted the idea of habit training through structured activity and close supervision by attendants. Clarke"s concern over supervision required more comprehensive clinical training of psychiatric workers. He established one of the first institutional training programmes for psychiatric nursing. In his Annugul_Regert for 1898, Clark called for after care or olinical facilities attached to mental institutions. 72 Many of these ideas were later applied to preventive work in psychiatry directed not toward the adult insane but toward diagnosis and prevention in children.

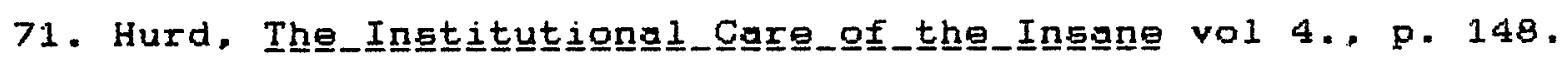

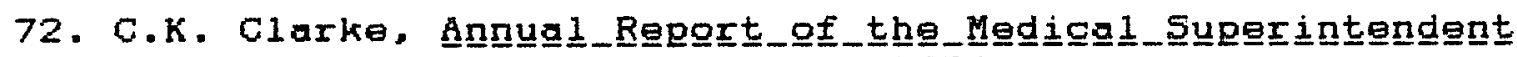

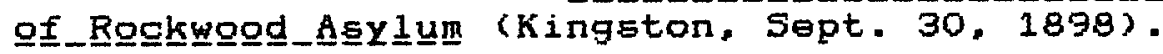


Clarke viewed mental illness as divided into two groups, organic and inorganic forms based on Emil Kraepelin's classificatory biological scheme. Kraeplin's original nosology of insanity was derived from studies in his Munich clinic. Clarke, as did Kraepelin, discounted psychological or motivational issues in psychiatric practice. 73 Clarke felt that organic defects which were noncurable needed to be separated from nonorganio preventable or potentially curable cases. Systematic laboratory work in bacteriology and pathology was emphasized by clarke as an essential tool in the diagnosis of mental disease. Clarke felt that all forms of insanity were distinct disease entities identifiable through medical pathology. He also emphasized psychopathic conditions in mental disease. All patients were to be considered violent. This made him adamantly opposed to mixing peychiatric with other medical patients as in inpatient treatment in general hospitals.

Both of these views predisposed Clarke's opposition to a dynamic or psychoanalytic approach to peychiatry. Freud emphasized that mental health and illness was a continuum based on learned or psychological characteristios rather than exclusive categories. This emphasis on organic syndromes and hostility to

73. Emil Kraepelin (1856-1926) pioneered a medical or clinical approach to psychiatry based on observation, desoription and systematic data collection which can be juxtaposed with dynamio or psychoanalytio psychiatry. His olassification soheme for mental illness described distinct disease entities of organic origin which were considered to be discoverable through psychophysiological and psychopharmacological research. Franz $G$.

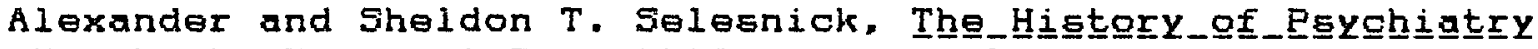
(New York: Harper \& Row, 1966) pp. 162-5. 
paychoanalytic perapectivea had a great deal of impact on Canadian psychiatry due to Clarke's increasing power and 1nfluence. 74

In 1907 Clarke persuaded Hon. W.A. Hanna, the Provincial Secretary of a reform government in Ontario. to send a delegation to study the new methods in psychiatry developing in Europe. 75 The report Clarke and his colleagues submitted was a persuasive rationale for the establishment of a psychiatric clinic attached to the University of Toronto Medical School. The clinic was to be oriented toward medical research, medical education and clinical patient care. The description resembled The Henry Phipps Psychiatric Clinic established some years later at Johns Hopkins University Medical School under Adalf Meyer. The difference between Clarke's proposed Clinic and Meyer's at JHU was that the Toronto Clinic was to be publicly funded. 76 Initially, the

74. This was in contrast to the increasing interest in psychoanalytic perspectives in the United States in the Progressive era; see Grob. Menta﹎_IIIIness_and_Amer pp. $120-1$.

75. During the first decade of this century the Ontario Government was deeply concerned with the increasing numbers of chronic patients and the subsequent tax burden of the provincial asylums. As in the united states, asylums which had predominantly sheltered short term acute care patients in the mid-nineteenth century were increasingly caring for chronic long term patients by the turn of this century. This greatly contributed to an increase in the absolute numbers of the institutionalized insane.

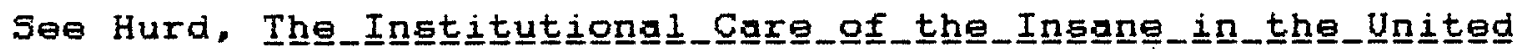

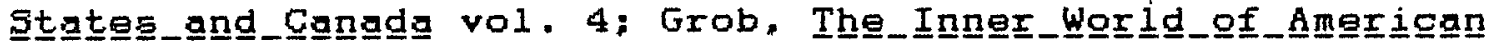

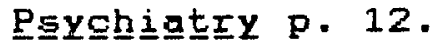

76. C.K. Clarke, Edward Ryan, and Hon. Dr. Willoughby, "Report," published in Hon. R. W. Bruce Smith, "Report of the Inspector of Hospitals," Ontario, 1909; also se日 "Provincial Budget Estimates," 1907. 1908, 1909. 
Ontario government was favourably inclined toward aupporting the proposed facility.

Clarke accepted a position as the first Professor of Psychiatry at the University of Toronto in anticipation of the implementation of his proposal. This represented a significant professional move for institutional psychiatry from mental hospitals toward an established place in university settings. It allowed for changes in the education of psychiatrists as well as the expansion of laboratory research. Clarke used the peychological laboratory at the University of Toronto to experiment with intelligence testing as a form of diagnosis for mental defects.

In 1908, Clarke was made Dean of the Hedical Faculty at the University of Toronto. He also served as Visiting Psychiatrist at the Toronto General Hospital. Clarke's mixed view of reformism and conservatism in psychiatric care quickly came into conflict with more liberal innoyators in canadian psychiatry. This was especially the case with D. Campbell Meyers. In 1906. D. Campbell Meyers had been named Neurologist-in-Charge of a Department for the Treatment of Nervous Diseases in the Toronto General Hospital. 77 Meyers' concept of mental illness was much less rigid than Clarke's. Meyers' innovation in caring for peychiatrio patients in general hospitals directly clashed with Clarke's concern about violent behaviour and the need for specialized

77. D.C. Meyers "Neuropathic Wards in General Hospitals," in

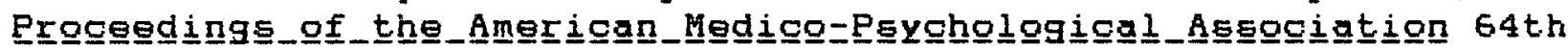
Annual Meeting. Cincinnati, Ohio, May 1960, p. 262. 
paychiatric services in paychopathic hospitala. D.C. Meyer'a views tended toward a psychoanalytic perspective in conceptualizing mental disorders as a continuum from normal to abnormal rather than absolute. He felt that mental iliness could be prevented or avoided in its early stages. He spoke for the more psychoanalytic view that outpatient care could prevent patients from reaching a point where they would have to be institutionalized. Meyers' view was not to become the dominant one in Canada.

In 1909. Clarke became Chief of the Psychiatric Service at the General which placed him over Meyers. Clarke increasingly expressed his concern that "if we must open our doors to patients suffering from various peychosis, we do so at very great risk, especially when patients are either homicidal or suicidal. No amount of foresight in a building not specially equipped will provide againet a tragedy occurring." 78 clarke sought a way to remove Meyer from the hospital. He obtained authorization from the Board of Trustees to set up an outpatient clinic in opposition to the in-hospital nervous ward Meyers conducted. In his haste to remove mental patients from a general hospital setting he did not perceive that the outpatient idea would work against his interests. He compounded this oversight by hiring Ernsst Jones, a British psychiatrist trained in psychoanalysis. Ernest Jones came to Canada in 1908. He was made the

78. C.K. Clarke, "Medical Superintendent's Report," Regort

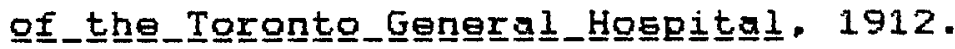


Director of the out-patient paychiatric clinic, Canada's first. Jones had previously been a Demonstrator in Pathology and Medicine, and Associate Prafessor in Psychiatry at the Toronto Asylum where he had been introduced to Clarke. Part of Jones' training had been with Kraepelin in Munich which attracted Clarke's support. Jones had also been trained in psychoanalysis under Jung and Freud. Jones' vereion of the clinic supported a psychoanalytic perspective more typical of D.C. Meyer rather than Clarke. Clarke felt that the clinic should screen patients for admission to institutions and Jones felt that the olinic should keep patients out of institutions. The clinic opened in December of 1909 and by September of 1910 had cared for 267 patients. When Toronto General was moved into new quarters on College street in 1313. Clarke seized the opportunity to close the clinic. Jones returned to England ending a brief Canadian flirtation with psychoanalysis. Jones had been, however, active in meeting American psychiatrists such as Adolf Meyer and August Hoch. His influence in Canada in introducing Freudian thought was subverted by Clarke. Jones' stay in Toronto contributed to the legitimation of Freudian thought in the United States considerably more than it ald in Canada. 79

In December of 1910 the Univereity and the Toronto General

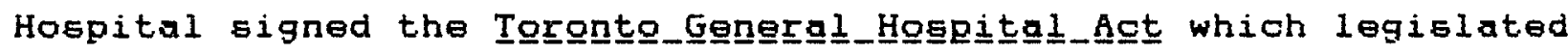
that the heads of clinical university departments should also be

79. See Ruth Ley5, "Meyer's Dealings With Jones: A Chapter in the History of The American Response to Psychoanalysis,"

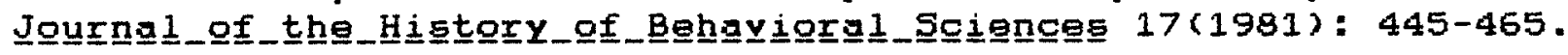


heads of corresponding hospital departments. As Dean of Medicine at the University, Clarke was made Medical Superintendent of the Toronto General. Clarke again argued atrongly for the gstablishment of a Uniyersity Psychopathic Hospital with clinical services similar to Kraepelin. 80 This would provide the kind of biological basis for psychiatry and segregation which clark favoured. While some funds were procured for the hospital the funding for psychiatric care was overpowered by a competitive and rocal lobby for prison reform. 81 Glarke's version of a paychiatric hospital and clinic was not fulfilled. 82

Helen MacMurchy as a Mental Hygiene Advocate In 1914, four years before the actual founding of the CNCMH, the Canadian Medical Association appointed a committee on mental hygiene with public health activist and physician Helen MacMurchy, as Chairperson. MacMurchy asked for a year so that the committee "might present a comprehensive resume of the progress made in mental hygiene in this and in other countries and we hope also to be prepared to make suggestions for further

90. Robert Pos, J. Allan Walters and Frank G. Sommers, "D. Campbell Meyers, 1867-1917: Pioneer of Canadian General Hospital

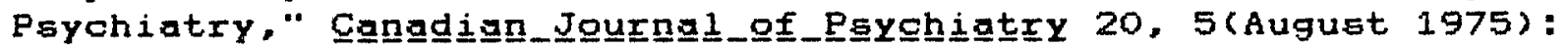
393-403. $146-7,155$.

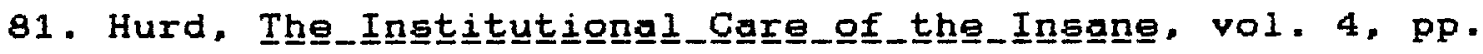

82. The Institute of Psychiatry at the University of Toronto, opened 58 years later in May of 1966. was named after Clarke. 
progress in the conservation of mental health in Canada." 83 The report of the Committee on Mental Hygiene to the Canadian Medical Association was not presented since the 1915 meetings were canceled.

Helen MacMurchy laid much of the public health ground work for the Canadian mental hygiene movement. Mackurchy, however, was not interested in psychiatry or professional standards as such, although her posts were impressive. MacMurchy was Professor of Medicine at the University of Toronto. first Medical Examiner of Toronto Public Schools, Provincial Inspector of the FeebleMinded, Inspector of Hospitals, Prisons and Public Charities, as well as Chief of the Division of Child Welfare, established under the Dominion Department of Pensions and National Health in 1920.84 She was a major force in developing mental hygiene concerns in public policy in Canada, and she was instrumental in public health issues which touched Ganadian children.

Mackurchy brought together the Canadian eugenics and mental hygiene movements. Eugenical overtones were significant aspects of the early mental hygiene movement in both the U.S. and Canada. The formation of the Canadian National Committee for Mental Hygiene came together around the issue of mental retardation

83. Helen MacMurchy, "Report of the Committee on Mental

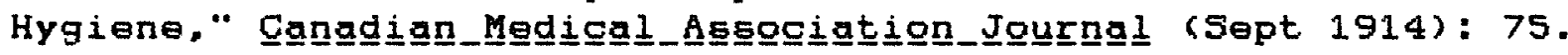

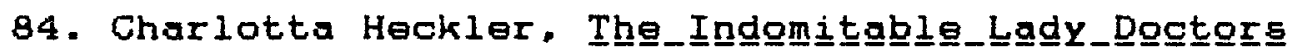
(Toronto: Clarke Irwin Co., 1974), pp. 140-224; E. A. Hardy and

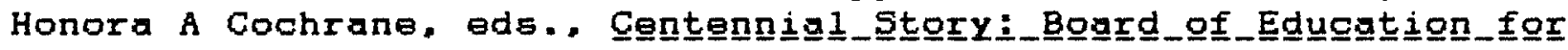

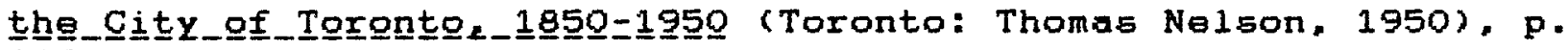
129 . 
rather than mental 1linesa. Helen MacMurchy was influential in arousing concern over the presence of feebleminded and delinquent populations as a long term public health hazard.

The first committe日 of the American Medico-Psychological Association on applied eugenics included leaders in the NCMH on its executive committee. This included Lewellys F. Barker, walter E. Fernald, Irving Fisher, Elmer E. Southard, and Robert M. Yerkes. 85 Applied eugenics in the United States was exemplified by the Eugenics Research Association with its conferences at Cold Spring Harbor. Rockefeller funds were important in the establishment of Cold Spring Harbor and the expaneion of eugenical ideas on social hygiene which crossed into mental hyglene. 86

Ganadian eugenics was similarly concerned with illegitimacy, venereal disease, criminality and prostitution. A public protest had been initiated in 1896 at a National Council of women in Canada by A.M. Roseburg of Hamilton. By 1899 looal councils were petitioning their respective legiblatures urging the provision of custadial facilities for "feebleminded women." By 1913, 50 societies existed for the "protection" of the feebleminded. 97

85. For a description of this movement ser Mark H. Haller,

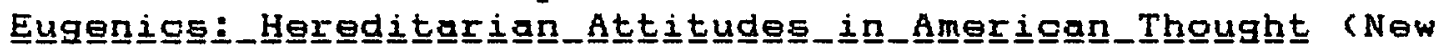
Brunswick: Rutgers University Press, 1963). pp.71-3.

86. Jerome D. Greene, "Principles and Policies of Giving," 2 Oetober 1913: R.B. Fosdick "Plan for the Development of the Bureau of Social Hygiene," 23 October 1915; Rockefeller Foundation, "Minutes," 27 October 1915, pp. 3108-9; Hist. 900, 1 , yol. 6, pp. 1450, 1531, 1584-7, RAC. N. Tarrytown, N.Y..

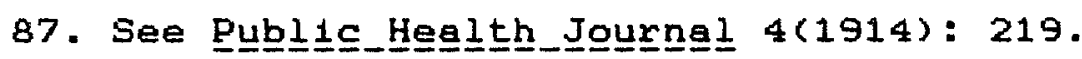


Mackurchy was involved in an official inveatigation to determine the actual number of mentally defective women in the province. In 1906 she was appointed the Inspector of the Feebleminded in the Department of the Provincial Secretary. 88 In 1908 a society was organized in Nova Scotia which concentrated on children. 89 The membership of the Toronto society became the nucleus around which the Canadian national committe日 was organized. 90

Mackurchy's early experiences contributed to her official positions on public health policies in eugenics and mental hygiene. Her intereste tended to concentrate on the family and child health. She became the first women intern at the Toronto General Hospital after graduating from the University of Toronto. She did Graduate work in Pennsylvania at the Women's Hedical College where she also studied under Sir William Osler. MacMurchy's tenure on the Medical Faculty at the Univereity and Toronto General Hospital from 1905 to 1920, coinoided with C.K. Clarke. From 1913 to 1920 Mackurchy was Assistant Inspector and then Inspector of Hospitals. Prisons, and Public Charities for the Department of the Provincial Secretary of Ontario.

88. Helen MacMurchy, "Report on Feebleminded," Annngugal_Regengt

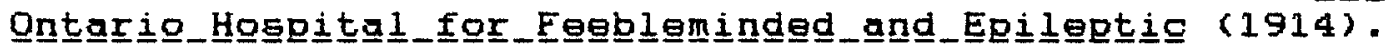

89. Nova Scotia League for the Protection of the Feebleminded. "Minute Book," 4 June 1908, p. 1; Archives Nova Scotia Division of the CMHA, quated in J.D. Griffin, "Mental Health Ganada," ch. 1, vol. 1. Greenland-Grifin Archives. Toronto. This society expanded its charter and changed its name to the Nova Scotia Society for Mental Hygiene in 1920.

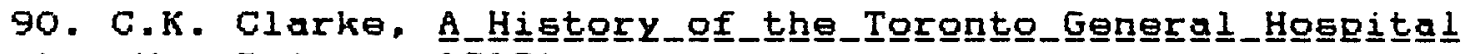
(Toronto: Wm. Briggs, 1913). 
MacMurchy was a decisive thinker and not shy about her opinions. In 1910 she was appointed the first medical examiner for the Toronto School Board. James L. Hughes, an outstanding progressive educator, was Chief Inspector of Toronto Schools (1874-1914) at the time. Mackurchy became embroiled in a major confrontation with Hughes over the jurisdiction of medical services in the schools. Hughes placed the school health service, which had been initiated by the Local Council of women, under his own jurisdiction. Mackurchy wanted the eervice controlled by health authorities. She resigned from the position as examiner within a year in protest over Hughes insistence on keeping it under the school board. In 1917 a referendum settled what became an ongoing controversy. Medical inspection was placed as a result of the referendum, as MacMurchy had desired, under the control of the Department of Health. Seemingly the service did not suffer from the controversy. By the second year of the service, 1911 , there were nine medical examiners and nineteen nurses. 91

In 1910, MacMurchy had also been appointed in charge of medical care of the Andrew Mercer Ontario Reformatory for Women. In 1912 she conducted a special survey into the care of children at the Industrial Sohools located in Toronto and in Mimico. Her work brought her into the position of serving as an expert witness in the Juvenile Courts identifying mental defects. In 1913 she assisted in a special investigation into the Toronto juvenile court system. As Inspector of the Feeble-Minded in

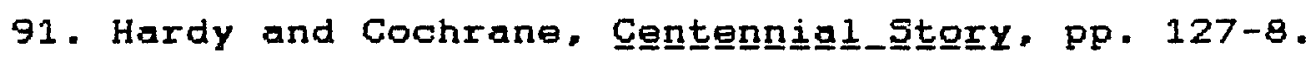


Ontario, Mackurchy had studied and written reports on the widespread danger of racial decline if action was not taken to curb the problem. 92

MacMurchy's views were compatible with Clarke's in that she advocated the identification and segregation of defective populations. She also favoured widespread public educational campaigns and civic action. MacMurchy's concern with

feeblemindedness was as a cause of immorality and crime. She was interested in identifying and egregating mentally defective delinquents. She wanted to establish testing services for children brought before the court. She asked clarke to help set up a Juvenile psychopathic clinic in the General Hospital for this purpose. Clarke was confronted with his ideologioal disagreement with mixing medical and psychiatric facilities. In order to maintain the formal separation of the medical and clinical service, the voluntary social service department was asked to eponsor the juvenile peychopathic olinic. The head of the service, Mrs. D.A. Dunlap, agreed. The clinic was subsequently opened under the auspices of the social rather than medical services of the hospital on April 8, 1914. MacMurchy introduced Clarke to Clarence Hincks who was hired to direct the clinic with another young physician 0.C.J. Withnow. By 1919 this

92. Ontario, Provincial Secretary's Department, Feebleminded in Ontario, RegortE. 1908, 1910, 1913-15; Helen MacMurchy, "The Relation of Feeble-Mindedness to Other Social Problems, "National Conference of Charities and Corrections, Progegegings XLIII, 1916.

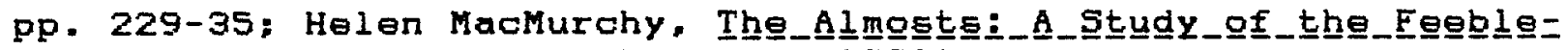
Ming므르 (Boston: Houghton-Mifflin, 1920). 
clinic had handled over five thousand children as caseg referred through the juvenile court. 93 The juvenile psychopathic clinic brought together the major canadian figures in the formation of the National Committee, MacMurchy as advocate, Clarke as first Medical Director, Hincks as Assistant and Dunlap as a mentor. To an extent greater than the others, MacMurchy's background was influenced by the scientific medicine and public health reformism characterized by Johns Hopkins. Her contacts with Clarke and Hincks could not but have reinforced their perspective and drive toward preventive issues in Canadian mental hygiene. 94

Clarence M. Hincks: Prospector for Mental Hygiene Clarence Hincks was internationally influential in mental hygiene policy in the inter-war period. He titled his unpublished

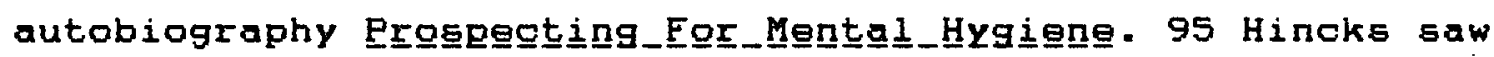
himself as prospected for contributions from wealthy patrons in order to support preventive efforts in the mental and public health movement.

Hincks early experience in psychiatry was with children. He was appointed Medical Inspector of Toronto Schools in 1912. He

93. C.K. Clarke, "The Story of the Toronto General Hospital

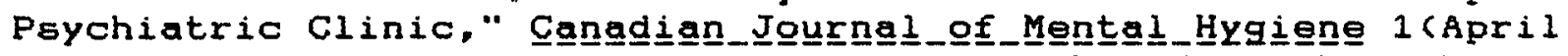
1919): 31. It was the first Canadian court based psychopathic clinic and served as a forerunner to the forensic Psychiatric Services and Family Court Clinic established many years later in the 1950 s.

94. "Helen MacMurchy," Biographical files, Greenland-Griffin Archives, Toronto.

95. Clarence M. Hincks, "Prospecting For Mental Hygiene,." Glarence Hincks Papers 8,6, Gre日nland Griffin Archives, Toronto. 
held this position until he became actively engaged in work with the Canadian National Committer for Mental Hygiene. In addition to school inspection, private practice, and his work with the Juvenile clinic, Hincks was also appointed psychiatrist in the Toronto Department of Health. Hincks was Assistant Medical Director of the Canadian Committee under Clarke from 1918 to 1924. After Clarke's death in 1924 he ascended to the Medical Directorship. In 1930 he became General Director over both the U.S. and Canadian Committees. He worked largely out of the U.S. office in the 19305 . He returned to the canadian Committer in 1939, to serve as Medical Director until 1943 when he was succeeded by John D. Griffin. Hincks acted as a consultant to the Canadian Committee until 1953.

Hincks seryed in a role in Canada which combined applied science and public advocacy in fund raising. Like Thomas Salmon, Hincks acquired his psychiatric expertise and his reputation as a man of science largely by way of experience. He successfuliy applied his personal talents in organizing and fund raising to his work in mental hygiene. He was not trained in psychiatry and did not conaider himgelf a qualified paychiatriat. 96

Hincks' abilities and disabilities resembled Beers'. Hincks had significant poychiatric problems dating from his early adulthood which were similar but not as severe as Begrs. Hincks was never institutionalized but his incapacitating mood swings seriously interfered with his work. Hincks tended to begin the

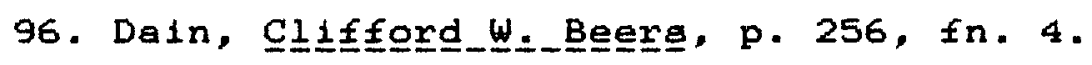


year with enthusiastic viaions of accompliahment. As the year progressed and setbacks and minor disappointments added up. he would become depressed. After a period of rest he would be able to return to work again. Hincks was extremely productive when he was not depressed which made up for the times when he could not work. Unlike Beers he did not make his mental problems public until after his retirement. Hincks and Beers were drawn together by their cyclical moods and mutual enthusiasm for the mental hygiene movement. They also added to the problems of the National Committees on the occasions when their moods coincided either in the direction of being depressed or wildly enthusiastic. Both men were charismatic figures and extremely persuasive speakers, successful fund raisers and organizers. 97

Hincks' apprenticeship in psychiatry was in Clarke's psychopathic clinic at Toronto General. His work with the children referred from the juvenile court, and his affiliated work as medical inspector of schools occurred at a formative period of his own thinking. The experiences forged a direct link to Hincks' enthusiastic role in the establishment of the canadian National Committe日 for Mental Hygiene. In Hincks' words:

After working with Dr. Clarke in the out-patient clinic for two or thre日 years I became restless and impatient. I felt that the knowledge about mental iliness and

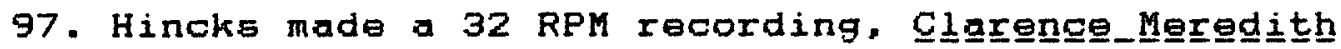

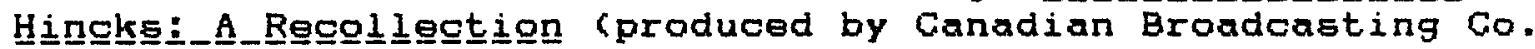
released by the Canadian Mental Health Association. 7 february. 1965), where he discussed his work with the mental hygiene movement. He also discusses his own psychiatric problems. record and tapes in Greenland Griffin Archives. Toronto: personal interview with John D. Griffin, 20 July 1986. 
mental deficiency which we had acquired ought to be put to use somehow across canada. I knew that many of our asylums were inadequate and our immigration screening was poor. I was aware that we were not doing what should be done to help rehabilitate the psychiatric casualties among our soldiers. No one was doing anything about prevention. 98

In late 1917 Hincks approached Glarke with the possibility of developing some plan to expand psychiatric care in Canada. Clarke suggested a visit to New York to discuss the issue with U.S. authorities in "medical, psychiatric and neurological science." Hincks left immediately on this quest for suggestions and idegs. In the process of his inquiries he was introduced to Clifford Beers. Hincks had attended the Fourth International Congress on School Hygiene in Buffalo. New York in 1913. 99 He met Beers at that time and wrote about him in a column for the

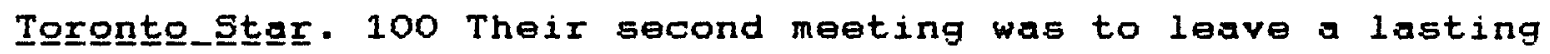
impression. Beers offered Hincks a copy of his book and explained his vision of an international association for mental hygiene. 101

98. Hincks, "Prospecting for Mental Health," p. 29.

99. NGMH "Annual Meeting," 5 April 1913, pp. 82-143.

100. "Report of the Permanent International Committee." Meeting of the Permanent International Committee, Fourth International Congress on School Hygiene, "Proceedings," New York, 1913, pp. 113-63; Clarence Hincks, "International Conference on School Hygiene in Buffalo." Torontog_Stgax (26 August 1913): John D. Griffin. "Mental Health - Ganada: The Chronicle of a National Voluntary Movement. The Canadian Mental Health Association, 1918-1980," May 1981, vol. 1, p. 13. GreenlandGriffin Archives, Toronto.

101. Clarence Hincks to CWB, 6 January 1918, Hincks Papers 4. 3; also J.D. Griffin, "Mental Health Canada," vol. 1, pp. 13, 17. Greenland-Griffin Archives, Toronto. 
Hinckg was fascinated by the idea of a Canadian National Committe日. Upon his return to Toronto. Hincks wrate Beers of his decision to start an organization. "It is my aim to widen the scope of the Ontario Association ffor the Care of the Feebleminded]." The issue of feeblemindednese was to be subsumed as a "sub-committee" of the more comprehensive National Committes. Hincks continued. "I think that this will be easy because probably Dr. C.K. Clarke will be elected to the Presidency lof the Association for the Protection of the Feebleminded]." 102 Hincke began to plan the first me日ting. It was not long before he wrote Beers, "I have interviewed practically all the Toronto people I would like to see connected with committee, [such as] Sir Robert Falconer, Lady Eaton...the nucleus of a strong Canadian National Committe日." 103 Beers was summoned to Toronto to meet the first select group of potential members and donore. The meeting was held at the home of Mrs. D.A. Dunlap, head of the social service unit which hosted the psychopathic olinic. 104 Thirty national leaders in social, political, and business, as well as medical circles were invited to meet Beers. After introductory comments by Clarke and

102. Clarence M. Hincks to GWB. 25 January 1918 and 5 December 1918, Hincke Papers 4, 3, Gre日nland Griffin Archives, Toronto.

103. CMH to CWB, 12 February 1918, Hincks Papers $4,3$. Greenland-Griffin Archives, Toronto.

104. CMH to CWB, 12 February 1918, 16 February 1918; CWB to CMH 14 February 1918, "telegram." 21 February 1918, Hincks Papers 4. 3. Griffin-Greenland Archives, Toronto. 
MacMurchy, Beers made an impassioned speech for the establighment of a Canadian mental hygiene committee.

The audience proved particularly receptive and the canadian National Committee was launched with acclaim. Twenty thousand dollars in pledges financed the incipient organization. 105 Charles F. Martin, a physioian from Montreal, was made President. It was hoped that by splitting the leadership between the Montreal and the Toronto group, the national character of the organization would be strengthened. An impressive group of vice presidente were commandeered, including: Lord Shaughnessey, Sir Lormer Gouin, Sir Vincent Mereith and Sir Robert Falconer. C.K. Clarke became the top executive officer as medical director and Clarence Hincks was made his assistant and secretary. The executive board consisted of Colin K. Russel. Peter H. Bryce, J.A. Dale, C.J.O. Hastings, W.H. Hattie, Vincent Massey, J.D. Page, C.A. Porteous, and Peter Sandiford.

The roster of members reveal a broad section of the canadian established elite. The deans of medical facilities, university presidents, premiers, top governmental chiefs of staff, and major business executives figured prominently in the CNCMH membership. While the Committee was national in scope. two-thirds of the members were from Canada's most heavily populated provinces of Ontario and Quebec. Unlike the American committee which was

105. "List of the First Organizing Meeting. 26 February 1918;" CWB to D.A. Dunlap, 11 March 1918, Hincks Papers 4, 3, Greenland-Griffin Archives. Toronto: Torongto_Globe (27 February 1918). 
dominated by medical leaderahip, the memberahip of the Canadian Committe日 was from a cross section of influential citizens. Thirty-five per cent of the members were related to the medical profession. twenty-two per cent were in official governmental positions and seventeen per cent were business leaders. Social and philanthropical leadership comprised twelve per cent of the Committee's memberahip.

The actual organizing work was largely done by Beers and Hincks. Both were enthusiastic about the effectiveness of what they called "drawing room meetings" or "teas" similar to the one at the Dunlap's. Hincks encouraged the expansion of the concept into other parts of the country. Beers agreed to go anywhere there was an audience. 106 Hincks took full advantage of his social contacts. Lady Eaton, as an old friend of Hincks, was a case in point. She recalled that "[Hincks] called me and asked me to help him with one of these meetings" and that "\$10,000 was pledged" that afternoon for the cause of mental hygiene. 107 The Committee continued to expand but in a controlled manner. The Committe日 decided from an early stage not to encourage local groups but to emphasize a atrong and unified national organization which would work through other voluntary and

106. CWB to G.K. Clarke, 14 March 1918, CWB to CMH, 20 March 1918. Hincke Papers 4, 3, Greenland Griffin Archives, Toronto.

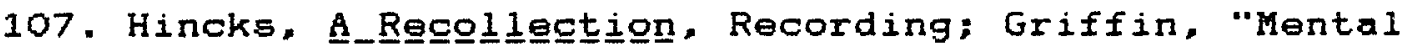
Health-Canada," vol. 1, p. 25, Greenland Griffin Archives, Toronto. 
governmental agencleg. 108 within three montha of the firat drawing room meeting, an organizing meeting of the executive committer was held at Chateau Laurier in ottawa. A constitution very similar to that of the National Committee in the United States was adopted. An official thank you note was sent to Beers for his help in setting the CNCMH in motion. 109

Glifford Beers found a world view compatible with his own in the organization of the Canadian Cammittee. 110 Significantly, he did not resent the professional leadership of the canadian mental hygiene movement especially as it was balanced with an elite nonmedical group of promoterg. Clarence Hincks' methods of organization and fund raising were similar to the methods Begrs' favoured. Clarke's and Hincks' institutional reform orientation clashed less with Beers' advocacy for the insane than Salmon's scientific public health reform. 111 The Canadian National Committee, its influential membership cajoled by Hincks' and Beers' charismatic speeches, forged ahead in a way which had eluded the early years of the American committee.

Beers tried to retain his authority over the progress of the

108. CMH to CWB, 18 November 1918,22 November 1918, Hineks Papers 4, 3, Greenland Griffin Archives, Toronto.

109. CMH to CWB, 8 May 1919, Hincke Papers 4, 3, Greenland Griffin Archives. Toronto.

110. CMH to CWB, 7 April 1922, 21 April 1922, 1 July 1922; C.K. Clarke to CWB 4 December 1922, Beers Papers 3. AFMH Archives, CMC, NYC.

111. John D. Griffin "The Amazing Careers of Hincks and

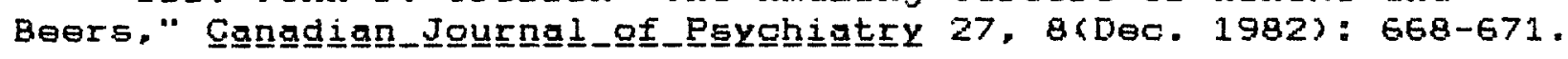


Canadian movement after the war. This included attempta to shape both funding and the direction of research. The Rockefeller Foundation with its ample resources loomed as a major source of support yet these potential funds also undermined Beers" influence as a powerful fund raiser. When Hincks approached Beers with the idea of sending in a proposal to the Foundation on the study of delinquency, Beers tried to supress his enthusiasm. 112 The propasal was very clase to the work which the Rockefelier Foundation and the Commonwealth Fund were in the process of coneidering on the advice of Thomas Salmon. Beers declared the studies on delinquency unfit for Canada as local not national efforts. 113 In spite of Beers' effort, he was not able to retain his position of influence in Canada any more than he could in the United states. Mental hygiene had a momentum of its own. The establishment of the Canadian National Committer eignaled the convergence of the medical model, peychiatry, and the provision of large scale funding. In 1919, John D. Rockefeller Sr. made a personal plea to the Rockefeller Foundation Board of Trustees for special attention to be paid to Canada as partners in the War. Five million dollars were set aside by the Rockefeller Board of Trusters with the intention of improving medical education. In the United States, medical

112. CMH to CWB, 24 June 1918; CWB to CMH, 26 June 1918, Hincks Papers 4, 3, Gre日nland Griffin Archives, Toranto.

113. CWB to CMH, 12 April 1919, 21 November 1919; CMH to CWB, 29 February 1919, 6 November 1919, Hincks Papers 4, 3, Greenland Griffin Archives. Toronto. 
education had been largely funded through the General Education Board. The G.E.B. was restrieted in its mandate to the United States. The appropriation of the five million dollars opened up the possibility of the establishment of an International Education Board and an International Health Board. 114 In 1918 the Laura Spelman Rockefeller Memorial was established with a capital of seventy-four million dollars and the express mandate to "promote the welfare of women and children." 115 The mental hygiene campaigns prior to the war, the psychiatric issues concerning the future of society raised by Thomas salmon in government and philanthropic circles, and the mass intelligence testing of soldiers during the war, served to refocus medical Ieform efforts toward social psychiatry and mental hygiene. The Canadian and the United States National Committees for Mental Hygiene benefitted from the aroused concern over mental well-being.

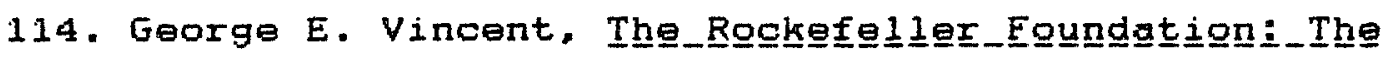

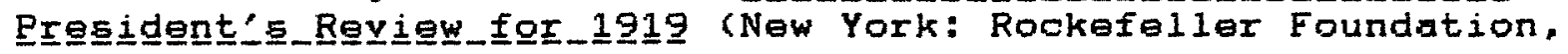
1920 ).

115. Laura Spelman Rockefeller Memorial, Eingzl_Repgrt (New York: Rockefeller Foundation, 1930). 
They who say all men are equal speak an undoubted truth, if they mean that all have an equal right to liberty. to their property and to their protection of the laws. but they are mistaken if they think men are equal in their station and employment, since they are not so by their talents.

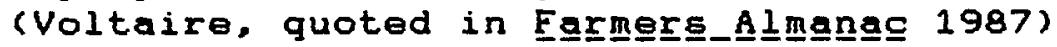

A great truth is a truth whose opposite is also a great truth. (Thomas Mann. Essegy_on_Ergeud quoted in Jerome Kagen,

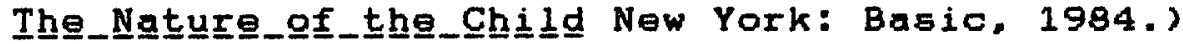


THE DEVIANT CHILD AND PSYCHIATRY: THE INVENTION OF A MENTAL HYGIENE OF CHILDHOOD

The working hypothesis of the mental hygiene movement was that mental illness had to be prevented in childhoad. Mental hygienists, in the establishment of child guidance clinics, contributed to the professionalization of child psychiatry. It is not accidental that a psychiatric concern over children originated in an interest in delinquency. The juvenile court laws were among the first to describe, in the doctrine of parens patriag, a new relationship between the etate and the child in the twentieth century. While this principle prescribes the state's ultimate authority to protect the welfare of ohildren, it has also legitimated intrusive public policies into family life and practice. 1 The early peychological olinics attached to juvenile courte constructed a pathology of the young offender which was not reducible to idiocy or retardation. Differentiating between children on the basis of causal types of maladaptive tehaviours was an innovation of child guidance. Child guidance took on the status of a social movement in the period after world War I.

Disruptive behaviour, such as truancy and lying, which had indicated a moral problem in the nineteenth century, became a twentieth century medical and subsequently psychiatric problem.

1. For a discussion of the impact of parens patriae, see $W$.

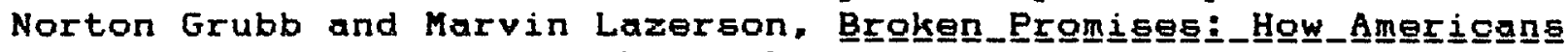

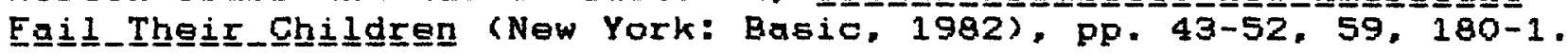


Problems of all kinds were ldentified with underlying medical impairmente. While the emotionally disturbed, underprivileged. underachieving, different, exceptional or epecial children were causally linked to negative experiences, poor learning habits, and improper supervision, the medical perspective tended to disregard the significance of class, ethnic background or cultural priorities. The medical rationale for identifying children as normal or abnormal was that such distinctions were both useful and olinically verifiable. Medicine defined as applied public health advocacy included both a psychological and social realm. Mental abnormalities, it was argued, could be diagnosed, cured or monitored through scientific methods.

This view reflected the eimultaneous effects of the new medical climate and the rise of psychoanalytic and psychiatric thought as part of a soientific study of man. Iesues of mental disorder became interwined with children's policy. Just as the differentiation between normal and abnormal influenced the structure of children's institutions, such as courts, schools and family welfare, peychiatric language and ideology became a part of the knowledge base of professionals responsible for overseeing these institutions. A rationalized nomenclature of childhood did not come about by chanoe. There was a systematio element interjected by the conscious forethought of thase in a position to develop new practices and to illustrate their views in policy demonstrations. Even so, dieagreements and controversies abounded in both policy and practice. A schematic typology of childhood 
achieved widespread distribution across the United States and Canada in the first half of the twentieth century. Yet, the controversies over the nature of children and their proper treatment endured. This reflects the eclectic origine of child oriented policy and practice in social as well as legal and academic traditions.

Legal Origins of the Paradigm: The Doctrine of Parens Patriae State as opposed to federal legislation in the United states traditionally regulates family life as well as criminal proceedings. Generally, federal laws do not have jurisdiction over the placement of delinquent or dependent children. Juvenile and family courts were established by state legislation. Illinois paseed the firet provieions for Juvenile courts in the United States in 1899. In canada the first legislation on delinquency was the Children's Protection Act of 1893 in the Province of Ontario. It provided for the establishment of children's aid societies and the commitment of delinquent and dependent children to them by court order. However, in Canada criminal justice is within the exclusive jurisdiction of the federal Parliament. Consequently, most delinquent acts had 1 imited or no jurisdiction in provincial law. In 1894, the federal parliament made provisions which allowed for separate trials for all canadian children under 16. It did not provide for probation. The first modern juvenile delinquents act became law on July 20, 1908. 2

2. Canadian Corrections Association, "Brief to the Department of Justice Committee on Juvenile Delinquency" Draft 4 , 1962, pp. 1-2, MG 28 I 391, 61, PAC, Ottawa. 
The source of legitimecy for the power of government whether state, provincial, or federal to intervene in the private lives of its citizens lies partly in the fundamental police power of the nation-state. This power legitimizes the passage of legislation regulating social life with the intention of maintaining order and protecting the welfare of citizens. In the case of children's policy the doctrine of parens patriae was a critical aspect of the subetantive rationale for interventionist policies. Derived from British law, this doctrine shaped both U.S. and Canadian law. 3

Parens patriae, literally "parent of the country," refers to the sovereign role of government to act as guardians to persons with legal disabilities such as infants and mental incompetents. 4 The concept was derived from thirteenth century British law and the assumption of guardianship over well-born lunatics and idiots by the British monarch. This eliminated the potential for abuse by heirs who would profit from disinheriting incompetent family members. From the fourteenth to sixteenth century the principle applied only to guardianship and property issues concerning the wealthy propertied classes. The Poor Laws of 1601 opened the door for the creation of a dual standard of governmental intervention which encouraged widespread authority over poor families and

3. Susan B. Hershkowitz, "Due Process and the Termination of

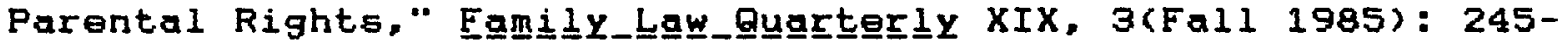
296: Ian Grant, "The 'Incorrigible'Juvenile: History and Prerequisites of Reform in Ontario." Gangadian_Jgurngal_of_Family

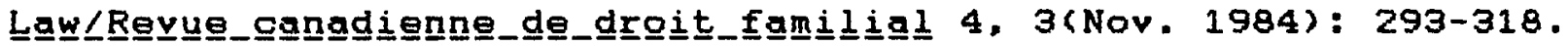

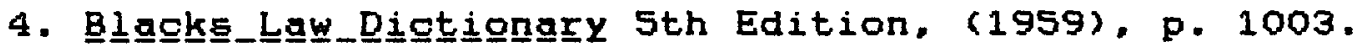


relaxed interventions into self-aufficient economically stable families. Another major transition occurred in 1722 when the court of chancery in Britain derived the concept of applying parens patriae to protect poor children from the power to protect well-born lunatics. 5 By the early nineteenth century British chancery courts began to exercise this power in private custody disputes between parents over children. This concept was gradually broadened in the nineteenth century to include delinquency where it became the cornerstone for the juvenile courts. In these developments, parents legally lost their claim to absolute authority over their offepring. This fundamentally revised the rights of parents which were subsequently seen as derived from the governmental authority rather than as a natural right. Under parens patriae, control over children was conferred upon parents by the body politic as a trust. Failure by parents to faithfully discharge this trust justified governmental intervention. 6

Legislation on children and family in the united states and Canada followed the British precedent in utilizing the doctrine of parens patriae. In both cases, as in the British precedent, the principle is applied primarily to the poor. 7 A case in

5. Eyre $v$ Shaftsbury. 24 Eng. Rep. 659 (ch. 1722) cited in Hershkowitz, "Due Process," p. 256.

6. In Wellesley $v$ Wellesley, 4 Engl. Rep. 1078 (H.L. 1828), a father's custody petition was denied because he was living in adultery and not considered morally $f i t$.

7. Hershkowitz, "Due Process," p. 251, Grant, "The Incorrigible," p. 302 . 
Connecticut, In 1884, upheld a statute authorizing the removal of minors from their family if they were in danger of being brought up to lead idle or vicious lives. 8 Other cases permitted state intervention into any area of child rearing without any demonstration of parental inadequacy. 9 Juvenile court legislation in both the United states and Canada made no basic provisions for due process or the right to council. An explanation of the charge, consequences of an admission, or necessity of pleading guilty or not guilty, were not guaranteed. 10

In Canada the strength of the model of parens patriae, and its legal application without the right to counsel. largely went unohallenged until the post world war II era. 11 The juvenile court's authority to intervene in the family unit remained intact from 1908 to the 19605 . The issue with delinquency tended to focus on the distinction between "hard core" oriminality and

8. Reynolde $v$ Howe, 51, Connecticut, 472 (C.P. 1884).

9. State Y Bailey, 157, Indians, 324, 61, N.E. 730 (1901), cited in Hershkowitz, "Due Process," p. 250.

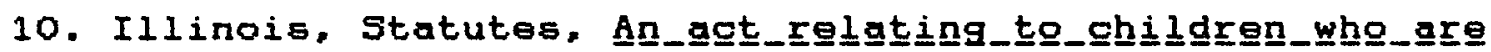

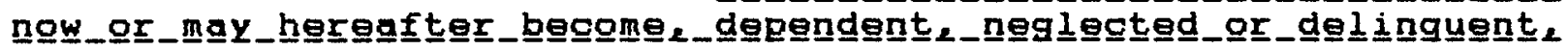

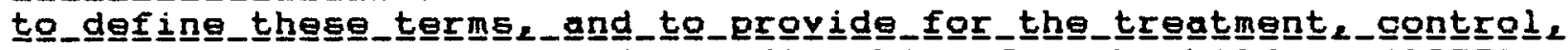

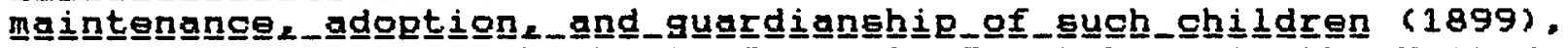

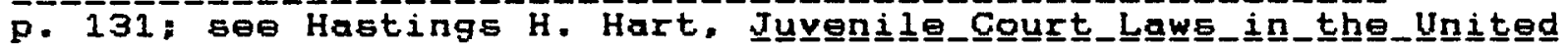
Statege (New York: Charities Publication, 1910); on Canada see: An Act_Respecting_Juyenilie_Delinguents 7-8, Edw. VII (1908), ch. 40 (Gan.), amended $19 \mathrm{GeO} . \mathrm{V} .(1929), \mathrm{Ch} .46$

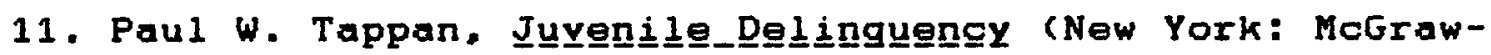
Hill, 1949), see ch. 9; Ornan W. Ketchum, "The Unfulfilled

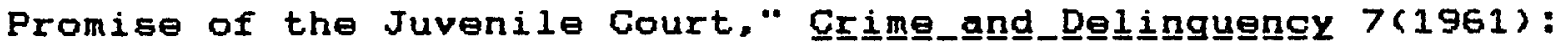
97-100. 
"soft core" criminality. The institutional separation of delinquent hard core from dependent soft core populations was an issue of importance from the mid-ninete日nth to mid-twentieth century. 12 Ontario is the best studied example. 13 The first separate institution for juvenile offenders at Penetanguishene was opened in 1857. The legislation under which it operated, The

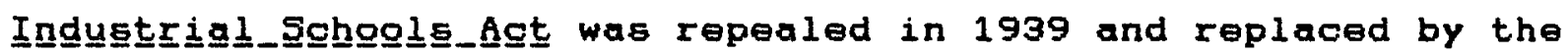
Trgeining_Sghgolg_fㅌ․ This act was repealed by the Ontario Legislature in 1975. 14 More recently issues of children's rights have come to the forefront in Canada. These issues have been greatly magnified by the revision of the canadian Constitution Act in 1982 and the passage of "The Charter of Rights." 15 From a much earlier date the presence in the United States

12. Grant, "The Incorrigible Delinquent," p. 298-302.

13. Susan Houston, "Victorian Origins of Juvenile

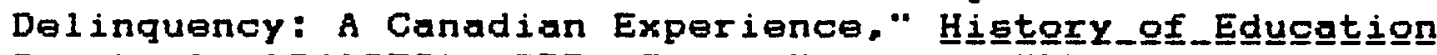
Quaㅡㅡ토프y 12(1972): 255; Susan Houston, "The Impetus to Reform: Urban Crime. Poverty and Ignorance in Ontario, 1850-1875," Ph.D. Thesis University of Toronto, 1974; Richard Splane, Sogeia 1

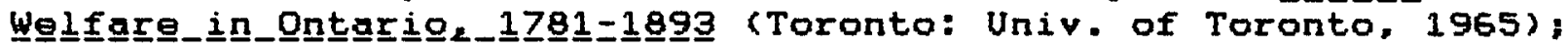

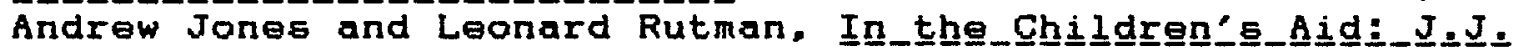

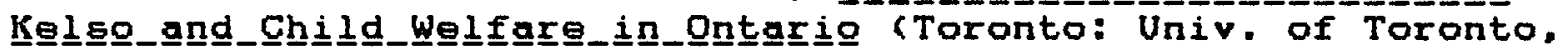
1981).

14. An_ACt_to_Amend_the_Training_Sghooles_ACt S.0. 1975. 0.21 ; The Iraining﹎.

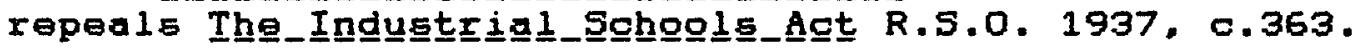

15. Department of Justice, A Consglidgation of

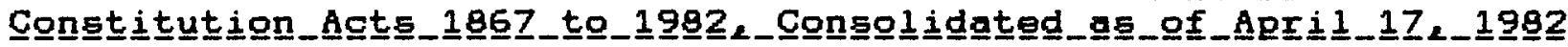
(Ottawa: Canadian Government Publishing, 1983); Canadian Corrections Association, "Brief to the Justice Committee on Juvenile Delinquency," Draft 4, 1962, 28 I 391, PAC, Dttawa;

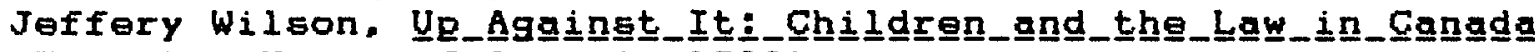
(Toronto: House of Anansi, 1980). 
of the Constitutional protection of individual rights led to persistent attempts to limit governmental jurisdiction over family relationships. The first challenges date from the period after world war I. 16 In the United States, this century is characterized by the constitutionalization of family law. Children's constitutional rights under the 14th Amendment were affirmed by the Supreme Court in 1923. The state can not arbitrarily interfere with the family relationship. 17 other court cases affirmed a "zone of privacy" immune from state regulation unless the state is justified by a compelling interest. 18 The extent of the ability of state laws to liberally exercise parens patriae rests on a failure to subject child neglect and delinquency legislation to constitutional limitation. To the extent that constitutional rights are affirmed, the state power of parens patriae. is limited in the united states.

The courts, however, not only limit but affirm the parens patriae powers of the state. They have done this by designating the child as immature and therefore incompetent to act in his/her own best interest. On this basis the state is justified in limiting the substantive rights of children, and to act in their behalf. 19 While the power of the juvenile court to intervene in

16. Se日 Hershkowitz, "Due Process," for a discussion.

17. Meyer v Nebraska, US 390 (1923).

18. Griswald v Connecticut, 381, Us 493 (1977): Rue v Wade, 410, US 113 (1973); Elsenatadt $v$ Baird, 405 , US 439 (1972).

19. Ginsburg $v$ New York, 390, US 629, 650 (1968); Parkham $v$ J.R., 442, US 584, 603 (1979). 
a child's life is affirmed, in order to do so the court must also provide substantive due process. That is, the court must consider the merit of protecting larger social values and the potential infringement on individual rights to life, liberty, and happiness as guaranteed by the constitution. The motive of the court is important. The court must act to rehabilitate and not to merely punish in its dealings with minors. 20

The compromise between due process and eubstantive due process in Juvenile court cases from 1923 to the present have elevated the importance of the medical perspective as a rationale. The individualized medical orientation serves to support the argument for state intervention. Developmentally. children are defined as lacking full capacity for individual choice and therefore they are in need of protection. Inadequate families similarly are a justifiable concern of the state.

The mental hygiene or medicalized paradigm places emphasis on an individualistic perspective. This underscores individual over group rights and provides a continuity to the argument that there are non-interpretive (therefore unbiased) means for making decisions concerning competence. These arguments also tend to side track the more explosive issues of the dual standards between oriminal and civil law and their application to different populations reflecting age, gender and class. Medical processes are deemed neutral and ahistorical making competence a supposed criterion-evaluated status rather than a product of social

20. MoKeiver v Pennsylvania, 403, Us 528 (1971). 
evaluation.

The broad substantive standards of the early canadian and U.S. statutes treated dependent, neglected, and delinquent children without distinction. For example, the 1929 revision of the Canadian Act blurred the distinction between dependent and delinquent children. Children in both cases were more simply categorized as in need of help. The blurring of delinguent and dependent categories was supported by the popularization of the childhood gaze and the diagnostic use of the medical model. Children brought before the court were considered at risk for physical and mental illness. The mental hygiene movement incorporated the parens patriae arguments which subsequently became part of the evolution of mental hygiene practices. The doctrine of parens patriae negated the need for due process since the court's purpose, by its mandate, was to serve the best interests of the child. The medical model, which made delinquency a matter of maladjustment and illness, served to support the parens patriae perspective in that it negated the value of due process. The right of the ill to be treated was in substantive terms greater than the right of a noncompetent individual, the child in this case, to choose ill health over health. 21

Social Origins of the Paradigm

Child Peychiatry

While child oriminals were recognized in the nineteenth

21. See subsection 17 (2), discussion Grant, "The Incorrigible," p. 304. 
century, insanity was looked upon as an adult problem. Mention of insanity in young children remained theoretical or descriptive rather than a policy issue. William Perfect (1787), Benjamin Rush (1812), and J.E.D. Esquirol (1839) described psychoses of childhood. Esquirol attempted to differentiate mentally defective from psychotic children. William Griesinger in an early German text (1845) devoted a chapter to "insanities of early life," as did Henry Maudsley (1867). The British alienist, Charles West (1871) argued with Maudsley that child and adult diseases should be separately conceptualized. B.A. Morel, a French psychiatrist, advanced the theory of childhood problems as "retrograde metamorphosis," a rapid undoing of evolutionary progress in one individual. G. Stanley Hall more or less reversed this idea in his recapitulation theory where individual growth follows the evolutionary process of mankind from savage to civilized. This contributed to Hall's notion of adolescence as an intermediary stage reflected in a period of "storm and stress."

The first attempted systematic view of ohild psychiatry was a theoretical work by Hermann Emminghaus in 1887. Freud laid the foundation for what has become the conceptual basis for ohild

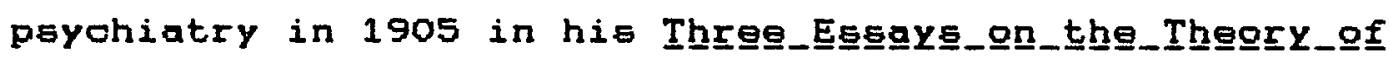
Sexu미른. Three years later he psychoanalyzed a child, Hans, through talks with his father. Freud saw Hans only once. Freud's interests remained distinetly adult oriented, but his idea that the treatment of adult psychosis required an introspective search into childhood events gave impetus to the psychiatrio examination 
of children. Adolf Meyer'a paychoblology also introduced a dynamic attitude toward the origins of mental illness as a developmental iesue. Technical advances in psychometry in the ability to measure individual differences added a predictive element based on differential expectations according to intellectual capacity. Psychometry legitimated the presence of inequalities which were not remediable. This was a relatively inaccurate tool which nevertheless was used to differentiate the cause of retardation in organic processes as distinguished from environmental factors.

The child psychiatry movement evolved in conjunction with the child guidance movement. Melanie Klein and Anna Freud became active in child psychoanalysis in the 1920s. Anna Freud migrated to England in the late 19305. 22 The first English language text in child psychiatry, written by Leo Kanner, was not published until 1935. 23 Psyohotherapy with children was underdeveloped and formally unrecognized in the United States and Canada until after the second world war. The contributing developmente leading to child psychiatry included the expansion of out-patient and

22. Henry Maudsley. The_Physiglogy_and_Pathololggy_of_the_Ming (New York, 1867), p. 292 chapter on "Insanity of Early Life;"

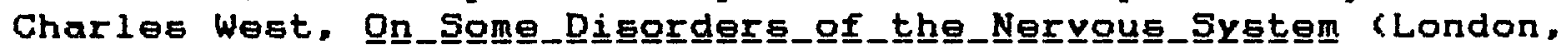
1871): See Stephen Kern, "Freud and the Birth of Child

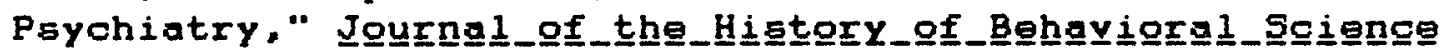
6(1970): 360-368, Kern argues that a medical specialty in child peychiatry had evolved in Europe.

23. Leo Kanner, Chhilld_pgychigatry (Springfield, Ill.: Charles C. Thomas 1935); Leo Kanner "History of Child Psychiatry," in A.M. Freedman and H.I. Kaplan, eds., Gomprehehengi PEychiatery (Baltimore: Williams \& Wilkins, 1967). 
in-patient psychiatric services for children. This was

accompanied by the creation and continued expansion of a nosology of psychopathological disorders in childhood. Both these events were fostered by the mental hygiene movement. Where the institutionalization of adults came under increasing criticism residential services for children expanded largely without controversy. 24

\section{Childhood and Preventive Mental Health}

A combination of forces came to play in focussing the mental hygiene movement on childhood as the key to preventive mental health. A very early theoretical attempt at a preventive approach

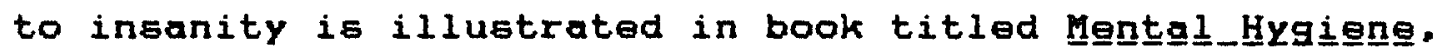
written by a pione日r asylum psychiatrist, Issac Ray, and published in 1863. The hypothesis is curiously olose to Adolf Meyer's concept of psychobiology in addressing an integrated approach to behaviour as a combination of physical and mental processes. 25 Ray emphasized predispositions to "gross

24. Committee on Child Psychiatry, Psyghopathhologigal

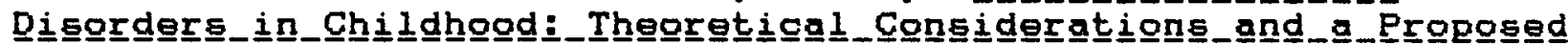
Glagesifígation Group for the Advancement of PEychiatry Report No. 62. (New York: GAP, April 1967). American Psychiatric Association

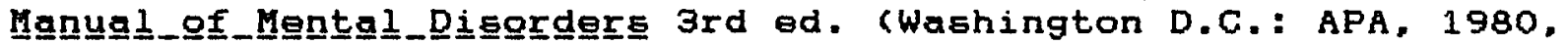
reprinted 1984); World Health Organization. Manual_olof_the

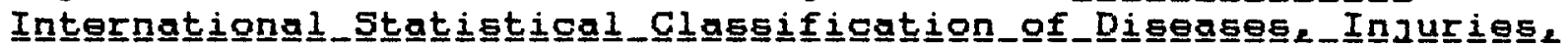

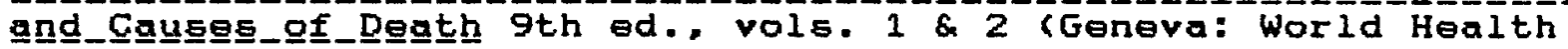
Organization, 1977); Robert Castel, Francoise Castel and Anne

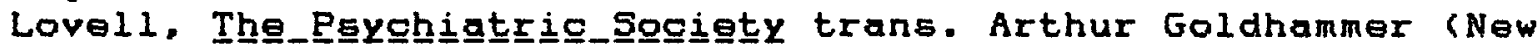
York: Cornell Univ. 1982), p. 107.

25. Issac Ray, Mental_Hygiene (Boston: Ticknor and Fields, 1863); the first work using the term mental hygiene was by William Swe日tser, Mentaㅡ늡ygienne (New York: J. \& H.G. Langley, 1843); English physician J. Hawkes, "On the Increase in

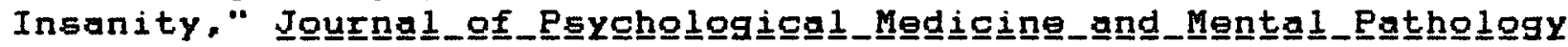


eccentricity" and "derangement" which could "strike down its victim in the freshness and vigour of youth; [or] it may wait until the mind has stood many a shock and passed through many a trial.". 26

Ray was a part of a small number of early alienists in the United States and Canada, including Joseph Workman, who took an interest in prevention and a fleeting theoretical interest in child rearing and family life as causing insanity. 27 The application of a preventive applied psychiatry was to await the birth of the child guidance clinic.

Nineteenth century social changes were critical to the development of the twentieth century mental health paradigm with its focus on reforming public policy in the direction of prevention and children. Children had to be segregated into age specific categories before their cognitive and emotional 1 ife could be identified as different from adults and as having significant consequences in later life. Secondly, children had to be formally attributed age specific statuses legally and institutionally. This included separate legal categories for normal, dependent, neglected, delinquent and defective child populations. These events occurred over a relatively long period

18. 5 (1857): 508-21, called for "sanitary reform" in the prevention of mental illness.

26. Ray, Mental__Hygiene, pp. 18-19.

27. Joseph Workman, "Discussion on Dr. Ray's Paper on Mental

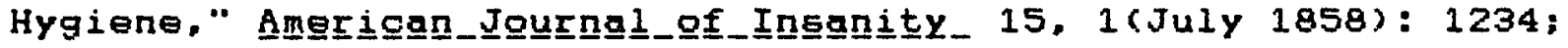
Norman Dain. Concegetg_of In (New Brunswick, N.J.: Rutgers University Press, 1964), pp. 94-97. 
of time and laid the basis for the child guidance movement as structured by the NCHH and Commonwealth Fund after World War I. The segregation of children was a prior condition for the advent of a psychiatry of childhood. Institutions in the nineteenth century moved from the nondistinction of age status altogether to age as a paramount consideration in social policy. The public school movement is the most obvious example of the advance and legitimation of age specificity. It is also noteworthy that schools became compulsory public institutions for children for most states in the U.S. by the end of the century. 28 Elementary sohooling became common before it became compulsory in Canada. 29 The nineteenth century developed a variety of other public institutione which aleo evolved toward the separation of child and adult groups. Asylums, workhouses, almshouses, prisons, and special schools were restructured in

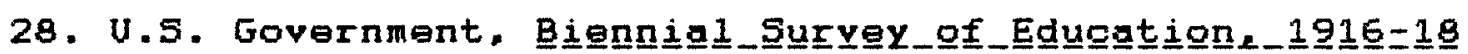
vol. I (Washington D.C.: U.S. Government Printing office, 1918), pp. 414-5; also see John G. Richardson, "Variation in the Date of Enactment of Compulsory School Attendanee Laws: An Empirical

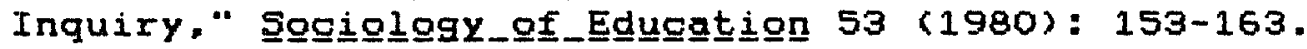

29. The British North America Aot of 1867 brought about the Confederation of four British North American colonies forming modern Canada. Section 93 designated that education be a provincial responsibility. The administrative arrangements of the school systems differed widely between provinces. This differentiation continued as new provinoes entered the Confederation. See J. Donald Wileon and Marvin Lazerson. "Historical and Constitutional Perspectives on Family Choice in Schooling: The Canadian Case," in M. Manley-Casimer, ed., Family

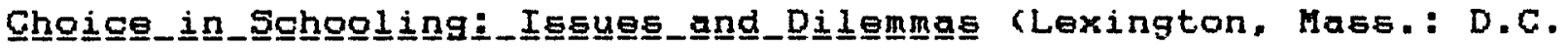
Heath, 1982). pp. 1-22; The campaign for compulsory education extended over a period of 26 years in Manitoba (1890-1916). Quebec resisted even longer. See Richard Henley and John Pampaliis, "The Campaign for Compulsory Education in Manitoba,"

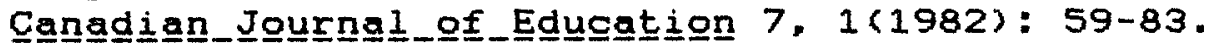


order to differentiate between various classes of defective, dependent, and delinquent populations. Asylums and hospitals for the insane were part of the trend to olaseify and differentiate various populations but the emphasis was not on youth.

Mental hospitals and asylums were largely filled with adult populations. In 1880 the average age was 43.5 years. Seventeen per cent were over the age of 60 years. 30 A great number of those incarcerated as insane were alcoholics or were suffering from the debilitating effects of advanced syphilis. This remained the major factor in commitment until the late 19205. The expansion of public institutions for the insane took place in the mid to late 18008 . The early years were marked by an optimism which has been termed a "cult of curability." 31 Prior to 1820 only one state in the United States took responsibility for the insane. By 1875 there were more than 60 inetitutions in 32 states. The "cult of curability" waned in the face of what appeared to be a gigantic increase in the number of insane in the general population. Insanity was increasingly thought to be due to hereditary factors of biological origin independent of

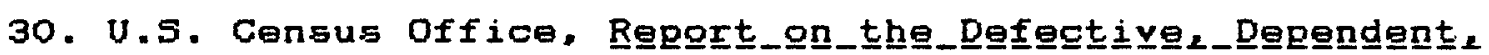

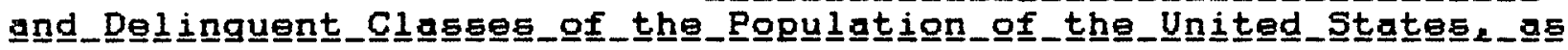

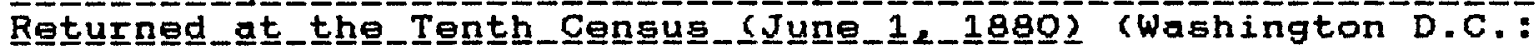
Government Printing Office, 1888), pp. vii-xli.

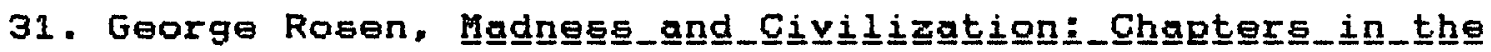

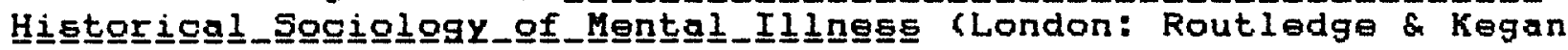

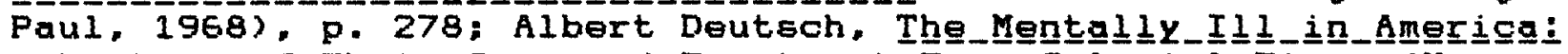

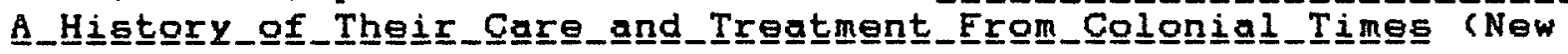
York: Doubleday. Doran, 1937, reprint New York: Columbia University Press, 1967), see ch. 8, p. 132. 
paychological characteristica. 32

In Canada, the first provincially operated lunatic asylum was established in New Brunswick in 1835. Dorothea Dix, an early advocate for the reform of the treatment of the insane, campaigned in the Maritime provinces of Canada as well as in the New England states. 33 Alarming statistics concerning the census of insane from the United States and Britain also encouraged the growth of Canadian asylume. By 1913 there were 28 institutions representing all ten provinces. 34 In the early years in both the United States and Canada the insane were often put in nonspecific institutions such as jails and almshouses. Similarly, there were no legal restrictions to placing juveniles in the asylums.

The blurred division between youth and adult is witnessed in the "Record of Lunatios in the Temporary Lunatic Asylum in the Gity and Parish of saint John from the first of January to the thirty first of December 1837." 35 There are 54 cases cited, of

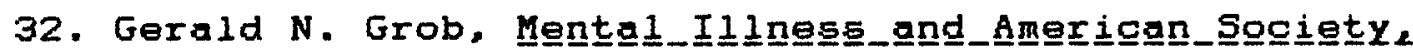
1975=1949 (Princeton, N.J.: Princeton Univ. Press, 1983), pp. 8, $10.14-7$.

33. "Dorothea L. Dix and Canadian Institutions," in Henry B.

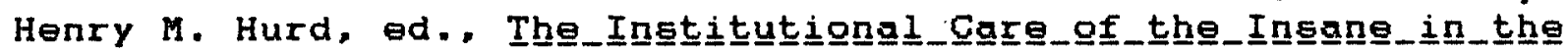

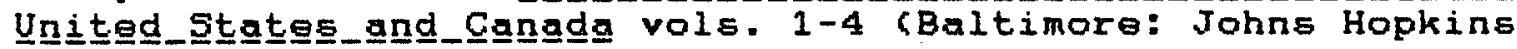
Univ. Press, 1916, reprint New York: Arno Press, 1973), I: Appendix IX. Another influential advocate for the growth of mental institutions was public school movement leader, Horace Mann. See Jonathan Messerli, Horgace_Manni_A_Bigograghy (New York: Alfred A. Knopf; 1972), pp. 122-37.

34. Data compiled from the extensive survey conducted by

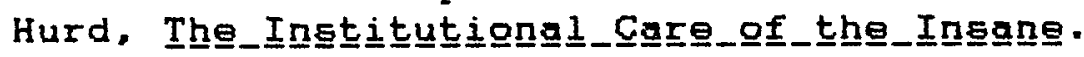

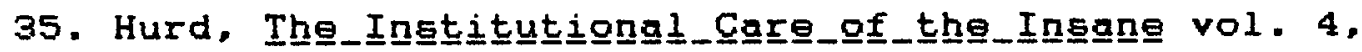
"Appendix to Journal of House of the Assembly on New Brunswick, 1936-37." pp. 98-9. 
these there are six minors, four nineteen year olds, one fourteen and one eleven year old. These cases also illustrate the degree to which insanity as a moral affliction was coneidered curable. The eleven year old, Michael Mullen, is identified as being afflicted with "ordinary insanity." Admitted the 24th of August, he was discharged as "cured" less than a month later on the 18 th of September. The fourteen year old is cited as an "idiot" who was "remaining unimproved." Two "furiously mad" nineteen year old females are also oited as discharged as "cured." Another nineteen year old was discharged "improved" while the fourth afflicted with "ordinary insanity" remained "unimproved." 36

The Orphans' Home and Female Aid Society was incorporated in Toronto in 1851 by members of the city's elite. 37 The concern with neglected children on the streets of Toronto led to a variety of institutions from reformatories to industrial schools and an array of charities. 38 One change in the disposition of dependent and neglected children which altered their placement in non-age segregated settings was the enactment of legislation which regulated children's aid societies and controlled the

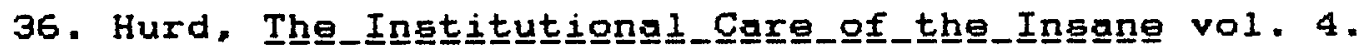

37. Names of board members were identified as wives and daughters of the Family Campact families by Richard B. Splane,

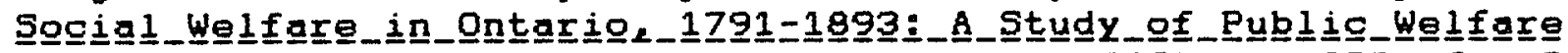

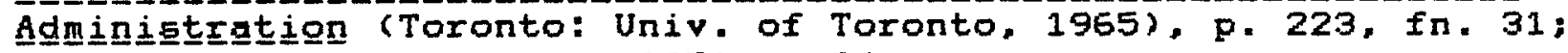
also se日 Canada, Stat $\underline{\text { utteg }} 1851, \mathrm{C} 34$.

38. Susan Houston, "The "Waifs and Strays" of a Late Victorian City: Juvenile Delinquency in Toronto," in Joy Parr,

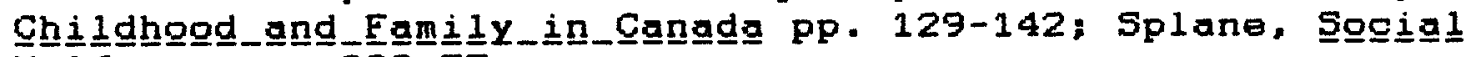
Wele르보. pp. 223-77. 
placement of children in private and institutional care. 39 In Canada a Royal Commission on the Prison and Reformatory System of Ontario was set up in 1890 with $J$. W. Langmuir as chair. An outcome of the Commission was the "The Children's Charter," or "Gibson Act," passed in 1893, which led to the appointment of J.J. Kelso as Superintendent of Neglected and Dependent Children. 40 Problems in Canade were exacerbated by similar problems in the United Kingdom. One English solution was to send 73,000 pauper children from the United Kingdom to Canada between 1869 and 1919.41 The idea of exporting homeless children was suggested in part by practices of the New York Children's Aid Society. 42

39. For example: "An Act in Addition to an Act to Establish the Board of State Charities," in Massachusetts, Agțs_and Resglyes (Boston, 1869), ch. 453; also "An Act Relating to the State Visiting Agency and Juvenile Offenders," in Massachusetts, A드트므르_Resglyes (Boston, 1870), p. 262; New York passed similar legislation in 1892; Rhode Island in 1898; there were efforts to place children on probation or in families; see, Homer Folks, "The Care of Delinquent Children," Progeegdinge_of_thhe_Natigonal

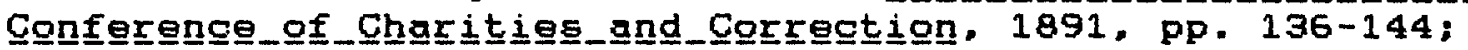
Ontario legislation was pasegd in 1893. Ontario, Statututes (1893), ch. 45 .

40. "An Act for the Prevention of Cruelty to and Better Protection of Children," Ontario, Statutetes (1893), ch. 45; see Splane, Sqgigl Welfarge_in_Qntarig. pp. 268-75; and, Andrew Jones

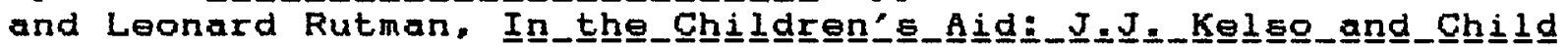

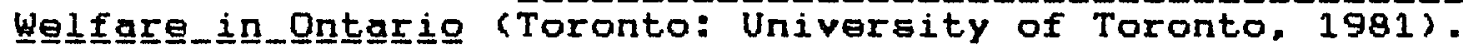

41. Canada, Department of Immigration, File \#3115, "Inspection of Children-General File," vol. 1, Andrew Doyle, Em

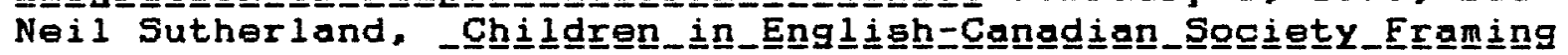

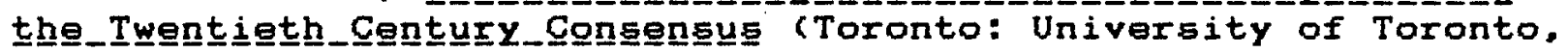
1976, reprint 1982), pp. 4-5; On England se日: Margaret May, "Innocence and Experience: The Evolution of the Concept of Juvenile Delinquency in the Mid-Nineterenth Century." Vịgtor Stㅡ느므토 17, 1(Sept. 1973): 7-29.

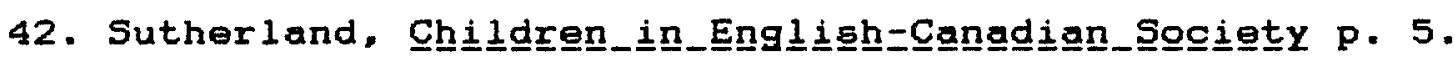


The Children' Ald Society of New York was formed in February of 1853 by Charles Loring Brace. This society was incorporated in 1855 under the lawe of New York. The first large gift was from Mrs. William B. Astor, wife of the city's principal property owner. 43 The Children's Aid Societies worked to remove vagrant and destitute children from the city streets. One of Brace's solutions was to put homeless boys up for adoption in the western states. The problem of unattended children who wandered the streets appeared real. The Chief of Police in New York reported 10,000 vagrant children in the city, the captain of the eleventh ward cited that out of 12,000 children between five and Eixteen only 7,000 attended school leaving 5,000 on the street. 44 The goal of the Children's Societies was the placement of neglected and dependent children in "proper" controlled child specific settings. As the nineteenth century wore on reformers favoured family or more "natural" settings in foster placement and adoption over orphanages and other institutional placements for needy youth. There was a great deal of discrepancy between the ideal goals of reform efforts and the realities of their

43. Charles Loring Brace, "The Children's Society of New York: Its History, Plan, and Result," in the National Conference

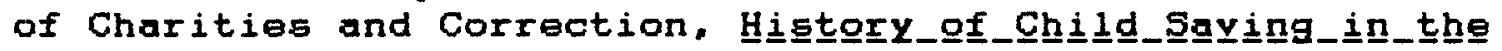

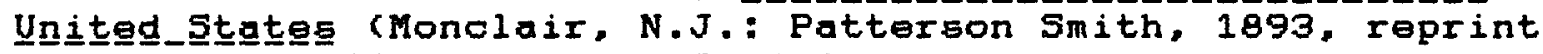
1971), pp. 1-36, se日 pp. 4-5, 8-9.

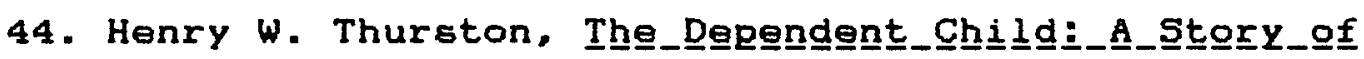

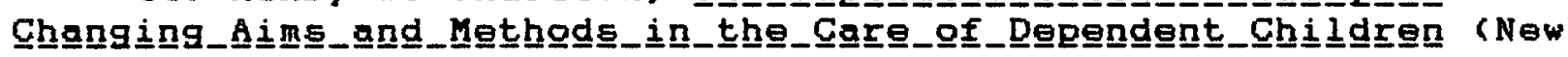
York: Columbia Univ. Press 1930), pp. 96-7. 
accomplishments. 45

The practice of the interstate placement of children led to the passage of laws restricting and regulating the practice. Fiftern states enacted laws by 1915 with 28 states regulating the disposition of dependent children by 1924. The arguments for legislation included "public feeling of responsibility for the protection of childhood" as well as a corresponding perception that the children were being exploited. 46 It was not until after 1915 that foster home placement was designated for "disturbed children" who were removed from homes identified as "unsuitable." 47

The most important single change in children's legal policy was application of the principle of parens patriae to children and the institutionalization of the juvenile courts mentioned earlier. The separate courts generally served juveniles between six and sixteen years of age. Previously a child under common law over the age of seven was considered to be criminally responsible in most states. The establishment of the juvenile court not only

45. Anthony Platt, "Introduction to the Reprint Edition," in

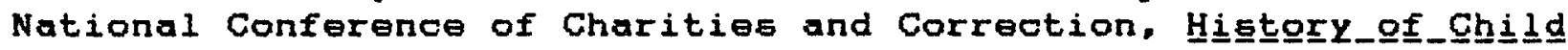

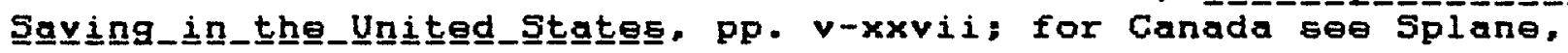

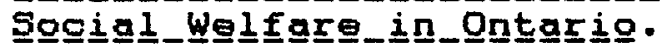

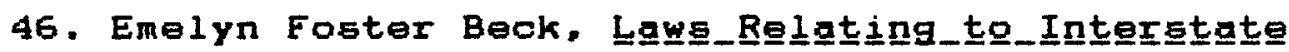
Pl $\underline{\text { g c }}$ ement_of Bureau No. 139 (Washington D.C.: Government Printing, 1924), p. 1 .

47. Raymond M. Glasscote, Michael E. Fishman and Meyer

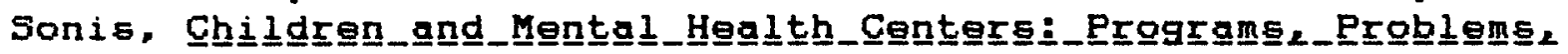
Prgesgegts (Washington D.C.: Joint Information Service of the APA and NAMH, 1972), p. 13. 
separated the child from adult proceedings and placement but redefined the child offender not as a criminal but as a delinquent. 48 In this way the child gained the protection of the court but lost certain rights to the protection of due process. These courts attracted all varieties of child and family problems and placed them before the prerogative of the magistrates. The use of probation was a signifioant addition to child placement since it necessitated the expansion of services and personnel to overse日 these provisions. Children's services increasingly concentrated on professional guidance through the school and home rather than through reaidential institutions.

The Illinois Juvenile Court Law of 1899, as the first statutory example, became a model for similar legislation in twenty-two other states. 49 The Juvenile Delinquency Act of Canada, a statute of 1908 , also reflected the Ilinois

legislation. 50 Child dependency problems were increasingly seen

48. Grace Abbott, "Part II: A Topical Abstract of State Laws Governing the Trial and Disposition of Juvenile Offenders," in

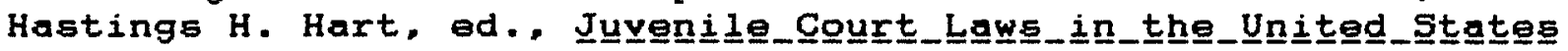
(New York: Charities Publication, 1910), p. 122.

49. "An act to regulate the treatment and control of dependent, neglected and delinquent children," 1899, see ch. 23.

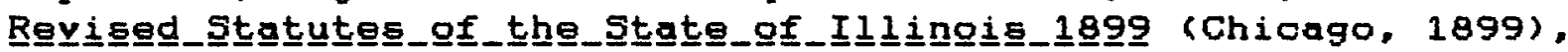
p. 131; John Koren. "A Summary of Juvenile Court Laws in the

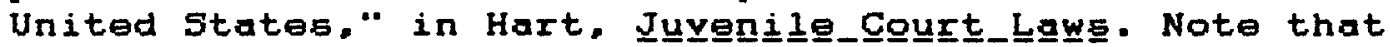
Massachusetts and New York had earlier legislation which designated separate court sessions for children in 1872 and 1892 respectively but they did not enact statutes specifying unique courts until 1906 and 1909 .

50. Canada Statututes (1908), ch. 40; Neil Sutherland "Towards Inteligent and Progressive Legislation for the Prevention of Grime": Preparing the Way for the Juvenile Delinquents Act, 1886-

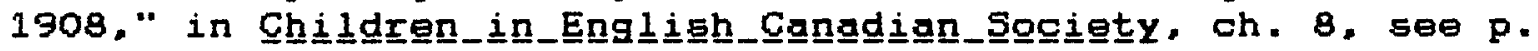


as "the story of the complications of poverty, Immorality and other delinquencies, disease and mental defect." 51 The courts of Illinois by law dealt with three classes of children, namely, the dependent or neglected child (homeless or destitute), the child who was in the street instead of school (truant), and the delinquent child (violators of the law, incorrigible children, and those growing up in "idleness and orime"). 52 A consolidation of earlier laws, the juvenile court legislation combined the industrial and training school acts along with all laws relating to dependent children, distinguishing the child from adult by age in terms of the process of atate intervention and the possibilities for placement. 53

The first child guidance clinic originated in affiliation with this court. The idea of a neurological clinic evolved in large measure out of the Juvenile Protective Association in conjunction with the encouragement of Julia Lathrop, then of Hull House settlement, later Chief of the Children's Bureau. Lathrop 122 .

51. Emma 0. Lunberg and Mary E. Milburn," Stories Illuetrating the Problems Dealt with by the Board of Children's

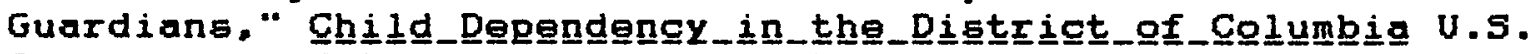
Department of Labor, Children's Bureau Publication No. 140 (Washington D.C.: Government Printing, 1924), p. B6.

52. Illinois, Reyiegd_statuuteg, oh. 23, sec. 169, and ch.

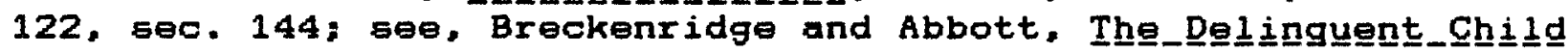

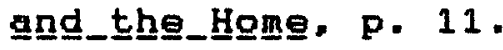

53. "Testimony of Judge Merritt $W$. Pickney," given before the Cook County Civil Service Commission, Nov. 22 and 23, 1911,"

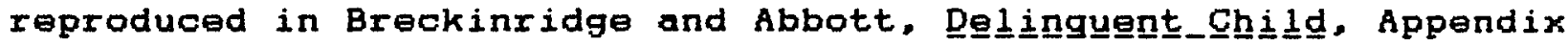
II. p. 203. 
was appointed chair of a committee to set up an investigatory team to study the causes of truancy and delinquency. 54 Adolf Meyer suggested a physician and neurologist, William Healy, as principle investigator. Lathrop invited Allen Burns, of the Juvenile court, and Healy to Hull House to discuss the establishment of a special court-affiliated clinic for children. Member of the Baard of Trustees of the Juvenile Protective Association and local philanthropist, Ethel s. Dummer agreed to fund the experiment for five years. 55 In 1909, Healy, a secretary, and Grace Fernald, his first assistant psychologist, began a consultant service in the juvenile court of Judge Pinckney. After six months the "team" began to do pre-trial examinations of the defendants to advise the court of the "true cause" of the child's delinquency. 56 It was decided to officially open a Juvenile Psychopathic Institute in affiliation with the court to more thoroughly study the young offender.

There were few earlier precedents for such a clinic. The very first olinio for children was oreated in 1896 by Lightning Witmer, professor of peychology at the University of Pennsylvania. A principal in one of the public schools asked

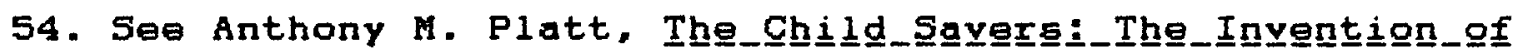
Delinguengy (Chicago: University of Chicago 1969), pp. 92-100 on the role of both Jane Addams and Julia Lathrop.

55. Ethel S. Dummer, "Life in Relation to Time," in Lawson

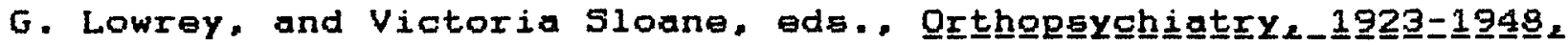
Ret American Orthopsychiatric Association, 1948), pp. 3-13.

56. "Testimony of Judge Merritt W. Pinckey," see p. 234. 
Witmer to examine a boy who wouldn't learn. Witmer determined that the child was visually impaired. Witmer established a clinic for the remediation of practical disabilities of learning which he termed clinical psychology. Witmer worked exclusively with mentally retarded children and did not interpret aberrant behaviour as reflecting peychiatric problems other than mental retardation. 57

One further example of the early clinical examination of children occurred at the Vineland Training sohool for the Feebleminded under the direction of Henry H. Goddard, one of $G$. Stanley Hall's students. Gaddard introduced mental testing into an institutional environment. In 1910 he published an American version of the French 1908 Binet-simon intelligence scale. He also described connections between low test scores and various forms of social deviancy, elaborating in the process three different classes of fe日blemindedness: imbeciles, idiots, and marons. Goddard closely associated fe日blemindedness with immorality and criminality. Italian anthropologist Cesare Lombroso had developed a similar theory on criminality and the biology of degeneracy based on physiognomy. Lombroso's view was subsequently discredited. Nevertheless, the ability to test clinical features of mental processes in intelligence tests furthered a renewal of a Darwinian approach to deviant behaviour.

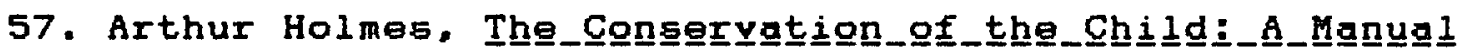

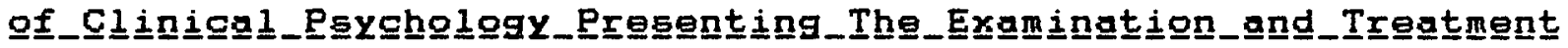

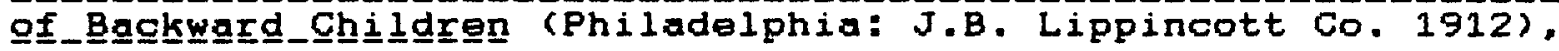
pp. 28-9. 
In 1909, Healy opened the precedent-getting Juvenile Psychopathic Institute. Healy experimented with Binet-simon intelligence scales as revised by Goddard. One of Healy's goals was to examine the relationship between delinguency and "bad heredity" in feeblemindedness. However, Healy moved away from degeneracy theories and eugenic arguments of "born bad." He concluded that the inheritance of mental peculiarities and physical characteristics had a bearing on delinquency but there was no direct inheritance of discrete criminalistic traits. He found most of the delinquents' intelligence normal. This left the way open to the interpretation of problems of delinquency as due to other learned factors, such as family influence and emotional disturbance. Did "extroverted symptomatic behaviour.. in morbid fantasy life..precede pathological lying and accusation?" Healy never completely resolved this question. 58

In 1913 Augusta F. Bronner joined the clinic. She was a peychologist trained at Columbia under learning theorist Edward Thorndike. She had been attracted to the clinic during a summer class she took from Healy at Harvard. As a prelude to his growing recognition, Healy gave two lecture sessions at Harvard, in the summerg of 1912 and 1913. Healy began to publish a series of articles on systems for recording data on criminals (1909. 1913), tests for mental classification (1911), case studies, epilepsy, causes of crime (1912), inheritance, female delinquency (1913)

58. William Healy and Augusta F. Bronner, "The Child Guidance Clinic, Birth and Growth of an Idea," in Lowrey and Sloane, grthhgesyghigttxy, pp. 14-49. 
and retardation (1914). In 1915 he published his major work The

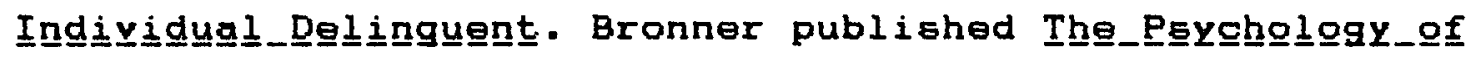

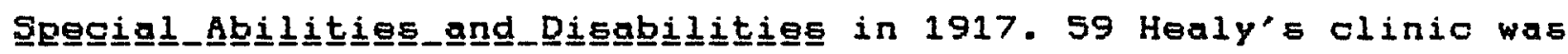
the first to add the component of mental unbalance to children in a clinical setting which became the trademark of child guidance. Healy's clinic was a beginning which had a profound effect on Thomas Salmon of the National Committee for Mental Hygiene. The first similar clinic in Canada was the one set up by C.K. Clarke in Toronto under the direction of Clarence Hincks in 1914. 60

Thomas Salmon and Child Guidance: The Early Years When Salmon joined the NCMH in 1912 he undertook mental hygiene surveys of institutions which housed large numbers of delinquent and dependent children. In an early survey of Baltimore, ten per cent of the children were identified as abnormal. Salmon's early solution to the problem of the insane and defective stressed prevention through deportation. This new line of inquiry took him into an area where deportation was not a solution. Salmon turned to earlier prevention.

Salmon's argument that preventive mental hygiene necessarily concerned children evolved over several years. Children had

59. William Healy. The_Indị

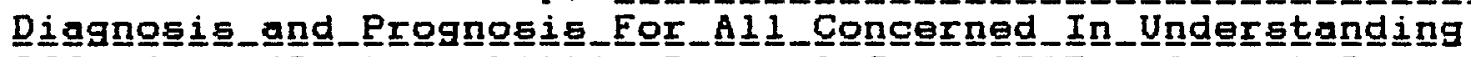
off fenderes (Boston: Little Brown \& Co.. 1915); August Bronner, The

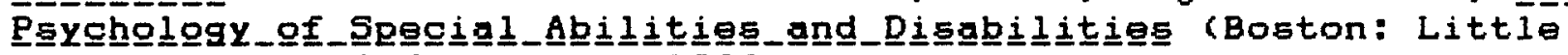
Brown \& Co., 1917, reprint 1926).

60. Alexander and Selesnick, "Developments in Child Psychiatry," p. 376. 
figured prominently in the 1912 NCMH mental hygiene exhibit. Henry Goddard's approach to the feebleminded and the popular emphasis on eugenics was evident as an influence. 61 salmon extended the mental hygiene surveys to cover mixed adult-child institutions. He came to stress the importance of studying a variety of institutions rather than just the hospitals for the insane. Salmon's list of institutions to be examined included: almshouses, jalla, achools, and institutions for the feebleminded, orphaned, dependent or neglected child. Salmon turned his attention toward early intervention through the juvenile court, parental or truant school, public school, and finally the family home. He argued the incontrovertible fact that the insane population was dispersed throughout these settings and that many of these social settings were either specifically organized for children or had mixed age populations.

Salmon followed the evolution of the Chicago juvenile court and peychopathic clinic by way of the overlapping membership between child savers and mental hygienists. For example, Jane Addams and Julia Lathrop were active in both arenas. Adolf Meyer's served as an early consultant to the juvenile court and encouraged the establishment of the psychopathic clinic. Salmon also followed the development of Meyer's psychiatric clinic and laboratory at Johns Hopkins University which was designed to

61. National Committer for Mental Hygiene and the Committee on Mental Hygiene of the New York State Charities Aid Association, "Mental Hygiene Conference and Exhibit," Nov. 8-15, 1912; see Henry Goddard, The_Kallikgk_Egmily (New York: Mackillan, 1912). 
serve both adulta and children. The establishment of the Children's Bureau under the Department of Labor legitimated the emphasis on solving social problems by focuseing on ohildren's issues. President Theodore Roosevelt's warning at the 1909 white House Conference on Dependent Children that the "ranks of criminals and other enemies of the state are recruited in an altogether undue proportion from children bereft of their natural homes and left without sufficient care," was an added impetus to action. White House Conference spokesmen claimed that in 1904 there were ninety-three thousand institutionalized dependent children, fifty thousand additional neglected and dependent children in private homes, and twenty-five thousand juvenile delinquents. 62

By 1915 Salmon was ready to put forth a comprehensive proposal which began to pull these ideas together into a preventive framework. This was also his first year as a paid employeg of the Rockefeller Foundation. Salmon proposed to the Foundation a comprehensive study of the psychopathology of crime as "a chronological arrangement of the material...from childhood." 63 Salmon suggested a clinical study of the inmate

62. Theodore Rooseve1t, "Conclusions of the white House Conference on Dependent Children, Special Message by the

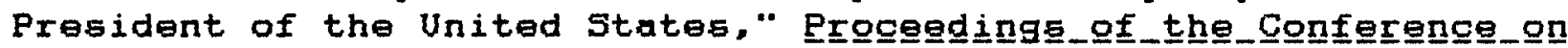
the Caxe of Dependent_Chil Senate Document No 721 , (Washington D.C.: Government Printing Office, 1909), pp. 8-14.

63. Thomas W. Salmon, "Bureau of Social Hygiene, Institute of Criminology: Study of the Paychopathology of Crime." proposal submitted to the Rockefeller Foundation, [probably 1915]; also "Memorandum regarding Director for Studies in the Psychopathology 
population of Sing Sing prison which was to cooperate with a "mental clinif" in the children's court of New York. city. Salmon first suggested that william Healy be made the director of the project, however, Healy declined the offer. Bernard Glueck, a psychiatrist Salmon had met while in the Public Health Service, accepted the position. 64

The atudy at Sing Sing was begun in 1916 with an appropriation from the Rockefeller Foundation of $\$ 47,000$ over three years. The mental clinic for children was opened in Franklin C. Hoyt's court in New York. Successive appeals to the Rockefeller Foundation to continue support for the study of the psychopathology of crime emphasized the "essential" connection between the sing sing study and the children's court. The clinic was to create guidelines for other clinics, and to "standardize research studies": on psychopathology and delinquency. 65 The purpose of the clinical studies were to "discover unstable, mentally deficient and mentally disordered individuals who, later, would in many instances, go to prison for offenses committed not because of criminal instincts but because of mental

of Crime." Thomas Salmon Papers 4, 2, AFMH Archives, Payne Whitney Clinic Library, CMC, NYC.

64. See Glueck's statement on the Sing sing study in the "Mental Hygiene Section," of the National Conference of Social

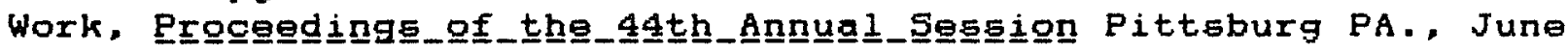
16 to 17,1917 , pp. 391-454; salmon, "Memorandum Regarding the Director."

65. Thomas W. Salmon, "Appeal to the Rockefeller Foundation." 19 November 1918, Thomas Salmon Papers 3, 4, AFMH Archives, Payne Whitney Clinic Library, CMC, NYC. 
Inefficlency or mental abnormality of one kind or another." 66

Glueck later described Salmon's part in structuring the Sing Sing research in 1 ta relationship to child guidance:

Indeed from the very first, Doctor salmon was particularly interested in having us bring to light the intimate relationship between childhood maladjustment and later eriminal careers... Moreover...he had always emphasized a preference for preventative measures as against the purely corrective enterprises and the sing sing studies he looked upon as a prelude to child guidance. 67

Salmon was not as shy as Healy in drawing direct connections between children filtered through the juvenile court and mental i11ness. He saw the courts as institutions which were age specific but which still failed to make the distinctions between various age related populations in terms of normal and abnormal development and predilections. Salmon pushed the NCMH to take the position that in the children's court "the greater proportion of the difficulties do not deal with oriminalism at all, but with many other disorders of conduct which, for administrative convenience, are dealt with by that tribunal." Further. "in many instances police intervention has not been the initial step in bringing them to public notice. Sick children, neglected

66. Thomas W. Salmon, "Mental Hygiene: A Report on Work Carried on by the National Committee for Mental Hygiene with Appropriations Made by the Rockefeller Foundation, Jan. 1. 1915 to Dec. 31, 1916." Thomas Salmon Papers 2, 3, AFMH Archives. Payne Whitney Clinic Library, CMC, NYC; Clifford Beers, "Report to the Rockefeller Foundation," February 1918, see pp. 1-2, RG 1.1. 200, 33, 373, RFA, RAC, N. Tarrytown, N.Y.

67. Bernard Glueck, "Thomas W. Salmon and the Child Guidance

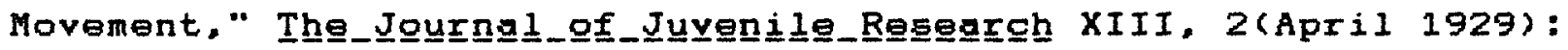
80. 
children, paychopathic children, feebleminded children, all come to this court whenever their conduct seriously interferes with standards established by social conventions." 68 salmon, in this way, moved the idea of a children's psychopathic clinic away from the etudy of delinquency and criminality and toward the general atudy of childhood abnormality outalde of the court.

Salmon, as head psychiatrist of the Expeditionary Force in France during World war $I$, drew up extensive plans for psychiatric services during war time. He also developed civilian versions of these plans elaborating what he saw as the battlefield of "everyday life." The first line of this battle was to be in out-patient care for school children and in-patient children"s units in general hospitals. Psychiatric Institutes would have out-patient services for disturbed children in child guidance clinics. State psychiatric hospitals and treatment centers would have out-patient and in-patient services for all age groups. Ideally the child guidance clinic would not be set up under the oriminal justice system, or in affiliation with the courts or reformatories. Instead, they would be connected with university based research hospitals which would also provide advanced peychiatric training in child poychiatry. 69 1918.

68. Beere, "Report to the Rockefeller Foundation," February

69. Thomas W. Salmon. "Memorandum Prepared at the Request of the Secretary of War," 18 July 1919, p. 1, Thomas Salmon Papers 3. 3, AFMH Archives, Payne Whitney Clinic Library, CMC, NYC; Norman Fenton and Thomas Salmon, eds., "Neuropsychiatry," $\underline{U}_{-} \underline{S}_{-}$

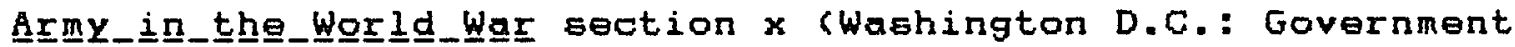
Printing office, 1950). 
After returning to civilian life Salmon began to badger the Rockefeller Foundation to proceed with what he was beginning to see as the most urgent area of psychiatry. Salmon wrote Edwin Embree of the Foundation, "We are used to saying that the children's courts constitute the first line of attack on the problem of juvenile delinquency but truancy from school is an even earlier phase of anti-social tendencies." 70 By the end of 1919 several pilot studies along these lines had been conducted under the auspices of the NCMH with Rockefeller Foundation support. One such study was undertaken on truant boys in Public School No. 31 in New York city. A personelity study of prostitutes was undertaken by the New York Probation and Protective Association. This study was done in the mental hygiene clinic of the Gity Health Department of Newark. New Jersey where children were sent from the juvenile court. A study of domestic relations was funded in the juvenile court of Norfolk, Virginia, in addition to a short survey of the opportunities for study in conrection with the juvenile court of Savannah, Georgia. 71

Seven years had passed since the establishment of the Rockefeller Foundation and five years had elapsed since the trustees had employed salmon as an advisor and consultant in

70. Thomas $w$. Salmon to Edwin Embres, 13 June 1919, Thomas Salmon Papers 2, 5, AFMH Archives, Payne Whitney Clinic Library, CMC, NYC.

71. Cited in "Appeal to the Rockefeller Foundation," draft presumably by Salmon dated 11 November 1920. Thomas Salmon Papers 2. 5, AFMH Archives, Payne Whitney Clinic Library, CMC, NYC. Also see for early appropriations, Rockefeller Foundation, "Minutes," 24 May 1916, p. 4058, RFA, RAC, N. Tarrytown, N.Y. 
mental hygiene. In January of 1920 Foundation officiala and friends gathered at the Gedney Farms Hotel in New Jersey to discuss the future of mental hygiene work and its organization with reference to other RF projects and boards. The Foundation had originally considered a separate division on mental hygiene. The hiring of Salmon and support for the NCMH had been a compromise in this regard. Salmon sincerely hoped to convince the Trustees to develop a general division on mental hygiene similar to the General Education Board or the Sanitary Cammission. The purpose of the division would be to do research and provide demonstrations in preventive work emphasizing the mental hygiene of childhood, psychiatric studies of delinquency and crime, and the expansion of graduate training facilities including fellowships for psychiatrists and other related mental hygiene professions. Salmon felt strongly that "the great hour for American psychiatry [was] at hand." 72 salmon argued:

The success of a few tentative psychiatric excursions into the field of criminology, the attempts to deal with the roots of mental disease in ohildhood rather than to devote out efforts wolly to managing them in adult life, the success of psychologists in devising group methods of arranging people with reference to their native intellectual endowment and the distinot tendency on the part of the public to replace by intelligent interest, credulity, and ignorance regarding everything that has to do with mental 1 ife, all have combined to open new fields for the practical

72. Thomas $W$. Salmon to Walter B. James, 9 April 1919. attached to TWS to George E. Vincent, 9 April 1919, RG 1.1, 200, NCMH 1919; RF Hist 900-1, yol. 6, pp. 1424-6, RFA, RAC, N. Tarrytown, N.Y. 
application of peychiatry. 73

The participants gathered at the Gedney Farms Conference on the 17th and 18th of January included Rockefeller Foundation President George Vincent, William Welch from Johns Hopkins, Abraham Flexner and Edwin Embree of the Foundation staff along with salmon. The others at once agreed with the contents of Salmon's proposal and yet remained unconvinced that a separate division on mental hygiene was called for at that time.

Salmon was greatly disappointed but perhaps he should not have been. Mental hygiene had, in fact, been incorporated into the workings of other previously established boards by the time of the Gedney Farms Conference. The Rockefeller Foundation took care of the fields of public health, medical education and medical research throughout the world. The General Education Board advanced the field of education in the United States. The International Education Board and International Health Board were designed to take on projects on health and education without national restrictions. This included health and education in Canada as called for by John D. Rockefeller Sr. in his 1919 ,plea for research and work in Canada. The Laura Spelman Rockefeller Hemorial, founded in honour of John D. Rockefeller Sr.'s first wife, was designed to look after social science and social technology, child study and parent education, and interracial relations.

73. Thomas w. Salmon to Walter B. James, 9 May 1919, RG 1.1 . 200, NCMH 1919, RFA, RAC, N. Tarrytown, N.Y. 
The Laura Spelman Rockefeller Memorial was incorporated with capital of $\$ 74$ million in 1918 with the mandate to "promote the welfare of women and children." 74 The rationale was that through the social sciences "might come more intelligent measures of social control that would reduce such irrationalities as are represented by poverty, class conflict and war between nations... Through a greater understanding of man and his relation to other men the growing power over the forces of nature would more likely be applied for good than for evil." 75 The Memorial's work evolved slowly in the years 1919 to 1922 . In 1922 Beardsley Ruml was made the Director. By 1924 child development demonstration research, which closely followed Salmon's prescriptions, were well underway. By 1926 it was the "dominant" activity of the Memorial. In the 1927 Report of the Trustee Committee of Review. child study and parent education was central and "virtually the single program of the memorial for the welfare of children." 76

Four months after the Gedney Farms Conference. Salmon was approached by Dr. Max Ferrand, the Medical Director of the Commonwealth Fund. The Fund wanted advice on potential programmes concerning child welfare and delinquency. In July, the Assistant

74. See tinal report: LSRM, Annugal_Regort (New York: Rockefeller Foundation, 1930): the Memorial produced Annual Reports from 1919 to 1930, the last is a synopsis of its activitios and finances.

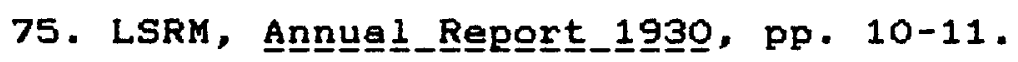

76. LSRM, Annuuㅡ_Regort_1930, p. 17. 
Medical Director, Samuel Fairly, followed up on the initial contact. Salmon was asked to prepare a proposal outlining the ideal project if financing were no object. 77 salmon's proposal and discussion on it led to the organization by Ferrand of an invitational conference to be held from the 11 th to the 14 th of March 1921 at Lakewood, New Jersey. The topic was to be the prevention of juvenile delinquency. 78 The temporary advisory committee for the conference was composed of Max Ferrand, Thomas W. Salmon, William Healy, Augusta Bronner and Bernard Glueck, as well as J. Prentice Murphy (Director of the Children's Bureau in Philadelphia). H.C. Morrison (Professor of Education at the University of Chicago). Judge Charles w. Hoffman (Court of Domestic Relations in Cincinnati), and Martha Falconer (Director of the Department of Protective Measures of the American Social Hyglene Association.)

The importance of the conference was reiterated later by Bernard Glueck, "whatever the vicissitudes have characterized the child guidance movement since then and whatever its future may come to be, nobody can question the fact that this movement had its birth at the Lakewood Conference in 1921 ... It was Doctor Salmon who contributed most to its deliberations and to the final

77. Walter Ruggles to E. Harkness, 7 June 1924, Thomas Salmon Papers 4, 5, AFMH Archives, Payne Whitney Clinic Library, CMC, NYC.

78. "Report of the Conference on the Prevention of Juvenile Delinquency Held at Lakewood, N.J., March 11-14, 1921," Thomas Salmon Papers 4, 2, AFMH Arohives, Payne whitney Clinic Library, CMC, NYC.. 
shaping of the report... He was unquestionably the leading spirit." 79

Healy, in recalling this conference, claims that salmon proposed that Healy and Bronner's work, then with the Judge Baker Foundation in Boston, be expanded into the community and that Healy and Bronner declined, suggesting instead that new demonstrations be made. 80 It is unlikely that salmon intended any demonetrations to remain attached to one olinical eetting or that they remain an outgrowth of a court. Salmon had consistently argued for the extension of work in psychopathology to community level investigations on multiple fronts. This approach was illustrated in the Sing sing Prison study. After the war he became more adamant on this point not only with the Rockefeller Foundation but in numerous addresses and speeches such as the one 3 September 1919 at the annual meeting of the American Institute of Criminal Law and Criminology. In this address he gives credit to his ideas to Healy's work, Bernard Glueck's studies and the lessons from his own war experience. His main point, however, was

79. Bernard Glueck. "Thomas W. Salmon and the Child Guidance

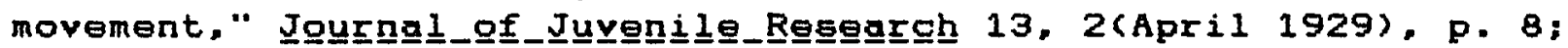
also. Paul 0. Komora. "Child Guidance Glinics: One of the Promising Developments in the Field of Mental Hygiene." newsclipping dated Jan. 7. 1927. (typed notations), probably from P. Komora, "Child Guidance." [about 1927] Thomas Salmon Papers 4. 8. AFMH Archives, Payne Whitney Clinic Library, CMC, NYC.

80. Cited in William Healy "Oral History Interviews conducted by John C. Burnam, Jan. 1960," (transcript), pp. 94-5,

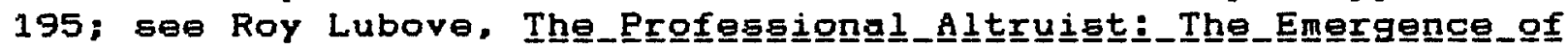

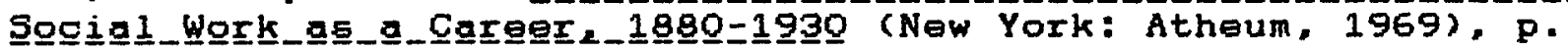
258, fn. 11; note that the Judge Baker Foundation did receive funds from the NCMH and RF in the $1920^{\circ} \mathrm{s}$ and $1930^{\circ} \mathrm{s}$. 
that even though "the children'a court is the outpost in the psychiatric study of delinquency" it was necessary in the future to "prevent the first departures from acceptable conduct." 81 From this standpoint, it was necessary to create centres, the Judge Baker Foundation in Boston was cited as one, which did research which went beyond courts and prisons, and, instead became a part of the "general advance of psychiatry." 82 Further, salmon claimed, "the study of the abnormal mind" should "extend the frontiers of psychological medicine" which would eventually "repay the debt which the medical oriminologist awes to the clinical paychiatrist." 83

The theoretical facus of the Lakewood Conference did not remain with the juvenile offender. Following Salmon's preventive prescriptions, medical, psychological, and social aspects of delinquency were to be enlarged in the direction of:

demonstrations in teaching and treatment, and, by the development of new centres of research in strategic locations. 84 The new centres were to concentrate on schools rather than courts with

81. Thomas W. Salmon, "Some New Problems for Psychiatrio Research in Delinquency." read at the Eleventh Annual Meeting of the American Institute of Criminal Law and Criminology. Boston, Mass.. 3 September 1919, p. 10. reprinted Ment므_Hygiene IV. 1(Jan. 1920): 29-42; also reprint No. 73 NCMH, draft copy in Thomas Salmon Papers 3, 4, AFMH Archives, Payne Whitney Clinic Library, CMC, NYC..

82. Salmon, "Some New Problema," p. 10.

83. Salmon, "Some New Problems," p. 11.

84. "Conclusions and Recommendations," Repgrt_of

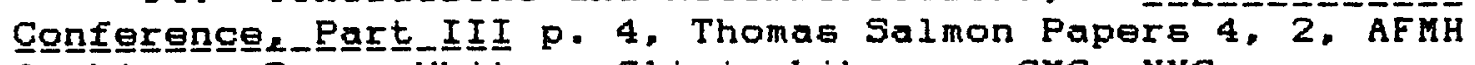
Archives, Payne Whitney Clinic Library, CMC, NYC. 
the idea of expanding the "scientific conception of disorders of conduct and their treatment." 85

Importantly, this extension of services to the school authorities and teachers were to be carried out through the extension of social casework, visiting teachers, and a variety of specialized school visitors. 86 The resulting programme was a very contemporary sounding version of extramural services in education carried out by specialized personnel who concentrated on identifying and remediating individual differences in learning, conduct, and personality. The provision of multiple educational functions inside and outside the self-contained classroom offered a substantial functional implementation of the progressive educational ideal.

While mental retardation and sexual deviance were cited as contributing to antisocial conduct and insanity, the family was also noted as potentially dangerous influence which could "deprive children of stabilizing influences and subject them to the disadvantages of institutional care or inadequate foster care [which] contributes to delinquenoy." 87 In general, the phenomenon of delinquency was looked on less as an end goal of study in itself but rather as a symptom of developmental problems in personal and social disorganization.

Additionally, Salmon stressed the need for the provision of

85. "Conclusions and Recommendations."

86. "Conclusions and Recommendations, pp. $4,6$.

87. "Conclusions and Recommendations," p. 6. 
adequate personnel. Wlthout properly trained paychiatriats, services were doomed to lag. This reflected salmon's problems with finding enough psychiatrists to fill the needs of his own programmes in the Army. Salmon turned to the practical solution of the development of programmes for training in the semiprofessional categories of psychiatric social work and public health nursing as alternatives to having all work conducted by what at the time was a very inadequate supply of prychiatrists. His belief in the uses of social workers to provide rudimentary psychiatric services, which he pioneered in the Army and with the Smith programme, is evident here. Salmon also spoke adamantly for the development of university facilities in clinics attached to medical schools. This would provide training for medical personnel in psychiatry in conjunction with an opportunity for clinical practice with children.

\section{Parens Patriae and the Mental Hygiene Paradigm}

The nineteenth century contributed to a heightened sense of the importance of childhood and the expansion and segregation of the ohild from adult institutions. Public concern over deviant and dependent populations also focussed on youth in the perceived need for the expansion of parens patriae powers for public and charitable intervention into family life. This time frame coincided with the medicalization of psychiatry and its expansion outside of the asylum. The perception of the child as unique led to the possibility of exclusive classifications of childhood problems. 
Pareng patriae was increasingly influenced by the medical model of preventive mental hygiene work with the young. These complementary perspectives claimed legitimacy based on the child's best interest and the general good. The twentieth century professionalization of juvenile court workers, social workers, educators, public health and child development experts was a corollary of expanded concepts of parens patrias responsibility. 88 Thomas Salmon, the National Committees for Mental Hygiene and their philanthropic mentors served as twentieth century advocates for the extension of public responsibility for child life. The successful medicalization of social practice relied on the testimony of a new class of experts In the behavioural and social sciences.

The mental hygiene prescription for legitimating preventive intervention into child mental and physical welfare came into focus at the Gedney Farms and Lakewood Conferences. Thomas Salmon played a major role in drawing the connection between philanthropic funding agencies and a policy orientation which converged the medical model in problem solving. the new preventive psychiatry, and the preoccupation with children, into a very powerful prescription for social action.

88. Se日 Grubb and Lazerson, B프kㅡㄹㅡ_P포요토톹. p. 114. 


\section{CHAPTER FIVE}

\section{U.S. CHILD GUIDANCE DEMONSTRATIONS: MEDICALIZING MALADJUSTMENT}

The Commonwealth Fund Programme

The concept of the prevention of delinquency was to spiral outward and away from the juvenile courts toward the school, family and community. The proposals of the National Committer for Mental Hygiene which were largely developed by Thomas Salmon took their ultimate form in the work which grew out of the Lakewood and Gedney Farms Conferences. In this process the basis was laid for the legitimation of an applied psychiatry of abnormal mental and emotional processes in childhood. The transformation of the joint project of the Commonwealth Fund and the National Committee Program for the Prevention of Delinquency is taken up in this chapter. Proposals for research on the psychopathology of delinquency have made substantial contributions to a psychiatry of infancy, childhood and adolescence. Psychiatric perspectives have in turn influenced the professionalization of ather related disciplines in social work, psychology and education.

In April 1921, Salmon consulted with Commonwealth Fund directors on the Lakewood proposals. That November a five-year programme was formally adopted which was put into operation in December of 1921. 1 Four divisions were created to overseg the study of methods for the prevention of delinquency. The effort was to coordinate demonstration field clinics with the training

1. Arthur H. Ruggles to Edward S. Harkness. 7 June 1924. Thomas Salmon Papers 4, 5. AFHH Archives, Payne whitney Clinic Library, CMC, NYC. 
of profesalonal ataff. This was specifically to include the training of psychiatric social workers and to expand visiting teacher programmes to introduce mental hygiene into educational practice in schools.

The first division created was a Bureau of Child Guidance under the auspices of the New York School of Social work. The Bureau was initially directed by Bernard Glueck. The intention was to train fifte日n social workers a year in mental hygiene and psychiatry. Training was done in conjunction with course work, field work, demonstration treatment clinics, and community gervice.

Glueck's reports for the first two years indicate the underlying concern with delinquency. However, the therapeutic focus was on "the strong emotional qualities" of the parentchild relationship. Glueck pursued this perspective in a presentation to the American Psychiatric Society on the "nervous child." Glueck felt that a "significant conclusion which a reading of our records leads to, is that we are discovering, and actually putting into practice on a fairly large scale, the means for the eradication of the evil influences upon the life of childhood." 2 One hundred children were treated the first year. Over the next five and a half years 1.050 children received consultation services, 822 were received for treatment, and 591

2. Bernard Gluegk, "Annual Report of the Bureau of Children's Guidance," 22 December, pp. 2-34; "Memorandum from Dr. Glueck covering the work of the Bureau of Children's Guidance as of October 1, 1923," CF 65, RAC, N. Tarrytown N.Y. 
cases were completed. Lying and disobedience were the most common "symptoms of misconduct" cited, with the amorphous designation, "facial grimaces" and "bunking out" the least common reason. Morbid fears, depression, and shyness figured more prominently than "conflict with the law." The latter category was separate from the more likely referrals for "disorderly conduct in school" and "stealing." Eighteen public schools had been served with the cooperation of 4 churches, 5 hospitals, and 23 social agencies. The families of patients and clinic staff appraised the outcome of therapy as successful in approximately half of 61 cases in an in-house survey. 3

Registration for the training program topped 2,504 classes with 944 different students enrolled in courses. Courses included social psychiatry, psychiatric social work, psychopathology, case conference, clinical psychiatry, mental testing, and personality differences. 4 Over two hundred students were involved in field work. The School was credited with 39 graduates in mental hygiene. The Commonwealth Fund provided 70 fellowships during the

3. "Preliminary Report to the Commonwealth Fund from the New York School of Social Work on the Operation of Division I of the Delinquency Program During the Period Deo. 11921 to June 30, 1927, CF 65, RAC, N. Tarrytown, N.Y.

4. "Annual Report to the Commonwealth Fund on the Operation of the Bureau of Children's Guidance by the New York Schaol of Social Work as Section I of the Program for the Study of Methods for the Prevention of Delinquency Covering the Year 1924-1925," pp. 4-6; Porter R. Lee, "Annual Report of the New York School of Social Work to the Commonwealth Fund on the Operation of the Bureau of Children's Guidance as Section I of the Program for the Study of Methods for the Prevention of Delinquency Covering the Year Ending September 30, 1926," pp. 4-5, tables I and IV. CF 65, RAC, N. Tarrytown, N.Y. 
winter terms and 36 summer fellowehips. 5

The work under Porter R. Lee. Director of the New York

School of Social Work, and Marion E. Kenworthy, who took oyer the Directorship of the Bureau after Glueck, championed the development of an applied peychiatry of child life. Marion Kenworthy developed what she called an "ego-libido analysis of case material." The Bureau held twelve conferences which exchanged psychiatric theory on problem children on an international basis. During the mid-twenties in Europe, Anna Freud and Melanie Klein, were independently applying psychoanalytic theory to children.

In 1927, at the end of five years work the Bureau was concluded as a demonstration and an Institute for Child Guidance was created which operated until 1933. The elaborate training programme for psychiatric social workers continued with supervisors from the New York School of Social Work and Smith College. The emphasis remained on the role of parents especially mothers and case-based psychiatric therapy. 6

A second section of the Commonwealth Fund programme created a National Committe日 on Visiting Teachers in affiliation with the Public Education Association. The purpose was to expand mental hygiene wark in the classroom. Many of the visiting teachers were

5. "Preliminary Report." pp. 1-3.

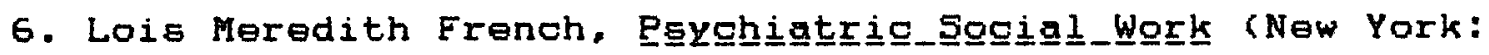

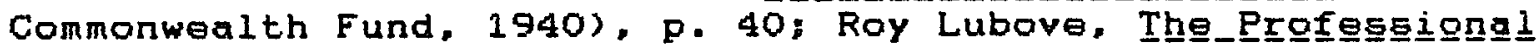

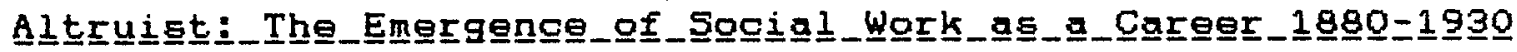
(New York: Atheneum. 1969), pp. 98-99. 
actually trained in peychiatric social work. Howard $w$. Nudd, Director of the P.E.A. also served as committee chairman. The work was seen as "educating teaching staff into a different attitude toward children." Publio School 64 was the early site of this cooperative project. The programme was run by Jane culbert, staff executive of the P.E.A. section on visiting teachers. The objective of the visiting teacher programme was to extend preventive work similar to that of the psychopathic clinics attached to Juvenile courts into public schooling. 7 Schools were viewed as natural mental hygiene laboratories.

School age maladjustment in the classroom was interpreted as contributing to delinquency in adolescence and insanity and criminality in adulthood. The solution to school problems were to be turned around through teacher intervention. The purpose of schooling was reinterpreted to make children happy and healthy. The acquisition of knowledge in academics was considered secondary and occasionally detrimental to mental health. Teachers in this view had to become expert mental hygienists. This required a different kind of professional education for teachers if schools were to successfully function in correcting processes of childhood socialization. Visiting teachers were to provide

7. Barry C. Smith, "Report of the General Director, November 1921, Child Welfare. Program for the Prevention of Delinquency," p. 35, LSRM 3, 111, 1113, RAC, N. Tarrytown, N.Y: for a good source on the courts se日. Katharine F. Lenroot and Emma 0 . Lundberg. "Juvenile Courts at Work: A Study of the Organization and Methads of Ten Courts." in U.S. Department of Labor,

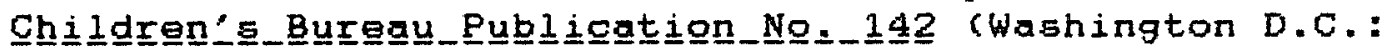
Government Printing, 1924), p. 97. 
on-aite training and conaultation aervices for classroom teachers. The conceptual rationale was to instill in teachers progressive ideas on the mental and emotional life of children.

The complexity of the commonwealth Fund programme made it necessary to create a coordinating body. This was to be done by a Joint Committes on Methods of Preventing Delinquency which was established as an executive policy making board designed to overse日 the various aspects of the child guidance programmes. The Joint Committee was to consist of Thomas Salmon of the NCMH; Bernard Glueck of the Bureau of Child Guidance: Harold R. Lee of the New York School of Social Work; and Harold W. Nudd representing the Public Education Association. 8 The primary concern of the Joint Committee was to coordinate the training work of the Bureau and the visiting teacher programme of the P.E.A with the creation of demonstrations in child guidance and the proliferation of actual clinics.

The establishment of demonetration clinics was the most important part of the programme. This aspect of the work was to be carried out by the National Committee for Mental Hygiene. A Division on the Prevention of Delinquency was organized along with a Department of Experiment and Demonstration and a Department of Psychiatric Field Service. The work of this division of the Commonwealth Fund Program was to demonstrate on a grassroots level the applicability of psychiatry to problems of delinquency. This was to be done by establishing and operating

8. Smith, "Report of the General Director," p. 32. 
child guldance clinics in local communities. This made local cooperation and eventually local funding emphatically important. These clinics were intended to serve as models for more permanent clinics to be established and operated by local organizations at the end of the demonstration.

The Commonwealth Fund's part in the child guidance elinic work was to provide monetary support and to act as a consultant in policy. The National Committee for Mental Hygiene was to oversee the actual operation of the clinics. The Commonwealth Fund originally provided $\$ 15,000$ a year for the maintenance of the NCMH Division on the Prevention of Delinquency and $\$ 26,000$ a year for a field service. The expansion of the work is illustrated by the fact that by 1924 these budgets had increased to total $\$ 140,000$ a year. 9

From the Prevention of Delinquency to

Community clinios

The objective of the National Committee for Mental Hygiene and the Commonwealth Fund Program on the Prevention of Delinquency was to demonstrate the usefulness of applied psychiatry in solving the social problems of criminality, insanity and adult dependency. 10 Child guidance clinice were to provide a community educational service as well as to train

9. Arthur H. Ruggles to Edward 5. Harkness, 7 June 1924, Thomas Salmon Papers 4, AFMH Archives, Payne Whitney Clinic Library, CMC, NYC.

10. "The Mental Hygiene Program of the Commonwealth Fund and Some Evidence of its Value," (typescript), pp. 2-5, CF 66, RAC, N. Tarrytown, N.Y. 
mental hygiene professionala. They were alao intended to stand as protocols for the development of public policies. The clinics over the course of the demonstrations detached themselves from the juvenile justice system. As they did so they focussed on community services and intervention into family life. Field consultant and subsequent director of the NCMH Division on Community Clinics, Gsorge S. Stevenson, noted that the therapeutic approach relied heavily on treating the parent and to that extent appeared to fall in the field of adult psychiatry. 11 However, it was the parent-child aspect of mental hygiene which became elaborated into child and community psychiatry. The functions of staff were clarified in the development of a tridisciplinary model of a psychiatrist as director, at least one psychiatric social worker and one or more psychologists. At the beginning of the demonetrations it was hoped that all personnel would have a broad background in "biological training." Clinics also pursued the intrusion of mental hygiene into the curriculum of related disciplines especially education and social work. This was actively supported with fellowship grants from the Rockefeller Foundation and the Commonwealth Fund. 12 The

11. George S. Stevenson and Geddes Smith, eds., Ghild

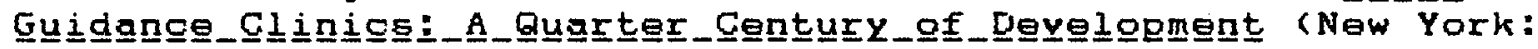
Commonwealth Fund, 1934 ). The Division on Community Clinics was the continuance after 1929 of the Division on the Prevention of Delinquency.

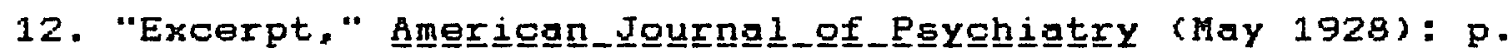
1075; Commonwealth Fund. "Prevention of Delinquency Program Mental Hygiene," 9 September 1927; "Proposed Budget NCMH 1925," all in CF 65, RAC, N. Tarrytown, N.Y.; also see George $E$.

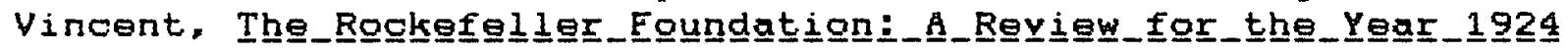


Individual cage gtudies which comprised the clinical experiment also served an educational function. Records on 3500 case studies were accumulated to be used as "scientific human studies," and "research material." 13

In 1922 in preparation for the Program for the Prevention of Delinquency, the NCMH sent out questionnaires to over 200 Juvenile courts. 14 Applications were solicited for the development of juvenile court psychiatric services to be provided by the National Committee with appropriations from the Commonwealth Fund. Formal requests were received from Norfolk, Virginia; St. Louis, Missouri; Washington D.C.; Buffalo, New York: Savannah. Georgia: Birmingham. Alabama: Los Angeles, California; and Springfield, Massachusetts.

Thomas Salmon was made Chair of the committee to decide on the location of the demonstrations. The committee also included Judge Charles W. Hoffman of Cincinnati, J. Prentice Murphy of Philadelphia and Emma Lundberg who was with the federal

Children's Bureau. Lundberg was an active researcher for the Bureau, contributing to numerous Bureau publications which helped to disseminate information on the children's courts and olinics. At the December meeting it was decided that it would be useful to

(New York: Rockefeller Foundation, 1925), pp. 23-26, 38 .

13. "Report on the Work of the National Committee for Mental Hygiene," p. 4, CF 65, RAC, N. Tarrytown, NY.

14. Commonwealth Fund, "Minutes of the Jaint Committee on Methods of Preventing Delinquency," 22 February 1922, CF 376. RAC, N. Tarrytown, N.Y. 
keep records of "favorable comments concerning the work of the section" to be used in later evaluations and for educational purpases. 15 These favourable comments evolved into the elaborate publishing programme of the Commonwealth Fund which was fundamental to diseeminating mental hygiene and psychiatry in this century. One report cites a total of 94,949 copies of mental hygiene literature diftributed by May 1, 1928. 16

The education programme and literature helped popularize mental hygiene for both lay and professional constituencies. The expansion of auxiliary personnel in mental hygiene related fields enhanced this effect. Ironically the growth of professional psychiatry could not match the more widespread growth of social work and psychology. Nevertheless, in the United States psychiatric and psychoanalytic orientations began to infiltrate the social and behavioural sciences. As these workers came to dominate olinical practice they brought a simplified psychiatric perspective with them into the field. While mental hygienists deliberately extended the psychiatric medical model into social work, nursing, and teaching, it was originally intended that medigal personnel would serve as the ultimate leaders. The

15. Commonwealth Fund, "Minutes of Joint Committee on the Methods of Preventing Delinquency," 26 April 1922, CF 376; Also

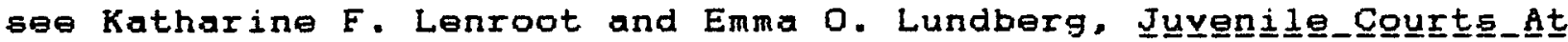

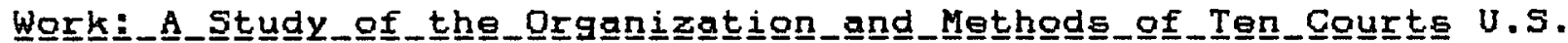

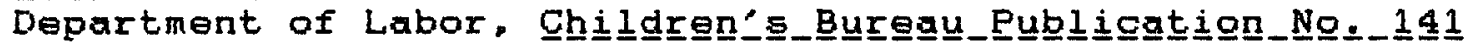
(Washington D.C.: Government Printing, 1923).

16. "List of Publications Published by the NCMH," November 1927 LSRM 3, 35, 368; "The Mental Hygiene Program of the Commonwealth Fund and Some Evidences of Its Value." pp. 13-4. [probably 1928], CF 66, RAC, N. Tarrytown, N.Y. 
problem of maintaining this ideal cen be seen from the earliest demonstrations.

The clinical demonstrations were experiments in the implementation of public policy. An evolution can be seen in the programme format, organization of the clinic in relationship to patients and community services, and in therapeutic orientation. Early unstable short term demonstrations related to the juvenile court hardly resemble the sophisticated community coordinated services of the later projects. The National Committee for Mental Hygiene and Commonwealth Fund staff and consultants adjusted the programme as they went along. Child guidance was shaped by practical consideration of what worked and what did not. Social and economic conditions in the 19205 and 19305 resulted in a boom-bust effect. Several clinics elosed in the 1930s. Even the fact that clinical psychiatric services for children remained largely inadequate or absent in the inter-war period, the spread of the mental hygiene model for social action extended both geagraphically and temporally well beyond the eight demonstration sites and the permanenticlinice that became their legacy.

The firet demonstration set up the long term issues confronting community clinics in child guidance. The major consideration in terms of organization was to pick the site. This was ultimately related to establishing a context likely to result in the creation of a permanent facility. Funding was a perennial problem centering on whether public or private funds would support the service most reliably. In terms of operating the 
clinic, personnel problems were paramount. Providing trained personnel with support services placed priority on the nesd for peychiatrists. The lack of poyohiatrists resulted in an emphasis on training programmes for auxiliary personnel and the increased use of social workers and psychologists. The therapeutic approach undertaken by a clinic was related to the training of personnel.

\section{St. Louis: The Juvenile Court and Child Guidence}

st. Louis, Missouri was chosen for the first demonstration since volunteer psychiatric work had been carried out in the juyenile court for fourteen years. The demonstration also had the strong support of the president of the Missouri Society for Mental Hygiene, the juvenile court judge, the public health department, probation officer and other social organizations. 17 The demonstration was to last eight months beginning in April 1922.18

The st. Louis demonstration modeled the staff ideal of a psychiatrist, a psychologist, and psychiatric social worker. This three-fold personnel arrangement was developed by Thomas Salmon and his assistant at the National Committee, fellow prychiatrist V.V. Anderson. The hiring and organization for the demonstration was actively pursued by Salmon and Anderson in the early stages

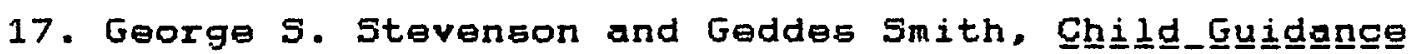

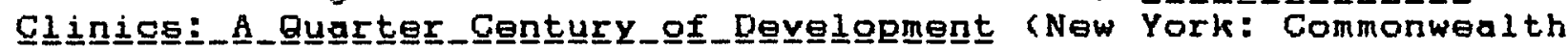
Fund, 1934$)$, pp. $23-26$.

18. E.G. Steger, et al, "The Psychiatric-Child Guidance Ginic: A Study by the Department of Health of the Community Council, St. Louis, Missouri," n.d. received by the Commonwealth 8 January [presumably 1925], GF 66, RAC, N. Tarrytown, N.Y. 
of the work. 19 They hired psychlatrist Thomas Heldt to direct the clinic with the assistance of psychologist E.K. Wickman, and psychiatric social worker Mildred Scoville, as well as a secretary and record clerk. Scoville later left clinical work to become an executive assistant with the Commonwealth Fund. The methods of operation developed by Salmon and Anderson were intended to serve as models for future demonstrations.

To procure patients, invitations were extended to circuit court judges, the chief probation officer, directors of social agencies as well as private charitable agencies and hospitals to recommend patients. Long term support was also elicited from these agencies. The National Committee hoped to set up a regional traveling service as well as set the ground work for a permanent peychiatrio clinic for children. Thre日 hundred cases were se日n by the clinic during the demonstration. 20

The NCMH demonstration in St. Louis came to an end in December 1922, and the staff of the NCMH was sent on to the next demonstration. For a short time after the demonstration the work was continued by volunte日rs. Supplies and a secretary were donated by members of the St. Louis Medical Society. NCMH and

19. V.V. Anderson and Thomas W. Salmon, "Address on the Work of the st. Louis Clinic" presented to the American Association for the study of Feebleminded, in St. Louis, cited in Commonwealth Fund, "Minutes," 24 May 1922, CF 376, RAC, N. Tarrytown, N.Y.

20. Commonwealth Fund, "Minutes," 22 March 1922, 24 May 1922, p. 77, CF 376, RAC, N. Tarrytown, N.Y. 
Commonwealth Fund executives served in a consultative role. 21 In Maroh of 1923, a city ordinance authorized the establishment of a permanent psychiatric clinic. In May, the demonetration clinic was taken over by the Department of Public Welfare with a permanent staff and advisory board. 22 The advisory board hoped to be able to serve four groups, the courts, schools, volunteer social work agencies, and the public at large through classes in parent training. It became apparent that the elinic primarily served the court and that it could not adequately indulge in services to groups outside of the courts. 23 Funding and staffing difficulties plagued efforts to follow-up the clinical reports into school and family spheres. The NCMH and the Commonwealth Fund continued to provide consultative services and to evaluate the clinic throughout the 19205 and into the 19305.

The st. Louis clinic was not considered ideal in the eyes of the National Committee. NCMH officials tried, however, to look on the bright side in that "we should not be entirely pessimistic regarding this clinic. Although it is undoubtedly poor in comparison with other olinics established under the Fund's programme, [Stevenson] feels it is probably very much better than about 40 to 50 per cent of all the clinics listed in the

21. E.G. Steger, "To the Consultant Staff of the Psychiatric-Ghild Guidance Clinic." p. 2, CF 66, RAC, N. Tarrytown, N.Y.

22. Steger, "To the Consultant Staff."

23. Steger, "To the Consultant Staff." 
Directory." 24 Much of the problem was with personnel. The permanent Director, William Nelson, was considered to be inadequate in training and scientific knowledge even though he was dedicated and active in the etate mental hygiene society. NCMH officials felt that "while his background and insight are insufficient to build this clinic up to the level it should reach, he is active within these limitations." 25

Evaluating clinical personnel was a common practice. The National Committee and Commonwealth Fund took an active part in recruitment to positions and hiring in the various clinics across the United States. Reputations were fostered and spheres of influence widened for favoured individuals and the reverse was true for less favoured individuals. Often however, there was little choice in that there were so few trained professionals. especially in peychiatry. Reports on the clinics and memorandums by National Committee for Mental Hygiene and Commonwealth Fund employees Eerved as a cumulative record file in an informal employment service useful for distributing fellowships as well as trained personnel. 26 It was a method of regulating the quality of applicants and training programa. It was not always successful.

24. Barry C. Smith, "Conference with Dr. Stevenson and Miss Bassett," 12 March 1929. CF 66, RAC, N. Tarrytown, NY.

25. "Report of the Division on Community Clinics of the National Committee for Mental Hygiene July 1, 1927 to October 1, 1927," p. 5, CF 66, RAC, N. Tarrytown, N.Y.

26. Milton E. Kirkpatrick to M.C. Scoville, 21 April 1941, CF 67, RAC, N. Tarrytown, N.Y. 
In addition to personnel problems, the St. Louls clinic also had problems with an uncooperative governing board and intrusive city politics. The clinic was threatened with collapse in 1925 and 1926. It was not until 1927 that the budget was passed by the city council without a question. The clinic was severely cut in the depression and finally closed as a psychological service in child guidance in 1933. 27

Case study records from the st. Louis demonstration reveal a therapeutic procedure which included a descriptive life histary report, physical examination with psychological testing and a peychiatric interview. The results of the clinical examination in court-referred cases were given back to the court where 74 per cent of the referrala orlginated. The outcome of the demonstration supported salmon's claim that prevention had to occur before the juvenile court stage. Case records seemed to indicate that children coming into the court had previous records of misconduct in the records of schools and other social agencies. This perception was significant for it encouraged within the preventive framework a concentration on schools and social service agencies to catch pre-court delinquency.

Examples of the clinical case reports show little to substantiate the sensitivity of the conclusions of the case workers in their identification of predelinquents. The following description is taken from a case report submitted by William Nelson, the

27. Mildred Scoville to Barry C. Smith, "Memorandum, Re.: Interview with George Stevenson," 13 June 1932, CF 67; RAC, N. Tarrytown. N.Y; Stevenson and Geddes, Ghild__Guidgngeg p. 26. 
clinicel Director.

A 12 year old boy was referred to the olinic by an unstated agency for being "disobedient and stubborn." He had recently completed the sixth grade. His parents were Greek immigrants. His mother never learned to speak English. There werg seven children in the family one of whom was physically handicapped. His father owned a pool hall and thus had a steady income at what was sern as a dubious enterprise. The "harmany" of the home was credited as "excellent." A physical exam noted that he had flat feet and poor vision in one eye though in general he was "well developed and nourished." During the psychological interview he tended to be "inattentive" and he performed poorly on grammar and abstract vocabulary tests. The psychiatric interview states that he was generally responsive. friendly and honestly answered questions. The report noted that he confessed that "he has smoked cigarettes some, but has nat gambled. He admits masturbation, but denies heterosexual experiences. He is fonder of his mother than his father. He wante to be a locomotive engineer." 28

The diagnosis was that the child was afflicted with

"borderline feeblemindedness" and had discernable "character difficulties." The fact that he had made average progress in the sixth grade was given less credence than the fact that he scored closer to a fifth grade level in the psychological exam probably due to his poor grammar and vocabulary. These deficiencies were not surprising considering his dual language background. Instead of taking into account the case history as a mitigating factor influencing the scores on standardized tests, he was placed at a mental age of 9 years 7 monthe which put him in the borderline category of an I.Q. of 76. The summary of the report emphasized that it is doubtful his mental capacity could be stretched beyond

28. William Nelson, "Report of the Psychiatric Clinic," 18 August 1925, pp. 1-4, GF GG, RAC, N. Tarrytown, N.Y. 
the aixth grade and that vocational training "ahould embrace the limits of his constructive imagination." 29

In spite of the "harmony" of his home the report is critical. "The tendency to over-indulge him is excessive" and it "is desirable that an Americanization programme be introduced." His association with older boys and his mother's lack of English were cited as emotionally traumatic. "It is doubtful that much improvement will result in him unless the home situation is changed, and it is recommended that he be placed in a foster home and an attempt be made to rehabilitate the [family]." 30 It is unclear from the report what if any recommendations were followed in this case. It is apparent, however, that there were considerable discrepancies between procedural formats and the capability of staff in carrying out recommendations in practice. Evidence of the long term impact of this olinic is provided by a 1966 follow up study done on the St. Louis Municipal Child Guidance Clinic. Five hundred and twenty-four children seen between 1924 and 1929 were located to find out the $k$ inds of problems they had developed as adults. 31

29. Nelson, "Repart," p. 4.

30. Nelson, "Report."

31. The group when found had a median age of 43 years. The researchere tried to interview all of the individuals rather then rely on hospital records or established reports of psychiatric histories. Five per cent of the subjects located were determined to be schizophrenic which is fully five times the expected or normal incidence rate of schizophrenia in the general population.

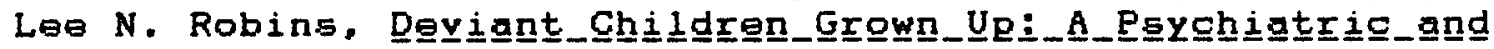

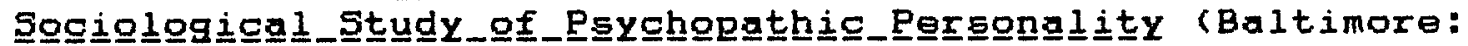
Williams \& Wilkins. 1966), pp. 239-244. 
The concluaions of the study were threefold. It was

determined that antisooial behaviour in childhood was a "powerful predictor of poor adult outcomes." Secondly, researchers found social class was not a predictor of adult failure. 32 It is interesting to note, in relationship to this second conolusion. that factors which correlate with class such as educational level and job level attained in adulthood did emerge as significant predictors of adult mental problems. The children in the st. Louis sample who grew up to be identified as troubled were found to have achieved low educational standing and subsequently went into low-paying and low-status jobs and consequently had achieved a relatively low class standing. 33 Finally, children with mild disorders but whose father was antisocial greatly increased their chances of a "poor outcome." 34 A loosely constructed control group of children in the public schools who did not get into trouble as children and therefore were not remanded to the clinic were found to have grown up to live normal lives relatively free of divorce, hospitalization and crime, in spite of a similar

32. Robbins, Devilant

33. See Auguet B. Hollingshead and Fredrick C. Redlich,

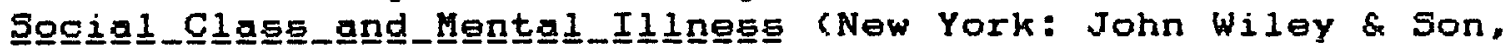
1965), where significant differences are found between class position and diagnosis and treatment of mental iliness. However, schizophrenia tended to have the same incidence across class lines, pp. 226-7. On class and life cycle differences se日 pp. $360-7$.

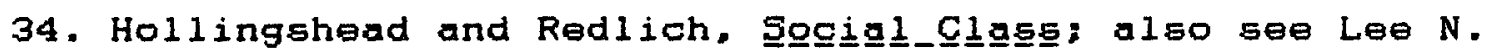
Robbins, "Antecedents of Character Disorder," in Merrill Roff and

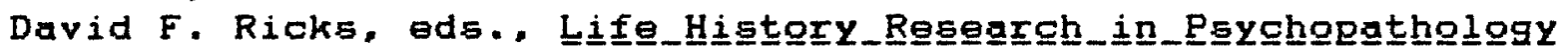
(Minneapolis: Univ. of Minnesota Press). pp. 226-239. 
economic standing as children in the clinic group.

This study tells us something about the long term consequences of clinical treatment in childhood as much as the effects of original predispositions to mental illness. The study underscores belief structures about the life chances of children who come before Juvenile courts and whose mental and emotional status came into question in childhood. The follow up also brings into question the consequences of intervention which contributed to specific outcomes. It is interesting that individuals once preselected as having had maladaptations to what was considered acceptable behaviour remained at high risk for reselection years later.

\section{Norfolk: City Demography and Successful Clinics}

The second clinic opened in Norfolk, Virginia in 1923. This clinic is considered to be the sole failure of the demonstrations. It was concluded that a child guidance clinic was too Epecialized a service for a relatively small community. By the NCMH's belated demographic assessment, Norfolk did not reach a population level conducive to the support of a clinic far another twenty years. The population was 115.777 in 1920.35 The Norfolk experience seemed to suggest that small cities or rural areas had to be especislly well-represented by sympathetic local agencies and financial resources in order to to sustain a stable

35. George 5. Stevenson, "Child Guidance and the National Committer," In Lawson G. Lowrey and Victoria Sloane, eds..

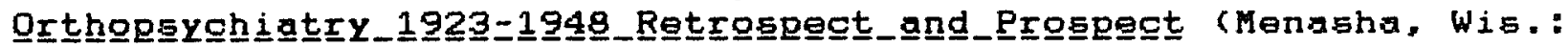
George Banta Publishing for the American Orthopsychiatric Association, 1948), pp. 66-67. 
permanent clinical service in poychiatry. 36

During the demonstration the clinic seemed to function well. The clinic was directed by Bruce B. Robinson, a graduate of Harvard Medical School with psychiatric training at the Boston Psychopathic. He had served as the Chief of the Neuro-Psychiatric Division in New York City and in the U.S. Veterans Bureau. 37 Of the 247 cases cited by Stevenson the largest group seen in the clinic or thirty-two per cent were from the juvenile court: 38 Anderson as head of the NCMH Division on the Prevention of Delinquency cites in his annual report that 84 cases were handled the first month with 310 cases over the eight months of the demonstration. Close to two hundred of the children studied were said to have improved their behaviour and adjustment to school conditione. The majority were under ten years old and approximately one-third tested "supernormal - their difficulties being in personality rather than the intellectual field." 39

social service exchanges were established with students from Smith College along with volunterr psychiatrists and a probation officer. Still, the greatest problem with the Norfolk demonstration was an inability to properly do follow-up work. This was attributed to the "exceedingly poor grade of social work

36. Stevenson, "Child Guidance," p. 1.

37. V.V. Anderson, "Report of the Division on the Prevention of Delinquency From November 1, 1922 to November 1, 1923," LSRM 3. 35, 368, RAC, N. Tarrytown, N.Y.

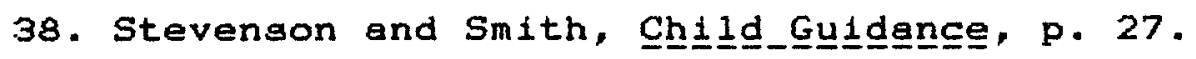

39. Anderson, "Report of the Division," pp. 14-15. 
done by the local agencies." 40

The greatest contribution of this clinic was in the attempted use of local facilities and volunteers including the Bar Association, Medical Society, Women's Clubs, Parent-Teacher Associations, central council of social agencies, home and school leagues, churches and nursing associations.

The downfall of the clinic was that it was confronted with major political opposition which resulted in financial problems after the demonstration. The mayor and city council had promised to provide \$12,000 for the continuance of the clinical service. However, the city manager opposed the clinic. Anderson describes the city manager as "a very unreasonable person, who took pride in saying that he thought all social workers were croaks." 41 The Director of Public Welfare opted for a smaller part-time clinic with a budget of under $\$ 9,000$. This was opposed by the NCMH and further plans for a clinic were tabled by the city council. 42 A traveling unit operated by the state intermittently served Norfolk into the 1930 .

\section{Dallas Child Guidance and the Community}

The NCMH decided that preplanning for a demonstration would eliminate failures. The Dallas demonstration was well-planned. Dallas, a city of 200,000, was chosen and educational work in the community was initiated prior to the opening of the elinic.

40. Anderson, "Report of the Division," p. 14.

41. Anderson, "Report of the Division," p. 16.

42. Anderson, "Report of the Division," p. 18. 
Pledges were secured in writing and agreements with organizations and the operation of the clinic specified. The voluntary and cooperative efforts of local professionals and university personnel paved the way for more formal contact between professional training in mental hygiene in related fields and clinical contact in the community. The trend toward community involvement in prevention was to become a permanent feature of clinical practice.

The Dallas demonstration was successful because it was innovative. It moved clinical services away from the courts toward a substantial preventive model in community services. It had strong community and regional support including two local universities, Baylor and Southern Methodist. By 1927, 1,535 children had passed through the demonetration elinic. 43 Only 4.9 per cent of the clients were referred from the court. The largest number, fully 54.6 per cent were referred from relatives. This made the clinical service significantly less court-oriented and more clearly directed toward clinical community service. 44 Due to previous problems with public financing and political quarrels, private financing was arranged after the demonstration through the community chest. The demonstration was not without other problems over control of personnel, resources and policy but these were resolved without permanently damaging the

43. "Dallas Child Guidance Clinic." CF 66, RAC. N. Tarrytown, N.Y.

44. "Dallas Child Guidance Clinic." 
viability of the clinic. 45 In 1927 the NCMH placed E.M. Perry, one of the Commonwealth Fellowship trainees, in the Directorehip of the olinic. NCMH and Commonwealth Fund spokesmen kept up correspondence with him on the progress of the work. 46 Child guidance was moving out of the court room and toward the sohool room.

\section{Twin C1t1es Demonstration:}

The University and Public School Connection

The dual problems of permanent funding and the availability of permanent adequately trained personnel remained the majar persistent issues to be resolved in clinical procedure. One of the solutions to these problems were attempted by following the Dallas example and Salmon's early prescription for connecting the clinic with a University.

At the time of the Dallas demonstration the Minnesota legislature authorized an educational programme in preparation for the establishment of a psychopathic olinic in the Medical School. The University of Minnesota's medical school was one of the more advanced in the country. Minnesota was one of the few public institutions to receive a hearty recommendation in Abraham

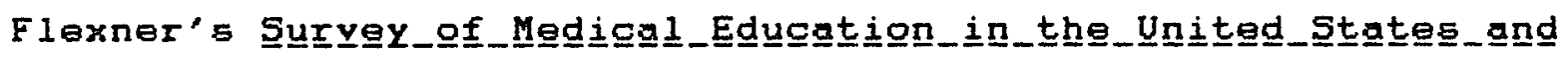

45. Barry C. Smith to Harold I. Gosline, 6 August 1925 , attached: "Report of Study of Dallas Child Guidance Glinic Made at Request of Its Board of Directors," 27-30 July 1925, initialed by Ralph P. Truitt and Lawson G. Lowrey, CF 66, RAC. N. Tarrytown, N.Y.

46. "Report of the Division of Community Cinics of the National Committe日 for Mental Hygiene July 1, 1927 to October 1, 1927," p. 5, CF 66, RAC, N. Tarrytown, N.Y. 
Cennada for the Carnegie Foundation in 1910. 47

The University demonstration was to serve Minneapolis and St. Paul as a one year demonetration beginning in November 1923. The clinic was directed by Lawson $G$. Lowrey with an experienced field staff transferred from Dallas. Ginic staff simultaneously taught in departments of psychology, education, medicine or sociology at the University. Fully thirty-nine social workers spent up to three months at a time in supervised training in psychiatric social work, three fellows in psychiatry, two psychologists and six social workers as well as volunteers provided more than adequate personnel.

This clinic, for the first, time established professional standards for staff and provided trained personnel to meet these standards. The first training of Fellows in Psychiatry was pioneered by this demonstration. This olinic also used students

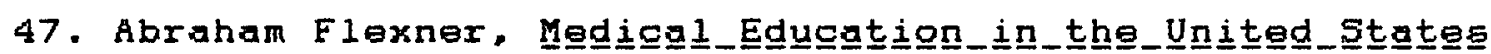
and_Canglada Carnegie Foundation for the Advancement of Teaching. Bulletin Number 4 (New York: Carnegie Foundation for the Advancement of Teaching. 1910). Minnesota was advanced in public health efforts for sanitary control and hygiene, olinical work with mental retardation. This was due to the leadership of the University Presidents: Cyrus Northrup, George E. Vincent (later President of The Rockefeller Foundation), James R. Angell, (later President of Yale); and. Dean of the Medical School: Frank Wesbrook (later President of the University of British Columbia). Al1 of whom advanced scientific medicine in the University. Frederick Kuhlmann, G. Stanley Hall's student, taught at the University of Minnesota in 1903. In 1910 he became Director of Research at the Minnesota school for the Feebleminded at Faribault. In 1922 his department was moved to st. Paul as the Research Bureau of the Minnesota State Board of Control (1ater Bureau of Mental Testing). Kuhlmann pioneered standardized intelligence tests for infants and children aged 3 months to fifte日n years. 
with paychiatric training from Smith College School of Social work to a greater advantage than any previous clinic. This set a model of cooperation for specialized training in localized settings which cooperated on a national basis in providing experts in specified areas.

The demonstration made a contribution in organization by being the first to have an intimate relationship with a school district. Lowery was able to take advantage of the fact that public school officials in Minneapolis had expressed an early interested in child guidance.

Six hundred and ten cases were studied during the demonstration. Thirty seven were referred from social agencies, twenty-five from parents or relatives and nineteen percent from the public schools. The juvenile courts did not refer individuals except through the social agencies. 48 This appraach emphasized researoh and community work rather than inetitutional and legal systems which concentrated on pathology.

Efforts to provide a permanent clinical service out of the University of Minnesota were not succeseful. It was thought that this would be possible when in 1923, the legislature appropriated $\$ 15,000$ for mental hygiene. George stevenson initiated a traveling service with regular branches in Duluth (st. Louis County) and at the Teachers College in Mankato (Blue Earth County). A central clinic was to operate out of the university. These olinics were to utilize peychiatric social workers and

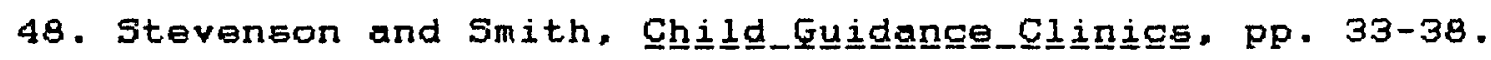


public health nurseg in cooperation with the Child welfare Board and to service rural areas on a rotating basis. These efforts were terminated June 30,1925 when the legislature was not. forthooming with an appropriation. 49

Plans for a permanent olinic in Minneapolis were initiated before the end of the University demonstration. The permanent clinic was organized as a part of the public school system not the juvenile court system. Joint funde were secured from the public schools, the local department of public welfare and the community chest in addition to funds from a local philanthropy interested in public health, the Amherst H. Wilder Charities.

In 1924 a school survey was conducted. The firet stage of the survey consisted of a rating sheet filled out by teachers. The children were individually rated on 37 personality traits on a descriptive scale with five alternatives. Questions ranged from perceived intelligence to behaviour characteristics and attitudes toward peers and authority figures. For example, question 19 asked the teacher to rate the child's personality as "repulsive." "disagreeable," "unnoticed, colorless," "colorful," or "magnetic." 50

From the results of this survey problem children were eingled out for extensive interviews with the teacher, parent and child. The child was given a physical examination and

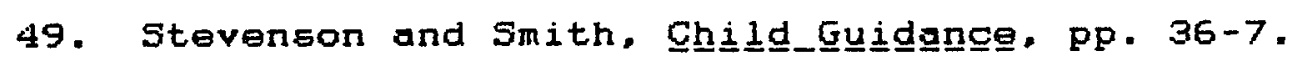

50. "Instructions for Using the Rating Scale" and attached "Case Reports, Longfellow School Survey, Minneapolis, Minnesota, 1924," GF 66, RAC, N. Tarrytown, N.Y. 
psychometric tests. Six children were singled out in the kindergarten and low first grade. Of these there were five boys and one girl. The most common complaint was for hyper-activity, fatigue, and talkativeness which translated as "Jabbering" on the rating sheet. 51 Two of the children were seen as seriously emotionally disturbed with constitutional elements cited by the investigators as contributing to their instability. 52 The essential difference in the reports for these two boys in comparison with the children cited as having mild problems were that they had parents who were typed as over attentive. Both children were recommended for removal from their parents home if conditions were not improved. One child was, in fact, sent to live with an aunt and uncle as a result of the report. The girl who was recommended because of stealing was the only child determined to be essentially normal. This is the only instance where punishment was recommended. The parents were cited as uncooperative in two cases. One mother refused to come to the school to discuss the report. In another case, the "over attentive" parents of the "worst boy" refused to accept the seriousness of their son's emotional problems. 53

The staff of the Minneapolis clinic included smiley Blanton as director and Florence Goodenough as psychologist. Goodenough

51. "Instructions for Using the Rating Scale."

52. "Case Reports, Longfellow School Survey. Minneapolis, Minnesota. 1924," CF 66, RAC, N. Tarrytown, N.Y.

53. "Case Reports." 
became well known for her paychometric teata for preschool children such as the Goodenough Draw-A-Man Test. Blanton continued in the child guidance field participating in the Los Angeles demonstration clinic. The first book on child guidance was written out of the experiences of the Minneapolis clinic. Thomas Salmon wrote a preface for the volume explaining the importance of the work. 54

Case studies from the clinic described by Blanton illustrate the psychoanalytic theoretical perspective which was combined with behavioural therapies involving basic health regimentation and "habit training." Adjustment was explained in terms of a conflict between "ego and the group." Authority structures which elicited "repression and expression" had to be moderated by the clinician to offeet negative influences of the problem parent, especially the mother, on the potentially problematic child. The "nervous child" was the result of unfortunate psychological environments. The effort was to try to avoid removing the ohild from the home if possible and to concentrate on successfully regulating the parent's behaviour. Secondarily the clinic sought to change the classroom teacher's behaviour toward the child and to monitor the child's activities outside of the home without interference from parents. 55 Most of the children were

54. Smiley D. Blanton and M. G. Blanton. Chịild_Guidgange New York: Gentury, 1927; Also typesoript of Salmon's introduction dated 12, 15 December 1926, Thomas Salmon Papers 4, 7, AFMH Archives, Payne Whitney Clinic Library, CMC, NYC.

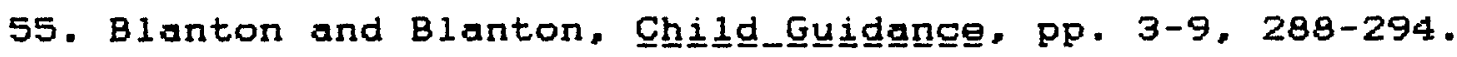


recommended for similar therapies including rigid schedules for eating. sleeping and play. Parent training in child development and discipline, and the solicitation of teacher cooperation in the provision of extra in-class attention was also used. For example, one seven year old girl was brought to the clinic as "very anxious and nervous, with marked twitching of her whole body." Her parents said she oried frequently and bit her nails. Teachers reported "a slight stutter when she tried to recite in class." The physical exam cited only that she was "round shouldered" and had "circles under her eyes." Her intelligence test placed her two years above her chronological age. Her family was considered good since her father was a successful lawyer, but her mother was typed by the olinio staff as an "over anxious and nagging parent."

At the clinic the child was placed in a special fatigue study under Dr. Max Seham. 56 Therapy consisted of:

1) an "extra feeding at half-past three;" 2) twelve hours of sleep with two rest periode after meals "with a pillow under her back," and thirty minutes rest after school. 3) She could play for one hour intervals only. 4) She was given two minute exercises to be performed twice a day, and 4) eye glasses. 5) Her mother was forbidden to talk to her about lessons or to go to the school. The mother was also given instructions on how to control her "anxiety." 6) The school was to allowing the child to pass out papers in the classroom and the teacher was to encourage her to make friends and be

56. Max Seham authored a parent training manual titled The Tír툐_Ghilld published by Lippincott which was the result of his studies of fatigue. He arranged such things as sleeping schedules by age groups for normal child development. Blanton emphasizes that sleep problems are a matter of bad habit formation. 
confident. 57

That summer the child was sent to a camp which agreed to follow al of the special inetructions for diet, rest and play. She was said to have been cured of her nervousness by the end of the year. Another child was given nearly identical therapy to cure her symptoms of "running and never walking" and being so overtalkative that "she was a great nuisance to teachers." 58 From the interviews in the school survey, teachers often represented stumbling blocks to therapy and potentially caused other problems as well. One child recommended for therapy was from a class which had acquired the reputation of being filled with problem children. The teacher who had inherited this group that year is quated as saying that she "hates the group" and resents having to teach any of them. Further the child referred for therapy was one of four over-active children "whom the teacher [especially] does not like." Unable to change the teacher's attitude the olinic advised that the family to "move to a better neighborhood" in order to avoid the school. 59

In 1924 a permanent olinic was also set up in st. Paul funded by the Amherst $H$. Wilder Charities. The St. Paul clinic was in a less advantageous position than the Minneapolis clinic under Blanton. It was 1855 well connected to the public school

57. Blanton and Blanton, Ehilid_Guidgngeg, pp. 212-24.

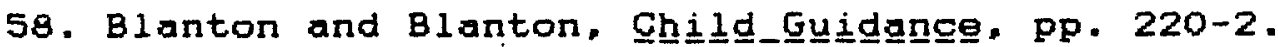

59. "Case Reports, Longfellow School Survey, Minneapolis, Minnesota, 1924," GF 66, RAC, N. Tarrytown, N.Y. 
syatem and other community organizationa. Additionally it was financially dependent on the Board of the Wilder Charities which was composed of relatively non-sympathetio business men. The clinio was repeatedly required to justify its funding on a "per capita cost" basis. The Board's insistence on business rather than medical criteria for evaluation was seen as an "educational problem" by Commonwealth and the NCMH leaders. The clinic and its director were criticized by NCMH and Commonwealth Fund officials for not successfully "selling" the idea of mental hygiene to the Board and community. 60

The director. Dr. Stiffler, tended to resist participating in what he saw as publicity and not education or mental hygiene. Representing the position of the NCMH, stevenson persisted, suggesting that forty cases from the clinic be used over a year not only as a case study of childhood problems but also for community educational purposes. Facts on the cases, he argued, could be used as evidence in the argument for the worth of mental hygiene aervices. Problems could illuatrate community deficiencies in funding and facilities and the long term cost of neglecting these necessities. 61

60. "Report of the Division on Community clinics of the National Gommitte日 for Mental Hygiene. July 1. 1927 to Ootober 1. 1927," pp. 5-7. CF 66; George S. Stevenson. "Visit to Minneapolis - May 10. 1927." "Visit to St. Paul - May 10. 1927." attached to Barry C. Smith to George S. Stevengon. 1 June 1927. CF 66: Memorandum to B.C. Smith from M. Scoville. 13 June 1932, P. 3, CE 67. RAC, N. Tarrytown, N.Y. Paul."

61. Stevenson, "Visit to Minneapolis, " and "Visit to St. 
The educational problem was exacerbated by the fact that Stiffler's elinic was viewed competitively with Dr. Blanton's which highlighted differences of opinion and style. 62 Even though the clinical work under stiffler was considered good and the training programmes for the University of Minnesota and Smith College "very adequate, the NCMH evaluated stiffler as marginally competent as a clinic director. 63 The st. Paul clinic consequently laboured under continuous pressure and was constantly threatened with being disbanded even though it served its community clinical function.

\section{Cleveland: Mental Hygiene And The Unified Community}

The Cleveland demonstration unified services which operated to serve the entire city. The solution in this case was to expand the psychiatric service already underway under the auspices of the Children's Aid Society into the broader base of a mental hygiene oriented child guidance. The mental hygiene staff in effect merged with the prior functions of the Children's Aid Society. These services operated in tandem by June 1, 1926, six monthe before the end of the demonstration. The second year of the demonstration was unusual. The Welfare Federation contributed funding for a continuance which was deemed necessary to refine the techniques effected by the merging of functions of a more

62. Stiffler also felt that Blanton was "discourteous" to him which tended to make him less willing to learn from Blanton's perceived success. Stevenson, "Visit to St. Paul." Paul."

63. Stevenson, "Visit to Minneapolis," and "Visit to St. 
traditional welfare service with the mental hygiene ataff.

The Cleveland demonstration opened in December of 1924 . It accepted 706 clients out of 1,015 referrals during the demonstration. Of these 533 were given full clinical services and the others were given consultative service. Close to thirty-six per cent were referred by social agencies, twenty-four per cent by parente or relatives and thirty per cent by the echools. The juvenile courts only referred seven and a half per cent with another two and a half per cent referred by medical personnel and health related agencies, less than one per cent were referred by private physicians. Parent referrals were seen as problematical in that they reflected a high per capita cost to the clinic in terms of time and resources since there were no cooperating agencies to share services.

The sharing of services among agencies was attempted in fifteen per cent of the full study cases which amounted to a case load of nearly 200. This was done by setting aside specific consultation hours for social workers and psychiatrists to meet with outside agencies to consult on specific cases. This approach was seen as effectively carrying educational work, that is the dissemination of the ideological perspective of mental hygiene. into these agencies and into the community through diversified authority atructures. The ergument followed that this dissemination of mental hygiene "equipped the community to meet. its whole problem and to get at behaviour problems before they 
became court problems." 64 The success of this approsch 1 s cited in the inclusion of a psychiatrist and social workers in the city day nursery and free kindergarten. The nursery psychiatrist also provided testing services for the Jewish Orphan Home. The local hospital and dispensary extended its psychiatric and mental hygiene program in response to the demonstration. 65

Additional educational work was done through publications, informal lectures and formal courses at Western Reserve University in the School of Applied Social Science and the School of Education. Special efforts were made to provide peychiatrio training for local visiting nurses, probation officers, school attendance personnel and supervisory staff operating welfare agencies. Fellows were trained in psychiatry through the Commonwealth and Rockefeller scholarships and psychiatric social workers were trained in cooperation with smith College. The permanent clinic was supported by the establishment of the Cleveland Foundation, 66

Cleveland had vied favourably with Los Angeles a year earlier as the seventh demonstration. Cleveland had sophisticated social programmes directed toward mental hygiene including a clinical psychiatric service operated by the Children's Aid Society. The Welfare Federation had previously established a

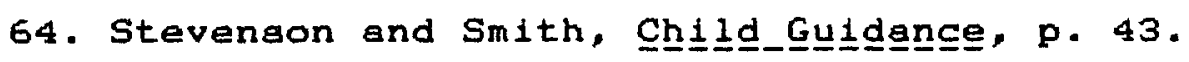

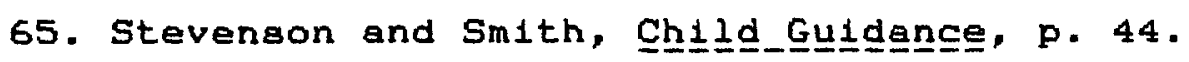

66. "Foundations Showing an Interest in the Mental Hygiene Field," May 1935, CF 67, RAC, N. Tarrytown, N.Y. 
mental hyglene committee which initiated the demonstration. Similar to Los Angeles, the NCMH was concerned with the provision of funds for a permanent clinic after the demonstration. These model clinics could not fulfill their purpose if they disbanded with the loss of Commonwealth Fund support and NCMH personnel. The NCMH also wanted each clinic to contribute to the overall knowledge about the successful arganization of clinical services. In Cleveland, there appeared to be a well-developed consciousness scattered throughout eeveral agencies for the need for mental hygiene. The presence of a well developed consciousness was 1955 viaible in the case of California.

\section{California: Orthodox and Unorthodox Mental Hygiene}

The NCMH and the Commonwealth Fund set up a demonetration in Los Angeles. They were interested in increasing the influence of the child guidance clinics on a regional basis. They also wanted to take advantage of favaurable conditions for expanding mental hygiene work in general and to provide facilities for the training of expert personnel especially in peychiatry. It was hoped that they could encourage medical training in psychiatry on a national basis by providing clinical training and making available space for internships. Yet, the California experience to the contrary illustrates over the long term, the popular simplification of the mental hygiene model and the transition toward the use of nonpsychiatric personnel: California was an especially receptive environment for mental hygiene. State policies had long been concerned with the regulation of different 
children. It was partly out of this policy interest combined with the economic drain of the 1930 s that the medical model was successfully entrenched but in a form detached from medical leadership.

The Juvenile court in California was established in 1903. California's policies on exceptionalities in children coincided with the development of its education system. This reflected the state's rapid growth, overwhelmingly immigrant population, and the use and necessity of imported labour especially in the mines and railroads. The first exclusionary clauses in 1866 separated children on the basis of race. Health and character traits entered the exclusionary clauses in 1870 and 1874 respectively. Children with contagious diseases and children of the very poor or those who exhibited "filthy and vicious habits," could be barred from public schooling. The concern with different children and differential public responsibility toward those so designated encouraged the development of special classes to segregate children who did not warrant complete exclusion but who were seen as detrimental to the well being of normal children in regular classes. Parental schools for children lacking adequate parental guidance were established in 1903, the same year as the juvenile court. 67

67. John G. Richardson, "Special Education and Minority Misclassification: An Historical and Sociological Perspective," PhD Dissertation University of California Davis, 1975: Jane R. Mercer and John G. Richardson, "The Emergence of Mental Retardation as a Social Problem: A Natural History of ClaimMaking and Responding Activities," in Nicolas Hobbs, ed. " IEs

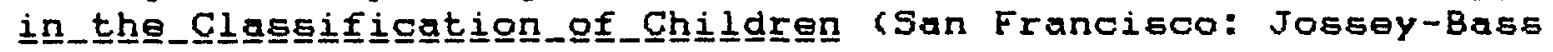


The juvenile court law as amended in 1915 remanded individuals under the age of 21 to a separate court. Significantly, the law did not define delinquency or dependency but instead described fourteen circumstances for which a child could be brought before the court. These circumstances included "behavior-difficulties, physical, mental and social handicaps which cause or tend to cause a child to need the protection and guardianship of the state." 68 The court was to act as a surrogate parent. The role of the judge was played by a women "referee" who heard all the cases brought against girls and all cases brought against boys under 13 years of age. The exact qualifications for the referee was not determined by law but Miriam Van Waters, a progressive advocate of the court and refere日 in the 1920s. felt that "a thorough knowledge of psychology, mental hygiene, sociology and anthropology..that deal with criminology, cultural history of the race and of racial traita and capacities, [was] much to be desired." 69

Los Angeles had been one of the first cities to request a demonstration through the NCMH Division on the Prevention of Delinquency. NCMH officials nated that the city had a progressive Juvenile court programme under Miriam Van Waters and an active

68. Miriam Van Waters, "The Socialization of Juvenile Court Procedure," in Ernest B. Hoag and Edward H. Williams. CÉ $\underline{i} \underline{\text { me }}$

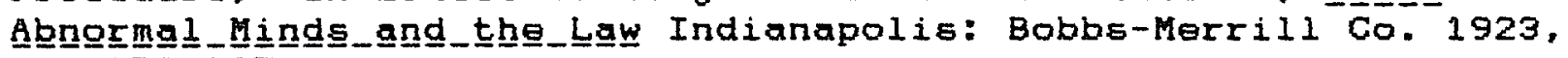
pp. $158-167$.

69. Van Watere, "The Socialization." p. 160. 
mental hygiene oriented school programme which included special classes under Elizabeth Wood. 70 The original worry was to secure from the onset the means to make the clinic permanent at the end of the demonstration, a lesson learned from the Minneapolis and St. Paul experience. The local committe日 which formed to secure community support and resources later organized as the southern California Society for Mental Hygiene. 71

The Los Angeles clinic was opened in January, 1924 with three psychiatrists, two psychologists and up to six psychiatric social workers with an additional four social workers in training. The increased staff numbers also reflected strategies learned from the earlier clinics. It was decided to concentrate in this demonstration on carefully selected cases in order to insure a successful demonetration as a model for other clinics and to serve educational functions in the community. Mentally retarded children and those with known mental illness were exoluded from clinical service or given brief work ups and "consultative" services. In addition, the clinio only received 10.7 per cent of its 300 cases from the juvenile court and only 8 per cent from social agencies. The majority of the cases were

70. The eugenical overtones of the rational for these courts is evidenced in Ernest B. Hoag and Edward H. Williams, Grimme_A Co., 1923). This is a treatise on the Los Angeles and other Juvenile Courts. It has an introduction by Henry Goddard and a special chapter by Miriam Van Waters. "Socialization of Juvenile Courts,." pp. 158-67.

71. Anderson, "Report of the Division, November 1, 1922 to November 1, 1923," p. 30, CF 66, RAC, N. Tarrytown, N.Y. 
parent or relative referred. This is in contrast to the Minneapolis olinic which received less than half of its clients from parent referrals and 20 per cent from the schools. Parent referrals tended to be younger children who scored higher on intelligence teste. 72 This is an indication that this selfselected sample tended to represent families with a higher class status.

Parente with higher occupational and educational levels tended to be more interested in and open minded about psychiatric explanations of behaviour. They were also more likely to believe in the therapeutic power of science to solve problems. These families would be more likely to seek consultation and to cooperate with clinical therapy. The trend toward parent referrals altered the original clinical orientation toward lower class, poor and immigrant families. It reflects a practical recognition that what was termed environmental problems. Coften in fact economic and political in naturel, persistently defied solution by way of the individualistic therapies offered by the clinic staff. The rationale for encouraging this change in client population. was that this decision contributed to a preventive appraach to problem children. Studying young difficult children who did not have blatant physical or environmental explanations for their emotional and behavioural difficulties was said to advance therapeutic intervention before the child developed

72. Stevenson and Smith. Shíld__Guidange pp. 39. 
problems aubject to school or community referral. 73

The L.A. demonstration was directed by qualified personnel. Ralph P. Truitt served as director, with Christine Leonard as the chief psychiatrist. The demonstration staff managed to take part in more general community organizational processes directed toward integrating child guidance into other social and medical resources in the community. The state Board of Education, for example, was interested in developing guidelines for counselors in schools. The clinic also acted as a consultant service to Los Angeles Public Schools as they experimented with ways to handle problem children. These efforts had direct follow ups in Long Beach and Sacramento. After the demonstration, the service was continued under the auspices of the community chest. An affiliated clinic in Pasadena was operated by pooling the staff of the two clinics. This alternative contributed to the financial survival of the two clinics during the lean years of the depression. 74 Los Angeles served as one of the training centers in paychiatry under the NCMH fellowship program. At the successful conclusion of the demonstration. Truitt was made the Director of the National Committe日 Division on the Prevention of Delinquency. Leonard was traneferred to Philadelphia to assist Frederick H. Allen in another demonstration. The NCMH and Commonwealth Fund kept in touch with the olinic. Their reports

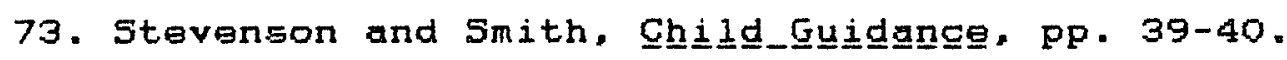

74. "Memorandum," Barry Smith to M. Sooville, 12 February 1929, CF 66; "Memorandum," Mildred Scoville to Barry Smith, 13 June 1932, pp. 5-6; CF 67, RAC, N. Tarrytown, N.Y. 
and memos cite no fault with the operation of the clinic nor ita personnel and management, problems which had plagued the earlier clinics in their struggle to achieve permanent status. 75

The regional aspects of expanding services and encouraging psychiatric education was noticeably less successful. Activities in the Los Angeles area in the mid-thirties illustrate the problems and peculiar success of the model of mental hygiene in that it encouraged psychiatric perspectives but not the use of psychiatrist. The two local medical schools, the University of Southern California and College of Medical Evangelists (Seventh Day Adventist) had no programme for psychiatry in medical education. Dr. Aaron Rosenoff who did some teaching at the College of Medical Evangelists felt that the greatest demand was for courses for teachers, social workers and lay public, not doctors.

A mental hygiene clinic was set up by the Los Angeles County Health Department under the Director and the Chief of Medical Social work. The staff consisted of a half-time psychiatrist, half-time psychologist and a full-time psychiatric social worker. The clinic was closed, however, after a year and a half due to budget cuts during the depression.

While county officials were interested in resuming services in mental hygiene they disagreed about the placement of the

75. "Report of the Division on Community Clinics of the National Committee for Mental Hygiene July 1.1927 to Dotober 1 , 1927," p. 7; "Memorandum," Barry Smith to M. Scovil1e, 20 February 1929, p. 2; "Conference with Dr. Stevenson and Miss Bassett," 12 March 1929: CF 66, RAC, N. Tarrytown, N.Y. 
service under the health department. There was little impetus to integrate services which proliferated but were disconnected and lacked a atandard making body. Alternative locations for mental hygiene services alternated between public health facilities. schools, social welfare and the courts. Mental hygiene which had helped professionalize these areas in its own image could not claim any one sphere.

The public schools ran a one-half day clinic for nervous and behaviour problem children under a psychiatrist. The Mental Hygiene Unit of the Health Service Section of the Los Angeles Board of Education, as it was called, served only 100 children a year. The children were referred by medical examiners and nurses who typically took "no interest in the case beyond referring it."

The Long Beach City School system provided a combination medical and child guidance service which was considered paor due to inadequate staff. It primarily worked with the "athletic neede of the High School" and special problems. There was however, a psychiatrist, James Houloose, as the Supervisor of Health Services. Nonetheless, the visiting teacher, Helen Knax, did most of the work through teachers and principals. A school peychologist was available on a part-time basis.

The only true child guidance clinic was the Los Angeles Child Guidance Glinic which had been initiated with the Los Angeles demonstration. In spite of the fact that a number of activities used the title child guidance and spread a popularized psychiatric perspective there was only one functional clinic with 
fully qualified personnel after ten years. 76

Norman Fenton and Mental Hygiene for the Common Man

The proliferation of alternative and unorthodox forms of mental hygiene was exacerbated on the state level. The Commonwealth and NCMH staff in a review and evaluation of mental hygiene activities was not happy with the trend. Mental hygiene as popularized by one psychologist, Norman Fenton, was viewed as not orily "superficial" but "dangerous." 77 Fenton was very successful in simplifying and packaging the mental hygiene paradigm over the objections of the NCMH.

The California Bureau of Juvenile Research was active in smaller communities in the state. The Bureau had employed a psychiatrist and psychiatric social worker from 1929 to 1931 in a traveling olinic which worked out of Whittier state school for Boys. With the continued financial stress of the 1930 s both the Whittier programme and work done by Miriam Van Waters with the courts were curtailed.

The psychiatrist and psychiatric social worker were eliminated. The remaining peychologist, Norman Fenton, took over what was left of the programme moving the headquarters to Claremont Callege where he taught summer courses in child guidance to teachers and psychologists. Fenton's avowed goal was to assist school departments in the establishment of child

76. M.C. Scoville. "Psychiatric Activities in the Los Angeles Area," 11-18 May 1936, pp. 1-7, GF 67, RAC, N. Tarrytown, N.Y.

77. Scoville, "Paychiatric Activitieg," p. 5. 
guidance services at a negligible cost.

In Santa Barbara he set up what he called a "Child Guidance Conference Program." The school-based programmes utilized a halftime psychologist. Teachers, principals and school nurses acted as social workers. The school physician, private physicians and the psychologist did psychiatric examinations. The recommendations were carried out by school personnel or releyant community workers such as probation officers. Fenton's motives for initiating services, which noticeably lacked professionals in psychiatry or a uniform scientific approach to problem children, were considered Euspect by the NCMH: Commonwealth Fund officers intimated that he was using mental hygiene for personal gain. The proliferation and apparent success of Fenton's programme seemed to undermind the spirit of scientific child guidance. 78

Fenton was not deterred by the oriticisms of the NCMH nor by their insistence on the dominance of a psychiatrist in a position of leadership in clinical practices. Such criticisms also did not seem to inhibit Fenton's popularized economical version of child guidance from spreading. In fact, it was a simplified model which came to dominate school practices. The streamiined model adopted a paychiatric overview of problem children, but used psychologists and relatively untrained personnel to implement programmes in schools. After serving as Director of the Bureau of Juvenile Research for the state of California. Fenton went on to become Professor of Education at Stanford University. He

78. Scoville, "Psychiatric Activities," pp. 6-7. 


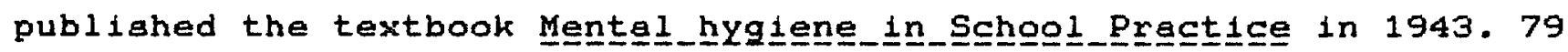

This book was in its sixth printing in 1949. 80

Fenton continued throughout his career to popularize and simplify the ideology and practice of mental hygiene. In this process he developed systematic methods for implementing his own version of mental hygiene clinical practice in schools. His textbook was directed at classroom teachers, school

administrators and laymen who were to carry out mental hygiene work with children. As the jacket cover of the text advertises you can also "send for our catalog of tests and guidance materials" to acquire a complete package capable of implementing a mental hygiene programme in your community. Fenton relied on peychological and educational test batteries such as the stanford Revision of the Binet-Simon Intelligence Scale. Sample forms and blanks were provided in the appendix of the textbook and a second appendix provided hints and categories for classifying children. Those interested could acquire for fifty cents Fenton's school case work manuals, "The Counselor"s Approach to the Home." and "The Coungelor'a interview with the student." 81

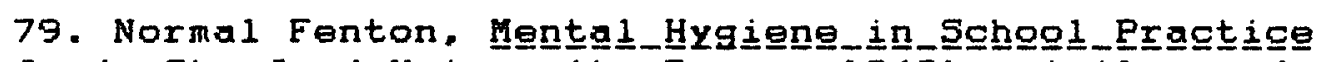
(Stanford: Stanford University Press, 1949); similar and earlier

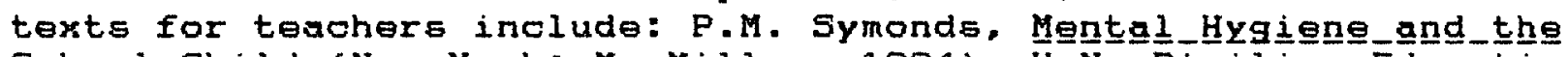

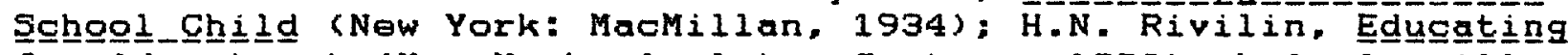

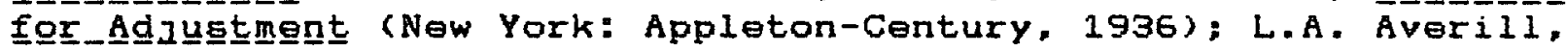

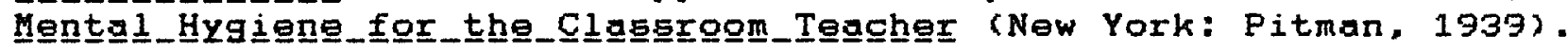

80. Fenton, Mental

81. Fenton, Mental_Hygiene. Appendix I, pp. 403-411; Appendix II, pp. 412-3 provides four classification systems: his own, that of the Worchester State Hospital Child Guidance Clinic. Lawson Lowrey's and Sprague's Universal Classification of 
Fenton also helped popularize the notion that mental hygiene could not only be utilized inexpensively but that it was essential for social progress. 82 Ultimately. Fenton argued that mental hygiene contributed to "education, recreation, social security, standards of health, labor, housing and medical care" on a state and national level. Internationally it was to contribute to "international morale" and "powerful co-operation for peace and human welfare." 83 Fenton dealt a death knell to mental hygiene as means of reducing the social and financial burden of crime in society by the prevention of delinguency. "Over a period of years this may result," he asserted, "but mental hygiene should [better] be described as useful for the improvement of the happinesg and effectiveness of all children." 84

Fenton described mental hygiene in Deweyesque phraseology as the key to practicing a democratic way of life by fulfiling individual personality development. 85 Mental hygiene, as

Psychiatric problems. The manuals cited were published by Stanford University and the textbook Mental__Hygiene_in_Sghgol Pracㅌㄷㅇㅡ was also distributed in mimeograph form for distribution to teachers.

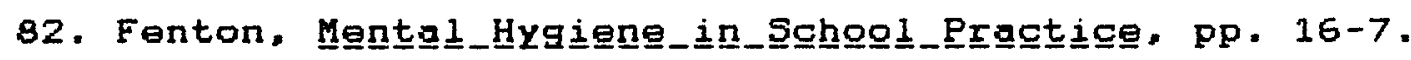

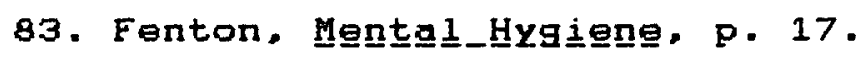

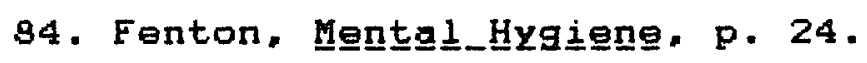

85. Fenton, Nental_hygienge, pp. 139-40; Dewey contributed to a popularization of the idea of a symbiotic relationship between

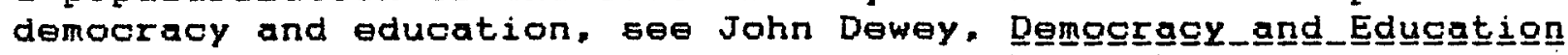

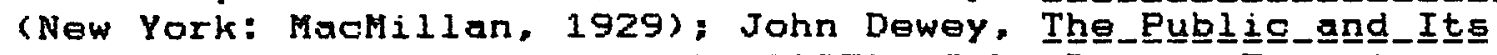

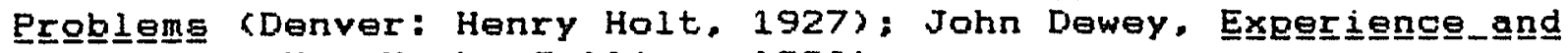
Eㅁuㅡㅁㅡㅡ토므 (New York: Collier, 1938). 
sensitive to individual differences was put forth as the means to achieve democratic values in education in general and specifically in school administration. Conflicts between an ideal of equality between citizens and the goal of supporting excellence and ability in education plagued the rise of public education in the United States. The solution to the argument turned toward the provision of equality of opportunity. Mental hygiene provided a point of mediation in this dilemma as it became inetitutionalized in social policy after the second world War. 86

The only problem Fenton foresaw in using mental hygiene to perfect the selective role of schools was the potential for personality difficulties and maladjustments in school personnel. Teachers were especially singled out as potentially unstable. Maladjusted teachers presented a serious problem since mental hygiene in the schoole relied heavily on teachers and there was no provision for psychiatric leadership as in the NCMH model child guidance clinics. Principals as a "parent person" were suggested as possible replacements. 87 Very similar concerns were

86. Fenton, Menten1_Hygiene, p. 95; pp. 342-44; see for example. Charles W. Eliat, "Equality of Opportunity," in w.

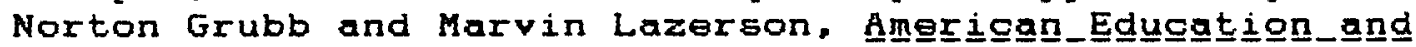

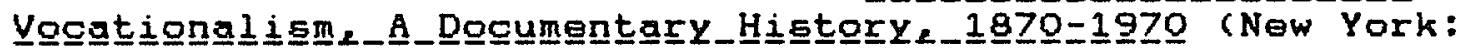
Teachers College Press, 1974), pp. 134-46; Higher_Education_fon

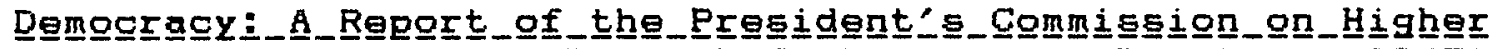
Equecation (Washington D.C.: U.S. Government Printers, 1947); and,

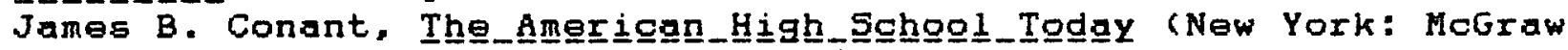
Hill, 1959).

87. Fenton, Mentel_ Hygiene, p. 335, 341. 


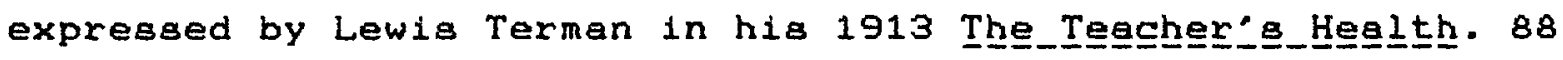
Fenton's arguments and programmes were especially compatible and mutually supported Terman's popularization of testing in schools and the efficacy of intelligence scores illustrated in his studies of the gifted. 89 Terman also served in the inter-war period as President of the American Psychological Association beginning in 1923. Terman and his students dominated the APA during this critical period in the development of professional school psychology. The institutionalization of the school peychologist in public education was the cornerstone of Fentan's madel.

\section{Philadelphia}

The Philadelphia elinic also reflected larger trends in child guidance characteristic of the demonstrations. The ultimate goal of the demonstrations was to establieh permanent clinical facilities for children. It came to be recognized that success required careful site selection, longer demonstration periods and integrated services. The clientele also changed from juvenile delinquents to middle class referrals. The therapeutic model, with its underlying moralism, adapted to these changes as it became more professional.

Philadelphia was an ideal site. There was a long and sophisticated precedent in olinical services including Lightning Miffin).

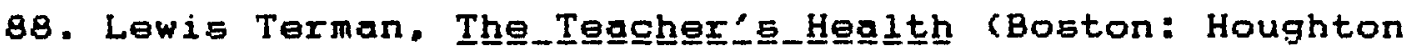

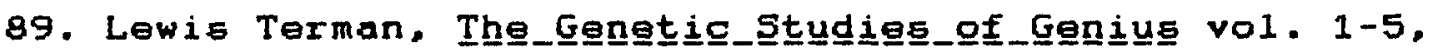
(Stanford: Stanford University. 1925-1956). 
Witmer's early clinic at the University of Pennsylvania. The Pennsylyania Hospital for Mental Diseases had a history dating back 170 years. There was active mental hygiene work underway in the Children's Aid Society, Public Charities Association of Penneylvania and the juvenile court. The first juvenile court law of Pennsylvania dated from 1901. A 1904 revision stated that: "juvenile offenders, [that is, dependent, neglected, incorrigible and delinquent children under 16], should be wisely controlled, not imprisoned; and the courts' powers, as to children..should be diatinct from their criminal law powera." 90

The demonstration clinic opened in March of 1925 with a projected test period of two years. The longer time period was seen as necessary in providing the clinic with enough stability to succeed as a permanent organization. The clinic provided services to a variety of social agencies and experimented with collecting fees for the first time. While the majority of cases were referred from social agencies the number directly brought in by parents increased over the demonstration period. It was argued that parent referrals represented a heavier burden to clinic staff in the absence of cooperative agencies. A screening process was initiated whereby an application for help was not considered sufficient for service.

Parents who could not demonstrate. in an initial interview.

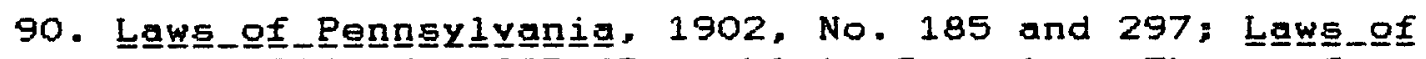
Pennsylvañia, 1903. No. 205 (Preamble); See also. Thomas J.

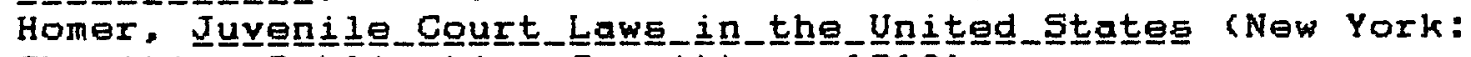
Charities Publication Committee. 1910). 
their need and willingnegs to cooperate were discouraged from participating in the clinic's programme. 91 Specified arrangements for appointments and fees were arranged prior to the initiation of clinical services. The idea of fees and a more contractual arrangement with clients was new, reflecting the trend toward more cooperative and affuent patients and away from the early involuntary services characteristic of the first clinica.

Even though the number of children referred by parents increased, social agencies remained the single most important referral source. Of 744 cases accepted during the demonstration clase to forty-six per cent were from agencies. Of the 362 full study cases close to forty-nine per cent were handled cooperatively with social agencies. 92 This aspect of child guidance, which was first emphasized during the cleveland pragram, continued to be expanded in Philadelphia. Only 12.6 per cent of the cases were referred from the public schools and less than 3 per cent came from the juvenile court system. 93 This latter figure was contributed to by the fact that the court supported its own psychiatrist and schools were also building up independent facilities.

91. This was sometimes put as assisting the applicant into making an independent decision not to continue. See Almena Dawley. "Treatment Possibilities in the Application Interview,"

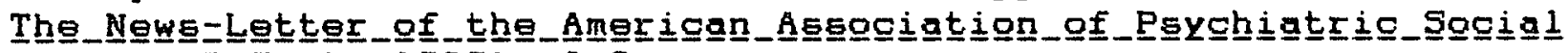

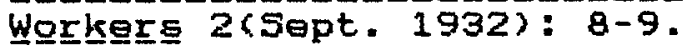

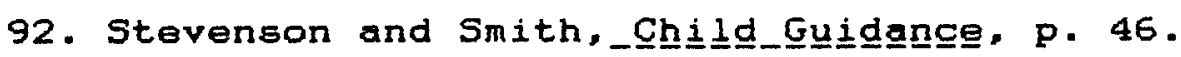

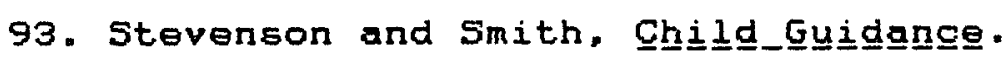


Community educational work wag emphasized as a function of the clinic. The fact that parent referrals increased indicates to some extent the success of this campaign. The effort to educate the public in peychiatric explanations of social behaviour became increasingly important as a clinical function from the St. Louis Clinic to this last demonstration. Inter-agency cooperation reflected a measure of the success of mental hygienists in placing peychiatry in the curriculum of related mental health fields. Similar training facilitated cooperative therapeutic approaches and was a final step in this elaboration of curriculum. The olinic supported an active programme to reach the general public, including public lectures and course work as weli as published articles. A monthly bulletin was published by the Philadelphia Clinic's Board of Directors.

clinical training of personnel was carried out through fellowships in psychiatry offered by the NCMH. Fellows in psychiatric social work through smith college were trained at the clinic. The clinic also helped to train students in psychiatry from the University of Pennsylvania. After a period of independent financing to prove its stability, the clinic was accepted as a part of the Welfare Federation in December 1929. 94 Case records of the Penneylvania clinic from 1925 to 1945. reveal three separate orientations in the form of therapy and ideological perspective. Attitudes on parent-child and especially

94. "Report of the Division on Community Clinics of the National Committe日 for Mental Hygiene. July 1. 1927 to October 1 , 1927." p. 10. CF 66. RAC, N. Tarrytown, N.Y. 
mother-child relationships changed on the part of clinic staff. 95

Most early therapy was directed toward changing the parents behaviour in an effort to change the child's environment. Between 1925 and 1931 the clinical staff emphasized a no nonsense form of "correction and instruction." In the 1930 s this attitude turned toward a more flexible form of therapeutic manipulation emphasizing "support and reassurance" toward the parent. Children came to be seen as causally involved in their own maladjustment. Interpretations of troubled Eamily relations expanded. They could be seen as by-products of psychological or genetic factors as well as envirommental conditions which lead to patholagies. After 1936, the emphasis became more distinctly "psychodynamic" dealing with attitudes and emotional states. 96

The increasingly sensitive attitude toward the mother's personality and emotional state corresponds to the development and spread of psychoanalytic thought as well as developments in child peychiatry. The idea that the mother was a prime suspect in causing later pathological conditions follows directly from psychaanalytic theory. Changing therapeutic appraaches to motherhood reflected developments in the recognition of the child as a psychiatric subject.

95. Margo Horn, "The Moral Message of Child Guidance, 1925-

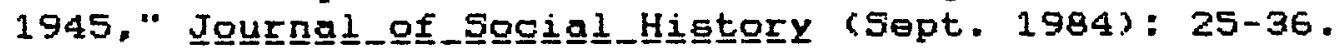

96. Horn, "The Moral Message of Child Guidance, 1925-1945," pp. 25-36. 


\section{The Success of the Message of Mental Hygiene}

Even considering the various problems of the demonstrations between 1922 and 1927, the number of child guidance clinice rapidly expanded with the Commonwealth programme. 97 only ten clinics opened between the end of world war I and the launching of the Division on the Prevention of Delinquency in 1921. After the creation of the Division the number of clinics jumped to 72 by 1926 and to 102 by the end of the demonetration period in 1927. By 1930. 500 permanent community olinice were in operation. This figure stood at 617 in 1935 when the first textbook on child psychiatry was published in the United States. 98

Figures on the number of true child guidance clinice vary widely depending how one defines clinical services for children. Clinice diverged in their olientele as being exclusively for children or marginally accepting children. Clinical affiliations varied from hospitals, universities, courts, schools and a great variety of public and private welfare agencies. Staff varied in the orientation of their training toward medical disciplines or the social and behavioural approaches to individual therapies. Clinice were adapted to community size and resources.

George Stevenson of the National Committee took a restrictive view of the number of operational clinics in a letter

97. L. G. Lowrey, "Psychiatry for Children," Ammerígan

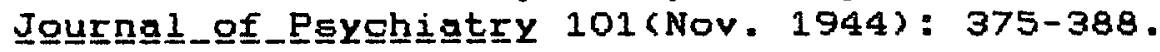

98. Lowrey, "Psychiatry for Children," pp. 375-388; M.A. Clarke. "Direotory of Psychiatric Clinics in the United States1936," Mente1_Hygienge 20 (January 1936): 66-129. 
to Barry Smith comparing 1921 and 1936. He cites only two full time child guidance clinics in 1921: the Institute for Juvenile Research in Chicago and the Judge Baker Foundation in Boston. 99 By 1936 only 39 full time clinics are cited as providing full time multiple services in child guidance. 100

Preparations for the end of the programme had been in the offing since July of 1927. The Philadelphia and Cleveland demonstrations were closed July 1 and officially replaced with permanent, lacally supported elinics. Of the demonstrations in eight cities seven had become permanent. In addition, clinics had been started with funding assistance and advice in Richmond, Milwaukee and Baltimore. Cincinnati, Louisville, Colorado Springs and Charleston, had initiated olinics without funding or assistance but based on the NCMH model. Charlotte, San Diego,

99. However, Stevenson acknowledges that Boston Psychopathic under Thom provided in ite eervice to children the equivalent of a child guidance clinic. Seven other clinics are recognized but are considered so substandard that "in aggregate they are equivalent to one full time olinic." G.S. Stevenson to B.C. Smith, 1 May 1936. CF 67, RAC, N. Tarrytown, N.Y.

100. There were thirty others which were full time and used the claseic three-fold model for personnel including a psychiatrist, psychologist and psychiatric social worker. This equaled 39 top quality guidance olinios in 1936. acoording to Stevenson. Six additional clinics provided excellent services but only on a half-time basis, twenty-six others offered services on less than a half-time basis. On a level comparable to the 1921 Boston Psychopathic, Stevenson listed thirty-one operational clinics but they were said in the aggregate to be equal to only six ideal full-time child guidance clinics. To illustrate the level of particulare noted by Steveneon: he mentioned thirtyeight clinics observing the tridisciplinary personnel model but who used the term "social worker" rather than "psychiatric social worker." For this reason, he estimated that they are only equal to seven full-time ideal child guidance clinics. G.S. Stevenson to B.C. Smith, 1 May 1936, CF 67, RAC, N. Tarrytown, N.Y. 
Houston and Birmingham were in planning atages for starting clinics. Nine states had organized state mental hygiene societies and ten states had official departments of mental hygiene inoluding Illinois, Maryland, New Jersey, New York, Narth Carolina, Ohio, Pennsylvania, Virginia and Colorado. Colorado had a state mobile unit and another was planned in Virginia. The Institute for Child Guidance was established in New York with the NCMH continuing in its advisory capacity. The NCMH was to administer fellowships in psychiatry and psychology in conjunction with New York School for Social Work and Smith College School for Social Work. The Rockefeller Foundation supported fellowehips in social poychiatry in five medical schools. The visiting teacher program in conjunction with the Public Education Assaciation had established in-service training and mental hygiene curriculum in sixty-three communities. They were planing to begin seven others and had sixteen requests to prepare plans. The Commonwealth Fund publications in mental hygiene were used in one hundred colleges, universities and normal schools for instructional purposes. The field service had plans to continue survey work collecting data on mental hygiene. It is appropriate that the Division on the Prevention of Delinquency which was to continue to carry out the work of the demonstrations was to be renamed the Division on Community Clinics. 101

101. Stevenson to Smith, 1 May 1936. pp. 12-16; Executive Committes to the Board of Directors. "Report on the work of the National Committee for Hental Hygiene." Submitted at the Annual 
The National Committee for Mental Hygiene continued to try to monitor the quality of child psychiatric clinics into the 19405. The NCMH created the American Association of Psychiatric Clinics for Children in 1940 to regulate and systematize mental hygiene clinics for children. The AAPCC saw itself as a "standard-setting agency." The secretariat and field eervice were shared with the NCMH Division on Community Clinics. In 1949 there were only 55 qualifying member clinics and 18 training centres for community child psychiatry. 102 The difference in the number of actual clinics and the ones designated as standard-setting is indicative of a prevalent problem with psychiatric child guidance. Even with the active work of the Commonwealth Fund and Rockefeller Foundation in providing fellowships, it was extremely difficult to attract qualified medical personnel into psychiatry and especially into community or child psychiatry. 103 The result was a work-load emphasis on peychology and social work. Similarly, it was not a psychiatrist who intervened in schools so much as counselors trained in psychology and psychiatric social work.

Mental hygiene as an optimistic ideology, nevertheless. viewed its programmes as positive and successful. The Program on Meeting December, 1927, LSRH 3, 35, 368, RAC, N. Tarrytown, N.Y.

102. Jules V. Coleman to M.C. Scoville, 29 November 1949; George S. Stevenson to M.C. Scoville, 9 June 1947, CF 67, RAC, N. Tarrytown, N.Y.

103. Milton E. Kirkpatrick to M.C. Scovil10. 21 April 1941. CF 67, RAC, N. Tarrytown, N.Y. 
the Prevention of Delinquency as self-evaluated at the termination of the demonstrations boasted that child guidance had become a familiar concept "adopted throughout the country." Mental hygiene information was commonly distributed in the general communication and educational media. 104

Psychiatric perspectives had been successfully infiltrated into the curriculum of social work, education and psychology. For example, when the Institute of Child Guidance with the New York School of Social Work lost its Commonwealth Fund support in 1932, Barry Smith's argument was that its function in stimulating psychiatric curriculum and encouraging other training centres was complete. 105 It had served its purpose and other philanthropies or governments would continue to build on the professionalization of social work. Although the Commonwealth Fund regretted withdrawing. Smith felt that in light of the pressures of reduced funds and increased needs due to the crisis of the depression, financial aid could be utilized in more critical areas.

A similar outcome awaited the Visiting Teacher Program which had been carried out in conjunction with the P.E.A. Other mechanisms were being developed to serve the function af spreading progressive perspectives through in-service training. At the end of the three year demonstration in visiting teacher

104. "The Mental Hygiene Program of the Commonweath Fund and Some Evidences of Its Value," typescript, p. 14, CF 66, RAC, N. Tarrytown, N.Y.

105. B.C. Smith to C.M. Hinoks. 7 January 1932, GF 67. RAC, N. Tarrytown, N.Y. 
services, 48 communities in 32 different atates had initiated a programme. It was reported that 15,439 children had received benefits. 106 This was but a small indication of what was to amount to a flood-tide in terms of the dissemination of psychiatric perspectives as they influenced the professionalization of education.

The reparts of eugenically oriented mental hygienists that one million subnormal children populated the nation's gramar schools had by 1928 encouraged the establishment of teacher training in special education in a dozen or more schools including programmes at Teachers College. Columbia University and at the Training School for the Feebleminded at Vineland. One third of the states had some kind of legislation on special children by the late 1920s. While the professionalized curriculum for teachers did not mention psychiatry by name, the emphasis inoluded "sociology and psychology." In educational measurement, teste of intellectual capacity were being complemented by a new compeling interest in tests of "non-intellectual traits" including "attitudes, character and emations." It is stated that the new approach to children included "actual observation and study...of mental and emational reactions...behavior, tests of personality and mental hygiene." 107

106. Benjamin W. Fraizer, "Teacher Training," In United States Department of the Interior, Office of Education. Biennial

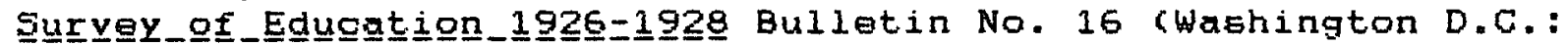
Government Printing, 1930), p. 344.

107. Fraizer, "Teacher Training," pp. 323-4. 
These developments had been greatly legitimized by the white House Conferences of 1909 and 1919. The first conference called by President Theodore Roosevelt emphasized child dependency. The conference had initiated the Children's Bureau which supported and conducted survey work. In 1919 a similar conference was called by the Children's Bureau under woodrow Wilson. In addition to the 1909 concern over child labour, education, and public health was added the topios of mental hygiene. juvenile courts, illegitimacy, rural social work and "scientific literature on child care." 108 These latter topics were the major concern of the 1930 conference called by President Herbert Hoover. 109

\section{Slaughtering the Innocents}

The field of child guidance started as an "excursion of psychiatry into the problems of delinquency." 110 out of the demonstrations in the prevention of juvenile delinquency emerged a combination of peychiatrist, social worker and psychologist as a team approach to the study and treatment of problems of

108. See "Foreword." and Homer Folks, "Socially Handicapped: Dependency and Neglect," in White House Conference on Child

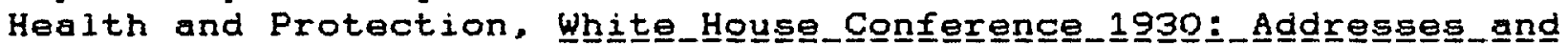

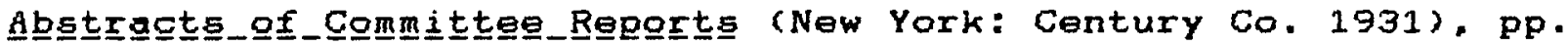
v-viii, 319-322; other addresses and committee reports are also relevant.

109. Folks, "Socially Handicapped." Twenty years after the first conference and the establishment of the mental hygiene movement the work of nearly eyery committee touched on concerns which complemented the concerns of mental hygienists.

110. "In our neglect and other failures [we are]... slaughtering the innocents." This comment is taken from Ray Lyman Wilber, "A Survey and Challenge," White_Housse_Confererence_on_Child

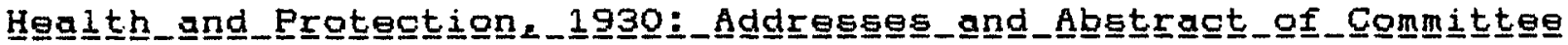
Reports (New York: Century Co.. 1931), p. v.: Section IV. p. 305. 
childhood. Significantly the fleld of delinquency as originaliy studied by Healy and Bronner at the Juvenile Psychopathic Clinic and Judge Baker Foundation was abandoned for a more general fusion of the clinical services with a more generalized connotation of behaviour problems. By 1930 the white House Conference on Child Health and Protection declared childhood as "the golden period for mental hygiene." 111

David M. Levy, in the 1947 Thomas W. Salmon Memorial Lecture at the New York Academy of Medicine, observed that "the field of behaviour problems actually became a kind of euphemistic name for the entire field of child poychiatry, for in the child-guidance clinic or institute, every variety of neurosis or psychosis, of mental aberration or diefase, may be accepted for treatment, as well as so-called "primary" behaviour problems." 112 As these clinics ceased to be attached to the courts they became a part of school systems or hospital services often dependent on local welfare agencies. The movement continued to spread psychiatric language and perspectives into other disciplines as well as contribute to the medicalization of childhood.

111. Section IV, Committee B, William J. Ellis, chairman,

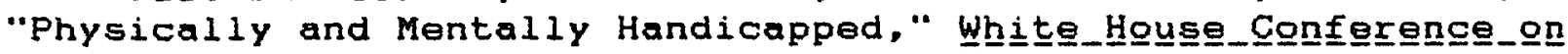

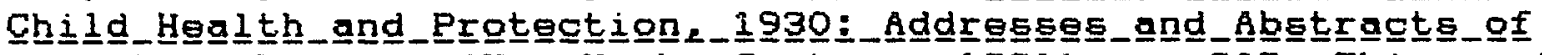

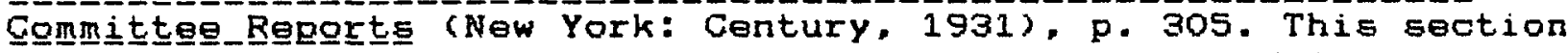
also includes "Bill of Rights for the Handicapped Child," see p. 291 .

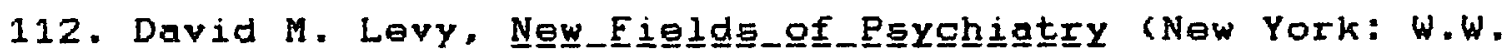
Norton \& Go.), p. 41 . 


\section{CHAPTER SIX}

MENTAL HYGIENE IN CONTEXT: EUGENICS TO

\section{PREVENTIVE PSYCHIATRY IN CANADA}

In Canada the isgue of juvenile delinquency did not provide the basis for a paychiatry of childhood. Unlike the United States, the juvenile court movement expanded slowly and the inclusion of a psychiatric child guidance clinic was a notable exception. 1 Court affiliated child guidance services were established in Toronto, Montreal, Winnipeg and Vancouver, among other jurisdictions in Canada. None of these clinica, however, operated in full accordance with the United States National Committee'a view of child guidance. According to George Stevenson, the Director of the NCMH Division on the Prevention of Delinquency, NCMH approved full-gervice clinics required the medical leadership of a psychiatrist, assisted by clinical paychologiats and a psychiatric social workers. 2

The child guidance movement in the United States with its psychiatric input was an outcome of the demonstration projects of the National Committee for Mental Hygiene and the Commonwealth Fund. There was no Canadian counterpart to the $\$ 400,000$ budget which the Commonwealth Fund spent annually on the prevention of

1. Gordon S. Mundie, "Juvenile Courts in Canada," Cạnąalianan

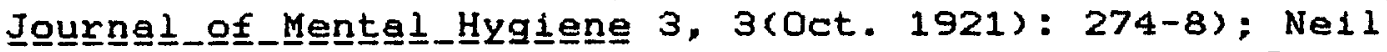

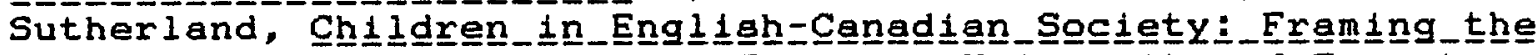
Twentieth_Century Congengug (Toronto: University of Toronto, 1976 , reprint 1982 ), p. 130.

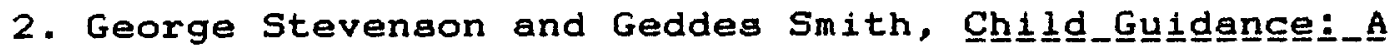
Querte﹎_Centuuy_of_Development (New York: Commonwealth Fund, 1934). 
delinquency in the United States. The Canadian Committee had considered requesting similar funding after World War I. Clifford Beers had discouraged Clarence Hincks from pursuing this idea with the Rockefeller Foundation on the grounds that it was too local a problem and did not have national or international appea1. 3

Juvenile courts in Canada were legally grounded in the 1908

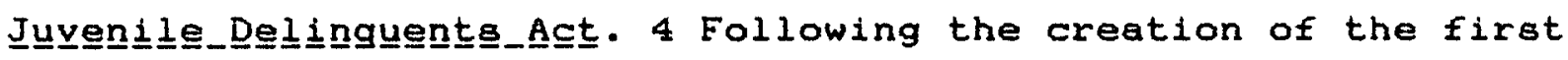
Juvenile court in Winnipeg, local courts were set up in Halifax, Nova Scotia; Charlottetown, Prince Edwards Island: Montreal, Quebec; in Ottawa and Toronto in Ontario; and Vancouver and Victoria, British Columbia. By 1921, jurisdiction over juvenile cases was expanded to 23 court districts including Saskatchewan and Alberta which passed general provincial legislation. 5

The medicalization of delinquency in the United Statea, out of which the child guidance movement grew, was first initiated in the Chicago juvenile court on the asgumption that delinquents and predelinquents were mentally retarded. Healy's and Bronner's findings that they were not mentally incompetent opened the

3. Clarence M. Hincks to CWB, 24 June 1918; CWB to CMH 26 June 1918; CMH to CWB, 28 June 1918 and $4 \mathrm{July} 1918,23 \mathrm{July}$ 1918, Hincks Papers, Greenland Griffin Archives, Toronto.

4. Canada, Śtatút

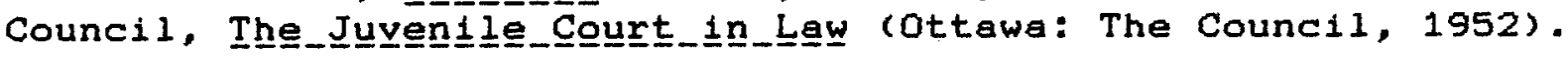

5. See Sutherland, ChLildren, pp. 125-6; also, Helen Gregory

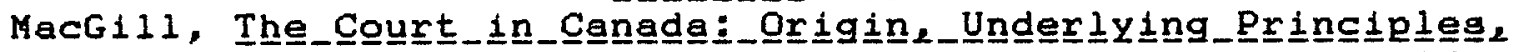

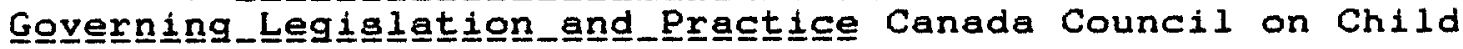
welfare Publication No. 17 (Ottawa: The Council, 1925); Canada

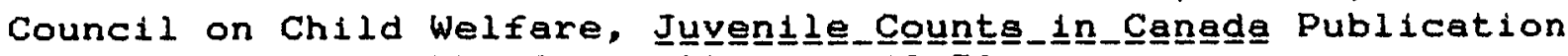
No. 121 (Ottawa: The Council), pp. 46-51. 
passibility that their antisocial behaviour was caused by emotional maladjustments. This supported the establishment of a new branch of psychiatry called orthopsychiatry. Orthopsychiatry was defined by practitioners as "the endeavour to obtain straightness of mind and spirit." Orthopsychiatry and mental hyglene developed paychotherapeutle methods for children which contributed to the formalization of child paychiatry in the United States in the 1930s. 6 This progression was not characteristic in Canada.

Mental hygienists were, nonetheless, vocal in their arguments for psychiatric services attached to juvenile courts in order to conduct mental examinations. 7 In spite of the Canadian National Committee for Mental Hygiene's advocacy, which claimed that 69 per cent of the children brought before the court were defective, the argument was not embraced by the courts. 8 The

6. Lawson Lowrey, "Orthopsychiatric Treatment," in Lawson G.

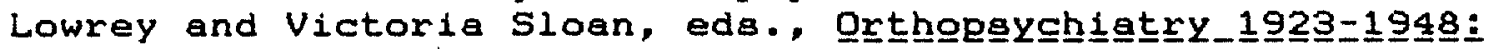
Retrosgeect_and_Prospect (Methasha, Wis.: George Banta for the American Orthopsychiatric Association, 1948), pp. 524-49; also see in the same volume, "The Birth of Orthopsychiatry," pp. 190210, and William Healy and Augusta Bronner, "The Child Guidance Clinic: Birth and Growth of an Idea," pp. 14-19.

7. See for example, Colin K. Russel, "The Feebleminded in

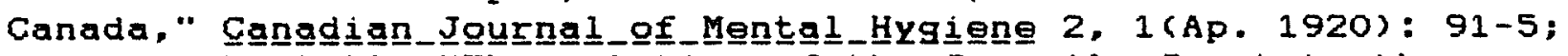
Helen G. MacGill, "The relation of the Juvenile Court to the Community," Ganadian_of﹎. Menta﹎.Hyqiene 1, 3(Oct. 1919): 232; C.K. Clarke, "Juvenile Delinquency and Mental Defect," Canadian

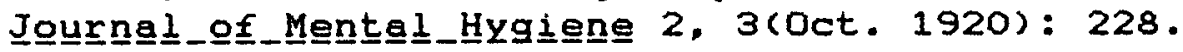

8. Helen MacMurchy, "The Relation of Feeblemindedness to Other Social Problems," in National Conference of Charities and Corrections, Proceeedings XLIII(1916): 229-35; Helen MacMurchy,

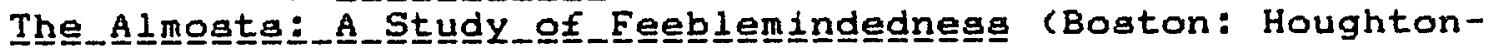
Mifflin, 1920). 
Canadian court's parens patriae mandate was not enhanced by a psychiatric perspective. Charitable intervention into child life was considered a benevolent responsibility based in "a broader application of the parental spirit, a profounder faith in the power of affection to chasten and discipline." 9

The problem of the lack of personnel trained in paychiatry was noted in a 1920 survey of the juvenile courts by the CNCMH 10 Six courta were described. Winnipeg was found to have the most complete child guidance service. The presence of a psychiatrist attached to the Winnipeg juvenile court was a unique addition matched only in Canada by the Toronto court. The court in Winnipeg was sustained in part by funds from the provincial government of Manitoba. It boasted a separate judge who did not serve in other courts and who was salaried as were the three probation officers and a school attendance officer. Up to the time of the survey 1289 children had passed through the court. In spite of its status as the best court in Canada, actual physical and mental examinations were not routinely conducted except with "repeaters." 11

The minor psychiatric emphasis in Canadian child guidance did not preclude the development of a case study approach to

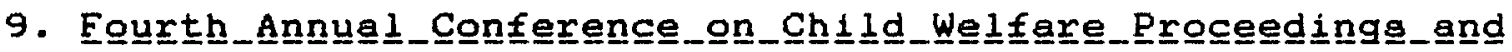
Pagers, winnnipeg.1923 (Ottawa: King's Printer, 1923), see Judge Harkeness' comments, pp. 163-5; Sutherland, Chilildxxen, p. 131 for a discussion.

10. Mundie, "Juvenile Courts in Canada."

11. Mundie, "Juvenile Courts in Canada." 
welfare services with children. Such services were often conducted with the help of voluntary organizations instead of professionals. The CNCMH report on court clinics found that with the cooperation of other social agencies a "great deal" of the cases were followed up on some kind of a routine basis. Even with the volunteer follow up services only 28 per cent of the cases were put on probation in Winnipeg. Montreal, in contrast, paroled 75 per cent of the casea. Approximately one-third of the children in Toronto were paroled, a figure closer to Winnipeg. The CNCMH does not offer an explanation for this discrepancy but lamented the fact that very few children were remanded to full-time institutional care by any of the courts. 12 Clarke and Hincks remained convinced that delinquency was an indication of genetic abnormality.

\section{Child Immigration and Mental Hygiene}

The child immigration issue, in many ways, superceded the Juvenile delinquent issue in Canada. Immigration was an early concern of U.S. mental hygieniste such as Thomas Salmon. 13 In the period between 1891 and 1921, the Canadian population increased from almost five million to almost nine million. 14 In

12. Mundie, "Juvenile Courts," pp. 276-7.

13. J.D. Page [Chief Medical officer of the Port of Quebec], "Immigration and the Canadian National Committee for Mental

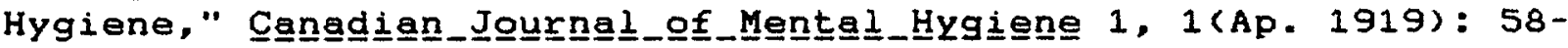

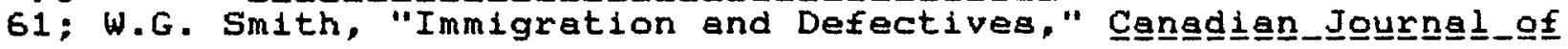
Ment므_Hygiene 2, 1 (Ap. 1920).

14. N.C. Urquart and K.A.H. Buckley, eds., Higtóníical

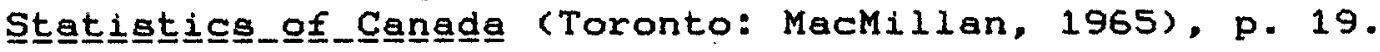


the Weatern provinces up to 42 per cent of the children under ten years old had parents who were foreign born. 15 Increases in the foreign born population was argued to contribute to social problems from criminality to labour agitation. 16 The objective was not to stop immigration but to ensure "quality" immigrants. Child migration was a special case of concern to Canadian mental hygienists. Between 1869 and 1919, 73,000 children were sent from various part of the United Kingdom to Canade under the auspices of charitable organizations. The earliest group came from the Kirkdale Workhouse in Liverpool under the supervision of Maria S. Rye, followed shortly by children from the Revival Refuge and Home of Industry of Spitalsfield, London with Annie MacPherson. 17 Even though the practice was critically reviewed with regard to its benefits for children, child savers connected

15. Canada Dominion Bureau of Statistica, Cenginug vol. 1 (1921), pp. 542-3; vol. 2, pp. xil-xiii; also see Warren

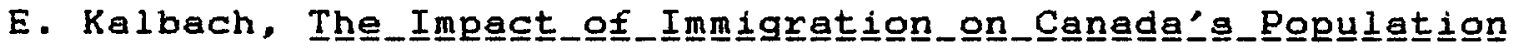
(Ottawa: Dominion Bureau of Statistic, 1970), pp. 71-4, 87-93.

16. W.G. Smith did a study of immigration from the mental hygienists viewpoint which was published in four articles:

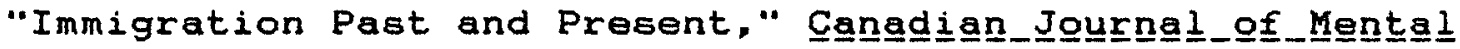
Hyqiene 1, 1 (Ap. 1919): 47; continued 1, 2(July 1919): 130; "Oriental Immigration," CJMH 1, 3(Ap. 1920): 73; C.K. Clarke, "Report of the Medical Director," in CJMH 2, 3(Oct. 1920): 252-

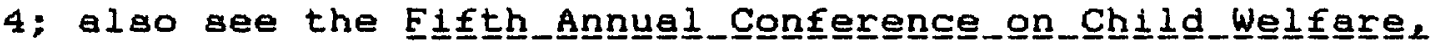

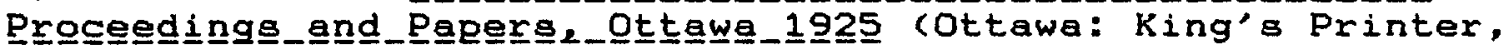
1925), p. 59 .

17. On the child immigration movement see, Joy Parr,

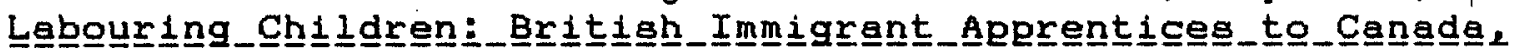
$1869=1924$ (London: Croom Helm, 1980); Gall H. Corbett, Baxnnaráno

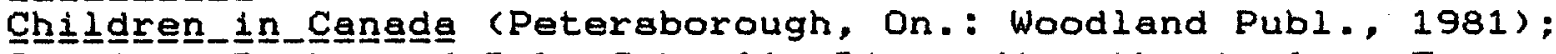

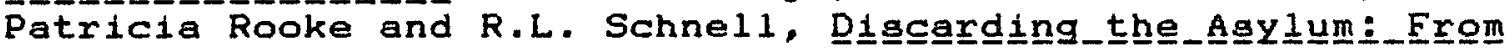

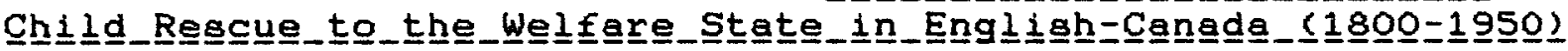
(Landham, Md.: Univ. Press of America, 1983), Ch. 7; K. Begnell,

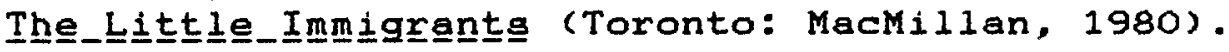


with organizing the movement saw themselves in confident and benevolent terms. 18 The rationale was to remove children from unhealthy environments and to provide them with the presumed advantages of Canadian society.

Canadian mental hygienists, with their eugenical concerns, took exception to this practice. They atressed the dangers of immigration policies which did not include strict regulations barring defective individuals. 19 Mental defects were interpreted as the root cause of social problems engendered by genetically inferior "low-class" immigrant populations. They were wary of the English Poor Law tradition of exporting the criminal, the pauper and the unhealthy. The CNCMH cited U.S. atatistics to illustrate the connection between foreign born and degenerate genetic stock which contributed to feebleminded and insane populations. 20 Canadians demanded that British officials, guch as those connected with the Barnardo Home, allow mental screening so that no defective child could enter Canada. 21

18. See Andrew Doyle's report, Emigraxation_on_of_Pauper__Chílidgren to으므므므 8 Feb. 1875; Canada Department of Immigration File no. 3115, "Inspection of Children - General File," vol. 1, (zerox);

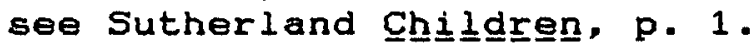

19. Jasper Halpenny, "One Phase of the Foreign Invasion of

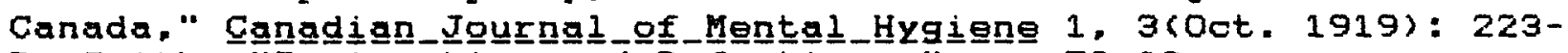
5: Smith, "Immigration and Defectives." pp. 73-89.

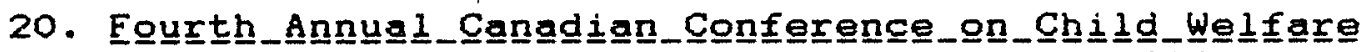
Proceegdings (winnipeg, Manitoba, 11-14 September 1923.)

21. Doyle, Emigration_of pauper_Chilldren ( 8 February 1875) 'Inspection of Children - General File,' vol. 1; Sutherland, Chilildren, ch. 1; Canadian Council on Child welfare, Prosegedings

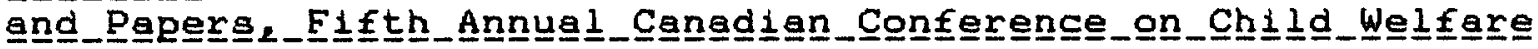
(Ottawa: 1925, Ottawa: Department of Labour, 1926), p. 189. 
The National Committee for Mental Hygiene and the Canadian Council on Child Welfare became actively involved in pointing out the dangers of child immigration in order to underscore their opinion that defective children had been admitted in the past. Clarke and Hincks drew upon their seven years of experience with cases from the Toronto General Hospital Soclal Servicea Department. They argued that of 840 unmarried mothers who gave birth in the hospital, eighty-one had been brought to Canada as girls by Barnardo officials. 22 They further claimed that between 1915 and 1924, of 131 women treated at the hospital who were known to have come to Canada under the auspices of a juvenile immigration agency, seven were insane and 131 mentally defective. Barnardo children were argued to have become a burden on the provincial government. 23 Records were compiled by C.K. Clarke, his son Eric Clarke, and Clarence Hincks, on 125 Barnardo children whom they examined between 1917 and 1924 . Over half of the children were identified by Clarke and Hincks as mentally defective, insane or "soclally diseased."

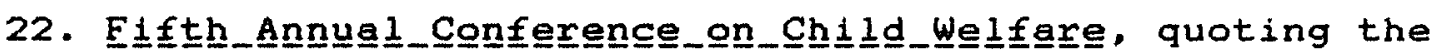
Toronto Generai Hospital Social Service Department, Soc1al

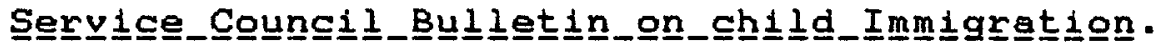

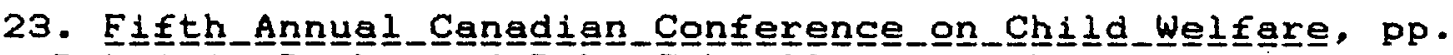
188-9; Patricia Rooke and R.L. Schnell argue that immigrant children actually had more psychological problems than other children because of abuse, neglect and the traumatic experience of immigration. See, "The King'g Children in Engligh Canada: A Psychological Study of Abandonment, Rejection and Colonial

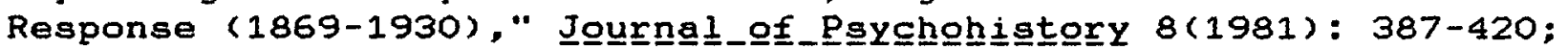
and, "Imperial Philanthropy and Colonial Response: British

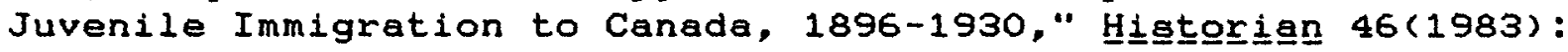
56-77. 
These inflammatory views were spread with same success in public and professional forums such as the Canadian Conferences on Child welfare. In spite of the fact that one delegate to the 1925 Conference felt that "it was easier for a sinner to get into Heaven than for an emigrant to get into Canada." the general consensus of the meeting appeared to aupport the CNCMH'a view that immigration policy was a disaster. The unknown extent of the problem of the number of defectives in Canada supported the CNCMH'a contention that survey work was needed. 24

\section{Eugenica, the Survey and Clinic in Canada}

The period between 1918 and Clarke'g death in 1924 was the first phase of organized canadian mental hygiene. 25 Surveys conducted by C.K. Clarke and Clarence Hincks were an important part of the early work. The provincial surveys gathered statistics in juvenile courts, gaols, schools, homes for dependent children, industrial schools, hospitals for the insane and retarded. The search for "mental abnormala" included "insane, feebleminded and epileptic" classifications in populations ranging from dependent children and delinquents to prostitutes, Immigrants and criminals. The surveys were also used as "educational" devices to influence provincial politics and 189.

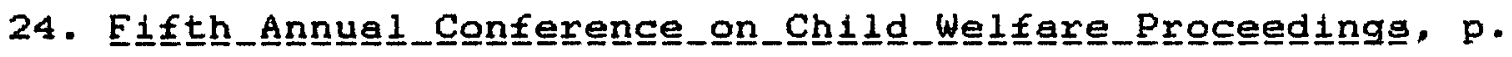

25. Canadian Medical Association, Canadian_Natínonal

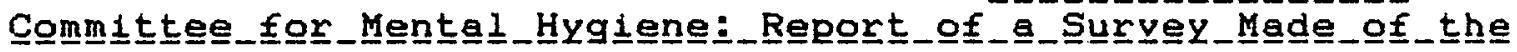
organizat ín divides the early activities of the CNCMH into three phases: $1918-1923$; $1924-1928$; and 1928 to 1932 . 
institutions as well as urban legislation, where possible, concerning any organization which served children. 26 The survey work most clearly approaches a search for a definition and formalization of categorieg of abnormality. 27 The work in Ontario and Quebec was especially interesting since the National Committee was the most active in these provinces.

In Toronto, the connection between the staff members of the National Committee for Mental Hygiene and Toronto General Hospital was critical to the organization of the movement. C.K. Clarke and Hincks conducted a comprehensive review of the work of the psychiatric clinic from April 1914 to April 1922. The survey included 5,600 cases which had been classified by the clinic out of over 6,000 referrals. 28 The clinic served both child and

26. For example, Clarke and Hincks arranged to keep the Manitoba survey confidential if reforms were carried out by governmental officials. Over $\$ 2 \mathrm{million}$ was, in fact, spent over the next three years on mental hygiene related public works. A

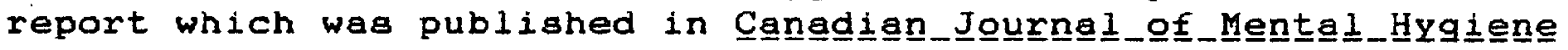
1, 1 (April 1919), applauded the government. This was in sharp contrast to the grim "Confidential Report," of the "Survey of Manitoba," (1918), especially in 1ts description of the "Home for Incurables, October 8, 1918." J.M. Armstrong, the Provincial Secretary thanked Hincks and attributed the reforms in Manitoba to the CNCMH, J.M. Armstrong to C.M. Hincks, 14 March 1919 , Hincks Papers, Greenland Griffin Archives, Toronto.

27. See "Mental Hygiene Survey of British Columbia," Cange日 Hygiene Survey of the Province of Sagkatchewan, CJMH 3. 4 (Jan. 1922); "Nova Scotia Survey," CJMH 3, 1 (April 1921); "Survey of the Province of Manitoba," CNㅡㅂ 1, I (April 1919): other surveys and the confidential reports are in the Greenland Griffin Archives, Toronto.

28. C.K. Clarke, "Study of 5,600 Caseg Passing Through the Psychiatric Clinic of Toronto General Hospital; also "a Study of 767 Cases of Illegitimacy," part of "CNCMH Study of Toronto General," (typescript), Greenland Griffin Archives, Toronto. 
adult populations but the number of minors under twenty years of age constituted 62 per cent of the case load. This included 212 infants between the ages of one and five years, and 816 school age children between $s i x$ and ten years. Preadolescents and adolescents constituted the largest age group with 1788 cases between eleven and fifteen years. 29 There were alightly more males than females. Clarke listed 280 cases of "Juvenile psychosis." He typed 168 juveniles as having dementia praecox, 25 of which were cited as having a combination of dementia praecox and mental deficiency. Another 44 children were clasaified as psychopathic, 28 as epileptic, 13 with general paresis and 2 as manic depresaives. Of the 130 children referred from the immigration service and subsequently identified as retarded, all but 3 came from the Barnardo Home. 30

Sources of referral to the Toronto clinic included the public health department, public achoola and social agenciea as well as the juvenile court. Clarke noted that "before the establishment of a psychiatric department in connection with the juvenile court the great majority," of these defective children would have simply been labeled "delinquents." 31 Clarke and Hincks were aware that their insistence on the genetic abnormality of delinquents conflicted with other studies in the United States, notably Healy and Bronner. Clarke's argument was

$$
\begin{aligned}
& \text { 29. Clarke, "Study of } 5,600 \text { Cases." } \\
& \text { 30. Clarke, "Study of } 5,600 \text { Cases." } \\
& \text { 31. Clarke, "Study of } 5,600 \text { Cases," p. } 1 \text {. }
\end{aligned}
$$


that child immigration in Canada had encouraged the entrance of defective children which added to other problems such as delinquency and prostitution. Clarke saw a need for early identification and he recommended permanent institutionalization to prevent immoral behaviour and the spread of defective genes. One nineteen year old girl listed with a mental age of twelve was used as an example. She left school to work when she was fifteen years old. She began to frequent "dance halls" and was once caught stealing. Due to the fact that there was nothing unusual In her appearance, Clarke found her prognosis poor especially in that her "good looks make it difficult to save her from hergelf and society from her evil influence." 32

Clarke used three general categorical types under the term mental abnormality: mental deficiency, mental diseases and deviant conduct. Sometimeg intelilgence tests were used to determine mental incompetence but Clarke often made observational determinations of pathology which had little objective grounding in scientific fact. Clarke's use of labels included Goddard's unfortunate categories of mental deficiency as morons, imbeciles and idiots. He also used such descriptions as: "feebleminded, moral imbeciles, dull normals, slightly mentally retarded and apparently normal." To add to the confusion Clarke added high and low grades in his determination of defectiveness. One fourteen year old was cited as having a "gluggish brain" because

32. "February 1, 1921 - April 22, 1921," in "CNCMH Study of Toronto General," Greenland Griffin Archives, Toronto. 
"she does not know the name of Lake Ontario and says Toronto has a population of one million." 33

Clarke also included behaviour as a category of mental abnormality. Individuals typed as odd, disruptive or immoral could be recommended for special classes, permanently institutionalized or deported in apite of an "apparently normal intellect." It is this group which fits most closely with the early studies on juvenile delinquency which brought Thomas Salmon, the Commonwealth Fund and the NCMH in the United States to child guidance and child paychiatry. For example, case descriptions from Clarke's institutional surveys of the Children's Aid Society, Women's Gaol Farm, and Victor Mission Rescue Home in 1922 and 1923, describe children and youth from one to nineteen with a series of disparaging labels. 34 Most objectionable were individuals clarke considered immoral or who had bad habits such as "selling booze." This also included thieves, truants, weak characters, and "dope fiends." Children with undesirable associations were variously interpreted as: "frivolous, carefree, vagrant, incorrigible or easily led." other children are cited for faults such as running away, not dressing themselves properly, not being able to read, having speech problems, "acting childish," being ignorant of information which

33. "February 1, 1921 - April 22, 1921."

34. CNCMH reports and notations by Clarke and Hincks or the secretary Marjorie Keyes, on surveys are in Greenland Griffin Archives. Toronto. They are unclassified or were in the process of being classified during my visit. 
Clarke personally considered obvious. Clarke was critical of children who he felt were untruthful or lazy, faults which he Identified with a "lack of ballagt," a euphemism for a lack of emotional stability or maladjustment.

Clarke did not digtinguigh developmental differences between adults and children. He used quasi-psychiatric terms when he felt the child indicated a potentially chronic mental dysfunction.

This included designations such as "psychopathic, general paresis, manic depresgives or dementia praecox," as well as the lesa formal "nervous types, the emotionally unstable and shallow natured." Physical stigmata were considered indications of mental dysfunction. Such descriptions ranged from poor teeth, eyes or hearing, to the shape of the cranium, ears, hand or palate. One child simply "looked odd."

It lo significant that clarke saw all of these types of abnormal designations under the more general heading of mental diseases and that he saw them as biologically based, morally offensive and potentially dangerous. Labels were indiscriminately applied to all age groups, although the younger children were more likely to be deferred for future follow ups. The records of one eight year ald where diagnosis was supposedly deferred described him, nevertheless, as "not to be trusted." Clarke observed that he had "behaviour faultg" and that he was at minimum "bad tempered."

A few children received positive reports. One child of eight with a mental age of over nine was credited as being "no trouble" 
and "good natured" even though she was illegitimate and her mother was listed as a "moron." Another child of seven, also illegitimate who also had a "speech defect" and was "deaf" nevertheless received the favourable note of "seeming bright [and] plays."

As Medical Director, C.K. Clarke dominated this period along with Clarence Hincks in his position as Secretary and Assistant Medical Director. Clarke's preoccupation with segregating the abnormal from the normal dominated the focus of the National Committee. This was consistent with clarke's perspective on the role of psychiatry and the danger to soclety of the mentally 111. It also followed from his disagreement with paychoanalytic theory and the underlying continuum between normality and abnormality. Many of the documents produced by the CNCMH during this perlod tended toward what Adolf Meyer earlier had identifled as "legislative propagandizing" rather than scientific research. Eugenical studies on mental retardation historically tended to be nonacademic and inflammatory. Works such as Richard L. Dugdale's study of the Juke family in 1874 described the dependent and delinquent as genetically defective. Eugeniciats argued that such families produced generations of diseased criminals, prostitutes and paupers. 35 Clarke followed in this tradition.

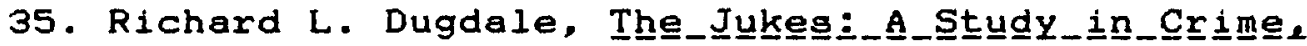
Pauperigm, and Heredity (New York: Putnam's Song, 1874, 4th

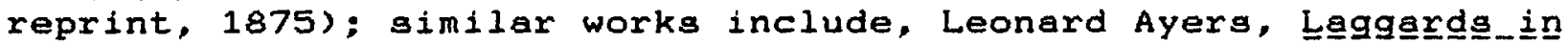

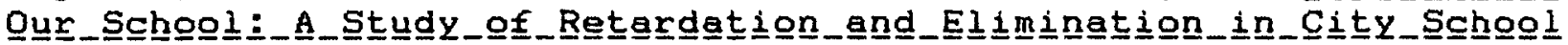
Systems (New York: Charitiea Publication Committee, 1908); Henry

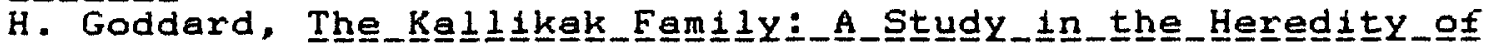

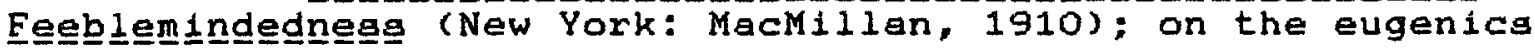




\section{Psychiatry in Montreal}

The mental hygiene movement in Quebec was also grounded in its earliest stages in a eugenical approach to mental problems. As early as 1894, the National Council of Women had vaiced an interest in "different" children. The next year hereditary factors were discussed as aignificant in the case of feebleminded women. It was suggested that local councils throughout the Dominion make an inquiry. One hundred and fifty reports were returned from the province of Quebec. 36 Failing to interest government officials in adult "defectives" the Montreal Local Council decided to concentrate efforta on backward children. In 1904 they conducted a survey of gaols, asylums, hospitals and schools. The next year the Council asked the Protestant Board of School Commissioners to open special classes for retarded children. This group continued to be active and to petition the government and ather officials for clinics, special schools and Juvenile justice reform. Delegations were sent from Montreal in 1915 to Sir Robert Borden requesting the establishment of a Royal Commission on Mental Hygiene. In 1918 another delegation petitioned the Dominion government to establish a bureau of public health devoted to child welfare, vital statistics,

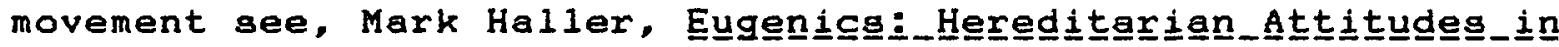
A mer 1 can_thought (New Brunswick: Rutgers, 1963); Richard

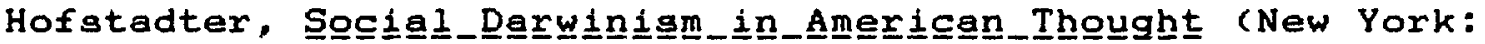

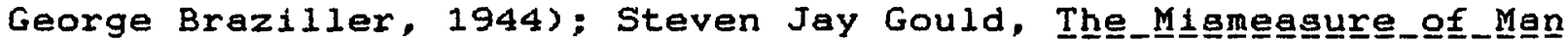
(New York: Basic, 1982).

36. Carrie M. Derrick, "The Montreal Local Council of Women

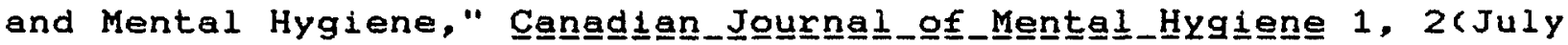
1919): $141-4$. 
venereal disease and mental hygiene. 37

The Montreal Council set up a booth on eugenica and mental hygiene at the 1918 Baby Welfare Exhibit. They succeeded in attracting the attention of Sir Lomer Gouin in their description of the relationship between "heredity, feeblemindedness and other social problems." 38 This exhibit served a purpose parallel to the 1912 exhibit of the U.S. National Committee. Upon requeat it toured other provinces after the Baby Welfare Exhibit cloged. 39 The Montreal office of the CNCMH, which opened March 1 , 1919, was more paychiatric and medically inclined than the Toronto group. The President of the National Committee, Charles F. Martin, was in charge of the Quebec section. His attitude toward mental hygiene differed from Clarke'a. His concerna were understandably more medically oriented in that he did not come from a background in institutional psychiatry but in academic medicine.

C.F. Martin took advantage of the presence of the first class medical school at MCGill University. Martin was a spokesman for medical education. His father-in-law was on the Board of Directors of the Royal Victoria Hospital. The close connection between McGill Medical School and the Hospital helped to secure

37. Derrick, "The Montreal Local Council."

38. Derrick, "The Montreal Local Council."

39. I.N. Cole, "Mental Hygiene and the Baby Welfare Exhibit

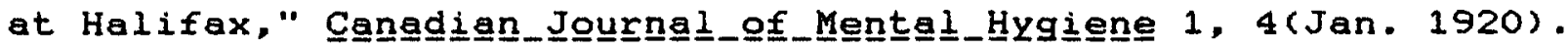


Rockefeller funds for expansion in 1920. 40

Martin's first official action as President of the Mental Hygiene Committee was to formalize a clinical psychiatric service in Montreal. Twelve days after the opening of the Quebec office of the CNCMH a part-time outpatient clinic was set up at the Royal Victoria Hospital. The clinic was held every Wednesday afternoon and served both adults and children. It was supervised by Colin Russel, Gordon Mundie and A.G. Morphy. They were assisted by one full-time social worker and two part-time social workers. In the first geven monthg 188 patienta were examined. 41 Psychiatric services had been nominally provided by Colin Russel prior to the Royal Victoria Hospital Clinic. The clinic opened with four physicians who had received training by William Tait, a professor of psychology at MCGill University. The early referralo were dominated by mentally deficient patienta. This reflected the eugenical emphasis of the early work by the Montreal Local Council of Women. Gradually, however, a larger variety of patients was seen as referred by the Family Welfare Association, the Women's Directory, the Children's Bureau, the Catholic Social Service Guild and the Federation of Jewish

40. "Report of the Proceedings of the Second Annual Meeting," Vancouver, B.C., 22 June 1920, CMHA Papers, MG 28 I 391, PAC, Ottawa.

41. "Report of the Associete Medical Director, Montreal, P.Q." in the "Report of the Proceedings of the Second Annual Meeting of the Canadian National Committee for Mental Hygiene," Vancouver, B.C., 22 June 1920, pp. 7-9, CMHA Papers, MG 28 I 391 , PAC, Ottawa. 
Philanthropies. 42 Among the 701 patients tabulated by 1922 , there were 10 infants and 278 adolescents. Male adolescents slightly outnumbered the females just as in Toronto. This was said to be due to the fact that the juvenile court predominantly referred males. However, of the adult group three-fourths of the patienta were female. Court and aocial agenciea referred approximately the same number of patients. In comparison with the 156 court referrals there were 65 medical referrals from doctora and only 15 patients referred from family sources. 43 A little over one-third of the patients were determined to be feebleminded, one-quarter delinquent and one-fifth insane. A very small group of three percent were determined to be "paychoneurotic." 44

The problem of juvenile delinquency was considered an important issue in Montreal but it was only the non-Catholic Juvenile Court Committee which granted permission to have children examined by a psychiatrist at the clinic. Addresses before the Kiwanis Club and Rotary Club were made and a petition sent to Premier Taschereau to try to persuade him to use his influence to allow all children in the court to be screened. Cooperation was solicited from the Health Department under Dr. Boucher but the majority of the mental hygiene work continued to

42. Gardon Mundie, "The Out-patient Paychietric Cinic," The

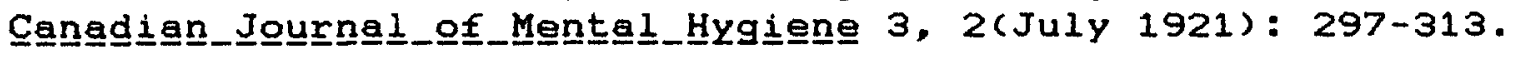

43. Mundie, "The Out-patient Psychiatric Clinic."

44. Mundie, "The Out-patient Psychiatric Clinic." 
be directed toward the English-gpeaking population. While the Quebec government allowed A.H. Deslodge of the Montreal Branch of the CNCMH to examine the children in the Boys' Farm and Training School at Shawbridge and to look into improving the classification of inmates of insane agylums, it avoided comprehensive public policies in mental hygiene in agencies which resisted interference. 45

In October of 1919 permission was granted for a survey of all of the pupils in Protestant Public Schools in Montreal. The original suggestion for the survey was in 1913. 46 Eight schools were surveyed and 355 children recommended by teachers were given the Stanford Binet individual intelligence test and 440 children were given the otis Group Intelligence Tests. All students were also "examined for neurotic conditions, paychosis and physical defects." 47 The primary purpose of the testing was to encourage the provision of special classes. The published version refers to Adolf Meyer's description of training "emotional needs." William White is also cited ag an authority who encouragea training geared toward individual difference with the goal of the child's "greatest efficiency and happineag." While mental testing was

45. "Minutes of the Combined Meeting of the Executive and Finance Committees," 17 February 1922, pp. 1-4, CMHA Papers, MG 28 I 391, PAC, Ottawa.

46. A.G. Morphy and William D. Tait, "Mental Hygiene Survey

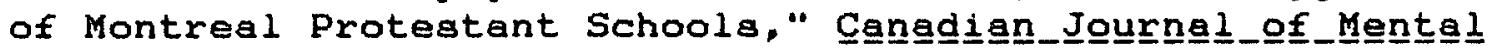
Hygiene 3, 1(April 1021): 49-53; "Report of the Proceeding of the Second Meeting," p. 8.

47. Morphy and Tait, "Mental Hygiene Survey." 
instrumental to the survey, the results of such tests were down played as only one of many tools for assessing children. 48

A similar study was done in non-Catholic achools in Toronto at about the same time by E.J. Pratt. 49 The differences between the two studies is interesting. The Toronto study was an exhaustive study on one school rather than a broader survey. While the Toronto study was considered to use a "paychiatric" approach in understanding "moody isolation," "explosive and irresponsible conduct," and "apathy or responsiveness," the emphasis was not on happiness or internal mental processes. Instead the focus was on identifying how children could be "efficiently" directed toward "industrial life." The intelligence scores were correlated with social factors such as gendex, father's occupation and the overall health of the child. 50 It was this type of nonpsychiatric social and occupational adjustment which was to dominate Canadian mental hygiene in the years to come. While the Montreal group was generally more

48. Morphy and Tait, "Mental Hygiene Survey;" William A.

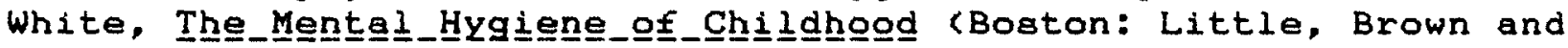
Co, 1919). White was a U.S. psychiatriat interested in child mental health. He contributed to the integration of psychiatry and paychoanalytic theory. See Gerald Grob, The_Inner_world﹎o요

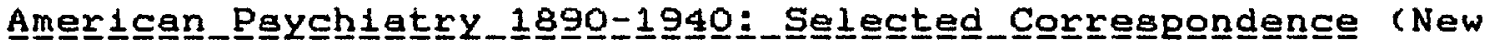
Brunswick: Rutgers, 1985), p. 106 .

49. E.J. Pratt, "The Application of the Binet-Simon Tests

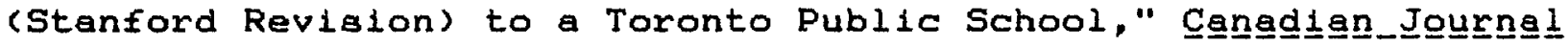
of Menta﹎_Hygiene 3, 1 (April 1921): 95-116.

50. Pratt, "The Application;" "Minutes of the Firat Meeting of the Sub-Committee on Educational and Industrial Paychology of the Canadian National Committee for Mental Hygiene," 3 December 1920, CMHA Papers, MG 28 I 391, PAC, Ottawa. 
oriented toward psychiatric and medical perapectives there was nothing to match the impact of medicalization in the United States.

\section{Britioh Survey of Child Guidance}

Differences in the Canadian and U.S. perspectives on child guidance are 1llustrated by a British survey of child guidance in 1928. In this year the London County Council sent a delegation to the United States and Canada to tour child guidance facilities. 51 They visited Montreal; Toronto; Roone, New York; Chicago; Washington D.C.; Boston; Yale Univeraity in New Haven, Connecticut and New York as well as mental ingtitutions in Massachusetts and New Jersey. The conclusions of the British delegation aheda light on the orlentation of Canadian policy away from psychoanalytic perspectives.

The Britiah observed that child guidance as an "American" invention had a wider impact in the United States than in Canada. The British concluded that social conditions in the United States created more delinquencies and maladjustments than other societies. The London Committee also concluded that the scope of child guidance which had begun with "the observation of child criminals," had become "altogethex wider than...expected." 52 It

51. Letitia D. Fairchild, "Child Guidance in America," London County Council Education Committee, Special Services SubCommittee, for information of members only, S.0. 450, enclosure 209A, 7 May 1928;" Fairchild was the Divisional Medical Officer. A copy of this was sent to the Commonwealth Fund, CF 66, RAC, $N$. Tarrytown, N.Y.

52. Fairchild, "Child Guidance," p. 1. 
was noted that the original object of dealing with delinquents had been transformed during the practice of the Commonwealth Fund programme. The report of the tour atates that: "this new emphasis on the constructive aspects of mental hygiene of childhood implies no abandonment of the specific aim of preventing delinquency, but rather the recognition that the best preventive technique is a broad and positive effort to redirect the energies of maladjusted children before they become problems in the community." Under the new expended definition of "problem children" came not only cases of "stealing, lyling, truancy, sex misdemeanour" but "a greet number of other failures and miafita whom our usual methods of handling entirely fail to relieve." 53 The Britiah found Canadian clinica more compatible with the child oriented work in London. Toronto and Montreal research and training in early childhood was said to resemble "theoretical work" In Britain for which they used the term "character training," 54 In Toronto, the mental hygiene efforts in school examinations were "simpler" than the United Statea counterparts and more easily adaptable to thetr own "efficient English school medical service." 55 The Cleveland guidance clinic was cited as the most "typical" clinic but it also differed most significantly from what the Committee found in either Toronto or Montreal. United States services differentiated from Britioh and

53. Fairchild, "Child Guidance," p. 1.

54. Fairchild, "Child Guidance," p. 6. 55. Fairchild, "Child Guidance," pp. 5-6. 
Canadian services in part because of the absence of governmental inspectors and full scale school health programmes. The clinics in the United States largely developed as privately funded and supervised enterprises rather than part of the publicly controlled services. The National Committee for Mentel Hygiene encouraged clinical services to remain under the auspices organizationg such as the Community chest because of problems they encountered with local public control. This tendency is referred to by the British delegation as the "peculiar political situation in American cities." 56

The object of the British Committee was to determine the advantage, if any, of introducing a programme of child guidance to London schools. It was concluded that the child guidance clinic was only marginally relevant to British child life even though the "essential causeg" of problems in childhood would be the same. The author or the report, Medical officer, Dr. Letitia Fairchild observes that "it is certainly true that there are more "problem children in America than in England, or rather I think It would be fairer to the children to atate that the American child finds life presents a harder problem to him than the English child." 57 Fairchild saw children in Canada and the U.S. as having cultural and generational conflicts unheard of in Britain. In the United States especially, racial problems, families disrupted by divorce, and urban violence are cited as a

56. Fairchild, "Child Guidance," p. 4.

57. Fairchild, "Child Guidance," 10. 
shocking heritage. Fairchild also saw children in the United States as additionally burdened by a competitive atmosphere and an overemphasis on standardized tests where the examiners lacked a benevolent consideration of the child. These factors were seen as contributing to a pressure to conform and to standardize child life in a way which caused maladjustment and delinquency. 58

"Getting Everybody Upset Over the Child."

The Canadian mental hygiene movement was similar to the United States movement in than it popularized a medical perapective in eliminating social problems prior to any substantial advances in scientific research concerning the causes or cure of mental abnormality. The movement tended to propagandize public policies more that it advanced scientific knowledge. Canadian mental hygienists, as did their U.S. counterparts, tended to do what Adolf Meyer found most irritating

58. Fairchild, "Child Guidance," p. 10. It is unknown how representative Fairchild was of the opinion of the other delegates. It is likely that her view was not extreme. It should be noted also that the smug attitude about the better conditions of British children over those in the United States in particular are contradicted by the problems of induatrialization, urbanization and poverty which plagued Britain. On Britiah child

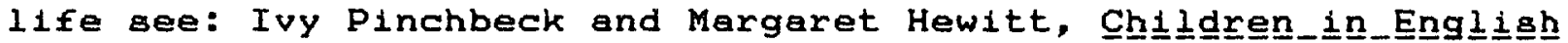
Socsiety 2 vols, From_Tutoo﹎.T1mes_to_the_Eighteenthh_Cent

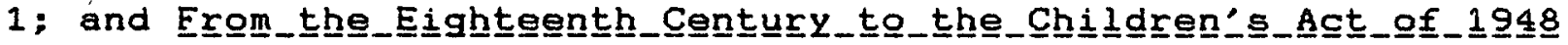
vol. 2 (Toronto: Univ. of Toronto, 1973); see also Neil

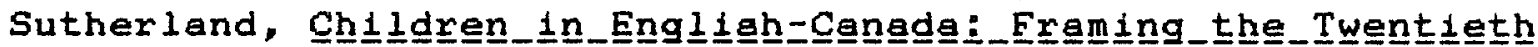
Centuㅗy_Congengua (Toronto: Univ. of Toronto, 1976 , reprint 1982); and Thomas E. Jordan, "Stay and Starve or Go and Prosper!' Juvenile Emigration from Great Britain in the

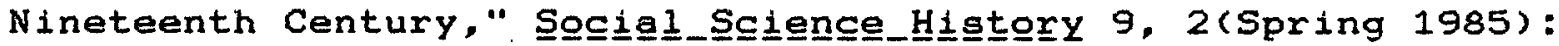
$145-66$. 
in getting "everybody upset over the child." 59

Unlike the U.S. movement the Canadian tended to use biological criteria rather than a psychiatric orientation toward the child. They emphasized eugenics and public health. This was reinforced by the sources of funding support for the CNCMH.

Early resources for mental hygiene came from Canadian contributions to the Lady Byng of Vimy Fund established by the wife of the Governor General in March of 1922. Lady Byng contributed ten thousand dollars and Sir William Price offered fifty thousand. Other pledges ranged from twenty-five thousand to one thousand dollars. Recruited by Hincks and Beers, the CNCMH's patrons were counted among the most powerful and affiuent members of Canadian society. The interests of patrons encouraged work which cooperated with business, government and established voluntary benevolent agencies. This orientation drew the Canadian National Committee away from the professionalization of mental hygiene related disciplines and encouraged identification and affiliation with voluntary and quasi-governmental agencies.

Social work in Canada often relied on volunteerism to provide services throughout the 1920 s and 1930 s. The few trained social workers in Canada remained dependent on professional organizations in the United States. While Canadian social work was not large enough to become independent it retained a measure of distance in order to address the unique aspects of welfare

59. Adolf Meyer to Gerry Morgan, 2 July 1930. Adolf Meyer

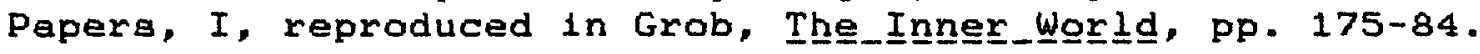


work in Canada." 60 The organization of workers in the mental hygiene related fielda of medicine, psychiatry, paychology and paychiatric aocial work was in general glower in Canada than in the United States. To the extent that projecta in preventive psychiatry required trained professionals, the lack of organization and expansion of professional personnel inhibited the movement. Advances in paychiatric social work in the United States was greatly encouraged after the first world war by the Commonwealth Fund Program for the Prevention of Delinquency. 61 The slowness of professional growth in Canada was partly due to the absence of funds and to differences in the timing and expansion of higher education. Rather than attempt independent organization Canadian professionals consistently gent delegationg to U.S. meetings and conferences.

The lack of professional atrength in welfare work in Canada

60. National Conference of Social work, Procoeedingag_Forty=

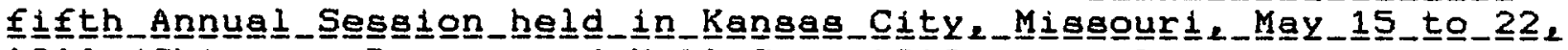
191 으 (Chicago: Rogers and Hall Co., 1919), see Frankwood Williams, "Division on Mental Hygiene," P. 509, also A.M. MacDonald, p. 35 .

61. See Porter R. Lee and Marion E. Kenworthy, Mentą 1 Hygiene_and_Social_borkk (New York: Commonwealth Fund, 1931); Lois

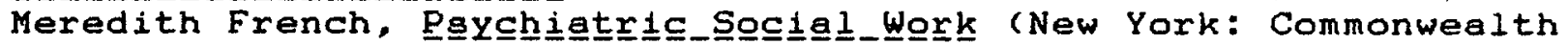
Fund, 1940); for secondary literature see Mary O. Furner,

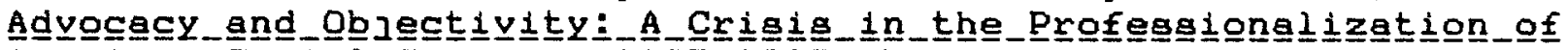

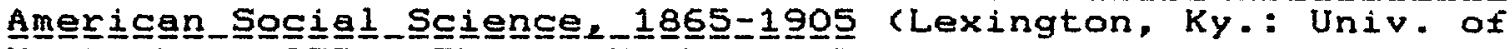
Kentucky, 1975); Thomas Haskeli, Emergence_of_Profesesionel_Social Scienence (Chicago: Univ. of Chicago, 1977); James Leiby, A_Hí

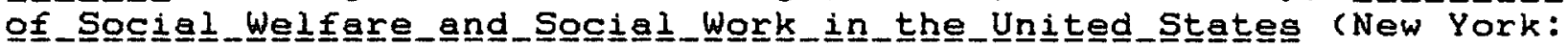
Columbia Univ. Press, 1978); Murray Levine and Adeline Levine, A History_of_the_Helping_Services (New York: Appleton-Century

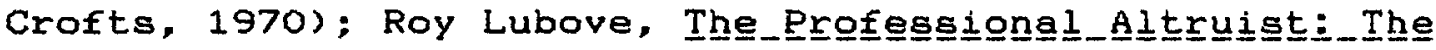

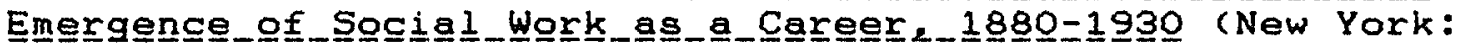
Atheneum, 1969). 
substantiated the strong charitable tradition. The Canadian Council on Child Welfare had a great deal of impact on the Canadian mental hygiene movement. The Council was composed of a number of affiliated autonomous agencies including the Canadian Association of Child Protective Officers, the Canadian National Committee for Mental Hygiene, the Canadien Social Hygiene Council, the Canadian Tuberculosis Association, the Religious Education Council of Canada, the Canadian Girl Guides Association, the Boy Scouts' Association, the Federation des Femmes Canadiennes-Francaises, and the Mothers' Allowance Commissioners of the Provinces. 62

The Council was an offshoot of the federal Department of Health which was established in 1920. In April, Helen MacMurchy was appointed as Chief of the Division of Child Welfare. That October she organized a cooperative council of 114 representativea of public and private agencies concerned with the health and welfare of children. The Council was mandated with the responsibility of organizing annual conferencea for educational purposes. However, under the aggressive leadership of Honorary Secretary, Charlotte Whitton, the Council assumed a central role in children'a policy in Canada. A national office was opened and Whitton became full time executive secretary. While the Council received secretarial help and some financing from MacMurchy's office, it was not a formal governmental body but remained

62. "Cooperating Agencies of the Canadian Council on Child

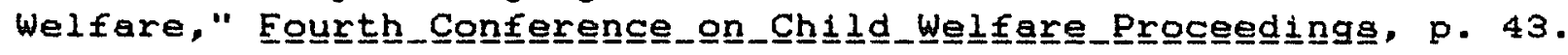


officially independent. However, the close link between the public and private realm is revealed in this case by the fact that when MacMurchy retired from the federal Division of Child Welfare in 1933, the Council asgumed the functions of the federal office. 63

In addition to providing a forum for discussion and a means of disgeminating ideas between profesaionals and volunteere whose diverge interests converged on children, the council contributed a massive publicity campaign directed toward the public. The

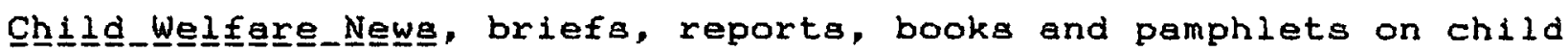
care and family life were distributed. 64 These works were complementary to the publications of the Division of Child Welfare auch as the widely dispersed Little Blue Book in the "Mother Series" written by MacMurchy. 65 MacMurchy's emphasis in this series helped shaped mental hygiene toward prevention in childhood as based in health care and socialization. The Council provided an ideal vehicle for the spread of preventive perspectives on child rearing. The Council's mental health

63. Norah Lewis, "Helen MacMurchy," May 1984; Charlotte Whitton, "The Canadian Council on Child Welfare, 1920." Cannagíian

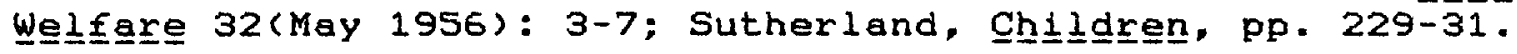

64. One of the first definitive books for Canadian professionals in child care was publiahed by the Council edited by Helen MacMurchy: Canada Department of Health, Handboooㅡ음

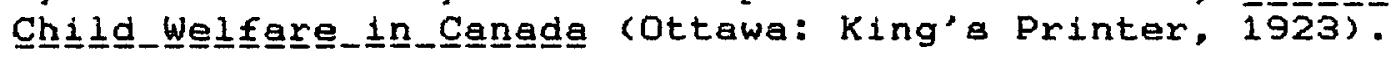

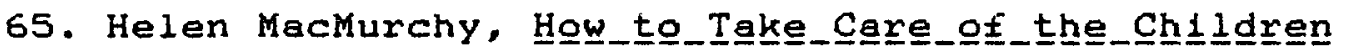
(Ottawa: King's Printer, 1923); between 1921 and 1923 the federal Health Department publiahed and diatributed 220,000 copies of

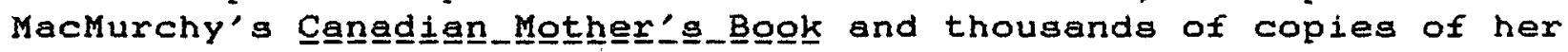
14 pamphlets in the "Little Blue Book" series, in addition to the Heㅡㅡ므므으․ 
interests in children was practical and applied. While both MacMurchy and Whitton encouraged fact gathering and scientific positivism, they did not encourage a psychiatric perspective. The character of Canadian mental hygiene was shaped by 1 ts ties to semi-official and governmental agencies concerned with disgeminating public health. 66 The Committee was also able to orient these other agencies toward mental hygiene perspectives which were compatible with their own interests. The Committee was deliberately conceived in this fashion. The Constitution stipulated a memberghip of 120 , one-third of whom were to be "recruited from the medical profession. The remaining two-thirds were chosen from recognized leadera in the Dominion." 67 The cooperation of voluntary and official advocacy for public welfare disallowed the Canadian Committee the autonomy which the U.S. Committee enjoyed in the pursuit of a psychiatric forum. It did strongly support the orientation toward public health in terms of preventive mental hygiene. It contributed to a collegiality in a kind of nexus of public and private power. 68

After 1924 the work of the Canadian National Committee for

66. See "Noteg and Newg," Canadian____ournngl_of_Mental__Hygiene 1. 3(Oct. 1919): 288-93, which ilsts other affiliations between CNCMH and voluntary associations and government.

67. "The Firgt Year of the Canadian National Committee for

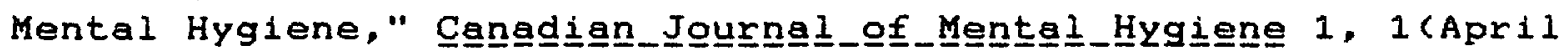
1919): $70-6$.

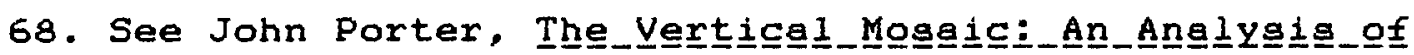

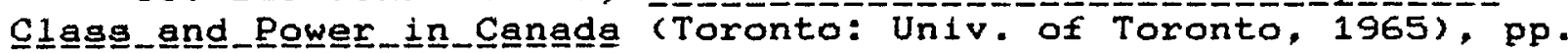
218-20; Wallace Clement, The_Corporate_Elite:_An_Angalysín_of

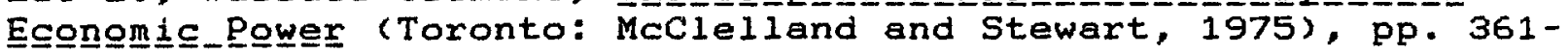
5 . 
Mental Hygiene was transformed by the input of funds from Rockefeller related philanthropy. The Foundation and its affliateg also encouraged coordinated support from government and voluntary donations in addition to its grants. The Rockefeller Foundation encouraged by way of matching funds the CNCMH's collegial relationahip with Canadian elites, governmental agencies and voluntary agencies such as the Canadian Council on Child Welfare. 69 The Rockefeller Foundation devoted millions of dollars toward Canadian public hygiene and child related demonstrations in the inter-war period. On the, 19 th of December 1919, at the executive meeting of the Rockefelier Foundation, a gift of fifty million dollarg from John D. Rockefeller Sr. was reported. He expressly noted that Canada deserved support in compensation for the prolonged war experience and that he would approve if part of the sum was devoted to medical education in Canada. 70 George Vincent, the President of the Foundation, wrote W.L. Mackenzie King, and other influential Canadians as well as the Deans of Medical Schools. At the February 25, 1920 meeting of the Foundation five million dollars were appropriated for Canadian public health and medicine. In May, after completing a survey of Canadian medicine, the Rockefeller Foundation voted

69. Tamara Hareven, "An Ambiguous Alliance: Some Aspects of American Influences on Canadian Social Welfare." His stoi트

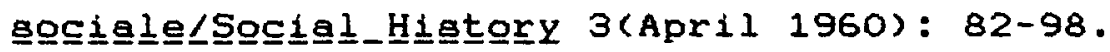

70. "The Rockefeller Foundation," 25 December 1919 (excerpt from a press release);" "Canada - Summary 1919-1920," RG 1.1, 427, 33, RFA, RAC, N. Tarrytown, N.Y. These gifta ralaed the total endowment received by the Foundation to $\$ 182 \mathrm{million}$. 
Dalhousie University half a million dollars for medical purposes. That September, McGill University and the University of Toronto were given one million dollars each to advance medicine and schools of public hygiene. The University of Manitoba acquired a grant of half a million and the University of Alberta and Universite de Montreal each a quarter of a million dollara. 71 These large sums of money to advance medicine and public health stimulated the professionalization of the disciplines critical to the mental hygiene movement.

The availability of support in public health areas encouraged the development of the movement in this direction. The eugenical emphasis of Canadian mental hygieniats conflicted with fundamental aspects of progressive reformism such as the juvenile court movement. The conflict was resolved after 1924 when the CNCMH atressed public hygiene as a part of their mental hygiene programme. This was compatible with "hygiene" as described by Adolf Meyer, as the "effort of medicine to make itself unnecessary." Medicine to Meyer included paychiatry. 72 Canadian

71. "Canada - Summary;" This file algo containg letterg to Vincent Massey and W.L. Mackenzie King as well as a correspondence over publicity which surrounded the disclosure of the gift. The Foundation disliked publicity primarily because it was often unfavourable. The question was raised whether the Foundation was dictating policy by such large donations.

72. See Adolf Meyer, "Objective Psychology or Paychobiology, with Subordination of the Medically Useless Contrast of Mental and Phyaical," Paper presented at the American Medical Association, San Francisco, June 1915, published in Jou

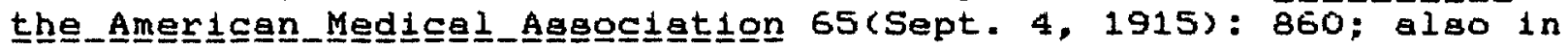

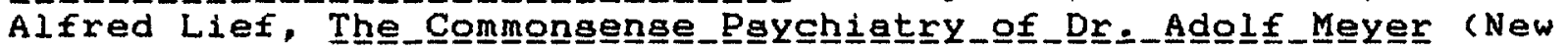
York: McGraw Hill, 1948), p. 397 . 
mental hygienista took this approach in trying to infiltrate "the normal ways of life with the means of obviating damaging conditions and processes." 73

Controversies over governmental responsibility for social welfare provided fertile ground for the shaping of mental hygiene perspectives. Mental hygiene was an optimistic paradigm in that 1t was ultimately concerned with prevention. As eugenical ideas shaped policies on what needed to be corrected in Canadian society, preventive public health opened opportunities for cooperative projects with other voluntary organizationa and government in the ultimate goal of building a healthy labour force and competent politicel constituency.

Preventive social psychology directed toward normal children combined with aggressive public health policies were characteristic of Canadian mental hygiene. They were also characteristic of the work of Rockefeller philanthropy in mental hygiene during this period. The Foundation and affiliated Rockefeller philanthropies devoted millions of dollars to child study research on normal child development in Canada and the United States between 1920 and 1940.74 It was in the area of child study research that Canadian mental hygiene made an international impact between 1924 and 1944 .

73. Meyer, "Objective Paychology."

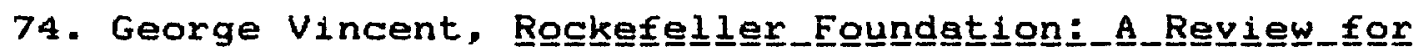
1926 (New York: Rockefeller Foundation, 1927), pp. 9-10; Rockefeller Foundation. Annual_Reportg (New York: Rockefeller Foundation, 1920-1940). 


\section{CHAPTER SEVEN}

\section{TRANSITIONS TO A MENTAL HYGIENE OF NORMAL DEVELOPMENT:}

\section{FROM MONMOUTH COUNTY TO TORONTO}

The mental hygiene movement contributed to a popular and professional preoccupation with reducing stress and making people happier and healthier. Mental hygiene in its early phases was not so much concerned with promoting adjustment. After the First World war preventive efforts to reduce mental defects and diseases were focussed on work with children. The objective of the mental hygiene movement evolved in two directions from this point on. On one hand, the objective was to classify and remediate abnormal behaviour. On the other hand, it was to Identify and preserve normal behaviour. This second orientation suggeated, in a new form, the turn of the century premige of the child-savers that the child who was not delinquent, defective or diseased should be "conserved" as a social asset. 1 Child savers and mental hygieniata similarly percelved that children needed to be trained to cope with a world which was increasingly complex and corrupting for the young and vulnerable. 2 Evolutionary

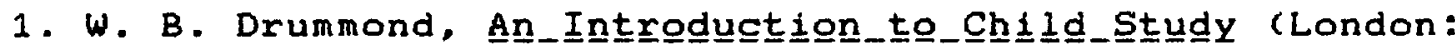
Edward Arnold, 1908); Arthur Holmes, The_Conservation_on_the Child (Philadelphia and London: J.P. Lippincott, 1912): Irving

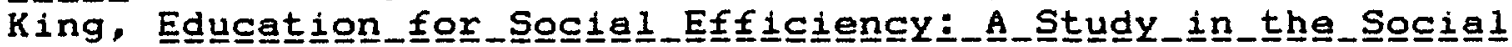

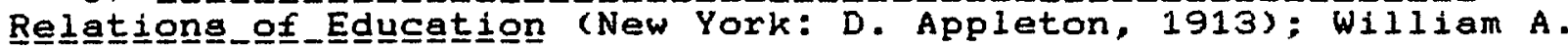
Mckeever, Training_the_Boy (New York: MacMillan, 1913); William A. White, The Mental_Hygiene_of_Childhood (Boston: Little Brown 1919, reprint 1923).

2. See for example, George C. Coe, What_Ailieg_Quㅍ﹎므느느? (New York: Scribner, 1926). 
theories and psychoanalytic perspectives suggested that biological and ingtinctual pasaiong had to be conformed to the contours of civilization in early childhood. 3

The challenge for mental hygiene after world War I was dual In the establishment of a science of normal development as well as the remediation and elimination of abnormality. The challenge of perfecting mental health also became a major focus of Rockefeller philanthropy. The Rockefellex Foundation supported mental hygiene from 1913 as the ultimate objective of preventive medicine. 4 Ironically, it was not any simpler to invent a science which fostered and preserved mental health than it was to found a science of curing illness or eliminating pathology.

In the United States Rockefeller philanthropy experimented with independent mental hyglene projects which eventually concentrated on child mental health rather than on illness. One aspect of the mental hygiene theme that became a major aspect of Foundation policy was the promotion of maternal and child welfare originally aupported through the Laura Spelman Rockefeller Memorial. It took a number of years to establish this positive

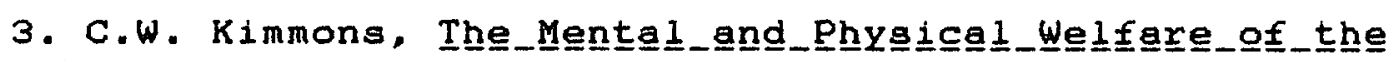
Chilild (London: Partridge, 1927).

4. Psychiatry was important under the leadership of RF Presidents George Vincent (1917-1929), Max Mason (1929-1936) and Raymond B. Fosdick (1936-1948), and Directors of the Medical Sciences, Richard Pierce (1919-1930), and Alan Gregg (1930-1954). See Raymond B. Fosdick, The_Story_of_the_Rockefellex_Foundation (New York: Harperg \& Bro., 1952); Rockefeller Foundation, Annnual Report (New York: RF, 1933), p. xviii; Raymond B. Fosdick, Thhe

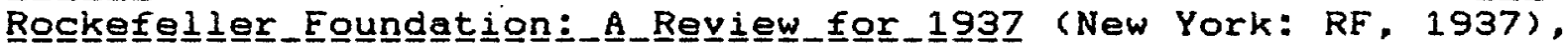
pp. 22-25, 26-27. 
mental health orientation concentrated in scientific research. Child study research attempted to provide the scientific basis for a developmental understanding of human life history from infancy through adolescence. Rockefellex policy in mental hygiene was first formulated in a demonstration project in Monmouth County, New Jersy and it was subsequently elaborated in Canada in child study research at the Univeraity of Toronto.

The Monmouth County Demonatration

The Monmouth County demonstration began as a joint project with the Commonwealth Fund, Rockefelier Foundation and the National Committee for Mental Hygiene. Monmouth County 1liustrates the split focus of mental hygiene as directed toward abnormality and normality. It illustratea the divergence of theae two aspects of the mental hygiene movement as they evolved into projects directed toward changing public practicea and policiea.

The Monmouth County demonstration was an outgrowth of the Rockefeller Foundation Gedney Farms Conference of 1920 and the Commonwealth Fund Lakewood Conference of 1921. The demonstration was a turning point in the eatablighment of the programme protocols which guided inter-War child development projects. At each of theae conferences Thomag Salmon put forth hia proposala for the prevention of delinguency as the key to the prevention of a variety of social problems from crime and dependency to immorality and insanity. The Commonwealth Fund subsequently undertook a programme foremat almilar to that deacribed by Salmon. However, the firat demonstration of Salmon's 
ideas under the programme was not supported by Commonwealth Fund money. It was supported by the Rockefeller Foundation. This project in Monmouth County. New Jersey is significant because it is a link between child guidance in the United States, the Rockefeller Foundation's independent support of mental hygiene, and, the extensive parent education and child development research projects initiated by the Laura Spelman Rockefeller Memorial in the mid-1920s in Canada as well as the United Statea. The Monmouth County Demonstration was the first project carried out by the National Committee for Mental Hygiene on the Prevention of Delinquency. It was initiated by a ten year old local voluntary association, the Monmouth County Organization for Social Service whose leaders constructed a proposal with Salmon in the early summer of 1921. 5 Geraldine Thompson, the president of the Monmouth County Organization, had approached walter B. James of the NCMH concerning the development of a programme to investigate the number of retarded children in the schools of the county. 6 James had directed the group to Salmon. "He was very

5. "Application to the Laura Spelman Rockfeller Memorial for an Appropriation of $\$ 12,000$ a year for a mobile mental hygiene clinic in Monmouth County, New Jergey," $12 \mathrm{July} 1921$, LSRM 3, 34, 558, RAC, N. Tarrytown, N.Y.

6. Concerns over the backwardness of the countryside in comparison with the rapid changes in urban centers flourished in the Progressive Era. Theodore Roosevelt appointed the Country Life Commisaion in 1907. In the inter-War years rural sociology was a burgeoning applied science. See Paul H. Landis, Rura 1n_Procega (New York: McGraw-H1ll, 1940); Thomas James," Applied Social Science and Planned Change in Education: The Case of Rural Sociology and School Consolidation," paper presented at the History of Education Society Annual Meetings, Stanford University, October 17, 1986. 
much interested," recalled Mrs. Thompson. He "said that the whole question of mental retardation and the problem of unadjusted children was an integral part of the problem of juvenile delinquency." The final proposal which was approved by the LSRM Board on October 7, 1921 was geared toward a vision of community, school based preventive work with children. 7

The LSRM thoroughly investigated the proposal and with Salmon's urging agreed to a five year demonstration. Twelve thousand dollars a year for two years was appropriated with work to begin in January of 1921 . 8 A reevaluation was to take place in late 1923 to secure funding for the remaining three years of the demonstration. Both the NCMH and RF were aware of Salmon'a intention to accept a position in paychiatry at Columbia University Medical School. V.V. Anderson; a staff member of the NCMH was to take over Salmon'a position. Salmon remained a consultant. The Commonwealth Fund's new director, Barry C. Smith, assumed that the Monmouth County demonstration was to proceed as if it was a Commonwealth Fund project but with appropriationg

7. Geraldine (Mrg. Lewis S.) Thompgon quote, "Conference Laura Spelman Rockefeller Memorial in Connection with the Monmouth County Organization for Social Service," 11 February 1926, LSRM 3, 34, 364, RAC, N. Tarrytown, N.Y.

8. Kathrine B. Davis, typed report dated 1 Auguest 1921 attached to "Monmouth County Organization for Social Service, Inc., An Application from Mrs. Lewis S. Thompson," also K.B.Davis "A Supplemental Report on the Request of Mra. Lewia S. Thompson," 14 September 1921; K.B.Davis to William S. Richardaon (Bureau of Social Hygiene) 14 September 1921 mentions a trip to Monmouth County and auggegtions from salmon concerning personnel. Raymond B. Fosdick to W.S. Richardson 19 September 1921 LSRM 3,34, 358, RAC, N. Tarrytown, N.Y. 
from the Commonwealth Fund replaced by the LSRM. Smith understood that the project was not to be reapongible to the LSRM. 9 Lawrence Frank of the LSRM staff was of a different opinion, however, he was open to the idea of a joint effort which would be mutually accountable. Rockefeller philanthropy at that time was developing its policy on matching funds and 1tg relationahip with other charitable organizations as well as governments. It appeared to be a wise use of money to collaborate with the Commonwealth Fund and to take advantage of the other resources associated with the programme on the prevention of Delinquency. The Monmouth County project was compatible with the ideologies of both philanthropies to the extent that they had both been influenced by Thomas Salmon since he had argued for such a project at both the Gedney Farms and Lakewood Conferencea.

The programme in Monmouth County was initiated in January of 1922 as a mobile clinic which moved between public schools in a rural area of the county. The staff consisted of the three fold team of psychiatrists, psychologists and social workers. Later public health nurses and visiting teachers were used extensively. The first effort was a survey of the schools. This consisted of extensive physical and mental examinations. The county had a total population of 100,000 of which the 23,000 children of school age were to be tested. The purpose of the study was to "disclose the presence or abaence of mental abnormality and

9. Barry C. Smith to T.W. Salmon, 30 September 1921, Thomas Salmon Papers 4, 2, Payne Whitney Clinic Library, CMC, NYC. 
... [to] tap the emotional life of the individual" child. It was to "discover pathological personality,...excavate for mental conflict, [and] analyze mental content. In short, to get a picture of the child as a whole...as a living adjuating personality." The survey concluded that ten percent of the children exhibited "well defined mental or nervoug disordera." Almost ten per cent showed "conduct disorders or tendencies toward criminal careers." 10 In the first school only one quarter of the children were found to be normal, half were found to be mentally abnormal or retarded in some way. 11 The mobile unit proved to be inadequate to meet the need project personnel felt they had uncovered. In the spring of 1923 a permanent clinic was opened and later subclinics were established for nine month to nineteen year old children and youth typed difficult, maladjusted, predelinquent or delinquent.

The evaluation process for the renewal of funda was begun in the spring with a conference attended by top personnel from the NCMH, LSRM and Commonwealth Fund. 12 Both the LSRM and the Commonwealth Fund pursued independent evaluations of the project's progress. Problems immediately surfaced concerning

10. V.V. Anderson, "Clinic Conducted by the Division on the Prevention of Delinquency by the National Committee for Mental Hygiene," pp. 9-10, 13, LSRM 3, 34, 364, RAC, N. Tarrytown, N.Y.

11. Anderson, "Clinic Conducted By the Division on the Prevention of Delinquency."

12. V.V. Anderson to Beardsley Ruml, 3 October 1923, attached schedule for the meeting; Geraldine (Mra. Lewis S.) Thompson to B. Ruml, 27 October 1923, LSRM 3, 34, 358, RAC, N. Tarrytown, N.Y. 
fundamental disagreements between the Monmouth County

Organization and the Commonwealth Fund programme as carried out by V.V. Anderson for the National Committee. Monmouth County officers felt that the original idea as structured by Salmon. which had been to their satisfaction, was not being developed. 13

The original proposal had emphasized educational work extending into the community with its primary focus on prevention. The psychopathic clintc under Anderson had concentrated on testing and evaluating individual cases. When confronted with accusations of conducting an esoteric and specialized study which did not have general community impact, Anderson attributed the failings of the project to a lack of funds. With the apparent approval of Anderson the Commonwealth Fund demanded that the Monmouth County Organization require the LSRM to fund the psychopathic clinic at twenty-five thousand dollars a year for the remaining demonstration. Further, Anderson was to have more control over personnel, equipment and fac1lities. 14

After consultation with Lawrence Frank, of the LSRM, the Board of the Monmouth County Organization decided to reject the Commonwealth Fund's offer to continue to superviae the clinic

13. Unaigned copy of a letter apparently from Geraldine Thompson to Lawrence K. Frank, 25 February 1924 which describes events and the position of the local organization. LSRM 3,34 , 359, RAC, N. Tarrytown, N.Y.

14. Barry C. Smith to John L. Montgomery (Executive Secy. of the Monmouth Co. Organization), 29 December 1923, LSRM 3, 34, 359, RAC, N. Tarrytown, N.Y. 
through the NCMH. The atipulations imposed by the Commonwealth Fund for the demongtration were deemed unacceptable. 15 The NCMH was forced to withdraw its personnel from the clinic and in so doing sharply curtailed the emphasis on the study of psychopathology of childhood. 16 The NCMH-Commonwealth Fund Project on the Prevention of Juvenile Delinquency and the furtherance of child guidance was separated from community based work on the normal child. The Monmouth County demonstration continued to pioneer what was to become classic projects in normal child development and parent education which characterized the work of the LSRM for the rest of the decade.

After the retreat of the NCMH, the Monmouth County Demonatration continued with local direction under the auspices of the LSRM. Lawrence K. Frank in his discussions with Monmouth County officiala constructed a new programme which was based on Salmon's preventive theme but which was no longer directly affiliated with or considered itself to deal with psychopathological research. The program was to be predominantly in parent education and training. 17

15. L.K. Frank, "Monmouth County Organization for Social Service Memorandum," 12 January 1924; L.K. Frank, "Memorandum: Monmouth County Clinic," 22 January 1924; John L. Montgomery to Barry Smith, 7 January 1924, 16 January 1924, 19 January 1924, LSRM 3, 34, 359, RAC, N. Tarrytown, N.Y.

16. V.V. Anderson to John L. Montgomery, 22 January 1924; George Stevenson to John L. Montgomery, 15 January 1924, LSRM 3 , 34, 359, RAC, N. Tarrytown, N.Y.

17. L.K. Frank to Kenneth Chorley, "Memorandum," 7 April 1925, LSRM 3, 36, 360 RAC, N. Tarrytown, N.Y.; Roy Lubove, The

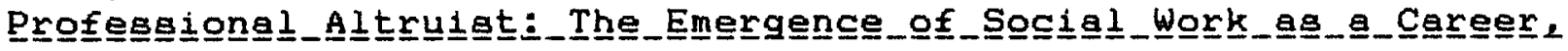


Patients were referred by parents, teachers, social workers, nurses, probation officers, judges and physicians. Parent training classes and child study groups were started which included habit clinica to correct incipient problems of adjugtment. Educational work was carried out by the distribution of Iiterature and lectures in cooperation with the Parent Teacher Association, medical societies and community service organizations such as churches and Rotary clubs. Twenty-three public health nurses extended work into the community along with social workers in training from Smith College. Visiting teachers were attached to the clinic to work directly in the schools. Two field representatives of the Central Patrol Bureau were also assigned to the project. 18

The Monmouth County demonstration cryatallized the mental hyglene format for both child guidance and child development. It also resembled aspects of the International Health Board'a work in the development of community public health clinics in the United Stateg as well a Canada. It ia eapecially linked with the mental hygiene work in child study with its built in educational

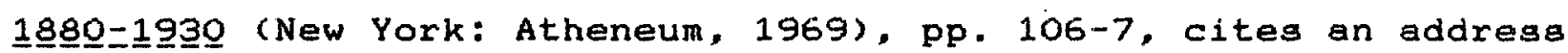
by Abraham Flexner before the National Conference of Charities and Correction in 1915. Flexner described his version of social work in ita pre-profegsional atatug as mediating community and professional services. In this "traffic director" function social workers through projects such as Monmouth County became increasingly independent by adapting the professional skills of others, particularly paychiatry.

18. Ruth Andrus to L.K. Frank, 27 Apri1 1925; 24 July 1925; Ruth Andrus, "Program Child Guidance, Last Quartex 1925," 1925 ; Ruth Andrus, "Proposed Program for 1926 and Suggestions for 19271930," undated, LSRM 3, 34, 360, RAC, N. Tarrytown, N.Y. 
element. This was critical to the orientation of research at the University of Toronto which the Rockefeller Foundation. General Education Board and the LSRM helped finance from 1924 to 1939. Psychology in Canada

In the United States child psychiatry had been an outgrowth of preventive efforts with wayward youth in child guidance. This was not the case in Canada except to a minor extent in Montreal. The major contribution of mental hygiene in Canada between 1920 and 1940 was not the advance of child paychiatry. It is significant that the discipline which was pushed forward during this period was child psychology and that this avenue of research and popular press was directed not toward the pathological child but the normal child. Building and preserving well-adjusted children was a new object of research. This was especially the case at the University of Toronto under the direction of E.A. Bott and William Emet Blatz.

Academic psychology and mental hygiene went hand in hand in Canada. As an academic and applied discipline Canadian psychology had a slow evolution. The first course in psychology was taught under the auspices of philosophy in 1843 at Toronto. James Mark Baldwin, American ploneer in paychology, introduced scientific psychology when he occupied a chair at the University of Toronto from 1889 to 1893. Baldwin was one of the twenty six founding members of the American Psychological Association organized by $G$. Stanley Hall in 1892. In 1893, Baldwin left Toronto for Princeton to initiate the first clinical laboratory at that institution 
which was later to house the work of Arnold Gesell's child study research. He went on to Johns Hopkins in 1903. In spite of a contemporaneous beginning with U.S. psychology, psychology in Canada has only separated itself from departments of philosophy in the majority of Canadian universities since the 1950s. 19 While historically the association of philosophy and paychology was not unique, the differentiation was made much more clearly from the $1880 \mathrm{~s}$ and $1890 \mathrm{~s}$ in the United States through the sustained influence of men with a research orientation. The emergent American univergity with 1tg emphasig on divergified scientiflc curriculum greatly aided this development. 20 The emancipation of paychology in Canada was directly connected with the work of Canadian mental hygienists. Baldwin's laboratory did not survive his departure. A clinical tradition was renewed at the University of Toronto in 1914 by E.A. Bott. Bott conducted an experimental rehabilitation centre for goldiers In 1916 which attracted the attention of University of Toronto President Sir Robert Falconer. 21

19. J.D. Ketchum, "II. Report on Social Paychology," in E.A. Bott, "Research Planning in the Canadian Paychological

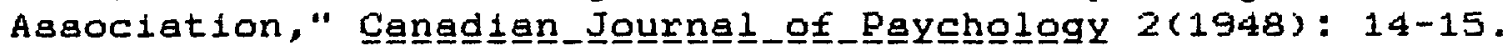

20. Edwin G. Boring, A_Higtotory_of_Experimentel 2nd edition (New York: Appleton-Century-Crofts, 1950, 1st edition 1929); Richard J. Herrnstein and Edwin G. Boring, A_Sogur $\underline{\text { ce }}$. B

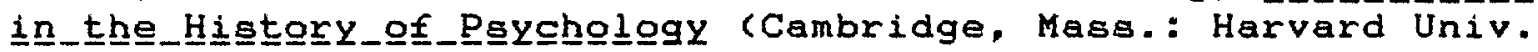
Press, 1965); Rand B. Evans, "The Origins of American Academic

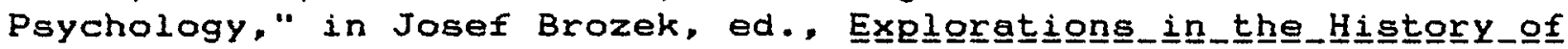
Paychology_in_the_United_Stateg (Lewiaburg: Buckneil Univ. Press, 1984, pp. 17-60.

21. C.R. Myers, "Notes on the History of Paychology in

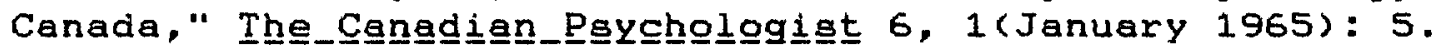


Bott was a founding member of the Canadian National

Committee for Mental Hygiene. Hia laboratory received official recognition by the university administration under the auspices of C.K. Clarke in 1919. The department of psychology was formally established in 1920 with E. A. Bott as head. It was the first department of psychology which was separate from philosophy in Canada.' 22 Bott was the head of the psychology department at Toronto for the next 37 years. In this capacity he was affiliated with every major mental hygiene activity which operated out of the University of Toronto until 1957. He was instrumental in establishing the Canadian Psychological Association as independent from the American Paychological Association in 1939. He has been acknowledged as the dean of Canadian psychology. 23 It was the unique contribution of Bott's department to child psychology which shaped the most well known work of the Canadian mental hygiene movement in its second phase beginning in 1924.24 Canadian mental hygiene received international recognition for its contribution to longitudinal research on the development of normal children. While the University of Toronto and McGill were the two leading institutions in this area in Canada. Toronto was

22. Myers, "Notes on the History of Psychology in Canada," pp. 4-19.

23. C.R. Myers, "Edward Alexander Bott (1887-1974)," Thhe

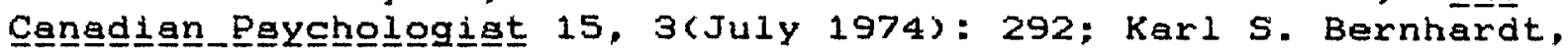
"Professor E.A. Bott," Canada'g_Mental_He日lthth (June 1957).

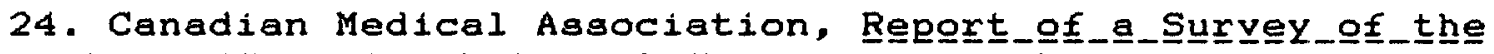

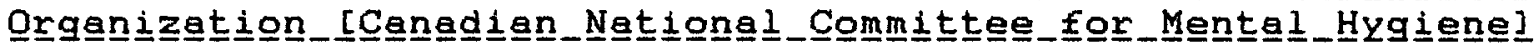
(ottawa: Metropolitan Life Inaurance Co., 1932), pp. 14-30. 
especially noted for studies in normal child psychology.

An Outline of CNCMH work: from abnormal to the normal child Before practical projects on a mental hygiene of normal development could be established it was necessary to redirect mental hyglene policy in the CNCMH away from disease and toward health. At the first meeting of the executive board of the CNCMH in 1919 a gift of five thougand dollars from Lady Eaton was announced with the stipulation that: "one thousand should be utilized for work in industrial peychology." E. A. Bott agreed to undertake a study and to outline a programme for useful research. 25 At the same meeting the members endorsed a recommendation to present a proposal to the Rockfeller Foundation for funds for "provincial surveys and allied inveatigations." 26 This latter link was to take some four years to develop. Industrial psychology led into the LSRM programme on the paychology of normal school children developed in 1924.

A subcommittee was formed on educational and industrial psychology. The members included Lady Eaton. Professor J.A. Dale and E.A. Bott. C.K. Clarke, C.M. Hincks, Professor J.R. Macleod and Mr Norman Burnette also attended the first meeting. Professors H.E.T. Haultain, C.B. Sissons, J.R. MacLeod, R.M. McIver and J.G. Fitzgerald were made ex-officio members. Dale,

25. "Minutes of the Firgt Executive Meeting (2nd Year) of the Canadian National Committee for Mental Hygiene, held in the office of Dr. C.F. Martin," 17 October 1919, p. 38, CMHA Papers, MG 28 I $39184 / 63$, PAC, Ottawa.

26. "Minutes of the First Executive Meeting." p. 47. 
one of the first professors of social science at Toronto, was made chair and Hincks acted as secretary. 27

Bott as the primary researcher began with the inevitable survey. He wanted to know the percentage of retarded children among those who left Toronto public schools to go to work. He was especially interested in children under the age of sixteen years. He also wanted to know the history of the first two years of the child's industrial life. Bott found that eighteen per cent of the total school enrolment left achool early. Theee children exhibited an average range of intelligence. Seventy per cent were under the age of fourteen and a half and ninety percent were under the age of fifteen and a half. Forty-five per cent of children leaving school did not get beyond the senior third grade which was not sufficient to serve their practical needs in Canadian society. Nearly sixty per cent had repeated grades. There was no provision in the Toronto schools to give such children well informed guidance. The children who left school for jobs often changed their position once or more during their first year of employment. Most of these children ended up working in factories or shops. 28

27. "Minutes of the First Meeting of the Sub-Committee on Educational and Industrial Paychology of the Canadian National Committee for Mental Hygiene," 3 December 1920, CMHA Papers, MG 28 I $39184 / 63$, PAC, Ottawa.

28. E.A. Bott, "Juvenile Employment in Relation to Public Schools and Industries in Toronto," outlined in "Minutes of the First Meeting of the Sub-Committee on Educational and Industrial Paychology of the Canadian National Committee for Mental Hygiene," 3 December 1920, CMHA Papers, MG 28 I 391, 84/63, PAC, Ottawa. 
Bott's findings marked an innovation in the thinking of the Canadian National Committee. Previously they had been overwhelmingly concerned with "attempting to solve the problems of abnormality." This study implied a similar lesson to the Canadian Committee as Healy's study of the juvenile courts had for the U.S. Committee in the innovative perception that behaviour problems could not be solely attributed to mental retardation. Bott took his findings one step further. Like Thomas Salmon, he saw the need to step in and take preventive measures before the child exhibited aigna of maladjugtment. Bott redirected mental hygiene as industrial and educational paychology toward the prevention of maladjuatment in the normal child. The subcommittee concluded:

While the accomplighments of the Committee have been considerable in the past, nevertheless activities have been somewhat hampered because of a prevalent opinion that our interests are centred wholly in the feeble-minded and insane. While there is not real justification for such an attitude, nevertheless it seems necessary to safeguard our future by laying emphasis on such work as is contemplated by the Department of Educational and Industrial Paychology. If proposed activities are put into effect there can be little doubt that the Committee will be performing a much greater national service than has been the case in the past. 29

The main body of the work as envisioned by the committee was to work directly with the public schools in providing psychometric testing of special needs children, devising a better system of promotion and grading, vocational guidance and special class organization as a means to "bridge the gep between school and

29. "Minutes of the Sub-Committee on Educational and Industrial Psychology CNCMH," 3 December 1920, CMHA Papers, MG 28 I 391, 84/63, PAC, Ottawa. 
industry." 30

The programme as outlined never evolved beyond the surveys of school children in Toronto and in Montreal. Neither of these studies significantly moved the study of normal children farther ahead. Part of the inability to push forward was financial. The CNCMH came up against difficult times economically which necessitated spending a great deal of time in fund raising activities. Between 1918 and 1922 the Committee had received pledges of $\$ 146,000$. Voluntary subscribers had been the most generous giving $\$ 96,000$ with governments appropriating $\$ 34,000$ and the Canadian Red Cross $\$ 15,000$. The Canadian Red Cross had agreed to cooperate with the CNCMH in May of 1920 . They had given a preliminary grant to the Committee for $\$ 5,000$. 31 In 1921 the Committee received $\$ 10,000$ each from the Canadian government and the Red Cross. These grants were discontinued the following year reflecting the economic downturn of Canada in the 1920s. 32 The Canadian Red Cross, similar to the Canadian National Committee, faced rising costs and the need for retrenchment. Costs were also escalating during this period. In 1918 the National Committee

30. "Minutes of the Sub-Committee," 3 December 1920.

31. "Report of the Proceedings of the Second Annual Meeting of the Canadian National Committee for Mental Hygiene," 22 June 1920, p. 11, CMHA Papers, MG 28 I $39184 / 63$, PAC, Ottawa.

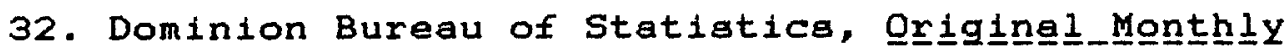

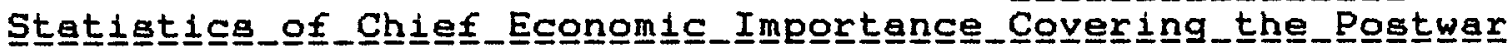
Per Business Statistics, May 1934, (Ottawa, 1934), P. 34; Royal

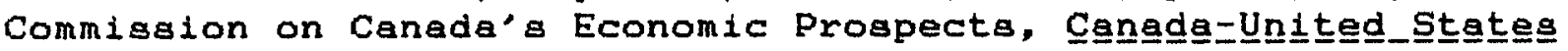

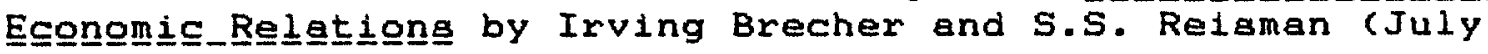
1957), p. 21 . 
spent $\$ 10,000$. In 1919 they topped $\$ 28,000$ and in 1920 this had climbed to $\$ 44,000$ with a corresponding figure for 1921 . On February 1, 1922 the Committee found itself with outstanding liabilities of $\$ 4,000$ and only $\$ 300$ in the bank. 33

Much of the work of the CNCMH over the next year was curtailed as a consequence of the financlal dilemma. Funds were not solicited during 1923 and the Committee struggled along on an bank overdraft amounting to $\$ 10,000$. The time and energy the Committee executives apent golving the financial problem finally met with success. Lady Byng of Vimy agreed during this crisis to have her name used for a fund to attract contributions for the Committee.

Personnel changes in 1924 also stgnificantly changed the functioning of the Canadian Committee. On the 20 th of January, the same month the Lady Byng of Vimy Fund was inaugurated, C.K. Clarke died. Clarence Hincks assumed full executive responsibility for the Canadian Committee. His first priority was to establish reliable funding. The problem was highlighted by the fact that several other major contributora to the CNCMH such as Sir William Price, Sir Edmund Ooler and Mr. D.A. Dunlop had also

33. "Minutes of the Combined Meeting of the Executive and Finance Committees of the Canadian National Committee for Mental Hygiene," 17 February 1922, CMHA Papers, MG 28 I $39184 / 63$, PAC, ottawa. 
recently died. 34

The Canadian National Committee from its formal

establishment had considered the Rockefeller Foundation as a possible source of income. In 1920 Hincks made an appeal to the Foundation for medical education in Canada which was "declined on the grounds that the Rockefeller Foundation was planning to cooperate directly with medical schools and leaders in medical education, rather than to further particular education programs." 35 In the face of the financial crisis of 1923, Hincks approached the Foundation again. On trips to New York, Hincks struck up a relationship with Edwin Embree, Secretary of the Rockefeller Foundation. 36 This friendship became quite close and personal as time went on. They had a similar philosophical and ideological orlentation. The families were summer neighbors, vacationing in the same Muskoka region of Ontario. Embree shared Hincks' long

34. "Report of the Minutes of the Executive," 14 November 1924, CMHA papers, MG 28, I, 391, 84/63, PAC, Ottawa. Price was a Vice President who contributed $\$ 60,000$ to the Committee. Osler was William Osler's brother who had contributed in numerous ways to the Committee since its inception. D.A. Dunlop was Chair of the finence Committee. He and his wife had also generously donated to the Committee.

35. This was Richard Pearce'g position which was not in fact carried out since the CNCMH was eventually funded with Rockefeller related grants. "Canadian National Committee for Mental Hygiene," part of the RF appraisal of CNCMH, 1939, p. 1, RG 1.1, 427, 1, 6, RFA, RAC, N. Tarrytown N.Y.

36. C.M. Hincks to E. Embree, 25 Eebruary 1924, RG 1.1, 1, 427 1, RFA, RAC, N. Tarrytown, N.Y. 
standing interest in social and mental hygiene. 37

In February of 1924 Hincks wrote Embree as a followed up to a conversation they had in New York. He inquired about the possibility of securing a grant for the CNCMH from the Rockefeller Foundation. Hincks wrote a proposal which outlined an experimental demonstration in a mental hygiene programme for public school children. 38 At a subsequent meeting of the RF Board, the Foundation considered the proposal favourably. They were interested in utilizing Toronto schoola and possibly schools in Edmonton, Alberta where Rockefeller Funds had bolstered the medical school at the University of Alberta. The rationale was that the NCMH in the United States had continued to puraue work with children in schools but it was limited to "delinquency rather than the general school problems of mental hygiene." It was deemed beneficial to "obtain the experience of different groups in different nations." It is noted that little work had been done in Canada and that as few as 120 special classes existed in the entire Dominion and that "these have been established almost entirely at the instigation of the Canadian National Committee." The Foundation decided that it would be

37. In the Hincks Paperg there is an extengive series of correapondence between Clere Hincks and his wife and the Embree's in the $1930 \mathrm{~s}$ which cover both personal events and Edwin Embree's continuing interest and support for CNCMH as President of the Rosenwald Fund. Clarence Hincks Papers, 2, 9, Greenland Griffin Archives, Toronto; Edwin Embree to Alen Gregg, 15 September 1939, A.G. to E.M., 15 September 1939; A.G. to C.M. Hincks, 22

September 1939, REA RG 1.1, 427, 1, 6, RAC, N. Tarrytown, N.Y.

38. C.M. Hincks to E. Embree, 25 February 1924. 
interested in pursuing such demonstrations for a sum somewhere between $\$ 50,000$ and $\$ 75,000$ at the rate of $\$ 15,000$ in annual installments. 39 Embree passed along the good newa to Hincks with the idea that they should get together and discuss project options more fully. 40

Hincks also pursued Rockefeller philanthropy by contacting Beardsley Ruml, Director of the Laura Spelman Rockefeller Memorial. In casual conversations, Hincks introduced the importance of the social aspects of mental hygiene with normal children. Ruml suggested also purauing these ideas with Lawrence Frank. Hincks during these conversations began to reshape his ideas toward parent education. He outlined "an attractive programme of mental hygiene information to mothers of canada who have problems in their own home," as well as school problems. 41 Embree encouraged Hincka to pursue the Foundation on multiple fronts. "By all means make such contacts as you can, either officially or personally with the officers of that organization." Hincks hoped to be funded by September of 1924.42

39. The actual role of the CNCMH in initiating special classes was exaggerated. However, in a broader sense this was correct in that the early eugenical societies for the care of the feebleminded argued for special classes. These societies also formed the basis for the CNCMH. "Minutes of the Rockefeller Foundation 27 February 1924, pp. 24033-24034, RG $1.1427,1,1$, RFA, RAC, N. Tarrytown, N.Y.

40. E. Embree to C.M. Hincks, 3 March 1924, RG $1.1427,1$, 1. RFA, RAC, N. Tarrytown, N.Y.

41. C.M. Hincks to E. Embree, 3 March 1924.

42. C.M. Hincks to E. Embree, 5 March 1924; Embree to Hincks 5 March 1924, RG 1.1, 427, 1, 1, RFA, RAC, N. Tarrytown, N.Y. 
During these negotiations Hincks had been on the lookout for suitable personnel to direct his proposed work with normal children. He needed to be able to find someone who had the qualifications which the $R F$ respected and who would give the project legitimate scientific research status. Hincks came upon a likely candidete in Wllliam Emet Blatz. The Foundation was at first skeptical of Blatz whom they thought of as a "brash young $\operatorname{man} . " 43$

$$
\text { Blatz's personality is an interesting factor in the history }
$$

of Canadian child study. He was a strong and determined leader who had a great deal of charisma. Not all of Blatz's students and colleagues found him charming or easy to work with. 44 The strength of Blatz's personality and convictions seem to have been Inatrumental in sustaining work at Toronto where it withered elsewhere in Canada during the depresaion.

The ninth son of a German immigrant tailor, Blatz was born in Hamilton, Ontario in 1895. 45 Bill Blatz was 29 years old at

43, Mary J. Wright, "The History of Developmental Paychology in Canada, Note 4: The Saga of William Emet Blatz," Part I., manuscript, Greenland-Griffin Archives, Toronto.

44. See Mary J. Wright, The_Hí

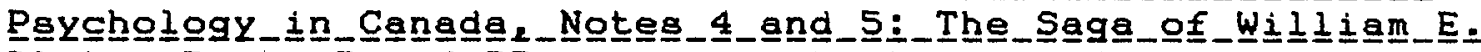
B a laudatory view from the standpoint of a student and colleague. For the opposite perception see psychiatrist and clinician Arthur

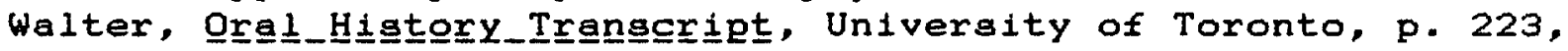
also a student. Walter states that, "I never truated Blatz." He would "argue a phrase for the turn of it," and was "quite slick."

45. Victoria Carson and Margery de Roux, W.E._B 1 a

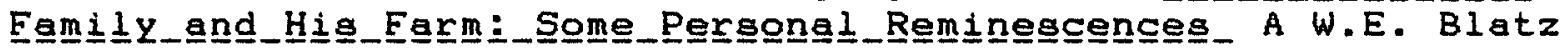
Memorial Paper (Bora Centre, 1975), Griffin Greenland Archives, Toronto; Mary Northway, "Child Study in Canada: A Carual 
the time he was recruited to Toronto. He was just completing his Ph.D. in psychology at the University of Chicago with a disgertation on the "Physiological Study of Emotions." His dissertation was on emotional responses where individual differences of reaction were gauged when a chair unexpectedly collapsed under a subject. His later theories on children developed the notion of habit training and the dominance of social situations as stimuli in the interaction of consciousness and physiological automatism. Blatz had acquired his Bachelora and Masters degree from the University of Toronto in 1916 and 1917 were he had worked with Bott on his rehabilitation programme with soldiers. He had gone on to achieve a medical degree in 1921 before taking a fellowship in psychology at the University of Chicago where he studied under the champion of functionalist psychology, Jameg R. Angell's student, Harvey A. Carr. 46 Hincks found Blatz very acceptable as the potential director of child study research due to his dual background in medicine and psychology. Hincks was Impressed with Blatz's research experience and willingness to return to Toronto.

History," in Lois M. Brockman, John H. Whitely and John P.

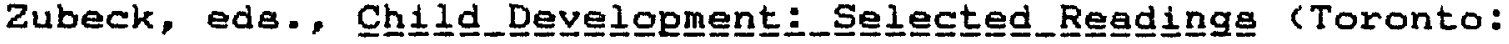
McCleliand and Stewart, 1973), pp. 13-46, see excerpts from Blatz's autobiography pp. 16-17; Wright, "The Saga," p. 7 .

46. C.M. Hincks to E. Embree, 17 March 1924, RG 1.1, 427, 1 , 1. RFA RAC, Tarrytown, N.Y.; Karl S. Bernhardt, "Dr. William E.

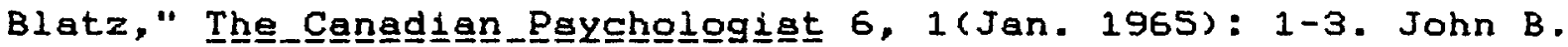
Watson and Beardsley Ruml were also students of Angell. See Carl Murchison, ed., A_Historgy_of_Psycholggy_in_Asutoobiogrageny worchester Mass.: Clark University Press, 1936, pp. 1-38 on Angell, pp. 69-82 on Carr. 
Hincks wired Blatz and had him come for an interview with Bott and J.R. Fitzgerald, the chair of the School of Hygiene at the University of Toronto which had also been supported by Foundation money. After the meeting Hincks invited Embree to interview Blatz. A position for Blatz was pieced together by combining the position as Director of the Centre for Child Study with a half-time appointment in the Department of Psychology. The Rockefeller Foundation matched the half time university salary giving the Directorship of the Centre the equivalent income of a full-time appointment at the university. 47

In April Hincks made an offlcial appeal for funding for a mental hygiene atudy of school children in Toronto. Additionally, he sought similar support for Montreal in order to balance the two main divisions of the Canadian National Committee. Meetings were set up with C.F. Martin in Montreal in this regard. After conferring with Richard Pearce of the Rockefeller Foundation, Hincks also hoped to acquire five travelling scholarships from the Medical Division of the Rockefeller Foundation for Canadian's to study paychiatry abroad. 48

On May 27, 1924, the Foundation Board of Directorg voted to "make posalble studies of the application of mental hygiene to the school system" in Canada. The sum of $\$ 75,000$ was subsequently appropriated for a five year period to begin July 1, 1924. The

47. Hincks to Embree, 17 March 1924.

48. C.M. Hincks to E. Embree, 28 April 1924, RG 1.1, 427.1, 1, RFA, RAC, N. Tarrytown, N.Y. 
sum was to be distributed at the rate of $\$ 15,000$ a year provided that contributions from Canadian sources at least equalled the Foundation pledge. 49 Shortly thereafter the Canadian press announced the gift. It was emphasized that the research was to prevent mental diseases. Hincks preferred to think of these as "minor maladjustments." Interest was aroused and letters arrived from A.H. Abbott, Director of the Canadian Red Cross and other mental hygienist from all sectors of the Canadian establishment. Sir Vincent Meredith, President of the Bank of Montreal; Dr. Helen MacMurchy, Chlef of the Division of Child Welfare; Dr. A.H. Desloges, Medical Director of Hospitals for the Insane for the Province of Quebec; Sir Robert Falconer, President of the University of Toronto; and, Sir Arthur Currie President of MeGill University wired congratulations. Hincks pointed out these accompliahmenta to Embree assuring him of the widespread influence the Foundation was to have through its support of mental hygiene in Canada. So

Hincks encouragement from Embree and his own discusgions with Beardsley Ruml led him to remind the Executive Committee of the CNCMH that:

Before discussing a tentative plan for the conduct of child studies, the Executive Committee should be informed of the interest of the Laura Spelman Rockefeller Memorial in our Canadian work. There is a likelihood of our Committee

49. "Minutes of the Rockefellex Foundation," 1920-1024, pp. 24114-6, RG 1.1 427, 1-11, RFA, RAC, N. Tarrytown, N.Y.

50. C.M. Hincks to E. Embree, 30 May 1924; Hincka to Embree, 5 June 24; Embree to Hincks, 10 June 1924, RG 1.1, 427, 1, RFA, RAC, N. Tarrytown, N.Y. 
receiving $\$ 20,000$ per annum, or some such amount, from the Memorial for our studiea of children of pre-achool age and for the inauguration of plans for parent training in mental hygiene. This interest of the Laura Spelman Rockefeller Memorial might well be kept in mind in formulating a policy in dealing with the Rockefeller grant, because the adminiatration of monies coming from both sources might well be unified. 51

The members present followed Hincks advice in resolving to find mutual interests between their own goals and the expressed interest of the RE. They especially hoped to advance the two largest population centres in Canada, Montreal and Toronto. Subcommittees for "Studies in the Application of Mental Hygiene to Children," were created toward this goal for each city. 52 This was an upbeat moment for the Canadian movement and a turning point. The support Hincks had garnered from the Rockefeliex Foundation was to provide aupport for child atudy development at four locations: in paychology at the Univeraity of Toronto and the University of Alberta, in educational paychology at Saskatchewan, and in psychology and psychiatry at McGill University. 53 Hincks was able to secure five fellowships from the Rockefeller Foundation and two additional awards from Lawrence K. Frank of the LSRM. This lattex fellowship was to send

51. "Report of the Special Meeting held in Montreal on Saturday, June 7 th to consider the administration of the Rockefelier Foundation appropriation of $\$ 75,000$ to the Canadian National Committee for Mental Hygiene." CMHA Papers, MG 28 I 391 $84 / 63$, PAC, Ottawa.

52. "Report of the Special Meeting."

53. J.D. Griffin, "Mental Health - Canada: The Chronicle of a National Voluntary Movement. The Canadian National Committee for Mental Hygiene," Book I, typescript, May 1981, p. 84, Greenland Griffin Archived, Toronto. 
teachers to study child development at Teacher's College, Columbia University. 54

Within a year of the Rockefeller Foundation appropriation the Canadian National Committee the Department of Mental Hygiene Research in Toronto was established in affiliation with the University of Toronto. 55 The Department was charged with applying mental hygiene principles to children in school attendance with the expressed intention of "preventing mental and emotional disorders." 56 Dr. J.G. Fitzgerald was made chairman with committee nembers to include President Sir Robert Falconer; Hon. Dr. H.J. Cody, chairman of the Board of Governors of the university; Mr. C.B. McNaught; Mr. Vincent Massey; Mr. Hugh Kerr; Professors Peter Sandiford, R.S. Brett, and E.A. Bott. Clarence Hincks. E.A. Bott, W.E. Blatz and E.D. MacPhee of the psychology department were to act as research directors. 57 The budget was to be provided by the Rockefeller Foundation with matching funds to be secured through the Lady Byng of Vimy Fund.

A aimilar Department of Research was eatablished in Montreal. The MCGill affiliated group. was to focus on the

54. "Report of the Annual Meeting of the Board of Directors and of the Executive and Finance Committees of the Canadian National Committee for Mental Hygiene," 14 November 1924, CMHA Papers, MG 28 I $39184 / 63$, PAC, Toronto.

55. C.M. Hincks to Normal S. Thompson, 26 June 1925, Thompson to Hincks, 1 July 1925, RG 1.1,427, 1, 1, RFA, RAC, N. Tarrytown, N.Y.

56. "Medical Director's Report," 19 June 1925, CMHA papers, MG 28 I $39184 / 63$, PAC, Ottawa.

57. "Medical Director's Report," 19 June 1925. 
"prevention and control of juvenile delinquency and to the organization of a demonstration mental hygiene clinic." The Division was to grant assistance and vital statistics to the courts, reform schools, probation organizations. The Executive Committee was to consist of Sir Edward W. Beatty. President of the Canadian Pacific Railway as Chair; Sir Arthur Currie, President of MCGill University: Doctors C.F. Mertin, C.K. Russel, G.S. Mundie, A.B. Chandler and Clarence Hincks. The research directors were Professor J.W. Bridges and Dr. W.T.B. Mitchell. 58 President George Vincent, of the Rockefeller Foundation, took an active interest in the work in Canade and the relationship between the operation of the regearch and the University. 59 Canadian work was illustrative of the problem of the scientific management of a major philanthropy a mandate to better mankind without distinction of national boundaries and capital trusts with restrictions such as the General Education Board or the Laura Spelman Rockefeller Memorial. The question was how to most efficiently cover public health, medical research and training, child study and mental hygiene. The Foundation was in the early phases of formulating internal revisions which were to take place in 1928. It was controversial among Foundation officials at the time whether funds should be funneled through

58. "Medical Director's Report," 19 June 1925, CMHA Paperg, MG 28 I $39184 / 63$, PAC, Ottawa.

59. C.M. Hincks to George Vincent, 9 August 1925; E. A. Bott to E.R. Embree, 21 June 1926, concerning the establishment of the Board of Governors for the project. RG $1.1,427,1,1$, RFA, RAC, N. Tarrytown, N.Y. 
the Canadian Committee or to go directly to universities or other agencies. 60 Nor was it clear whether the International Health Board, the Medical Division, or the LSRM should be solely responsible for the work or if each branch should independently pursue aspects of mental hygiene which crossed their domain. This was resolved out of practice as well as in policy imperatives. In 1928 the Rockefeller Foundation streamlined the functions of the General Education Board and International Education Board in medical education, and the LSRM in the social sciences by merging some of their work with the Foundation. The regult combined resources amounting to $\$ 203 \mathrm{million}$. 61 The different divisions of the Foundation tended nevertheless to work relatively independently. Over time, funds were more likely to be provided directly to official public agencies rather than the CNCMH. BY 1928 funds were furnished, for example, to the National Research Council in Washington D.C. to develop medical research and education in the U.S. and Canada. 62 The CNCMH, however, often served as an informal intermediary or administrative agency which supported ongoing work through evaluations by way of surveys and consultation services. The Foundation saw itself as stimulating

60. C.M. Hincks to E.R. Embree, 9 July 1926, with an exchange of comments between Embree and Richard Pearce among others of the RF staff. RG 1.1, 427, 1, 2, RFA, RAC, N. Tarrytown, N.Y.

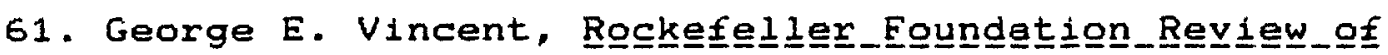
Work, 1928 (New York: Rockefeller Foundation, 1929), pp. 10, 22 , 50-1; Rockefeller Foundation, Annua﹎_Report__1928 (New York: Rockefeller Foundation 1928).

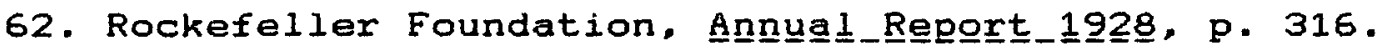


public responsibility for public health and encouraging private initiative. This was a continuation of the early policy of having demonstrations evolving permanent independent funds other than the Foundation. In this regard, the work in Toronto was successful in that the University of Toronto took over full responsibility for the CNCMH initiated work in child study research and parent training in July 1930. 63 MCGill was simply unable to take over this respongibility and the programmes in Montreal ground to a standstill with the departure of the principal researchers in child study and psychiatry.

Shortly after work under the Rockefeller Foundation grant was begun in 1924 successful negotiations were completed between the University of Toronto, MCGill University and the CNCMH with the Laura Spelman Rockefeller Memorlal. The Memorial agreed to provide $\$ 100,000$ annually toward the establishment of two university based laboratory nursery schools. The grant had three objectives: 1) the intensive study of preschool children; 2) a demonstration in parent training; and 3$)$ the establiahment of standards for child directed services in public agencies. 64 The funds from the LSRM at the rate of fifty thougand dollarg per annum to each university were to be matched by Toronto and MCGill. The CNCMH was to provide administrative support.

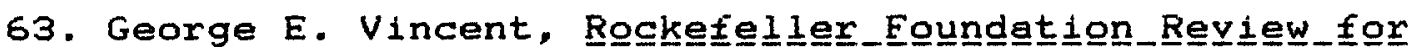
1927 (New York: Rockfeller Foundation, 1928), pp. 9-10; Canadian Medical Association, Report, p. 23.

64. "Medical Director'g Report," 19 June 1925, CMHA Paperg, MG 28 I $39184 / 63$, PAC, Ottawa. 
A department of paychology in the Medical Faculty of McGill was created with the hiring of Professor J.M. Bridges in 1924 . Courses in normal and abnormal psychology were taught to medical students, nurses and arts graduates. Research was conducted in the juvenile courts and on the mental instability in college studenta. 65 In 1925 a nurgery school was opened under the direction of A.B. Chandler. Kathrine M. Banham Bridges conducted research on the measurement of social and emotional development in preschool children. 66 W.T.B. Mitchell's wife, a registered nurse, became director of the Montreal Parent Training Division. Parent training courses and materials were prepared in conjunction with pediatricians and psychiatriats. Twelve monthly newsletters were also distributed by the Provincial Department of Health to all mothers of newborn children throughout Canada. 67 The nursery school was discontinued in 1931 when the CNCMH decided to concentrate their work in Montreal in the establishment of a Mental Hygiene Institute. Both J.M. Bridges

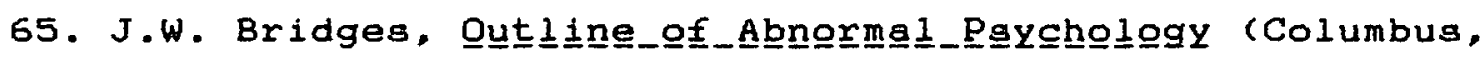
Ohio: R.G. Adams, 1925); J.M. Bridges, "A Study of a Group of

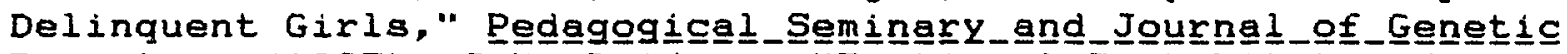
Paycologgy (1927); J.M. Bridges, "Emotional Instability of College

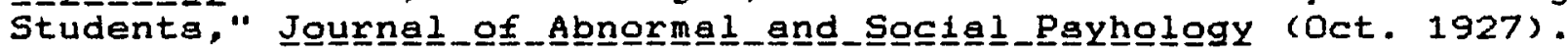

66. Kathrine M. Banham Bridgeg, "Critical Noteg on Mental Tests for Children of Pre-school Age," Pedagogical__Semingery XXXIV (March 1927); K.M.B. Bridges, "The Occupational Interests of Three-Year-Old Children," Pedeggogical__Semingaxy XXXVI (Sept. 1927); K.M.B. Bridges, "A Pre-school Character Rating Chart,"

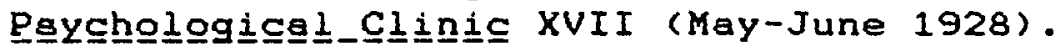

67. "Account of Five Years of Activity of Child Study in Canada Financed in Part by the Rockfeller Foundation For the Consideration of Dr. Richard M. Pearce," RG 1.1, 427, 1, 7, RFA, RAC, N. Tarrytown, N.Y. 
and Kathrine M.B. Bridges terminated their research in mental hygiene. 68

The similarities and differences in the two Divisions of Mental Hygiene Research are instructive in understanding their different outcomes. The parallel projects in Toronto and Montreal had the same origin in that they were both initiated by Clare Hincka. Both were primarlly funded by the same source in the Laura Spelman Rockefeller Memorial. Both were conceptualized as research and service projects to advance mental health goals. In spite of the similarities of their origins, the two programmes differed significantly in their structure. The work at the University of Toronto was dominated by the general sponsorship of the Department of Psychology. It's management committee represented other interesta in the university including the School of Hyglene ag well as social work. Even though Blatz was officially qualified as a doctor, his professional interest and research were nonmedical. The work in Toronto was conducted through demonstration school settings at Regal Road School and St. Georges laboratory nursery. McGill was developed under the auspices of the Department of Medicine. It was administered by a physician, Colin K. Rugsel. At MCGill a laboratory school was established, but primary work was conducted in a clinical setting in affiliation with the general hospital, courts, and other

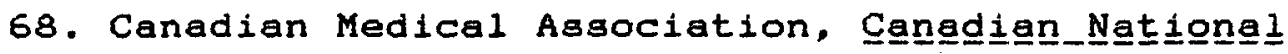

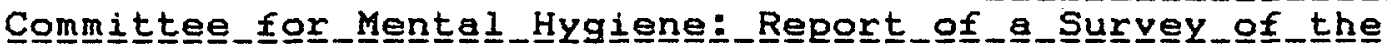

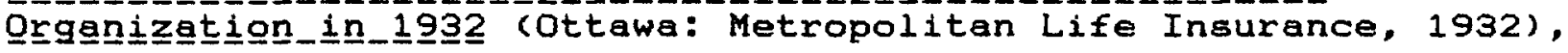
pp. $26-7$. 
agencies outside of the school.

Toronto Child Study

The first school demonstration in Toronto was Regal Road School Project. Permission was granted in October of 1924 by the Toronto Board of Education to allow the Toronto Research

Department of the CNCMH access to the public schools. 69 Regal Road was an experimental public school of 1,400 children. The objectives of the research were to: 1) make a longitudinal study of conduct deviations and adjustment of school children primarily by way of observation. 2) Secondly, the classification of the causes and possible treatment for maladjustments were to be worked out through a testing program. Treatment included the reorganization of promotion and also "reeducation" with individual cases to incorporate parental practices as well as school practices. Regal Road was supervised by $W$. E. Blatz in association with E.D. MacPhee and later with William Line. 70 The first avenue of research at Regal Road was to give intelligence tests to all of the children. In cooperation with the school's principal, Mr. Richardson. E.D. McPhee experimented with homogeneous grouping. The school was put on a tracked promotion system which utilized a classification of children into slow, average or fast moving groups. A control group of a

69. J.G. Fitzgerald to R.H. Crowley, Chlef Inspector Schoola Toronto Board of Education, 6 May 1926, RG 1.1, 427, 1, 2, RFA, RAC, N. Tarrytown, N.Y.

70. Canadian Medical Aasociation, Canadien National

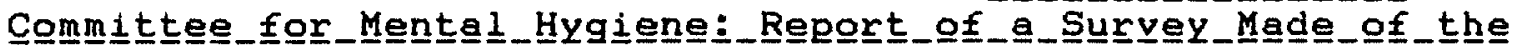

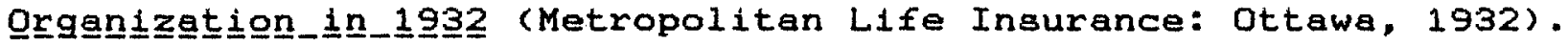


heterogeneous $\mathrm{mix}$ of slow to bright children was used to evaluate the effectivenegs of this method of insuring proper school adjustment by proper placement. Bright children were also studied separately where they were allowed to skip grades and advance more quickiy in some cases. 71 The argument advanced in this research was that maladjuatment and behaviour problems in achool were due to poor classification. Children who continued to exhibit problem behaviour were followed up on a home basis. Hincks explained the rationale for this in the contention that:

upwards of 25\% of mental and nervous disorders are caused or accentuated by unsatisfactory home and school methods that are now in vogue in child rearing. It is possible that Canada will assume a degree of world leadership in fighting mental abnormality as a result of research studies. 72

Unlike Clarke's earlier surveys, Blatz attempted therapeutic interventions as well as the compilation of statistics. The behaviour studies for example, included a listing of all misdemeanorg emergent in a achool getting. The figures were listed by grade and years with approximately eleven thousand the total for 1926/7, ten thousand for $1927 / 8$ and $n i n e$ thousand for 1928/9. Individual cases were selected from the survey lists and studied independent1y. Between $1925-6$ and $1929-30$, close to eight

71. CMA, Cangegian_Nationgnal_Committtee; J.G. Fitzgerald to R.H. Crowley, 6 March 1926.

72. C.M. Hincks, "Report of Medical Director to Board of Directors and Supporters of the CNCMH," 19 October 1925, CMHA papers, MG 28 I $39184 / 63$, PAC, Ottawa. 
hundred such special cases were reviewed. 73 A typical and easily solved case included an 11 year old boy who vomited and had crying fits after meals resulting in poor school attendance. The parents were instructed to ignore the attacks and to encourage recreational activities. Soon after, the child was reported recovered. 74

Other cases were not so simply adjusted. One girl was first reported in 1925 for disobedience and writing notes in class. The next year she was reported for lying, stealing and truancy at school. She was later caught stealing at Eatons Department store. Soon after she began to stay out all night. The following year she flunked the first course in the High School of Commerce. She was eventually brought before the juvenile court for immorality and placed in a correctional Lodge. After running away from the Lodge she was again caught stealing and sent to a reformatory. After two years in the reformatory a position was found for her by Blatz working for ten centa an hour. Blatz and hig researcherg provided supervision and continuing surveillance. 75

The Regal Road Project was attached to other atudieg as well. J.D. Ketchum undertook an investigation of street boys and their chums. Developmental records were kept for several years on

73. Toronto Research Division, "Report Upon a Five Year Experiment in Mental Hygiene Research in Regal Road School, Toronto," 31 March 1930, RG 1.1, 427, 1, 7, RFA, RAC, N. Tarrytown, N.Y.

74. Toronto Research Division, "Report."

75. Toronto Research Division, "Report." 
out of school activities of one hundred children. 76 Additional work was carried out through the juvenile court and in connection with industrial psychology and vocational guidance. E.A. Bott took a special interest in this work as most closely linked to his interests in industrial and educational psychology. 77 Research in industrial paychology at Toronto begun by Bott was followed up by S.N.F. Chant. 78 Chant utilized both the juvenile court and Infants Home and other community groups for longitudinal research. Chant also conducted a study of personnel problems at Toronto's largest department store. The hope was to be able to integrate knowledge about childhood maladjustments with vocational maladjustment in adult populations. 79 Chant went on to establish the Department of Psychology at the University of British Columbia. Blatz was instrumentally involved in all of these spheres. He supervised the projects and acted as a consultant for attached agencies guch as the juvenile court as

76. "Account of Five Years" Activities on Child Study in Canada Financed in Part by the Rockefeller Foundation: For the Consideration of Dr. Richard M. Pearce," RG 1.1, 427, 1, 7, RFA, RAC, N. Tarrytown, N.Y.

77. "Information to Truateea, Canadian National Committee for Mental Hyglene," 9 February 1926; F.W. O'Connor to E.A. Bott, 9 February 1926, RG 1.1, 427, 1, 1, RFA, RAC, N. Tarrytown, N.Y.

78. Bott took a short leave to study at the Yale University Laboratory of Psychology where Robert Yerkes was doing research in testing. Arnold Gesell was also at Yale involved in child study research.E.A. Bott to F.W. O'Connor, 23 March 1926; E.A. Bott to C. W. Wells, RG 1.1, 427, 1, 1, RFA, RAC, N. Tarrytown, N.Y.

79. Canadian Medical Association, Report (1932), p. 24. 
well as the public schools in the 1930's. 80

An Education Divigion was established by the National

Committee to distribute information associated with the projects. This included the publication of articles in medical journals, nursing journals, social welfare and teachers magazines, as well as popular newspapers and bulletins. Traveling fellowships of twelve thousand dollars apiece were eventually developed with Rockefeller support in order to help provide leadership training in mental hygiene. As in the United States, the lack of facilities for the training of professional personnel was a long term problem. The fellowships were to allow Canadians to acquire training in Europe and the United States in lieu of the development of Canadian inatitutions. Clarence Hincks was one of the first reciplents of a travelling fellowship. He spent six months, from October of 1925 to April of 1926, in Europe visiting medical and psychiatric facilities and clinics under the auspices of the Rockefeller Foundation. 81

The LSRM trustees were especially interested in parent training. To acquire additional support for this aspect of the nursery school project, Mr. A.F.C. Fiske, third Vice President of Metropolitan Life Insurance Company was approached. Fiske was able to procure from Metropolitan Life a grant of two thousand

80. Canadian Medical Association, Regort (1932).

81. C.M. Hincks, "Report of the Medical Director," 19 Detober 1925, pp. 1-2, CMHA Papers, MG 28 I 393 84/63, PAC, Ottawa; C.M. Hincks to E. D. MacPhee, 27 March 1926; E. Embree to C.M. Hincks, 24 August 1926; Hincks to Embree, 9 April 1926, 19 April 1926, RG 1.1, 427, 1, 2, REA, RAC, N. Terrytown, N.Y. 
doliars toward a parent education project affiliated with the nursery school. The understanding was that if "a satiafactory programme of parent training" was devised Metropolitan Life would be forthcoming with increasingly large appropriations on an annual basis. Part of the original conceptualization of the project was to "make direct contact with fathers and mothers," as well as preschool children. 82

The St. George's School for Child Study opened January of 1925. It was to be operated in full cooperation with the Toronto Department of Health, the dental services and nuraing services of the Public Schools of Toronto as well as the paycholagy department, public hygiene and medical schools in the university. St. George's was organized in two divisions to correspond to its related but dual mandate. The nursery school diviaion, established in January, was followed the next November by the parent education division. Blatz was in control of the child study centre supported by his colleagues in psychology. E. A. Bott

82. Hincks, "Report," p. 2: Viviana A. Zelizer in Préịing

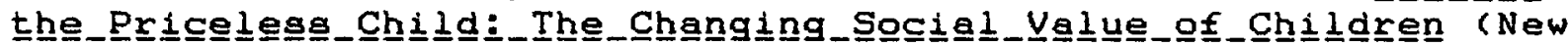
York: Basic. 1985) gives us some hints about why companies like the Metropolitan were eager to support research such as described here. Zelizer argues that children's insurance was sold on a "child saving rhetoric, atresging the pricelesg emotional value of children above their cash value," pp. 117-37, p. 125. A perusal of paperg read before the American Life Convention between 1906 and 1952 and the Medical Section Papers from 1910 show an early and increasing interest in public education as a means of seliing insurance and as a means of reducing the outlay of insurance companies by preventable accidents and iliness. By 1919 the conservation of health and insurance were well linked.

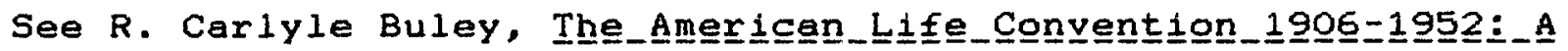

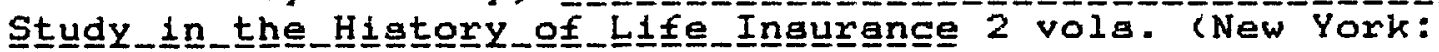
Appleton-Croft 1953), see appendices, vol. 2, pp. 1188-1279. 
provided administrative assistance in practical affairs, chaired staff meetings, and, designed and made the play equipment. Helen Bott, his wife, played a significant role in regearch and in the scholarly work of the parent education division of the nursery school. 83

Between 1926 and 1938, the two divisions of the nursery school and parent education worked in tandem. Within the first three months of its exiatence the parent education diviaion enrolled sixty parents. This is not surprising since parents of the children enrolled in the school were required to attend parent classes. Blatz introduced a longitudinal element into the project by having parents register their children for the nursery school at birth so that the children could be observed from infancy. The children were followed regularly after they left the preschool until they were ten years old. Blatz did not attempt to recruit from the middle and lower classes. The children who participated in this programme read like a who's who of prominent families in Toronto society. The popularity and prestige of the programme was encouraged by the exclusive policy of the ataff and their efforts to recruit and to use the parenta as advocated to teach other parents. Unlike other pioneer mental hygiene efforts in Canada, where trained workers were often imported from the United States or received European training, Blatz utilized and expanded a local work force. One reason for the success and

83. Mary J. Wright, "The History of Developmental Paychology in Canada, Note 4: The Saga of William Emet Blatz," part 1, typescript, Greenland-Griffin Archives, Toronto. 
longevity of the programme in its particular form was Blatz's success in inspiring dedication, loyalty and a team spirit among his students and volunteers. 84 This cohesive quality probably had negative consequences as well. The family like circle of Blatz and his followers in the long run contributed to the perception that Blatz had insulated his theory into a kind of dogma. 85

Instructional books for parent education were produced in the first four years of the programme by Blatz and Helen Bott. 86 There was very little time lag in general between the clinical studies produced by Blatz and his students and publicizing their content. An in-house quarterly journal the Eerenent_Egducegtiong Bullㅌㅌㅌㅡ produced papers from scientific journals such as the

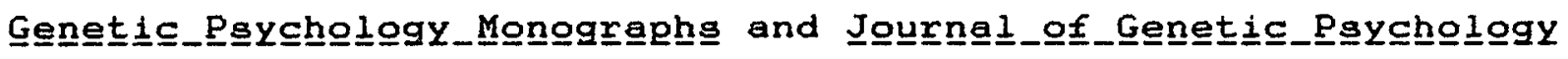
as well as Child Centre research. In 1933 the University of Toronto Press established a special Child Development Series, the first edition of which was produced by Helen Bott.

84. Mary J. Wright, "The Saga of William Emet Blatz," part 1. 85. For example, Murphy Gardner (Columbia Univ.) wrote to L.K. Frank, 23 January 1935, regarding a GEB sponsored conference on child paychology held in New York City, 19-20 January 1935: "Of course folks like Bill Blatz are going to go ahead with their ideas without regard for disturbing questions of this sort, but, most of us I like to think are still educable." GEB 9301,3 , 370, 3866, RAC, N. Tarrytown, N.Y.

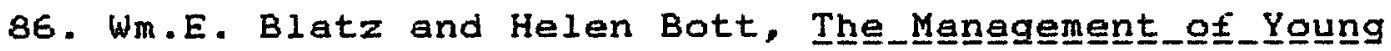
Childgren (New York: Morrow, 1930); Wm.E. Blatz and Helen Bott, Parrentas_and_the_Pre_School_Child (New York: Morrow, 1929); Blatz's other instructional works included Nursengy_Equeation:

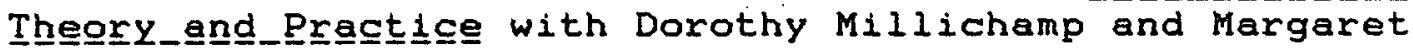
Fletcher, and We_Go_to_Nurgery_schogl with Marjorie Poppleton, both (New York: Morrow 1935). 
In the $1930 \mathrm{~s}$ the productivity of Blatz and his team had won recognition throughout North America which greatly helped surviving the otherwise lean years of the depresaton. In the early $1930 s$ he became the Director of Windy Ridge Day School for children aged 2 to 8 . He applied his preschool ideas to primary grades emphasizing attitude formation and moral development in the older children. As his popularity grew he lectured widely in Canada and the United States extending his audience to medical students, a seminar for graduates in psychiatry and outpatient demonstrations at a psychiatric hospital at which medical students gained clinical experience. 87 In 1934 international publicity was acquired through Blatz's work with the Dionne quintuplets. For two years from the time the girls were eighteen months to four years Blatz planned and directed the daily routine and play opportunities of the children with the approval of their medical management committee, caretakers and nurses. In 1937 and 1938 a collection of the studies on the training programme was published as a part of the Child Development Series. 88

Partly due to the collaboration acrogs the university on the Dionne quintuplets, Blatz was able to persuade the administration of the advantage of making the child Study Centre into an Institute for Child Study. Opened in 1938, it was the first such institute at the Univergity of Toronto. Blatz and his colleagues

87. Mary J. Wright, "The Saga of William Emet Blatz," part 1. see p. 9 .

88. William E. Blatz, et al., The_Five_Sigtenerg (Toronto: University of Toronto, 1937, 1938). 
were well on the way to evolving their own distinctive version of the promotion of mental health in normal children. Blatz believed that the promotion of mental health should be primarily the outcome of parents and educators working together. His central notion was the promotion of "security" as a goal. Blatz's version of security was not a static state of safety but a state of mind characterized by serenity meaning a faith in ones own ability to successfully deal with future events. The key to educating children to be secure was to teach them to accept the consequences of their own actions which he argued was acquired in early experience. First the child developed a dependent security on his caretakers where habits of bravery, curiosity and selfesteem were built. The child guidance plan was to emancipate the child toward the development of independent responsibility through increased freedom to make independent decisions and to abide by the consequences of those decistons. Coping with ones own successes and failures were the essence of healthy mental development according to Blatz.

Blatz's theories reflected his training at Chicago. Blatz, as did Chicago psychologists, Harvey Carr and James R. Angell champloned functionalist paychology as opposed to structuraliam or behaviorism. Functionalist paychology at Chicago was influenced by Darwinist theories. Human behaviour was correlated with the adaptation of mental states where practical habits of conduct, as biological actions, also reflected emotional patterns. These patterns were said to become engrained because 
they were accessful in achieving useful ends for the individual. One objective of functionalist research was to elaborate individual variations along every conceivable psychological dimension. Functionalists stressed the testing of human differences and the application of the information gained to educational practices. Most contemporary applied psychology has a functionalist component. 89

James R. Angel1'a orientation toward psychology corresponded, in many ways, to the programme Blatz developed for child rearing. Angell underscored, as did Blatz, the "problem of intelligence, with special reference to the history of instinct and emotion." He felt that gelf-control "may be regarded as the basic category of consciousness." Angell, used a concept similar to Adolf Meyer's psychobiology where he emphasized the "psychophysical" aspects of human action which viewed the bodymind continuum as a reciprocal relationship concerned with "the process of habit." 90 Blatz substantively continued along these lines of thought in his own development. Blatz elaborated a perspective which combined a Canadian vision of democratic government which depended on parent education and child training

89. Albert R. Gilgen, Amer II:-A_Profilie_of_the_Discipline (London: Greenwood Press, 1982), see opening chapter and p. 128 .

90. See James R. Ange11, "James Rowland Angell," in Carl

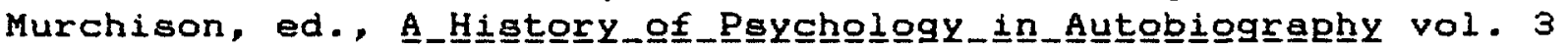
(Worchester, Mass.: Clarke University Press, 1936), pp. 28-9. 
was a keystone of democratic social structure. 91 Blatz's concern in the socialization process was with the development of willful control and conscious thought as opposed to unconscious mental processes or simple habitg. 92 Hig approach distinctly opposed psychoanalytic theory.

Blatz was equally alienated from behaviourist perspectives. Most noticeably he shunned reward systems as undermining selfcontrol. As opposed to functionalism, behaviouriatic psychology emphasized the manipulation of the environment rather than mental habits in order to change behaviour. Overt actiong became the focus of attention because of their observable and measurable quality. Animal studies were often conaidered as informative ag research on human subjects. While the extremely reductionist argument of behaviourist B.F. Skinner appearg diametrically opposed to paychoanalysia, fundamentally behaviourism and paychoanalyais have theoretical points of convergence as opposite sides of a similar argument even where they diverge as therapeutic models. Behaviouriam became increasingly influential in the U.S after 1920. Neither behaviourism nor psychoanalysis enjoyed such popularity in Canada. Blatz, in opposition to behavioural models, was concerned with the acquisition of human dignity, not a psychology which would move mankind beyond human

91. Wm.E. Blatz, Ung Clarke, Irwin \& Co. 1944), see the Introduction.

92. See William E. Blatz, Human_Secur University of Toronto, 1966). 
dignity as in Skinner's thesis. 93

Blatz's functionalism was also distinct from structuralism. Structuralism was orlginally derived from wilhelm Wundt'a work brought to the U.S. by Edward B. Titchner. Early structuralism placed an emphasis on laboratory studies of the mind and consciousness using introspective techniques. Just as Blatz disregarded unconscious processes he opposed introspective methods in the study of human behaviour. This introspective form of structuraliam was also in disregard by the $1920 \mathrm{~g}$ in the United States. A new structuralism combined with functionalism was popularized in the 19308 which emphasized stages of development and cognition as in Arnold Gesell's and Jean Piaget's theories. Blatz's ideas became more dynamic in this way as his research continued and as he developed his "security theory."

However, Blatz's view of mental hyglene involved child guldance and training rather than the uncovering and understanding of innate unfolding stages. Blatz remained distinct in his approach as structural functionalist. The purpose in parent training was not to have parenta understand to advantage the developmental stage their child was going through but to train the perent to menipulate their child'a development towerd the desired goal of serenity. Serenity was the ultimate life goal of all living things, according to Blatz. Education was directed toward this goal in fostering the acceptance of the consequences

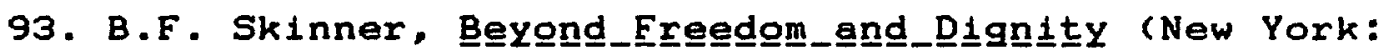
Knopf, 1971). 
of ones own acts. In this way all education was ultimately an individual process, in Blatzian perspective, directed toward the attainment of mental health. 94

Blatz attracted and trained a number of graduate students who went on to dominate child study research in Canada. For example, one of the firat to publish wag Mary Salter (Aingworth) who constructed for her doctoral thesis (1940) a self-reporting scale to access the security level of young adults as opposed to defensive behavioura (insecurity). Much of this research was disseminated through the University of Toronto Press. 95 Other important students and colleagues include Mary Northway, Dorothy M1111champ, S.N.F. Chant, S.R. Laycock, W1111am Line and John D. Griffin.

The outbreak of war in 1939 interrupted the advance of clinical research at Toronto but it contributed to the dissemination of Blatzian theory. 96 In times of full mobilization a substantial majority of the children were in need of day care facilitiea and there was a great ahortage of trained personnel to staff these facilities. The spread of Blatz's work

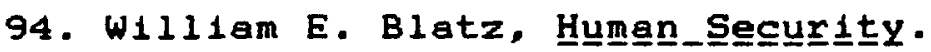

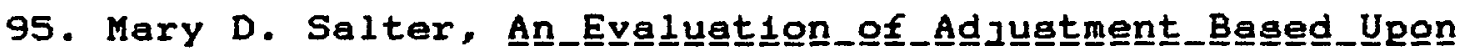
the_Concept_of_Secuxityy Univergity of Toronto Studieg in Child Development Series, No. 9 (Toronto: Univergity of Toronto, 1940); for a list of publications and tests on human security see Blatz,

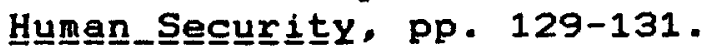

96. Mary D. Salter Ainsworth, "The Significance of Service in England," in Agnes N. O'Connell and Nancy Felipe Russo, eds., Modelels_o으_A psycholology (New York: Columbia University Press, 1983), pp. 201-19. 
was facilitated by the need for war time child care in Britain. Blatz produced his first war time book in 1940.97 Eaxly in the war E.A. Bott consulted with Sir Wilson Jameson, Chief Medical Officer to the Ministry of Health and Board of Education of England and Wales on the problem of child care in Britain. After soliciting the help of President Cody of the University of Toronto and Vincent Massey, Canadian High Commissioner to Britain, the CNCMH was brought in to devise a means of Canadian assistance. Blatz, Hincks, and Stewart Jaffery, of the Department of Social Work of the University of Toronto, visited Britain in the fall of 1941. Hincks organized the Canadian Children's Service in 1942 which oent three groups of workers to Britain. The first group was composed of elementary school teachers to fill vacancies in the ataff of London County Council Schools. The second group consisted of sociel workers who acted as receptionists in areas where children were evacuated from the inner city. Blatz was in charge of the third and most critically needed group to train nursery child care reservista for the day care facilities. 98

Blatz established in Birmingham a training achool for child care workers in the wartime day nurseries, nursery schools and infant schoola. Blatz had stressed in the 1941 visit the dangers of using untrained teachers with young children. In July of 1942

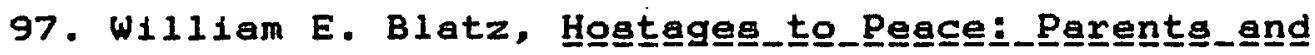

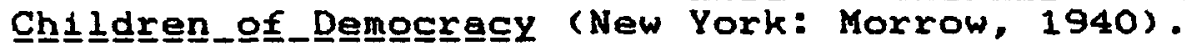

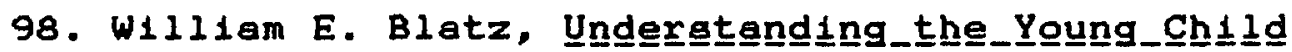
(Toronto: Clarke, Irwin, 1944), pp. v-vil. 
Garrison Lane Nursery opened in a core area of Birmingham. With four to five helpers from the Toronto Institute Blatz took fortytwo children aged two to five years and trained forty student child care reservistg. 99 Blatz's five helperg were senior members of the Institute of Child Study including: Dorothy M1111champ, Margaret Fletcher, Mary MaFarland (Smith), Mary Wright, and Anne Harris (Blatz). 100 Garrison Lane was a full day adaptation of the shorter length preschool programme at the University of Toronto. The trainees were taught Institute theory and methods. By the end of the summer the programme was well established and Blatz and three of the senior staff returned to Canada. A second contingent from Canada arrived in late August. Garrison Lane functioned until 1944. A 1944 monograph was directed toward disseminating Institute theory and method throughout Britain. It was republished in Canada and the United States.

Blatz's long term contribution to British education is difficult to assess. However, associates maintain that there is good reason to believe that his impact was substantial. 101

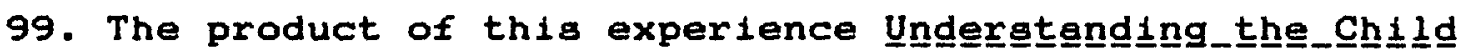
was also published in Britain, (Bickley Kent: University of London), and in the U.S., (New York: William Morrow), both in 1944. It was reprinted eight times between 1944 and 1965.

100. Mary J. Wright, "The History of Developmental Paychology in Canada, Note 5: The Saga of William Emet Blatz, Part II, 19381950," typescript, Greenland-Griffin Archives, Toronto.

101. Mary J. Wright a senior staff member of the Institute trained by Blatz who also participated in Garrison Lane makes this argument in "The Saga of William Emet Blatz," part 2, p.5; also interview with John D. Griffin, July 20, 1986, Toronto. 
Significantly, Blatz's ideas on early chlldhood education were widely disseminated in Britain during the war years on a variety of levels. Blatz and $\mathrm{hls}$ followers also set up strong mechanisms for their continuance. For example, Garrison Lane offered week length classes in adminiatration as well as child care reservist training. These classes were fully enrolled. Visits from other public officiala were a daily occurance at the school. 102 Blatz also achieved personal recognition as an authority on early childhood education and was in demand as a lecturer where he was often presented along with other notables such as Anna Freud. 103 It has been noted that the informal early childhood education offered in British nursery classes and schools since the Plowden Report of 1967 have much in common with the type of education promoted by Blatz. 104 Lillian Weber, an American professor of early childhood education at New York'a City College, was atruck with the similarities between the demonstration and laboratory nursery schools in the United States and British infant schools. She conducted a survey of flfty-six British schools. In her exhaustive descriptions she noted that educatora in these achoola often used terminology characteriatic of Blatzian views of

102. Wright, "The Saga."

103. Anna Freud as a refuge from occupled Europe was also actively disseminating her ideas during this period.

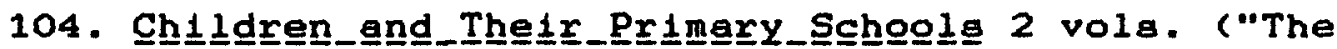
Plowden Report") Report of the Central Advisory Council for Education (England), (London: Her Majesty'a Stationary House, 1967). 
education, such as "serenity" as an educational goal. 105 Joseph Featherstone, a contributing editor to the magazine The_New

Repubㅡ느트 and a professor at Harvard, wrote three articles in 1967 describing the post World War II revolution in infant schools in Britain. 106 Lillian weber and others like her adapted these Ideas into a U.S. context. 107 Blatz's contribution to educational theory and practice may have in the long term been indirect by way of his contribution to early childhood education in Britain and its subsequent influence on the open education movement of the $1960 \mathrm{~s}$ and $1970 \mathrm{~s}$.

Blatz's contribution may have been subtle in the long term, however, his short term influence during the war on nuraery education in Canada was decisive. His authority in Ontario was straightforeward. By the fall of 1942 there was a growing need in Canada, as there was in Britain, for child care facilities and War time nurseriea. The Welfare Council of Toronto argued that children were left without adequate care when mothers were

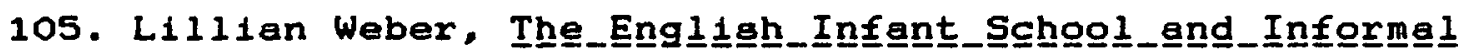

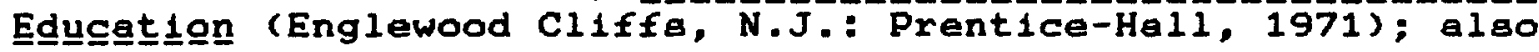
Wright, "The Saga," part 2, p. 5 .

106. Featheratone wrote three articles in The New_Republí (August 19, September 2, and September 9, 1967). Joseph

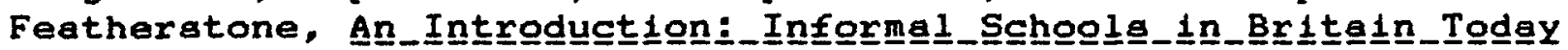
Anglo-American Primary School Project (New York: Citation Preas,

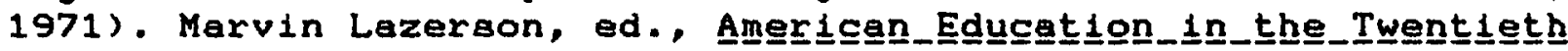
Centuㅡy (New York: Teachers College Press, 1987), "Introduction" p. 44 and the selection from Joseph Featherstone, pp. 177-182, notes this influence in the context of American educational reform in the 19608 .

107. See the three excerpts from Lillian weber in Charles

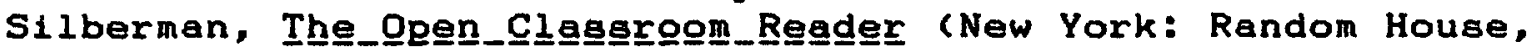
1973), pp. 22-6, 148-66, 467-80; also Featherstone, pp. 133-8. 
recruited for essential War work. The provincial and federal government were petitioned for help. 108 In July, a cost sharing agreement was worked out between Ontario and the federal government on day care facilities. Ontario initiated the programme and was the only province to take advantage of it on a large scale. This was at least in part due to the presence of the Institute with its rocal contingent of authorities on the subject. Dorothy Mililchamp of the Institute was asked to join the Department of Public Welfare to direct the new day nursery project. She recruited Institute trainees to help her. NonInstitute workers who jolned the programme were not allowed to provide simple custodial care for children but were strictly trained in the teaching role characteristic of the Toronto Institute.

Due to the shortage of trained teachers, emergency training classes were initiated at the Institute of Child Study. The first students received a full pre-War curriculum in research and methods. However, it became increasingly clear that the situation demanded the production of teachers not researchers. The initial training sequence which lasted for eighteen months was cut to $s i x$ months and finally to four. In 1943 a one year bachelors programme was formalized.

Since Millichamp and Blatz were both preoccupied with other War work during this period, psychologists Karl Bernhardt and

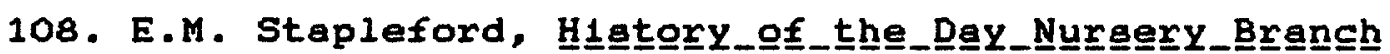
(Toronto, Ontario: Ministry of Community and Social Services, 1976), P. 2 . 
Mary Northway, who had relatively little experience with early childhood, were pressed into service to teach courses at the Institute. They modeled their curriculum on the precedent set by Blatz. The clarity of the Blatzlan formula for teacher education was evident. A definable "Ontario traditional early childhood format was eatabliahed which endured for more then two decadea." 109

It is interesting that when the federal government withdrew from day care after 1945, Ontario continued 1ts assistance to these facilities. In contrast, Quebec eilminated such funding. The Ontario Day Nurseries Act drafted in 1946 was passed in the spring of 1947. This law specified that day nurseries had to meet apecifled atandards and be licensed. Blatz and his colleagues were asked to set out these standards. Blatz's suggestion was aimply to "juat tell them to do what we did at the Institute." 110 The final version of the act, in fact, specified that the time table was to conform to the standards of the Institute of Child Study of the University of Toronto. A similar statement was included in every subsequent revision of the act until 1968. The 1946 Ontario Day Nursery Act was a model piece of legislation as one of the firet of its kind in the United States or Canada.

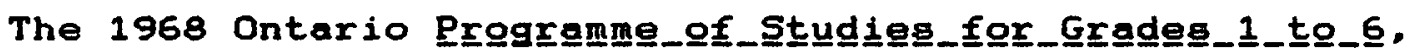
carried on a more aubtle version of the Blatzian formula for

109. Mary J. Wright, "The Saga," part 2, p. 6.

110. Dorothy Millichamp and Mary L. Northway, Converersatíngng

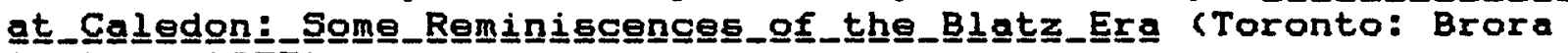
Centre, 1977). 
education in that it describes the practice and goals of education in ways compatible with Blatz's teachings. They also reveal an articulation of the evolving concept of parent education in character training. The primary percept was that children should be educated for social responsibility, service to al1, and adaptability to change, including an explicit emphasia on cooperation and getting along with others. The school was to provide "meaningful experiences in situations that require the exercise of qualities of helpfulness, self-direction and acceptance of responsibility." 111 This is, in a sense, an updated definition of what Blatz meant by schooling as fostering a personal acquisition of security.

Educational reforms based on developmental perspectives in the $1960 \mathrm{~s}$ and $1970 \mathrm{~s}$ apear to have been pushed aside by the more current emphasis on educational basics and accountability. 112 However, if a distinction ls made between the free school movement and open classroom movement it becomes more apparent that the 1deology of structured progressive classrooms more typical of the open classroom have historically been compatible with scientific efficiency. Blatzian psychology can be seen in

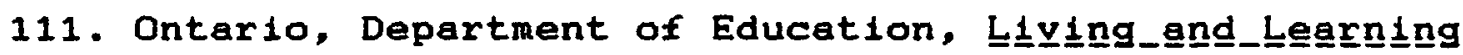

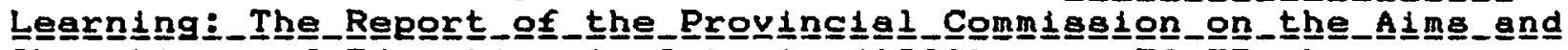

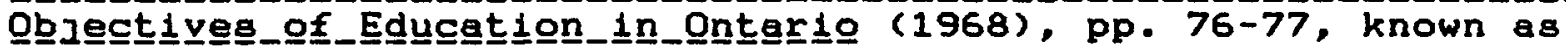

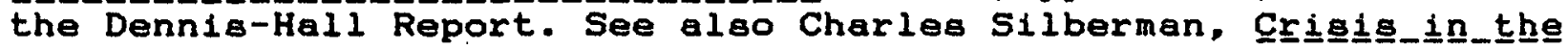

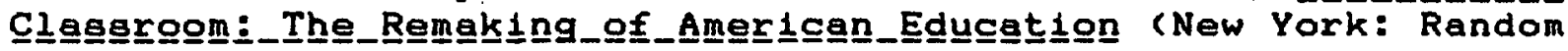
House, 1970), p. 115 where he quotes the Ontario report.

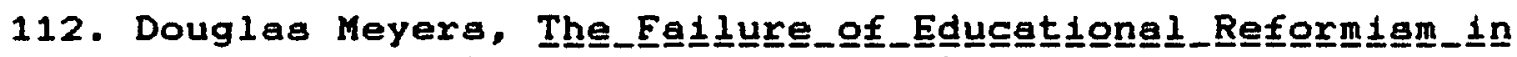
Canade (Toronto: McClelland \& Stewart, 1973). 
contemporary forms as the individualization of self-development.

\section{A Normative Paradign}

While Canadian child paychology made a unique contribution to twentieth century perceptions of normal development, the transition from a preoccupation with abnormal development may not have come about if it was not for the philanthropic support and advocacy of the CNCMH, the Rockefeller Foundation and the Laura Spelman Rockefeller Memorlal. Rockefeller Grants to promote the development of mental hygiene and paychlatry in Canada from 1924 to 1937 amounted to well over three hundred thousand dollars. In evaluating Canadian progress with reference to these funds in 1939, Alan Gregg regretfully adnits that "the results of these appropriations to the Canadian Committee November 1939 are difficult to describe... Except for the growth of psychological work on chlldren at Toronto where Blatz has become established and much of the work incorporated in the university department of psychology, it would not appear that there is much perceptible residue from this series of collaborations... Though the sums expended were used in ways to meet local and temporary needs I can not point to any continuing and conspicuous results." 113

Gregg was evaluating the policy of the Foundation as well as the impact of the research it funded. The Rockefeller Foundation had not reconciled its approach to mental hygiene with other medical and public health work. There was a question whether

113. Alan Gregg, "Canadian National Committee for Mental Hygiene," p. 2, RF 1.1, 427, 1, 6, RFA, RAC, N. Tarrytown, N.Y. 
mental hygiene should be a direct function of the Foundation or relegated to one of the Foundation'a affiliatea or branches. A less favoured view was that mental health research should be a support programme handled by other agents such as the National Committees for Mental Hygiene. Gregg came to the conclusion that "It would be my considered opinion that Dr. Pearce was right in holding in 1920 that the Rockefeller Foundation should cooperate directly with medical schools and leaders in medical education in Canada in preference to alding special programs." 114

The Laura Spelman Rockefeller Memorial contributed to the development of a normative paradigm of mental and physical growth created in research institutions such as Toronto. The Memorial also helped distribute these ideas through parent training and professional education. While the specifics of the generalizations about developmental processes have changed, more important than the specific content of the message about normality and abnormality was the institutionalization of the idea that we can scientifically validate standards of normal physical and mental functioning. Blatz, as one researcher, used this criteria in a very contemporary sense to individualize education as a form of self-development.

114. Gregg, "Canadian National Committee." 


\section{CHAPTER EIGHT}

\section{INFANCY TO ADOLESCENCE: ROCKEFELLER PHILANTHROPY}

\section{AND THE PARADIGM OF NORMALITY}

During the period between world War I and World War II Rockefeller philanthropy supported growth and developmental studies which established acientific medical basis for the cultural perception of a unique and sequential mental world of childhood and adolescence. Without this we would not have elaborated the terrible twos and the teenage monster of post World Wer II notoriety. G. Stanley Hall grounded hia paychology of youth on biography and philosophy. 1 Mental measurements in intelligence testa as correlated with age did not tap the progress of bone growth, maturation of the nervous and reproductive system with mood and behaviour changes. Much of the current information on growth, development and timing of maturation, which are taken as close to self-evident, are in fact concepts which have only recently been integrated into a conceptual framework which circumscribes the modern phenomenon of growing up. 2 Part of this process necessarily involves the transformation of social institutions which surround the growing

1. Dorothy Ross,_G__Stangnley_Hell Prophenet (Chicago: University of Chicago Press, 1972), pp. 148-79, makes the point that Hall's "aggressive scientiam" was matched by his "philosophical impulses" and desire to "formulate a scientific philosophy compatible with religion," p. 179; also see

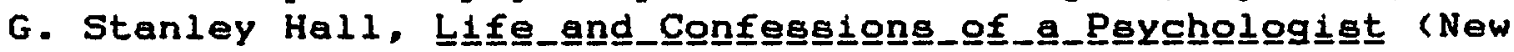
York: D. Appleton, 1923).

2. See Louise J. Kaplan, Adololescence :-The_Fagrewelli_tto Chiㅛㅁㅡhoog (New York: Simon and Schuster, 1984). 
child. This includes family, school, and community orientation toward the newly apparent and now the seemingly inevitable phenomenon of age related developmental stages.

Research on child development was initlated by the Laura Spelman Rockefeller Memorial and continued by other Rockefeller funds after the Memorial was merged with the Rockefeller Foundation in 1929. While the numerous research projects carried out by these funds were given various degrees of guidance by Rockefeller officials, the projects were diverse. Yet, they all shared an emphasis on medical knowledge, scientific methodology in research and the application of research findings to administrative practice. The consistent objective was the remediation of "real-life" problems in families, schools and clinics.

The Laura Spelman Rockefeller Memortal began with a practical mandate in parent education. Over the long term the Memorlal'a major contribution was in applied research in child paychology. The Memoriala guiding principles were clear:

The Memorial had no interest in the promotion of scientific research as an end in itself; its motive wes not sheer curiosity as to how various human and social phenomena came to be and all; the interest in science was an interest as one means to an end, and, the end was explicitly recognized to be the advancement of human welfare. 3

The express guiding policy of the Memorial, to further applied knowledge, shaped the character and direction of

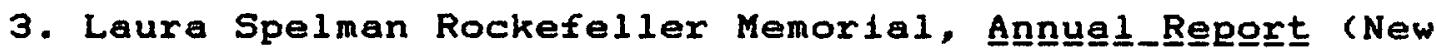
York: Rockefeller Foundation, 1930), p. 10. 
scientifically oriented child related research in the decades after 1920. To the degree that the Memorial subatantially influenced the shape and character of inter-War scientific child study it also contributed to the conceptualization of the ideal healthy infant, child, and adolescent. The images of normal childhood which emerged as if full-formed in the post world war I perlod had been constructed by way of clinical studies and intentional propaganda for public consumption. The demonstration period in child study was largely oriented toward middle class families in the United States. This was similar to child study in Toronto. A model was created, however, which spread far beyond a limited class circle. The technological ability to advertise model families, children and social relationships, expanded the constituency of child study research. The popular press and the expansion of viaual media greatly contributed to the dissemination of popular concepts of what was normal.

What was described as normal in clinical studies was interpreted as good and desirable signs of positive development on a family, school and community level. The concurrent effort to train teachers, social workers, and health care profesalonalg the technology of scientific child nurture insured this normative paradigm a place in public policy as well as public ideology.

The most significant research priority for the LSRM was that the methodology be scientific. The major difference between sentimental child study of the Progressive Era was the institutionalization of a scientific bias for validating 
knowledge about children. Much of the scientific basis for child development was a product of longitudinal child growth research whlch involved: 1) anthropomorphic measurement, 2) paychological measures, 3) physiological data, and 4) medical record taking. Studies of normal children began with school age but encompassed a range from infancy to adolescence by the end of the 1930s. Two major sets of data were compiled from the early childhood studies of the $1920 \mathrm{~s}$ and the adolescent studies of the 1930s. Literally thousands of children across the country at research centres became case histories.

These studies were unique. They established the scientific standards for evaluating physical and mental maturation in human populations. The underlying rational in the fostering of social adjustment and mental health was an adaptation of the mental hyglene framework. The ultimate goal was a form of universal mental health in that adjusted children would logically grow up to be mentally competent adults who contributed to the social well-being of the body politic. Since the Rockfeller Foundation had as itg mandate the fielda of health, medical education and research. The Memorial was to develop the related social sciences into a technology of human relations. 4

The Research Centers: Infant and Child Studies The research centres developed by the LSRM in child studies have had a major impact on an academic, medical and popular

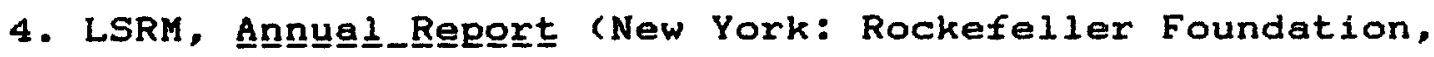
1930), p. 9 . 
concept of infancy, childhood and adalescence. Five major centres initiated by the LSRM are cited in the literature. There were actually closer to fifteen. The figure five usually includes the most distinguished and successful programmes in the Iowa Child Welfare Regearch Station; the Institute of Child Welfare at the University of California, Berkeley; the Institute of Child Welfare at the University of Minnesota; the Clinic for Child Development of the Institute for Human Relations at Yale University; and the Child Development Institute at Teachers College, Columbia. 5 Two additional centres are eclectically substituted for those cited above, including the University of Toronto, St. George' s School later Institute for Child Study, and Cornell University where the American Association of University Women'a did research on rural education and eating behaviours of nursery school children. MCGill is rarely mentioned, most likely because of the deemphasis on child atudy in the mid-thirties.

The programme emphasis varied. For example, Minnesota maintained a nuraery school laboratory with connectiona to school age children. Yale concentrated on Infant growth and the determination of norms for mental and motor development. Teachers College studied nursery school children and family relations, focussing on personality development rather than growth. In eddition there were eight other centers which were an ongoing part of Rockefeller related advocacy of child welfare research.

5. "The Present Situation in Child Reaearch," GEB 9301 , 3, 369, 3849, RAC, N. Tarrytown, NY. 
In cooperation with the Brush Foundation, physical growth studies from infancy to adolescence were pursued at Western Reserve. At the University of Chicago, the Committee on Child Development maintained a Central Record Bureau which coordinated the Depertments of Psychology, Education and Home Economics in keeping records of children from elementary through high school age. Walter Dearborn at Harvard launched a major twelve year growth study which maintained case records on twenty-seven thousand children through the Department of Public Health. At Johns Hopkins University the Department of Psychology worked on mental and motor development of preschool children. Stanford University Department of Psychology concentrated on longitudinal studies and the testing of intelligence. The Child Research Council of Denver in cooperation with the School of Medicine of the University of Colorado did research on infancy. The MerrillPalmer School in Detrolt studied nursery and school age children. Proposals for studies at Moosehart, Illinols and Atlanta, Georgia were a major consideration of the $1930 \mathrm{~s}$. In the $1940 \mathrm{~s}$ the G.E.B. Board decided to devote resources for education and child study in the southern states. 6

Research at the State University of Iowa concentrated on Infancy and preschool development. Oriented toward rural and

6. "Minutes of the Meeting of Committee on Child Growth and Development," 22 December 1936 GEB $9301,3,369$, 3849; "Minutes of the Meeting of Committee on Child Growth and Development," 15 March 1937; "Minutes of the Meeting of Committee on Growth and Development," 3 June 1937, GEB $9301,3,369,3850$, RAC, N. Tarrytown, N.Y. 
environmental 18sues, Iowa researchers became enveloped in nature-nurture controversies with Stanford researchers. The University of California established unique longitudinal programmes which followed children from infancy through preschool into school age. Urban researchers carried out definitive clinical studies in Berkeley and Oakland which investigated the psychobiological characteristica of adolescence.

These last two projects are described as case atudieg of Rockefeller research on child life. They represent two variations on normal child research. Iowa was one of the earliest projecta. Its origins were volunteeristic and publicly supported. Berkeley wag funded at a later date after public leglalative aupport failed. The origins of the project reflect a maturation of the interests of Rockefeller philanthropy in the scientific atudy of the child. The Berkeley project extended into the 1940 s and therefore became a part of more contemporary methods of data distribution. In the 1940 s Rockefeller philanthropy was drawing its projects on child atudy to a close. This was part of long standing Rockefeller policy that all major projects had finite time periods and that unused funds reverted back to the principle endowment.

The research in Iowa and Berkeley also had their similarities which were consistent with Rockefelier interests in the projects. Both centres are considered to have made substantial scientific contributions to theory and practice in child development. The biological measurements on age related 
mental and physical stages standardized at Iowa and Berkeley are st11l considered definitive. The staff of the centrea represent major figures in these areas of research from Bird $T$. Baldwin and George Stoddard at Iowa to Herbert Stoltz, Harold Jones and Jean Walker MacFarlane at Berkeley. These centres created optimistic, individualistic and deterministic ideological perspectives on child life which epitomize the impact of the childhood gaze.

\section{Iowa Child Welfare Research Station}

The Iowa Child Welfare Research Station is unique among the group of research centres cited above. It predates the creation of the Memorial and it is the only research centre with a guarantee of its continued existence by a special legialative act of the state. LSRM funding helped focus and shape the research carried on here but it did not set up the programme or initiate the concerns which started the station. Iowe is a good example of the relationahip between the philanthropy in contributing to, and shaping through consultation and support, locally generated advocacy. The direct connection of the station with state government and public support was a favoured model for Rockefeller Foundation related work. However, the example of Iowa did not become a model for other states.

$$
\text { In a very real sense the Iowa Child Welfare Research }
$$

Station was a product of the progressive child saving movement. The original idea for the station was a response to a succesaful 
statewide campaign by Mrs. Cora Bussey Hillis. 7 After sixteen years of advocacy work for child health, Hillis and her associates were able to acquire the support of key figures in the President of the University of Iowa, Thomas H. MacBride, and first Chair of the Psychology Department and Dean of the Graduate College, Carl E. Seashore. B Eventually the popular support of three hundred thousand Iowa citizens was able to move the state legislature. 9 The legislative statute was approved on April 21, 1917. It created the Station as an integral part of the University of Iowa with its objectives: "the investigation of the best scientific methods of conserving and developing the normal child, the dissemination of the information acquired by such invegtigations, and the training of students for work in such

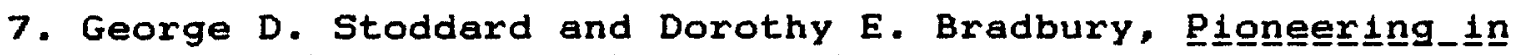

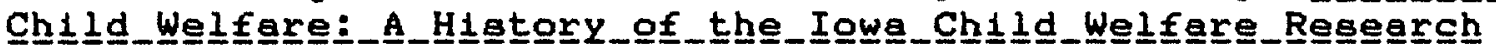
Steteton $1917=1933$ (Iowa City: University of Iowa Press, 1933); Ginalie Swaim, "Cora Bussey Hili1s: Woman of Vision," The

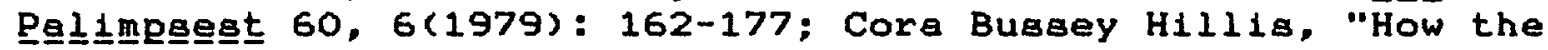
Iowa Child welfare Research Station Came into Being," unpublished manuscript, August 1919, Cora Bussey H1llis Papers, Iowa State Hiatorical Department, Division of the State Hiatorical Society of Iowa, Iowa City, cited in Henry L. Minton "The Iowa Child Welfare Research Station and the 1940 Debate on Intelifigence: Carrying on the Legacy of a Concerned Mother," Jounrnal_of

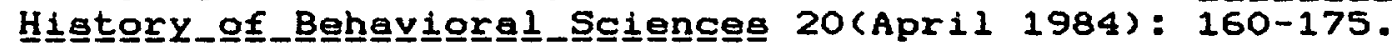

8. Carl E. Seashore, "Carl Emil Seashore," in Carl

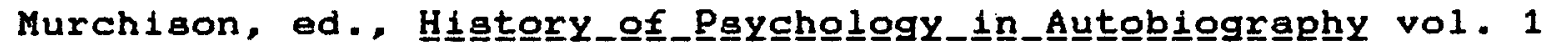
(Worchester, Mass,: Clarke Untveraity Press, 1930), pp. 225-97; Carl E. Seashore, Pioneering_in_Psychology (Iowa City: University of Iowa, 1942).

9. George D. Stoddard, "The Second Decade: A Review of the Activities of the Iowa Child Welfare Research Station, 1928-1938"

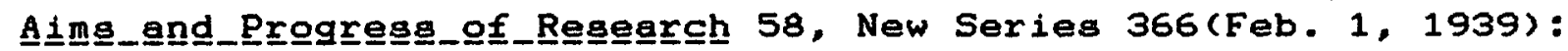
1 . 
fields." 10

The successful propaganda and growing concern in Iowa over the health and welfare of children was encouraged by related popular movement such as advanced by the Iowa branch of the National Congress of Mothers. Mother's Congress activist, Mrs Mary T. Watts of Audubon, Iowa, ploneered in the "better babiea" movement and was an originator of another movement termed "fitter families." Watts" concern was with eugenical family fitness. She set up a programme at the Iowa State Fair beginning in 1911 which provided a "competition" for families involving genetic classification. As one newspaper article reported: "That coveted blue ribbon with which owners of prize livestock is rewarded at the state fairs will be duplicated at the same fairs for whole families who prove, after varlous tests, to be one hundred per cent healthy and sound." 11 Watts managed to get publicity for her campaign and to give mental and physical examinations to hundreds of children and parents through her work at state fairs in Iowa and Kansas.

The Iowa project was a part of the larger trend acrosa the country not only in eugenica but in child health. On a national basis, the Federal Children's Bureau had been waging a battle

10. State of Iowa. "Chapter 282, Iowa Child Welfare Research Station: An Act to establish and maintain the Iowa Child Welfare Research Station and making an appropriation therefor."

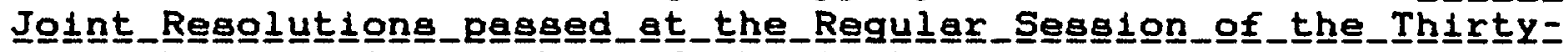
Seventh_Genergl_AsBembIy_of_the_Stgte_ofof_Iowa .

11. Undated news clipping, "Entire Families May Enter Lists For Blue Ribbons," LSRM 3, 43,450, RAC. N. Tarrytown, N.Y. 
since its inception in 1912 for child health and welfare. In 1914 children's advocate, George B. Mangold wrote, "Health is no longer a purely individual matter; it has become the concern of the community. Preventable infant mortality is a social crime." 12 The federal Sheppard-Towner Act of 1921 was the legislated success symbol of the campaign for public intervention in order to protect the health and well belng of infants and mothers. During its span of enactment from 1921 to 1928 seven million dollara were released for granta-in-aid for state governments to promote the conservetion of child life. 13 The Sheppard-Towner Clinica provided supportive services for the Iowa State Program of Parent Education. 14

The Iowa Child Welfare Research Station's priority was the discovery of a sound knowledge base with which to improve child health and welfare. The legislature provided $\$ 24,000$ annually for research but as early as 1920, Bird T. Baldwin, the first Director of the Station was actively pursuing an expansion of the

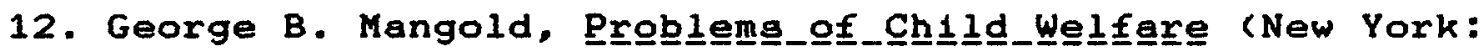
Mackilian, 1914, 2nd edition 1924), p. 123.

13. "An act for the promotion of the Welfare and hygiene of maternity and 1nfancy, 1921" U. (Apr11 1921-March 1923), pp. 224-6; see U.S. Department of Labor, Children's Bureau, "The Promotion of the Welfare and Hyglene of Maternity and Infancy: The Adminiatration of the Act of Congress of November 23, 1921," Bureau Publication No. 146 (Washington: Government Printing, 1925); also, Robert Bremner, ed., Chly 1 ligreng

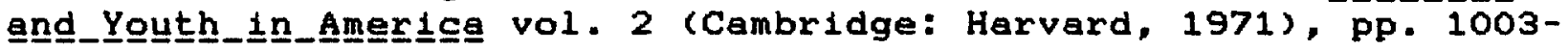
1025 .

14. May Pardee Youtz, "Iowa State Program of Parent

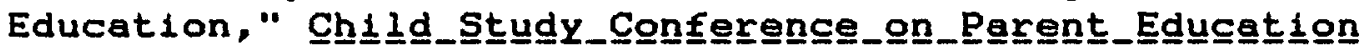
Bronxville, New York, October 1925, pp. 93-98, LSRM 3, 5, 27, 284, RAC, N. Tarrytown, N.Y. 
programme with the financial assistance of the LSRM. Psychology, nutrition, eugenics and a section called social betterment were the topics of early studies. Baldwin cooperated with the Medical and Dental Colleges, College of Education, the Extension Division, Home Economics, School of Public Nursing and Department

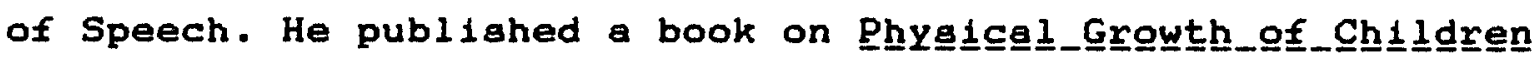

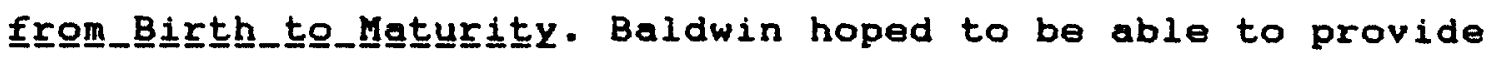
clinical and laboratory services for the atate of Iowa in such a way as to become a national clearing house for child welfare research. 15 Baldwin emphasized that Iowa occupied both the geographic and apiritual heartland of the nation.

A child study and parent education division was organized in June of 1924. The LSRM contributed to extension work in child study-parent education. 16 One hundred thousand dollara over five yeara was approprlated to "supplement and extend the research program." 17 In 1925 the State Board of Education deaignated the Station as the coordinating centre of all of its child welfare research and public education for the state. Thig act unified the work of the University of Iowa, the Iowa State College and Iowa State Teachers College into a single project format. After a lengthy period of negotiation the LSRM agreed to a ten year

15. Bird T. Baldwin to Mr. Richardson, 8 December 1920, LSRM 3, 40, 416, RAC, N. Tarrytown, N.Y.

16. "Ch1ld Study and Parent Training," LSRM 3, 30, 315, RAC, N. Tarrytown, N.Y.

17. "Memorandum Concerning Child Study Program," September 1925, LSRM 3, 30, 351, RAC, N. Tarrytown, N.Y. 
commitment to the Iowa project beginning in 1928. These funds allowed for the proviaton of new laboratory facilitiea where the "all round problems of child growth and behavior" were taken up. The Iowa Station also emphasized nutrition studies, phyaical growth and anthropometry, paychology broadly interpreted to include infent behaviour, mental development, motor development, musical development, social and personal adjustment and mental hygiene. The studies began at birth in a laboratory for newborns maintained by Dr. Orvis C. Irwin who conducted experiments with early reflexes and learning behaviour in infanta. 18

The ten year mark of the Station was a transition point. Baldwin died in 1928 and George D. Stoddard became the Director. This year also signaled the first installment of the ten year LSRM grant and the stations maturity as a multiple functioning state wide service which developed a new knowledge base through research, demonstrated its effectiveness, and disseminated its conclusions in terms of practical educational material. Stoddard citea the "wise council" of the new Univeraity of Iowa Prealdent Walter A. Jessup, Dean Carl E. Seashore, Beardsley Ruml and Lawrence K. Frank as contributing to the auccess of the work. 19

The actual work of the station was eclectic. The nutritional studies with the advent of the new biachemical laboratory took up

18. See George D. Stoddard, "The Second Decade: A Review of Activities of the Iowa Child Welfare Research Station," Aimg_and

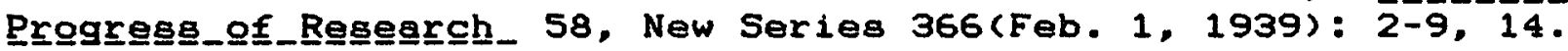

19. George D. Stoddard, "The Second Decade: A Review of the Activities of the Iowa Child Welfare Research Station," A1 1 me_eng

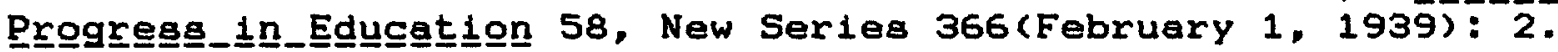


metabolic functioning and the physiological effects of too little food. Clinical studies on rats were used as well as studies of children from orphanages and private homes. In the late $1930 \mathrm{~s}$ the nutrition research received awards from the Borden Milk Company and the American Home Economica Association for establishing that the "average" child"s diet was deficlent. 20 Phyalcal growth studies began with Baldwin's own work. Data was synthesized from anatomic, anthropometric, and statistical material over a ten year period. H.V. Meredith collected ninety thousand values for eighteen anthropomorphic measures on twelve hundred males and a similar number of females over fourteen years. This type of data was used to create charts on estimated child growth and development. C.H. MCCoy and his associates formulated a procedure for securing and evaluating the physical status of children which was subsequently made avallable to public schools nationwide. The Station was extremely effective in disaeminating its findings. As of December 1938, $1.5 \mathrm{milli}$ on standards and testing materials had been distributed to appropriate agenciea, nine hundred thousand popular bulletins and pamphlets were distributed to the public and forty-two thousand technical monographa were published for a professional audience. Of the nine hundred publications of the station one quarter contributed to child paychology and child behaviour. Most of the publications were in the form of popular bulletins most of which dealt with parent

20. The reference is to the work of Amy L. Daniels published in 1938 . 
education. Over one hundred others addressed preschool socialization and training. Physical growth and nutrition were also major topics. Other popular subjects included general child development research or research in allied fields which was reviewed or abstracted. 21 The station cooperated with and found "a bridge between the work of the Station, viewed as a whole, and the citizens of the State," In the American Association of University Women, American Legion Auxiliary, Iowa Congreas of Parents and Teachers, Iowa Farm Bureau Federation, Iowa Federation of Women's Clubs, Iowa League of Women Voters, Iowa State Assoclation of Social Welfare, Iowa State College, Iowa State Department of Health, Iowa State Department of Public Instruction, Iowa State Medical Society, Iowa State Physical Education Association, Iowa State Teachers Association, Iowa State Teachers College, Iowa State Tuberculosis Association, the University of Iowa and the Women's Christian Temperance Union of Iowa.

The Station's research in child psychology assumed a distinguished trend. This was to emphasize environmental factors in understanding the physical and mentel capacities of children. Studies were carried out from infancy through school age using the University laboratory preschool and community data as well as urban and rural school studies. 22 Conclusions, In work such as

21. Stoddard, "The Second Decade," pp. 11-12.

22. Bird T. Baldwin, Heredity and Environment-Or Capacity and Training?" Joun B1rd T. Baldwin and Lorle I. Stecher, "Mental Growth Curve of 
that of Harold Skeels, supported the premise that "illegitimate children of dull and feeble-minded mothers and out-of-work or labouring fathers, if placed in good homes in early infancy, will turn out to be bright children as measured by the best tests now available." 23 Beth L. Wellman's work supported a similar idea that children attending the preschool laboratory gained twenty I.Q. points. 24 Kurt Lewin was added to this staff in the 1930 s by a General Education Board grant covering a three year period. His work in the field of social and topological psychology again emphasized social factors. The Iowa Child Welfare Research Station pioneered and stayed at the forefront of regearch on the connection between inteliligence and environment.

There are several contextual and temporal reasons for this

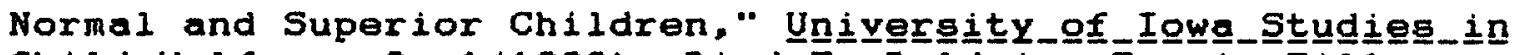
Chilld welfere 2, 1(1922); Bird T. Baldwin, Eva A. Fillmore and

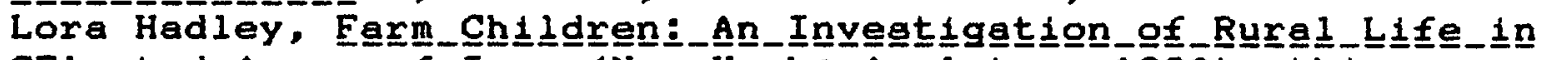
SElecteded_Areeg of of_Iowe (New York: Appleton, 1930), this was published two years after Baldwin's death.

23. Staddard, "The Second Decade," p. 6; Harold M. Skeels, "Iowa Studies of the Mental Growth of Children in Relation to the Differentials of the Environment: A Summary," in Guy Montrose

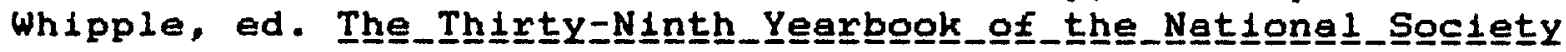

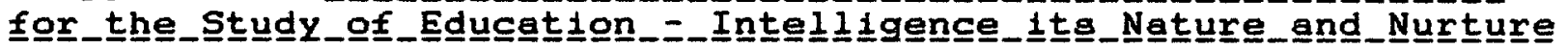
Part 2, (Bloomington, Ill: Public School Publishing, 1940), pp. 281-308.

24. Beth L. Wellman, "The Effect of Preschool Attendance

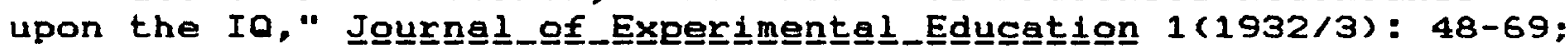
Beth L. Wellman, "Some New Basis for Interpretation of the IQ,"

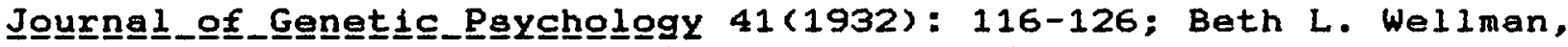
"Physical Growth and Motor Development and Their Relation to Mental Development in Children," in Carl Murchison, ed. Hanglaboonk

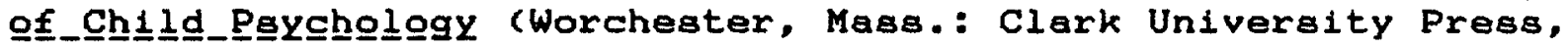
1931), pp. 242-77; Beth L. Wellman, "Iowa Studies on the Effects

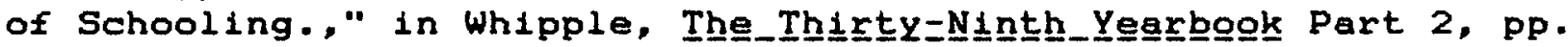
281-308. 
emphasis. In addition to the orientation and interesta of the original research team the Station's mandate was to pursue the scientific guidance of normal children. The emphasis was on the prevention of physical and mental aberration. The Station from an early date participated in rural programmes extending itself into the community. As hard times enveloped the agricultural heartland a natural laboratory was created which illustrated what happens to normal people, families and children under stressful social conditions. New Deal politics also encouraged environmental solutions to social problems. It is noteworthy that the researchers at the Station did not question the underlying biological basis of intelligence. They emphasized the factors which could alter or direct changes for the better in populations which were often poor and underprivileged. This was in keeping with the larger trends in mentel hygiene research where the moralistic and eugenical overtones of the early aurveys were considered unscientific. In the 1920 s backlash developed over the Army Alpha and Beta testa and the extreme conclusions drawn from them in the vast numbers of mentaliy retarded and defective. 25 In the 1930s, the racist overtones of eugenicists policies were brought into question. 26 Both social scientist and popular journalist criticized eugenical arguments based on an innate

25. Mark H. Haller, Eugenics:_Hereditan $\underline{1}$. American_Thought (New Brunswick: Rutgers University Press, 1963), pp. $112-3,159$.

26. Hallex, Eugenígs, p. 159. 
intelligence hierarchy in human populations. 27 As the fascist movement advanced in Europe in the 1930 s extreme hereditarian and racist positions became less tenable and less subject to popular support. 28 Even the most vocal eugenicist had somewhat moderated their position by the late 1930s. 29 It is interesting that by the 1940 s the environmental orientation of the Iowa Station had come into public conflict with Lewis Terman'a work in intelifgence at Stanford. 30

The so-called nature-nurture controversy was of long otanding by the 1930s. 31 The mental hygiene movement was informed by the evolutionary theory of social Darwinism and the development of experimental biology and its application to preventive medicine and public health. 32 The position that mental retardation, mental illness and social disorders from

27. N.J. Block and G. Dworkin, The_Ig_Controverergy (New York: Pantheon Books, 1974), see "The Lippman-Terman Debate," pp. 4-44;

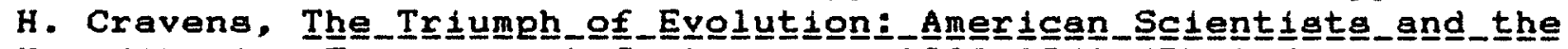

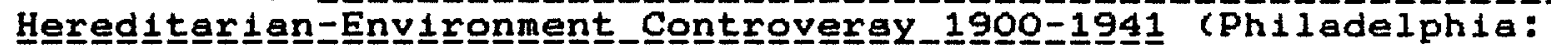
University of Pennsylvania, 1978).

28. Haller, Eugengiçs, pp. 179-80.

29. Steven Jay Gould, The_M1smegeuxye_of_Men (New York: W.W. Norton, 1981), ch. 5, "The Hereditarian Theory of Ia," pp. 146233, see pp. 191-2 especially on Lewis Terman; also, Haller, Eugenics p. 94; for a relevant review of current literature on genetics see Chriatine M. Shea's book review of Daniel J. Kevles, In__thhe_Name_of

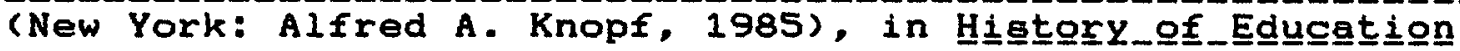
Quaㅡ트트니 26, 4(Winter 1986): 621-6.

30. Minton, "The Iowa Child Welfare Research Station," pp. $160-3$.

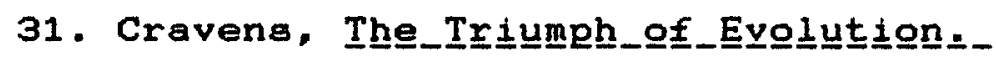

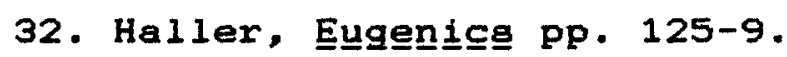


immorality to criminal behaviour were grounded in hereditary tendencies had been spread by mental hygienists since the inception of the movement. Mental hygiene had also increasingly served to moderate these views in light of its preventive orientation. The extremist position of segregating and isolating the unfit and abnormal in an effort toward their elimination was reconstructed by the emphasis on prevention with the young and on the nurturence of normality. By the 1930 a the emphasis on normality was well developed. The LSRM concentrated its preventive research model on social and environmental factora rather than on biological and genetic absolutes. The effort to make minor adjuatmenta and conaerve and create health through education came into direct conflict with the underlying assumptions of the leading developerg and advocates of mental testing. The conflict existed to the extent that testing advocates based the efficacy of IO in unchangeable biological fact. This latter position was advocated by Henry Goddard, Lewis Terman and Robert Yerkes. 33 The notion that intelligence was subject to social and environmental factors was viewed as heretical by Terman and his followers. The views of the Iowa

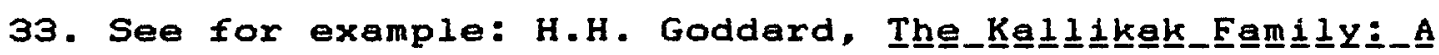
Stuㅡㅁ﹎of

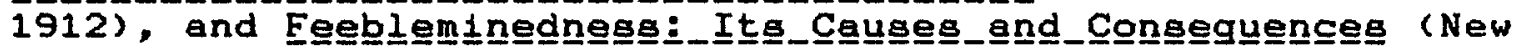
York: Mackilian, 1919); L.M. Terman, The_Meseurement of Intelligence (Boston: Houghton Miffiln, 1916); and The Intelelijgence_of_School_Children (Boston: Houghton Miffiln, 1919); Robert M. Yerkes, "How May We Discover the Children who Need Special Care?" Mental 1 Hygiene I(1917): 252-9; "Man Power and Military Effectiveness: The Case for Human Engineering_Journgel_of

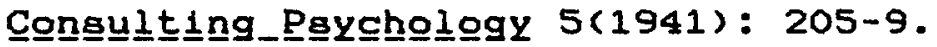


Child Welfare Research Station were seen as positively dangerous in their optimism. This 111 will was returned by Stoddard's group. The arguments and counter argumenta were often overtly hinged on questions of scientific validity and bias. 34

The development of the concepts of inteliigence can be followed in the three yearbooks published on the subject during the inter-War period by the National society for the Study of Education. The 1922 volume, "Intelligence Testa and Their Use," elaborated the usefulness of these tests as diagnostic tools. 35 The 1928, volume whose preparation committee was chaired by Lewis Terman, drew upon the controversial nature of the topic but sided it toward the hereditarian position. 36 In 1937, George stoddard proposed that a third volume be devoted to the topic. He was designated as the chair of an eight man committee to prepare the text. Members of the Iowa Child Welfare Research Station including Stoddard and Beth Wellman found themselves in sharp opposition to the positions of Lewis Terman and his student Florence Goodenough, then at the University of Minnesota Institute of Child Welfare, and Quinn MoNemar another student who

34. See the discussion by Minton. "The Iowa Child Welfare Research Station," pp. 160-3, 168-72.

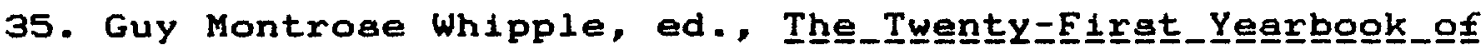

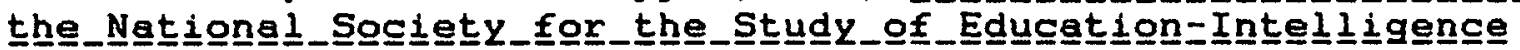

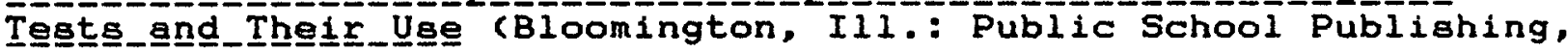
1922).

36. Guy Montrose Whipple, ed., The_Twenty-Seyenth_Yearboogk

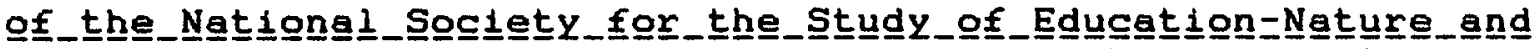
Nuruture Parts 1 and 2 (Bloomington, Ili.: Public School Publishing, 1928). 
later became Terman's biographer. The 1940 NSSE Yearbook on Intelligence became a cornergtone for the nature-nurture controversy pictured as a dichotomy between conservative and liberal views of the role of blology in human intellectual potential in the post-War period.

The infighting about nature-nurture in some ways confused the issue more than it defined two opposing positions. The debate questioned the use of IQ scores but not the efficacy of the underlying paradigm concerning the nature of human intelligence and its capacity for being captured in a discrete set of scores. 37 Both the stanford group and the Iowa group accepted the basic premises of mental testing and the clinical validity of scores on such tests. Their positions differed in the extent to which they interpreted extraneous variablea as algnificantly altering the long term consistency of scores and whether environmental intervention in childhood could improve adult functioning. An earlier debate among the first advocates of Ia testing addressed the paradigm itself. Frederick Kuhlmann, Terman's peer at Clark University and a fellow pioneer in testing, invented the IQ score as the ratio between mental age and chronological age. He declined to use this measure, later popularized by Terman, because he felt it was inaccurate. While Kuhlmann believed in innate intelligence represented by the ability to think abstractly, he felt that intelligence tests tapped only the effects of training. Intelligence as tested was therefore

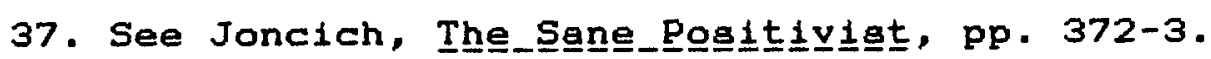


variable and subject to change. 38

A sophisticated sociological critique of testing was presented by W.I. Thomas in 1923. Thomas noted that "taken in themselves statistics are nothing more than symptoms of unknown causal processes." 39 Thomag emphasized the need for the atudy of social processes including types of "life-organizations" in light of their historical evolution. 40 Thomas was not impressed by Robert Yerkes contention that: the "government records determined that 47.3 per cent of all Americana called out in the draft for enlistment in the war were mentally deficient, [that is], they had the mentality of a twelve-year old child or less." Thomas responded: a "report of this kind loses all significance, because it makes no provision for lack of uniformity in the social influences." 41 The Iowa-stanford debate of 1940 was on similar ground. The debate as argued by the nature alde of the disagreement is illuatrative of the strength of the paradigm of mental testing and the reification of Io acorea as verified reality. 42

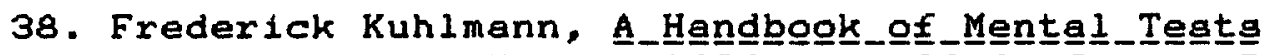
(Baltimore: Warwick and York), 1922, pp. 32-3; Joseph Peterson,

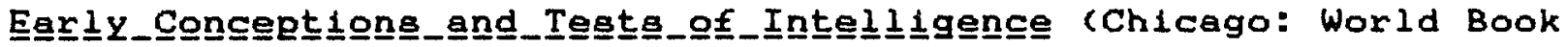
Co., 1925).

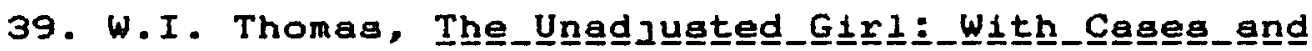

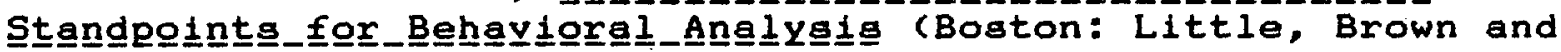
Co. 1923, pp. 244-5).

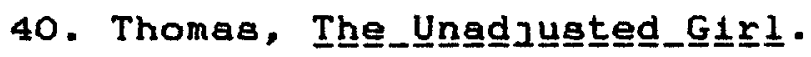

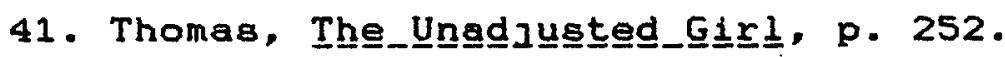

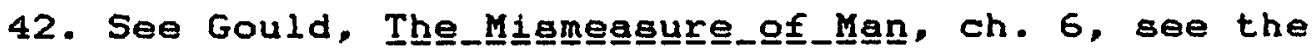
discussion on pp. 234-320. 
The University of California Studies

Unlike the Iowa Child Welfare Research Station, the LSRM's support for the Institute of Child Welfare at the University of California came largely after the formative period of Rockefeller related foundations in their orientation toward child atudy and parent education. Similar to Iowa, the Memorial took advantage of an ongoing interest in child study and parent education which may not have prospered in the same way without the advantages of the funding and supportive collaboration of the staff of the LSRM, General Education Board, and the Rockefeller Foundation.

California attempted to enact, as had Iowa, a state funded institute for child study. This proposal was put before the legislature in 1921 backed by a Save the Children Committee headed by Mrs. Josephine Rand Rogers. The original argument was put in terms of the prevention of delinquency. 43 The bill was favourably reported from the Education Committee but tabled by the Finance Committee. In a second attempt to pass the legislation in 1923, the support of Stanford President David Starr Jordan, Lewis Terman and psychologist olga Bridgman of Berkeley were noted along with prominent religious and social leaders. 44 A bill was finally passed but "conflicting schemes

43. Fller in support of Assembly B111 161, "Save the Children," and attached propaganda in favour of legislation for a Child welfare Research Center, n.d., LSRM 3, 43, 452, RAC, N. Tarrytown, N.Y.

44. "Mrs. Rogers Sends Message by Radio: Address on Child Welfare Bill Broadcasted From Hale's Before Its Defeat, " Mex Hergeld__ 10 May 1923, LSRM 3, 43, 453, RAC, N. Tarrytown, N.Y. 
for the control of the proposed station" by the Berkeley faculty led to the rescinding of the leglalation. The LSRM was willing at this point to provide supportive funding for the institute but as Lawrence Frank noted there was little to do "but walt until such time as the consolidation scheme has been developed, when the plan thereof will be submitted informally for our consideration." 45 A plan was developed and legislation enabling the establishment of an Institute for Child Welfare was passed on July $1,1927$.

The plan was to include a nursery school, child study centre and research facilities to be used cooperatively between several departments of the univeraity. 46 A proper director for the Institute was essent1al. Dr. Herbert Stoltz, who had been Assistant Superintendent of Public Instruction in California in charge of parent education, was appointed to this position. Stoltz was familiar with Rockefelier philanthropy aince he had previously secured a three year LSRM grant, of $\$ 22,500$, for parent study through the State Department of Education. 47 Dr. Harold E. Joneg, of the Paychology Department at Columbia University, was appointed Director of Research.

45. Lawrence K. Frank to Faculty and Officers, University of California, Berkeley 6-12 March 1925, LSRM 3, 43, 452, RAC, N. Tarrytown, N.Y.

46. L.K. Frank to Ethel Richardson, 15 April 1927, LSRM 3, 43, 452, RAC, N. Tarrytown, N.Y.

47. "Extract from a Letter on the Conference of Modern Parenthood, Los Angeles," January 1927; Beardsley Ruml to W.J. Cooper [Superintendent California State Department of Education] 19 November 1928; "Sponsor's Report," 4 October 1928, LSRM 3, 27, 281, RAC, N. Tarrytown, N.Y. 
In all of these diverse and semi-coordinated activities, Herbert Stoltz was a pivitol figure. Medical degrees from Stanford and oxford gave him excellent credentials. He occupied a position in Medicine at Stanford until the first World War. Upon his return from combat in 1917, he accepted a position as Asalatant Superintendent of Public Inatruction in California in charge of physical education, an early form of school and mental hygiene. After $s i x$ years he was made State Supervisor of Parent Education.

Stoltz, in collaboration with Harold Jones, organized the Child Welfare Institute at Berkeley. In 1932, as the Institute's research increasingly focussed on the Oakland Public School Syatem and money for salaries dwindled, Stoltz accepted a position as Assiatant Superintendent in Dakland. He maintained a part-time position with the Institute and continued his research into physiological processes in adoleacence. He joined the Oakland Public School adminlstrative staff full-time in the late 1930 . Hia research and writing was facilitated, during thia period, by his marriage to Lois Meek [Stoltz], who had previously been Director of Parent Education at Columbia University. Meek joined the faculty at Stanford. She was also an organizer in the American Association of University women who worked closely with the LSRM in scientific child study. Stolz and Meek collaborated on monographs based on the Berkeley and Oakland data.

Stoltz's fine reputation and experience in state government, as well as his medical background, made him especially qualified 
in the eyes of the Rockefeller Foundation ataff. He enhanced this support by skillfully coordinating the diverse interests represented by local governments, state level bureaucracies, university administrations and philanthropic funding agencies. Stoltz seemed to epitomize the selfleas pursult of science, in the view of the Foundation staff and his peers, in that he tended to downplay his own role and to sacrifice his own rewards for the benefit of others.

Stoltz'a successors, Harold Jones and Jean Walker MacFarlane also proved to be effective advocates for the Berkeley project. Harold Jones, a psychologist educated at Amherst and Columbia University, came to Berkeley with a part-time appointment in Paychology and as Director of Research at the Institute. He assumed the directorship when stolz officially left the position for Oakland. Jean Walker MacFarlane, whose husband Donald A. Mackarlane was also a researcher at the Institute, was a Berkeley graduate. She served half-time in paychology and half-time at the Institute in charge of child guidance. MacFarlane also proved to be an aggressive and able adminiatrator when she became the Director of the Institute in 1938.

The Berkeley project represented almost a pure model for the Rockefeller Foundation's belief in the power of progress and science to establigh truth. The inter-war studies on normal children underscored the attempt to harness the power of medical science applied to clinical atudies. The Rockefeller Foundation staff felt that these efforts were sure to reveal the secrets of 
human behaviour.

This optimism was not borne out in the social sciences, however. In 1927, the officers of the Laura Spelman Rockefeller Memorial and the officers of the other Rockefeller philanthropic funds began the process of evaluating scientific child study in relationship to their priorities in child study and parent education. One critic, who participated in a 1926 dinner and conference on child study and parent education held in New York City, raised typical questions concerning the priorities of the Memorial. This individual concluded that much of what he had heard at the conference was "sllly twaddle." He explained:

The prevaliling tenor seemed to be a sophomoric attempt to show what was wrong, or at least, that calling everything black, white, and visa versa was indicative of mental progress. 48

This type of criticism cut deeply. The question of great import was whether or not it was possible that the "demonstration work had gotten far ahead of the field covered by research and that to some extent at least we [the Foundation] have gotten the cart before the horse?" 49 Edmund E. Day, Director of Social Science for the RF and G.E.B. emphasized the distinction between "child study as fact finding and parent education as fact-using...the action for the present would seem to be to turn the Memorial's energies primarily to the promotion of fact finding projects and

48. LBD to Beardsley Rum1, "Your Memorandum of March 11th to the Memoriala Trustee Committee of Review on Child Study and Parent Education," 15 March 1927, LSRM 3, 31, 329, RAC, N. Tarrytown, N.Y.

49. LBD to Ruml, "Your Memorandum." 
agencies." 50 All agreed that child study research was of vital importance and none really questioned the validity of applying this knowledge, the emphasis and timing, however were questioned. The Berkeley research came on the heels of this internal soul searching. The research priorities and conservative approach to publiahing material and parent education at Berkeley are reflective of the new mood. A large portion of the LSRM funds were distributed to the medical science division directed by Alan Gregg. The Rockefeller medical model of pure and productive research followed by methodical clinical applications were to be applied to research on children. One outcome was a highly biological orientation toward paycho-aocial phenomena. While psychology and medicine dominated over paychiatry, the underlying format was rooted in paychoblology and consciously oriented toward scientific research applied to human behaviour as the epitomy of mental hygiene in preventive public health.

The sharp and penetrating insight of science was to reconstruct social perceptions concerning human development from infancy through childhood and adolescence. The adolescent, for example as a previously moral-metaphysical state of youth in its period of becoming, was scheduled to be biologically valldated by way of anthropometry and metabolic growth charts. The slowness of the studies and their sometimes arcane reaults ended up being a testimony, in this view, to their validity, for the research was

50. Edmund E. Day to Beardaley Ruml, "Chlld Study and Parent Education," 17 March 1927, LSRM 3, 31, 329, RAC, N. Tarrytown, N.Y. 
painstaking and exact. The systematic cumulative methodology, the emphasis on medical and physiological data, standardized teata and the use of apparatus in collecting information were at the forefront of the technologies of the day. Clinical efforts revolved around the attempt to solve human problems on an Individual basia. The painstaking and longltudinal design of the research, as it came to be formulated, proved castly and probably would not have been done without large sustaining grants.

The first grant was initiated in 1927. The Laura Spelman Rockefeller Memorial appropriated $\$ 300,000$ to be distributed to the University of California for the Institute for Child Welfare at the rate of $\$ 50,000$ annualiy for $\$ 1 x$ years, expiring June 30 , 1933. 51 The LSRM was encouraged in its support for the Berkeley research centre by lettera from such persons as John B. Watson. 52 California newspapers gave full credit to the LSRM for

51. "Interview with President Sproul, University of California with Mr. L.K. Frank," 21 November 1932, GEB 930, 1, 3, 374, 3907, RAC, N. Tarrytown, N.Y.

52. John B. Watson to Beardsley Ruml, 10 June 1927, LSRM 3 , 43, 452, RAC, N. Tarrytown, N.Y; Watson was in a phase of popularizing his ideas on behaviouriam in the 1920s. Watson recelved an LSRM grant to study development in children in 1923. He employed a Columbia doctoral student in paychology and wife of paychologist Haxold Jones, Mary Cover Jones to do much of the field work which included clinical observation and the effects of conditioning on childhood fears. See the Uníyergity_of Publications_in_Psychology vol. 1 and 2, respectively 1916 and 1919; See David Cohen, J_B_-_Watgon:_The_Founder_of_Behayiorism (London: Routledge \& Kegan Paul, 1979), see chapters 9 and 10, and on Jones, 196, 200-3, 206-8; "To the President of the University," 15 October 1928, LSRM 3, 43, 453, RAC, N. Tarrytown, N.Y. 
the establishment of the research centre. 53 In spite of the Foundation's belief in its work, the Memorial was not unique among Rockefeller philanthropies in being displeased with such publicity which potentially attracted criticism as well as praise. 54

\section{The Berkeley Survey and Research on Infancy and Childhood} There were three components to the Institute for Child Welfare studies in child development in the firat aix years from 1927 to 1933. Sixty bablea were enrolled in a atudy of infant growth. Each child was given repeated systematic examinations and anthropometric measurementa were charted. Two thirds of the original infants in this study were still being examined at least monthly six years later. Secondly, the establishment of a nursery school provided a group of one hundred children who provided cumulative data on their development. Third, and perhaps most important in the long term, was the Berkeley survey and guidance experiments, which began rather modegtly, developed into a model for long term cumulative data bases in adolescent development. The study began as a study of child development and parent training using for the first time two groups of children one

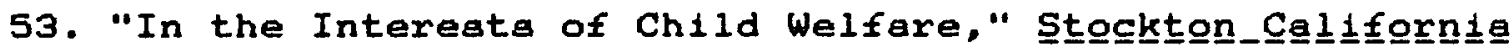
Rec으므 12 July 1927.

54. Beardsley Ruml to W.J. Cooper, 19 November 1928, stated explicitiy: "The Memorial would appreciate it if no public announcement were made of this gift, other than that which is made as a routine matter in your annual report." LSRM 3, 27, 281; "Report of the Committee on Review," stated that the "policy of anonymity and its continuance is atrongly urged;" May 1929, LSRM 3, 31, 329, RAC, N. Tarrytown, N.Y. 
being a control to test the efficacy of clinical intervention into child life and family practices. The project was expanded in 1930 to include studies of school age and finally adolescent development which coincided with the adolescent study conducted in Dakland. The three Berkeley progects as an expanding systematically collected data base worked in tandum.

\section{The Child Over Time}

The Berkeley Survey began with a study of the causes of the low infant mortality rate in Berkeley. A representative sample of 150 Infants born to parenta residing in Berkeley were originally chosen to be followed for one year. This was expanded to 400 cases. The collection of cumulative data in what amounted to a longitudinal study concerned with development became the chief activity of the Institute. Over twelve hundred children residing in communties surrounding the university were followed. Seven hundred homes were visited. Information was gathered from private physicians, public health, school and hospital records to supplement the direct contact of the Institute ataff. 55 A child guidance clinic was established in May of 1928 by arrangement with the Diviaion of Pediatrica of the Medical School. This child guidance clinic was unique in that it was specifically aimed at pre-school age children "who manifest gerlous undesirable behavior symptoms." The clinic was conducted by Jean Walker

55. "Progress Report University of California," 15 November 1929; "Progress Report University of California," 29 October 1930, LSRM 3, 43, 453, RAC, N. Tarrytown, N.Y. 
Macfarlane. 56

The Berkeley survey and guidance study compared two groups of 124 children. Extensive systematic data was collected on one group including physical, social and mental characteristics, family background and genetic data. This group received extensive counseling as well as routine follow ups on a case atudy basis. The second group was to serve as a control. These families received no counseling and also did not receive the extensive testing of the first group. This latter fact presented some problems in assuring that the two groups were in fact comparable for scientific comparison. MacFarlane was aware of this potential problem but rationalized the policy in that the second group should have as little interference as possible. MacFarlane, however, felt justified at the conclusion of the earliest phase of data collection that the guidance group demonstrated fewer "problems" in development than the control group.

Methodological issues in data collection and interpretation were considered an important part of the study in what was termed a pioneer field. The systematic accumulation of data was explained by MacFarlane as a "real life clinical approach." Frequency figures on problems by age and sex were tabulated. The completed data on the group of 21 to 60 month olda showed the persistency of some specific problems. Not surprisingly, these problems included thumbsucking and restlesaness. Also not aurpriaingly temper tantrums and fears showed up but were less

56. "Progress Report," 29 October 1930, pp. 6-8. 
persistent. The researchers also found that individual children differed remerkably in their degree of social and emotional flexibility or rigidity. 57 In addition to the frequency curves for 21 to 60 month olds three typical case histories were graphed from the early data to be compared with the groupa normative data. Thia included mental, phyalcal and personality development for "a problemless child... a child with increasing personality disturbances (our most unstable youngster).. [and] one for a child with decreasing personality and behavior difficulties." 58

\section{The Institute and Nursery School}

The first year of the Institute a nursery school was established and a number of seemingly diverse studies were undertaken. The Institute comprised administrative offices, research laboratories, a library and the nursery achool but its sphere of operation included several university departments and the adjacent communities which aurrounded the univergity. The staff boasted two physicians, a paychologist, a social case worker, a public health nurse, three nursery school teachers, seven part-time research assistants, three technical assistants, a secretary and matron. 59 The work force was soon engaged in

57. "History and Pregent Status of the Child Guidance Research Progrem at the Institute of Child Welfare University of California," April 1935, GEB 930, 1, 3, 374, 3909, RAC, N. Tarrytown, N.Y.

58. "Excerpts from a letter from Doctor Jean MacFarlane, Institute of Child Welfare, University of California, Berkeley," 17 July 1935, GEB 930 1, 3, 374, 3909, RAC, N. Tarrytown, N.Y. p. 1 .

59. "To the President of the University," 15 October 1928, 
collecting and assembling data assisted by various university departments and governmental agencies. The Departments of Education, Household Science, Hygiene, Psychology and Zoology were prominently represented in research from the beginning. The Institute also established direct contact with hundreds of parents living in Berkeley and Oakland. Community lialsons included the Berkeley Health Department, Berkeley School Department, the Berkeley Day Nuraery, Oakland Public Schools, Richmond Public Schools and Alameda Public Schools, the State Hygiene Laboratory, the Alameda Tuberculosis Association, the Fred Finch Orphanage and eleven hospitals in Oakland and Berkeley and over one hundred practicing physiciana in these citieg. 60

The diversity of the Institute's constituency was reflected in its research. In the first year numerous atudies were initiated, many of which became a part of longitudinal studies which involved cumulative data. Day nuraeries connected with public schools were studied through the Education Department. In a separate study a standardized teat was devised for measuring educational and general ability levels in parents. Over six hundred case studies were collected for the standardization and revision process. Mental ability and the effects of certain types of infection were investigated through the Department of Zoology. Another project in zoology was a study of pair differences in monozygotic and dizygotic twing. Mineral metabolism was

60. "Progress Report: Univeraity of California," 15 November 1929, LSRM 3, 43, 453, RAC, N. Tarrytown, N.Y. 
investigated by a team from the Department of Household Science using subjects from an orphanage in Oakland. Graduate students in the Department of Psychology pursued the influence of birth rank upon intelligence. In cooperation with the Berkeley School Department, Executive Secretary of the Department of Visual Instruction, and the local Parent Teacher Association a atudy of sixteen thousand school children was conducted in relation to the attendance, habits, interests, and attitudes of young children exposed to motion pictures. 61

The nursery school conducted by the Institute was also used as a research laboratory. A study was conducted on the development of the foot including stagea of growth in relationship to walking. Fifty cases were followed. The development of intelligence was pursued in a cumulative study of sixty cases with a schedule of tests which began at eighteen months. Three different measures were used in this investigation and compared to teacher ratings in an attempt to judge the validity and reliability of mental examinations of the very young. Language development was recorded in over one hundred hours of records which were analyzed according to growth of vocabulary, sentence patterns and functional use of language in social control. Harold E. Jones, the Director of Research for the Institute was actively involved in the development of right and left handedness according to genetic origins and the increase in

61. See the First Annual Report of the Institute of Child Welfare for the year 1927-28: "To the President of the University," 15 October 1928, LSRM 3, 43, 453. 
dexterity with age. He also studied emotional thresholds using gelvanic measurements with his wife, J.B. Watson'a former research assistant, Mary Cover Jones, who was now a Research Associate at the Institute. 62

Six apparatus assemblies for laboratory studies were devised in the firat year of the Inatitute's work. The type of equipment illustrates the nature of the studies undertaken. A tachistoscope which moved pictures across a screen horizontally at controlled rates was devised to measure exposure time for recognition. A reaction time measurement device was developed to investigate unconditioned and conditioned reflexes including hand-eye coordination. An exposure rotator controlled by the child-subject was created which measured the period of observation. This was taken as an indicator of the child's interest. Calibrated strip charts were made as activity recorders to study patterns of activity and the total amount of activity. A multiple choice apparatus operated by buttons which opened into a reward compartment when the correct response was signaled was invented for use in studies of the learning process. A photographic studio was set up to take motion pictures for observation and analysis of behaviour. This included the capacity for slow motion analyais of behaviour. 63

The nursery school operated from October to May during which time it undertook training in elimination, eating, sleeping, care

62. "To the President of the University," pp. 4-5. 63. "To the President of the University," p. 6 . 
of personal belongings, out-of-doors activity and social relations for the twenty three children enrolled. Emphasis was placed on a minimum of adult interference. The children were followed both at school and at home on an individual basis and phyaical and mental teatg were conducted regularly. A regearch assiatant was employed for six months to introduce methods of child care and child training devised in the nursery school to day nurseries. The Institute contributed to the establishment of a model cooperative nursery school called "The ChIldren's Community." which was operated under the auspices of the College Women's Club. The Nursery School also participated in a Speech Defect clinic on Saturday mornings in cooperation with volunteer workers and the State Department of Education.

The Role of Philenthropy in Adolescent Research In spite of the sometimes amorphous conclusions of the research in child study, the systematic methodology employed by MacFarlane and even more the topic of research in detailed scientific longitudinal data on human mental and phyaical development, impressed Foundation officials. Lawrence Frank wrote to Alan Gregg after visiting the Institute that it was "unique both in the wealth of cumulative material on child and family situations and in the use of an adequate control group to test the desirability of guidence procedures. If these children can be kept under observation by the clinic until they move into the adolescent years and then followed in their personality development and social adjustment, the full length study will 
provide something that has never before been attempted but is of the utmost value for the future of paychiatry and mental hygiene." 64 Gregg visited the Institute shortly after Frank's visit and was also impressed with the cumulative data on "anthropometric, medical, paychiatric and paychological" grounds. He supported the continuance of the funding. 65

The move into adolescent research was a major atep at the Institute. The Foundation had, in fact, encouraged the Institute to take this atep in 1930. Although aeparate from the adolescent study, which was independently funded, the guidance study was seen, as indicated above, as supplementing the adolescent data as the original group aged.

In the spring of $1931, \$ 91,000$ was appropriated from Rockefeller Foundation directed LSRM funds, for the use of the Institute of Child Welfare and Oakland Public Schools for the study of adolescents. At the rate of $\$ 13,000$ a year for seven years the appropriation, known as Grant \#77 For Research in Adolescence, became effective July 1, 1931. The Dakland Public Schools Administration was to receive $\$ 13,900$ for the first year and $\$ 13,200$ the second. 66

64. LFK to A. Gregg, Memo "Subject: California Guidance Study," 28 May 1935, GEB 930 1, 3, 374, 3909, RAC, N. Tarrytown, N.Y.

65. Alan Gregg diary, 25 June 1935; 27 June 1935, GEB 9301 , 3, 374, 3909, RAC, N. Tarrytown, N.Y.

66. Gregg diary, 25 June 1935; funds were appropriated from the RF controlled Spelman Fund as successor to the LSRM; Lawrence K. Frank to Herbert Stoltz 21 May 1934; LKF, "Interviews, viait to the University of California; study of adolescents," 4-9 
The first two years found the study $\$ 13,000$ over budget. 67 A plea from University of California President, Robert Sproul and Dakland Public School Superintendent, William A. Givens received a positive recommendation. L.K. Frank contributed to this decision by way of an explanation of the need for additional tests and measurement equipment including an $\mathrm{X}$-ray machine, biological testing materials, and equipment for motor and physical development. This resulted in additional appropriations. The Institute was to receive $\$ 10,200$ in $1934-5$ and $\$ 7,900$ in $1935-6$

In 1935 Robert J. Havighurgt visited the Institute and Guldance clinic and came away convinced of the importance of the adolescent aspects of the study and the complexity of "research in this field which must be carried on patiently over a relatively long perlod (ten years?) before sufficient data will be available for the testing of various conclusions and hypothetical conclusions, and that the work of the Institute 18 being conducted in a very cautious, conservative spirit." 68

The belief in the necessity of a long gestation period in adolescent research was later reiterated when, in 1940 , the

February 1934, GEB $9301,3,374,3908$, RAC, N. Tarrytown, N.Y.

67. Robert Sproul to General Education Board, 3 May 1934, "Summary of Principal Activities in the Growth Study of Adolescents at the End of Two Years of Data Collection," 1 January 1934, GEB $9301,3,374,3908$, RAC, N. Tarrytown, N.Y.

68. R.J.H. and J.P.M, "The Programs of Adolescent Study at the University of California and in the Dakland Public Schools, in Relation to Educational Problems," 22 May 1935, GEB 930 1, 3, 374, 3909, RAC, N. Tarrytown, N.Y. 
General Education Board appropriated an additional $\$ 200,000$, for ten years for the benefit of completing the longitudinal atudy of adolescents. Robert Havighurgt, who took over the responsibility for overseeing the Rockefeller grants to the project after Lawrence K. Frank resigned to take over the Presidency of the Josiah Macy Jr. Foundation, pointed out that: "This is the only grant the General Education Board made to extend over such a long period [twenty years] in connection with its support of research in human development.." 69

Validating Storm and Stress: The Reality of Adolescence Adolescent research in Oakland began in 1930 with a group of one hundred boys and an equal number of girlo selected from sixth grade classes in Claremont Junior High School. The effort was to develop a sample for a long range study of normal adolescent development. The children selected were not necesserily representative of either the schools or Oakland in general but were apparently normal children from families who were expected to remain in the area long enough to be studied without interruption. The area in the north eastern portion of Oakland is reasonably middle class and the children voiced an intention to go to the academic high school rather than to the alternative technical high school. University High School, the secondary education institutional goal, functioned as a part of the Oakland Public School system. The emphasis was on physical development in

69. R.J. Havighurat to Professor Tolman, 9 September 1940, GEB $9301,3,375,3912$, RAC, N. Terrytown, N.Y. 
the years of puberty. In addition a second group slightly larger In number who were already in high school was selected to be used for exploratory studies and testing. 70 The method included anthropometric, photographic and medical examinationg and record taking twice a year at the Institute. These examinations included skeletal proportions, development of sex characteriatics, dental development, muscular development, subcutaneous tissue development and physical handicaps. A physiological battery of tests were performed once a year to encompass basal metabolism, respiratory rate, blood pressure, body temperature, pulse rate, vital capacity, auditory, visual, olfactory and association word atimuli upon akin resiatance changea and on other physical measures. Individual and group psychometric tests where conducted yearly to determine general intelligence, reading, math and learning ability. Group and individual tests were also made with ratings based on observation, parental, teacher, peer and self ratings. These tests were geared to determine personality traits indicative of attitudes toward peers, teachers, school activities, home and civic responsibilities, sex, academics, suggestibility levels, ambitions and leadership aptitude. The group tests alone took over thirty hours with the Terman group intelligence scales. The individual tests used the stanfordBinet. Interviews and observations of the children taking the tests were converted to statistical measures used to supplement

70. L.K. Frank, "Visit to University of California Institute of Child Welfare, 4-9 February 1934, GEB $9301,3,374,3908$, RAC, N. Tarrytown, N.Y. 
the scores on the intelligence test itself. Three visits to the children's homes were made by psychiatric social workers. Medical histories were complled as well as sleeping, eating and recreational habits.

\section{Biology and Adolescence}

Herbert Stoltz and Lois Meek Stolz's work on adolescent

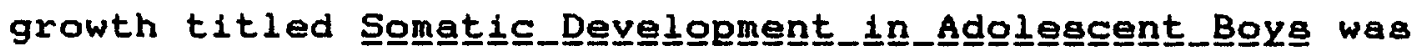
characteristic of the approach to age and status taken in the Berkeley atudies. 71 stoltz felt that adoleacence should not be considered a chronological category but a physiological category. He developed growth charts, one hundred and eighty of which were published in the four hundred pages of his work on somatic development. Unlike Wingate Todd, of Western Regerve, who worked on a similar problem, Stoltz did not want to rely on one meesure auch as skeletal development. Stolz combined skeletal data, sexual maturation and metabolic changes. 72 The Yegar $\underline{b}$ oogk also illustrated the general model of adolescence to be disseminated to teachers, university faculty in departmenta of education including inservice training, medical schools and schools of social work. A strong emphasis on the biological underscored the

71. Stoltz's work which was a summary of over ten years of data collection was subsidized for $\$ 5,000$ and published through MacMillan in 1950. Excerpts appeared in the collected Yearbook Grants in Aid to I 48049, F.M.Rhind, "Interview with Harold Jones Re: Publication Yearbook," 4 May 1943 and outline of "Yearbook on Adolescence," GEB $9301,3,374,3911$, RAC, N. Tarrytown, N.Y.

72. R.J. Havighurat, "Summary of Viait to Institute of Child welfare," 29 April 1937 to 12 May 1937, GEB $9301,3,374,3910$, RAC, N. Tarrytown, N.Y. 
"human animal's developmental characteristics." Biology was, however, offset by cultural expectations and pressures of home and community. Statistical and standardized measures of physical development and mental processes in learning and intelligence were reflected in social adaptation and adjustments to social class, culture and peers. Problems of adolescence were seen as pressures from society as well as internal problems stemming from early childhood. Schools were especially responstble for identifying the stage of growth of the individual and aiding in the individual's adaptation to cultural valuea including social and political attitudes. The identification of problems incorporated the relationship between parent and child in the adolescent's search for independence, sexual identity and vocational orientation. The ability to get along with othera including popularity, leadership training and the development of skilis figured as a aignificant stage in adolescent growth. Adolescence was clearly seen as a challenge for teacher training and for school administration. 73

\section{Peychiatry Versus Psychology}

In spite of what was termed a psychiatric and psychological emphasis the one omisaion was the lack of a paychiatrist on the Institute staff. The staff was heavily weighted toward clinical psychology. The Directora, Jean MacFarlane and Harold Jones were psychologiata. Scientific medicine was represented by Herbert

73. An abstract of the chapters is given in the proposed outline of the Yegerbook. 
Stolz. While the emphasis was scientific and clinical there was no input from a paychiatric or specifically a psychoanalytic perspective. Of the Rockfeller staff, Alan Gregg and Lawrence Frank were especially intereated in having the longitudinal data collected in the Berkeley research analyzed by a psychoanalyst. Throughout 1937 and 1938 various ways were discussed to provide this kind of input. 74 Eventually a five year grant was offered to refugee paychoanalyat Erik Homburger Erikaon.

Erikson, who had been working at Yale, joined the Institute staff in 1939. MacFarlane was intereated in having Erikson do detalled psychoanalytic case study reports and to elaborate his perspective at meetinga. Erikson did not mind observing the children and doing clinical therapy but he saw very little value in writing up each cage in the manner in which MacFarlane preferred. He worried about how his case study data might be used or interpreted by others. He preferred to work at home rather than the clinic and disliked the practical and atheoretical tone of the Institute staff meetings. During this period, Erikson completed a monograph he had begun at Yale and did summer studies on Indian children with A. Kroeber, the well known anthropologist. He also devoted considerable time to the

74. Robert Sproul to R.J. Havighurst 17 March 1937: R.J.H. to R.S, 25 March 1937, GEB 930 1, 3, 375, 3914; R.J.Hevighurst, "Summary of Visit," 29 April 1937 to 12 May 1937; R.J.H to Jean MacFarlane, 4 April 1938; J.M to R.J.H. 6 April 1938; R.J.H to J.M., 18 April 1938, GEB $9301,3,375,3910$; R.J.Havighurat, "Interview - Visit University of California Institute of Child Welfare," 28 June 1938 to 5 July 1938, GEB $9301,3,375,3911$, RAC, N. Tarrytown, N.Y. 
observation of children's play. In fact much of the data for

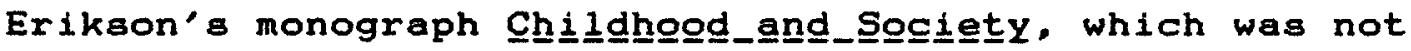
published until years later, was begun during this period. 75 In 1942, Erikson took advantage of other offers and left to collaborate with war related work on morale before the five years of his contract was complete. He retained ties on a part-time basis with the Institute while he did research on racial tensions and black white relations in the San Francisco Bay Area in the late 19408. He also acted as a consultant for the Well Baby Clinic and Director of Child Guldance at Oakland Hospital, where graduate students from the Institute at Berkeley were sent for clinical experience. $76 \mathrm{His}$ early years at Berkeley were not considered particularly successful by MacFarlane or Alan Gregg. 77 The effort to promote psychiatry in scientific child study floundered, in this case, partly because of a personality conflict between MacFarlane and Erikson. 78 It also reflects the

75. Erik H. Erikson, Chlilidhoogd_and_Society (New York: w.w. Norton, 1950, 2nd edition 1963, 3rd edition 1985).

76. Flora M. Rhind, "Interview Exik Homburger," 17 September 1947, GEB $9301,3,375,3914$, RAC, N. Tarrytown, N.Y.

77. Robert J. Havighurst, Interview "Erik Homburger Erikson Guidance Study University of California," 20 December 1940, GEB 930 1, 3, 375, 3912; Jean MacFarlane to Alan Gregg, 18 November 1941, Alan Gregg to MacFarlane, 21 November 1941, GEB 930 1, 3 , 375, 3914, RAC, N. Tarrytown, N.Y.

78. Erikson also had problems at Yale with Arnold Gesell. It is interesting that Gesell was seen as having a difficult time working with others in general. Gesell's work in child study had begun in 1911. It was in part funded by Rockefeller related philanthropy from 1920 to 1944 . His clinic was moved from the Education Department at Yale to the Institute of Human Relations and at this juncture was in the process of being moved again to 
differences in theraputic orientation between psychiatry and psychology.

\section{Social Scientific Data and Adolescence}

The Oakland adolescent studies, as part of the Berkeley data set, did not employ until very late, and then only briefly, someone trained in social science. Foundation staff noted the lack of a systematic analysis of the social and environmental factors in the adolescent experience. In an effort to remedy this situation a fellowship was belatedly awarded, in 1940, to Buford Junker, a student of Lloyd Warnex at the University of Chicago. Junker was to do social placement charts for each child and to conduct parent and child interviews. He spent very little time on the case study material. Even though Junker's fellowship was renewed in 1941, he accepted another position before the data was complete. Warner noted that a proper analysis of the community would have taken another two to three years research.

The extraneous information on social factors gathered in the study were detailed enough to allow for an interpretation in a study published in 1974 on childhood in the depression. 79 Glen Elder came upon the archival data from the institute in the $1960 \mathrm{~g}$ after the Institute for Child Welfare had been renamed the

the School of Medicine. Arnold Gesell, "Memo," 21 October 1938, attached Alan Gregg, "Note," and "Correspondence between Gesell and Homburger," 19, 18, 16, 20, 29 October 1937; Alan Gregg, "Diary" 3 Januery 1938; James R. Angell to Alan Gregg, 31 October 1938 GEB $9301,3,376,3925$, RAC, N. Tarrytown, N.Y.

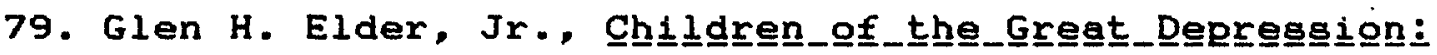

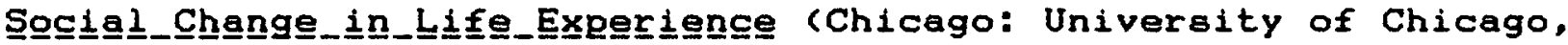
1974). 
Institute for Human Development. Elder analyzed this material forty years after the project had been initiated by Herbert Stoltz and Harold Jones. Elder's study was rather remarkable in that it asked the unasked question behind the Oakland study, namely: What was the impact of the historical specificity of the times on growing up? Elder does not address, however, W.I. Thomas point that social, economic and political variables affect data collected under the guise of clinical and medical fact. Elder was aware that the sociological questions he asked were not the questions of the original researchera. Elder felt that the researchers were, nevertheless, sensitive to social 1sauea. Since clasa measures and other social variables were not included in the research design it would seem that the researcher's sensitivity to political, social and economic factors was, contrary to Elders' conclusion, minimal. The Foundation's awareness of the lack of input from social science had as little or less impact as the effort to interject a psychiatric perspective.

Sociological analysis was clearly extraneous to the ongoing intent of the child guidance study in Berkeley or the Oakland study of adoleacence. The intention was to capture blological and psychological adaptations to physical development. This was reflected in the major findings of the research. Researchers sought an ultimate reality in human growth cycles. The proposals and research summaries totally omit comments on social, political and economic questions. Harold Jones, for example, summarized the 
making of adolescence as "basically a biological phenomenon... The general hypothesis may be offered that the anthropometric and physiological changes of adolescence affect an individuals behaviour through four channels of psychosomatic relationship." 80 The channels included: 1) "physiological equilibria" which required behavioural adjustment; 2) changes in intra-organic stimulation or physiological "drives," indicated by "lowering the thresholds to stimulation related to sex;" and 3) quantitative growth in abilities and patterns of abilities such as muscle strength. 4) Finally, adolescence represented changes in group status manifested in a "pressure system" which necessitated critical adaptation. This was seen as causing a transformation in activities, attitudes and interests. 81

The adolescent research evolved with the growth of the children. The data as seen from Elder's study many years later was unique in its continuity. The continuity was hard won in terms of its financing, complicated by the necessity of negotiating the University, Institute, School District's and the Foundation's interests. By the late 1930s, the General Education Board and Rockefeller Foundation were moving on to other major projects. Following their established policy, no effort was to take on a permanent status. Similarly, child oriented research was expected to find other means to sustain itself through

80. Harold Jones to Robert J. Havighurst, "Report: Adolescent Growth Study," 4 Apr11 1939, GEB $9301,3,374,3914$, RAC, N. Tarrytown, N.Y.

81. Jones to Havighurst, "Report." 
permanent institutions and other granting agencies. The directors of Rockefeller philanthropy had hoped that this point had been reached in the mid-1930s with the establishment of the National Research Council on Child Development. Foundation funds appropriated for scientific child research turned increasingly, in the 1940s, toward the coordination and analyais of research findings and the distribution and publication of authoritative information.

The Establishment of Progress: Distributing the Berkeley Data Rockefeller officiala were concerned that findings be effectively distributed in order to encourage the continuation of research efforts and to improve public welfare. They were also wary of the premature release of unreliable findings. The funds for the child study projecta, first initiated by the LSRM, had been transferred from the LSRM to the RF Division on Medical Science in 1929, these had been taken up by the General Education Board Program on Child Development in 1933. Support was extended to 1950 to complete the compilation and analysis of data. The continuation of the various projects in child and adolescent development research represented twenty years of painstaking work. It seemed time to seriously provide for the dissemination of the research results.

Robert Havighurat and Alan Gregg were convinced that the Berkeley studies represented a unique and significant contribution to available knowledge on human development. As a consequence, they sought multiple forums to put this information 
before other researchers, professionals, and the public.

Publication became an important part of the continued funding. 82 The provision for publication was due, as Havighurst states, to the fact that "we have come to accept the fact that much of the publication of results of this research must be subsidized. Many of the most valuable studiea cut across the conventional lines dividing psychology, physiology, anatomy and sociology, and consequently cannot be easily published in the journals of particular sciences." 83 Havighurst was apparently supported in his belief in subsidizing publication. He noted that once after $\$ 6,000$ had been requested for publication purposes, the day after an inter-office memo was sent to Rockefeller Foundation President Raymond B. Fosdick, the sum was approved. 84 In one year, four theses, two monograph series including six publications, eleven articles and seven other abstracts or papers on Institute research were published from Foundation funds. 85 Further appropriations in the 1940 s produced the Stoltz' Yearaㅁo으﹎ㅡㅇㅡ

82. R.J. Havighurat, "Memo Concerning the Guidance Study at the University of California," 19 January 1938; w.W. Brierley to R. Sproul 16 December 1938, GEB $9301,3,374,3911$, RAC, N. Tarrytown, N.Y.

83. R.J. Havighurst, "Publication of Results of Research at the California Institute of Child Welfare," 22 December 1938, GEB $9301,3,374,3911$, RAC, N. Tarrytown, N.Y.

84. Havighurst, "Publication of Results."

85. Jean Walker MacFarlane, "A Statement of Objectives, Points of View..." 26 October 1938, GEB 930 1, 3, 374. 3911, RAC, N. Tarrytown, N.Y. 


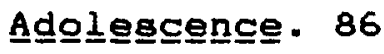

Direct parent education had never been the primary aim of the Berkeley Institute; however, hundreds of undergraduate and graduate students were afforded the opportunity for directed observation of children through the Departments of Psychology and Education. This was considered to be a form of parent education by the Institute staff. Parent education was also considered to be fostered by discusaion meetinga, parent conferencea for parenta of nursery school children and those of the intensive infant study, as well as for the parents in the cooperative nursery school, The Children's Community. The most significant aspect of the Institute's contribution to parent education was in cooperation with the State Department of Education. In this capacity the Institute helped in the organization of parent study groups in Berkeley, San Francisco and Oakland. Rockefeller grants directly to the state, initiated by stoltz prior to the establishment of the Institute, facilitated the growth of parent study throughout California. State-conducted parent study groups came to constitute one outlet for child study research undertaken at the Institute. This differed in several respects from parent education conducted out of the other research centres typified by Toronto or Teachers College Columbia where educated middle class parents of children at university affiliated Institutes

86. F.M. Rhind, "Interview with Harold Jones Re.: Publication Yearbook," 4 May 1943; there is also an outline of the "Yearbook on Adolescence," GEB $9301,3,374,3911$, RAC N. Tarrytown, N.Y. 
participated in mandatory classwork. The California parent study work resembled more closely the rural education projects in the southern states or early Monmouth County parent education. The effort was to draw parenta with problem children who might not otherwise receive expert advice and parents of normal children who might not otherwise receive guidance and counseling in parenting.

\section{Professional Education and Knowledge in Human Development} The dissemination of child study research to professionals was also a growing objective. One effort to put expert advice into an effective information diatribution ayatem was the National Research Council. The creation of the NRC Committee on Child Development and the Monograph Serieg on Child Development and Abstracts in the 1930 s was not sufficient to distribute and synthesize the volume of research produced over the years of support for scientific child study. Further, it seemed abundantly clear that a coordinating body should be created to screen the information and to serve as a quality control. To this purpose, Robert Havighurst, took a position at the University of Chicago as Secretary of the Committee on Human Development. Havighurst directed the Collaboration Center in Child Development which was created with G.E.B. funds in 1943. 87 This project was an

87. F.M. Rhind, "Request from Dr. Tyler for continued support of the University of Chicago's Center of Documentation and Collaboration for the Study of Human Development and Behavior," 5 January 1943; Robert Hutchins to Flora M. Rhind, 8 Apri1 1943; $w$. $W$. Brierley to Robert Hutchins, 11 December 1943; FMR, "Interview University of Chicago Child Development Center Collaborators, D.A. Prescott, R.J. Havighurst" 17 November 1943, 
outgrowth of the Center of Documentation and Collaboration for the Study of Human Development and Behavior at the University of Chicago which had operated since 1930. It also continued the work of the Commission on Teacher Education of the American Council on Education set up in 1938 under a G.E.B. grant of $\$ 250,000$. 88 It was specifically to "synthesize knowledge about human growth, motivation, learning and behavior" in light of the "implication for the education of teachers." The fifteen collaborators representing the major research centres in child study developed out of the work of the LSRM. As experts in their fields, the collaborators were to state the "scientifically validated generalizations or principles" from the "research findings in the biological, paychological, soclological, and medical aciencea." Further, they were to select from these generalizations the concepts which should be distributed to professionals working with children and youth. A sequence of undergraduate course work was to be developed as well as minimum standerds of knowledge which would "permit a person to make valid judgments" as to which of the generalizations "apply to that child in a particular situation." 89 The results were to be distributed through

23 July 1943, 16 August 1943; Robert J. Havighurgt to F.M. Rhind. 11 Dctober 1943, GEB 1, 3, 375, 3920, RAC, N. Tarrytown, N.Y.

88. "Inter-University Collaboration to Further Research in Human Development and Behavior and to Extend the Use of Research Findings in the Education of Professional Persons," 15 March 1944, GEB $9301,3,375,3920$, RAC, N. Tarrytown, N.Y.

89. "The University of Chicago Announcement of the Continuation of the Collaboration Center on Human Development and Eduction," 6 October 1943, p. 2; Collaborators included: J.E. 
Committee Reports. A newly organized subcommittee on Standards of the American Association of Teachers Colleges was to relay information to over 175 institution concerned with professional education and to college administrators, curriculum committees and professors of psychology and child development.

The Institutionalization of Childhood and Adolescence

The knowledge secured by private foundations in their support for child study research and parent education has in large measure defined the cycle of human growth and development as currently underatood. The data base from this "pioneer area of investigation" lasted, as the G.E.B. projected, for the next fifty years. With minor alterations it has brought us into the 1980s. The G.E.B.'s presumption that "significant insights with important educational implicationa will be secured," has also proved realistic. 90 The coordination of child rearing with scientifically verified age related biological and psychological traits did not free children from stress and anxiety. Nor did it avoid adult fallures. It coincidentally produced age apecific pressures and cultural adaptations. The definition of the psycho-

Anderson of Univ. of Minnesota, H.H. Anderson of Univ. of Illinois, Wm. Greulich of Weatern Reserve, Kal Jensen of Univ. of Wisconsin, Arthur Jersild of Teachera College Columbia Univ., Harold Jonea of UC Berkeley, Mark A. May of Yale, Willerd Olsen of Univ. of Michigan, Sidney Pressey of Ohio State, L.W. Sontag of Antioch College, Alfred Washburn of Univ. of Colorado, Robert Sears of Univ. of Iowa, Harvey Murray of Harvard. "Document D" 15 March 1944, GEB $9301,3,375,3920$, RAC, N. Tarrytown, N.Y.

90. "Report on the Program in Adoleacent Growth and Development," pp. 8-9, GEB $9301,3,369,3850$, RAC, N. Tarrytown, N.Y. 
biological basis of adolescence, for example, in practice added unforeseen demands on teenagers, parents and social institutions.

The psychobiological understanding of the child derived from scientific child study in the inter-war period has persisted. Based in quantitative data and bolstered by the authority of science, it is a paradigmatic undergirding of modern social life. Child study research and parent education has, to a profound degree, shaped modern inatitutions from the family, to school, to community public services. It has hardly left untouched our own self-concepts and age-related anxieties, much less our attitudes and behaviour toward children and parenting, as personal and collectively experienced phenomenon. In so far as children are the harbingers of the future, changes in their status and emphasis on their socialization represent fundamental changes in social organization.

As W.I Thomas has so pointedly described in his studies on children in America in the 1920s, the ongoing disorganization and reorganization of definitions of any situation, including expectations of children, determine to a large extent the social reality collectively experienced. Further, societies are more or less successful to the degree that mutually recognized definitions of situations are considered valid and passed along as such by a majority of the people. Thomas" observation of social interaction remains a case in point, the extent to which men define altuations as real, they are real in their 
consequences. 91 From age-graded schooling to teenage peer groups, the social consequences age-specific norms can hardly be escaped in the experience of growing up in todays highly organized and bureaucratic societies.

The Rockefeller Foundation did not initiate the new medicine or the reformist tendencies of preventive medicine, the LSRM did not invent child study. Both the idea of child study and the pediatric orientation toward the supremacy of phyaiological functioning had nineteenth century precedents. However, the medicalization of human development achieved verified status by way of child study promoted by Rockefeller philanthropy in the inter-war years. It increasingly achieved formalized stature in public policies after the second world war. The psychobiological child is dissiminated as fact, promoted and funded by official agencies and professionals. Nonetheless, it is difficult to assess the degree to which parents and children with commonsense, speculation and introspection resist scientifically legitimated knowledge. Even so, the medical paradigm is a part of an official consensus on childhood and a trend in the secularization of modern life.

91. The Thomas Theorm as quoted by Robert Merton: "If men define situations as real, they are real in their consequences." For a discussion see, Robert K. Merton, "The Self-fulfilling

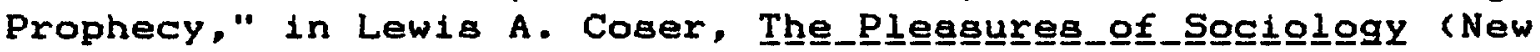
York: New American Library, 1980), pp. 29-47; Thomas, The

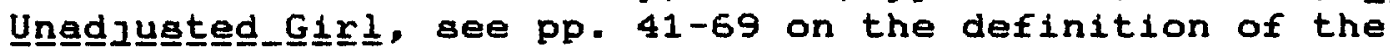

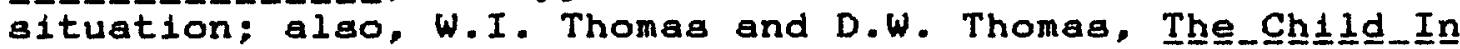
Ameríca (New York: Alfred A Knopf, 1928, New York: Johnson Reprint, 1970). 


\section{PART III}

\section{THE ESTATE: THE LEGACY OF THE PARADIGH}

The nations of our time cannot prevent the condition of men from becoming equal, but it depends upon themselves whether the principle of equality is to lead them to servitude or freedom, to knowledge or barbarism, to prosperity or

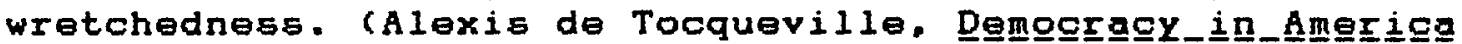
New York: Mentor, 1956, p. 317, first published 1835.)

Is not this poor child without knowledge, strength or wisdom, entirely at your mercy? Are you not master of his environment so far as it affects him? Cannot you make of him what you please? His work and play, his pleasure and pain, are they not, unknown to him, under your control? No doubt he ought to want to do nothing but what he wants, but he ought to want to do nothing but what you want him to do. He should never take a step you have not foreseen, nor utter a word you could not foretell. (Jean Jacques Rousseau, Emilie trans. B. Foxley, London: S.M. Dent, 1957, p. 84-5, first published 1762.$)$ 


\section{CHAPTER NINE}

\section{INSTITUTIONALIZING THE MENTAL HYGIENE OF CHILDHOOD}

The $1940 s$ have been typed as the "age of anxiety" shaped by the second world War. It was a decade of harsh realities and stubborn transcendent idealism concerned with collective morals, national identity and character. After 1949 there was a modification in this perception, the social isaue of critical importance became the search for personal identity, the age, so to speak, of Erik Erikson." 1 The mental hygiene movement contributed to the age of anxiety. The institutionalization of the childhood gaze in the 1940 s staged the identity crisis of post War childhood and adolescence.

The National Committeeg for Mental Hyglene gerved, from their origins, a mediating function between professional organizations, government, general purpose philanthropy and the public. After World war II the roles of the philanthropies and the Committees changed aignificantly in reaponse to the expansion of the public sector in governmental regulations and agencies. Secondly, organizations such as the American and Canadian Psychlatric Association became actively involved in overseeing and monitoring atandards for research and professional growth. These events were connected with increased general publicity on mental hygiene and the popularization of medical perspectives in the decade between 1940 and 1950. These trends usurped the former

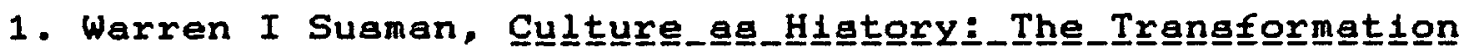

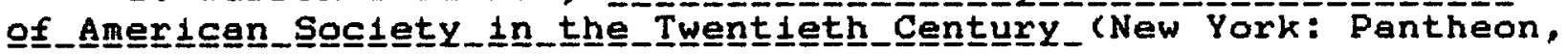
1984), p. 284 . 
role of the U.S National Committee, Rockefeller philanthropy. and, the Commonwealth Fund in mental hygiene work. In the United States, the National Committee, reverted to a less powerful national force, ita role conducted by more official and powerful agencies. The Canadian Committee retained a formal position as an agency which cooperated with and adviged government and the public in a semiformal symbiosis between public and private realma.

The White House Conferences on children record the formalization of ideas on the child's relationship to the state. Mental hygiene was of increasing importance in the programmes of the Conferences. Cenadian as well as U.S. delegates attended and participated. Although Cenedians did not necessarily draw the same conclusions, they were influenced by the perspectives and social mandates which came out of these gatherings.

A long standing precedent for governmental concern over children's welfare was get by the firat white House Conferencea on child welfare in 1909. This trend followed the secularization of charity to scientific philanthropy. 2 In the $1940 \mathrm{~s}$ the perceived need of children to be treated according to their age and developmental paychological atatus was incorporated into the standards of professional organizations, and mandated in governmental agencies. These ideas were made generally available

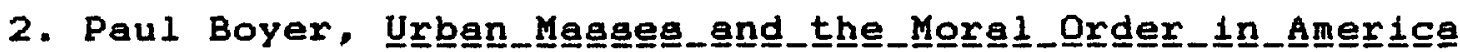
$1880=1920$ (Cambridge, Mass.: Harvard Univ. Presa, 1978), stressea the general trend toward the secularization of charity up to 1920. pp. 167-8. The mental hygiene movement and its ties with scientific philanthropy was a continuation of this trend after 1920. 
to the public through the popular media where they were gradually incorporated into commonsense, everyday knowledge.

\section{Children in a Democracy 1909 - 1950}

The first white House Conference in 1909 concentrated on family preservation. The next conference emphasized the child. The White House Conference of 1919 signaled the completion of a year long campaign for child welfare, the "Children's Year," sponsored by the Children'a Bureau. The White House gathering was the first of a series of Bureau sponsored mini-conferences which spread the perspective of psychiatry and mental hygiene brought to the attention of policy makers by mental hygienists during the first world War. The "mental hygiene of the child - the care of the instincts, emotions, and general personality, and of environmental conditions," over the firat seven years of life were emphasized as critical to adult health, education, morals and habits.

Training teachers and social workers in mental hygiene was given great priority. 3 The emphasis on the medicalization of the helping professiong was reflected at the National Conference of Social Work (which also represented Canadian social workers) where the firgt section on mental hyglene was initiated in 1917. The National Conference of Social Work was dominated by mental hygiene related concerns by the 1920 annul meeting. Paychiatric

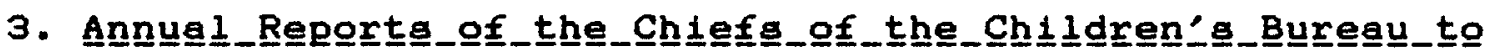
the Secretary_of Labor (Washington D.C.: Government Printing

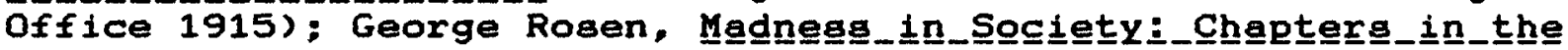

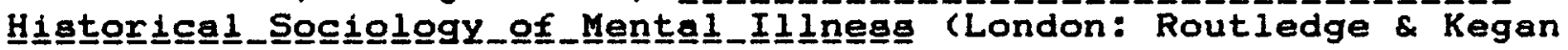
Paull, p. 296. 
social work had been successfully encouraged by the National Committee for Mental Hyglene through expanded training programs fostered by Thomas Salmon during World War I. A concentrated effort for auxiliary mental health training occurred in Canada after World War II. 4

The White House Conference on Child Health and Protection of 1930, called by President Herbert Hoover, reflected the research demonstrations in mental hygiene conducted by the National Committee for Mental Hygiene and philanthropies in the 1920s. 5 The White House Conference on Child Health and Protection was dominated by medical personnel and a whole-child approach which stressed mental hyglene. The conference also emphasized the need for elite professional leaderahip in government and private philanthropy in order to bring about reforms. 6

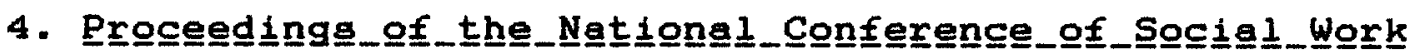
44th Annual Session, Pittsburg, PA, June 16-17, 1917. PP. 391454; Progceedings 45th Annual Session, Kansas City, Mo." May 1520, 1918, pP. 513- 28; Proceeedings 46th Annual Session, Atlantic City, N.J., June 1-8, 1919, pp. 335-413; Procesedings_47th Annual Session, New Orleans, LA, Ap. 14-21, 1920. Canada Department of

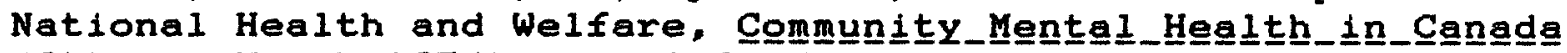
(Ottawa, March 1954), pp. 1-6, documents the continuing problems with poor facilities and the need for trained personnel at all levels.

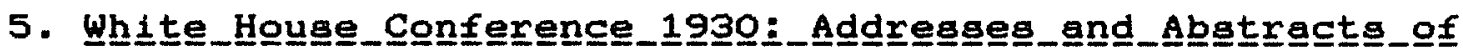
Committtee_Report으 (New York: Century Co. 1931).

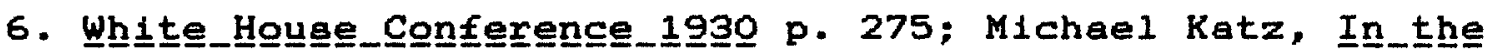
Shadow_of (New York: Basic, 1986), p. 144 emphasizes that the professionalization was in part a move my the American Medical Association to eliminate the residual place of females in health care delivery; See also, Sheila M. Rothman, A_women's.

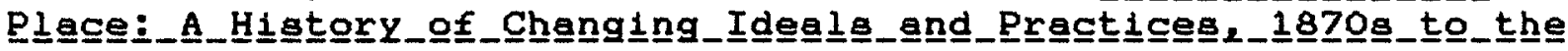
Present_(New York: Basic 1978), p. 126 . 
On April 26, 1939 the planning committee for the 1940 Conference met in washington. 7 It was to be the fourth such conference hosted by a President of the United States, at this time Franklin D. Roosevelt. It was the third conference organized by the U.S. Department of Labor, Children's Bureau. The General Education Board provided a grant of $\$ 47,000$ which was disbursed by the American Council of Education to meet the Conference's expenses. 8

The theme of the family "as the threshold of democracy" was similar to that of the first Conference in 1909. 9 The preservation of the economic well-being of the family was declared as the heart of the "conservation of the greatest of all our resources - our children." 10 As Francis Perkins, Secretary of Labor and Chairman of the Conference noted, the 1940 conference came upon the almilar problem of conserving children and family life from degradation as in 1909 but with the advantage of thirty years of experience and a greater sense of

7. U.S. Department of Labor, Children's Bureau, Connfẹerençe

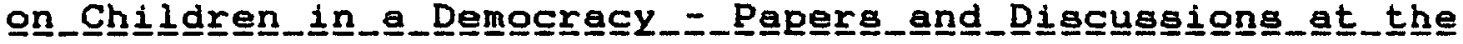

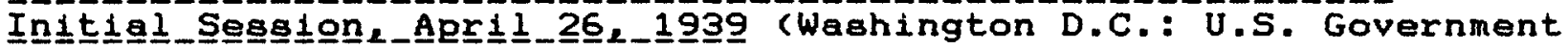
Printing Office, 1939).

8. U.S. Dept. of Labor, Pxoceedingrg_19 4 g p. 3.

9. Francis Perkina, "Opening Statement by the Chairman," General Session, Jan. 18, 1940, pp. 1-5; w. R. Ogg, p. 21 both in

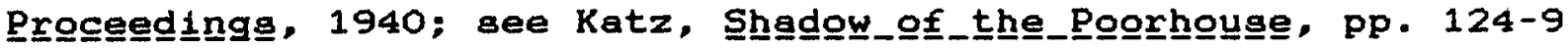
on the idea of family preservation as a child saving strategy.

10. "General Report Adopted by the Conference, January 19, 1940," in Prócee므모 after p. 126, pp. 1-81, see p. 10 . 
public responsibility." 11

The White House Conference on Children in a Democracy took place in January 1940 at the end of a depression and at the beginning of a devastating war. It addressed the disjuncture between democratic ideals and the social reality of U.S. society as systematically stratified. The Conference addressed the evident problems of economic and political disorganization in relationship to public responsibility for child mental health. Delegates to the convention clarified the rationale which became the basis for federal mental health policy after the war. It represented a turning point where mental hygiene took a formal place within the ideology of American individualiam as a modification in the relationship between the democratic state and the child. 12

The exposition of conference Ideals in 1940 added the political issue of mental and physical well-being as the basis for democracy and "brotherhood." This was to be accompliahed by following the prescription of validated scientific research on the basic needs of children. 13 This view also reflected the Canadian perspective as represented at the Conference by

11. Perking, "Opening, " Prgoceeedíngg pp. 4-5.

12. U.S. Department of Labor, Children's Bureau, Prococeedinga

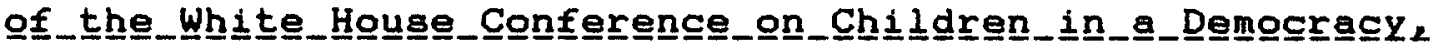
Wea (washington D.C.: U.S. Government Printing, 1940), pp. 4-5.

13. The goals as stated by Katherine Dummer Figher, pp. 1213; and Graeme Mitchell, pp. 13-17, Pxogceedings. 
Charlotte whitton. 14

The 1940 Conference coalesced the issues of previous Conferences. It moved child mental and physical health, educational opportunity and social welfare within the realm of entitlement rather than moral obligation extended by benevolent reformers. The Conference members further addressed the "scientific research" conducted in child development in the $1920 \mathrm{~s}$ and 1930 by incorporating distinctions between age groups by Identifying speciflc needs for preschool (3-6), school age (517), youth (16-20), and young adult (18-20) categories.

Restrictions and benefits were recommended according to agerelated needs with regard to family income, housing, labour, education, handicapping conditions and health care. 15

The 1950 Mid-Century White House Conference on Children and Youth took these prescriptions one step further than the 1940 Conference. For the first time personality development was the major topic of discussion which pervaded the conference technical papers and work group discussions. No aspect of the Conference was unmarked by the importance of the issue of mental health and the specifics of age-graded statuses apanning infancy and early

14. Charlotte whitton noted in an address to the Conference that "the mechanism of democratic government requires a citizen body that is atrong, intelligent, secure and happy, and that for the annoying internal aggression of poverty, suffering, disease, and insecurity there must be effort to the same degree that there

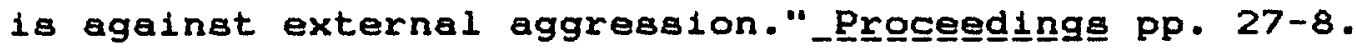

15. See "General Report," pp. 32-74. 
childhood through young adulthood. 16

\section{Mental Hygiene to Mental Health}

The Mid-Century White House Conference was a sounding board for forty years of formal mental hyglene organization. From Clifford Beers' first Society for Mental Hygiene in Connecticut in 1908 and the National Committee in 1909, the movement had changed and grown dramatically fulfilling, in many ways, Beers' dream. The state societies grew rapidly from the second society in Illinois in 1909. New York joined in 1910; Massachusetts, Maryland, North Carolina, and Pennsylvania in 1913. Over fifty state and local societiea operated by 1930 . By the 1940 a an amorphous group of approximately 200 state and local societies existed in a loose coalition with organizational characteriatica which varied from support groups to those which carried out clinical services. Membership was honorary and by invitation, reflecting an individual's pxevious record in mental hygiene work. The local and atate societies as autonomous from each other and the National Committee, served, at minimum, as publicity agents spreading the word of mental hygiene. Mental hygiene moved toward increased popular support and organizational specialization in the 1940s. 17

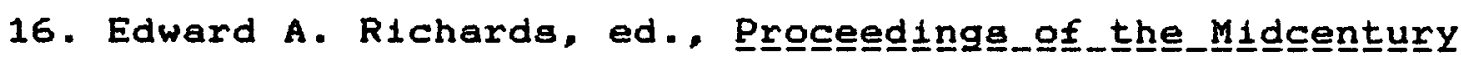

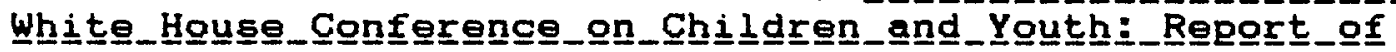

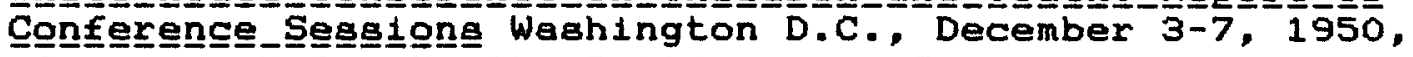
(Raleigh, N.C.: Health Publications Inatitute, 1951), pp. 150-65, a glance at the "Contents" 1llustrates the point.

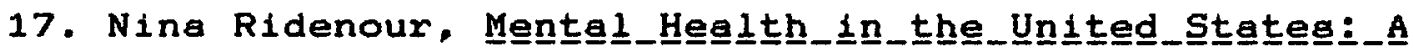

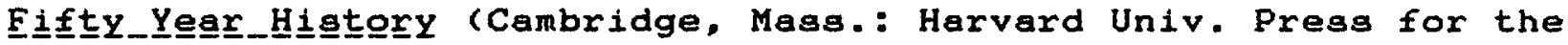
Commonwealth Fund, 1961), pp. 122-5, 66-70. 
During world war II mental hygienists worked closely with the Cenadian and U.S. Armies. William Line of the CNCMH served as Directorate of Personnel Selection and Social Services of the Canadian Army and the Canadian National Committee formed a civilian adviaory council to the Service. 18 In the U.S., conscientious objectora were asaigned by the Selective Service System to work in mental hospitals. A group of these individuals began to publish a mimeographed bulletin called "The Attendant." This publication utilized articles, photographs and such popular medie as cartoons to describe conditions and seek reforms concerning the treatment of mental illness. The Canadian National Committee sponsored a similar booklet titled "The Attendants Guide," which it diatributed to every mental hospital in Canada. 19 Supported by the American Friends Service Committee, a Civilian Public Service organization was Initiated in the United States which drew up an informal "mental hygiene program. "This was subsequently formally recognized by the Selective Service as the Mental Hyglene Program of the Civilian Public Service and placed under the direction of the National Committee for Mental Hygiene. After the War the program was renamed the National Mental Health

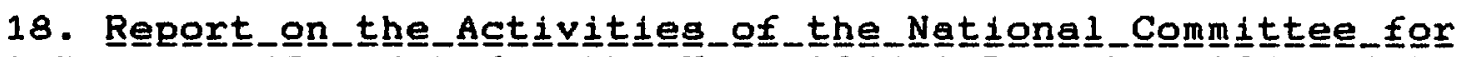

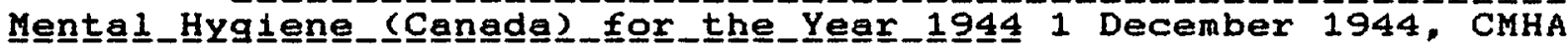
Papers, PAC MG 28 I $39184 / 63$, Ottawa.

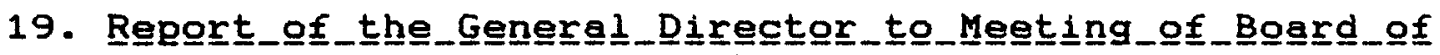

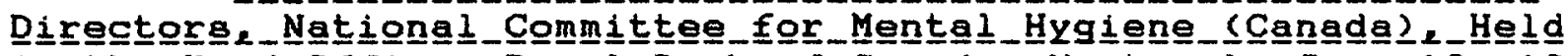

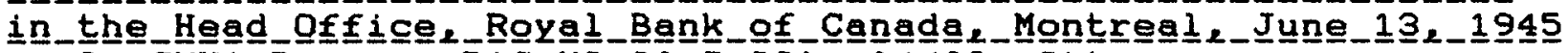
p. 2, CMHA Papers, PAC MG 28 I 391, 84/63, Ottawa. 
Foundation. 20 It was merged with the National Committee in 1950. During the war, in collaboration with the NCMH, the Mental Hygiene Program of the Civilian Public Service published fourteen hundred reports on conditions in mental institutions, including photographa which they made avallable to journalists and writers. 21 This publicity was part of a general public awareness campaign concerning mental health. In 1942 the New York State Committee on Mental Hygiene and the State Charities Aid Association collaborated in producing a series of dramatic sketches on mental 11 iness through the American Theatre Wing Victory Players (later called the American Theatre wing Community Plays). The popular press joined the voluntary associations in furthering public awareness of mental illness. Lif́e magazine published an expose of mental institutions called "Bedlam, U.S.A." in May of 1946.

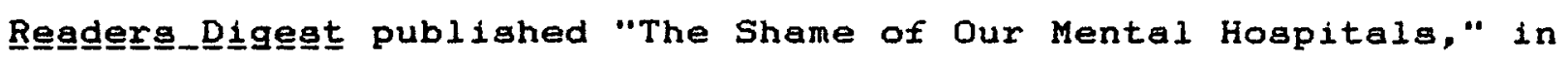

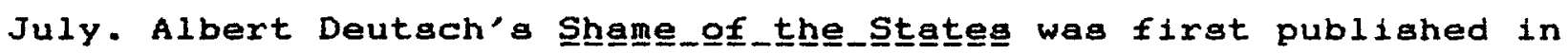
the New York dally newspaper $\underline{P}$ in a series in 1945. Deutach testified before a U.S. Senate committee: "The institutional care of psychotics has been traditionally mainly a state responsibility. It should remain so. But the job of getting

20. This is not to be confused with the American Foundation for Mental Hygiene which Beers initiated in the late $1920 \mathrm{~s}$ as a means of financial support for the National Committee. See Norman

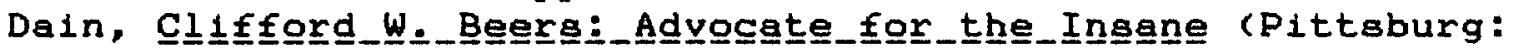
University of Pittsburg, 1980), pp. 236.247 .

21. Ridenour, p. 106. 
preventive devices and using them is a national responsibility." 22

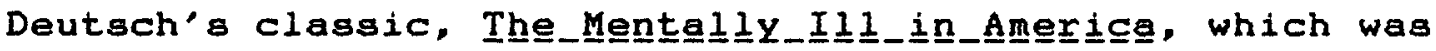
commisaioned by Beers and the American Foundation for Mental Hygiene in the mid-1930s and published in 1937, was revised and enlarged and reissued in 1949. 23

Television and radio were utilized as well. A gerieg of eight programmes on mental 11 lness titled, "For These We Speak" was distributed to 1,000 stations in the United States and Canada. Twentieth Century Fox dramatized Mary Jane Ward'a The Sngeke_p믄 in a 1946 film. The Columbia Broadcasting syatem produced an hour long documentary in 1949 narrated by William Menninger, called "Mind in the Shadow" which relayed the inadequacy of mental institutions. The National Film Board of Canada produced a similar group of related programmes called the "Mental Mechanisms Series."

Popularizing children'a needa predated the War. Lawrence $K$.

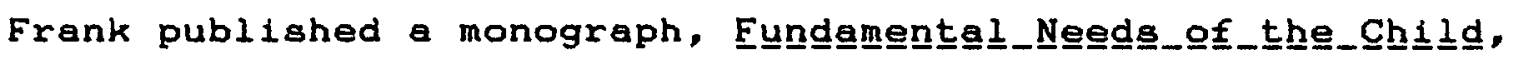

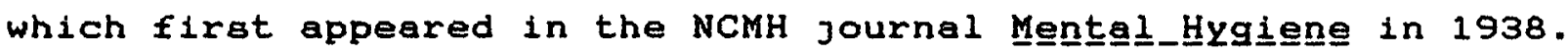
That same year the American Council on Education published

22. Mary J. Ward, The_e_nngke_pit (New York: Random House, 1946); Albert Deutsch, The Shame_of the_cities (New York: Harcourt Brace, 1948); U.S. Senate Committee on Education and

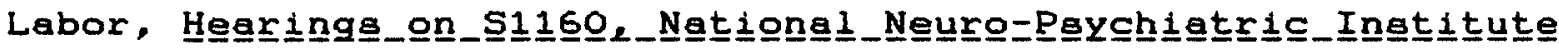
Act $79 t h$ Cong., 2 d sess., 1946 , p. 107.

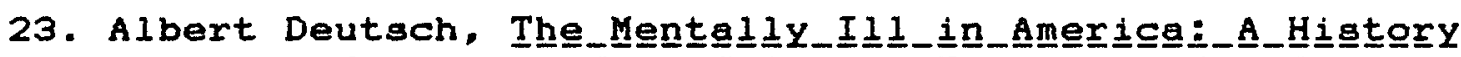

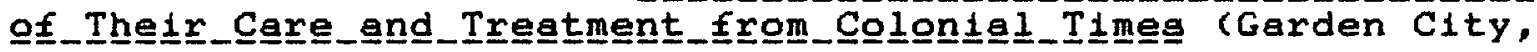
N.Y: Doubleday Doran \& Co. for the American Foundation for Mental Hygiene, 1937, revised and enlarged Columbia University Presi, 1949). Deutsch's book became the "standard comprehensive work on

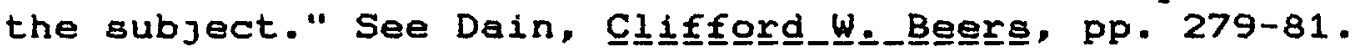


Emotioㅁ﹎.

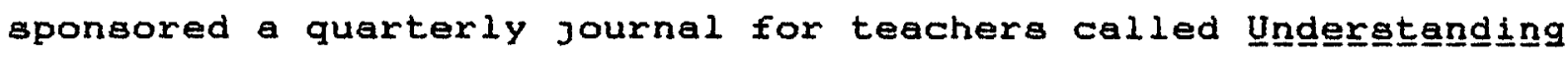

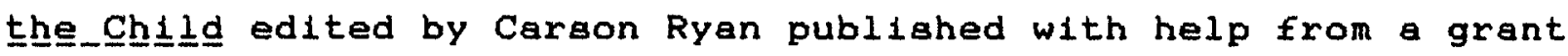
from the Carnegie Corporation. In the 1940 s popular media items on mental hygiene and child development expanded. Catherine Mackenzie produced a weekly column for the New_Yogkㅡ_times Magazㅡㅁㅛe called "Parent and Child." Virginia McMullin produced and Jessie Stanton moderated a 35 minute talk show called "The Baby Institute," In 1943-1944 on the Blue Network, forerunner to the present American Broadcasting Company. In Canada, S.R. Laycock, Director of Mental Hyglene Education for the Canadian National Committee gave workshops on child guldance at Home and School Clubs (an organization similar to the Parent-Teachers organizations in the U.S.). Laycock also gave addresseg to the Ontario Education Association and wrote popular articles for

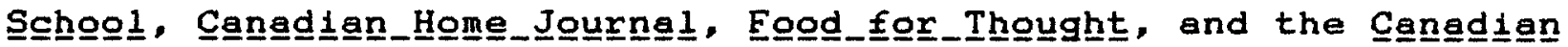
Nuㅗㅛㅛ. He produced a chart entitled "Child Needs." Over 150,000 copies were distributed by the Canadian Broadcasting Company. Copies were mailed to teachers by every Provincial Department of Education. 24 Benjamin Spock's popular The_Commongengnge_Bogok_on

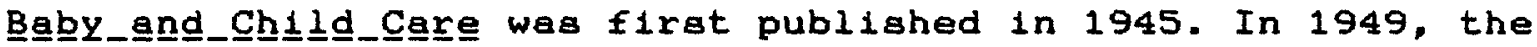
American Theatre Wing Community Plays and the National Committee for Mental Hygiene developed "Temperate Zone: Three Plays for Parenta about the climate of the Home." In 1950, the Mental

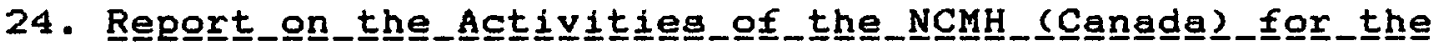
Yeegr_19 $19 \underline{4}$ _pp. $4-5$. 
Health Film Board produced a series "Angry Boy" which depicted the motivations behind a child'a delinquent behaviour and the work of a child guidance centre in curing his problems. Erik

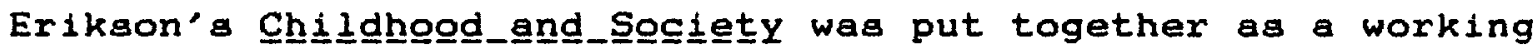
paper for the Mid-century White House Conference and published the same year. 25

The combination of the war, popular publicity, and the appeals of the National Committee for Mental Hygiene by middecade, brought about federal legislation the Committee and its philanthropic mentors had long sought. The passage of the U.S. National Mental Health Act in 1946 and the creation of the Netional Institute of Mental Health (NIMH) in 1949 culminated the NCMH efforts to expand governmental responsibility and financial assistance for research and mental health care services. 26

The collaborative work of the U.S. NCMH and the Foundations was coming to a timely transition point in 1950 . The National Committee for Mental Hygiene, the National Mental Health Foundation and the Paychiatric Foundation were merged in September of 1950 .

The Psychiatric Foundation was the fund raising arm of the American Psychlatric Association. It was put together under the direction of the National Committee for Mental Hygiene and the

25. See Ridenour, pp. 106-19, 102-3, 88-90 on the popularization of mental hygiene in the U.S.

26. U.S. Senate Committee on Education and Labor, Hean

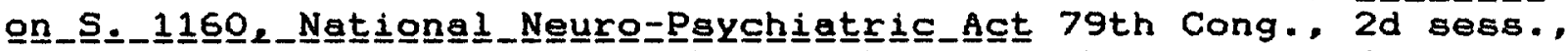

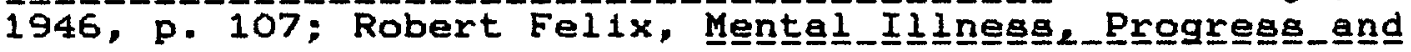
Progepecteg (New York: Columbia Univ. Presa, 1967). 
American Neurological Assaciation. It originated in the NCMH solicited funds for a hospital survey to be conducted by the APA. The Psychiatric Foundation was established as a repository for the distribution of funds.

The coalition of the three groupg, the Paychiatric Foundation, the NCMH and the Mental Health Foundation became the National Association for Mental Health. Owen Root was made President. George S. Stevenson continued as Medical Director, the position he occupled alnce Clarence Hincks resigned to return to Canada in 1939. The newly constituted Association took a mandate to serve as an umbrella organization for fund raising and public education concerning mental health primarily on a state and local level. 27

From 1915 to 1943 the Rockefeller Foundation had contributed over a million dollars to the NCMH. In January 1947, \$50,000 was approprlated for general expenseg for the Committee but half of this amount lapsed in December of 1949 because the condition of matching funds was not met. 28 After the reorganization of the National Committee requesta came in for support to initiate the new program by the National Mental Health Association. 29 The

27. Rockefeller Foundation, Minutes, 22 June 1951, pp. 51375-77 RG 1.1, 200, 32, 358, RFA, N. Tarrytown, N.Y.; Ridenour,

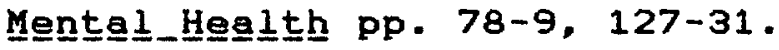

28. Rockefeller Foundation Minuuㅡes, pp. 51375-7.

29. Arthur H. Bunker to Alan Gregg, 12 March 1951; AG D1ary, "February 16, 1951 - New York," describing an interview with Owen Root and Arthur Bunker of the NMHA, RG 1.1, 200, 32, 358, RFA, N. Tarrytown, N.Y. 
Rockefeller Foundation agreed to a final general purpose dispensation of $\$ 100,000$ to the new Association. Consultation with other philanthropies disclosed similar appropriations from the Carnegie Corporation for $\$ 75,000$ and the Commonwealth Fund for \$50,000. 30 Alan Gregg noted, "we have stressed the importance of getting the Association independent of the large foundations. Though the present recommendation is a complete reversal of my previous attitude I think we cannot refuge to contribute anything, and that our position in the future will be better protected by a generous final grant than in any other way." 31

The Impact of the National Institute of Mental Health 18 witnessed in the expansion of 1 ts funds and services. By 1963 the modest $\mathrm{NIMH}$ budget of $\$ 8 \mathrm{million}$ had expanded to $\$ 144$ million. NIMH had sponsored 3,000 research programs and instituted 1,500 teaching programmea in paychiatry by 1963. The number of psychiatrists went from 3000 in 1944 to 17,000 in 1964. Mental health auxiliary workers increased by 30 per cent during this

30. Charles Dollard (President of the Carnegie Corp.) to Alan Gregg 29 March 1951, 22 May 1951; R.S.M. interview Charles Dollard 14 May 1951; A.G. Diary discussion of Oren Root and A.L. van Ameringen, National Association of Mental Health, 15 May 1951; Robert M. Lister to Oren Root 13 May 1951; Flora Rhind to Oren Root, 22 June 1951; National Association for Mental Health "Summary of Contributions and Pledges Received January 1, 1951 through December 31, 1951, 10 January 1952, RG 1.1, 200, 32, 365, RFA, N. Tarrytown, N.Y.

31. A.G.. "Main Points Amalgamation of National Committee for Mental Hygiene," (memo) 4 June 1951, RG 1.1, 200, 32, 365, RFA, N. Tarrytown, N.Y. 
same period. 32 Over the next five years the NIMH budget more than doubled to $\$ 361.5 \mathrm{million}$. The NIMH budget spent 29 per cent of its funds on manpower research, 28 per cent on research, 26 per cent on state and community programmes. The remainder went to service activities and programme management. 33

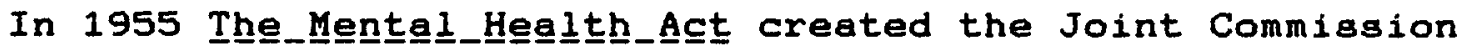
on Mental Illness and Health to report to Congress on the state of psychiatry. 34 A report was submitted in 1960 and published the next year. The Community_Health_Center andend_Retar was signed with strong presidential support in 1963. 35 This legislation signaled, in the U.S., the formal end of the asylum and the institutionalization of the ldea that paychiatric practice belonged in the community hospital, clinic or private practice. Canada also followed the trend to place mental health care within the human services system. It has been pointed out

32. Cited in Robert Castel, Francoise Castel and Anne

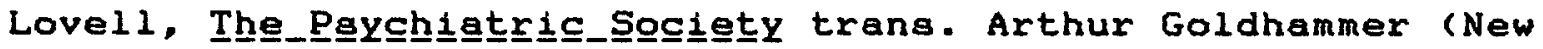
York: Columbia Univ. Press, 1982), pp. 59-60; also see, Eli A. Rubinstein and George $V$. Coelho, "Mental Health and the

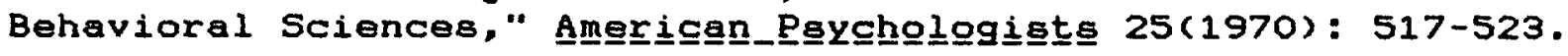

33. El1 A. Rubinstein and George V. Coelho, "NIMH Role in the Behavioral Sciences," in E.A. Rubinstein and G. V. Coelho, eds. , Behay Progrem_Regorts uS Public Health Service Publication 2064, 1970, pp. 1-11.

34. P.L. 182, passed 84th Cong., 1st segs., 28 July 1955.

35. Joint Commission on Mental Illness and Health, Actíng

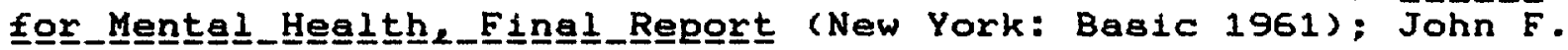
Kennedy, "Message from the President of the United States Relative to Mental Iliness and Mental Retardation," 88th Congres8, House of Repreaentetives, Eebruary 5, 1963, No. 58, p.

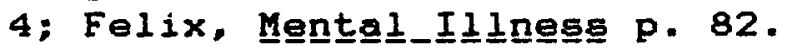


that public mental health care extended the range of the welfare system as it performed functions of control, surveiliance and normalization. Public services came to rely increasingly on psychology as a strategy for therapy and social control. 36 After 1950 the Canadian Committee retained a position closer to government than the U.S. Association. In 1945 Clarence Hincks, as Medical Director of the Canadian Committee became an advisor to the Department of National Health and Welfare formerly the Department of Pensions and Welfare. He outlined a plan for a national institute for mental hyglene. The Canadian National Committee recommended that the government provide mental health grants totaling $\$ 6,250,000$ with $\$ 4,000,000$ to provinces on a per capita basis, \$2,000,000 to improve existing facilities and \$250,000 for research and training. 37 Dominion Mental Health

36. Social control ia an old concept rather freely uaed by child aavers and mental hygieniats. The interpretation of the concept varied. On one hand it had a eugenical component justifying the rightful place of Nordic European groups to hold positions of leaderahip over inferior groupa. On the other hand, it referred to the generalized need for proper socialization and opportunity for the young in order to assure general social wellbeing. While the second view is less radical both interpretations seek to define and preserve well ordered communities in the face of social and technological change. The point here is that the cultural and ideological maintenance of social continuity increasingly adopted medical and psychlatric models which served to identify and control deviant and potentially deviant

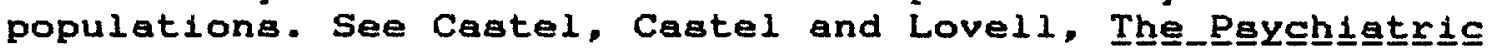
Society for a discussion of the psychiatrization of difference pp. 202-13.

37. Clarence Hincks, "Memo Presented to the Board of

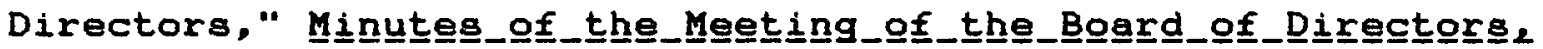

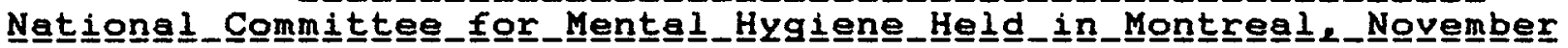
$8_{2} 1945$ CMHA Papers, PAC MG 28 I 391, 84/63, Ottawa; John D. Griffin "Mental Health - Cenada: The Chronicle of a National Voluntary Movement. The Canadian Mental Health Association 1918 - 
Grants were created along these lines in 1948. The grants did not directly benefit the Canadian National Committee. However, unlike the establishment of the National Institute of Mental Health in the United States, the Canadian grants subatantiated the continued position of the Committee in the guidance of public policy and mental health leadership. 38

In the 1940 s the Canadian Committee not only contributed to government programmes and increased its educational publicity but initiated major surveys and research oriented organizations and demonstrations. For example, in 1946 the Toronto Mental Health clinic was created. This was the first child guidance centre to conform closely to the U.S. child guidence demonstrations using the services of a psychiatrist, psychologist and psychiatric social worker. In 1952 the clinic was renamed the Hincks Treatment Centre with in-patient and out-patient facilities for children and young adults. Originaliy a cooperative effort between the CNCMH and Toronto Welfare Council with funds from the Community Chest and University of Toronto School of Social work, in 1952 the clinic became an independent agency with its own Board of Directors. 39

1980," (May 1981), P. 230, John D. Griffin Papera, GreenlandGriffin Archives, Toronto.

38. "Minutes of the Meeting of the Board of Directors of the National Committee for Mental Hygiene (Canada) Held in Montreal September 30, 1948," CMHA papers, PAC MG 28 I $39184 / 63$, Ottawa; Griffin, p. 230 .

39. J.F Boys, "The Birth of a Community Mental Health Clinic," MSW Thesis Univ. of Toronto, 1953; M. A. Briault, "History The Toronto Mental Health Clinic 1946-1954," MSW Thesis 
In 1947 Hincks retired and John D. Griffin took over the Medical Directorship of the Committee. A major school survey was undertaken which assessed mental hygiene teaching practices. The Canadian Education Association and the Canadian Public Health Association utilized the CNCMH for consulting services on mental hygiene. The second of these reporta was an explication of "a mental hygiene approach to education," with detailed deacriptions of child mental health problems and their remediation in clinical settinga. 40 The school aurveyg led to projecta in teacher training and demonstration pilot projects. One of the major demonstrations was the Forest Hill Village Project initiated in 1948 which did "paycho-social research in community mental health." 41 A liaison officer project which trained 80 teachers by 1960, combined academic child study, psychiatry, social work and education. An emphasis in the demonatrations, similar to the U.S. committee, was to initiate permanent projects to be taken

Univ. of Toronto, 1954; Griffin, "Mental Health," pp. 223-4.

40. "Minutes of the Board of Directors," September 30, 1948 p. 3, CMHA Papers, MG 28 I 391, 84/93, PAC, Ottawa; National Committee for School Health Research, A_Health_Survey_of_Canadian

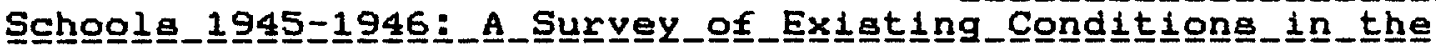

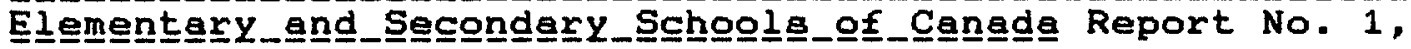
(Toronto: NCSHR, March 31, 1947); National Committee for Health Research, "A Health Survey of Canadian Schoola, 1945-1946, Report

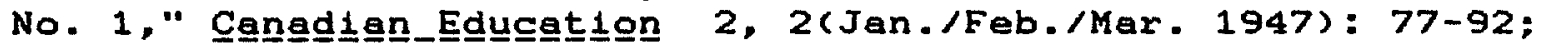
National Committee for School Health Research, "Second Report,"

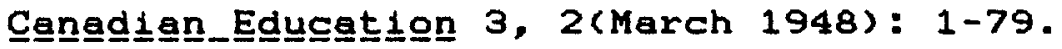

41. "Minutes, Meeting of the Board of Directors," 3 October 1949, CMHA Papers, MG 28 I 391, 84/63, PAC, Ottawa; J.D. Griffin and J.R. Seeley, "Education for Mental Health: An Experiment,"

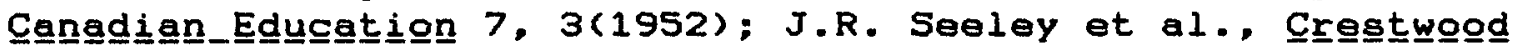
Heightes (Toronto: Univ. of Toronto, 1956). 
over by official bodies, university faculties and school boards. 42

As early as 1946 the Canadian Committee began to discuss expanding into a popular movement by encouraging the growth of provincial and local societies. 43 While local expansion had characterized the U.S. movement, from the beginning the Canadian movement had remained national and exclusive in its memberahip. In 1949 a new organization was proposed which would operate on three levels. The National level would essentially remain the same. It would continue with its technical staff to provide liaison and consultative services on a national level including task force surveys and public forums. It would be a major policy innovator for government. The provincial level of organization would provide liaison services between the local communities and the national organization, asaiating branch work and providing an Informational service. The local level would provide grasaroots services and gather information to pass on to the higher levels on actual community needs. 44 A similar organizational format exists to the present. The Canadian Association for Mental Health is the largest provider of non-public mental health services in

42. Griffin, "Mental Health," p. 236.

43. "Minutes of the Board of Directors," 17 December 1946. CMHA Papers, MG 28 I 391, PAC, Ottawa.

44. Board of Directors, "Proposed Activity of the National Committee for Mental Hygiene (Canada) During 1949-1950, Exploration of the Possibilities of Seeking the Partnership of the Canadian Public Through the Organization of Provincial Divielons and Local Branches," September 1949, CMHA Papers, MG 28 I $39184 / 63$, PAC, Ottawa. 
Canada. The Association in this way serves as an official public consultant, as a private provider and as an advocate for mental health policy. 45 The Committee was renamed the Canadian Association of Mental Health in 1950. The first provincial division under the new "white crosg" gymbol was created with the help of S.R. Laycock in Sagketchewan in November 1950. Divisiona were subsequently established in all ten provinces. 46

Canada as the first international committee retained a close connection to the international mental hyglene movement. The international growth of mental hygiene expanded over this period beginning with the Canadian affiliation in 1918. The first

International Congress on Mental Hygiene held in Washington D.C. in 1930. The Congress gathered more than 3,000 participants from 50 countries. The international movement also changed significantly in the 1940s. A second International Congress had been held in 1937 in Paris, however the international exchange was practically nonexistent for the next decade due to the war. The movement was reactivated in 1947 . In August of 1948 the Third International Congress on Mental Health was held in London.

45. This arrangement is not without its problems, David Randall and Paul Grocott, "Advocacy and the Delivery of Community Health Services: Do They Mix? A Saskatchewan Perspective,"

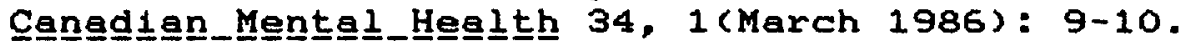

46. Christian Smith, untitled report to the Board of Directors describing a preliminary visit to Saskatchewan in

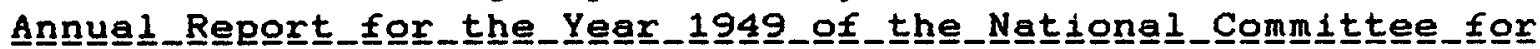
Mental-Hygiene CMHA Papers, MG 28 I $39184 / 63$, PAC, Ottawa; Murray Cherneskey, "A Touch of Laycock: A Study of S.R. Laycock: Educator and Apostle of Mental Health," M.Ed Thesis Univ. of Sasketchewan, 1978; Billie E.H. Housego, "Some Reflections on the Life and Times of S.R. Laycock," Univ. British Columbia, p. 161. 
In 1948 the World Federation for Mental Health was

established in response to a recommendation by the United Nations World Health Organization (WHO) and UNESCO. The first director was Canadian psychiatrist, Brock Chisholm, former General

Director of the Canadian Army Medical Services. The current world Federation has official consultative atatus with the United Nations and continues to work closely with the wHO and UNESCO. Children were an early and major consideration for the world Federation. English child paychlatrist, John Bowlby became a

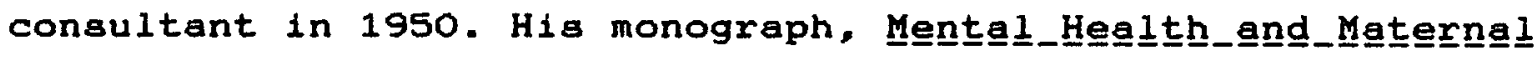
Gare was prepared under the auspices of the world Health Organization. Bowlby emphasized the importance of mother-love in the development of the child's character and personality. 47 Child mental health surveys were conducted on a world wide basis in 1960 with related areas of concern in education, industrialization, migration and crosa cultural attitudes toward mental disorders, professional training and research. 48

The Rockefeller Foundation also participated in the internationalization of mental hygiene. Part of the world wide campaign for public education on mental health was the issue of profesalonal training strongly endorsed by the RF. The

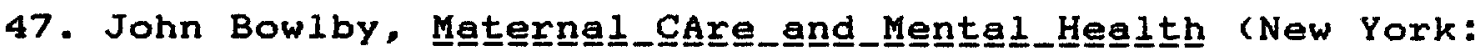
Columbia, 1951) a summary was published as Chí Growth_으느을 Abridged version by Margery Fry, ed. (New York: Penguin 1953).

48. World wide surveys of child health were conducted in 1960. On the international movement see Normal Dain, CII

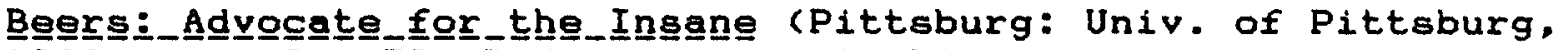
1980 ), pp. 244-53; Ridenour, pp. 66-70. 
Rockefeller Foundation extended its programmes in medical and psychiatric education around the world. Research activities were initiated in the United States, Canada, Great Britain, France, Holland, Belgium, Germany, Sweden, Norway and Switzerland. 49 The state of psychiatry, in general, was discussed through RF's network of inter-office correspondence in the $1940 \mathrm{~g}$. 50 Enthusiasm over advances in psychiatry was mixed, however. Problems within the profegsional asgociations in paychiatry reflected the continuing lag effect of the mental health field in comparison with natural and medical science. Rockefeller staff observations on the psychiatric profession were three fold. The Foundation questioned the gain in prestige afforded poychiatry by its role in the Second World war on the grounds that it was not based on scientific breakthroughs. The Foundation was becoming increasingly disturbed by the fact that poychiatry and psychiatrists failed to scientifically validate clinical procedures. Related to this, the Foundation staff had misgivings about the capability of psychiatry to become scientific. "Tested scientific knowledge" hed to come out of laboratories and Individual research. Instead, as Robert $S$. Morison of the RF noted, "There have been several times recently when I have felt

49. Fosdick, The_Stgory, pp. 130-1.

50. Chester I. Barnard to Joseph H. Will1s, "Inter-office Correspondence," 2 December 1946; J.H.W to A. Gregg. R.B. Fosdick, "Memo," 27 December 1946; J.H.W., to A.G., "Cantril's Letter of November 218t and article," 2 January 1947; J.H.W. to A.G., 25 June 1948; C. I. Barnard to A.G. 5 August 1948; C.I.B to A.G., "Memo," 5 August 1948, RG 3,906, 2, 18, RFA, RAC, N. Tarrytown, N.Y. 
that the leaders of American psychiatry are trying to establish truth on the basis of majority vote. This is, of courge, quite contrary to the usual scientific procedure of submitting evidence which can stand on its own merits in a candid world." 51

Chester I. Barnard, President of the Rockefelier Foundation in 1948, after reviewing documents on the Foundation's support for peychiatry came to the conclusion that there was an underlying fundamental "criticiam of paychiatry generally" implied in the record. Barnard admonished: "Isn't there any way to blast this situation? Doesn't a continued and general refusal to permit or attempt validation of psycho-therepeutic methods put everyone concerned, including ourselvea, in a position of promoting or carrying on a social racket? How can the charlatans be dealt with if the good men will give no validation but their own individual say sos? " 52

\section{The Professionalization of Psychiatry}

The advancement of professional education and leadership was a problem in the United States that was even more acute in Canada. The Group for the Advancement of Paychiatry (GAP) was established in the mid-1940s. It was affiliated with the American Psychiatric Association, the professional organization of both

51. Robert S. Morison to Chester I. Barnard, "Memo," 30 September 1948, p. 2, RG 3, 906, 2, 18, RFA, RAC, N. Tarrytown, N.Y; Robert S. Morison, a talented biologiat, took over the combined Divisions of Medical Science and Division of Natural Science of the RF in 1952 upon the retirement of the former Directors of these Divisions, Alan Gregg and Warren Weaver.

52. Chester I Barnard to Alan Gregg, 5 August 1948, RG3, $906,2,18$, RFA, RAC, N. Tarrytown, N.Y. 
Canadian and United States psychiatrists through the 1940s. GAP 11 lustrates the political process where professional psychiatric perspectives and mental health protocols were encouraged by the leadership of philanthropies. Similarly the establighment of an independent Canadian Paychiatric Association in 1951 is Instructive of the changing relationship between advocacy, psychiatric professionalism and government.

From the early Association of Medical Superintendents of American Institutions for the Insane (1844-1892), the American Medico-Psychological Association (1893-1921), to the American Psychiatric Association, psychiatrists had sought legitimacy and recognition for their field. Major movements toward organizational changes were occasioned by lay reformers first in Dorothea $D 1 x$ (1840s) and then C11fford Beers. 53 Prior to 1900 there was no systematic instruction in psychiatry. In the $1920 s$ Thomas Salmon and the NCMH urged psychiatric education as did C.K. Clarke in Canada. The need for certification by an outside board became a major isgue in the 1930g. The National Committee organized a Division on Psychiatric Education in 1930. The American Medical Association conducted a survey of mental hospitals which was resented by the APA as reducing the autonomy of psychiatry. The NCMH played a strong role in trying to gain autonomy and status while integrating psychiatry into medical curriculum. The American Board of Psychiatry and Neurology was

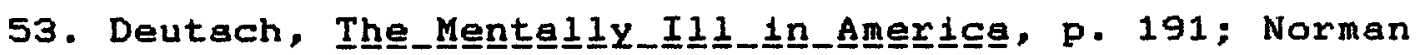
Dain, Menta﹎_I 1 lng Princeton Untv. Press, 1983 , pp. 266-87. 
not formally organized until October of 1934 . The discipline was still in a dire state of flux in 1942 as witnessed in a study of psychlatry in medical education. The Group for the Advancement of Psychiatry was organized in this juncture. Its role was to profesgionelize paychiatry as medical doctora whose clients were In outpatient clinics, child guidance clinics and private practice, and as public consultanta on a wider basis in human services. 54

The Group for the Advancement of Poychiatry was a product of philanthropic encouragement. Before World War II ended, Barry C. Smith of the Commonwealth Fund initiated discussions with army personnel and his own staff and the National Committee for Mental Hygiene staff over the organization of a planning conference for mental hygiene. The major concern was "paychiatric planning for personnel, training and service." 55 william C. Menninger, Surgeon General of the U.S. Army in charge of Paychiatry concurred with the need for the professionalization and training of psychiatrists and support personnel. $56 \mathrm{As}$ the conference format evolved it was determined that participanta were to be carefully picked. The exclusive group was to be confined to top government and clvilian repregentatives of medicine and psychiatry, as well as Foundation staff members. Those invited

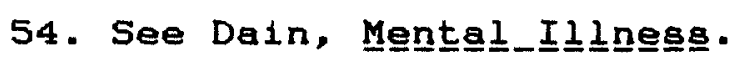

55. Barry C. Smith to M.C. Scoville, "Memorandum," 24 October 1944, CF 74, RAC, N. Tarrytown, N.Y.

56. M.C. Scovilie to Barry C. Smith, "Memorandum," 22 May 1944 CF 74, RAC, N. Tarrytown, N.Y. 
included Alan Gregg, Medical Director of the Rockefeller Foundation who had served as an Ald to Menninger during the war; Frank Fremont-Smith, Medical Director of the Josiah Macy Jr. Foundation: Lawrence S. Kubie of the National Research Council; Commonwealth Fund Executive Assistant Mildred Scoville and Medical Associate Lester J. Evans. Other Individuala were chosen because of their clinical experience or the "importance of their perspective or strategic position." 57

The Hershey Conference, so named for 1 ta location in Hershey, Pennsylvania, took place February 1-3, 1945. Nine recommendations came out of the conference including a call for: a continuation of paychiatric training and facilitiea in the military; continued research by the Veterans Administration on soldiers; the expansion of non-hospital facilities for mental hygiene; "Intensive efforts to arouse and inform" public forums on mental hygiene in churches, schools, industry and labour through the NCMH; expanded medical education in psychiatry especially as serving education and industry; comprehensive undergraduate medical education in psychiatry directed toward outpatient clinics and wards; graduate training in psychiatry combined with pediatrics and internal medicine; and the training and increased use of auxiliary personnel such as social work and

57. "Conference on Paychiatric Needs in Post-war Situation and Plans to Meet Them," 24 November 1944, (typescript), pencil on the side: "personal for B.C.S. for Bd. Report"; George S. Stevenson to Mildred Scoville, 20 October 1944, CF 74, RAC, N. Tarrytown, N.Y. 
psychology in "community services for mental health." 58

The Hershey Conference timing was conducive to change. At the next meeting of the American Psychiatric Association in Chicago the standing committee from the conference discussed active steps for furthering professional training in psychiatry and the certification and reorganization of clinical facilities. Funds were sought from the Commonwealth Fund and two immediate steps taken. The firat was to nominate and elect members of the committee to the council of the APA. Secondly, a semi-independent organization was created to be called the Group for the Advancement of Paychiatry. 59

GAP was exclusive from the onset. Limited to 150 members who had to "pass a rigid scrutiny as to serious interests, profegsional soundness and willingness to give promptly and freely of their own time and money." 60 In the words of william Menninger, who became the first chairman, GAP operated as a "small mobile striking force for American Psychiatry." 61

58. "Appendix I - Skeleton Report of the Hershey Conference. presented to the Directors at a meeting on 14 June 1945," CF 74 , RAC, N. Tarrytown, N.Y.

59. M.C. Scoville, "Group for the Advancement of Psychiatry Interview with Brig. Gen. William Menninger, Dr. Henry Brasin and Dr. Thomas A.C. Rennie," 29 June 1946, CF 74, RAC, N. Tarrytown, N.Y.

60. Scoville "GAP Interview," p. 5, the "Circular Letter No. 1" also downplays the exclusiveness of the membership, saying only that it is "informal" and comprised of "well established" APA members, p. 1 .

61. William C. Menninger to Mildred C. Scoville, 20 April 1948, CF 74, RAC, N. Tarrytown, N.Y. 
Committee members saw themselves as a forward action group within a conservative field. They tended to view the APA and the American Medical Association, as not having kept "abreast of the times." It was "too protective," "too cautioug" and lacking in "aggressive leadership." 62

By 1948 GAP had reached 1ta antlclpated memberahip of 150 . The group worked through fifteen functional committees. Fall and spring general meetings, interim committee meetings, the circulation of reports and "circular letters" for approval and revision kept members in close contact. The pace of the group is witnessed by the fact that from July 1947 to March 1948, five reports and 49 circular letters were publiahed and diatributed. The reports were mailed to researchers in the area and also to "many persons whom the committee believed could or should profit from the report." The social work report, for example, was sent to every member of the APA, and also to every member of the Association of Psychiatric Social Workers, made available for students in the field and "diatributed to every atate hoapital and Veterans Administration Hospital." Requests for orders of fifty to one hundred copies were "not infrequent." First printing

62. M.C. Scoville, "Group for the Advancement of Paychiatry Interview with Brig. Gen. William Menninger, Dr. Henry Brosin and Dr. Thomas A.C. Rennie," 29 May 1946; It is interesting that the "Circular Letter No. 1 Group for the Advancement of Paychiatry." by William $C$. Menninger, chairman, undated, was much more conciliatory toward the APA than Scoville's interview indicates. The circular takes pains to assure the members that "there is no desire to capture offices or promote rivalries, or to set up a new organization," $p$. 1. Both documents are in CF 74, RAC, $N$. Tarrytown, N.Y. 
of some reports in anticipation of their demand ranged from 7,000 copies on shock therapy to 10,000 on social work. 63

GAP attempted to gain "spheres of influence." It circulated information through the National Committee for Mental Hygiene to the scientific and lay press. GAP made major endorsements on social policy such as the President'g Committee on Civil Rights. Recommendations were also made on military training. It encouraged other organizations such as the World Health Organization created in 1948 which subsequently became a vehicle for the international mental health movement through the world Federation for Mental Health.

GAP's rapid rise in power and influence was due to the personal positions of its members. This reflected the policy decisions of the original Hershey conference committee in choosing to include only strategically influential members whose mutual support would serve to cross institutional and disciplinary boundaries. As Menninger pointed out in his report to Mildred Scoville: "Through its committee on Federal Agencies, GAP has had a definite and direct influence on the paychiatric work in various government agencies, not only of the United States, but through Canadian members, on the Canadian Government." 64 Members were in military service, public health

63. "Circular Letter No. 1," pp. 3-7; "Group for the Advancement of Psychiatry Meeting November 4, 5, 6." Year not cited but probably the agenda for the 1946 meeting, (typescript), pp. 1-6. CF 74, RAC, N. Tarrytown, N.Y.

64. Menninger to Scoville 20 April 1948, p. 10. 
administration, Veteran's Administration and as consultants to the Surgeon General. Other GAP members included consultants to the Federal Security Agency, Jolnt Research and Development Board, National Research Council, Federal Medical Services Committee and the Mental Health Advisory Committee (U.S.P.H.S.). Robert Felix, head of the federal Division of Mental Hygiene who was active who was made Director of NIMH was active in GAP. 65 Strateglc recommendations from GAP were funneled to government and to professional associations by members who routinely served on major policy making boarda and panels. 66

GAP's direct influence on the American Paychiatric Association was dramatic. "Extensive reorganization plans" were made for the structure of the APA with eleven of fourteen members on the reorgenization committee GAP members. A full time Medical Director was hired for the APA who was also a GAP member. Even though the GAP membership of 150 was dwarfed by the APA membership of 4,500, they "turned out full force" to nominate and elect members to three of four available seats on the APA council in 1947-8. GAP members then totaled five of the eleven council seats. GAP members chaired thirteen out of twenty-six standing APA committees. By 1948-9, GAP members held the positions of president, secretary and treasurer, seven out of twelve council positions, and chaired twenty of the twenty-aix standing

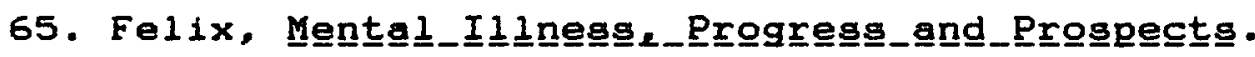

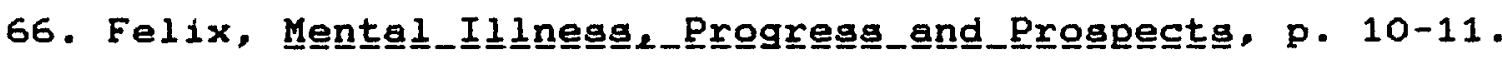


committees of the APA. 67

Criticisms of GAP are ingtructive in that the organizational character of the group proved more problematical for the American memberghip than for the Canadians. This was the case in spite of the fact that GAP addressed U.S. issues and appeared to be successfully advancing the status of psychiatry in U.S. medical circles. The Group for the Advancement of Psychiatry was accused by U.S. members of being an elitiat political body which had attempted a take over an egalitarian association of professionals. It was accused on one hand of serving propagandiatic purposes outaide the realm of science. Conversely, It was questioned on the basis of the self-proclaimed over scientistic standards it upheld in psychiatry. 68 One critic wrote: "GAP is a small, self-constituted body which has to a very great extent presumed to speak authoritatively for American Paychiatry... The continuance of GAP in the manner it is and has been functioning is a serious threat to the unity of the American Psychiatric Association." 69 Another member of GAP in a letter of resignation noted that: "One would not expect a self-elected 'leadership' group, eapecially while aubaidized, to recognize spontaneously the appropriate time for relinquishing its

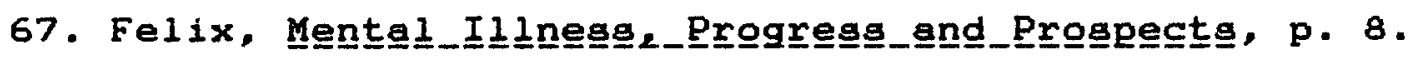

68. "Agenda Steering Committee Meeting - Asbury Park," 7 April 1949; The Committee for the Preservation of Medical Standards in Psychiatry, "Letter \#2" American Psychiatric Association, CF 74, RAC, N. Tarrytown, N.Y.

69. Karl Bowman to William C. Menninger n.d. excerpt in "Agenda," 7 April 1949. 
functions to a more broadly representative organization." 70 Another APA member who refused to join GAP resented the "Inference which the GAP tries to convey that it has a monopoly on the psychiatric knowledge of this country." Further, the political and manipulative nature of the group was seen as undermining paychiatry in that "the vast majority of the members of the Association...by inference are not considered to be competent enough psychiatrists to belong to the inner circle." 71 Some of these allegations were simply correct. GAP members consciously saw themselves as an elite vanguard. Members pushed a distinctive view of science and professionalism. An elite group within the APA it followed a hierarchical model in its internal structure. On one hand, the officers and membership of the committee were inflexible. Yet, membera were obliged to participate and committees were obliged to produce position reporta for general discuasion among members. The reports were circulated and a consensus was reached by having the report revised to conform to the disaenting opinions. The executive steering committee made decisions as to which reports would be published and circulated and to whom. These procedures resemble the internel dynamics of the foundations with their divisions and committee structures, with the exception that the foundationa delegated authority to various levels and did not require general

70. John Whitehorn to William C. Menninger, n.d excerpt in "Agenda." 7 April 1949.

71. Winfred Overholser to William C. Menninger, n.d excerpt in "Agenda" 7 April 1949. 
consensus. GAP, like the discipline of psychiatry itself, was riddled with contradictions. These included equally problematical elitist and democratic tendencies. The emphasis on the need for basic science research and standardization of training and practices before propagandizing results also contradicted the active compaigna to popularize paychiatric perspectives in afflileted disciplines and in the minds of the lay public.

Not all GAP members followed the rule that they must respond to the reports. For example, even an important GAP circular on the aims and objectives of the organization written to clarify their position vis-a-vis the general APA membership was answered by only two thirds of the GAP members. 72 Many members found the paper work demanded in the committees to be overbearing. Consequently external criticisms were matched by internal dissension.

The Canadian psychiatrista found less faut with the elite structure of the orgenization and 1ts dual sense of obligation to work for the whole. This conformed with the Canadien view of the role of leadership and its obligetions. The problem was that the purposes of the APA and GAP were increasingly directed internally and toward typically American problems. Not surpriaingly, financial lssues overshadowed the ability of GAP to become Independent or to expand its specific interests internationaliy. This also was brought to a head in 1949, in that, the

72. "Aims and Objectives of GAP," Circular Letter \#127, GAP; "Agenda," pp. 4, 6, CF 74, RAC, N. Tarrytown, N.Y. 
Commonwealth Fund, which had supported GAP, was to withdraw January 1, 1950. No other funds appeared forthcoming. 73 Canada, at this time, was concerned with issues in its own national development. Paychiatry in the United States and Canada was in different stages of development. Each context required new and innovative solutions. Canadian paychiatry was lesg developed than in the United States but it was not just a matter of catching up but of being structurally different in its relationahip to the Canadian government and to the Canadian Medical Association.

Reassessment of the relationship between Canadian poychiatrists and the APA contributed to the formal establishment of an Independent Canadian Paychiatric Aagociation in 1951. The CPA was founded after four years of discussion. Similar forces which had led to the creation of GAP occurred in Canada at the end of the War. The Canadian Paychiatric Association was in a sense the equivalent of GAP in the U.S. The Canadian Association was a product of a small group of Canadian mental hygienists who contributed to the collaboration of a self-identified vanguard contingent of Canadian psychiatrists, the CNCMH and the Canadian Medical Association. 74

The Canadian National Committee for Mental Hyglene and William Line, Directorate of Personnel Selection and Social

\section{3. "Agenda."}

74. Isabel Dickson, "The Canadian Psychiatric Association

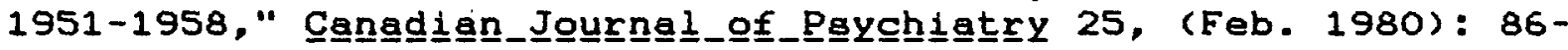
97. Dickson, the retired First Executive Secretary of the CPA, wrote this essay in 1958, it was reprinted in 1980 , edited by Charles A. Roberts. 
Sciences of the Canadian Army, initiated an Inter-gervice (military) Conference on Paychiatry in April of 1944. Psychiatrists and representatives from the Department of Pensions and National Health attended. 75 The Committee consisted of Clarence Hincks, William Blatz, J.C. Meakins of McGill and G. Humphrey of Queens. They initiated an internal educational campaign that January. Clarence Hincks convened a meeting of geventy-two Canadian paychlatriata to diacusa the future of psychiatry at the close of the war. It was noted that the return of psychiatrista who had worked in the cooperative canadian programme for evacuated children in the British Isles would return to Canada enlarging the group of qualified personnel in paychiatric-related disciplines, moderating to some extent the shortage of trained personnel. $76 \mathrm{~A}$ second conference of the inter-service psychiatrists was held headed by J.D. Griffin, Brock Chisholm and D. Ewen Cameron in 1945. This meeting took up the question of the advancement of post graduate training in paychlatry, the profeasional atatus of paychiatry and an increase in provincial services. A survey contacted every psychiatrist in Canada trying to draw them into "partnership with [the] National

75. "Report on the Activities of The National Committee for Mental Hygiene (Canada) for the Year 1944," 1 December 1944, MG 28 I 391, 84/63, PAC, Ottawa.

76. C.A. Roberta, "Major Changes in the Administration of

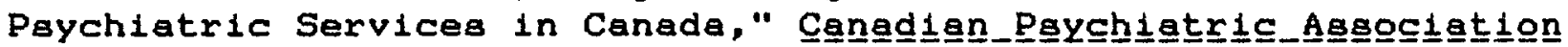
J으므므르 11, 3(June 1966): 229. 
Committee to promote progress." 77 Partly as a result of these meetings and inquiries, section on Paychiatry was established in the Canadian Medical Association in 1945. 78 By 1948 there was growing interest in creating an association independent of the CMA and APA neither of which were truly representative as spokegmen for the interegta of Canedian paychiatry. 79

The incipient association of Canadian psychiatrists took advantage of existing organizations since they lacked funds to establish independent meetings. At the 1949 Montreal meetings of the APA, an Interim Committee was formed. A new survey of Canadian Paychiatrists showed support for an independent organization. At the April 30, 1950 APA convention in Detroit, the group of Canadian poychiatrista formally voted approval. At the Canadian Medical Association meetinga a month later in Halifax, a committee which included J.D. Griffin of the Canadian Association of Mental Health, was instructed to draw up a

77. "Report of the General Director to Meeting of Board of Directors, National Committee for Mental Hygiene (Canada), Held in the Head Office Royal Bank of Canada, Montreal, June 13, 1945.

78. Dickson, "Canadian Psychiatric Association," p. 86. This is important because the forerunner to the APA in the United States predated the American Medical Association. The medical profession only began to overtake the superintendents of asylums in prestige in the late nineteenth century. American paychlatrists as medical scientist had to live down their background in administration. Psychiatry and medicine came to have an ambivalent, competitive and jealous relationahip with formal medical organizations. This was less the case in Canada partly because medicine never achieved the status of a sovereign profession as it did in the United States.

79. "Agenda Steering Committee - Asbury Park," 7 April 1949 CF 74, RAC, N. Tarrytown, N.Y. 
constitution and to apply for corporate status under Canadian law. 80 The organization was incorporated June 1, 1951 and the first formal meeting was held June 20, 1951 in Montreal coinciding with the Canadian Medical Association meetings. Its original membership totaled 143.

The Canadian Paychiatric Association remained weak in membership and consequently weak in funds since it was supported by members' dues. The Bulletin of the CPA (later the Cangadian

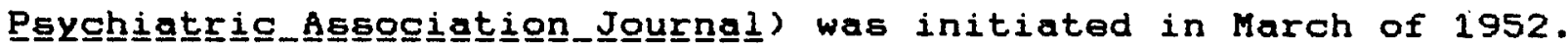
It was distributed under the aegis of the Ontario Health Department. Membership in 1952 had only grown to 182 out of the 685 paychiatrists in Canada. In 1956 the 437 members atill only represented 56.8 per cent of all Canadian psychiatrists. 81

The establishment of professional standards, certification of mental institutions, and expansion of paychiatric curriculum In medical schools has been a priority since the mid-1950s. 82 It was not an isgue easily solved. The Ontario Paychiatric Assoclation in 1973 still emphasized the need for training in paychiatry.

In 1958, a contingent of Canadian psychiatrists interested in children created a nucleus committe日 to gather information. A

80. The CPA was incorporated June 1, 1951. K.G. Gray, J. D. Griffin and Q.C. Griffin were instrumental in drafting the constitution and legal papers for incorporation, see Dickson.

81. Dickson, "The Canadian Psychiatric Association," p. 93.

82. Canadian Paychiatric Association, "Minutes of the 4 th Annual Meeting, August 30, 1954, see Dickson, "The Canadian Psychiatric Association," p. 96. 
report, in 1961, revealed a very uneven distribution of services. Outside of Quebec and Ontario, services concentrated on adult oriented facilities which carried heavy case loads involving children. 83

In the United States, the increase in the number of psychlatrists preceded the emphasis on children. In Canada the small number of practicing psychiatrists retarded the development of specializations auch as child paychietry. The Laidlaw Foundation funded a workshop in techniques of teaching child psychiatry in 1974, but the provision of professional psychiatrists did not dramatically increase even under the pressure of expanding community services in mental health. Toronto and Montreal remained the major training centres in Canada. Child psychiatry while a two year component in medical education at Toronto, MCGill and Queens, remained an unrecognized subspecialty in the Canadian Psychiatric Association. The Royal College had no separate examination for child paychiatry similar to the American Boards in Child Psychiatry. 84 Canadian psychiatrista found the push for paychiatric leadership in community level services a difficult challenge to meet considering the size of the Canadian profession. Similar to the U.S. one solution was to endorse the use of auxiliary personnel and to rely on public health education using the services of

83. Jean L. Lapointe, "Child Psychlatry Across Canada: An Outline of Current Facilities and Resources," CEgneng

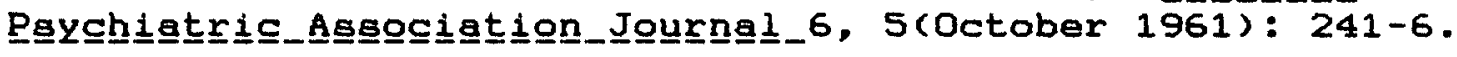

84. McConville, "The Future," p. 209-11.. 
medical doctors, teachers, psychologists, social workers and public health nurses. 85

The Clinical Classification of Abnormality in Childhood The classification of mental diseases was an important aspect of the effort to substantiate the medical validity of paychlatry. It was also a way of making psychiatry more readily accessible to auxiliary professions. In a series of reports on child mental health dating from 1951, GAP contributed to this enterprise. 86. The Group for the Advancement of Psychiatry set the clasafication of mental diseaseg, especially in children, as a major objective. In 1957 GAP produced a report on child psychiatry from its newly formed Committee on Child Paychiatry. 87 In 1966 the GAP Committee produced a monograph on

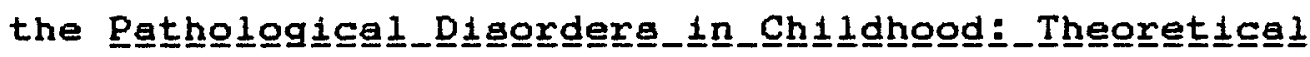

85. J.S. Pratten, "Presidential Address: Discipline and

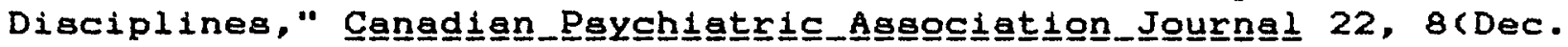
1977): 405-415.

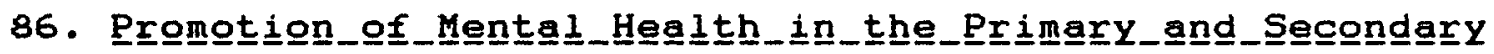

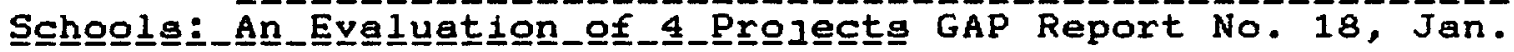
1951 ; The_Contrí

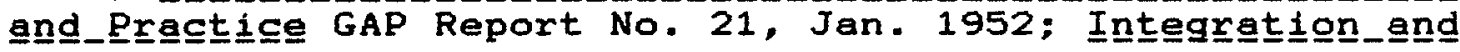

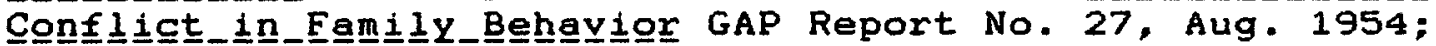

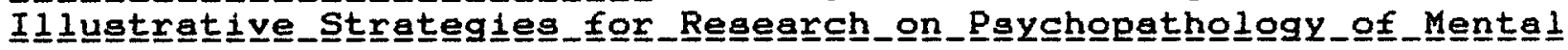

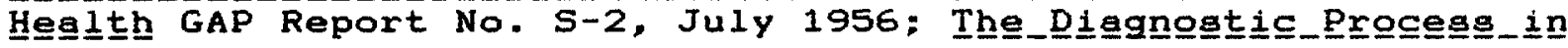
Child_Psychiatry GAP Report No 38, Aug. 1957; Bagig

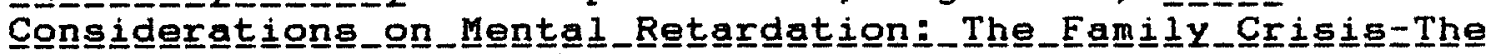

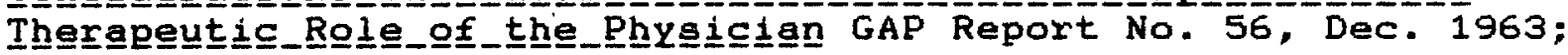
Sex_and_the_Coli No. 38 .

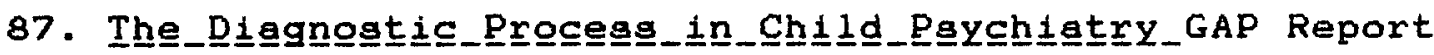




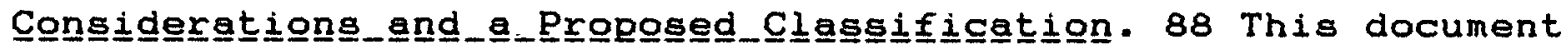
presaged the introduction of children into the official nosology of mental pathologies. Up to this time childhood mental pathology did not have separate classifications and was not formally singled out from adult mental illness.

The GAP Committee on Child poychiatry contributed to the creation and expansion of categories identifying infant and child-related mental illnesses which have grown exponentially in the Post World War II period. One third of the categories of mental disorders were cited as either "evident in infancy, childhood or adolescence," in the latest diagnostic and statistical manual of the American Psychiatric Association. which is used by both U.S. and Canadian psychiatrists. 89 In sddition to the thirty-six age related coded categories there are 182 additional mental disorders specifically noted as "appropriate for children or adolescence."

88. Group for the Advancement of Paychiatry, Committee on

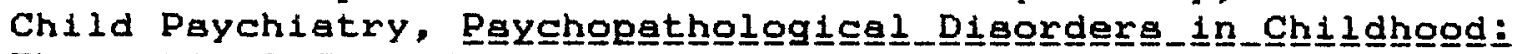

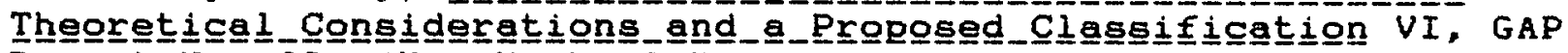
Report No. 62, (New York: GAP, 1966).

89. American Psychiatric Association, DSM $=I I I$, Dílagnostitic

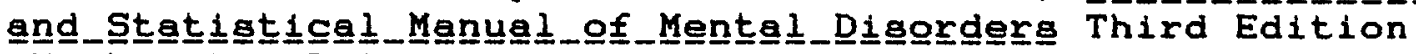
(Washington D.C.: American Psychiatric Association, 1984), p. 35; also see the related but slightly different version of the world

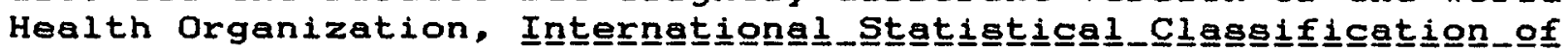
Disegses. ICD 9 Ninth Revision (Geneva: World Health Organization, 1978); World Health Organization, Manuel_of ICDE-9 Vol. I and II (Geneva: World Health Organization, 1977); Commission on Professional and Hospital Activities, The

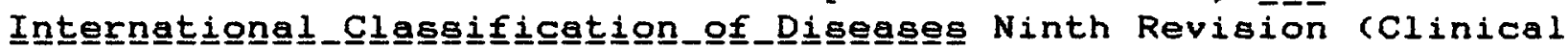
Modification, Ann Arbor, Michigan: Commission of Professional and Hospital Activities, 1978); The DSM-III containg notes on translating the ICD- 9 codes into DSM-III codes. Canada officially recognizes the APA's DSM-III. 
Since the late 1940 s young children and adolescents have been the fastest growing population identified as patients with mental disorders. The number of children and adolescents in mental institutions in the United States increased by 150 per cent between 1962 and 1973. By 1973, there were 26,000 children in mental hospitals with admisgiong predominantly for "personality disorders," "adaptation reactions" and "behaviour problems" as well as mental retardation. 90 In the United States, by 1966, there were 149 clinical centres specializing in childhood and adolescent mental disorders treating ten thousand juveniles. 91 By 1974, 340 centres had opened which treated thirty thousand children. 92 Overall, the number of patients under 25 years of age tripled between 1955 and 1972 when the number of adult patients most rapidly declined with the new emphasis on community and out-patient mental health facilities and the closing of atate hospitals. 93

90. National Institute of Mental Health Statigtical_Note. No. 115 (April 1975); Castel, Castel and Lovell, The Poychíngtrí Socsiety, see ch. 4 .

91. B.M. Rosen, M. Kramer, S.G. Willner and R.W. Redick, "Utilization of Psychiatric Facilities By Children: Current

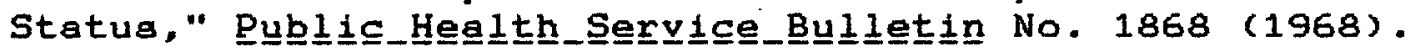

92. National Institute of Mental Health, Statílgticel_ Note No. 130 (April 1976).

93. There is reason to believe that there are substantial differences in age (ch1ld/adolescent), sex, rural-urban residence, income and psychiatric incidence and prevalence rates of mental disorders. In the U.S. for the institutionalized age group under fifteen there were seven times the rumber of boy $a s$

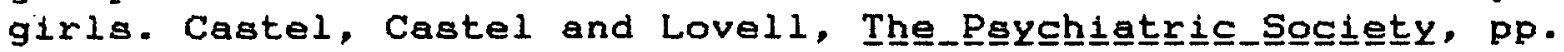
107-8; National Institute of Mental Health, Statistical_Note No. 91 (September 1973); and, No. 112, (March 1975); In the 15-19 age 
The major trends in hospitalized mental health care in the United States and Canada include increases of up to sixty-five per cent for: 1) social misfits and deviants who are considered dangerous but not necessarily clinically mentally ill; and 2) the so called "revolving door" patient. Both of these designations are dominated by minors. 94 The revolving door for children is created by the chance nature of the referral process. Children, depending on the referral source, their geographical location, and their individual aymptomology can end up in the "correctional, social service, special educational or mental health" system. 95 Further, the follow up and coordination of services with children is generally poor. 96

Class plays a large factor in the identification and type of theraputic intervention of mental disorders of all ages. This may be most decisive in the case of the young. Wealthier families can

group females dominate outpatient and general hospital facilities. Urban statistics are higher than rural. See Hamish Nichol, "Incidence of Psychiatric Treatment of Adoleacents,"

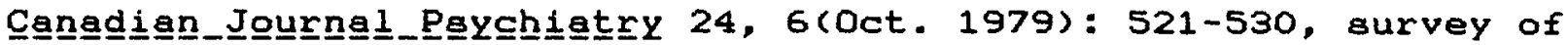
B.C. in 1966; also, B.M. Rosen, M. Kraimer, R.W. Redick and S.G.

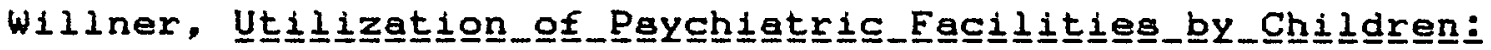

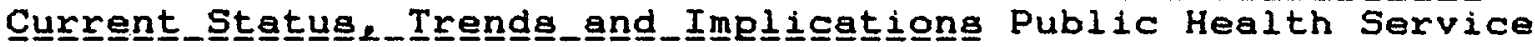
Publication 1868 (Wa. D.C.: U.S. Dept. Health, Education and Welfare, 1968); B.M. Rosen, A.K. Bahn, S. Shellow and E.M. Bower, "Adolescent Patient Served in Out Patient Psychiatric Clinics,"

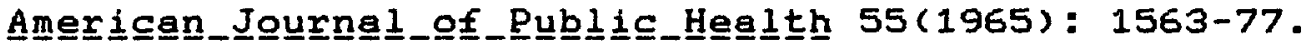

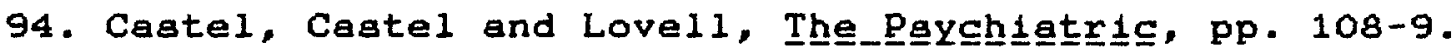

95. Naom1 I. Rae-Grant, "Roadblocks and Stopgaps: A Review of Factors Obstructing the Development of Comprehensive Child

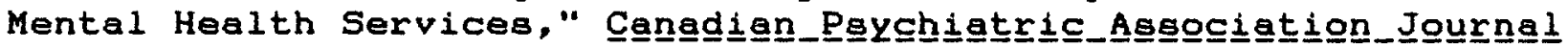
$21,6($ Oct. 1976): 433 .

pp. $433-40$.

96. Nichol, "Incidence," p. 529; Rae-Grant, "Roadblocks," 
pay for therapeutic settings in education or psychiatry. They can solicit private consultations with highly trained medical professionals. 97 "Less favored" families may be swept, involuntarily, into the correctional and social welfare system. Due to the prevailing lack of child psychiatrists, the dominant professional intervention, in most cases by necessity, relies heavily on medicalized but not medical professions in education, social work and psychology. 98

One of the legacies of the formalization of categories of mental disorders of infancy, childhood and adolescence has been the intrusion of a preventive medical paradigm into the lives of normal children. 99 This "surveillance" function of paychiatry, in weeding out potential deviance, is part of the essense of mental hygiene as preventive public health work designed to eliminate mental disorders and promote mental well-being through early identification.

97. Only 2 to 3 per cent of adolescent patients receive what amounts to expensive and long term psychotherapy, see Nichol, "Incidence," p. 529.

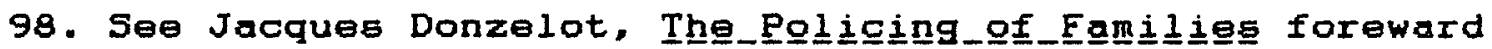
by Gilles Deleuze, trans. Robert Hurley (New York: Pantheon, 1979, original Paris: Les Editions de Minuit, 1977); Allan $V$.

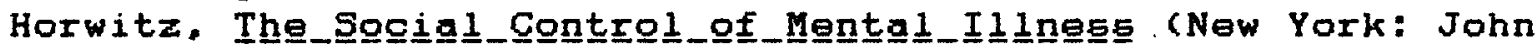
Wiley \& Sons, 1976); also see the classic on who gets treated, where and why by August B. Hollingshead and Frederick C. Redlich,

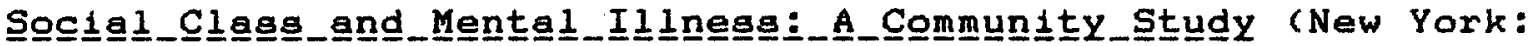
John Wiley \& Sons, 1958, reprint 1965).

99. See. DSM-III, p. 19. 


\section{CHAPTER TEN}

PRIVATE KNOWLEDGE BROKERS AND PUBLIC POLICY

CANADIAN AND U.S. STYLE

By mid-century mental hygiene advocates felt they had successfully established scientific standards for preventive mental health practices focused on children. "Ideas which were once strange," in the words of the Chairman of the Mid-Century White House Conference on Children and Youth, "achieved the high success of becoming...commonplace. Ideas like these: That all children have a right to childhood; that every child should have a home, and that no child should be separated from his parents save in grave and exceptional circumstances; that what is good for any child is good for all children." 1 The birth right of all children was asserted to be "a falr chance for a healthy personality." 2

The paradigm of preventive mental health contributed to the structure of twentieth century social institutions which have come to shape the experience of growing up. Mental hygiene legitimated public scrutiny into what were formerly private concerns. This happened to different degrees and for different reasons in the United States than in Canada. Mental hygiene

1. Oscar E. Ewing, "The Mid-century White House Conference on Opportunity and A Reaponsibility for Americans," in Edward A.

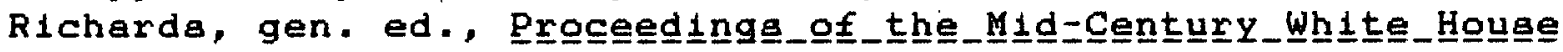
Conference_on_Chil Idxen_eng

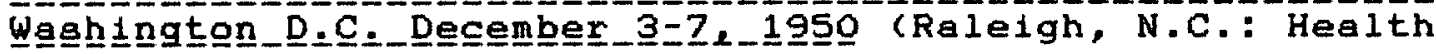
Publications, 1951). p. 43 .

2. Ewing, "The Mid-century White House Conference," p. 42. 
supported the political ldeology of the United States as grounded in the doctrinea of individualiam and equality of opportunity. Mental Hygiene in Canada substantiated traditional role of benevolent elites in the maintenance of social welfare, good government, and public order.

The mental hygiene movement illustrates the interconnection between knowledge, sources of knowledge, and the distribution of power in modern democratic states. Knowledge is an important source of power. It is especially important in modern rationalized socletiea dominated by bureaucratic forms of social organization. 3 One definition of bureaucratic administration, which Rockefeller Foundation officials would agree with, is the "exercise of control on the basis of knowledge." 4 Contemporary socleties increasingly depend on specialized knowledge derlved from prolonged training in educational settings. Acceas to special knowledge and training to a very great extent provides access to social and economic status as well. To this extent, knowledge provides access to class, status, and power. The upper strata of governmental and business decision-makers have advantageous access to advanced knowledge and they have the authority to use and to direct this information into practices. Similarly, the offlcers of large philanthropies, acientista and

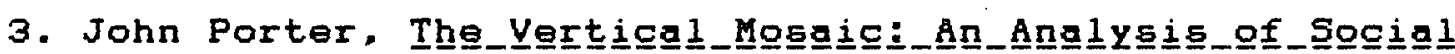

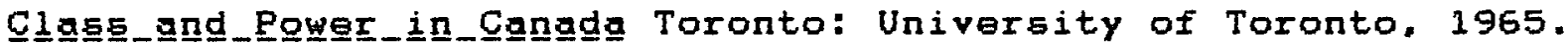

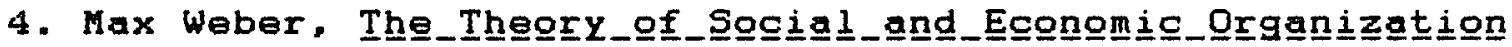
Tranalated by A.M. Henderson and T. Pargona (Edinburgh, 1947), $p$. 311. 
researchera produce and direct data which influences policy decisions.

Warren Weaver, who was Director of the Division of Natural Soience of the Rockefeller Foundation from 1932 to 1952 , notes the importance of the faith in knowledge to solve social problems. He identified this faith as underlying "practically all the activities of the great general purpose foundations." Weaver warned that "a critic who is not prepared to recognize, credit and share this faith is bound to misunderstand and underestimate many of the activities of philanthropic foundations." 5 The underlying issue concerning the relationship between philanthropy and the power to legitimize knowledge is not a question of science. The question behind the scientific orientation of philanthropy is the question of power and the politics of knowledge in decision-making. These are questions of distributive justice and the mechanisms of democratic control and legitimacy in modern induatrial capitaliatic states which value democratic political processes. 6

The Politice of Mental Hygiene

Medicine has been called the stepchild of philanthropy because of the support it has received from these sources. If we

5. Warren Weaver, "Concluding Remarks to Part II: The

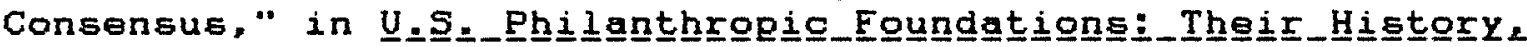
Strugtuㅗㄹㅗ_Manggement_and_Regord (New York: Harper \& Row, 1967), p. 441 .

6. See Charles E. Lindblom and David K. Cohen, Usablale

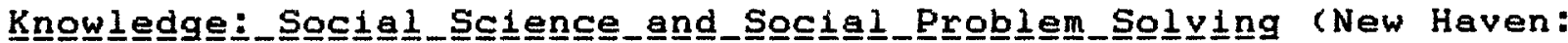
Yale, 1979), who raise some of these questions in en articulate and thought provoking form. 
interpret the stepchild metaphor to mean that the story of medicine has been a Cinderella story from rags to riches, then psychiatry is Cinderella's Cinderella before the glass slipper. 7 Rockefeller Foundation President Charles Barnard's frustration with psychiatry in the late 1940 encapsulated the problems the Foundation had with its broad and fundamental belief in the usefulness of peychiatry, and, its inability to transform this field into a dynamic scientific format. 8 where were the breakthroughs that bolstered the spirit of public health work at the turn of the century?

Psychiatry as a part of the Foundation's work dated from 1913, but it only became a major emphasis in 1933. Something over four million dollars had been spent before the formalized policy emphasis in the Medical Division in 1932. 9 The 1932 policy under Alan Gregg, which had gone into effect in 1933, had been in place a full decade by the mid-1940s. Approximately three-fourths of the Foundations appropriations for medical science had gone into projects in peychiatry or related fields over the ten year period. In 1943, the Rockefeller Foundation began to evaluate ite work in paychiatry. Gregg reflected, "1t was always pioneer work and pathfinding. We didn't add to what was already a substantial

7. The original statement was from William Welch. The Cinderella notation comes from an editorial "Cinderella's

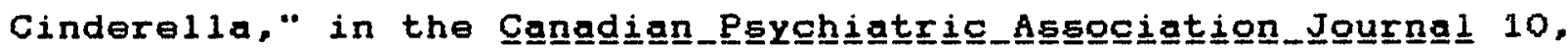
5 (October 1965): 323 .

8. Chester I. Barnard to Alan Gregg, 5 August 1948, RG3 906 , 2, 18, RFA, RAC, N. Terrytown, N.Y.

9. Fosdick, Thee_Stoory p. 129. 
nucleus; our gift created the nucleus complete or provided an indispensible fraction of it." 10

The original considerations for initiating work in psychiatry had been stated as: 1) the enormous economic loss attributable to nervous and mental diseases; 2) the "backward" state of the field; and 3 ) the need for improvement of general medical education which had neglected psychiatric considerations. 11 A survey conducted in seventy medical schools in the United States and Canada in 1933 seemed to bear out Thomas Salmon's admonition in 1920 that professionalization was the key to success. The outcome of the survey determined that there was a severe leadership shortage. Individuals, such as Adolf Meyer at Johns Hopkins, who had led the original revolution in medicine and psychiatry were nearing retirement. A new vanguard was

10. "Tentative Divisional Reports on the Postwar Program of The Rockefeller Foundation." June 1944, p. 16. Mimeograph, cited

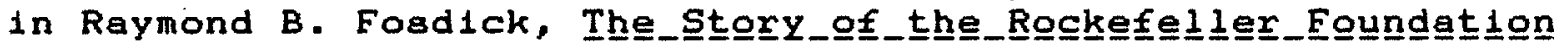
(New York: Harper \& Row, 1952), pp. 127, fn. 4.

11. Discussion on the programme in psychlatry began in 1928 , "Report of the Special Committee on the Division of Medical Education of the Rockefeller Foundation presented to the Board of Trustees meeting. 9 November 1929;" "A Brief Summary of the Conferences of Trustees and Officers," Princeton, November 1930; citations on the value of psychiatric research come from David $L$. Edsal1, "Memorandum Regarding Possible Psychiatric Developments," 10/3/30. (Edsall was Dean of Harvard Medical School and a RF

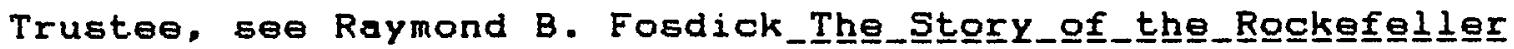
Foundetㅡㄴㅇㅡ (New York: Harpers, 1952), pp. 128-130; "Agenda for Special Meeting, Westchester Country Club," 11 April 1933; Flora M. Rhind to C.I. Barnard, 21 June 1948, RG3 906, 2, 18, RFA, RAC, N. Tarrytown, N.Y. 
needed. 12

GAP was an example in the 1940 s of an attempt to provide psychiatry with an advocacy group similar to the purpose served in the first half of this century by voluntary associations such as the National Committees for Mental Hygiene. The distribution of funds and intellectual guidance had often come from Foundation staff. Foundations have been identified with a gatekeeping function in their distribution of grants and fellowships. 13 It could also be said that foundations function in charity work as their creators once operated in the business world. The mejor general purpose foundations such as the Rockefeller Foundation were originally created by funds derived from wealth assoeiated with power over distribution. In a sense this was the original meaning of scientific philanthropy. The new charity work was to distribute knowledge about social practices as the businessman in a distributorship of manufactured goods mediates between the

12. Training fellowships and the development of departments of psychiatry, neurology and related fields took precedent in this ten years of effort to develop psychiatry. The Universities of Chicago and Yale were "given" departmente of psychiatry: HoGill's Institute for neurology and neuro-surgery was supported. Teaching was rounded out and extended by grants to the Institute of Psychoanalysis at Chicago, as well as to Tulane, Duke, McGill, Washington University. Harvard, Johns Hopkins, University of Colorado, University of Michigan and the Institute of Pennsylvania Hospital. A variety of studies were supported at institutes and universities in the United States, Canada and Europe which included research on brain chemistry, epilepsy, optics, neuro-anatomy, cytology, biochemistry, child psychology, physiology and neura-histology. "The Emphasis on Psychiatry," excerpt from Trustees'Confidential Report, October 1943, pp. 126. RG 3,906, 2, 18, RFA, RAC, N. Tarrytown, N.Y.

13. Coser, "Foundations," p. 337. 
manufacturer and commercial outlet. Distributors disperse goods, create markets and control supplies between wholesale and retail outlets. Similarly, foundations have served to regulate the flow of knowledge. In addition to the distribution of goods or knowledge are the production of the pathways upon which the products flow. In business this includes the roadways, rail and shipping networks. In knowledge systems this communication function includes support for conferences, fellowships, publications and correspondence. The creation of policy making boards and professional arganizations are like branch offices in the business of ideas. The overview of funding agencies can enlarge developmente in one sector and make links between selected sectors. Since world war II, this function of philanthropy has become more complex and more conservative precisely because of the increasingly amorphous interface between government and philanthropy.

The role of American foundations in this century can be characterized by a consistent intervention into public affairs. In the first two decades of the century the emergent general purpose philanthropies developed projects directly concerned with public health, education and welfare. The Rockefeller Foundation's work in the southern states through the General Education Board and Sanitary Commission are a case in point. 14

14. Sheila Slaughter and Edward T. Silva, "Looking Backward: How Foundations Formulated Ideology in the Progressive

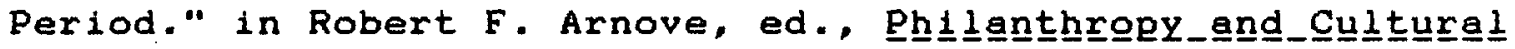

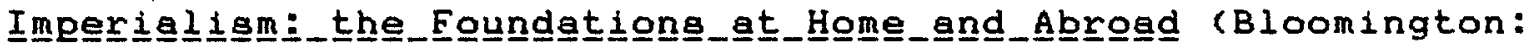
Indiana Univ. Press, 1980, reprint 1982), pp. 55-86. 
In the $1920 \mathrm{e}$ and $1930 \mathrm{a}$ the philenthropies concentrated on the production of knowledge through research. Foundation personnel saw themselves as disinterested and objective facilitators of science as an impartial means of problem-solving. During this same period government expanded its own participation in social welfare.

In the 1940s. government, to a significant degree, adopted the role of philanthropies in knowledge production by way of the creation of federal funding agencies such as the National science Foundation and National Institutes of Health. While foundations had organized activities on an international soale since their inception, after 1945 a network of intercommunication developed between philanthropy and government in domestic and foreign relations. 15 The tendency to interface private and public funds was also a tendency to inter-link foundation support for projects. 16 Spokesmen for "modernist" philanthropy in the postWar era have argued that the active role of foundations in guiding and shaping public policy is beneficial. Seientific philanthropy, in this modernist view, is argued to offer a valuefree, non-political perspective which productively contributes to

15. See, E. Richard Brown, "Rockefeller Medicine in China: Professionalism and Imperialism." pp. 123-46; Edward H. Berman, "Educational Colonialism in Africa: The Role of American Foundations, 1910-1945," pp. 179-202; and, Berman. "The Foundations" Role in American Foreign Policy: The Case of Africa.

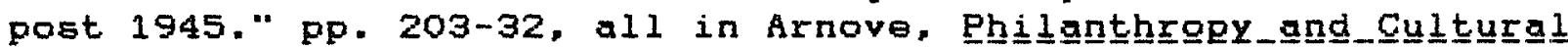

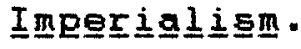

16. Mary Anna Culleton Colwe11. "The Foundation Connection: Links Among Foundations and Recipient Organizations," in Arnove,

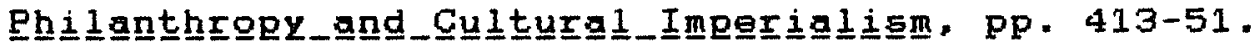


domestic policy and international relations. This argument rests on the assumption that a "value-free" science can be translated into a "value-free" social policy. Historically, this goal has proven to be not only over ambitious as a objective but has also proven to be illusory in practice. 17 The underlying assumptions the parameters of scientific "problems" may be biased precisely by the dependency on funds from organizations in business, government or philanthropy.

\section{Transitions}

The ideological importance of the argument that science is value-free, which in turn justifies the role of philanthropy in public policy, is illustrated by the struggle of the Rockefeller Foundation over its policy in promoting psychiatry. The Rockefeller Foundation in the 1940 s struggled to find ways to make psychiatry soientifically verifiable and productive as an applied medical speciality. The psychological and social sciences of human behaviour, however, consistently eluded the grasp of hard science. For all of the research dollars, institutes and conferences there was little reason to believe that an empirical body of knowledge had been developed after more than twenty years of work. The historical record seemed to mock any other contention. The economio and social deterioration of the

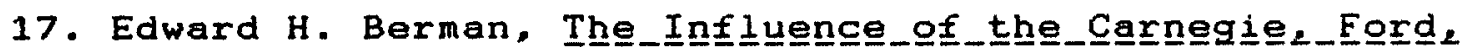

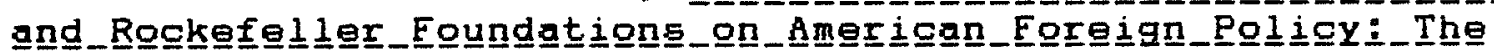
Ideoliogy_of_phílianthroopy (Albany: State Univ. of New York Press, 1983); Waldemar A. Nielsen makes a similar point, The_Big Foundations (New York: Columbia, 1972), in his study of philanthropy in the 1970 s wich was supported by the Twentieth Century Fund, p. 394. 
depression years culminated in the political upheaval of war ag a case in point. The Committee on Medical Education of the Group for the Advancement of Psychiatry put it bluntly. "The problem of medical education is not simply to train more doctors, but to train doctors who can help men and women to understand and live with themselves at a time when man's lack of understanding of himself and his misuse of his own powers has become a threat to civilization." 18

The value and ultimate truth of scientific discovery seemed redeemed in other fields of scientific research. For example, the the International Health Division had scored a major victory in 1937 with the discovery of a vaccine for yellow fever, in 1939 it brought a malaria epidemic under control in Brazil, and in 1940 it scored major battles against a potentially devastating outbreak of international typhus. The forties was not only a decade of war and social reconetruction but a major transition period for philanthropy which seemed justified in areas outside of psychiatry. In 1948 the World Health Organization was established in the United Nations. This organization served a very similar purpose to the International Health Division. The International Health Division was merged with the Rockefeller Foundation in 1951. It had successfully demonstrated effective procedure and organization justifying its advisory role in public

18. "Report of the Committee on Medical Education," undated but after the President's Commission on Higher Education (July 1946), probably January 1947, re: penciled notation on the side, CF 74, RAC, N. Tarrytown, N.Y. 
policy which, Foundation offlcials felt, was rightfully taken over by government. However, the formula did not seem to work for the programme in psychiatry.

Seven years of major funding for psychiatric research and medical education in psychiatry from 1933 to 1940 had not reaped a similar victory for a happier healthier population. Instead it seemed like humanity was embroiled in a flight from reason in a world gone mad. No scientific breakthrough seemed at hand. The evaluation of the programme did not question the underlying premise of the application of scientific principles to the field of human behaviour. To the contrary, the Rockefeller truste日s reaffirmed their commitment to the ideals and purposes of the programme on paychiatry. The leck of strong scientific gains, however, indicated a need for a reorganization. Part of this reorganization included a cut in funding for less research oriented endeavors such as the National Committe日 for Mental Hyglene. The Foundation had not yet ceased to hope that the social sciences would attain the status of the natural sciences. that somehow its knowledge would be cumulative, and, that the theories would become laws.

The Rockefeller Foundation has often been characterized as hesitant or conservative in the social sciences and an innovative scientific force in the natural and medical sciences. 19 More

19. Even Raymond Fosdick, The_Stogry characterizes the social

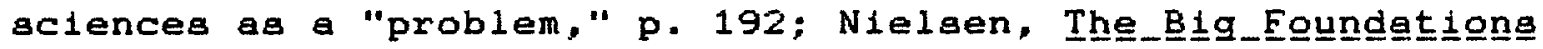
finds the "innovativeness," and "creativeness" of the foundations waning in the post world war II period, pp. 399-430; J. Craig Jenkins and Craig M. Eckert, "Channeling Black Insurgency: Elite 
accurately the Foundation has been "progreasive" and conservative in both areas. As a leader in general purpose foundations it has sought to bring about and encourage social change for the improvement of human life. This is a noble goal which looks to progress and social transformation. Foundation efforts have sought changes, however, in means without seriously altering the ende or existing social and economic structure. In this sense, Foundations are by their very nature profoundly conservative institutions. It has been argued elsewhere that progressive thought incorporated both traditional or establishment values and populist rhetoric. Various efforts to bring together these values lie a the very heart of American democracy. Such efforts also epitomize the differences between the United states and canada. A major turning point in the incipient development of canada was the disaffection of the colonial Loyalists who left the U.S. for Canada after the Revolutionary War. The republicans who stayed have continued the debate between ideals and social practices. The goal of shaping a national community through rationality and science, typifies the Rockefeller Foundation's objectives and format for action. The idea that society should be socially engineered, and that politice involved expert management over idealistio considerations of virtue or wisdom was also an idea

Patronage and Professional Social Movement Organizations in the

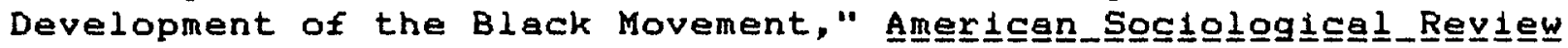
51, 6(Dec. 1986): 812-829, examine the question whether or not philanthropies have intervened in a consciously reactionary way in radical politics. 
commensurate with Foundation views. 20 The Rockefeller Boards have consistently sustained this particular perspective which justifies their own power in relationship to the public good. Expertise, efficiency and scientific objectivity are considered the legitimate basis for the Foundation's authority as policy and decision-makers. To this extent. Foundation spokesmen believed in the decision-making authority of elites defined as those who had joined the ranks of the competent, a supposedly neutral aristocracy of professionals and technocratic experts. In this perspective, these men epitomized the best the society could offer, and therefore were the ultimate representatives of the public good.

If social science had followed the path of medical soience and appropriately filled out the knowledge base for these experts, the argument would be complete, its validity selfevident. The problem with social science, and especially psychiatry, was that it remained annoyingly primitive and unscientific. The Foundation hoped for a discovery in this reluctant science which would "contribute to the settlement of strikes to the formation of a world order." 21 The conservatism of the Foundation was essentially in its transformation of the

20. See Robert N. Bellah, Richard Madsen, William M.

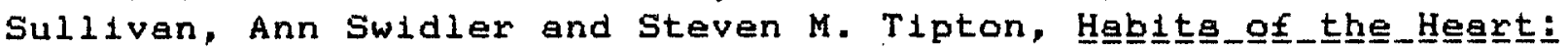

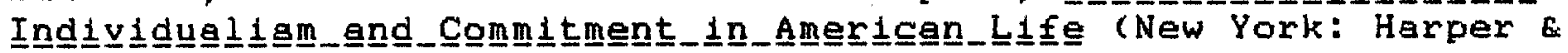
Row, 1985), pp. 261 for their discusaion on American veralons of the public good and especially on progressivism as a combination of establishment and populist ideologies of the 1880-1929 period.

21. Fosdick, The_Story, pp. 133-134, was President of the RF from 1936 to 1947 . 
childhood gaze into scientism. They assumed that all social problems could be cast in scientific and technological terms and that as competent social engineers they could make social accommodations which bypassed the political process. The medical model validated their essentially political stance. As an ideology the childhood gaze taken to this extreme eliminated political questions.

Foundation staff were generally not concerned with democratic principles in relationship to power. Even so, the Rockefeller Foundation has been strong in the area of civil and constitutional rights in terms of non-discrimination according to race, religion or national origin. These issues emphasized equality of opportunity, a standard compatible with the individualistio therapeutio ideology of mental hygiene. The individualistic ideology served to mask elase conflict and political exploitation. 22 The Foundation dealt with issues of inequality largely as problematic environmental conditions. These issues were considered capable of scientific solution as problems of meens not ends.

Foundation officials assumed that scientific prinoiples were beyond politics and economics much less popular debate. The responsibility of philanthropy to government was interpreted as educational. Philanthropy was to provide tested scientific

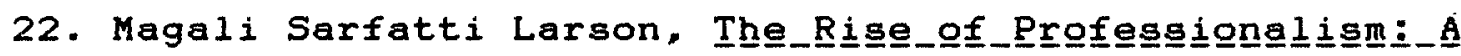

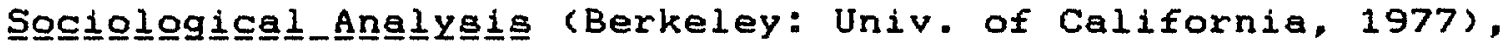
makes the point that the function of ideologiea is to make class and exploitation "invisible." 
programmes as protocols for policy. In the 1940 s this prescription for the transference of Foundation precedents to governmental function was being carried out. Foundation programmes were becoming public policies. This was hailed as a new corporate public order based on scientific progress.

\section{Expansion of the Private Sector as Public}

The NCMH played a strong role in the transition from policy advocacy as a private concern supported by philanthropy to a public function of government. The 1940 s was a decade of transition. In the U.S., the National Committee for Mental Hygiene was instrumental in the formalization of public mental health policy. In the mid-1940s, the National Committee lobbied Congress and drafted federal laws designed to expand the Mental Hygiene Division of the Public Health Service. The National Mental Health Act, passed in 1945, ultimately accomplished this goal. In 1949 the National Institutes of Health were established. The Mental Hygiene Division of the Public Health Service was reorganized under Robert Felix as the National Institute of Nental Health (NIMH). The National Institute of Mental Health took over the supervisory and funding functions which the Rockefeller Foundation and Commonwealth Fund had occupied in connection with the National Committee for Mental Hygiene. NIMH became the major funding agency for research, fellowships, the major construction of academic facilities, and the development of programmes directed toward mental health. In the United States the Mental Health Act made substantial federal 
financial resourcea avallable for mental health research. From 1947 funds were provided for the development of clinical peychology. In the early 1950 s funding for peychology was expanded to include all of the behavioural sciences. 23

The Rockefeller Foundation advocated governmental support for mental health research and development. The creation of NIMH signaled the accomplishment of the Rockefeller Foundation objective in the acceptance of Federal responsibility for what had been the Foundation's projects. The U.S. government was now the provider of research grants for mental health, and manpower training through programme development and educational fellowahipa.

The Commonwealth Fund also experienced direct organizational changes during this period. Edward S. Harkeness died in 1940. Harkeness had led the philanthropy initiated by his mother since 1918. Harkeness's increased interest in medical education and public health in the 1930 s was acknowledged by his successor Malcolm P. Aldrich. The orientation of the Fund changed. Rather than cooperative programmes and support for other agencies such as the NCMH the Fund turned to work directly with medical educators. An interest in psychiatry and community health was retained only until the retirement of Barry C. Smith in 1947. when Aldrich took over the General Directorship. The Public Health Division was eliminated and the Mental Hygiene Division dropped shortly thereafter. The advance of the public sector into 
what had been the preserve of philanthropy was a stated factor in the decision to drop some aspects of public health and mental hygiene work which was subsummed by government. For example, the Commonwealth Fund public health programme emphasized upgrading rural medicine and community services in the years between 1933 and 1946. The H111-Burton Act (Hospital Survey and Construction Act) of 1946 provided large federal grants precisely for this purpose. Similarly, the National Mental Health Act covered the Fund's traditional area in mental hygiene advocacy. 24

After World War II, not only government but the number and diversity of philanthropic funds directed toward professional medicine and medical research increased. The Rockefeller Foundation and its associate funds spent approximately $\$ 152$ million on scientific medicine between the first world war and the late 1960s. The Commonwealth Fund spent $\$ 110$ million on public health, of which $\$ 8$ million went directly to mental health. While the RF and Commonwealth Fund continued to support medicine, other philanthropies joined in. The Ford Foundation, which assumed national stature in 1950, was the largest. Ford spent nearly $\$ 350 \mathrm{milli}$ on medical schools and hospitals in its first fifteen years. In one year, 1956, Ford contributed s100

24. Jeanne L. Brand, "The National Mental Health Act of

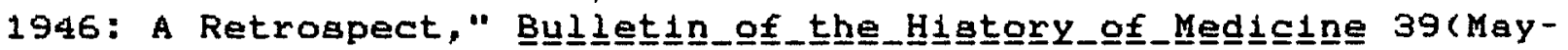
June): 231-244; Commiasion on Hospital Care, Hogeitêl_Care_in_the Uni "What's Inside the Black Box: A Case Study of Allocative Politics

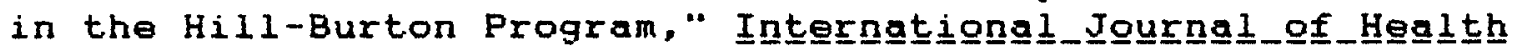
Services 9(1979): 313-339; see also Starr's discussion,

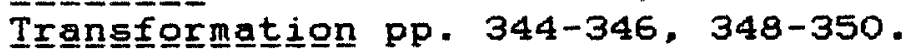


milition to private medical schools. 25 other funds auch as the New York Foundation, Josiah Macy Jr. foundation, Joseph P. Kennedy Jr. Foundation. W.K. Kellogg and Max F. Fleishmann Foundation also contributed millions of dollars to medicine in the first few decades after world war II. The 270 major foundations, which controled 87 per cent of the total philanthropic funds, spent up to 96 per cent of their approprlated resources on aclentific research. 26

The expansion of government in the world war II era resulted in a symbiotic relationship between the public interest as represented by government and philanthropic interests. Private money and philanthropically devised policy formats were taken under the auspices of public bureaucracies. Yet, the philanthropies have continued to support and to devise protocols for future developments in the expanding public and mental health industry. The outcome in terms of access to services, the relative position of professionals as policy makers, and cost

25. Joseph H, Hinsey, "The Role of Private Foundations: The Development of Modern Medicine." in Warren Weaver, $\underline{\text { L. }}$.

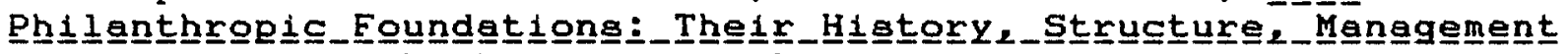
and_-Reco의d (New York: Harper \& Row, 1967), p. 261 .

26. Hinsey, "The Role of Private Foundations: The

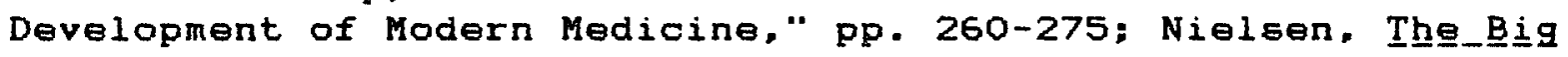
Fqundgtignns, pp. 78-98; Carnegie Corp. funding was for a survey of mental health services in education, Griffin, Mental_Health Book II, p. 236; Isabel Laird and $H$. Whitney, MentaI-Healthh-in

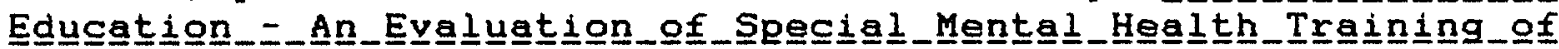
Selelected Teacherers (1954), Griffin-Greenland Archives, Toronto. 
effectiveness to the general public was at best mixed. 27

Governmental expansion into health was modeled on the formats laid down by philanthropy. This has been critical to the shape of developments in public health through the $1950 s$ and 1960s. Federal funds, in the U.S., established inter-linked governmental agencies by encouraging state and local level programmes through the use of incentive grants. These grants were enormously more comprehensive than the demonstration project grants in the inter-war period. The distribution of the governmental grants were not selective. They were made available to all governmental agencies meeting the Federally determined criteria.

In spite of the effort to ingtitutionalize new programmes rapidly the results were marginal. The mixed results of these programmes is illustrated in the effort to establish community based services. In 1955 the Health Amendmente Act (Title $V$ of the Public Services Act) provided short-term grants to encourage demonetrations in the area of community services. These grants, similar to the grants of the National Committee for Mental Hygiene, Commonwealth Fund, and R.F., were designed to stimulate local and state governments to assume the cost burden of these services. The 1955 legislation also provided for the creation of

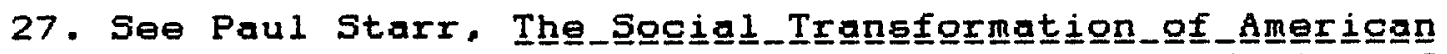

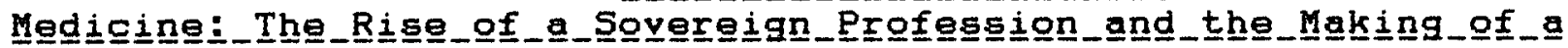
Vagt Indugstry (New York: Basic, 1982): see Nielsen, The_Biq

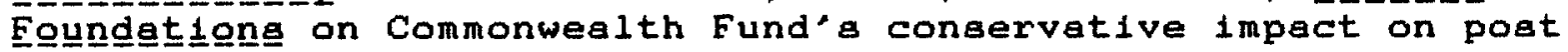
World war II medicine pp. 256-62; see also the classic on this

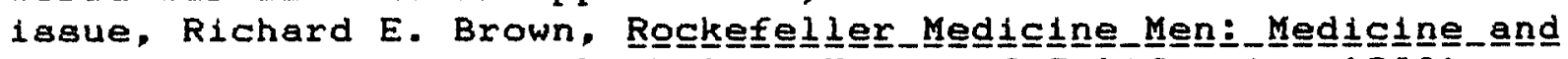

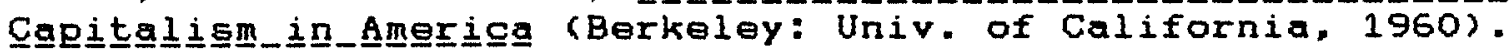


the Joint Commission on Mental Illness and Health. This Commission was designed to undertake the survey and analytical services which the National Committee for Mental Hygiene had provided with philanthropic funding for the past four decades.

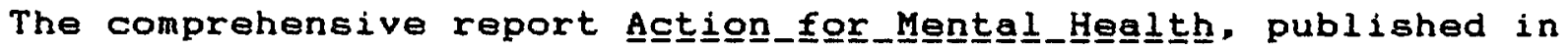
1961, laid the basis for the adoption of the Comprehensive Community Medical Centers Act of 1963. This act was designed to eliminate large scale public institutions for the mentally ill and to encourage local, state and private sources to develop community level services for preventive, clinical, diagnostio, consultative and acute care paychiatric aervices. This legislation contributed to the deinstitutionalization of patients in mental hospitals. It has not been as successful in stimulating adequate community level care, which was its original intention. The community service idea is a long-term formalization of public policy protocols evolved out of the collaborative programmes of philanthropy and the National Committee for Mental Hygiene. 28 The first models for the community services were the clinics and child guldance projects.

Social Values and the Institutionalization of Knowledge Just as mental hygiene was an aspect of the public health

28. George Stevenson who had been head of the Division on Community Clinics of the NCMH took over the General Directorship after Hincks resignation in 1939. Stevenson began to prod official channels to fund programmes in community mental health: "Project Designed to Develop Community Functions of a Mental Hospital," 1939; Stevenson's acceptance of the position as General Director was announced in April: NCMH to News Editor, "The National Committee for Mental Hygiene Announces Staff Changes," 6 April 1939, CF 67, RAC, N. Tarrytown, N.Y. 
movement from its earliest atagea, public policies in mental health care are a fundamental aspect of what is termed the modern welfare state. 29 Welfare services in the United States and Canada differ in comprehensiveness and intent to serve. In general, Canadian policy has evolved toward the attempt to provide comprehensive universal public health and public support services. 30 The United States tends toward residual services of basic needs for those who cannot provide for them on a personal basis, or who fall extremely low on social scales developed for the purposes of comparison. Supplemental services are provided to help individuals out of particular life crises. Both countries developed and expanded social security measures as a result of the depression. 31 Canada had developed prior examples of governmental eupport such as minimum wage legislation, mathers" pensions, and workman's compensation stemming from the first

29. Alexander S. Rogawski, "Mental Health Programs in Welfare Systema," In Gerald Caplan, ed., Agmer Psychinatryy Vol. 2, "Child and Adolescent Psychiatry, Sociocultural and Community Psychiatry" (New York: Basic, 1974), pp. 749-72; Group for the Advancement of Paychiatry, The

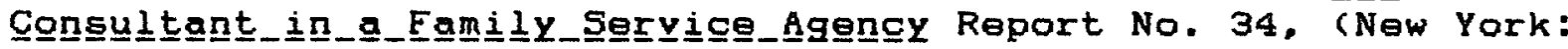
GAP. 1956); The Welfare System and Mental Health Report No. 85,

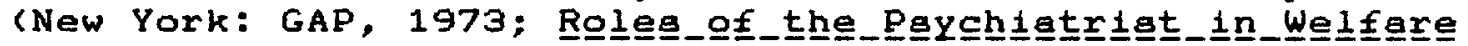
Agengieㄹ Report No. 86 (New York: GAP. 1974).

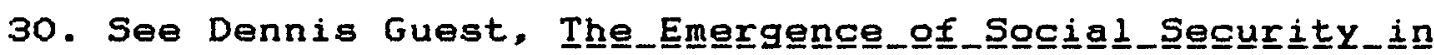
Cenede (Vancouver: Untv. of Britiah Columbia, 1982).

31. Guest, pp. 83-103; The Canadian Welfare Council, The

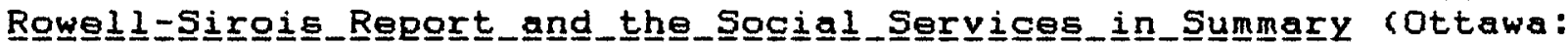
Canadian Welfare Council, 1940). 
World War, and the old Age Pensions Act of 1927. 32 Manitoba (1916), Saskatchewan (1917) and Alberta (1919) were the first provinces to establish mathers' pensions. 33 The Canadian Parliament had expressed interest in family allowances dating from 1929. 34 By the end of world War II, Canada had children's allowances and unemployment insurance in place. National health legislation on a cost sharing basis between the federal and provincial governments came into effect in 1958. By 196.3.98.8 per cent of the population was covered by hospital insurance. In 1961, the Royal Commission on Health Services recommended a comprehensive, universal health service administered by government and financed by provincial and federal funds. The Medical Care Act was passed in 1966. 35

The expansion of public welfare was not smooth in either Canada or the United states. 36 There were similar souroes of opposition to the expansion of the public sector in the provision

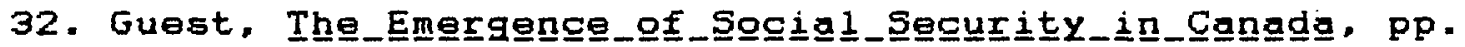

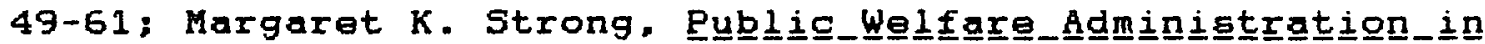
Canada (New York: Patterson Smith, 1969, reprint Univ. of Chicago, 1930).

33. Guest, p. 52, fn 12; on British Columbia see William Rasmussen, "An Evaluation of the Mothers" Allowances Programme in British Columbia," MSW Thesis, University of British Columbia, 1950.

34. Guest, pp. 73-7, 79 .

35. Canada, Report_of_tthe_Royal_Commiggion_on_on_Domin

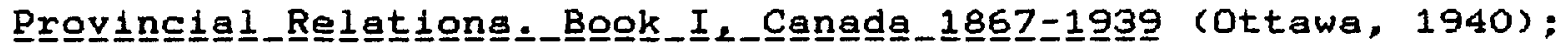

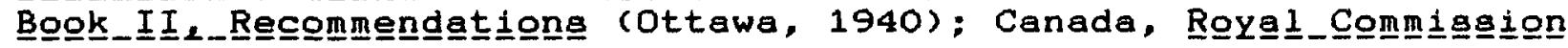

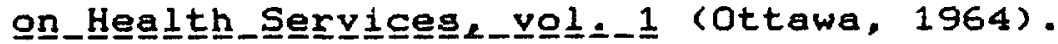

36. Tamara Hareven, "An Ambiguous Alliance: Some Aspects of American Influence on Canadian Social Welfare," Social

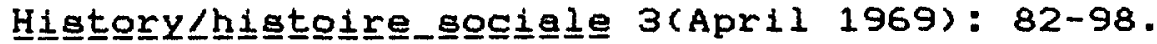


of welfare in both the United States and Canada. For example, family allowances, as a solution to poverty affecting young children, were opposed by Charlotte whitton, the executive director of the Canadian Council on Child and Family Welfare. 37 Whitton feared an undermining of parental responsibility and favoured a rise in real wages rather than governmental support. 38 Private charity organizations in both countries opposed public sources of relief to families on the basis of poverty. The argument was that public authority should be restricted to the provision of institutions for criminal, delinquent, mentally ill and mentally deficient groups leaving noninstitutional relief to voluntary agencies. Underlying this perception was an individualiatic interpretation of poverty. 39 This perspective was supported by the ideological stance of mental hygiene where poverty was interpreted as an indication of personal pathology and inadequacy. The provision of relief from this standpoint needed to be provided on the basis of a therapeutic medicalized relationahip.

Mental hygieniste, in both Canada and the United after world War I, argued for the legitimacy of publicly supported welfare

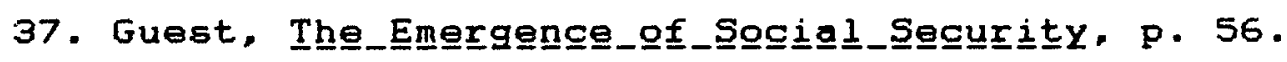

38. Charlotte Whitton (editorial), "Family Allowance,"

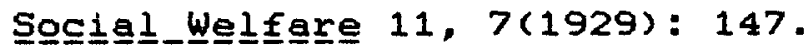

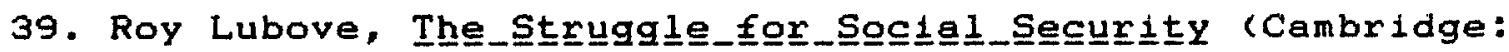
Harvard Univ. Press, 1968), p. 103. 
which included therapeutic relationships. 40 This was part of the push for the professionalization of mental hygiene related disciplines in the social sciences. Professional social work, public health nursing and psychology were in the process of taking over the traditional roles of voluntary charity. 41 In the United states, the successful control of professional medicine in the American Medical Association and the concurrent interests of the rising business of insurance created powerful lobbies which restricted the rapid advance of the public domain into their economic jurisdictions in health and welfare. 42 In the United States, the provision of welfare advanced with professional oivil service. An individualistic perspective on poverty was institutionalized. In Canada, the coverage was more comprehensive and a paternalistio perspective prevailed as civic authority expanded into public welfare. Volunteeristic organizations remained important in civic services as professionalization

40. Peter Bryce, "Mothers" Allowances." Sogial_Welélare 1 , $6(1919): 131-2$.

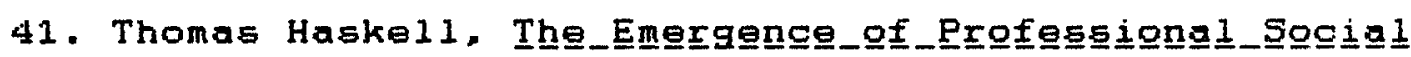
Sgience (Chicago: Univ, of Chicago. 1977); Roy Lubove, The

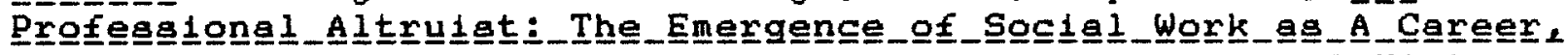
$1990=1930$ (New York: Atheneum, 1969); James L. Lieby, A_Higtgry

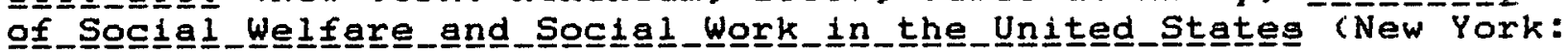
Columbia, 1978).

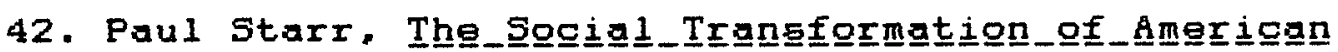

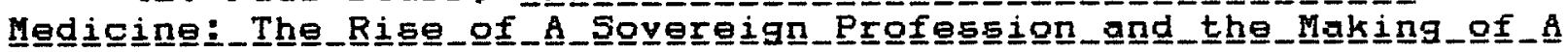
Vast_Industary (New York: Basic, 1982), pp. 232-290; Viviana A.

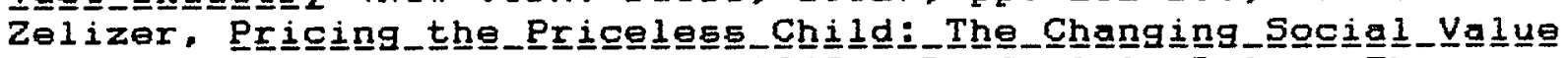
of _Chinidgren (New York: Basic, 1985); R. Carlyle Buley, The

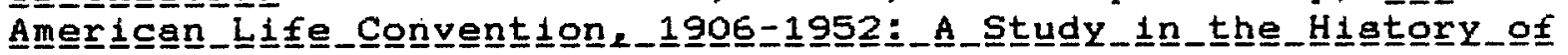
Lífe_Ingur 
occurred more slowly than in the United States. 43

Canada's concept of unfettered access to medical care as a social minimum in health care remains unparalleled in the United States. 44 Nevertheless, federal support programmes in the United States are funded on a categorical basis with grants designated for apecific utilization within limited programme boundarieg.

Federal programmes have broadened in the United States and proved costly, in spite of attempts to limit government responsibility. Federal spending for human services, largely by indirect means as opposed to direct grants, expanded from less than 55 billion to 590 billion in the twenty-five years between 1945 to 1970.45

The Politics of Individualism, Mental Hygiene

\section{and National Character}

The idea of solving social problems by preventing them from developing in childhood seems at once self-evident and incredibly self-righteoug. Perhaps it is understandable that the effort to put this ideology into practice made children a problem. In the United States it made the state's role in providing for children in a democracy, a source of major ideological discrepancies in

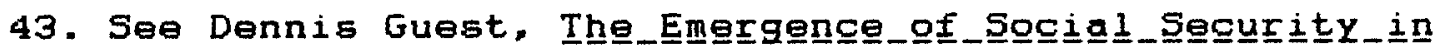
Gangada Vancouver: University of British Columbia. 1980. reprint 1982 .

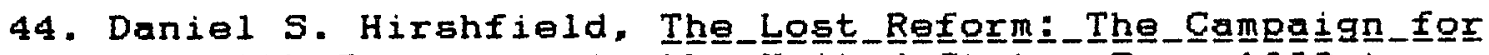

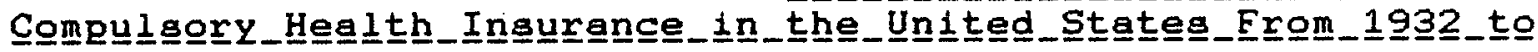
1943 (Cambridge: Harvard Univ. Press, 1970).

45. Bertram S. Brown and James D. Isbister, "U.S. Government Organization for Human Services - Implications for Mental Health

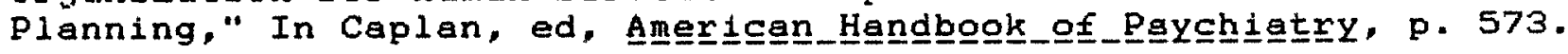


the practice of the American dream. 46 De Tocquevilie, who criticized the oddities of democracy one hundred yeara ago, found the source of discrepancies in democratic ideals and practice in unfettered individualiam. 47 The twentieth century found a solution in a concept of individualism which moderates ideals of democratic equality by the acknowledgement of human differences and the "natural" inequalities between men. 48 This resolution to the ideological dilemma gained scientific legitimacy from the medicalized perspective of mental hygiene.

Individualism, with its rationale in mental hygiene, has not meant so much to Canadians. Canada lacks the strong "charter myth" present in the U.S. Constitution and Bill of Rights which supported universalistic values and the existential right to individual freedom. Individualism had no preconstructed ideological niche for Canadians. One argument for the function of ideological concepts and ideological systems of thought is that they constitute a public rationale for the legitimacy of the

46. For a sensitive description and analysis of public responsibility and children in a democracy see W. Norton Grubb

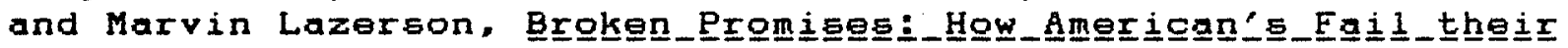
Chiㅣ묘트 (New York: Basic, 1982).

47. Alexis de Tocqueville, Demogrengy_in_Amerigg Richard D. Heffner, ed.. (New York: New American Library, 1956), pp. 189-92.

48. De Tocqueville was no champion of individualism: "Individualism, at first, only saps the virtues of public life; but, in the long run, it attacks and destroys all others, and is at length absorbed in downright selfishness." p. 193. While de Tocqueville saw individualism as originating in democracies and fostered by equality of condition. the modern new use of the concept was to mediate between equality of condition and equality of opportunity. 
state. Both the United States and Canada in popular media formally identify themselves with egalitaxian values over authoritarian values. Neither saciety supports a formal aristocracy or aristocratic institutions. 49 To this extent both socleties need to conceal or minimize the existence of inequalities and the basic structure of power and distribution which supports systematic uneven gains. 50 This is significantly more important for the United States than it is for Canada. The United States has formulated a vigorous self-image, derived in part from its revolutionary heritage, as a free people united in a democratic and egalitarian society. Individualism is part of this image.

Canada, on the contrary, has an anti-revolutionary heritage. W.L. Morton has noted that the character of Canadian institutions have been shaped by an historical and peychological allegiance to monarchy. Allegiance means that the state has an objective reality embodied in the succession of persons designated by parliament with hereditary rights. 51 Freedom and democratic participation in this view are guaranteed not diminished by the presence of a political order based on public rank and personal

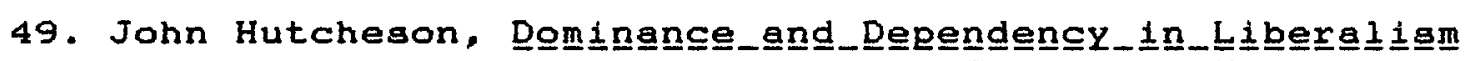

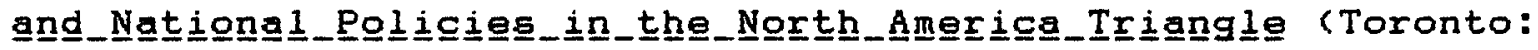
Mcclelland and Stewart, 1978), pp. 99-124.

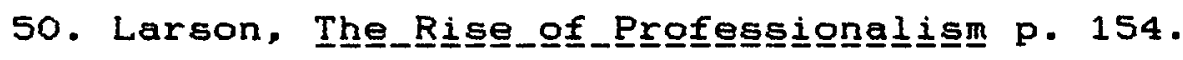

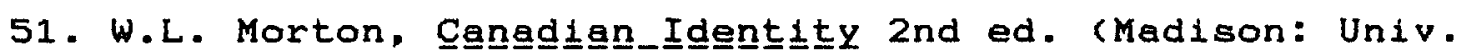
of Wisconsin: 1961,1972$),$ p. 99; also see Jacques Monet, "Maintaining A Constitution Worthy of Such a Country: Reflections

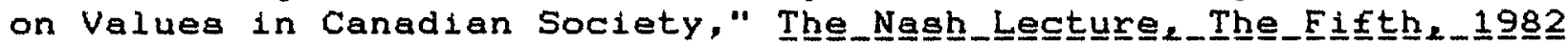
(Regina: Champion College, University of Regina, 1982) 
honour. Elites are seen as acting within a framework of larger interests which sustain a diversity of customs and rights under law in a way that the rational scheme of abstract principles in a republican democracy can not. 52 Republican ingtitutions based in popular sovereignty require the formation of a consensus on the part of citizens. The state exists subjectively in that it must be given assent by popular vote in periodic reviews. This places a premium on conformity and homogeneity not called for or considered desirable in Canada. The allegiance to social order and a moral respect between political factions take precedent as values over individualized notions of freedom as a political issue. While the United States with its republican institutions validates by law the right to life, liberty and the pursuit of happiness, traditionally Canadians have looked to peace, order and good government to do the same. Until recently the basis for Canadian rights was not in any one act but in an historical continuum. 53 Individual freedom, in this view is not a prior condition, but, proceeds from moral consensus and social order. Class structure is viewed traditionally as a source of order and therefore a source of freedom and democracy.

Canadians have tended to refrain from asserting any

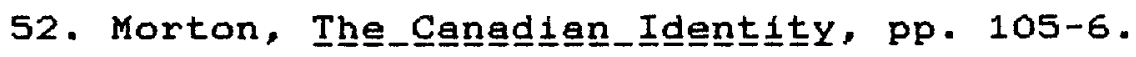

53. Monet, "Maintaining," p. 11; see Canada, Department of

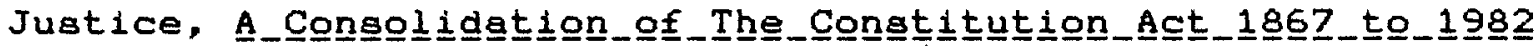
(Ottawa: Minister of Supply and Services, 1983), see "Canadian Charter of Rights and Freedoms," pp. 61-76. 
national "idee fixe" about their society. 54 Comparative studiea have identified, nonetheless national characteristics which strongly differentiate the United States and Canada. The characteristics focusing on values and belief systems are necessarily relative in that they reflect comparative differences rather than absolutes. This is not to say that there are not wide ranges of opinion and diversity of beliefs and values in any one society. World views which contribute to the perceived "rightness" of the social order must, nonetheless, be consistent enough to maintain a value system. As John Porter has pointed out, any working hypothesis on Canadian national character must begin with the recognition that "Canadians are a conservative people." 55

The shape of Canadian conservatism has much to do with Canadian as opposed to U.S. support for mental hygiene. For example, the Canadian public is more consistently conservative in their appreciation for the maintenance of the status quo, less committed to republican institutions and more tolerant of elite paternalistic leadership than U.S. citizens. This is not to say that the U.S. does not have its collegial relationship between groups who share elite statue and power or lack appreciation for

54. John porter, "Canadian Character in the Twentieth

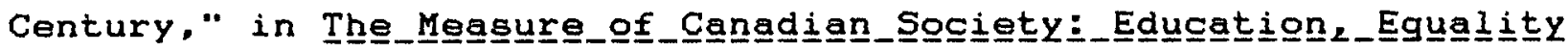
and__Qgggrtuninty (Ottawa: Gage, 1979), p. 92 .

55. Porter, "Canadian Character," p. 90. 
wealth and class status. 56 The American value system, however, demands that such configurations be systematically masked and justified. This has been done on the grounds of individualism. Canadians have been characterized as more law-abiding, less suspicious of governmental authority and more collectivist in orientation than Americans. Canadians are also more "particularistic." or tolerant and protective of cultural and group variations whether regional, or based in ethnic, religious, language or social practices. 57 In the United States the emphasis on individual achievement and competition serves to mediate what are otherwise viewed as suspiciously unequal variations in power relationshipe and class structure in American society. 58

Canadians have tended to view social differences in terms of ethnicity, language and religion. Policy questions have centred

56. C. Wright Mi11s, The_Power_Elitye New York: Free Press, 1956; G. William Domhoff, Who_Rulies_America? (Englewood Cliffs, NJ.: Prentice-Hal1, 1967; Mary Anna Culleton Colwel1, "The Foundation Connection: Links among Foundations and Recipient Organizations," in Robert R. Arnove, ed." Phililententhrropy_eng

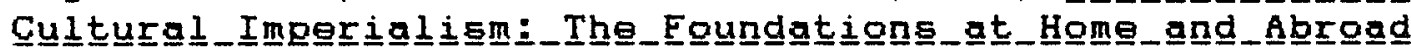
(Bloomington: Univ. of Indiana, 1980, 1982), pp. 413-52.

57. Seymour Martin Lipset, "Revolution and Counter Revolution: The United States and Canada," in Thomas R. Ford,

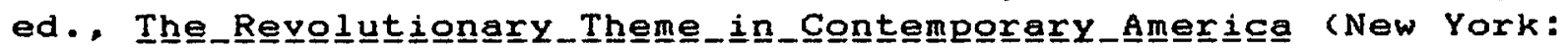
Basic, 1970), pp. 21-64; "Historical Traditions and National Characteristics: A Comparative Analysis of Canada and the United

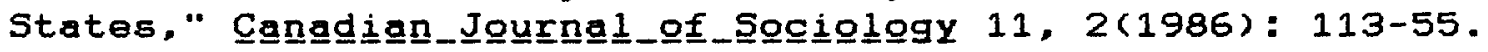

58. Porter, "Canadian Character," p. 99; Lipset, "Revolution," and "Historical;" also se日: S. D. CLark, The Develogeping_Cangedian_Communityy (Toronto: University of Toronto,

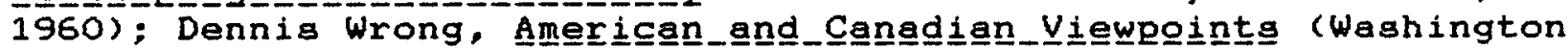
D.C.: American Council on Education, 1955). 
more recently on balancing the power and atatus of Canada's traditional dual French and English cultures and the relative position of immigrants with alternative traditions. Mental hygiene in Canada in its earliest, phases tended also to concentrate on group differences and to rationalize such veriationa a contributing to social and economic problema. Yet this particularistic view of mental hygiene with its eugenical overtones was disruptive in Canadian culture which ia fragile at thia level. 59 Eugenics gradually became less important as a rationale as mental hygiene turned to more positivistic aspects of public health. This transition also had the support of American philanthropy. Public health had less ideological implications and was compatible with a collectivist orientation directed toward the public good. It also had the basic support of both French and English factions even if state supported public health had to mediate with traditional charitable and church authority in this area especially in Quebec. The mixing of public and private spheres in paternalistic intervention by either charitable organizations or the state was not as problematical in Canada as in the United States.

The secularization of charity and the interrelationship between scientific philenthropy and government and the intermixing of public and private spheres has been described in the U.S. as synonymous with the problem of the separation of the

59. Kathleen McConnachie, "The Mental Hyglene and Eugenica Movements in the Inter-War Years," paper presented at the History of Education Society, Vancouver, B.C. October 1983. 
church and atate. 60 In Canada the integration between public and private spheres is more readily conceived as beneficial to the common good. Using the church and state example, the Canadian issue is not to delineate separate spheres but to promote general allegiance to the state while accounting for pluralistic interests. In the United States pluralism is interpreted as best represented by independence of action. In this view the consolidation of public and private interests that are not subject to popular review represent monopolizing practices which constitute a policy dilema. To the extent that mental hygiene is accepted as a scientific and, therefore, neutral decision-making criterion, it alleviates the policy dilemma in the United States. Mental hygiene is useful in Canada to the extent that it justified demands for conformity against those who did not exhibit the minimal allegiance to Canadian institutions required for peaceful social continuity. Yet, the mental hygiene input to national identity has never been as conceptually useful to a Canadian perspective as it has in the United states. A unified "national identity" has been elusive in Canada for a number of reasons, including its dual French-English heritage combined with anti-revolutionary and ecclesiastical traditions. So too, the demographic flow of immigration and emigration has contributed to Canadian multiculturalism and particularism. 61 Because of the

60. Nielsen, The_Big_Foundetiong, p. 397 .

61. John Porter, "Canadian Character," makes the point that Canada gained almost as many immigrants ( $7.1 \mathrm{million}$ ) as it lost to emigration ( $6.1 \mathrm{million}$ ) between 1851 and 1951 . Considering 
cultural impact of the larger and more powerful United States, a resistance to U.S. values has also been a source of Canadian identity 62

The divialveness of Canada's dual heritage was also a factor in Canadian continuity. 63 Historically English and French Canada, for all their cultural friction and incompatibilities, agree in their disagreement with the republican values of the United States. 64 The necessity of mediating the French-English dualism contributed to a pluralism or multiculturalism in Canada which makes an American style "melting pot" ideology impractical

that the total population of canada was $2.5 \mathrm{million}$ in 1881 , at any one time a large percentage of the population was strongly tied to its origins or in transition. This accounts in part for the importance of ethnic differences and the greater acceptance and retention of ethnic cultural variations in Canada as compared with the U.S. which was able to inundate immigrant groups into a majority culture. It also gives some insight into the lack of a Canadian identity as an idee $f i x \theta$.

62. S.F. Wise and Robert Craig Brown, Eangda_views_the

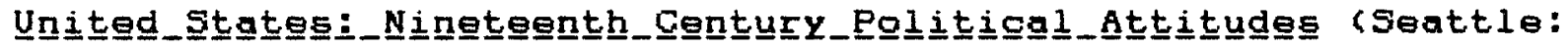
Univ. of Washington, 1967).

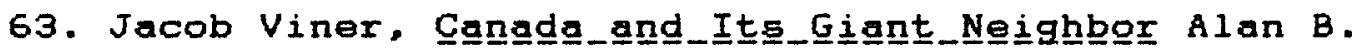
Plaunt Memorial Lectures, Carieton Univeraity, Ottawa, 30 January and 1 February, 1958 (Ottawa: Carleton Univ., 1958); Morton,

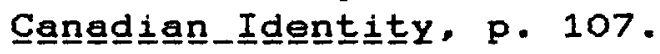

64. Hugh Maclennan, "A Society in Revolt," In Judith

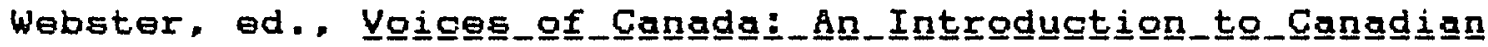
Gulltureg (Burlington Va.: Association for Canadian studies in the United States, 1977): Steven J. Arnold and Douglas J. Tigert,

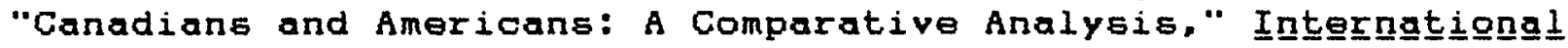

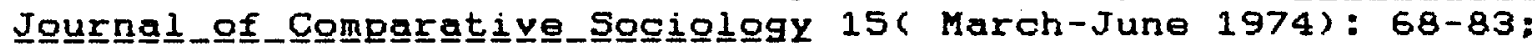

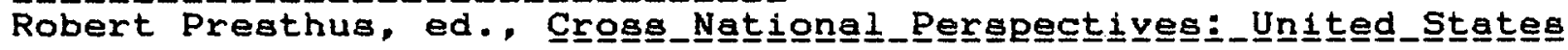
end_Cengede (Leiden: E.J. Brili, 1977 ); S.D. Clarke, in H.F.

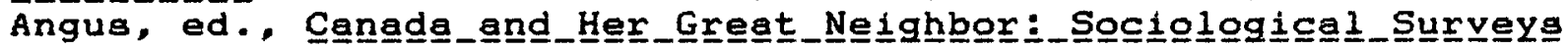

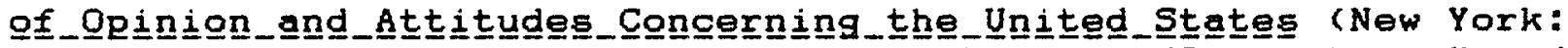
Ryerson, 1938); Porter," "The Measure;" Lipset, "Revolution," and "Historical Traditions." 
or impossible. Social change or moblitty has been much more readily conceived in ascriptive terms which do not impinge upon particularistic values. The Canadian view point, at least up to the post world war II era, found little advantage in individualistic interpretations of social realities. Canadian mental hygiene tended to focus on group variations. On the other hand, Americans with their more insistent grounding in democratic and egalitarian ideala found individualism an increasingly important explanation for discrepancies in social and economic power. The medicalized version of individualism argued that differences between social and economic status were products of scientifically accountable classless oriteria. In the United States the distinctions drawn by mental hygiene reinstated by way of individualism a universalistic orientation toward equality, the right to be unequal. The idea of inequality as innate, and, the necessity to deal with this fact, formulated the basis for an apolitical view of state policy. A stratified class structure was justified as providing for able leadership. Supposedly, the most qualified advanced to the top, and, conversely, the least able settle into positions compatible with their lesser abilities and talents. 65 Individual fulfillment, personality, and ability were central concepts in this version of the mental hygiene prescription for

65. See the classic, Kingsley Davis and W.E. Moore, "Some

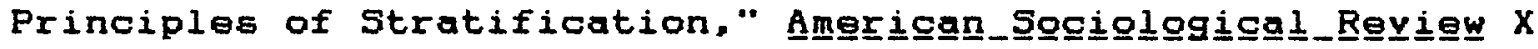
(1945). For a critique see Dennis $H$. Wrong, "The Functional Theory of Stratification: Some Neglected Considerations,"

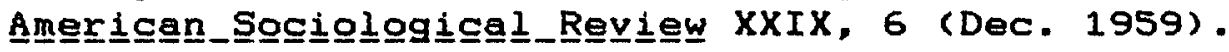


progress.

Canadian development did not foster an apolitical view of the state but a consensual politics of accommodation. The obsession was with national unity and identity in a society which has remained, in a sense, infinitely divisible. Traditional leadership with a benevolent orientation was not seen as a danger to democratic government but a key to ita functioning.

The American melting pot ideology favored universaliatic yalues and also depended on personalistic criteria to explain mobility. Personalistic values emphasized achievement, and legitimated success and failure on individualistic criteria. Mental hygiene with its individualistic emphasis, contributed to a process which masked the ascriptive advantages or disadvantages of ethnicity, class, race, gender or other group characteristics. This is in contrast to the more eugenical orientation of Canadian mental hygiene.

Mental hygiene, as a set of ldeas popularized and articulated by voluntary associations and private interests, was increasingly articulated and made available in this century to policy decision- makers in both the United States and Canada. One outcome was the medicalization of normality and legitimation of clinical abnormality. Mental hygiene has been more important in the United States in legitimating scrutiny into the personal world of the potentially aberrant.

In both countries, humanitarian motives aside, mental health programmes are sanctioned in the community because they are 
fundamentally agencies of control which foater social order. 66 The role of preventive mental health was ultimately to produce citizens who were not disruptive to the continuity of societal functioning.

The mental hygiene movement originated in voluntary organizations. It was perpetrated by communities of elites in two countries. In both instances the elites were interested in moderating social change and in conserving either traditional values, or social configurations, or both. In the United States mental hygiene eased the tensions between democratic ideals and practices by validating inequality. The individualistic therapeutic model inherent in mental hygiene's medicalized perspective was relatively incompatible with Canada's particularistic orientation. Canadian democratic values depended less on rationalizing political, social, and economic inequalities. Instead, public health aspects of the mental hygiene movement became widespread. In Canada, medicalization was a functional rationale for progress, but not the key to equal opportunity as it was in the United States. The mental hygiene movement took different paths in the U.S. and Canada as it reflected values which were products of divergent histories. 67

66. Harry R. Brickman, "Organization of a Community Mental

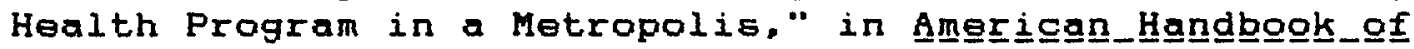
Psychiㅡ틑y p. 663 .

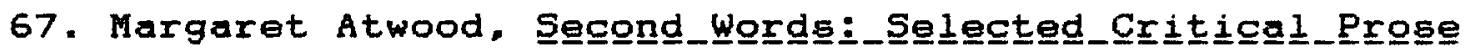
Boston: Beacon, 1984, p. $3 \overline{9} 2$. 


\section{THE LEGACY}

\section{THE CHILDHOOD GAZE IN THE TWENTIETH CENTURY}

\section{Canada and the United States have in this century}

illustrated the potential for industrial market economies to provide for increasingly high standards of living including health as well as material comfort. 1 The mental hygiene movement as an extension of public health care was instrumental in setting standards for mental health and 1 liness especially in regard to children and adolescents. Mental hygienists helped establish medical categories of childhood and youth as psychological and social realities, through child guldance, scientific child study and parent education. Mental hygienists constructed standards of normal human growth both cognitively and blologically. A model for social intervention was established in dealing with individual children or teenagers who deviated from these standards.

The prototypes of normal and abnormal infancy, childhood and adolescence were formulated by the beginning of the second world war. In the $1940 \mathrm{~s}$ the formal introduction of mental hygiene into public policies through public agencies greatly expanded. More importantly, the mental health paradigm was institutionalized ag a commonplace perception of the true nature of childhood.

1. "Canada Social Data Sheet I, Population, Demographic Characteristics, Health and Nutrition, Education, Employment and Income, and Consumption," p. 114; "United States Social Data Sheet I," p. 131, "Social Data Sheet II," "Comparative Social

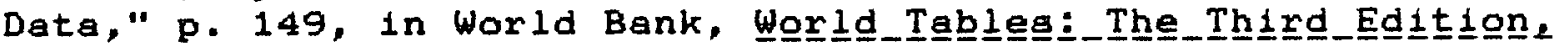

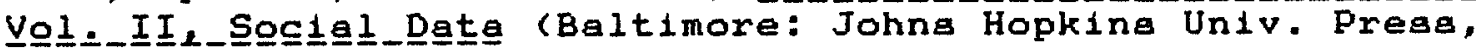
1983). 
Curriculum delineating developmental phases and the basic physical and psychological needs of each stage of growth were integrated into training programmes in the fields of health, education and welfare. 2 Concepts on the biological and social development of children on the part of Canadians and Americans did not differ greatiy. 3 This was in spite of variations in the degree to which poychiatry or poychoanalytic views were integrated into the cultural context of each country.

In the United States and Canada, refinements of their respective political and cultural ldeologies were part of an evolving process related to prior and ongoing social changes, including economic expansion and nation-building which were continuous from the nineteenth century. Industrialization, urbanization and technological changes greatly altered family and child life as it transformed social institutions. 4 These changes

2. See for example the textbook by Ernest $W$. Tiegs and

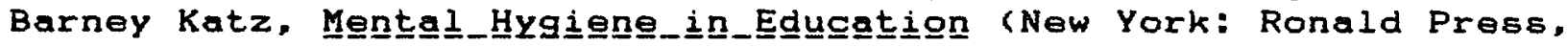
1941): George S. Tomkins, The_Common_Countengance:_Stagbillíty_and

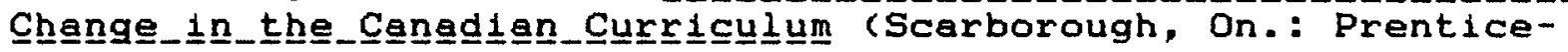
Hall, 1986), see "Medicalizing the Curriculum," ch. 9, pp. 17788 .

3. S.R. Laycock, as Educational Director of the CNCMH, produced numerous articles and radio series on the emotional and developmental needs of children. He also wrote for teachers, counselors, public health nurses and parents. See his books,

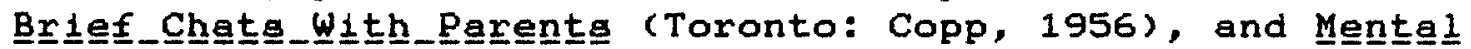
Hyg 1ene_in_the_School (Toronto: Copp, 1960).

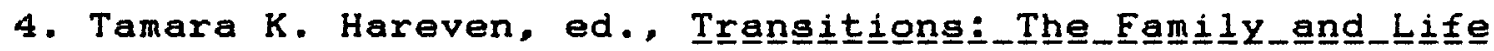

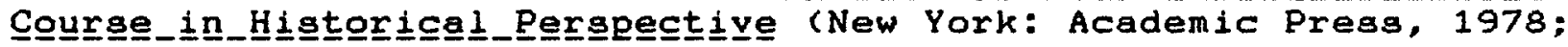
Tamara K. Hareven, "Modernization and Family History: Perspectives on Social Change," Signg 2(Autumn 1976): 109-206;

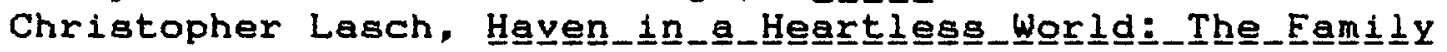
Besileged (New York: w.W. Norton, 1977). 
encouraged the development of professional disciplines and social configurations which were designed to regulate and oversee what had previously been private concerns in health care, education and child rearing. 5 At the end of the nineteenth and beginning of the twentieth century, medical science was a major underlying paradigm for social as well as public health reform. Medicine served as a successful model for the growth of graduate training in universities. 6 The growth of governmental and private institutional bureaucracies coincided with the training of technical experts and professionals whose mandate was to oversee public interests. 7 Mental hygiene formally helped shape these changes in the twentieth century as an applied version of the medical model.

The medical model as a scientific approach to human problem solving was derived from an earlier" and even more fundamental ideological transformation identified here with the childhood gaze, a product of the late eighteenth century. Modern social and

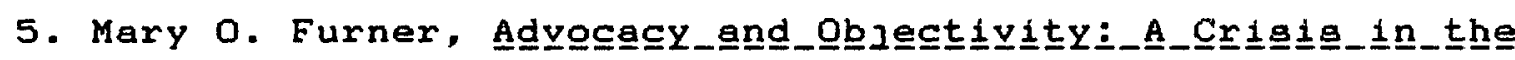

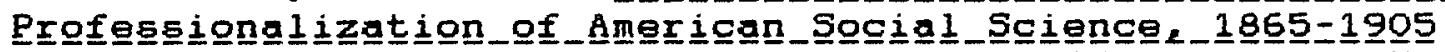
(Lexington, Kentucky: Univ. of Kentucky, 1979); Thomas Haakel1,

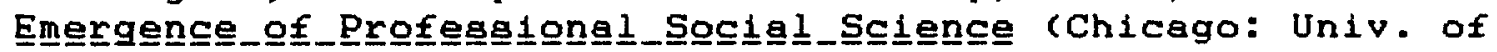
Chicago, 1977).

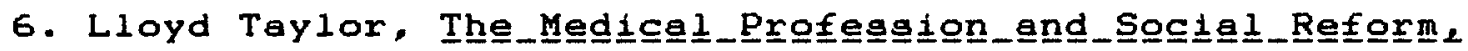

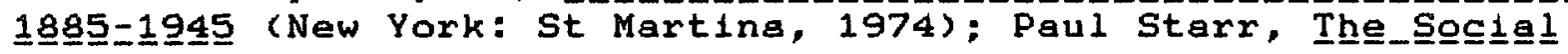

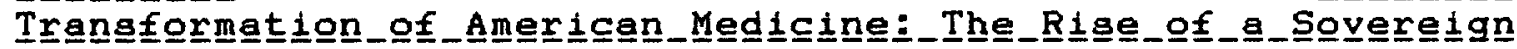

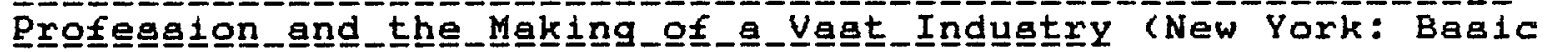
$1982)$.

7. Magal1 Sarfatti Larson, The_Rige_of_Profeggiongloligm:_A

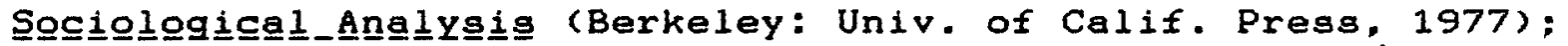

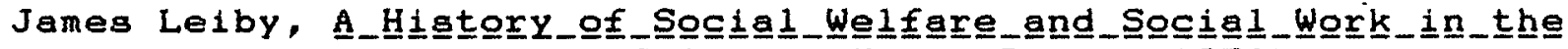
Unitted_Stetetes (New York: Columbia Univ. Press, 1978). 
behavioural sciences originated in this reorientation of knowledge which subsequently framed modern medicine and paychiatry, and, ultimately gave birth to the mental hygiene movement. The childhood gaze contributed to a reconceptualization of the relationship between the child and the family, and, the family and the larger social order.

The mental hygiene movement was complex. Like other Progressive Era social reform movements mental hygiene exhibited multiple and sometimes contradictory tendencies. On one hand, it was a scientific movement concerned with discovering absolute principles and systematically applying them as solutions to problems in social contexts. The intent was to create a more efficient and ordered society. On the other hand, mental hygiene was a humanitarian movement concerned with human rights and the alleviation of suffering. The object here was to raise the general level of well-being by eliminating immoral practices which caused corruption, disease and social disorganization. In interpreting these opposing trends it is instructive to examine the dualism inherent in the heritage of the childhoad gaze. The eighteenth century experienced what can be seen as two revalts. First, there was a revolt of the intellect against absolutist repression in political and religious thought and action. Second, there was a revolt of the masses for the rights of the common man. These two revolutions are usually integrated conceptually under the term the Enlightenment. However, they differed significantly in their fundamental orientation toward 
formalism and absolutiom. The first revolution, having an aristocratic orientation, favored formalism as the grounds for social order. Adherents did not object to all-powerful rulers. The second revolution considered superficial order unnatural and therefore harmful. Adherents preferred to diffuse power in a democratic orientation. 8 These distinctions are useful in understanding the long range impact of ideas which contributed to the formal mental hygiene paradigm elaborated by the National Committees and the philanthropies.

The first revolt of the Enlightenment rejected metaphysics and created a new rational basis for knowledge. It was a critique of traditional classicism and orthodoxy in intellectual thought as arbitrarily exercised by the Church and the state. The Enlightenment or Illumination was an aristocratic movement on the part of intellectuals who sought a basis for governance in human understanding and reason. The liberation, nonetheless, was a liberation of the senses and the intellect, not of political power for the underclasses. Intellectual spokesmen for these views auch as Voltaire and Locke sought to overthrow the political and intellectual rule of narrow traditionalism and

8. Paul Monroe, a turn of the century educational historian at Teachers College Columbia University, makes this point. Monroe identifies the firat revolt with the Enilghtenment or Illumination whose intellectual mentor was Voltalre (1694-1778) and the second with the Naturaliatic Movement ldentified with

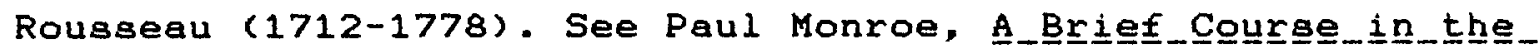

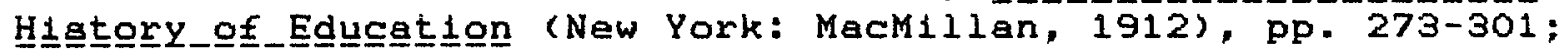
for a more contemporary discussion see, Robert Nisbet. The His stoy_of_the_Ideg_of_Progregess (New York: Basic, 1980), pp. 196$212,246-57$. 
dogmatism, and to secure power in a social order controlled by men of reason who constituted a new but still privileged elite. Social and political privileges were to be awarded to an aristocracy of intelligence and wealth as replacements for the old order aristocracy of family, position, and Church. The overthrow of the old order of classical and religious formalism was replaced by a new order of scientific and rational formalism. In this view: syatematic observation of procedure was a guide in thought, materialism was a standard in morality; and, selfinterest was a principle of action. It was a new form of absolutism. It is here that the intellectual and methodological origins of the childhood gaze are found.

The second revolt was directed toward social and political reorganization in the establishment of an ideal society. This Implied an invigorated moralism and sense of social justice. It constituted a democratic belief in natural processes, in the common man, in human experience and natural rights. The most obvious spokesman was Jean Jacques Rousseau. It is no accident that Rousseau pioneered the importance of educating children in revolutionizing social structure. The pursult of human hepplneas and welfare were seen as common natural rights not the privilege of the few. This was a return to the legitimacy of faith and emotion over reason. Primitive emotions, natural instincts and instinctive judgments formed a legitimate basis for action. This naturalistic tendency was the source of the sense of righteousness and reformism which characterizes the childhood 
gaze as a search for truth.

In point of fact these dual tendencies are inseparable in the childhood gaze as well as largely incompatible prescriptions for social action. Yet, these contradictions are present, if integrated differently, into U.S. and Canadian views of democracy. Social policy in areas such as child welfare are especially marked by the internal dynamics of these contradictions. The character of dependency, as self-imposed or a product of external conditions, and the resolution to the problem in government responsibility or volunteerism, remain topics of current policy debates. 9 Similar discrepancies can be seen in the evolution of disease control in public health reformism and the history of asylums and prisons. There are overt contradictions between: 1) institutional mandates directed toward efficient orgenization serving functions such as isolating the sick from the healthy, keeping inmates in custody; and, maintaining surveillance over them; and 2) the ostensibly ultimate objectives of curing the 111 through treatment or rehabilitating the deviant. 10

The most clear cut brokers of knowledge trying to mediate these dynamice, in the analysis presented in this thesis, have been the National Comittees for Mental Hyglene and the general

9. Michael Katz makes a similar point in his conclusion to,

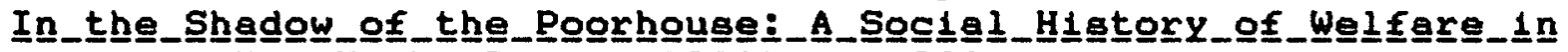
Amereㄴ들 (New York: Bas1C, 1986), p. 290.

10. Dav1d J. Rothman, Conş

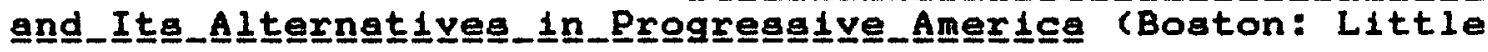
Brown, 1980). 
purpose philanthropies. Policy makers in mental hygiene adopted an intellectual rationale legitimated by the skepticism and rationality of the medical sciences in the Progressive Era which was coupled with a moral rhetoric, self-righteousness and idealism. Efforts to integrate scientiflc and moral order were largely focussed on the young.

The overlapping of moral prescriptions with scientific legitimacy created endemic problems in mental health policy concerned with children. These problems were apparent in the nineteenth century child saving movement. 11 The degree of compulsion warranted in interventionist policies in family and child life, prior to the second world War, increasingly relied upon medical and psychiatric perspectives on the nature of childhood. More recently, we have used science to frame questions on the best way to determine the real interests of the child. 12 The United States offers compulsory "child find" and special services from preschool (two years) to adulthood (twenty-one), an outgrowth of interpretations on natural rights. 13

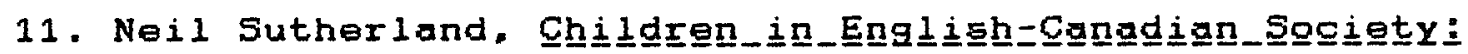

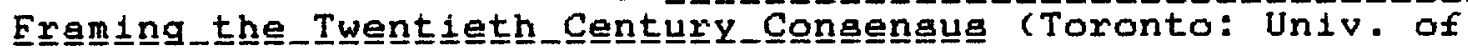

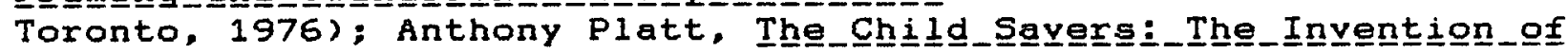
Del 1 inguency (Chicago: Univ. of Chicago, 1969).

12. Joseph Goldstein, Anna Freud, Albert J. Solnit and Sonja

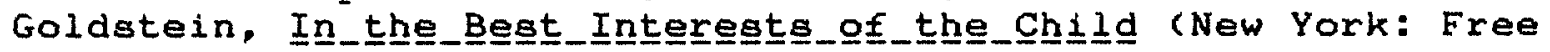

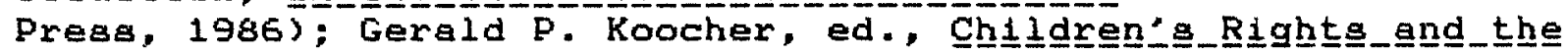

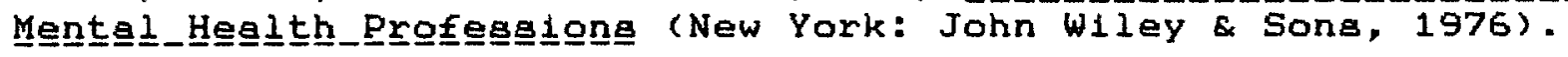

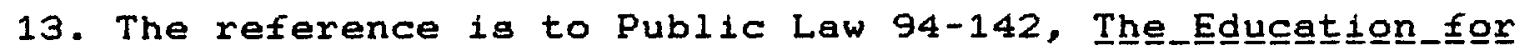
A I 1 I_H

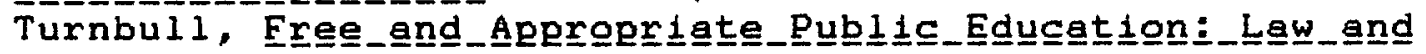
Implementation (Denver: Love Publishing Co., 1979); on the Canadian response see: J.S. Cushman, "The Background of Studenta 
Canada has become embroiled in the problematical area of rationaliy determining legitimate child and family righta. 14 These issues are a legacy of the childhood gaze.

\section{Afterthought}

What is the legacy of mental hygiene? Has it been in the reduction of social problems or, in fact, their production? Research in mental hygiene has articulated life stages in terms of biological and cognitive maturation. It has brought about the recognition that poor environments, Inadequate health care and negative experiences in childhood can cripple a child's life prospects. We have recognized that gevere emotional and mental problems are not just an adult phenomenon but that children are also afflicted with mental and emotional problems. Yet mental health problems in childhood are perhaps more treatable if their problems are dealt with early and effectively.

Both the United States and Canada have tried to develop

in Special Education and New Canadian Programs," The Sttudent_Survey_№_-1 141 (Toronto Board of Education for the City of Toronto, 1976); Anne Keeton, "Special Education: A Right or a Privilege in Ontario?" Intereschange 10, 3(1979/80): 66-77; Anne Keeton, "Special Education by Mandate or by Choice?" Orb́lit 44 , 9(1979): 6-9; Brigitte Kitchen, "Special Education and Inequality." Interg̣hange 10, 3(1979/80): 8 .

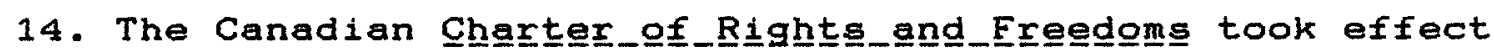
April of 1982; Brian J. McConvilie, "Children's Rights: For or

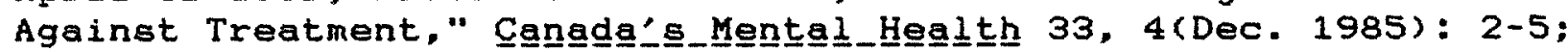
also, Ontario Miniatry of Community and Social Services, The

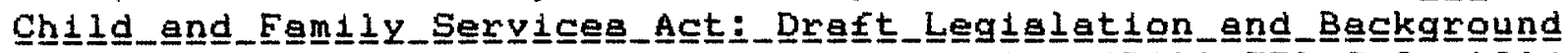

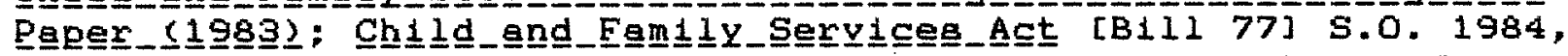
c. 55 makes diatinctions between punishment and treatment for juventles and requires periodic review; see, Douglas W. Phillips, "Ontario's Child and Family Services Act: Implications for Courts, Lawyers and Professionals Working with Children, Canada's Mental_Healthㅡ 33, 4 (Dec. 1985): 5-8. 
policies to address these issues and to nurture and protect children as future citizens and leaders in democratic social institutions. Nonetheless, in spite of increased services for mental health, the problem of mental disorder has increased along with the underlying social problems which mental hygiene sought to eliminate. Just as surely as child guidance did not do away with delinquency, we can argue that paternaliatic public policiea have in fact created the social phenomenon of the delinquent and mentally disordered child.

Social problems, such as delinquency and abnormal behaviour, are social constructs attached to social institutions and derived from socially produced conditions. 15 Mental disordera as a social problem are causally related to the society which produces both the disorder and recognizes the disorder as a problem. The irony of this perception was not lost on Lawrence K. Frank of the Laura Spelman Rockefeller Memorial, who did much both to identify social problems, and, to provide for their solution. He comments that trying to solve social problem la like "trying to cultivate a flower without the fruit." 16 The dilemma for reformers who wanted to solve crime, disease, poverty, delinquency, and war by way of mental hygiene was that they did not want to change any of the structures that had caused the problems. The effort was to make social institutions "work

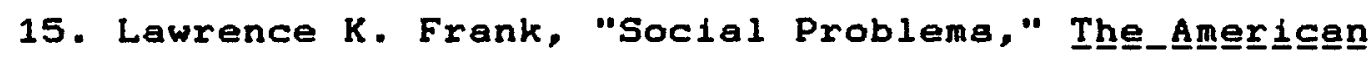

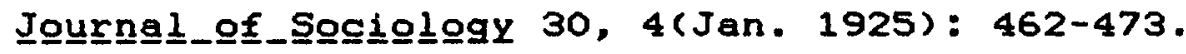

16. Frank, "Social," p. 467. 
better" without altering their basic character. Separating the problem of mental iliness from mental disorders, as a symptom of other problems, was increasingly unclear. Mental hygiene became a catch-all for problem solving through prevention. Even with the emphasis on correcting underlying causes the therapeutic model singled out symptoms grounded in an individualistic psychobiological framework. Mental hygiene became a way of exercising humanitarian values without addressing social structural considerations of an economic or political nature except in the most benign context of environmental issues. Willard Waller in the 1930 s noted that the shift from economics to psychiatry in the fleld of social work solved what was an inherent profeagional conflict between humanitarian and organizational mores." 17 Waller's discusaton on the relationshlp between values and the maintenance of organizational mandates is relevant to an understanding of why mental hygiene as a humanitarian ideology did not solve social problems but in fact contributed to their construction and maintenance:

organizational mores produce conditions which call the humanitarian spirit into activity; at the same time humanitarianism takes care of certain exigencies in such a way as to decrease the probability of sudden, violent changes in the organizational mores. 18

17. Humanitarian mores are the urge to make the world better and to remedy the miefortunes of others. Organizational mores are the basic structures upon which the social order rests such as national identity, religlous and family organization. Problems according to Waller emanate from organizational mores. Willard

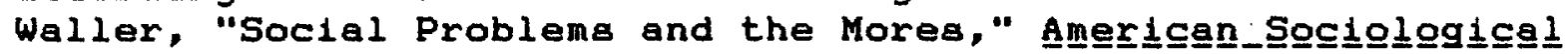
Rev1ew 1, 6(Dec. 1936): 922-33.

$$
\text { 18, Waller, "Soclal," p. } 932 .
$$


The question revolves back to the issue of who has the power to define the context in which a social understanding of what is a problem is agreed upon, that 18, the relationship between power and knowledge. The past century has witnessed an increase in the number of professional knowledge-makers who have acquired the power to construct social definitiona of altuetions. The establishment of social policies based on formal knowledge, whether their scientific validity is real or imagined, has cumulative outcomes in social practices. The mental hygiene movement has effectively contributed to the transformation of the family, school context and family court in the United States and Canada over this century. Regardiese of lta reflection of the "truth" of science, mental hygiene has become integrated into our cultures as common sense material, grounded in established authority structures.

Scientific truth in this sense is to be underatood in a circular relationship to power; the power, in this case, to produce new knowledge and to regulate and diatribute ayatema of ideas such as preventive mental health policy. In mental hygiene the focus has been on the proper public stance vis a vis the nature of childhood, that is, the establishment of professional knowledge defining the proper personal and collective behaviours to be followed by parents, teachers, social workers and counselors in order to conserve normality.

The power to eatablish knowledge as acientific in mental hygiene evolved from private spheres to increasingly public but 
still elite circles. The ability to manipulate the procedures for the circulation and development of knowledge was directed by the National Committees for Mental Hygiene, general purpose foundations, professional organizations and public agencies. Privatized monopolies over knowledge-making were gradually made public.

This study has followed the cumulated actions of individuals and organizations who were a part of the mental hygiene movement. The biographies of these individuals and organizations in their national context were interconnected and interdependent. Over the long term there emerged three major recurrent structures and processes: 1) the professionalization of knowledge; 2) the trend from private to public hegemony over the systems of ordering knowledge, and 3) the emergence of elaborate categories of human differences applied to young children.

The purpose of this study has not been to determine the correct relationship between the ideological content of mental hygiene and scientific truth as elaborated in the practices of mental hygiene in the medicalization of childhood. The goal has be日n to historically search back through events in the effort to "detach truth from its forms of hegemony, social, economic and cultural within which it operates." 19 It is only upon this basis that we can determine the relationship of public policy to the emergent structures of social organization.

19. Michel Foucault, "Truth and Power," in Eower

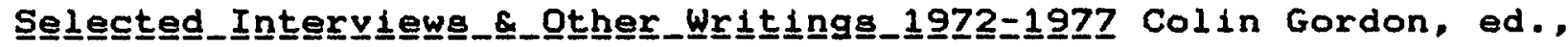
(New York: Pantheon, 1980), pp. 109-133. 
If we can learn from the mental hygienist's search for truth through the scientific examination of the child, it is that the uniqueness of any one situation occurs within the framework of re-occurring patterns. Control over centralized and monopolized resources in mentel hygiene research and training passed from the hands of a few individuals into interdependent groups of elites. The mental hygiene paradigm was structured by these expanding hegemonical units of elite advocacy orgenizations, that 1s, elite voluntary advocacy, general purpose foundations and growing state bureaucraciea. The leaderahip of philanthropies or the National Committees was far from absolute. Power was distributed first among Individuals and then among networks of participating groups. Nonetheless, social practices bolstered by conservative ideological perspectives tended to first construct then to reproduce new organizational structures with similarly placed elites. The free competition of ideas which first sought to establish the authority of medical science progressively reduced the criteria for competition so that only legitimated scientists in interdependent units could participate. Within the interdependent networks, auch as the committees for mental hygiene, the university besed research centres, the funding organizations, and professlonal associations, there were a number of competing struggles. The competitions on a personal and 1deological level such as the I.Q. and nature-nurture controversies, did not transform the underlying structural relationship between the particular form of legitimate knowledge 
In science, nor the structural hegemony of the interdependent organized monopolies over knowledge-making. Mental hyglene contributed to the blurring of private and public spheres in that it reduced popular access to knowledge-making while it favoured selective leadership. Due to the historical character of each society this was more of an ideological problem for social policy in the United States than Canada.

The question which remains unaddressed in this study is the role of individuals and groups methodically excluded from the formal production of knowledge. One must believe that informal theories and practices based on tradition and shared experience concerning child life have substantial impact on families and children. Nonetheless, accredited agencies have acquired over thia century the power to legitimize particular practices and perspectives on the nature and meaning of human development. To what degree do individuala and groups lacking authority to formally validete their own views, successfully address their own best interests in response to structured social change? The pattern of public intransigence and compromise in the face of social transformation is the other side of the story told here. 


\section{ABBREVIATIONS}

AAPC: American Association of Psychiatric Ciinics for Children AFMH: American Foundation for Mental Health Archives, CMC, NYC AMHF: American Mental Health Foundation

AM: Adolf Meyer

APA: American Paychietric Asaociation

APA: American Paychological Association

Beers Papers: Clifford Whittingham Beers Papers, AFMH

CELDIC: Commission on Emotional and Learning Disorders in Canada CF: Commonwealth Fund, Archives in RAC

CJMH: Canadian Journal of Mental Hygiene

CMH: Clarence Meredith Hincks

CMC: Cornell Medical Center, New York City

CMHA: Canadian Mental Health Asgociation

CMHA Papers: Canadian Mental Health Association Papers, PAC

CNCMH: Canadian National Committee for Mental Hygiene

CWB: Clifford Whittingham Beers

DBS: Canada, Dominion Bureau of Statiatica

DSM III: Diagnostic and Statiatical Manual of the American

Psychiatric Association, 3rd edition

GAP: Group for the Advancement of Paychiatry

GEB: General Education Board, Manuscript Collection in RAC

Greenland Griffin Archives: Queen Street Mental Health Center, Toronto

Hincks Papers: Clarence Meredith Hincks Papers, Greenland Griffin Archives

ICD-9: International Classification of Diseases. 9th edition

IHB: International Health Board, Papers in RFA

LSRM: Laura Spelman Rockefeller Memorlal, Manuscript Collection in RAC

NAMH: National Association for Mental Health

NCMH: National Committee for Mental Hygiene

NYC: New York City

NY: New York State

PAC: Public Archives of Canada, Ottawa, Ontario

RAC: Rockefeller Archive Center, Pocantico H111s, North

Tarrytown, New York

RI: Rockefeller Institute, New York City, now Rockefeller

University, Papers in RFA

RFA: Rockefeller Foundetion Archives, Rockefeller Archive Center RF : Rockefeller Foundation

Salmon Papers: Thomas W. Salmon Papers, Payne whitney cilnic Librery, Cornell Medicel Center, New York City, part of the AFMH collection

TWS: Thomas W. Salmon

WHO: World Health Organization

WJ: William James

JHU: Johns Hopkins University, Baltimore, Maryland 


\title{
BIBLIOGRAPHIC NOTES ON SOURCES
}

\author{
Commentary on Method
}

In his inaugural lecture as professor of French history at

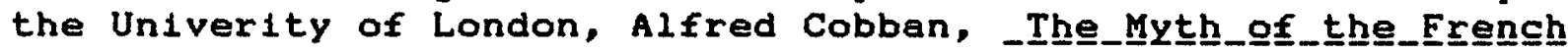

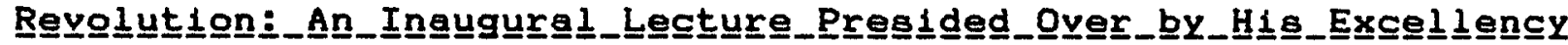
the_French_Ambassador University College, London, 6 May 1954 (London: H.K. Lew1s, 1955, reprint The Arden Library, 1978) addressed the problem of historical change. He pointed out two classic mistakes often made in assessing social transformations. The first by a scholar who looks to grand events and overwhelming social forces and argues for causation without context and the second who seeks biography of ideas in personal events and finds context but no history. Cobban's historiographical dilemma has orlented the focus of the questions asked in this research and has also aided in the organization of data.

Cobban suggests that good social analyais attempts to uncover the "mechanics of the process" of historical change, $p$. 8, which tie together the broader scale of historical time with the sequences of context. Wayne Urban, "Some Historiographical

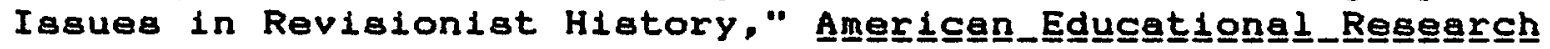
Journal 12(1975): 348-9, suggests studies in the Institutionalization of ideas. Sociologist, Basil Bernstein, "On Pedagogic Discourse," in John Richardson, ed., Handboook_oó_theogy

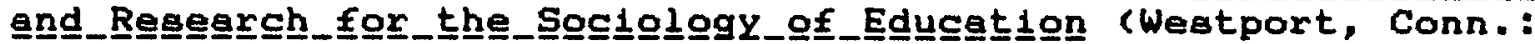
Greenwood Press, 1986, pp. 205-40) has noted that knowledge, especially formal curricular knowledge, can be thought of as having both 1 imits and structures which are reformulated to meet different needs in different contexts. Donald Fisher, "The Role of Philanthropic Foundations in the Reproduction and Production of Hegemony: The Rockefeller Foundation and the Social Sclences," So으의으이 17, 2(1983): 219-25, has illustrated the role of philanthropy in fostering the legitimation of certain sets of ideas and that in this process the boundaries between academic disciplines in the social sciences have been forged and reshaped. Sol Cohen, "The Mental Hygiene Movement, The Development of Personality and the School: The Medicalization of American

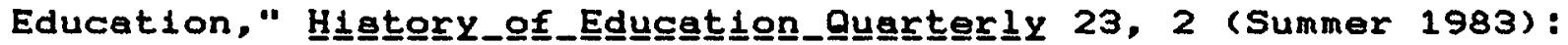
123-49, finds in mental hygiene a pattern in the "seamless web of history."

The attempt in this thesia is to link the mechaniams and strategies which organize specific sets of ideas on the well being of children within the sweep of historical continuity shaping the twentieth century. The broad base of mental hygiene suggests a comprehensive analyats as noted by Jacques Ouen, "Asylum Paychiatry, Neurology, and Mental Hyglene in 


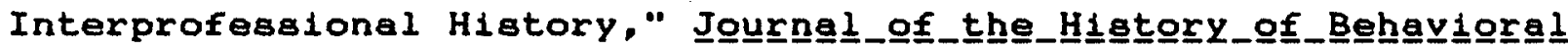
Scilence 13 (1977): 3-11. The linked phenomenon of sociel movements, organizations, men and ideas clarify the legitimation of formal knowledge as a social and historical process. This requires data sources which cross multiple levels where in Berstein's words, knowledge is "recontextualized."

Both primary and secondary sources are fully documented in the text. The footnotes can be used as a guide to references on specific pointe of intereat. While the literature cited in the footnotes are extensive, it is only a fraction of the total material examined in the research phase of this project. The purpose of the bibliography and notes presented here is not to reconstruct the material covered in the footnotes. The effort is rather to draw upon the less known and widely dispersed literature which draws together the major themes of mental hygiene, children and philanthropy. The discussion on primary sources is to call to attention two types of material related to mentel hygiene in archival and manuscript collections, government documents, proceedings of meetings and serial publications on one hand and published mental hyglene literature on the other. The secondary sources are subdivided into the major subject areas of interest. This includes: I. Children and Youth, including Children's Institutions, Family welfare and Parent Training; II. Medicalization in the Medical, Soclal and Behavioral Sciences as related to mentel hyglene; III. American Philanthropy; and IV. General and Theoretical litereture of relevance.

\section{PRIMARY SOURCES}

I. Notes on Archival and Manuscript Collections, Government Documents, Proceedings and Serlal Publications on Mental Hyglene.

A great deal of the available information on the mental hygiene movement 18 in archival and manuscript collections of organizations including the papers of individuala. The papers of Clifford Beers are essential as the individual who significantly contributed to the formalization of the National Committee for Mental Hygiene. A major collection of Beera papers including the organization and early history of the U.S. National Committee are in the American Foundation for Mental Health Archives, Cornell Medical Center, New York City. Correspondence and records of the NCMH are also in this collection. A personel view of Beers using this collection as well as his other papers is provided in Norman

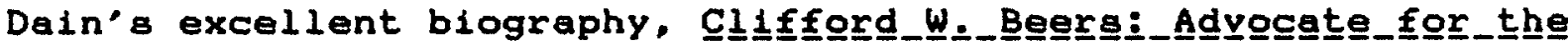
Insenene (Pittsburgh: Univ. of Pittoburgh, 1980). 
The Oskar Diethelm Archives of Paychiatry, Payne Whitney Clinic Library, Cornell Medical Center, New York City, houses the Thomas Salmon papers which are officially a part of the AFMH Archive collection. The transcripts from Paul o. Komora's interviews conducted in collaboration with Earl Bond, Salmon's

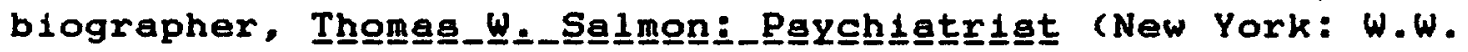
Norton, 1950) are included as well as drafts of Salmon's speeches, proposels for research and official correspondence.

The Griffin Greenland Archives, Queen Street Mental Health Center in Toronto, hold the most extensive collection on the Canadien National Committee for Mental Hygiene. This includea Clarence Hincks' papers and his successor, John D. Griffin's papers, the manuscript of Clarence Hincks biography and Griffin'a history of the CNCMH. It also contains original manuscripts on the movement, the aurveys and the records and date files of the CNCMH. In addition, the collection holds part of the original library of secondary paychiatric literature as well as psychiatric reports and surveys from the United States and Canada which influenced the Committee. There is also a complete set of tape recording of Hincks'speeches. The Public Archives of Canada, Ottawa, contain the Canadian Mental Health Assoclation Collection which constitutes the other half of the Greenland Griffin Collection. The CMHA papers (MG 28 I 391) have the minutes of the CNCMH, financial statements and other papers. The Canadian Paychological Association also has its original papers in the PAC dated from 1939 to 1977 (MG 28 I 161, Finding Aid 843).

The University of Toronto Archives, in the Department of Rare Books and Special Collections, Fisher Library, University of Toronto, have W11l1am Blatz'a papers (B-73-1091); and John David Ketchum's pepera (B-74-072, B-69-004). Rare Books and Special Collections also has the Institute of Child Study, St George'a School papers. The Institute of Child Study and Clarke Institute have separate archives, as well, containing additional records.

The papers and manuscripts of individuals and the National Committees are incomplete without primary documentation of the organized philanthropies which served as observers and contributors to social policies in mental hygiene and psychiatry. Rockefeller related philanthropy was a major contributor both in funds and policy in mental health research. Their phenomenally detalled and complete records provide insight into the strategies of policy formation as well as comprehensive records and first hand descriptions of the progress of projects. This study was able to address in its final form only a small selection of the materials avaliable in these files on the history of psychiatry, mental hygiene and children's policy. James E. Shelley's, A

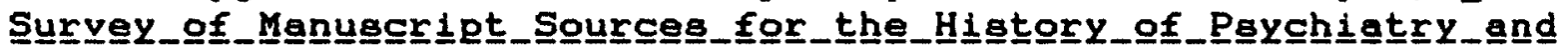

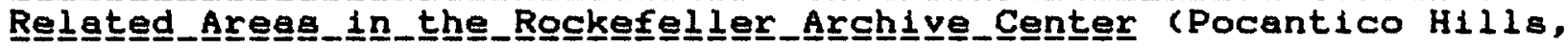


N. Tarrytown, N.Y: Rockefeller Archive Center, June 1985), 107 pages, gives an indication of the extent of Rockefeller involvement in this area on a world wide scale.

The Rockefeller Archive Center has pepers of individuals of interest including Edwin Embree (1925-1930); S1mon Flexner (18911946); Raymond B. Fosdick (1919-1936); Freder1ck T. Gates (18771939); Richard M. Pearce (1906-1930); George E. Vincent (19291945). Other individuals such as Alan Gregg, Max Mason, Jerome D. Greene, Norma S. Thompson, and Edmund E. Day have correspondence Interspersed with other collections. Alan Gregg's papers are not avallable but his diary 1 s transcribed and added as memorandums to other files, where relevant, on a regular basis. The Center also has a library of eecondary works, blbliographic files, a typescript history of Rockefellex philanthropy (RF History, Source Materiale 900 Hiat 1 , see vol. 1, 5, 6), complete collections of annual reports and related documents as well as archival collections from the Commonwealth Fund and the Julius Rosenwald Fund in addition to manuscript collections from related Rockefellex Boards as indicated in the sections below.

Rockefeller Foundetion Archives in the Rockefeller Archive Center includes Project Files; Administrative Program and Policy records; General Correspondence; and the documents of the International Health Board. The National Committee on Mental Hyglene and the Canadian Committee are extensively documented in the Project Files Record Group 1.1, series $200 \mathrm{U} . \mathrm{S}$. and serles 427 Canada. These files include detailed records of the organizations, proposals, records and evaluations of all projects, universities and other organizations which were relevant to the on going work. General Correspondence, Record Group 2 contains source material on the American Psychiatric Association and also psychiatry in World War II; Administration, Program and Pollcy, Record Group 3 series 906 is on psychiatry; 910 has records on psychology; International health Board documents are in Record Group 5. The International Health Board also produced, Annua﹎-Reports of 1nterest of 1 ta work in Canada on school health. The Rockefeller Foundation, Annual_Reportg (New York: RF, 1913-1975) were also useful overviews of the total work of the Foundation. The Reports indicate priorities as do the

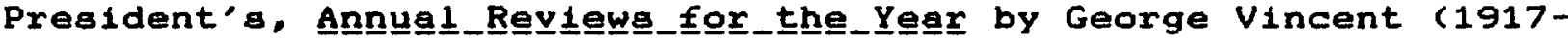
1929), and Raymond B. Fosdick (1936-1948) published by the Foundation.

Bureau of Social Hygiene Manuscript Collection, 74-950 (1911-1940), in the Rockefeller Archive Center was separate but closely related in philosophy and orientation to the early NCMH especialiy as concerned with prostitution, venereal disease, delinquency and crime. Record Group 1.2, subseries 3 has recorda 
on delinquency; subgroup 4 on Berkeley behavioral research; subgroup 5 has documents on the American Orthopsychiatric Association.

General Education Board (1902-1964), best known for 1ts work in the Southern states in education and public health also fostered the development of psychiatry, medical education and child study, Including the National Councll of Parent Education in the United States. After 1928 the GEB extensively supplemented the work started by the LSRM, see especially GEB 930, series 1 , subserles 3. The General Education Board also has Annual_Reportg (New York: The Board, 1918-1957); Report_of_the_Secresetery

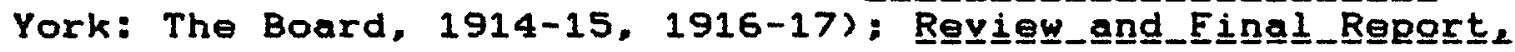
1902-1964 (New York: The Board, 1964).

The Laura Spelman Rockefeller Memorial, Manuscript Collection 74-960 (1918-1949), forewarded major innovative policy in child study research. Subseries 1 on public health has records among other things of the Massachusetts Soclety for Mental Hygiene. Subseries 5 has extensive documents on approximately 28 universities and child study or parent education project funded or considered for funding by the LSRM. In addition supportive agencles documented other than the U.S. and Canadian National Committee on Mental Hygiene include: the Child Study Association, American Home Economics Association, American Association of University Women. National Child Welfare Association, National Research Council, Parents Publishing Association and the National Federation of Day Nurseries. There are also files on the U.S. Department of Labor, Children's Bureau (1924-6) and the White House Conference on Child Care and Protection (1929-1930). Subseries 6 has records on the American Psychological Association, National Research Council, Social Science Research Council and the Institute of Human Behavior and Institute of Psychology at Yale University. The LSRM also produced, Annnual 1 Reports (New York: LSRM, 1919-1930).

The Commomwealth Fund Archives, at the Rockefeller Archive Center, contains the minutes and official records of the Fund, Boxes 375-7; correspondence, papers, reporta and evaluations on the Program for the Prevention of Delinquency and the National Committee for Mental Hygiene, Boxes 65-75; The Jolnt Committee on Methods of Preventing Delinquency including the news letters are in Box 396. The Division on Public Health which carried out child health demonstrations are in Boxes 83-98. The Commonwealth Fund also was a major disseminator of mental hygiene through its Division on Publications which was a subsidiary of the Joint Committee on Methods of Preventing Delinquency, see Boxes 121 171. Routinely published material such as the Annugel_Reporte are also useful guides to activities including the Institute for 
Child Guidance and the Joint Committee for the Prevention of Delinquency.

Background information was gleened from a variety of routinely published governmental documents from both federal, state and provincial sources. An overview of statistica is

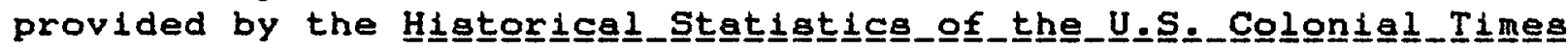
to음ํ의 2 Parta (Washington D.C.: Government Printing, 1978) and

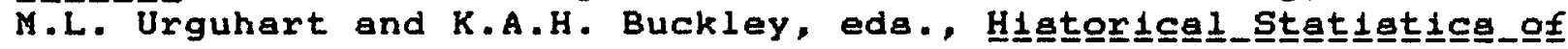
Caneda (Toronto: MacMilian, 1965). In many cases it was useful to go directly to Caneda, Dominion Bureau of Statiatics Cengausa, or the U.S. Department of Commerce Bureau of the Census, çengsus. The Canadian Bureau of Statistics, Office of Education produced Reports as did the Child Welfare Division from 1920 to 1932 . The Sessional paperg, annual reports of departments, institutions, boards, commiasiona and aurveya provide an overview of Canadian policies. U.S. Congressional record also provides background information and discussions on legislation. The Statutese_and

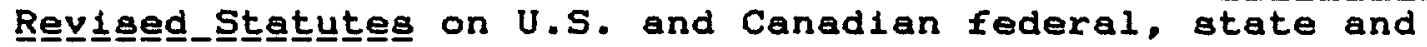
provincial levela document the formal policies adopted. In some cases guides to the early laws are essential. I found Blacḱn $\mathbf{B}$ Low Díc드으므y helpful. Also Canadian Department of Justice, A

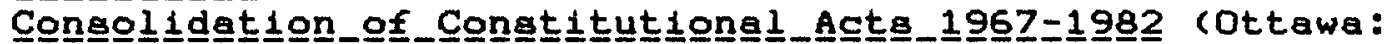

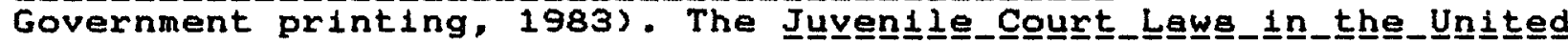
Sttenteg edited by Hastings H. Hart (New York: Charities pubilcation, 1910 for the Rusaell Sage Foundation) provided an excellent aurvey of early juvenile court lawa by atate. On Canada

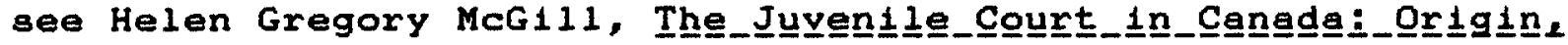

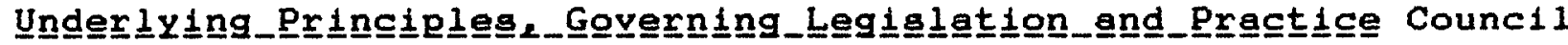
on Child Welfare publication No. 17 cottawa: Canadian Council on Child Welfare, 1925).

The mental hygiene movement through 1 ts surveys and leadership such as Thomas Salmon contributed to the gathering of uniform statistics on mental iliness. The compilation of information on diseases, injuries and causes of death was initiated in the first decade of this century. Mental diseases were included three decades later. Children only appeared in the past twenty years. See world Health Organization, Ingternnationgel

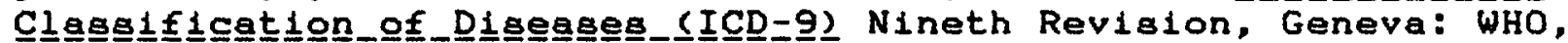
1979. The American Paychiatric Association also produces a manual which serves as an authority for the classification of mental disorders in Canada and the United States. The contemporary third edition shows the degree to which childhood mental aberrations have incroached upon official statuses for mental deviance, American Psychiatric Association, Di Manua﹎_of Menta﹎_Disondergers 3rd Edition (Washington D.C.: APA, 1980, reprinted 1984). While Canadians do not produce an independent classification but adopt the APA'a manual, independent surveys have been conducted. The Commiasion on 
Emotional and Learning Disabilities in Canada produced the CELDIC

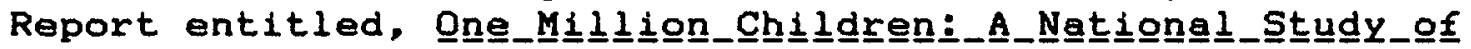

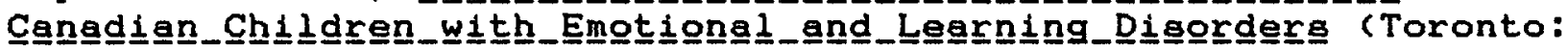
Leonard Crainford, 1970).

The proceedings and papers from numerous conferences in both the United States and Canada in diverse fields provided a measure of the disgemination of mental hyglene ldeas on childhood and the participation of mental hygienists. The role of scientific philanthropista in supporting conferences was indicated by documents from the archives juxtaposed with proceedings. The Mental Hygiene Conference and Exhibit, Procosegdings November 8 to 19, 1912 (New York: NCMH, 1912) indicates the propaganda level of the early movement. The First International Congress on Mental Hygiene, Proceegings 2 vols, held in Washington D.C. May 5 to 10 , 1930 (New York: NCMH, 1932) 11luatrate the degree to which the mental hygiene movement hed attracted world wide notoriety. (Some of the more interesting proceedings were the National Congreas of

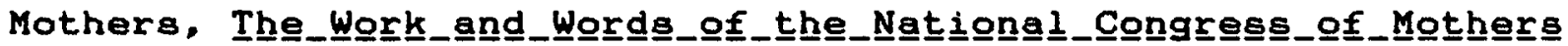
held in Washington D.C., February 17, 18 and 19, 1897 (New York: D. Appleton \& Co., 1897) and the Second_and_Thyr.

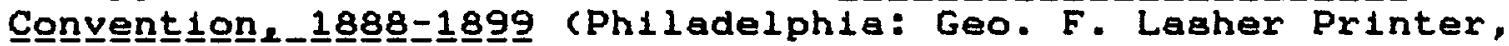
1899); Child Conference for Research and Welfare, Próceeduing vol 1, held at Clark University, July 6-10, 1909 (New York: G.E. Stechert \& Co., 1910); The International Congress of School

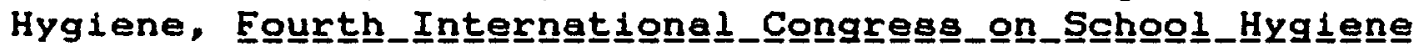
Traㅡ으트노으으 vol 1-2 (New York: Courier \& Co., 1914). The National Conference of Charities and Corrections, Procoseedingas 143(1874-1916), become the National Conference of Social work, 모으르르므몽 44-67 (1917-1940) are especially interesting as the impact of paychiatry and psychology on social work unfolds.

The United States Department of the Interior, Office of

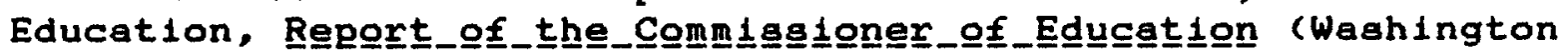
D.C.: Government Printing Office, 1916- 1958); the Unitted_statee B1enn스르_Sur

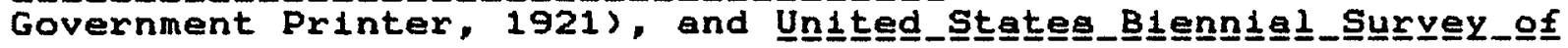

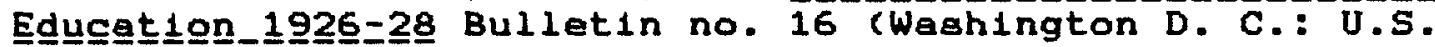
Government, 1930 ) provides a background on the bureaucretization and expansion of schooling including curriculum. The U.S. Department of Labor, Children's Bureau, Publilicationg (Washington D.C.: Government Printing) are an invaluable resource on two levels. The Bureau records the professionelization of charity work which paralleled and supported the mental health work with children of the NCMH, Rockefeller Foundation and Commonwealth Fund. The link between the NCMH and Jane Addems and Julia Lethrop from its inception illustrate the cross connections and mutual interests. The Bureau's surveys and studies also trace the progress of mental hygiene in juvenile delinquency, guidance clinics, health of dependent children and the general 
legitimation of child oriented services. See also Children's Bureau, Chilld_Cere_and_Child_welfagere (Washington D.C.: Children's

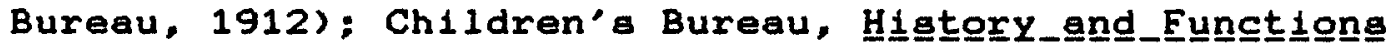
(Washington D.C.: U.S. Department of Labor, 1944); Children's

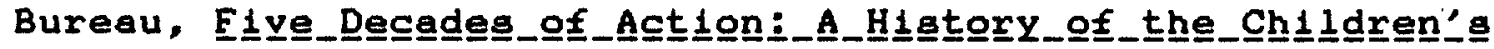
Bureau (Washington D. C.: U.S. Department of Labor, 1962).

In the United States the White House Conferences on Children provide a survey of the status of children as well as protocols for policy. Mental Hygiene became increasingly important as indicated by the white House Conference on the Care of Dependent children, Proceedings 1909, and the second set of conferences in

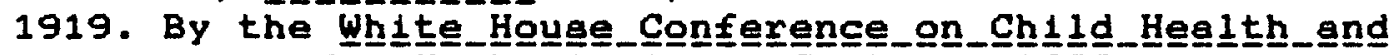
Protoeㅡ느은 (New York: Appleton Century, 1932) mental hygienlats

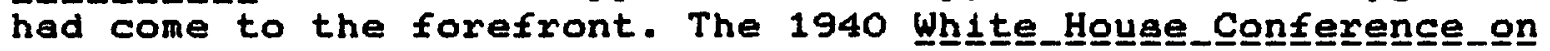

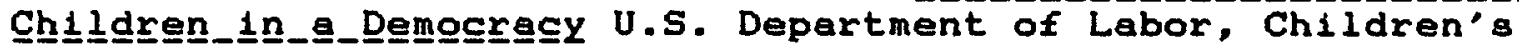
Bureau Publication No. 266 (Washington D.C.: Government Printing 1940) foreshadows some of the concerns after the War. The

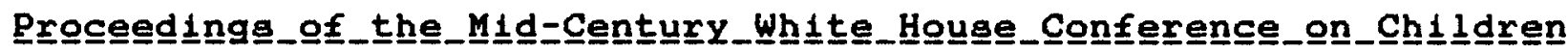
and_Y Youth Raleigh, N.C.: Health Publications, 1951) iliustrates the direct impect of paychiatry.

Annual and special reports of the Departments of labour and Health are an important Canadian source. The Canada, Department

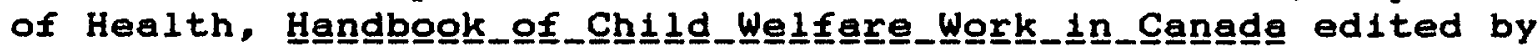
Helen MacMurchy (Ottawa: King'a Printer, 1923), provides an overview of the child health and welfare in the early 1920s. In conjuction with the Department, the Canadian Conference on Child

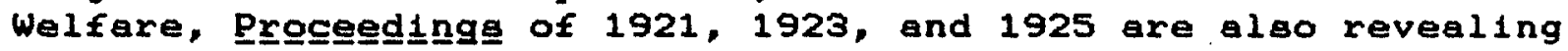
especially because of the close connections between the CNCMH and the Child Welfare Council. The Canadian Universities Nationel Conference, Report held at Chateau Laurier and the Univergity of Ottawa, May 22-24, 1929 gives an indication of developments in higher education in Canada. The Canadian Medical Association did a Regor느_on_thhe_organizatiㅡㅇㅡ_of the Canadian National Committee for Mental Hygiene which was published by the Metropolitan Life Inaurance Co. In 1932. Royal commissions in Canada often provide background material and projectiona for social policy almilar to the Presidential commissions and conferences in the United

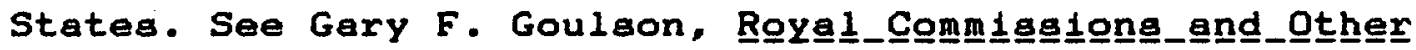

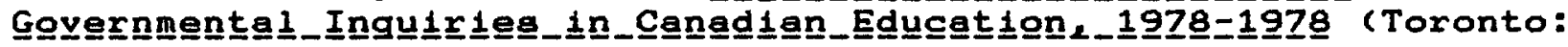
University of Toronto, 1981). For example see, the Robertson Commission, Royal Commission on Industrial Training and Technical Education, Report_of_the_Comm1seson (Ottawa: 1911); and the

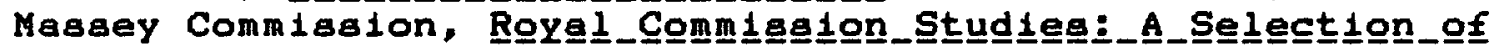
Esgagey﹎pregerared_Eor

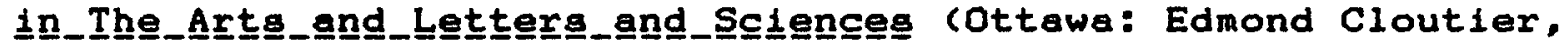
1952), see W11liam Line, "Psychology," Pp. 145-63; R.P. Noel Mailloux, "La Psychologie," pp. 165-78; and G.H. Ettinger, "Medical Research," pp. 317-36. 
Journals provide an overview of the professionalization of varlous disciplines and the impact of mental hygiene in this

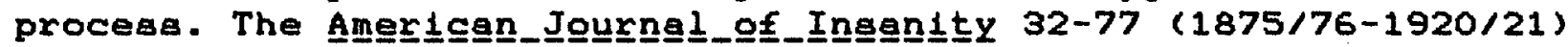

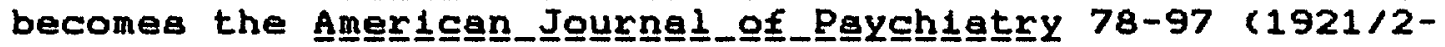

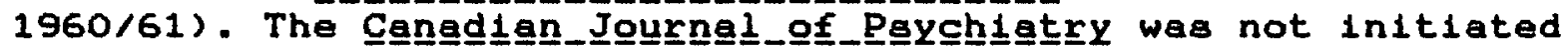

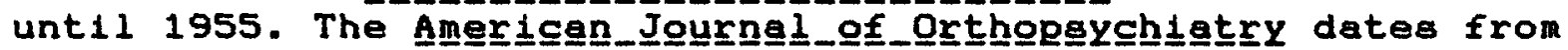
1930/31. The American Journal of Paychology was initated in 1887. The Canadian_Journnel_of_Peychology, in contrast, dates from 1947. Canadian_paychology

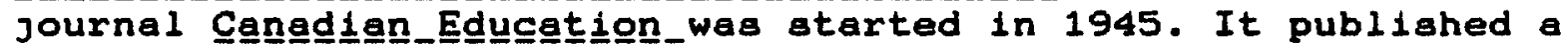
health and mental hygiene survey of schools in ita early volumea, see A.J. Philipa, "General Survey of School Health," Cannendilan

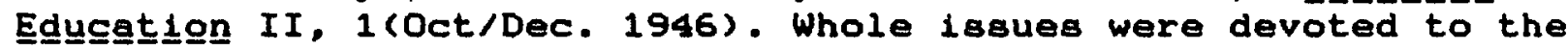
two reports, the second of which concentrated on mental health, National Committee for School Health Research, A.J. Philips,

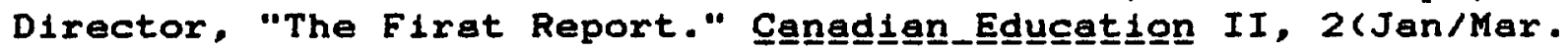
1947), and National Committee for School Health Research, "The

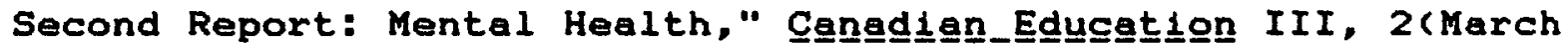
1948). Mentenl_Hygiene the publication of the NCMH was started in 1917. The CNCMH Initlated their ahort lived but very uaeful for

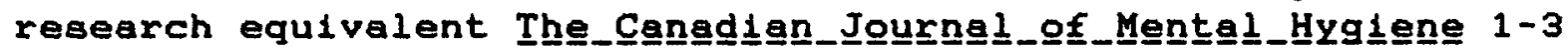
(1919/20-1921/22). A Mente日 supplemented the other serial publication. The U.S. publications served Canada until Canada's_Mental_Health was initiated by the Canadian Association of Mental Health in 1952. The Journngl_of_the

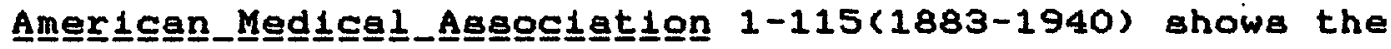
development of scientific medicine end the relatively weak

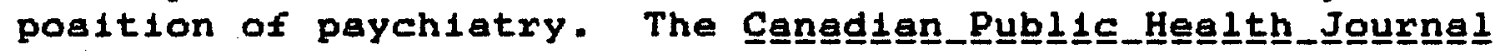
(1909-1939), American_Journal_of_public_Health_. 1 (1910) and the Publif_Hea 1 th_Nurse $1(1908) ;$ and the Public_Health_Nurges BuIㄴㅌt트 (1924-1939), showed the strong lmpact of psychobiological case work perspectives in this field in the interwar period. Nurses were nevertheless, superceded by soclal workers, especially in the United States, Soc1el_Work_Yeer_Book

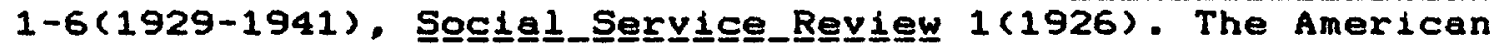
Association of Psychiatric Social Workers initiated a Newazletten

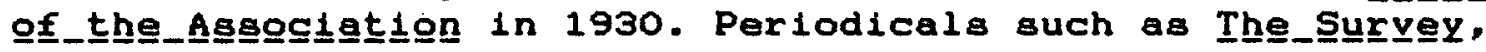
successor to Char itties_and_The_Commons touch on social work and mental hygiene in the transitional phases of professionalization.

\section{Published Primary Sources on Kental Hyglene}

Mental hyglenists produced a varlety of literature as one part of the conscious educational aspect of the movement in producing and disseminating a new knowledge base. A sample is provided of this valuable if unweldy source of information on the development and changes in ldeas and practices among mental hygienists. The criteria used in the determination of the 
significance of a work was whether or not it was cross referenced in other contemporary works at its time of publication. The literature tended to self-perpetuate 1deas. Much of the material was in an academic sense repetitive and reflected what Adolf Meyer called "propaganda" rather than a scientific advance. Some authors will be recognized as leaders in their flelds. Not all of these individuals would have identifled formally with the movement. However, figures such as Thorndike, who remalned peripheral in a consultant capacity at Columbia University, had immense influence in a larger sense. Peter Sandiford, a prominent Canadian mental hygienists was, for example, a student of Thorndike. The general trend ls from the overt moral messages of the early child study and eugenical literature toward a more rationalistic and scientific approach. The message was directed at the early profeselonals in the human or helping services as well as informed middle class parents. The literature also reflects the impact of external circumatances such as war, the expansion of schooling and the American fascination with sclentific efficiency.

Anderson, V.V. Mentel__Hygiene_in_Industxy. New York: Harpex \& Bro., 1929.

Arlitt, A.H._Adolesgent_Pgycholggy. New York: American Book Co., 1940 .

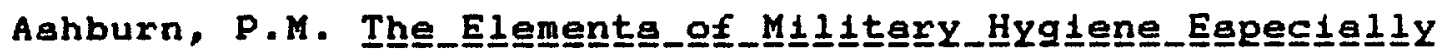

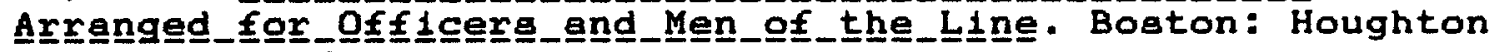
Miffin, 1915.

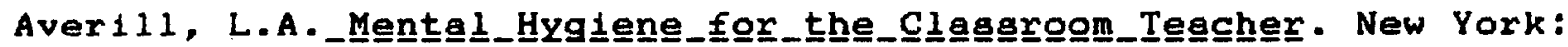
Chicago: Pitman Publishing Co., 1939.

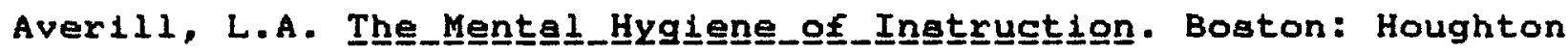
Mifflin, 1928.

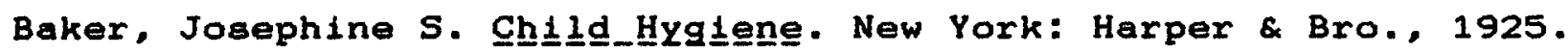

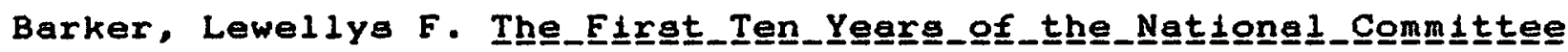
fox

National Committee for Mental Hygiene, 1918.

Barker, Lewellye F. "Public Health and the Future of the Commonwea lth." Trange日ectínons_of﹎the_Confererence_on_the_Eutuure

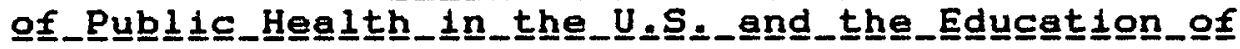

Sanitenriang. reprint Public Health Bulletin No. 126. Washington D.C.: Government Printing, 1922.

Bassett, Clara. Menteㅡㄴㅡygiene_in_thhe_Communnity. New York: Mackilian, 1934.

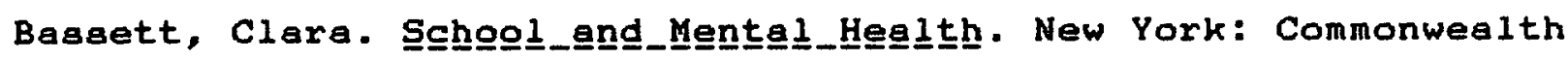


Fund, 1931.

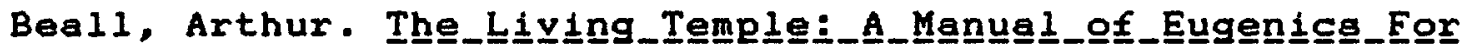

Parenta_and_Teacherg. Ontario: A.B. Penhale Publishing, 1933.

Beers, Clifford._A_Mind_Thet_Found_Itgenelf. preface by Robert Coles. Copyright 1907, New York: Longmans Green \& Co., 1908; 41st reprint, P1ttsburg: University of Pittsburg, 1981.

Beers, Clifford. "Some Intimate Remarks." Mentenl_hygiene. 19 (Oct. 1935): 16-28.

Beers, Clifford. "An Intimete Account of the Origins of the Mental Hygiene Movement." Mental_Hygiene. 15 (Oct. 1931): 673.

Bernhardt, Karl S. "Character Development in Ch1ldren." The

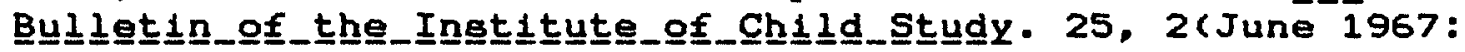
97.

Bernhardt, Karl S. "A Mental Hyglene Approach to Education."

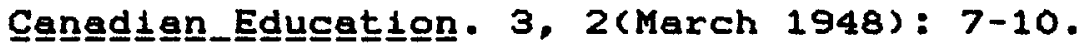

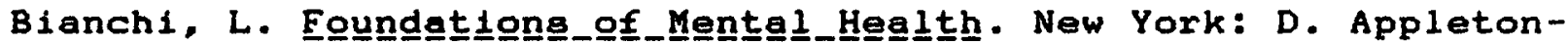
Century \& Co., 1930.

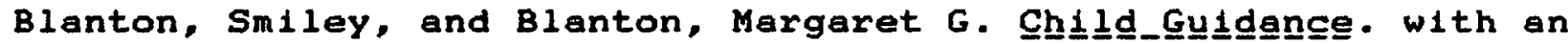
introduction by Thomes Salmon. New York: Century, 1927.

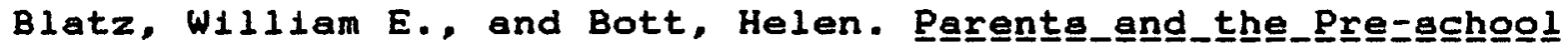
Ch1녀. New York: Wm. Horrow \& Co. 1929.

Blatz, William E., and Bott, Helen. The_Management_of_Young Chlilidren. New York: Wm. Morrow \& Co./Toronto: J.M. Dent \& Sons, 1930.

Blatz, William E., and Millichamp, D.A. "The Development of Emotion in the Infant." Chlild_Develogment_Series. No. 3 . Toronto: Univereity of Toronto, 1935, p. 58 .

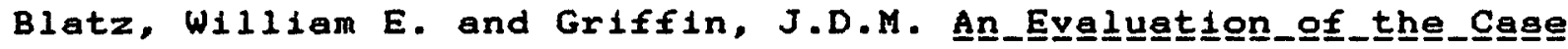

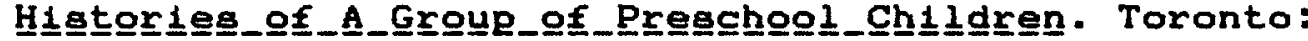
University of Toronto, 1936 .

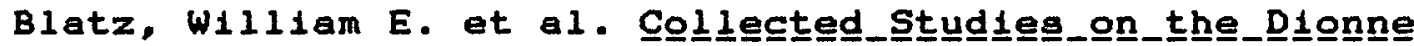

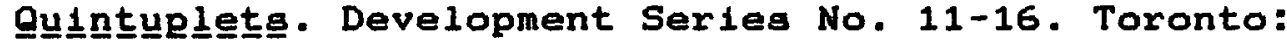
University of Toronto, 1937.

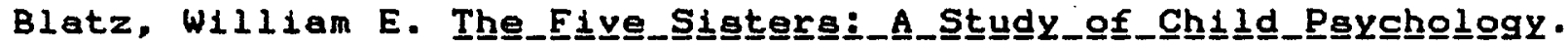
New York: $\omega m$. Morrow \& Co., 1938. 


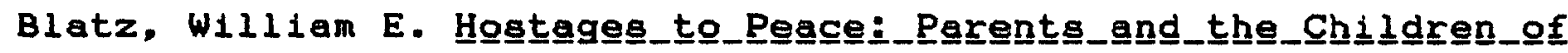
Demog도도. New York: Wm. Morrow, 1940.

Blatz, W1111am E. Ungerergtangling and Irvin \& Co. 1944, 8th reprint 1961 .

Blatz, W1ll1am E. Humen_Secuxityㅡㄴ.Some_Reflectiong. Toronto: University of Toronto Press, 1966.

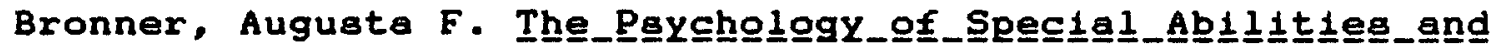
Disgab111t1es. Boston: Little Brown \& Co., 1917, reprint 1926 .

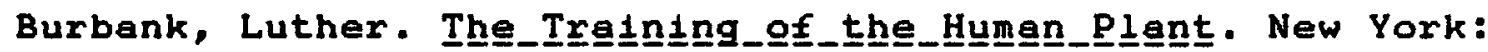
Century Co., 1907 .

Burt, Cyr11. The_Young Doelínguent. New York: D. Appleton-Century Co., 1925 .

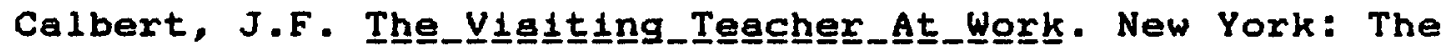
Commonwealth Fund, 1929 .

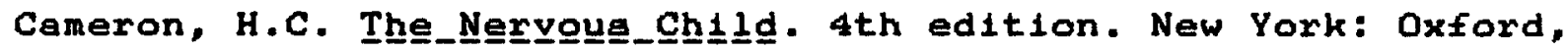
1929.

Campbel1, C. Macfie. A_Presegent_Day_Conception_of_Hentel D18oxdexs. Boston: Harvard University Press, 1924.

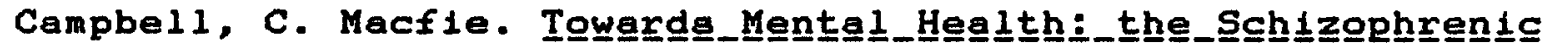
Problem. Boston: Harvard University Press, 1933.

Campbel1, C. Macfie. "Mental Hyglene in Industry." Mentel Hygiene. 5, 3(July 1921): 470 .

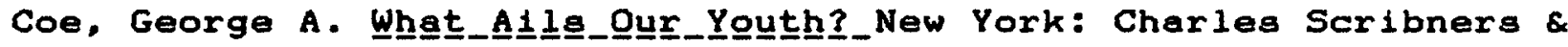
Sons, 1924, reprint 1926.

Cross, w.L., ed. Twenty=E1 ve_Yearg_After:__Sidelightg_on_the

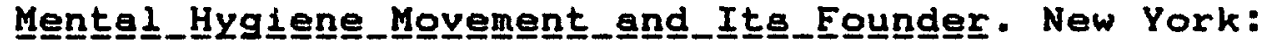
Doubleday, 1924 .

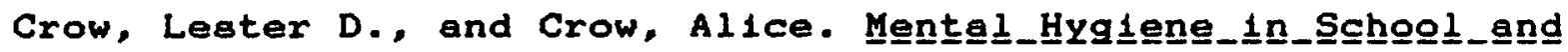

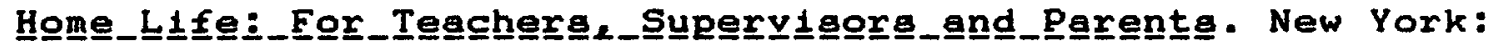
MCGraw-H111, 1942.

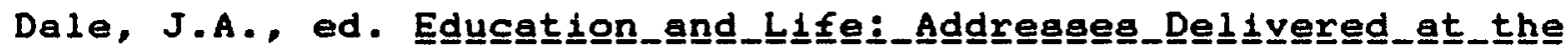

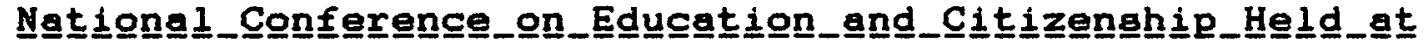

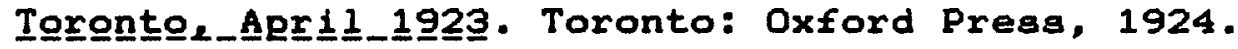

Davenport, C.B. The_trat﹎.Book. Cold Springe Harbor: Eugenics Record Office, 1912. 


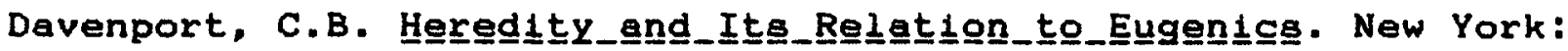
Henry Holt, 1911 .

Davis, Maurice R., ed. Social_Asgpectg_o으_Mental__Hygiene. New Haven: Yale University Press. 1925.

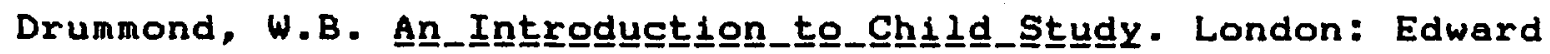
Arnold, 1908 .

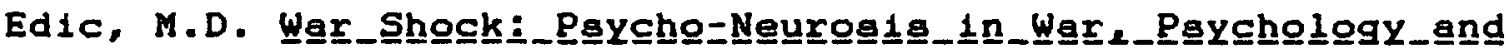
Treatment. London: William Huneman, 1917.

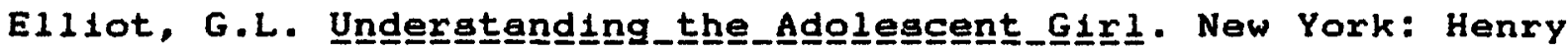
Holt \& Co.. 1928.

Fenton, Norman. "Adminiatrative Aspects of a Mental Hygiene

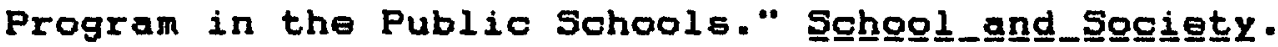
(September 24, 1932).

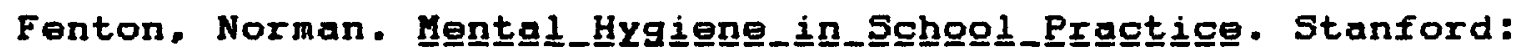
Stanford University Press, 1943, 6th reprint 1949.

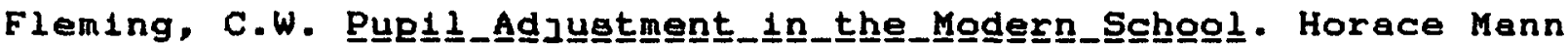
Studies in Education, New Series. New York: Teachers College Columbia Univeraity Press, 1931.

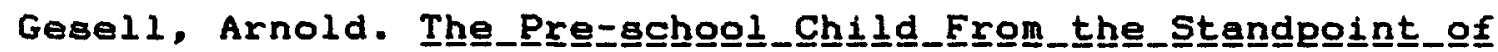

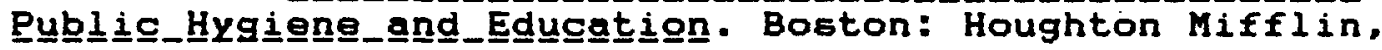
1923.

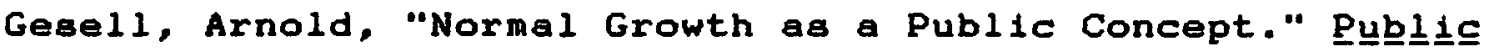
Heeㅛtㅡ_Nursse. $18,1(J u 1 y$ 1926): 394-99.

Gesell, Arnold. "The Mental Hygiene of the Pre-School Child." in

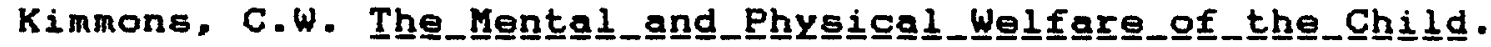
London: Partridge, 1927, pp. 37-56.

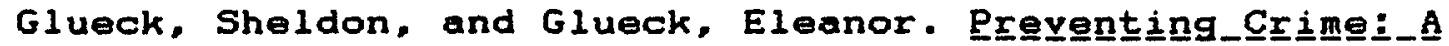
Symeogium. New York: McGraw-H1ll, 1936.

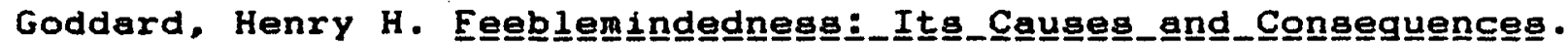
New York: MacMilian, 1914.

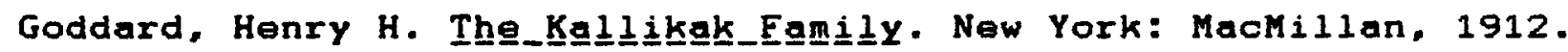

Goddard, Henry H. "The Problem of the Paychopathic child."

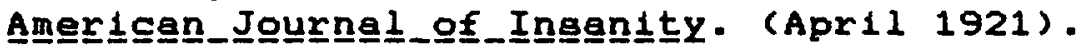

Griffin, J.D.M.; Laycock, S.R., and Line, William. Mental

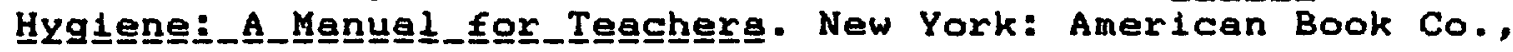
1940 . 


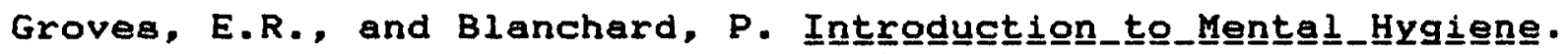
New York: Henry Holt \& Co., 1930.

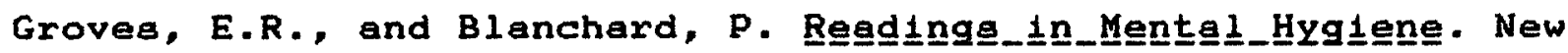
York: Henry Holt \& Co., 1936.

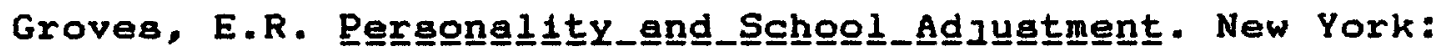
Longmans Green \& Co., 1931.

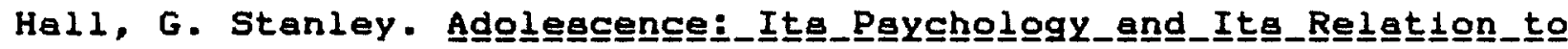

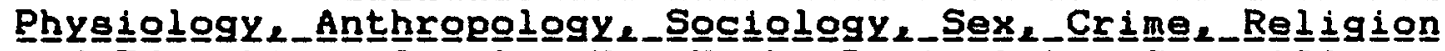
and Educetion. 2 vols. New York: D. Appleton Co., 1904.

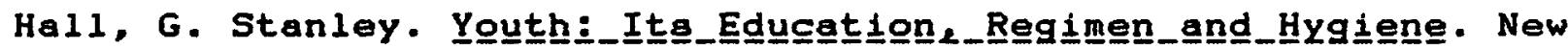
York: D. Appleton, 1906 reprint, 1922.

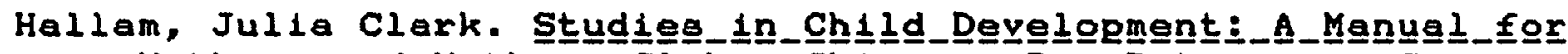

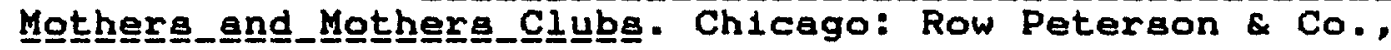
1913 .

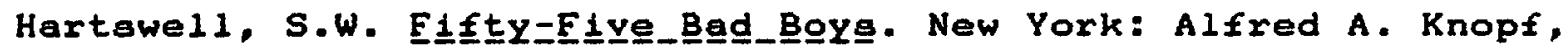
1931 .

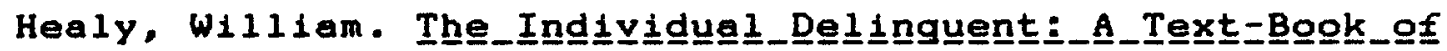

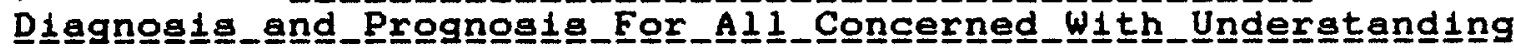
offenderg. Boston: Littie Brown \& Co., 1915 .

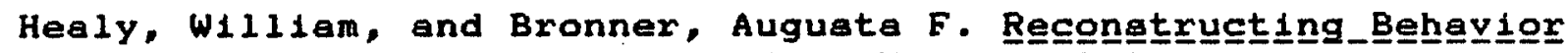
1﹎. Youtth. New York: Alfred A. Knopf, 1929 .

Healy, W1lliam, and Bronner, Augusta F. Trregetmentent_and_-what

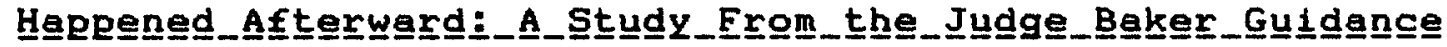
Center. Boston: Judge Baker Guidance Center Pubilication, 1939 .

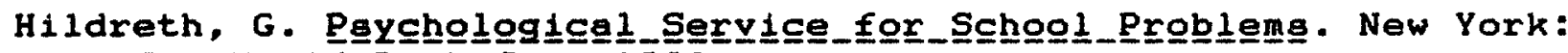
The Wor $1 \mathrm{~d}$ Book Co., 1930 .

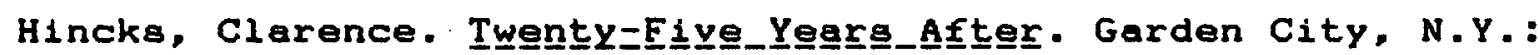
Doubleday Doran \& Co., 1934.

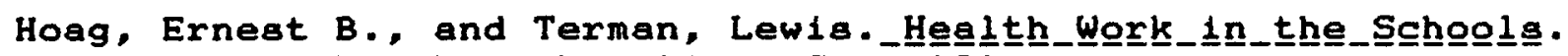
Boston: Houghton Miffiln \& Co., 1914.

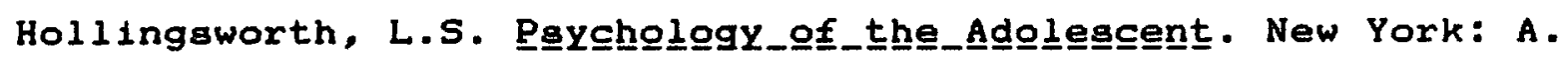
Appleton Century \& Co., 1928.

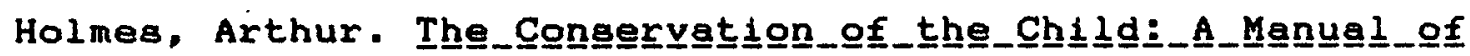

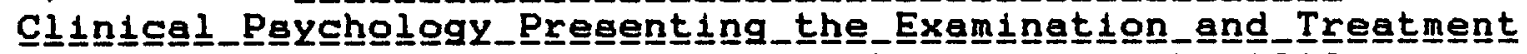

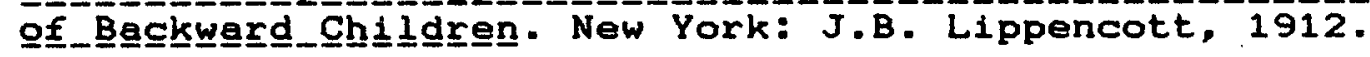

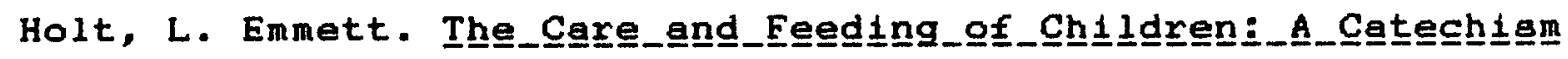


for _thㅡ_Use_of_Motherg_and_Chil Appleton \& Co., 1894, reprint 1921.

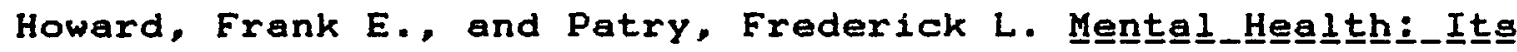

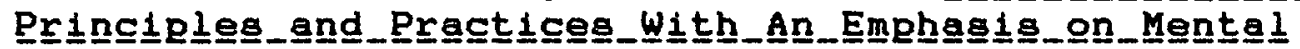

Deviations. New York: Harper, 1935 .

Kenworthy, Marion E. "Social Maladjustmenta in the Intellectually Normal." Mental_tyg 1enene. XIV (Oct. 1930): 837-44.

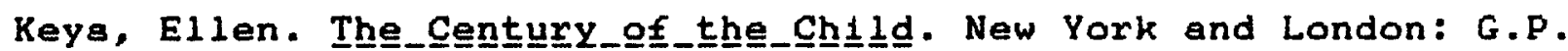
Putnam's Sons, 1909 , reprint 1912.

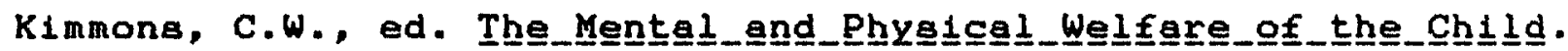
The Home School Library. London: Partridge, 1927.

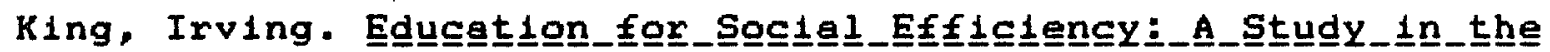

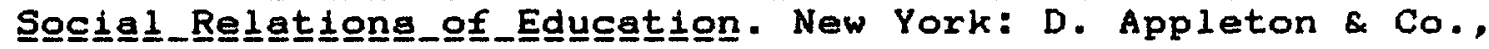
1913, enlarged 1915.

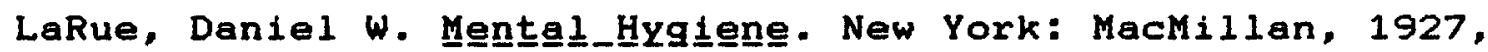
reprint 1932 .

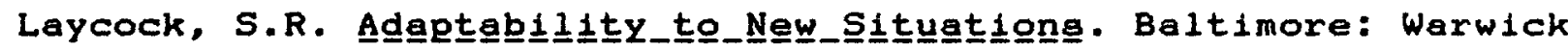
\& York, 1929 .

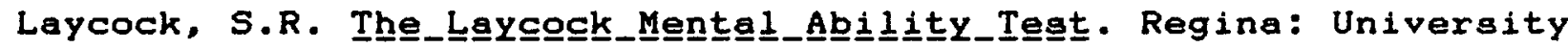
of Saskatchewan Book Store, 1933.

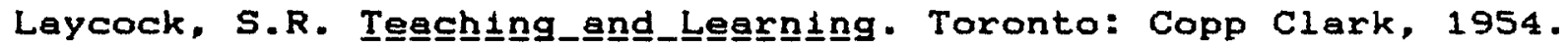

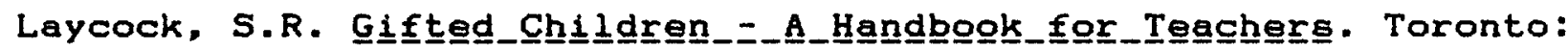
Copp Clark, 1957 .

Laycock, S.R. Mental_Hyglene_in_the_Schoogl. Toronto: Copp Clark, 1960.

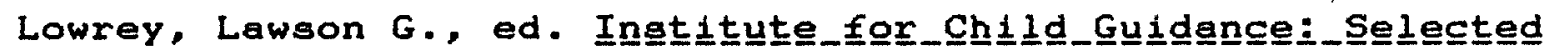
Reprinteg. New York: Commonwealth Fund, 1931.

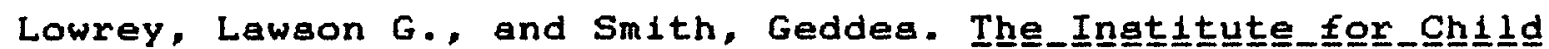
Guidaㅡㄷㅡ._1927=1933. New York: Commonwealth Fund, 1933.

Martins, E.H., and Russ, H. The_Adjustiment_of_Behavion

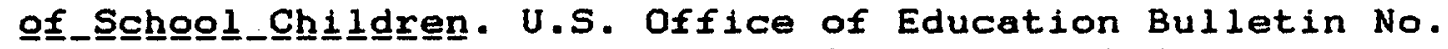
18. Washington D.C.: Government Printing, 1932.

Menninger, K.A. The He Humen_M름. New York: Alfred A. Knopf, 1930. Mikesell, William H. Mental_Hygiene. New York: Prentice-Hall, 1939. 


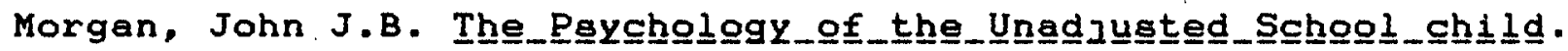
New York: MacMilian, 1924.

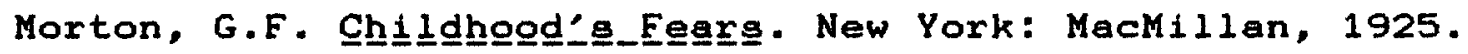

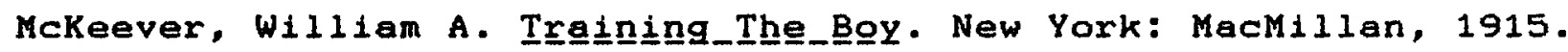

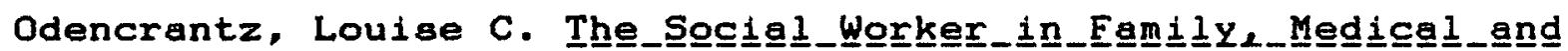

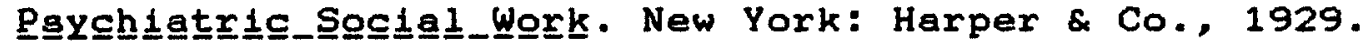

Osler, William. "On the Braina of Criminala." Cangedilan_Meglícal

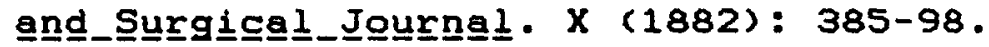

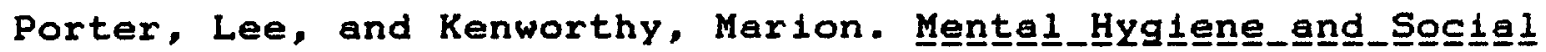
Work․ New York: Commonweelth Fund, 1931 .

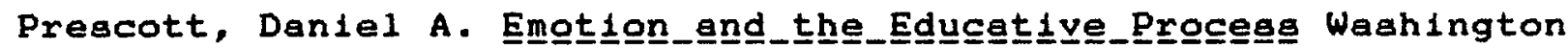
D.C.: American Council on Education, 1938.

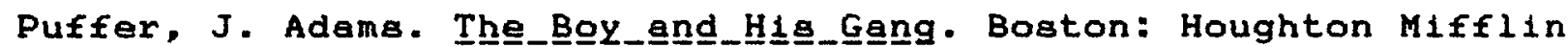
\& Co., 1912 .

Rasky, Frank. "Mental Hygleniat: He Straightens Out children"a Lives." Saturfouy_Night 60, 9(Nov. 11, 1944): 30-1.

Reynolds, Bertha C. "Environmental Handicaps of 400 Habit Clinic

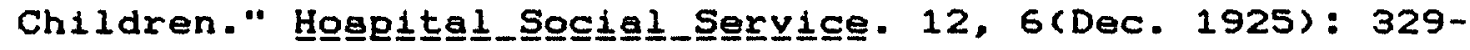
36 .

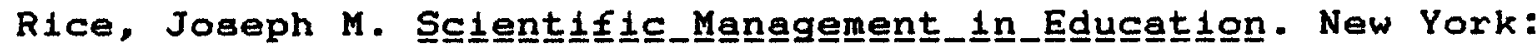
Hinds, Noble \& Eldridge, 1913.

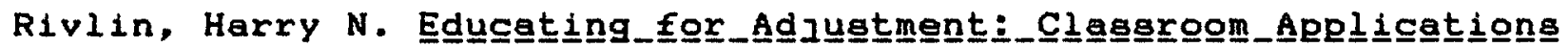

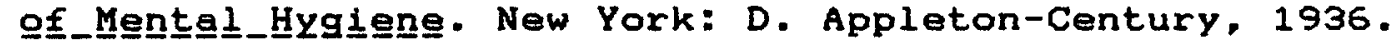

Rosanoff, A.J. Manuel_of_Paychịatryy_and_Mental__Hygiene. New York: John Wiley, 1938 .

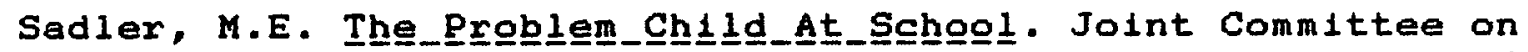
Preventing Delinquency. New York: Commonwealth Fund, 1925.

Sadler, M.E. Thhe_progblem_Chhilld__At__Home. New York: Commonwealth Fund, 1928 .

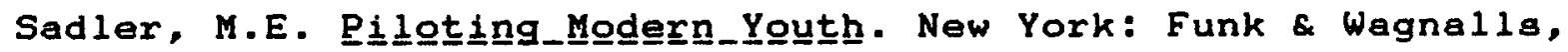
1931 .

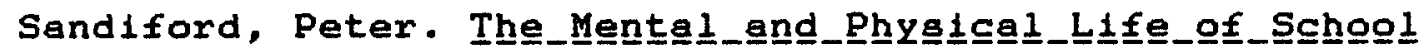

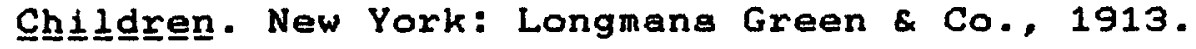

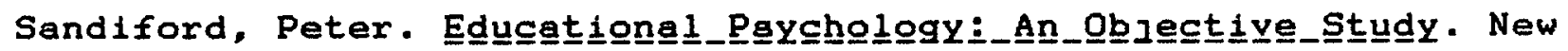
York: Longmans Green \& Co., 1939 


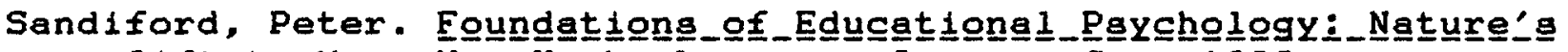

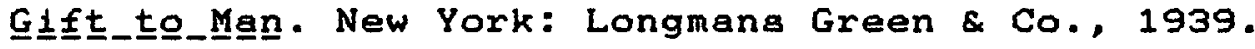

Shaffer, L.F. The_pgycholgogy_of_Adyugtment. Boston: Houghton Mifflin, 1936 .

Sherman, Mandel. Mental_Hyg1ene_and_Eduçatíngn. New York: Longmans Green \& Co., 1934.

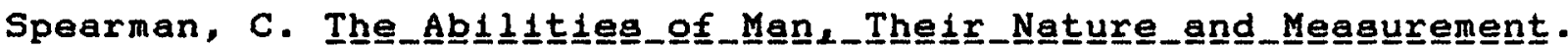
London: MacMilian \& Co. 1927.

Staff of the Institute for Juvenile Research, Paul Schroeder, Director. Chي11d_Guidance_Procedures, Methodg_and_Technigues

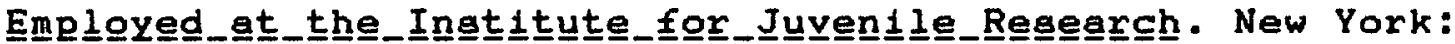
D. Appleton-Century Co., 1937.

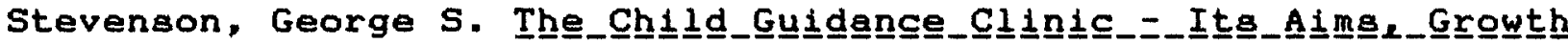
and Methonge. New York: National Committee For Mental Hygiene, 1932.

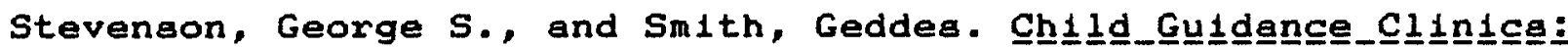

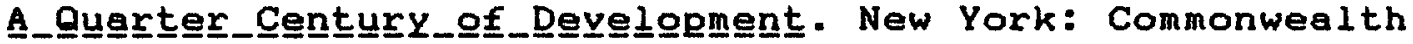
Fund, 1934 .

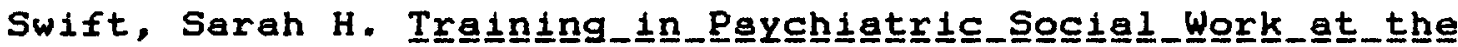

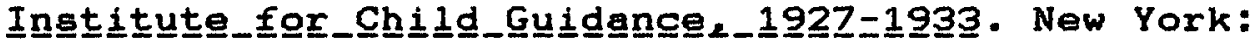
Commonwealth Fund, 1934.

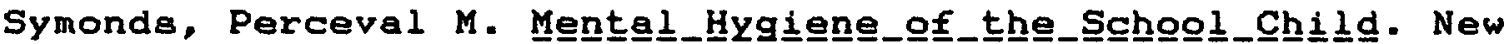
York: MacMilian, 1934.

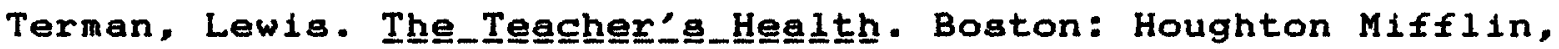
1913.

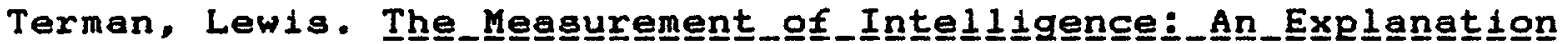

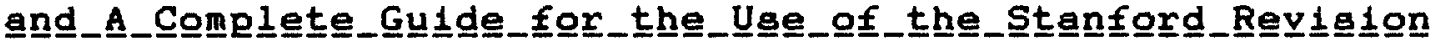

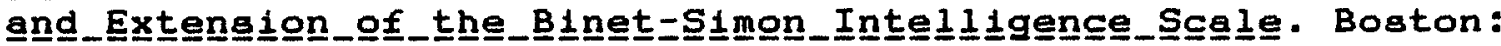
Houghton Miffiin, 1916 .

Terman, Lewis M. et al. The_Stanford_Reyigion_and_Extengion_of

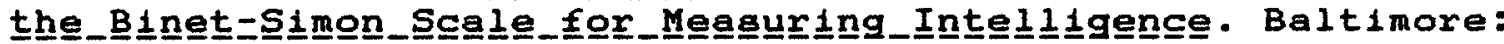
Warwick \& York, 1917.

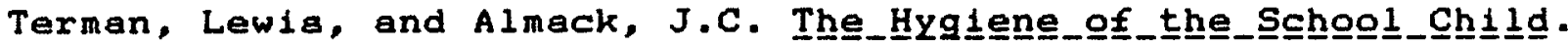
Boston: Houghton Miffiln, 1929.

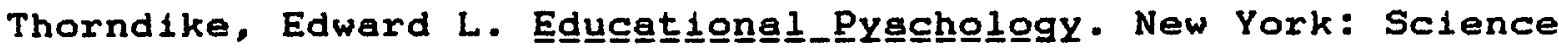
Press, 1903.

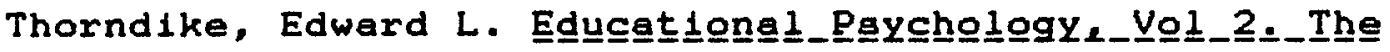




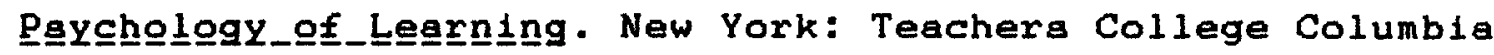
University Press, 1933.

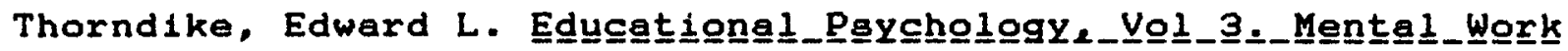
and_Fatigue. New York: Teachers College Columbia Univeraity Pres8, 1914.

United States Federal Security Agency Social Security

Administration, Children"s Bureau. Guid묨the_Adolescent. originally written by Thom, Douglas. Publication No. 225, Washington D.C.: Government Printing, 1933, reprint 1946.

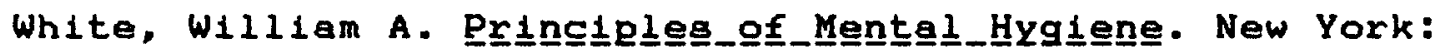
Mackilian, 1917.

White, W11liam A. Mental_Hyg1ene_of_Ch11ㅁhogd. Boston: Little Brown \& Co., 1919.

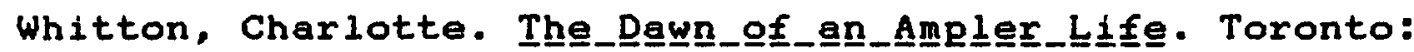
Mackilian, 1943.

Whitton, Charlotte, "Ch1ld Welfare Legislation Program 19251930." Canadian Council on Child Welfare, 1925.

\section{SECONDARY SOURCES}

I. Children and Youth: Historical and Sociologicel Sources on Children, Youth, Children's Institutions, Family Welfare and Parent Training.

The secondary literature on childhood and the family has increased dramatically since 1960 both in history and sociology. Revisionist social history and the new soclology contributed immensely to the study of children's institutions and policy. In the same way that the literature of the early decades of this century is revealing about the author's social concepts of childhood, more recent worka have created controversies which bring out some of the lingering contradictions on how we view the young. This atudy has profited from the variety of this literature.

Abbott, Grace. The_Child_and_the_State. 2 vols. Chicago: University of Chicago, 1938 .

Abrans, Philip. "Rights of Passage: The Conflict of Generations in Industrial Soclety." Journal_of_Contemporaay_H_tatogry 5, $1(1970): 75-190$. 


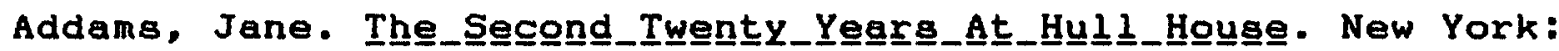
Mackilian, 1930.

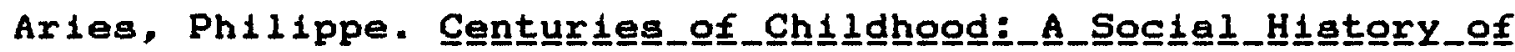
Family_Life. Translated by Robert Baldick. New York: Random House, 1962 .

Ashby, LeRoy . Sagy $\underline{1}$ ng_thhe_wa1 189 $9=1917$. Philadelphia: Temple University Press, 1984 .

Baker, Sara Josephine. Fighthting_For_Liffe. New York: MacMillan, 1939.

Bagne11, Kenneth. The_Litttle_Immigranta․ Toronto: MacMillan, 1980 .

Beales, Ross W. "In Search of the Hiatorical Child: Miniature Adulthood and Youth in Colonial New England." Amer Quenerterly . 27 (1975): 375-98.

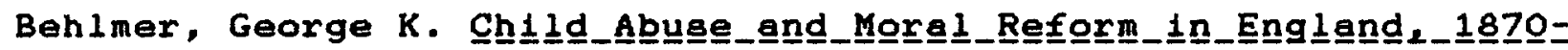
191ㅇ. Stanford: Stanford University Press, 1982.

Bloom, Lynn. "Its All for Your Own Good: Parent-Child Relationships in Popular American Child Rearing Literature,

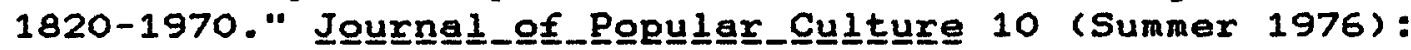
$191-8$.

Bowles, S., and Gintis, H. Schooling_in_Cegltegliget_Americe. New York: Basic, 1976.

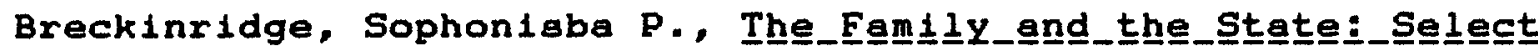

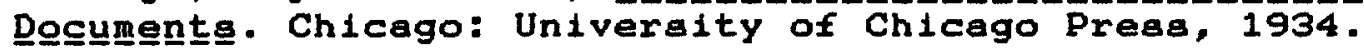

Breckinridge, Sophoniaba P. and Abbott, Grace. The_pelingnguent Chilㅁ﹎ond_the_Home. New York: Charities Publication Committee, 1912 .

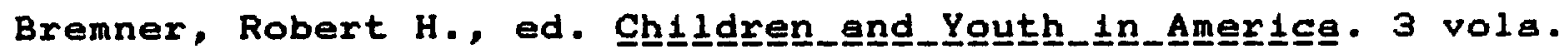
Cambridge: Harvard Univeraity Preas, 1970, 1971, 1974.

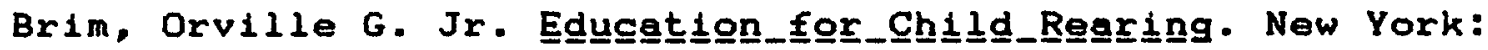
Russell Sage, 1959, reprint, Free Press, 1965.

Bronfenbrenner, Urie. "The Changing American Child - A

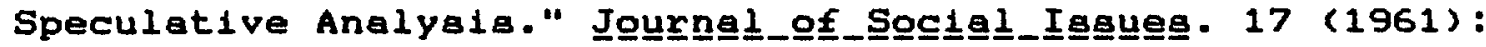
6-18.

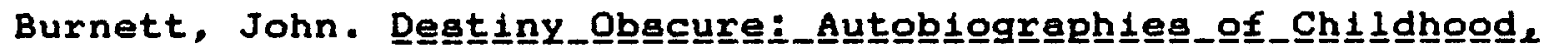

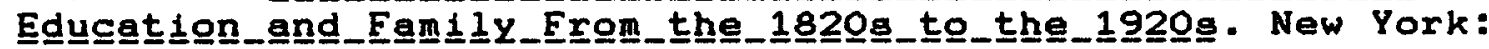
Penguin, 1984 . 


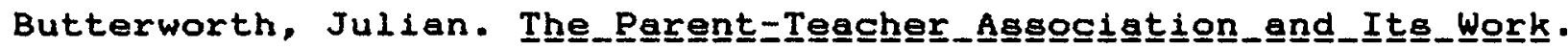
New York: Mackilian, 1928.

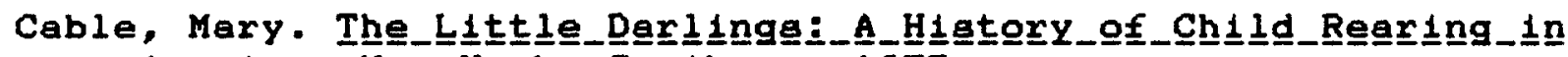
Amer 1 ca. New York: Scribner, 1975 .

Canadian Childhood History Project. A_B Chilldhoog:_Artiㅡ니요. Department of Social and Educational Studies, University of British Columbia (January 1987).

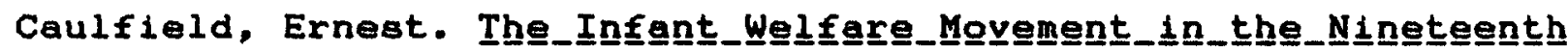
Centurury. New York: Hoeber, 1931 .

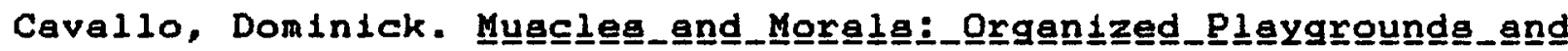
Ur $\underline{\text { b }}$ an_Refeform. Philadelphia: Temple University Press, 1981 .

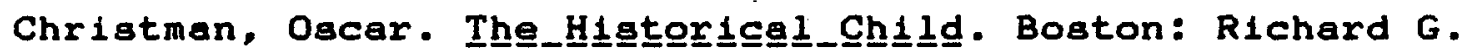
Badger, 1920.

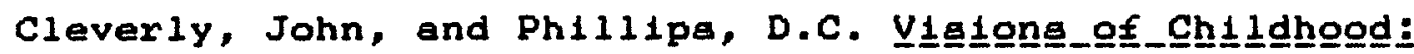

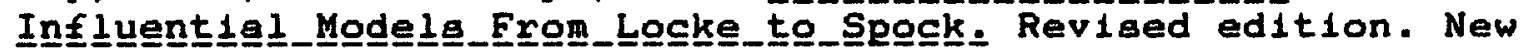
York: Teachers College Columbia University Press, 1986.

Clifford, Geralding Jonich. The_Shape_of_American_Eguucatíngn. Englewood Cliffs: Prentice-Hall, 1975 .

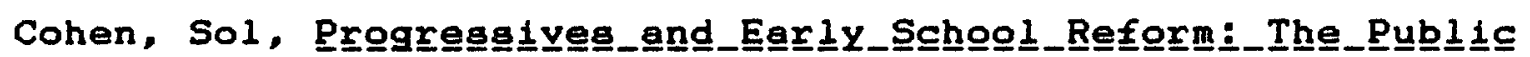

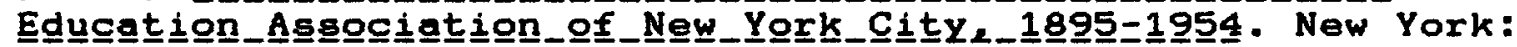
Teachera College Preas, 1968.

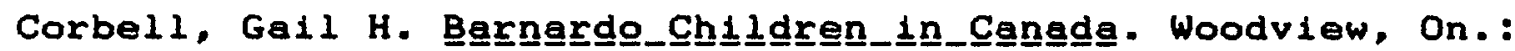
Homestead Studies, 1981 .

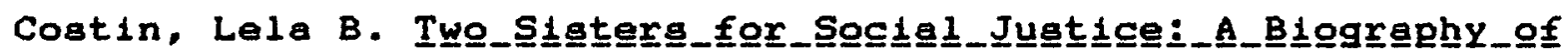
Grace_and_Edithh_Abbott. Urbana: University of Illinois Press, 1983.

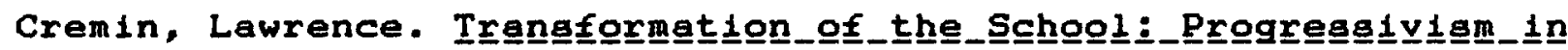

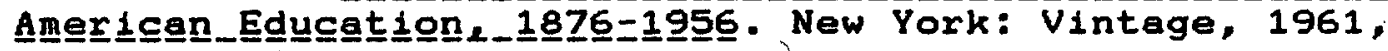
reprint 1964 .

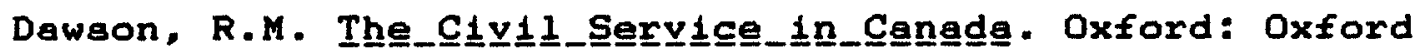
Un1versity Press, 1929.

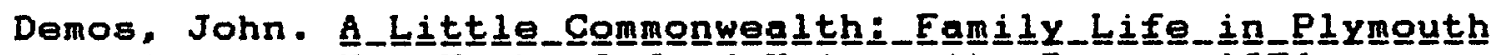
Cololony. New York: Oxford University Press, 1970.

Edward, John N. Egaㅛㅛㅍy_and__Change. New York: Alfred A. Knopf, 1969.

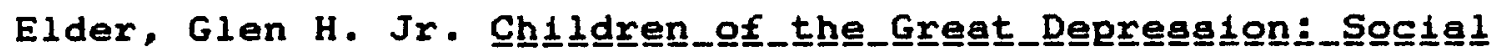

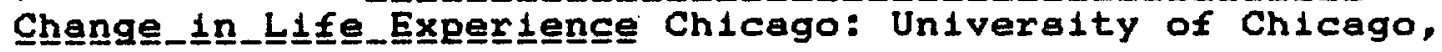


1974, reprint 1984 .

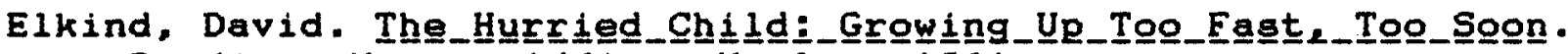
Reading, Mass.: Addison-Wesley, 1981.

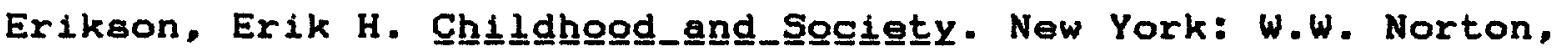
1950, reprint 1963,1985 .

Erikson, Erik H. Young Mann_Luthherer. New York: W.W. Norton, 1958.

Er1kson, Erik H. Identity_and_the_Liffe_Cycle․ New York: W.W. Norton, 1959, reprint 1980 .

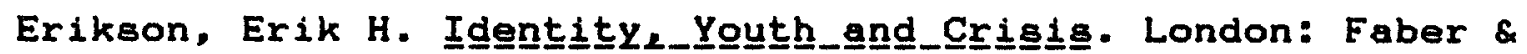
Faber, 1968.

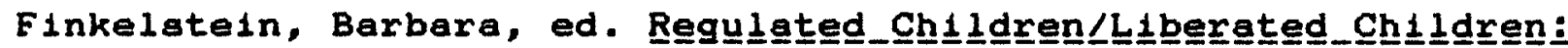

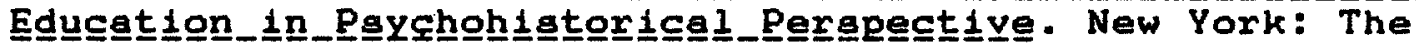
Paychohistory Preas, 1979.

Finkelstein, Berbara. "In Fear of Childhood. Relationships Between Parents and Teachers in Nineteenth Century America,

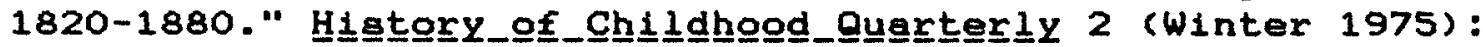
$349-78$.

Fox, Sandra J. "Juvenile Juatice Reform: An Hiatorical

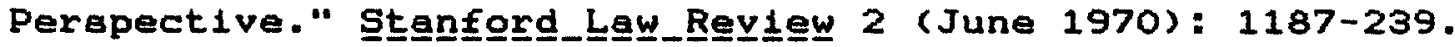

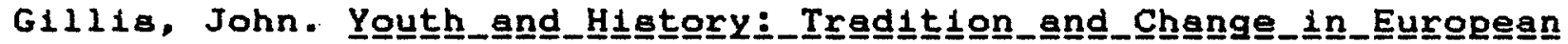

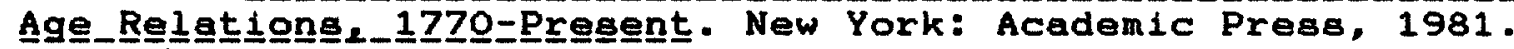

Goldstein, Joseph; Freud, Anna; Solnit, Albert J.; and Goldste1n,

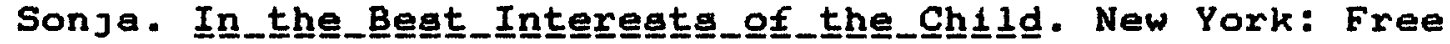
Press, 1986.

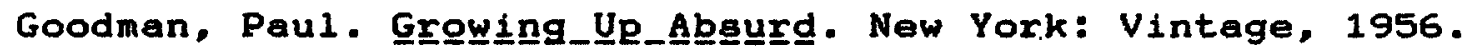

Graebner, William. "The Unstable World of Benjamine Spock: Social

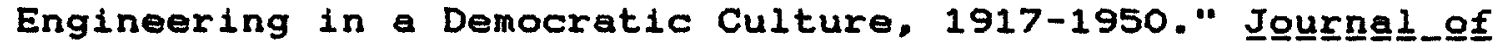

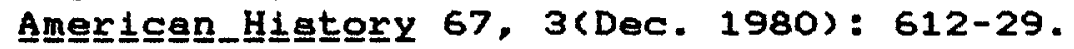

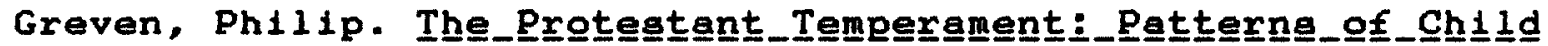

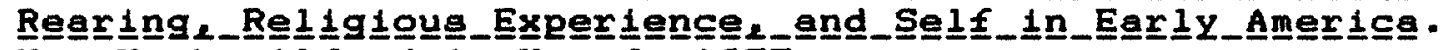
New York: Alfred A. Knopf, 1977 .

Greven, Ph111p. Foux

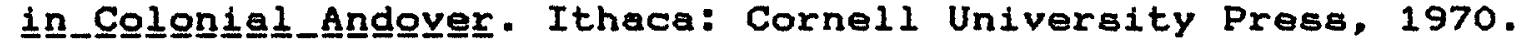

Grinder, Robert E., and Strickland, Charles E. "G. Stanley Hall and the Social Significance of Adolescence." Teeschers Coll lege_Record. 64 (Feb. 1963). 


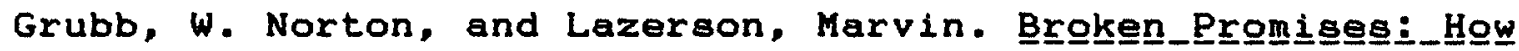

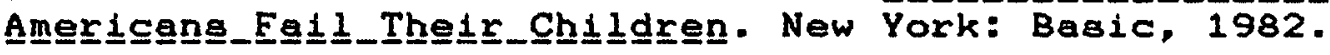

Grubb, W. Norton, and Lazerson, Marvin. "Rally' Round the Workplace: Continuities and Fallacies in Career Education."

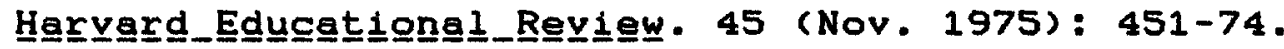

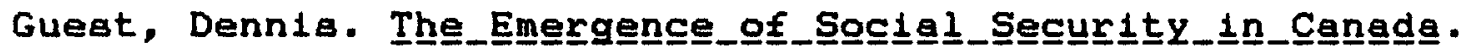
Vancouver: University of British Columbia Press, 1980, reprint 1982 .

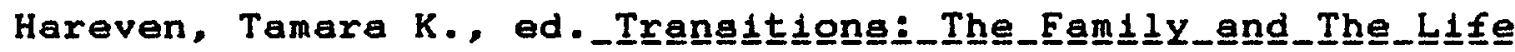

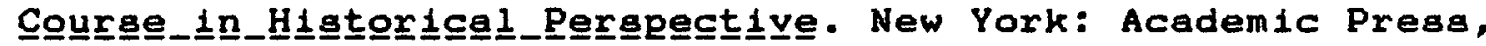
1978 .

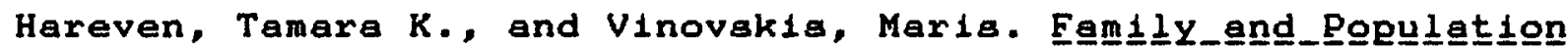

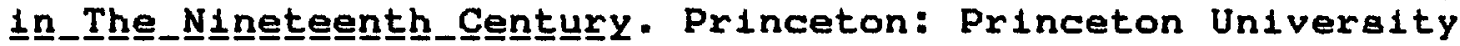
Press, 1978 .

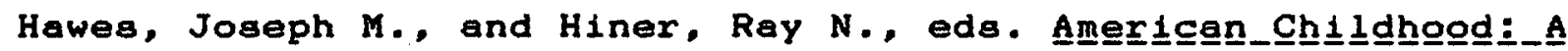

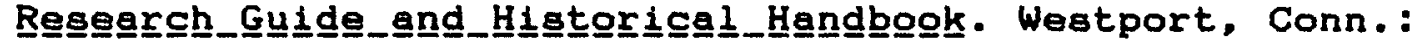
Greeenwood Press, 1985.

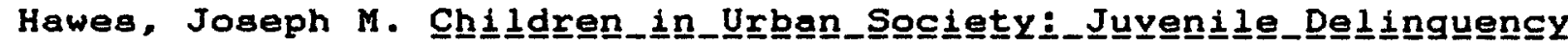

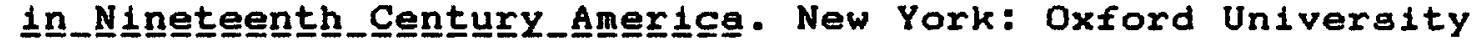
Press, 1971.

Heron, Craig. "Saving the Children." Acadienengig XIII, 1 (Autumn 1983): $168-75$.

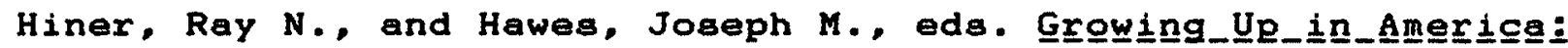

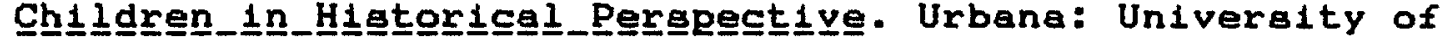
Ililnols, 1985 .

Heininger, Mary; Calvert, Karen; Finkelstein, Barbara; Vandell, Kathy: Macleod, Anne; and Green, Harvey. A_Cent트든_of

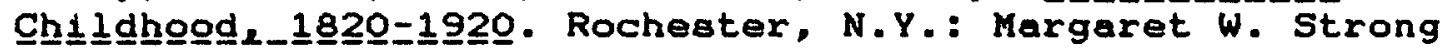
Museum, 1984 .

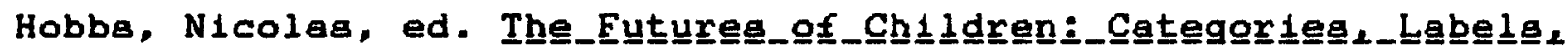
and_the토_Conseguences. San Francisco: Jossey-Bass, 1975 .

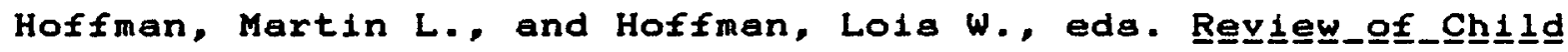

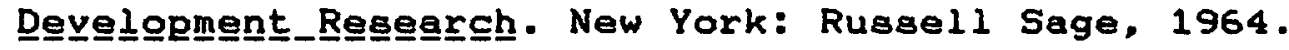

Hofstadter, Richard. "The Child and the world." Dagedal 1 ung. 91 (1961): 501-26.

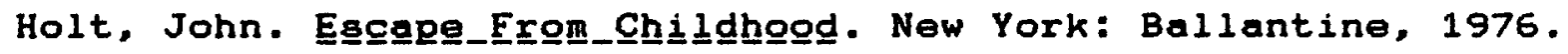

Horne, Margo, "The Moral Message of Ch1ld Guidance 1925-1945,"

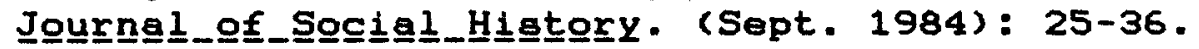


Houston, Susan. "Victorian Origins of Juvenile Delinquency: A Canadian Experience," In Katz, Michael B., and Mattingly,

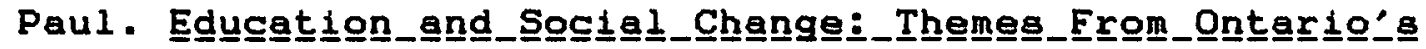

Pest. New York: New York University Press, 1975, pp. 83-109.

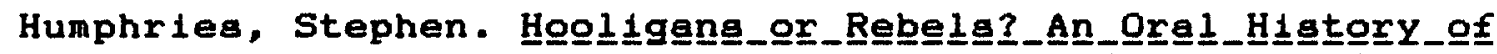

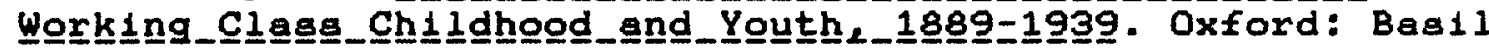
Blackwell, 1981.

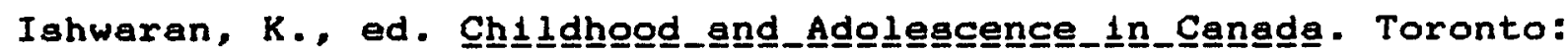
MCGraw-Hi11 Ryerson, 1979.

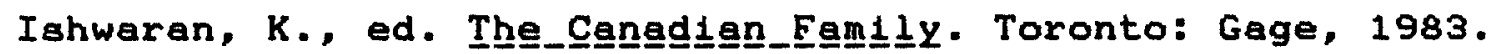

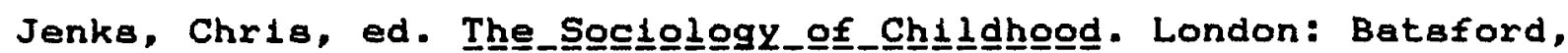
1982.

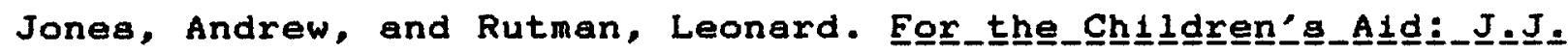

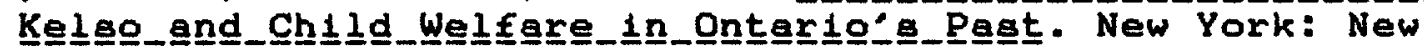
York University Press, 1975 .

Jones, David C.; Sheehan, Nancy M.; and Stamp, Robert M., eda.,

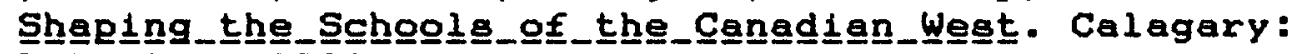
Detselig.'1980.

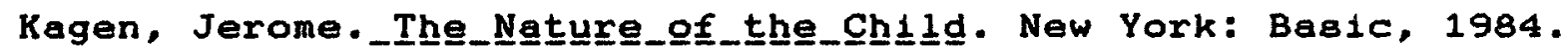

Kantor, Harvey, and Tyack, David B., eds. Worǩ﹎_Youtㅡ﹎. and

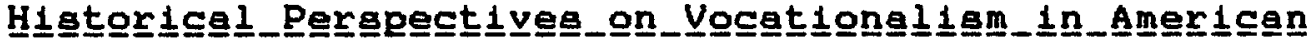

E므드트으. Stanford: Stanford University Press, 1982 .

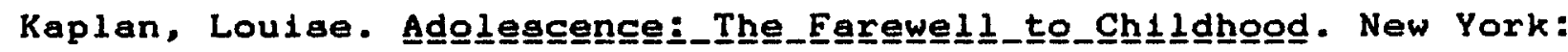
Simon and Schuster, 1984 .

Katz, Michael B., and Davey, Ian E. "Youth and Early Industrialization in a Canadian City." in Demos, John, and

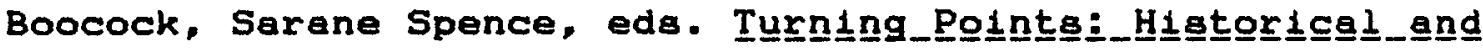

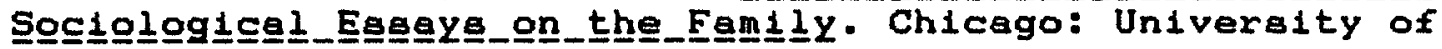
Chicago, 1978 .

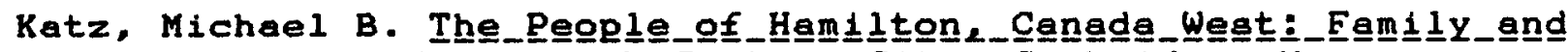

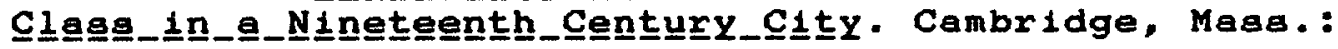

Harvard University Press, 1975.

Katz, Michael B. In $\underline{\text { The_Sh}}$,

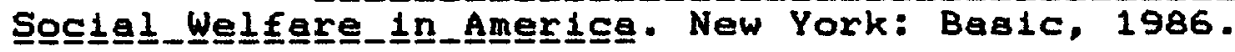

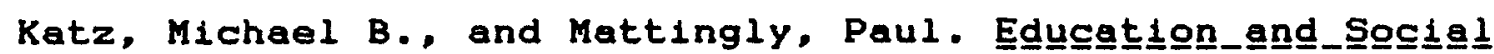

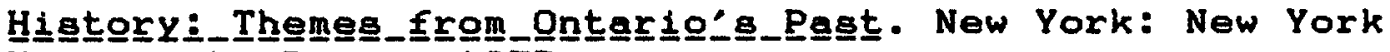
University Press, 1975. 
Kessen, William. The_éghild. New York: John Wiley \& Sons, 1965.

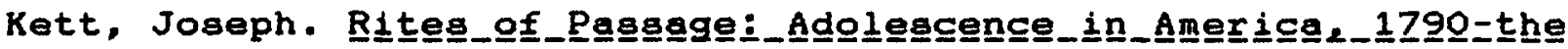
Present. New York: Basic, 1977.

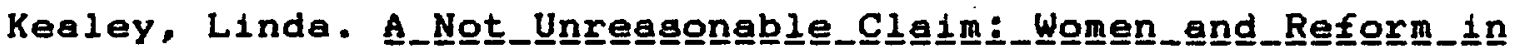

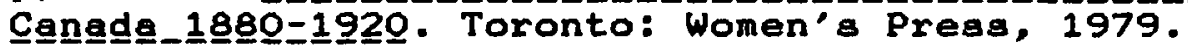

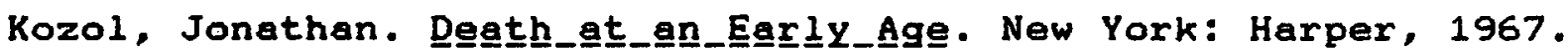

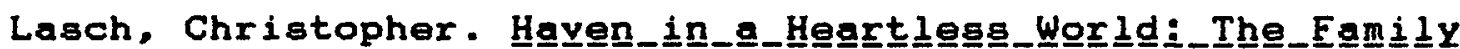
Beselged. New York: Basic, 1979.

Leslett, Peter, and Wall, Richard, eds. Houseghohold_and_Familyy_in Penst_Iime. Cambridge: Cambridge Univeraity Press, 1972.

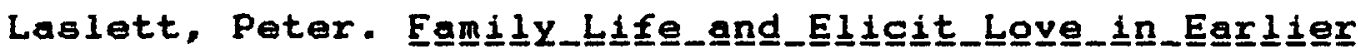
Generatílong. Cambridge: Cambridge University Press, 1977.

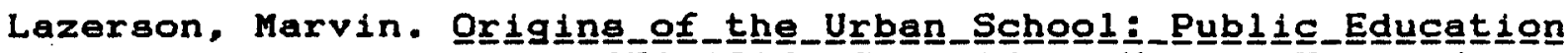
1ㅁ﹎. Massenchusettas_18 $10=1915$. Cambridge, Masa.: Harvard University Press, 1971 .

Lazerson, Marvin. "Progressive Era Educational Reform." in

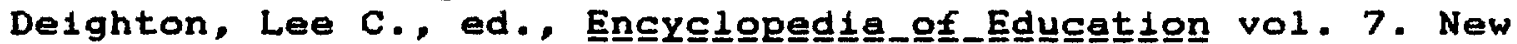
York: Mackilian, 1971, Pp. 256-62.

Lazerson, Marvin. "Urban Reform and the Schoola: Kindergartena in

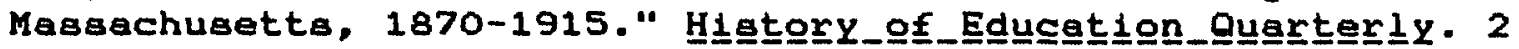
(April 1970): 84-102.

Lazerson, Marvin, "Educational Institutions and Mental

Subnormality: Notes on Writing a History." in Michael J.

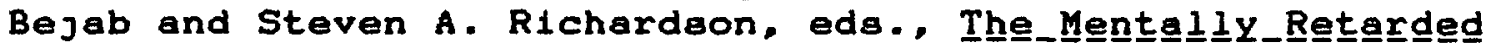

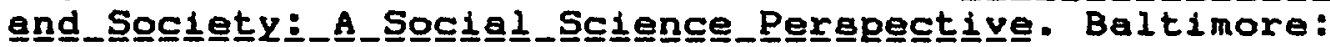
University Park Press, 1975.

Lazerson, Marvin. "Origine of Special Education." in Chambers,

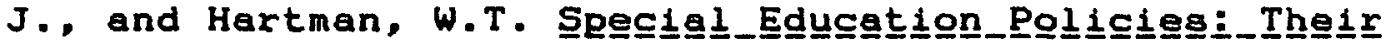

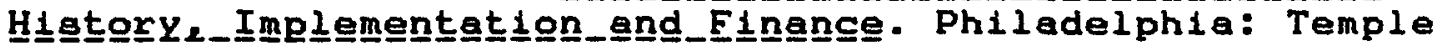
University Press, 1983.

Lazerson, Marvin, and Grubb, W. Norton. Amer

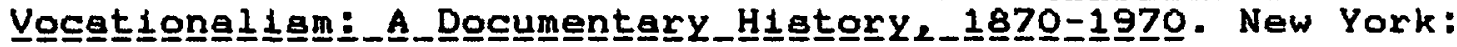
Teachers College Press, 1974.

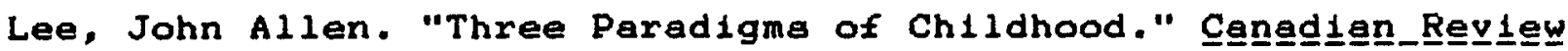

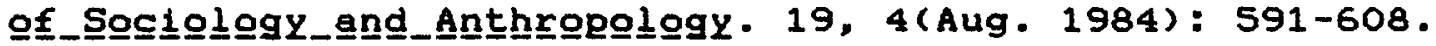

Lewis, Norah. "Creating the Little Machine: Child Rearing in British Columbia, 1919-1939." BC_Studieg 56 (1982/83): 4460 . 
Lew1s, Norah. "Physical Perfection for Spiritual Welfare: Health and the Urban Child, 1900-1939." In Rooke, Patricia T., and

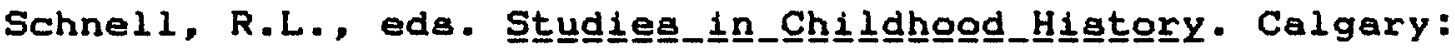
Delselig, 1982, pp. 135-66.

Lewis, Norah. "Advising the Parenta: Child Rearing in B.C. Duging the Inter-War Years." Ed.D. Thesis, University of British Columbia, 1980.

Lomax, Elizabeth. "The Laura Spelman Rockefeller Memarial: Some of its Contributions to Early Research in Child

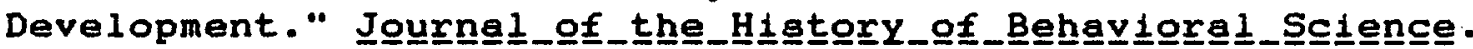
$13(1977)$ : $283-93$.

Lopez, Manuel D. "A Guide to the Interdisciplinary Literature of

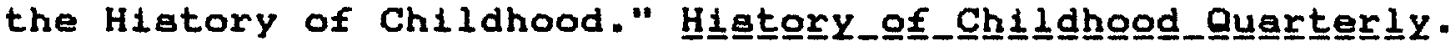
1. 3(Winter 1974): 463-94.

Matters, Diane. "The Boys Industrial School: Education for Juvenile Offenders." In Wilson, J. Donald, and Jones, David

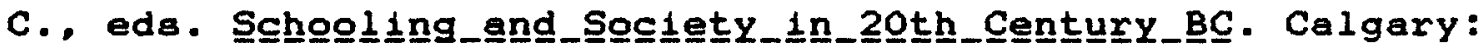
Delselig, 1980, pp. 53-70.

Matters, Diane L.J. "A Chance to Make Good: Juvenile Males and the Law in Vancouver, B.C." M.A. Thesia, University of British Columbia, 1978.

May, Margaret. "Innocence and Experience: The Evolution of the Concept of Juvenile Delinquency in the Mid-Nineteenth

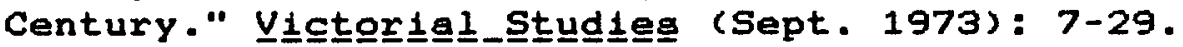

Mechling, Jay. "Advice to Historlang on Advice to Mothers."

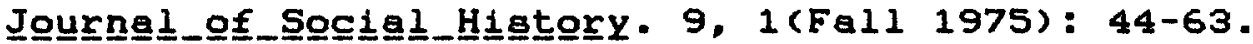

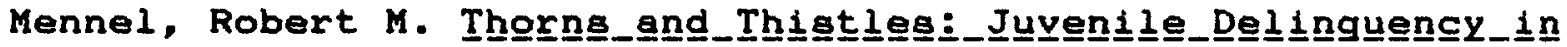

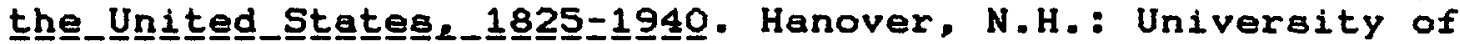
New Hampehire, 1973.

Meyer, John $w .$, and Boli-Bennett. "The Ideology of Childhood and the State: Rules Distinguishing Children in National Constitutions, 1870-1970." Amexicen_Sociological_Review 43 $(1978): 797-812$.

Musgrove, Frank. Youthh_and_the_Social_ordex. Bloomington, In.: University of Indiana Press, 1965.

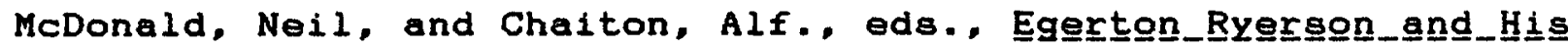
Times. Toronto: Mackilian, 1978 .

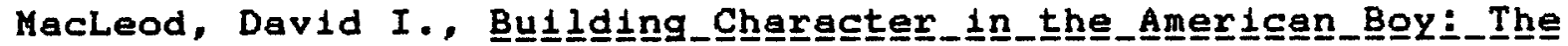

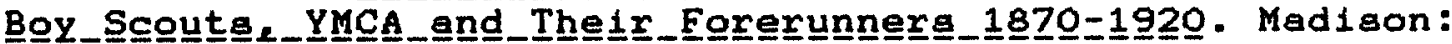


University of Wisconsin Press, 1983.

Macleod, David. "A Live Vaccine: The YMCA and Male Adolescence in

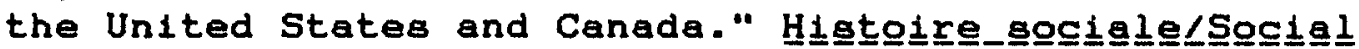
H보트오․ XI, 21 (May 1978): 5-25.

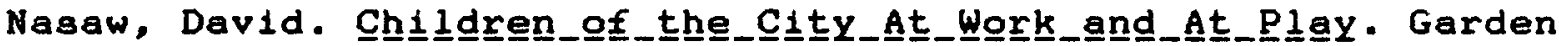
City, N.Y.: Anchor/Doubledey, 1985.

Northway, Mary. "Chlldatudy in Canada: A Casual History." in Brockman, Lois M.; Whitely, John H.; and Zubek, John P. Ch1ㅣㅁ﹎evelopment:_Selected_Readings. Toronto: McClelland Stewart, 1973, ch. 2 .

Parr, Joy. Lạbour

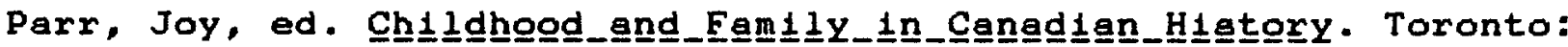
McClelland Stewart, 1982 .

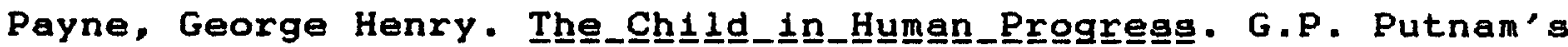
Sons, New York and London, 1916 .

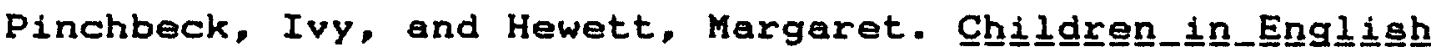
Sociiety. 2 vols. Toronto: University of Toronto, 1969, 1973.

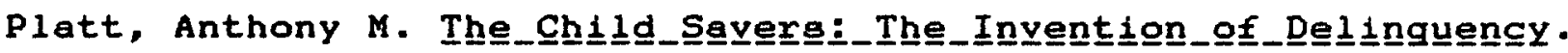
Chicago: University of Chicago, 1969, 1972.

Platt, Anthony M." "The Rise of the Child Saving Movement: A Study in Social Policy and Correctional Reform." The Annalg of

Platt, Anthony M., "Introduction to the Reprint Edition." National Conference of Charities and Correction. Hisetory_of

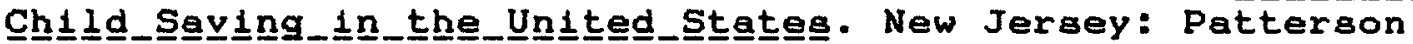
Smith, 1893, reprint 1971.

Plumb, J.H. "The Commercialization of Childhood." Horrizon. 18, $4($ Summer 1976): 16-22.

Plumb, J.H. "The Great Change in Children." Hoxizzon. 13, 1(winter 1971).

Prentice, Alison L., and Houston, Susan E. Familily,_Schhoog

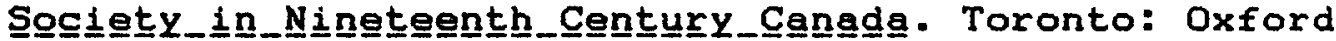
University Press, 1975.

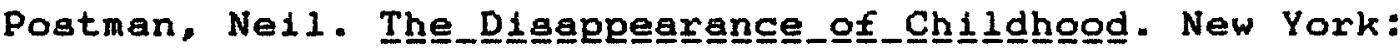
Delacorte, 1982 .

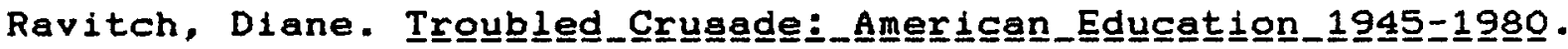
New York: Basic, 1983. 
Ravitch, Diane. The_Greget_Schoogl_warg. New York: Basic, 1974.

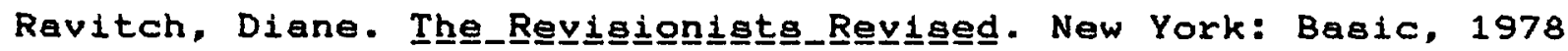

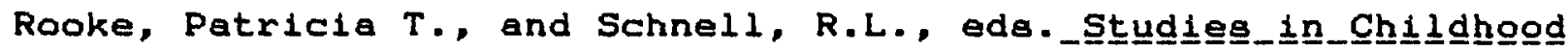

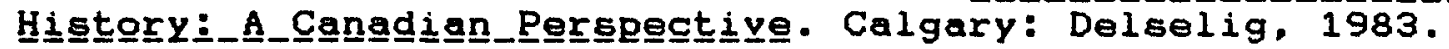

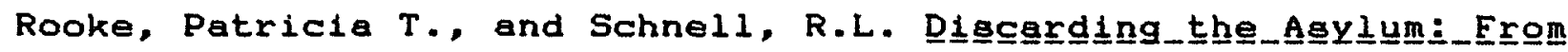

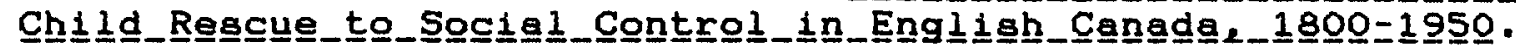
Landham, MD: University Press of America, 1983.

Rooke, Patricia T., and Schnell, R.L. "The King'g Children in Engliah Canada: A Paycho-Social Study of Abandonment, Rejection and Colonial Response, 1869-1930." Journnal_of Paych으느으느토. 8 (Spring 1981): 387-420.

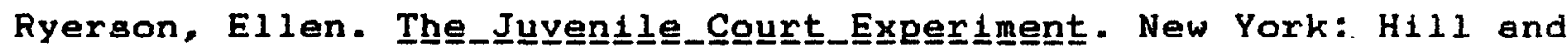
Wang, 1978.

Schlossman, Steven L. "Philanthropy and the Gospel of Child

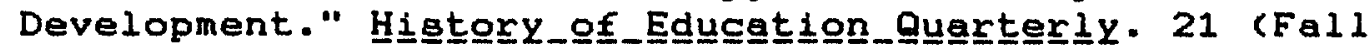
1981): 275-99.

Schlossman, Steven L. "Before Home Starts: Notes Toward a History of Parent Education in America, 1897-1929." Hargryar

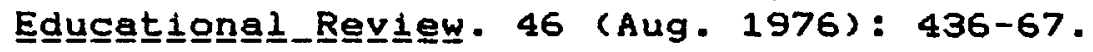

Schlossman, Steven L. "G. Stanley Hall and the Boys Club: Conservative Applications of Recapitulation Thory." Journal

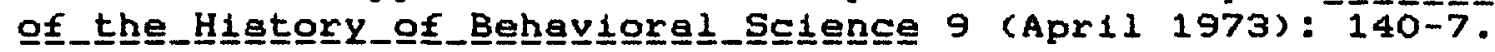

Schlossman, Steven L. "End of Innocence: Science and the Transformation of Progress, Juvenile Justice 1899-1917."

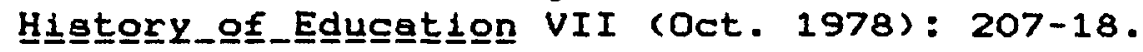

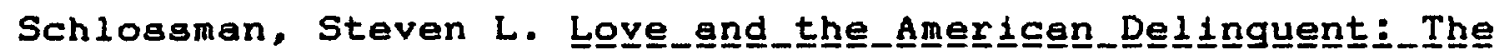

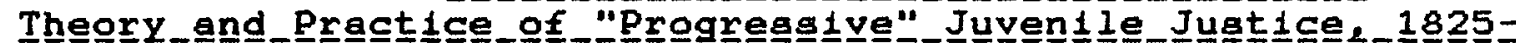
1920. Chicago: University of Chicago, 1977 .

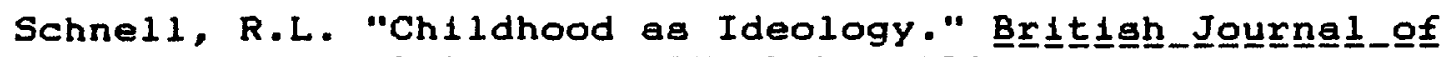

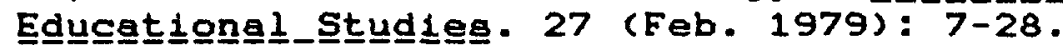

Sheehan, Nancy M., J. Donald Wilson, and David C. Jones, eds.,

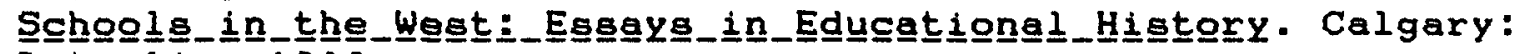
Detselig, 1986 .

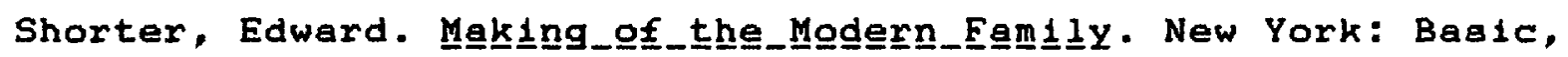
1975.

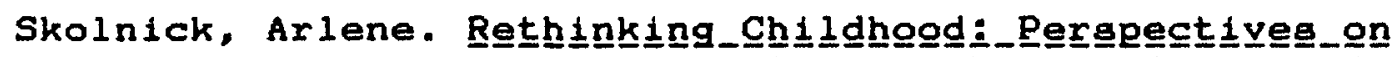
Development_and__Soćlety. Boston: Little Brown \& Co., 1976. 


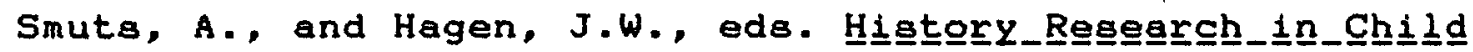

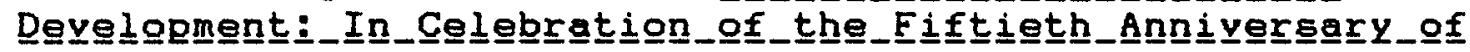
SSICD. Monographs of the Society for Research in Child Development. Chicago: Univeraity of Chicago, 1984.

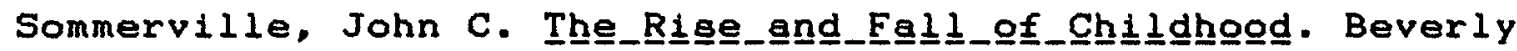
Hills: Sage, 1982.

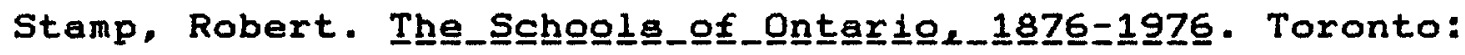
University of Toronto, 1981.

Stone, Geoffrey. "Freudianism and Child Rearing in the Twenties."

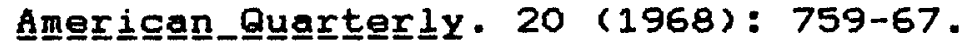

Stender, Celia B. "Sixty Years of Child Training Practices:

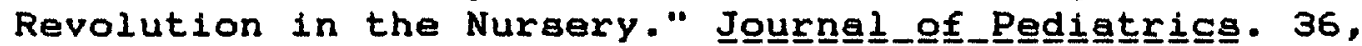
1 (Jan. 1950): 122-34.

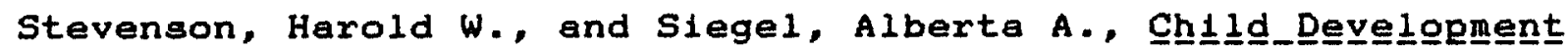

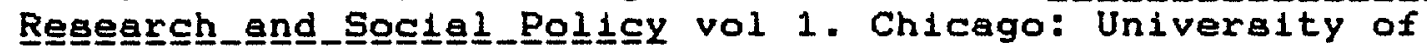
Chicago, 1984 .

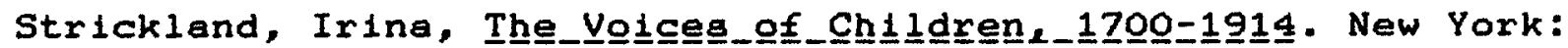
Barnes \& Noble, 1973.

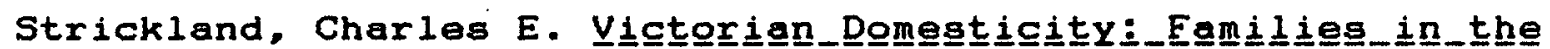

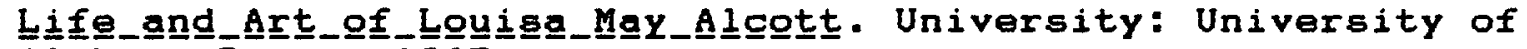
Alabama Prese, 1985 .

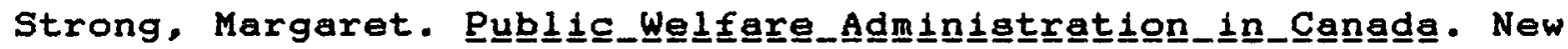
York: Patterson Smith, 1930, reprint, Chicago: University of Chicago, 1969.

Strong-Boag, Veronica, "Intruders in the Nursery: Child Care Professionals Reshape the Years from One to Five." In Parr

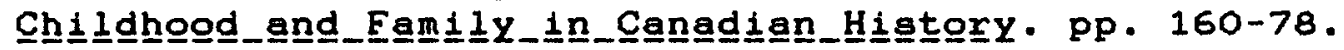

Strong-Boag, Veronica. "Canada'a Early Experience with Income Supplements: The Introduction of Mothers' Allowances."

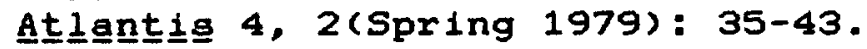

Strong-Boag, Veronica. "Wages for Housewark: Mothers" Allowances and the Beginning of Social Security in Canada." Jou

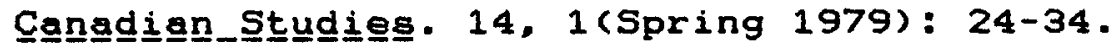

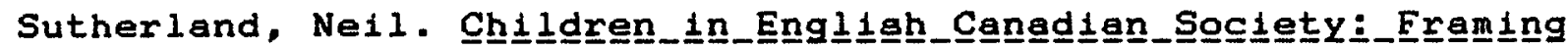
thhe_Twentiㅡ느느_Centuxy_Consensug. Toronto: University of Toronto, 1977, reprint 1982 .

Sutherland, Neil. "The History of Childhood: Some Notes on the

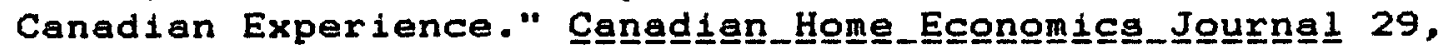




$$
1 \text { (Apr. 1979): 57-61. }
$$

Sutherland, Neil. "Social Policy, 'Deviant' Children, and the Public Health Apparatus in British Columbia Between the

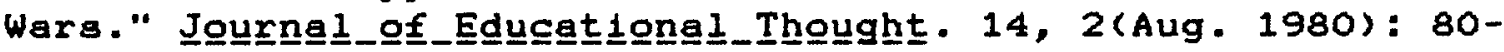
91 .

Sutherlend, Neil. "To Create A Strong and Healthy Race: School Children in the Public Health Movement, 1820-1920." Hís트ory

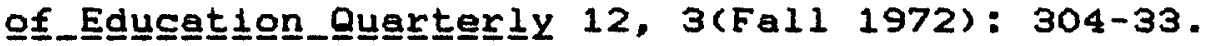

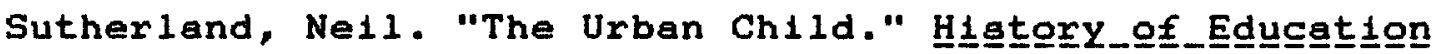

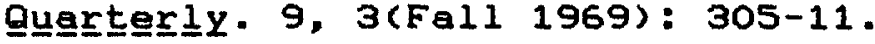

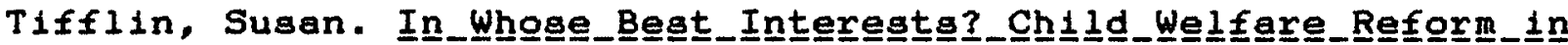
the_Progreseive_Era. Westport, Conn.: Greenwood Press, 1982 .

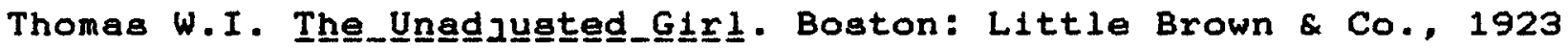

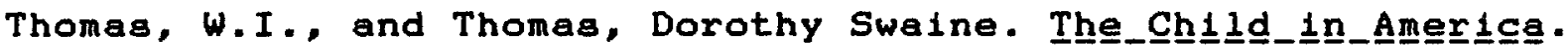
New York: Alfred A. Knopf, 1928.

Thuraton, Henry. The_Degendent_Ch11d:_A_Story_of_Chhanging_Aimg

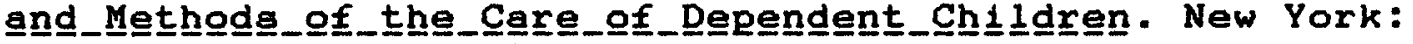
Columbia University Press, 1930.

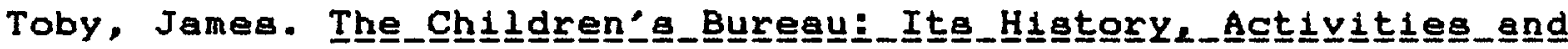
Orggenization. Baltimore: Johns Hopkins University Press, 1925 .

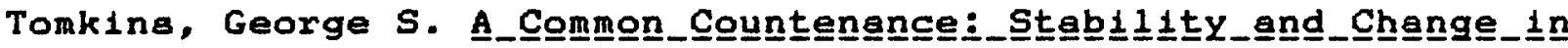

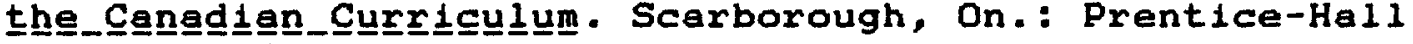
Canada, 1986 .

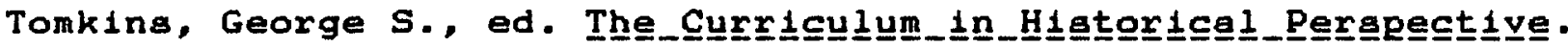
6th Yearbook. Vancouver: Canadian Soclety for the Study of Education, 1979.

Tomkins, George S. "Stability and Change in Canadian Curriculum."

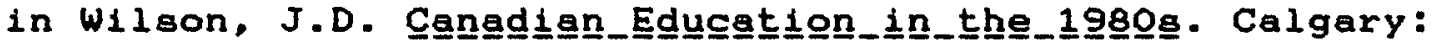
Detsel1g, 1981, pp. 135-58.

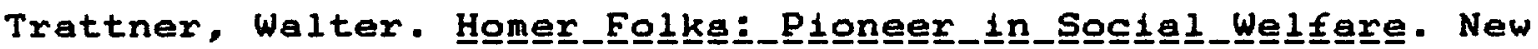
York: Columbia University Press, 1968 .

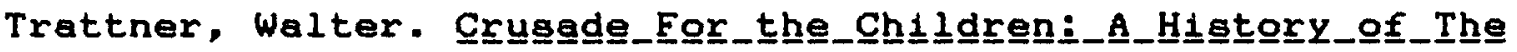

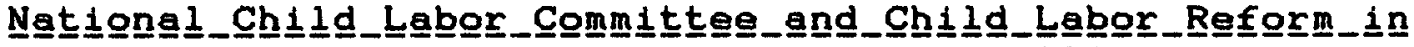
Ame토드. Chicago: University of Chicago, 1970.

Tyack, David B., and Hansot, Elizabeth, Mangagergooㅢ

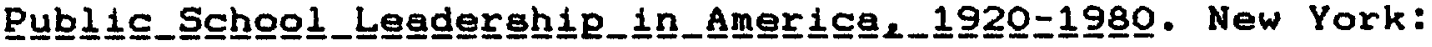
Basic, 1982. 


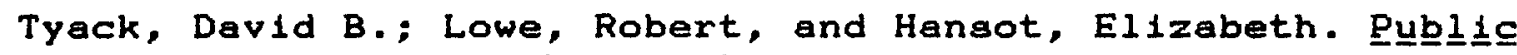

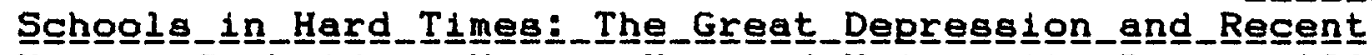
Yea

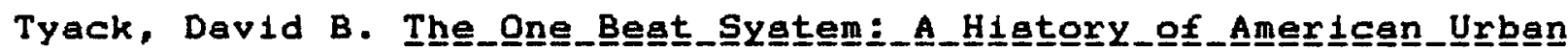
Educentín. Cambridge, Mass.: Harvard, 1974, reprint 1982 .

We1ss, Nancy Pottishman. "The Mother-Child Dyad Revisited: Perceptions of Mothers and Children in Twentieth Century

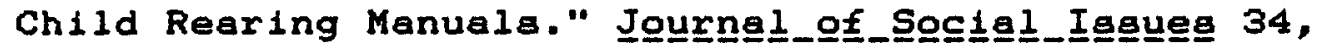
2(1978): 29-45.

Weiss, Nancy Pottishman. "Mother Invention of Necessity: Dr. Spock' Baby and Child Care." Amerisen_enuerteresly 29 (1977): 519-46.

Wilber, Harvey Dutton. "The Child Study Movement in America From its Origin (1880) to the Organization of the Progressive Education Association (1920)." Ph.D Thesis, Stanford University, 1945.

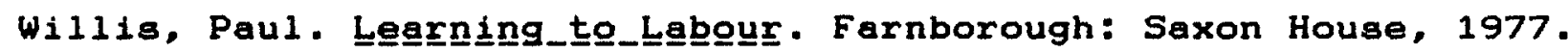

Wilson, Adrian. "The Infancy of the History of Childhood." Hiㅗ흐으느_and_Theory XIX (1980): 132-53.

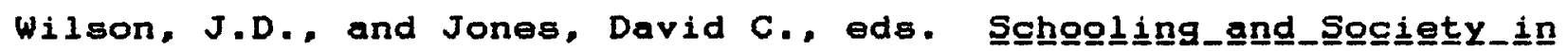

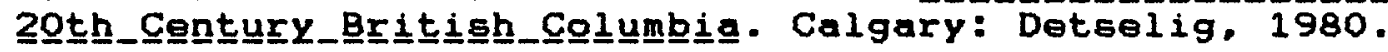

Wilson, J.D.; Stamp, Robert, and Audet, Louis-Philippe. Cẹneglịen

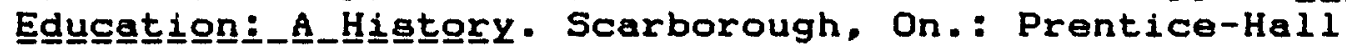
Canada, 1970 .

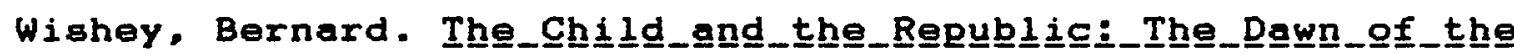

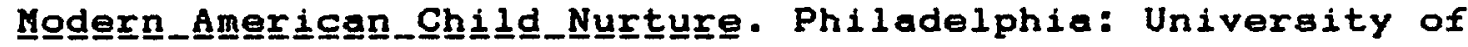
Pennsylvania, 1968 .

II. Medicalization: The Medical, Social and Behevioural Sciences as Related to Child Health and Mental Hygiene:

Mental hygleniata ldentified with preventive medicine and psychlatry. However, psychlatric perspectives were actively encouraged in the profesaionalization of public health, psychology, social work and nursing as well as teaching. There are two kinds of secondery literature in this area. The first, histories of the disciplines which mental hygiene influenced and in turn was influenced by. The history and soclology of the professionalization of medicine, psychiatry, paychoanalysis, psychology, social science and social work provides the context 
necessary to understanding the diverse impact of mental hygiene. It would have been impossible to cover these diverse areas in primary data resources. Additional useful literature on professionalization is included in subsection $D$ on general sources. Part of the professionalization process was the development of higher education especially in graduate education and research. The second major category of sources include biographical accounts of individuals and of organizations and institutions of relevance.

Abbott, Andrew. "The Emergence of American Psychiatry." PH.D. Thesis, University of Chicago, 1982.

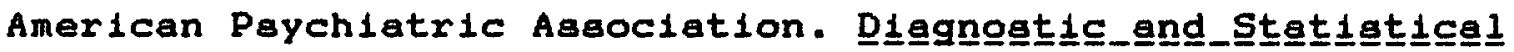
Manuaㅣ_of_Mental_Disogrderg. 3rd edition. Washington D.C.: APA, 1980, reprint 1984 .

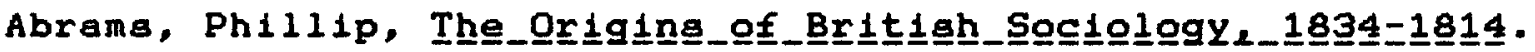
Chicago: Univeraity of Chicago, 1968.

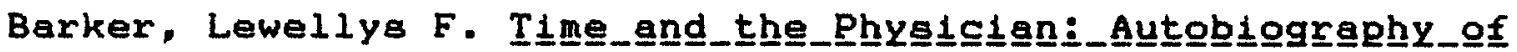
Lewelly lys_E__Barker. New York: G.P. Putnam's Sons, 1942.

Becker, Ernest. The_Revolution_in_Psychiatry:_The_New Ung

Berlant, Jeffery L. Profefegg1on_and_Monogoly:_A_Stuudy_of_Medicine

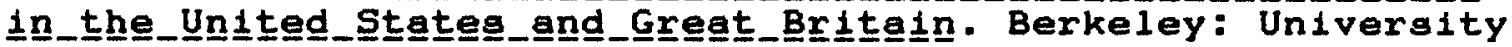
of California Press, 1975.

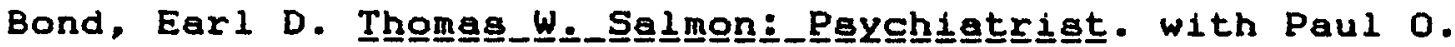
Komora. New York: w.W. Norton, 1950.

Borlng, Edwin G. A_Hisgtoxy_of_Experimentental__paycholology. New York: Appleton-Century-Crofts, 1929, reprint 1950.

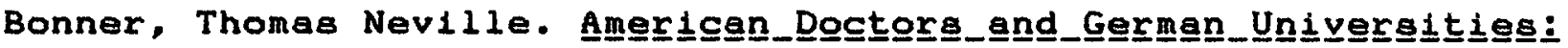

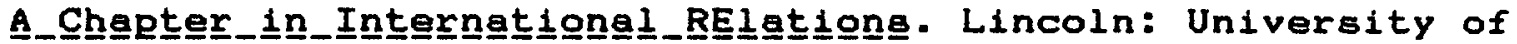
Nebraska, 1963.

Brett, George Sidney. A_H소트마_off_Paychhollogy. 3 vols. London: George Allen \& Unwin, New York: MacMillan, 1921.

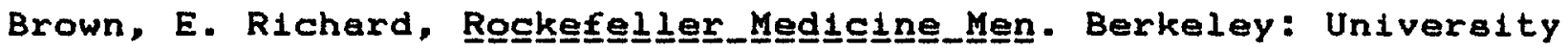
of Callfornia Press, 1960.

Buhler-Wilkerson, Karen. "False Dawn: The Rise and Decline of Public Health Nursing in America, 1900-1930." in Lagemann, Ellen C., ed. Nurging_Higtory._New_Perspectivese_New

Pogasibibilittieg. New York: Teachera College Preas, 1983, pp. 89-103. 
Burnham, John C. "The New Paychology From Narcisaism to Social Control." in Braeman, John, et al., eds. Changnge_ang

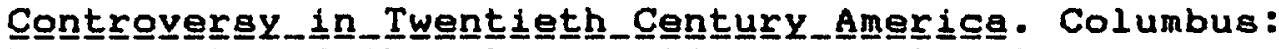
University of Oh1o Press, 1968, Pp. 396-8.

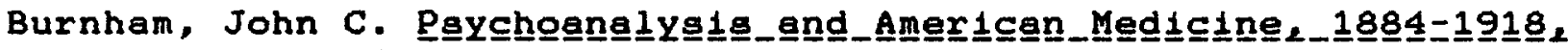

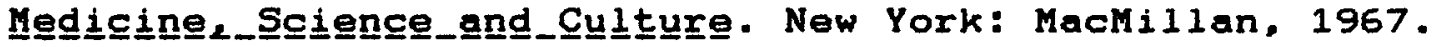

Burnham, John C. "Medical Specialista and Movementa Toward Social Control in the Progressive Era, Three Examples." in Israel,

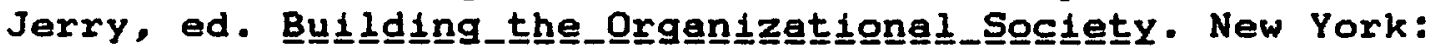
Free Press, 1972, pp. 27-30.

Burring, Walter L. "Preventive Medicine - Its Changing Concepts,

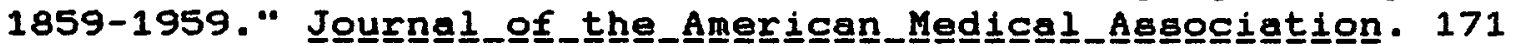
(1959): $2190-4$.

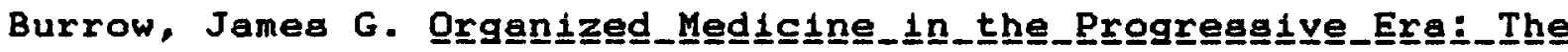
№ye_Towar Press, 1977.

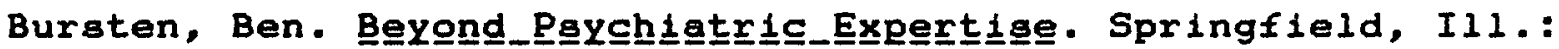
Charles C. Thomas, 1984.

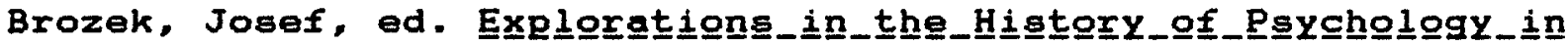

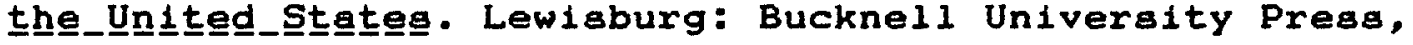
1984 .

Bryce, Peter H. "H1story of Public Health." Canadian_Iherapigat and__Sangitaㅛㄷ_Engingeer. I (June 1910): 287-91.

Bryce, Peter H. "The Story of Public Health in Canada." In

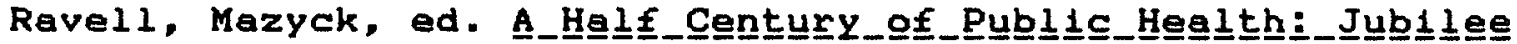

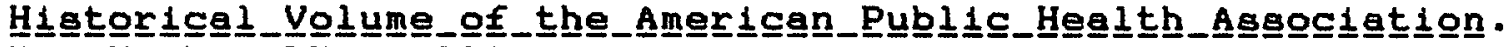
New York: APHA, 1921 .

Camfield, Thomas M. "The Professionalization of American

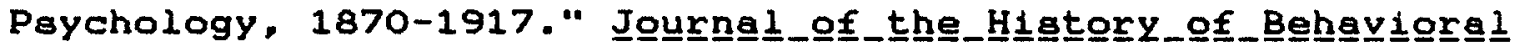
Scie모․ 9, 1 (Jan. 1973): 66-75.

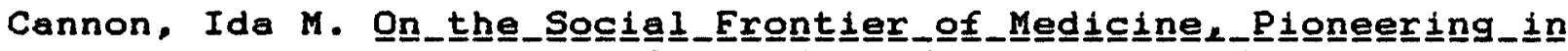

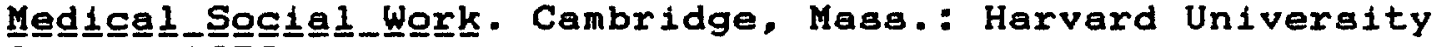
Press, 1952.

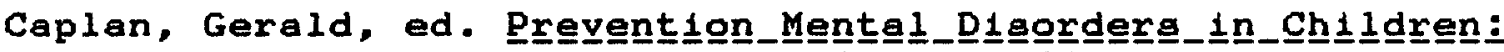

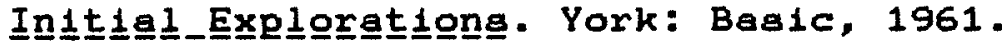

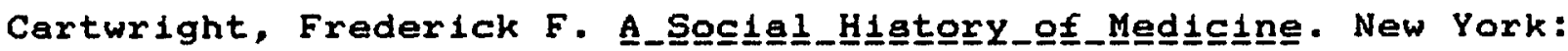
Longmans Green \& Co., 1917.

Castel, Robert; Castel, Francoise, and Lovell, Anne. The Pgychiat몯﹎.Society. Translation Arthur Goldhammer. New 
York: Columbia University Press, 1982.

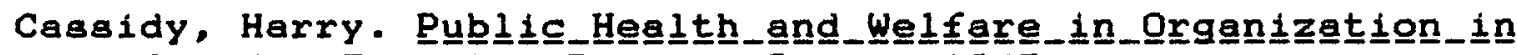
Canada. Toronto: Ryerson Press, 1945.

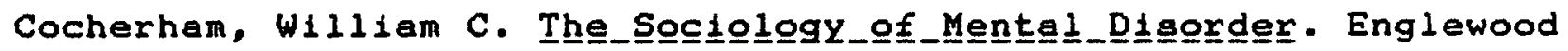
Cliff8, N.Y.: Prentice Hall, 1981.

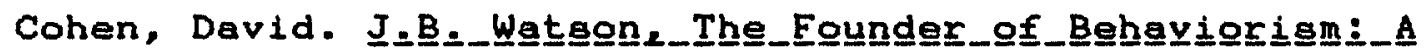

Bi

Commission on Emotional and Learning Disorders, One Millyion

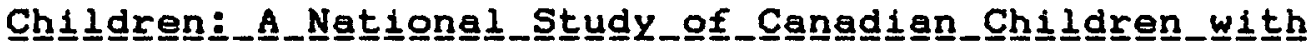

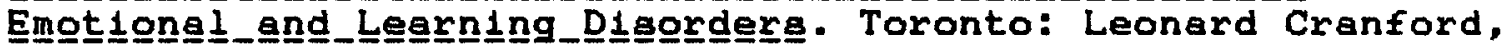
1970.

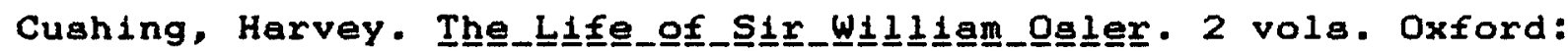
Clarendon Preas, 1926.

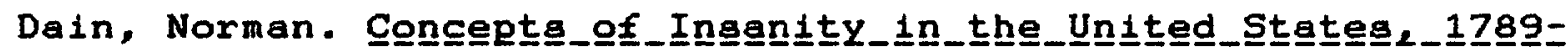
1866. New Brunswick: Rutgers University Press, 1964 .

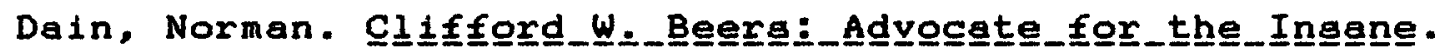
Pittaburg: University of Pittsburg Press, 1980 .

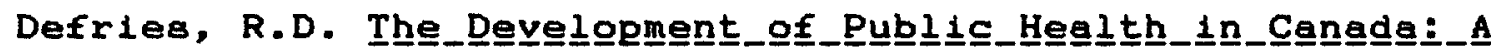
Review_of_the_Hi

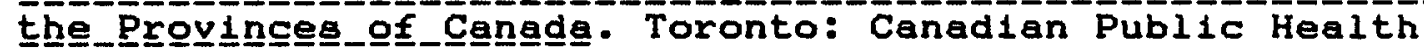
Association, 1940 .

Deutsch, Albert. "The History of Mental Hygiene." in Hall, J.K.,

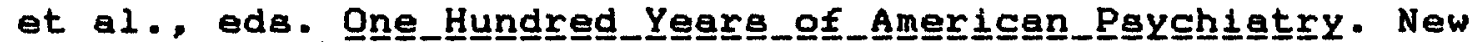
York: Columbia University Press, 1944, pp. 325-65.

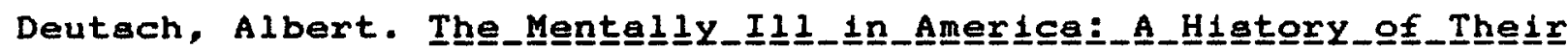

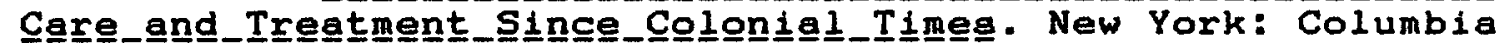
Universtiy Press, 1937 , reprint 1949 .

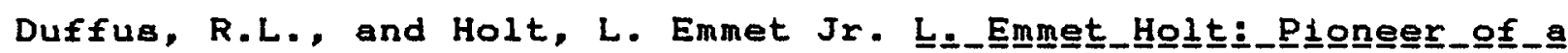

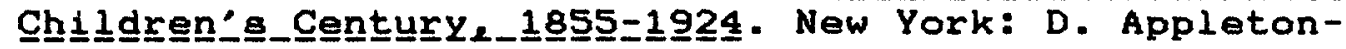
Century. 1940 .

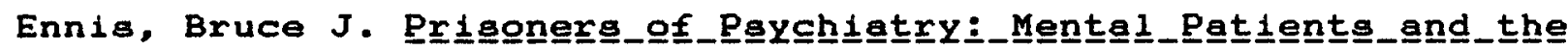
Law. Introduction by Thomas Szasz. New York: Harcourt, Brace Janovich, 1972.

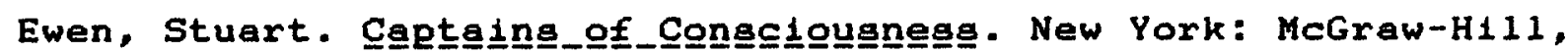
1976.

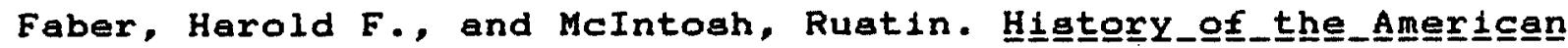

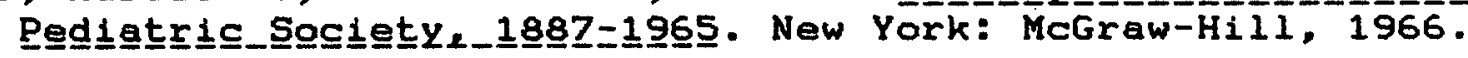




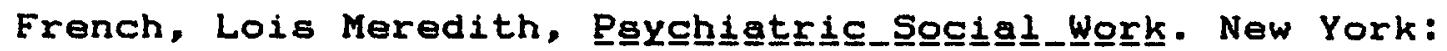
Commonwealth Fund, 1940.

Ferrel1, John A. "The Trend of Preventive Medicine in the United

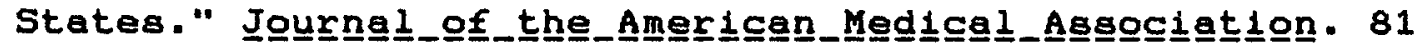
(1923): 1963-9.

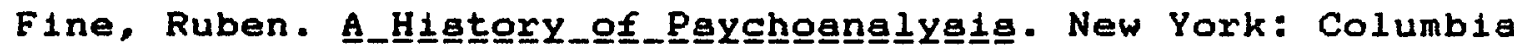
University Press, 1979.

Fleming, Donald. Williliem_Henry_Welch_and_the_Rige_of_Modern Medilsine. Boston: Little Brown \& Co.. 1954.

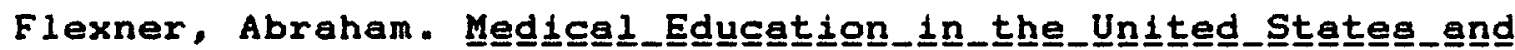
Cenada Bulletin No. 4. Carnegie Foundation for the Advencement of Teaching. (1910).

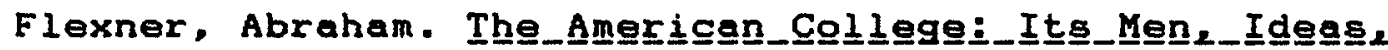
Institutions. New York: Century, 1908, reprint Arno, 1969.

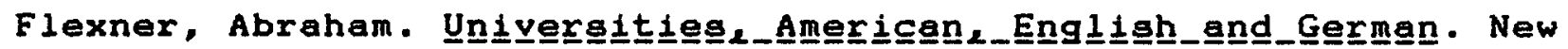
York: Eichelser \& Lewison, 1930 .

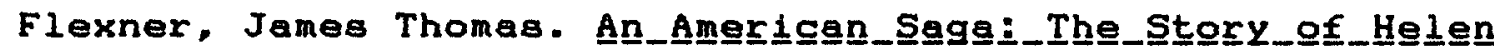

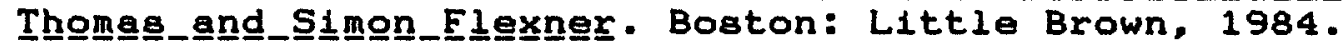

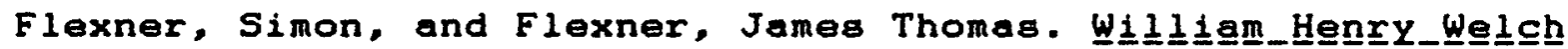

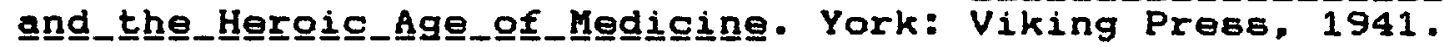

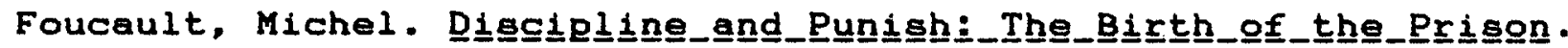
Translated by Richard Howard. New York: Vintage, 1977.

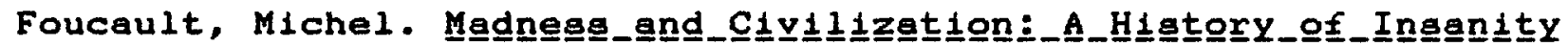
in_the_Age_of_Regegon. Translated by Richard Howard. New York: Vintage, 1963, reprint 1973.

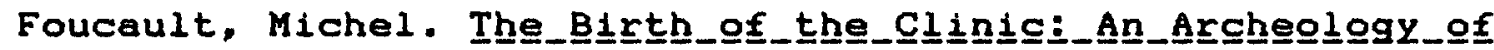
Medicel 1 - Perceptín. Translated by A.M. Sheridan Smith. New York: Random House, 1975.

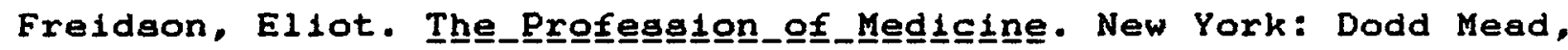
1970.

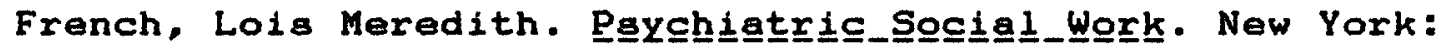
Commonwealth Fund, 1940.

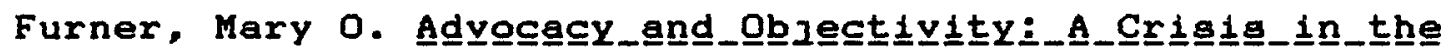

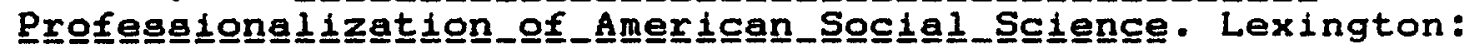
University Press of Kentucky, 1975.

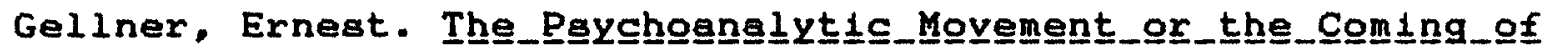
Unㅗㅗeㅗㅇㅡ. London: Paladin, 1985 . 


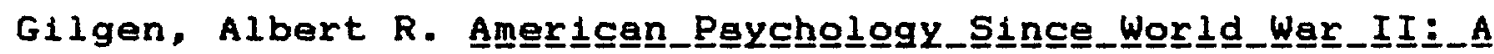

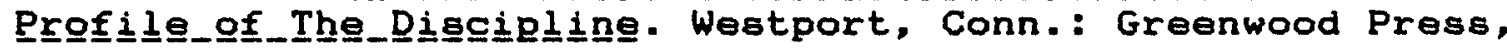
1982.

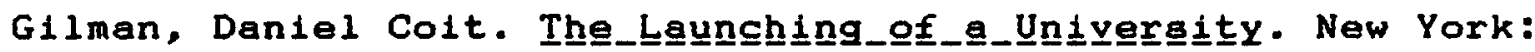
Dodd Mead, 1906.

Glasscote, Raymond M.; Fishman, Michael E.; and Sonis, Meyer, et

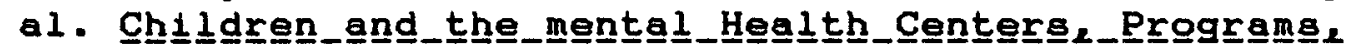

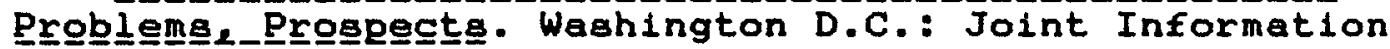
Service of the Amexican Psychlatric Association and the National Association for Mental Health, 1972.

Goode, William J. "Encroachment, Charlatanism and Emerging Professions: Psychology, Sociology and Medicine." American

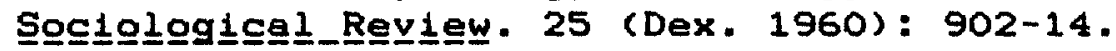

Goshen, Charles E. "The Background of Today" B Soclal Paychiatry." Menteㄴ_Heel토. 55, 4(Oct. 1971): 526-32.

Greenland, Cyril. "Servicea for the Mentally Retarded in Ontario,

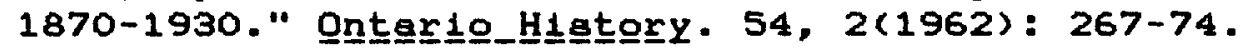

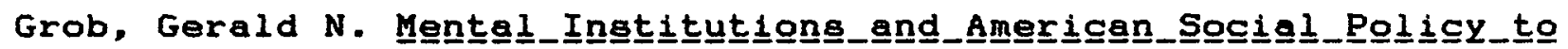
1875. New York: Free Press, 1973 .

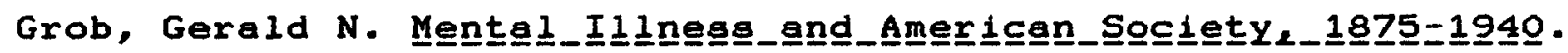
New Haven: Yale University Press, 1983.

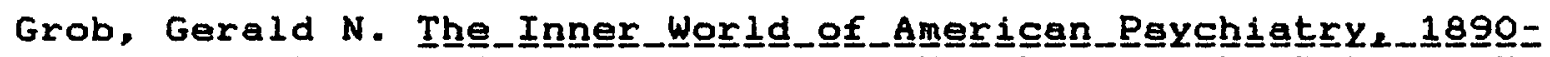

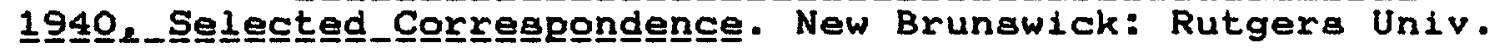
Press, 1985 .

Group for the Advencement of Paychiatry, Committee on Child

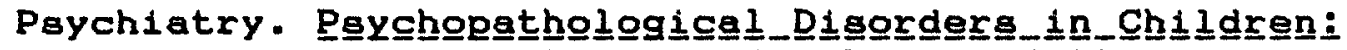

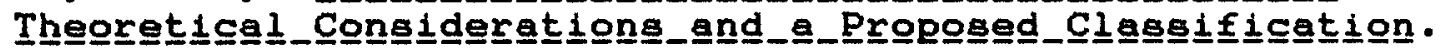
VI, 62 (June 1966).

Grunsky, Oslas, and Pollner, Marvin, eds. The﹎.Socilologgy_of__kental 1

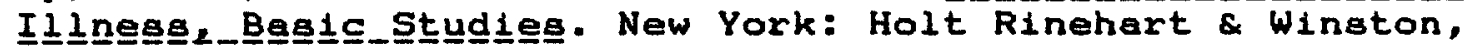
1981 .

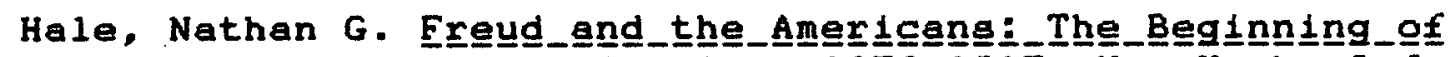

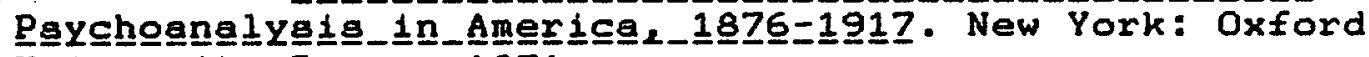
University Press, 1971 .

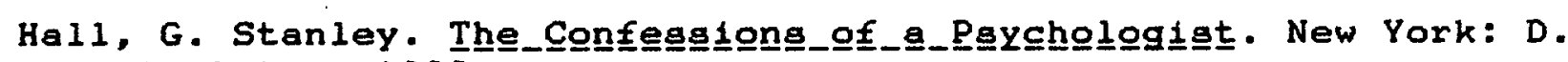
Appleton, $192 \overline{3}$.

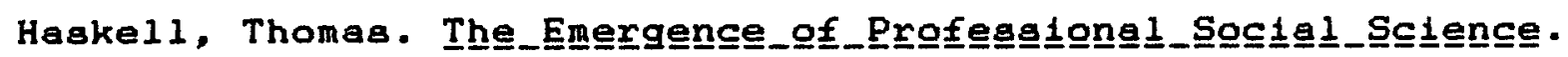
Urbana: Univeraity of Illinols, 1977. 


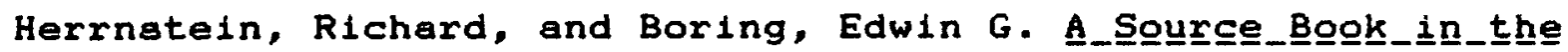
Histoㅡㄴ﹎of_Psychology. Cambridge, Mass.: Harvard University Press, 1965 .

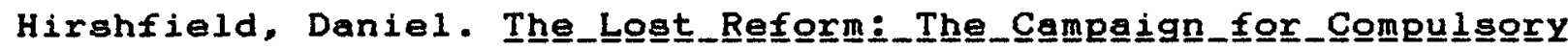

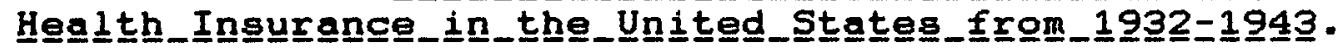

Cambridge, Mass.: Harvard Univerty Press, 1970

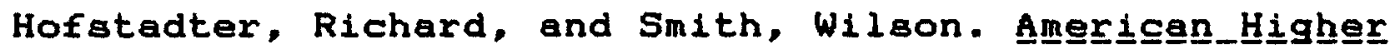

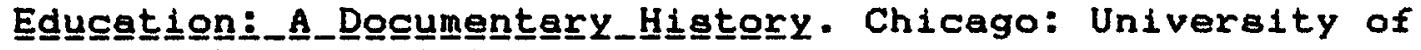
Chicago Press, 1961.

Hollingshead, August B., and Redlich, Frederick C. Claㅛa﹎ang

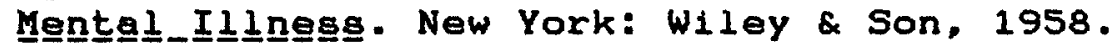

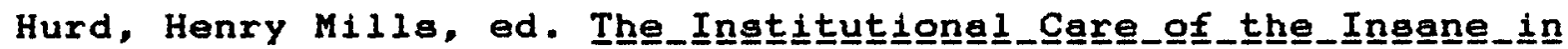

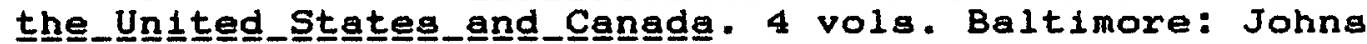
Hopkins Univ. Press, 1916.

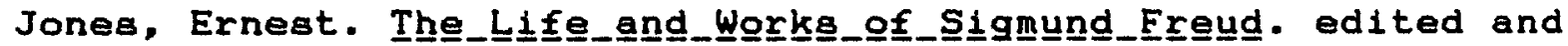
abridged by L. Trililing and Steven Marcus. London: Travistock, 1962.

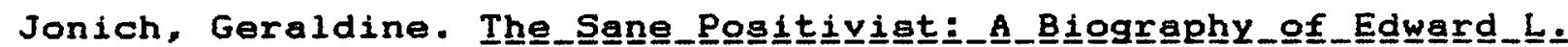
Thorgnglike. Middletown, Conn.: Wesleyan Univ. Press, 1968

Kanner Keo. Chhild__Pgychiotryy. 3rd edition. Springfield, Ill.: Charles C. Thomas, 1935, 1957.

Kaufman, Martin. Amer

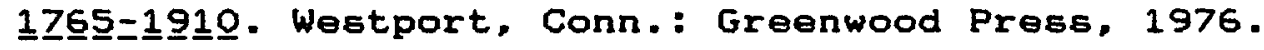

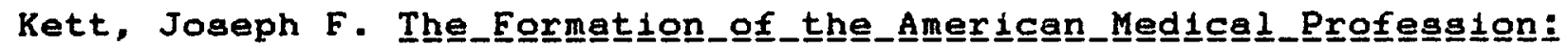

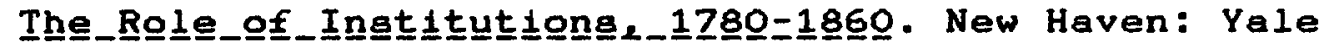
University Press, 1968.

Kitrie, N.N. The_Rght__to__Be_Differerent:_Deviance_and_Enfog Ihereey. Baltimore: Johns Hopkins Univerty Press, 1971.

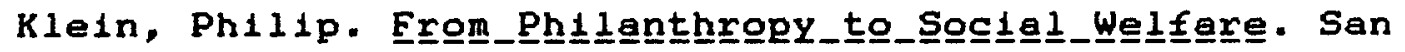
Francisco: Jossey-Bass, 1968.

Lagemann, Ellen Condliffe. Nura

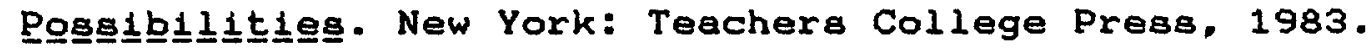

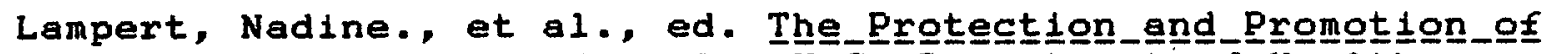
Mental_thealth Education and Welfare, Public Health Service Bulletin No. 1226, NIMH. Washington D.C.: Government Printing, revised 1965. 


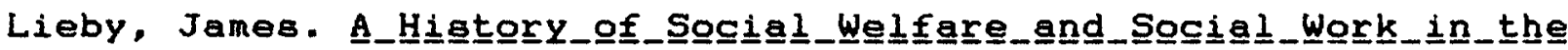

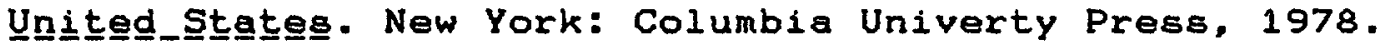

Levine, Murray, and Levine, Adeline. A_Sog

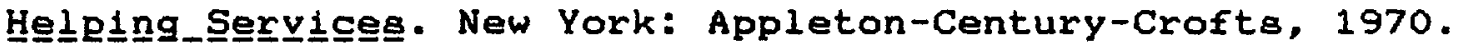

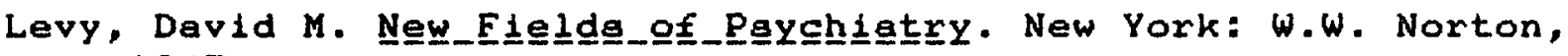
1947.

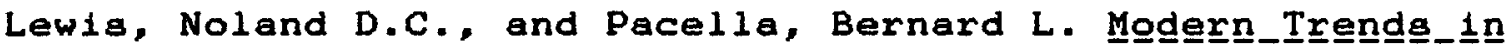

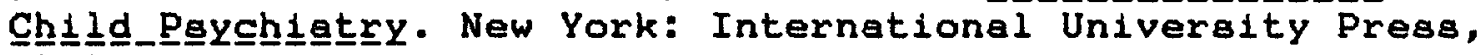
1945 .

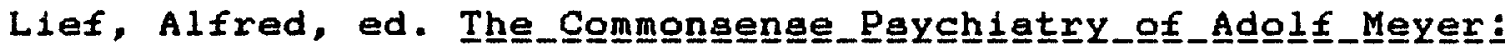
Eifty=Two_Selected_Pepers. with biographical narrative by Alfred Lief. New York: McGraw-Hill, 1948.

Lowrey, Lawson, and Sloane, Victoria. Orthhopsychiatry

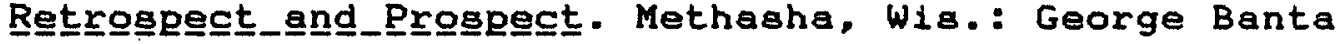
Publishing for American Psychiatric Association, 1948.

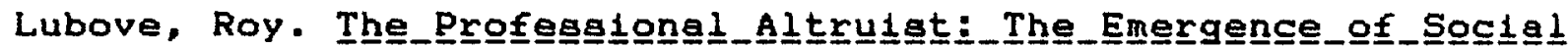

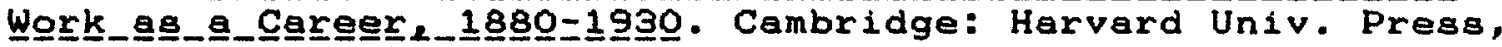
1965, reprint New York: Atheneum, 1969.

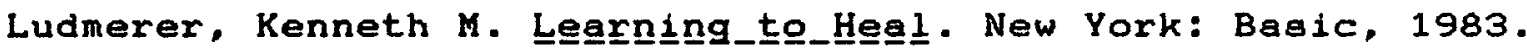

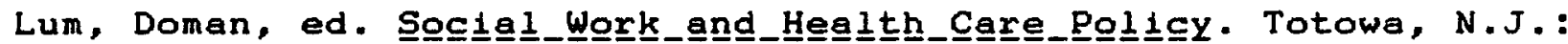
Allanheld, Oamun \& Co., 1982.

Metters, Fred. "In Defense of Common Sense: Mental Hygiene as Ideology and Mentality in Twentieth Century America." Progegeecte. 2 (Winter 1979): 459-516.

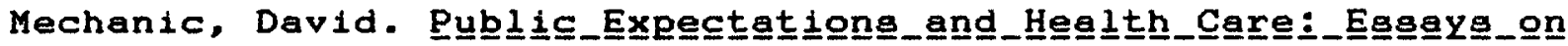
the_Changing_organizention_of_He日 wiley \& Sons, 1972 .

Metzgar, Walter P. "The Age of the University." in Hofstadter, Richard, and Metzgar, Walter. The_Develogment_of Ereegom. New York: Columbia 1955, pp. 277-506.

Meyer, Adolf. Peychoblology. Foreward by Noland D. Lewis. Springfield, Ill.: Charlea C. Thomas, 1957.

Meyer, Adolf. "The Birth and Development of the Mental Hyglene Movement." Ment트늡yg

Meyer, Adolf. "Thirty-Five Years of Paychiatry in the United States and Our Present Outlook." Amer Pgychígtry. 8 (July 1938): 1-31. 
Meyer, Adolf, Solllected_Papers. 4 vols. Edited by Eunice Winters. Baltimore: Johns Hopkins University Presa, 1951-1952.

Meyers, C.R. "Notes on the History of Psychology in Canada." Ihe

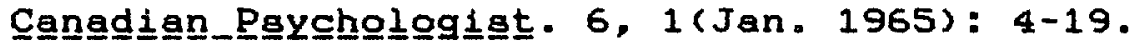

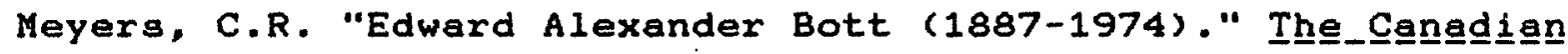
Paych으으의은. 15, 3(July 1974): 292-302.

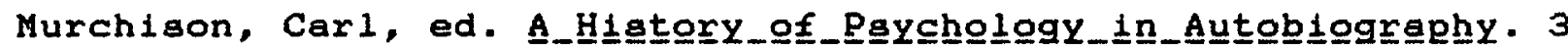
vola. Worchester, Masa.: Clark Univ. Presa, 1936.

McConnachie, Kathleen. "The Canadian Mental Hygiene and Eugenics Movement." Paper presented Canadian History of Education Society Annual Meetings, Oct. 14, 1983, Vancouver. BC.

McCullers, John C. "G. Stanley Hall'a Conception of Mental Development and Some Indications of Its Influence in

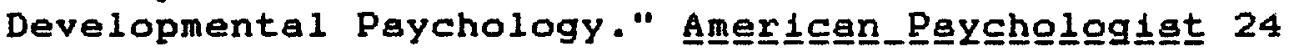
(December 1969): 1109-14.

Murchison, Carl, ed., A_H르to으y_of_pgychology_in_Biography. 3 vols. Worchester, Mass.: Clark University Press, 1936.

Page, Stewart. "The Mental Health Eatablishment and the Stifling of Change." The Cangedian Paycholiogisat. 14, 3(July 1973): 266-80.

Pederson, Paul B.; Sartorius, Norman; and Marsella, Anthony J.,

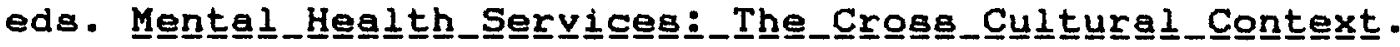
Beverly Hilis: Sage Publiahing, 1984.

Pitsula, James, "The Emergence of Social Work in Toronto."

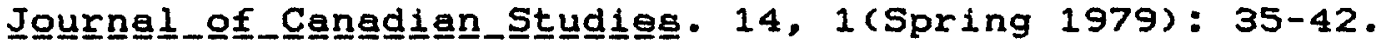

Quen, Jacques M. "Asylum Psychiatry, Neurology, and Mental

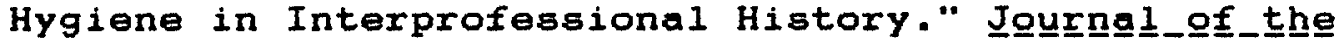

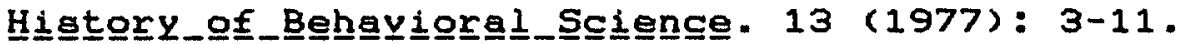

Ravenel, M.P., ed. Thee_Ameri

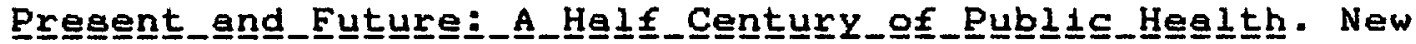
York: American Public Health Association, 1921.

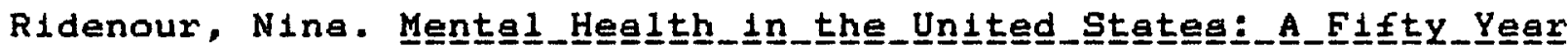
H1istory . Cambridge, Mass.: Harvard University Press, 1961.

Reiff, Philip. The_Triumph_of_the_Therapeutic:_Uges_of_Eaith Aftter_Ereud. New York: MacMilian, 1968.

Reiff, Philip. Erreudi_the_Mind_of_a_Moraligt. New York: MacMilian, 1979. 


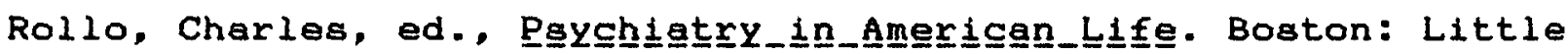
Brown, 1963, reprint Books for Libraries, 1971.

Robitscher, J.B. The_Powerg_of_Pgychigtexy. Boston: HoughtonMifflin, 1980.

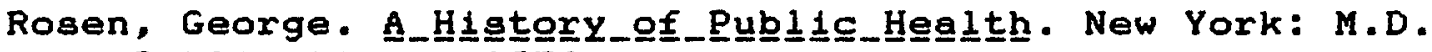
Publications, 1958

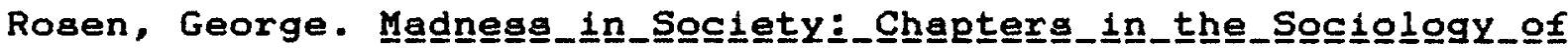
Mentaㅡ_Illinesg. London: Routledge \& Kegan Paul, 1968.

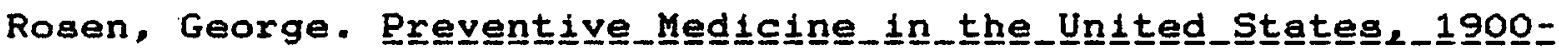
1975_Trends_and_Intenterpretetattiong. New York: Science History Publications, 1975.

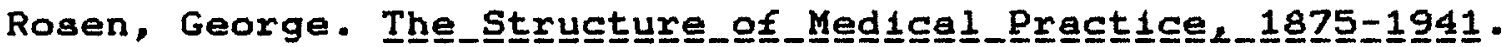
Philadelphia: University of Pennsyivenia, 1983 .

Rosen, George. "The First Neighborhood Health Center Movement:

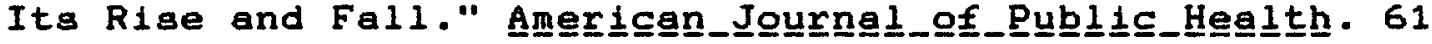
(Aug. 1971): 1620-37.

Rosenberg, Charles E. №_other_Godg:_Science_and_Amentic Thought. Baltimore: Johns Hopkins University, 1976.

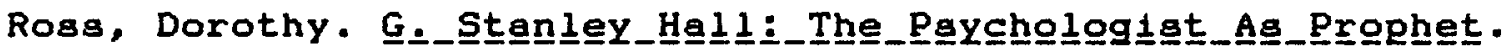
Chicago: University of Chicago, 1972.

Ross, Peter. "The Establishment of the Ph.D. at Toronto: A Case of American Influence." In Katz, Michael B. and Mattingly,

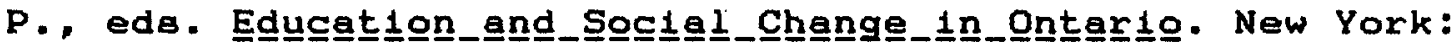
New York University Press, 1975.

Rothman, David J. The_Dígcoyery_of_the_Agylum:_Socilal_order and

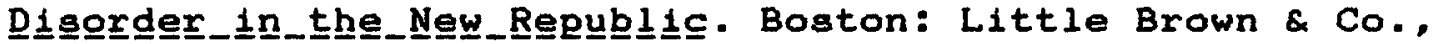
1971.

Rothman, David J . Congcience_and_Conyenience:_The_Agylum_end_Itg

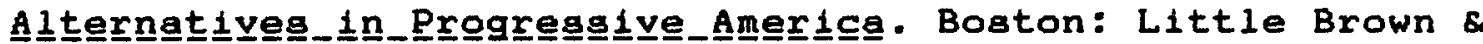
Co., 1980 .

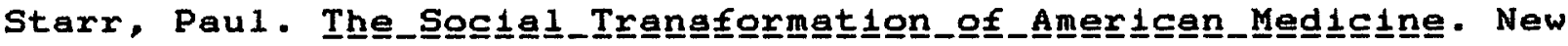
York: Basic, 1982.

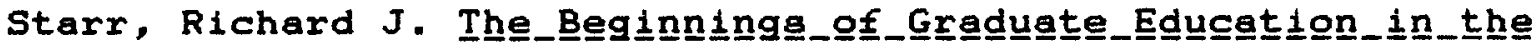
Uniteㅇ_Stateseg. Chicago: University of Chicago, 1953.

Sickerman, Barbara. "The Quest for Mental Health in America, 1880-1917." Ph.D. Thesis Columbia Univ. 1967.

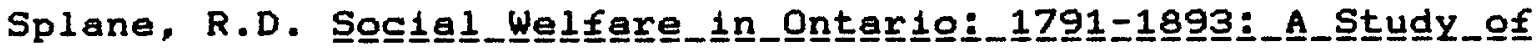




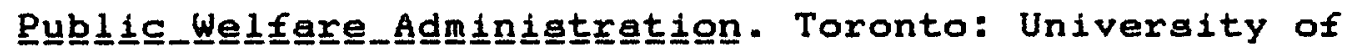
Toronto Press, 1985.

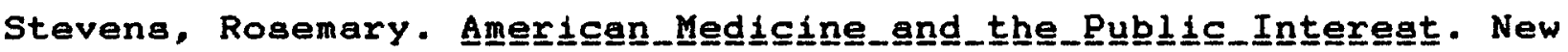
Haven: Yale University Press. 1971.

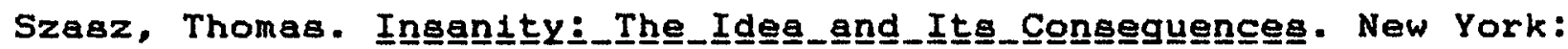
John Wiley \& Sons, 1987.

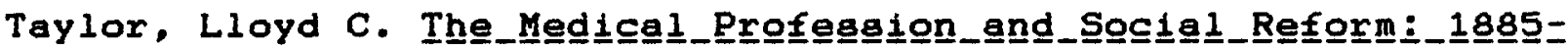
1945. New York: St. Martin's Press, 1974.

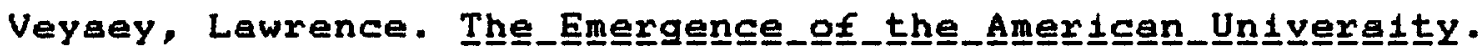
Chicago: Univeraity of Chicago Preas, 1965.

Welch, William. "The 25th Anniversary of Johns Hopkins Hospital."

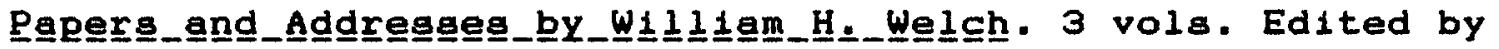
W.C. Bricket. Baltimore: Johns Hopking University Press, 1920, I: 25 .

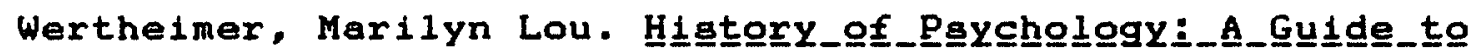
Sources. vol. 1. Paychology Information Guide Series, Detroit: Mich.: Gale Research Co., 1979.

Woods, Robert A., and Kennedy, Albert J., eds. Hanglbogok_-og Settllements. New York: Charities Publication Committee, 1911, reprint Arno Press and New York Times, 1970.

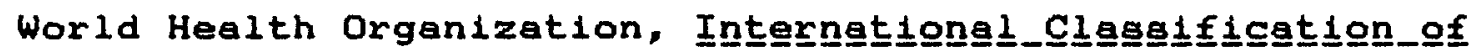

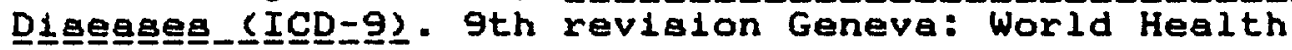
Organization, 1979.

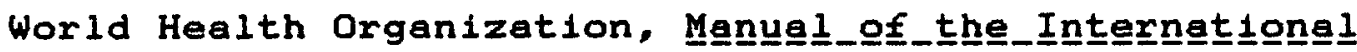

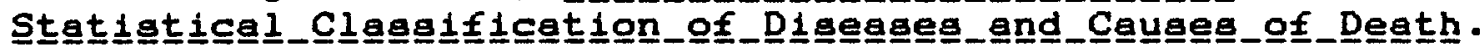
2 vols. Geneva: World Health Organization, 1977.

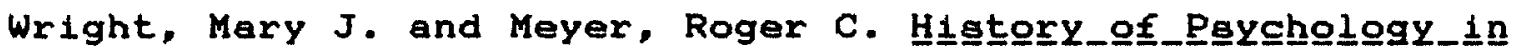
Cane묘. Toronto: C.J. Hogrefe, 1972 .

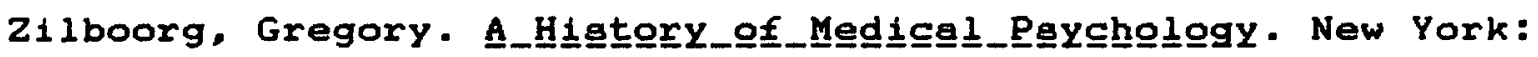
w. W. Norton, 1941 .

III. American Philanthropy in the Twentieth Century:

American philanthropy generated both commentary and controversy since the early decades of the twentieth century. The range is illustrated by the self-congratulatory descriptions of philanthropic work by philanthropists juxtaposed with the often blistering and sometimes unreasoned critiques of detractors. 
There is also a body of less inflammatory work some of which is by participants and other works by outside scholars. I found useful biographical studies, foundation produced programme summaries and participant authored chronicles of specific foundations as well as comparative descriptions of the work and structure of foundations. In the $1920 \mathrm{~s}$ and $1930 \mathrm{~s}$ a few studies were done by non-participants which attempted to place foundations in a social context. After World War II a new generation of critical analysis and historical commentary evolved which purposefully asked policy questions concerned with the role of foundations nationally and internationally.

The new focus was encouraged by the Congressional investigations of foundation in the $1950 \mathrm{~s}$ and by a Russell Sage Foundation Conference on the History of Philanthropy chaired by Merle Curti. Curti's Wisconsin History Project, funded by the Ford Foundation, was an outgrowth of the Conference. The Project produced a body of monographs and articles. Most recently, revisionist history and critical studies of American policy and social structure in the $1960 \mathrm{~s}$ and $1970 \mathrm{s,}$, which are detailed in the last section in the bibliography on general works, encouraged the development of critical and analytical investigations into the role of philanthropy. There is also a growing body of detailed descriptive work. Scholars have advanced aignificant questions on the relationship between philanthropy and democratic institutions. The secondary works on all levels facilitated the handling of primary data and integration of information on various boards, philanthropies and other social organizations. The more recent works raised important critical issues.

Anderson, James. "Education for Servitude: The Social Purposes of Schooling in the Black South." Ph.D. Thesis, University of Illinois, 1973

Anderson, James. "Northern Foundations in the Shaping of Black

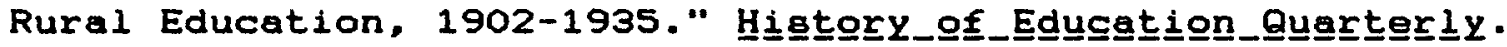
18 (1978): $371-96$.

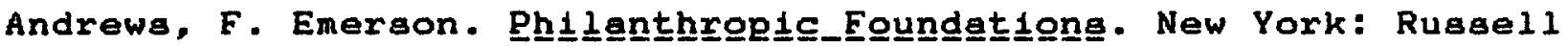
Sage Foundation, 1956.

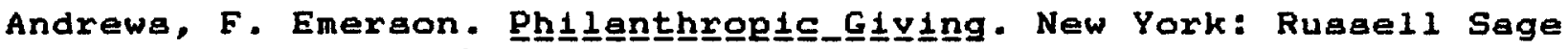
Foundation. 1950 .

Andrews, F. Emerson. Legal_Ingtyuments_of_Foundattiong. New York: Russell Sage Foundation, 1958.

Andrews, F. Emerson, and Harrison, Shelby M. Ameríican_Foung

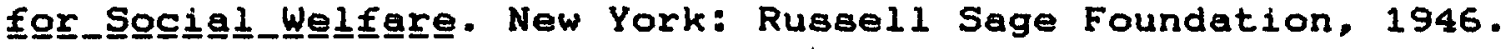

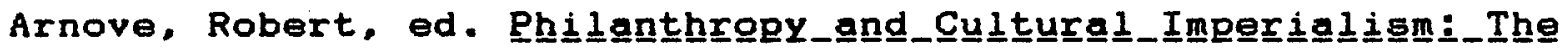


Eoung University Press. 1982.

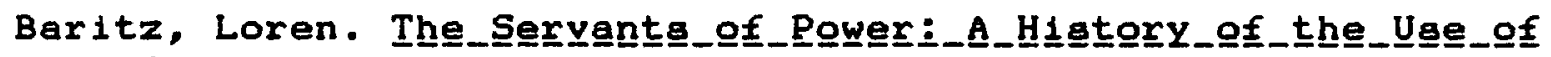
Socia﹎_Science_in_American_Indugtery. Westport, Conn .: Greenwood Press, 1960.

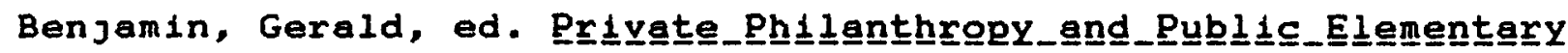

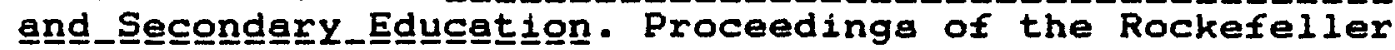
Archive Center Conference held on June 8, 1979. N. Tarrytown, N.Y: Rockefelier Archive Center Publication, 1980.

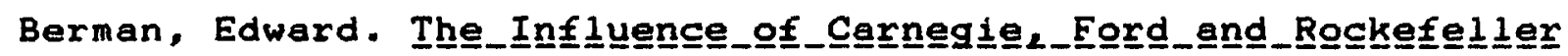
Foundationg_on_Ameri 1 can_Fon phlilanthropy. Albany: State University of New York, 1983 .

Berman, Edward. "The Extension of Ideology: Foundations Support for Intermediate Organizations and Forums." Comparaatyyㅡ

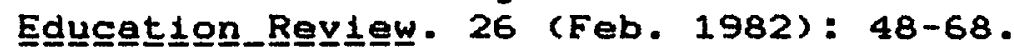

Berman, Edward. "Foundations, United States Foreign Policy and

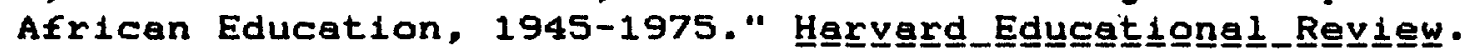
49, 2(May 1979): 145-88.

Bremner, Robert $H$. Americen_phillenthhropy. Chicago: Univeralty of Chicago Press, 1960 .

Carnegie, Andrew. The_Gogegl_of_weglth. New York: Century Co., 1900 .

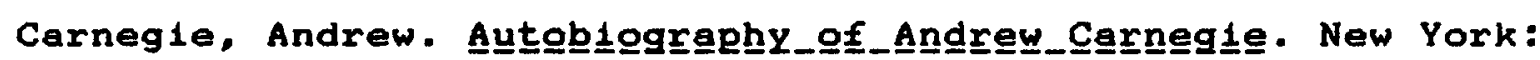
Doubledey, Page, 1909 .

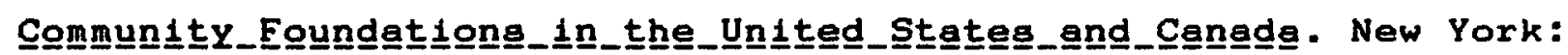
Council on Foundations, published annually.

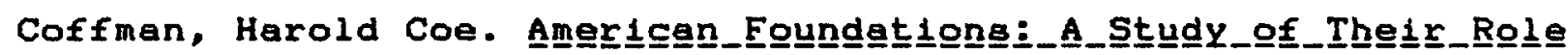

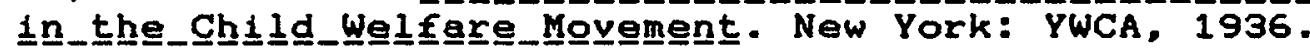

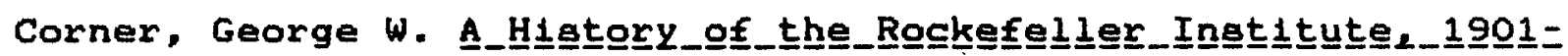

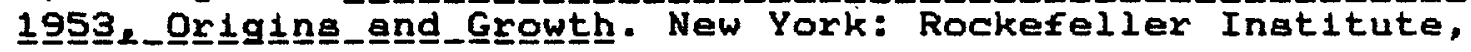
1964 .

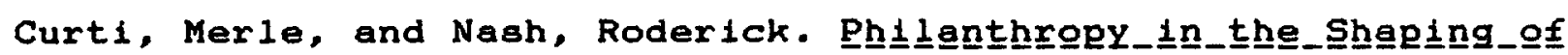

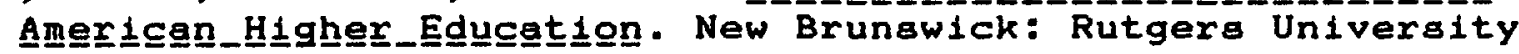
Press. 1965.

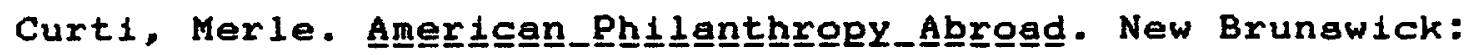
Rutgers University Press, 1963.

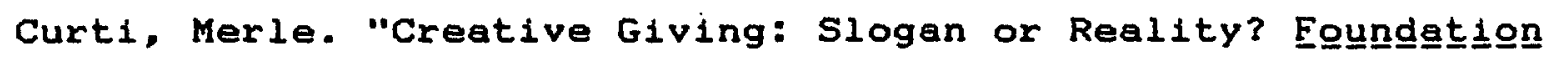


N토토. (Nov. 1962): 8 .

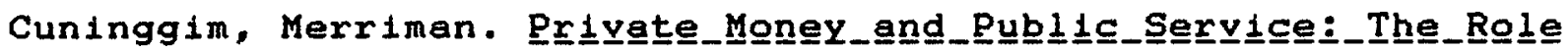

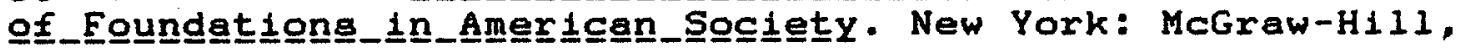
1972 .

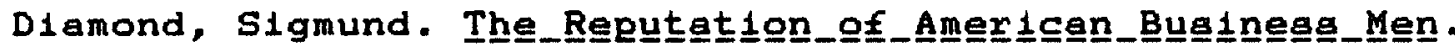
Cambridge, Mass.: Harvard University Preas, 1955.

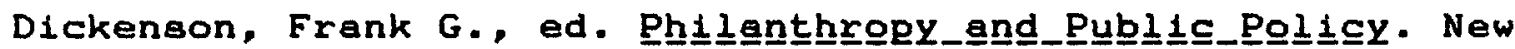
York: Columbia Univ. Press, 1962.

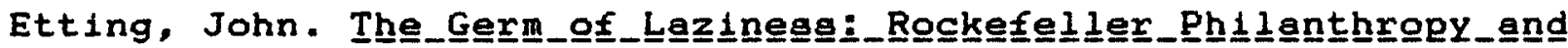
Publilic_Healthh_in_the_South. Cambridge, Mass.: Harvard Univerity Press, 1981 .

Faris, Ellsworth; Laune, Ferris; and Todd, Arthur J. Intêlılıgent Philenthreopy. Chicago: University of Chicago Press, 1930.

Fisher, Donald. "The Impact of American Foundations on the Development of British University Education." Ph.D. Thesis, University of California Berkeley, 1977.

Fisher, Donald. "The Rockefeller Foundation and the Development of Scientific Medicine in Great Britain." Minerve. XVI, $1(1978): 20-41$.

Fisher, Donald. "Rockefeller Philanthropy and the British Empire: The Creation of the London School of Hygiene and Tropical

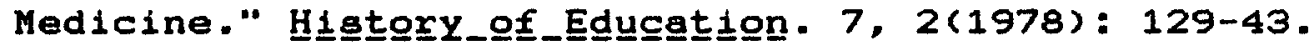

Fisher, Donald. "Amexican Philanthropy and the Soclal Sciencea in

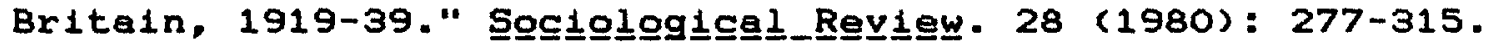

Fisher, Donald. "The Role of Philanthropic Foundations in the Reproduction and Production of Hegemony: Rockefeller Foundations and the Social Sciences." So으으loggy- 17 (1983): 206-33.

Fisher, Donald. "American Philanthropy and the Social Sciences: The Reproduction of Conservative Ideology." in Arnove,

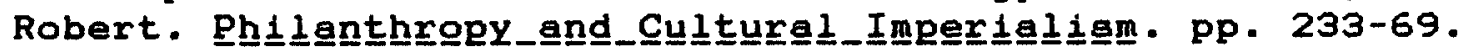

Fisher, Donald. "Rockefellex Foundation and the United States Social Science Research Council, 1923 to 1940." manuscript.

Flexner, Abraham. I_Remember. New York: Simon a Schuater, 1940.

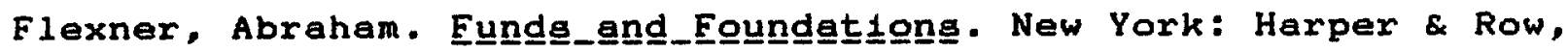
1952.

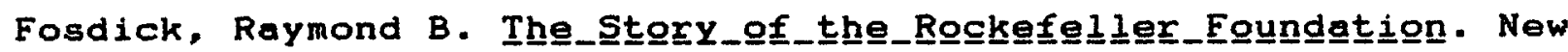


York: Harper \& Bro., 1952.

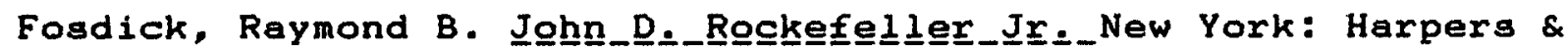
Bro., 1958.

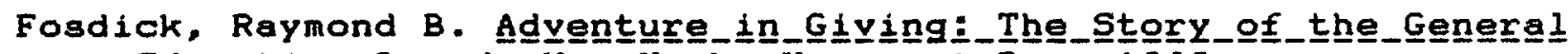

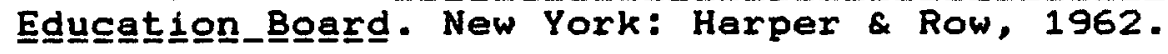

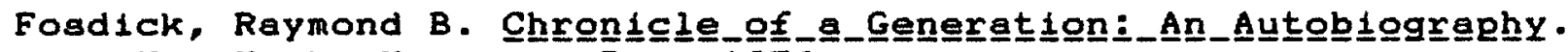
New York: Haxper \& Row. 1958.

Gates, Fraderick T. Chepters_in_My_Life. New York: Free Press, 1977.

Glenn, John; Brandt, Lillian; and Andrews, E. Emerson. Rugsegll Sege_Foundetㅡ을 $1907=1946$. vol 1. New York: Russell Sage Foundation, 1947 .

Goulden, Joseph G. The_e_Money_Gíverg. New York: Random House. 1971.

Geiger, Roger. "Voluntery Giving and the Reshaping of American Universities, 1900-1940." Paper presented at the History of Education Society Meetings, Chicago, Oct. 19-21, 1984.

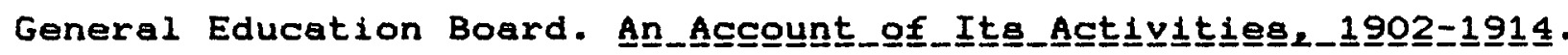
New York: GEB, 1915.

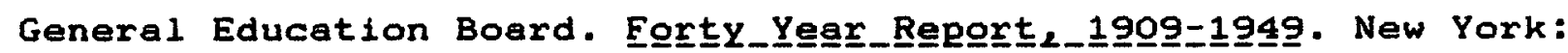
New York Foundation, 1949 .

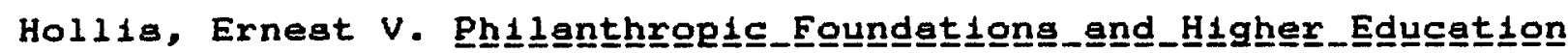
New York: Columbia Univeraity Press, 1938.

Howe, Barbara. "The Emergence of Scientific Philanthropy, 19001920, Origins, Issues, and Outcomes." in Arnove, Robert.

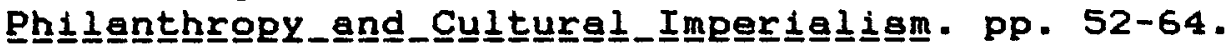

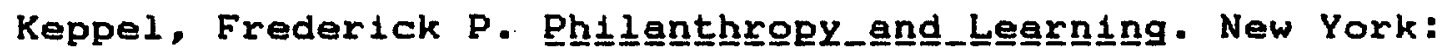
Columbia Univ. Press, 1936.

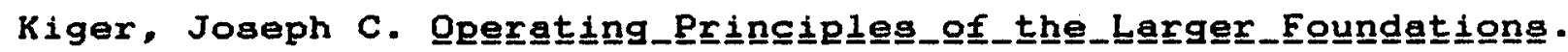
New York: Russell Sage Foundation, 1954.

Kirstein, George G. "Philanthropy, the Golden Crowbar." Ihㅡㄹ Nㅡ토스므. (Sept. 16, 1960): 239 .

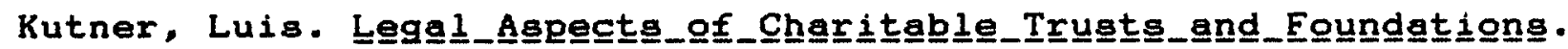
Chicago: Commerce Clearing House, 1970.

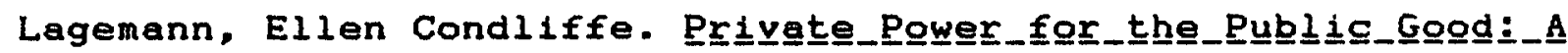

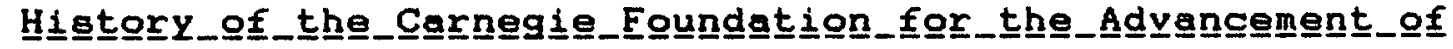


Teagchingng. Middletown, Conn.: Wesleyan Univ. Press, 1983.

Lagemann, Ellen Condliffe. "The Politics of Knowledge: The

Carnegie Corporation and the Formulation of Public Policy."

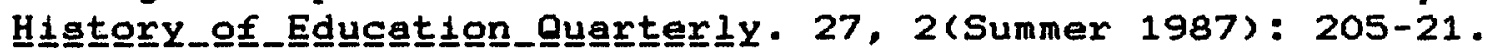

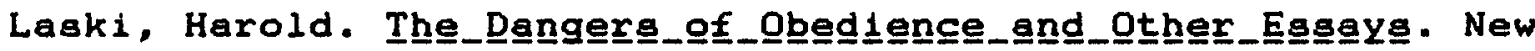
York: Herper \& Bro., 1930.

Lindeman, Eduard C. Weglth_and_Culㅡ느므. New York: Harcourt, Brace, 1936.

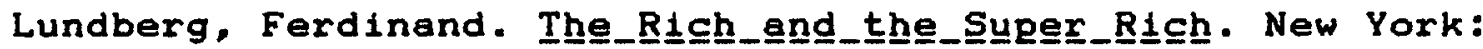
Bantam, 1968.

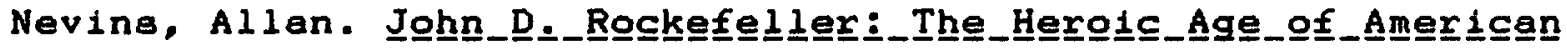
Entenerpxise. 2 vola. New York: Charles Scribner's Sons, 1940.

Nielsen, Waldemar A. The_B1g_Eoundetiong. New York: Columbia University Press, 1972.

Peterson, Peter. Chair of the Commisaion. Foundationgengeprivate

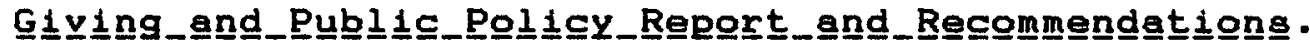

Chicago: University of Chicago, 1970.

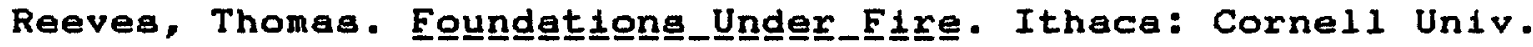
Press, 1970.

Reid, John G. "Health, Education, Economy: Philanthropic Foundations in the Atlantic Region in the $1920 \mathrm{~s}$ and 1930s."

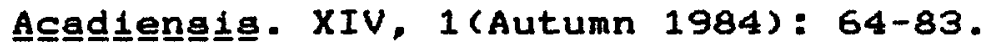

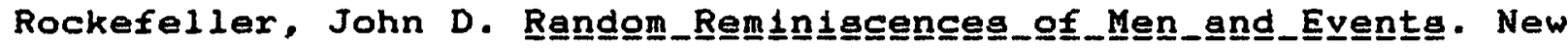
York: Doubleday, Page, 1909.

Rudy, William. The_Foundations:_Their__use_and_Abuse. Washington D.C.: Public Affairg Press, 1970.

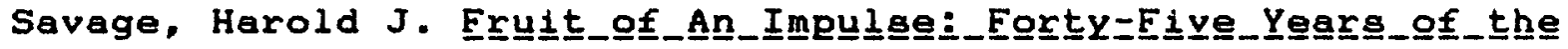

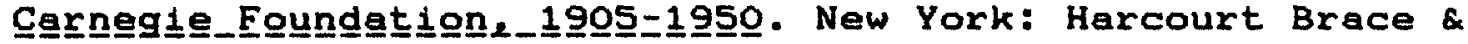
Co.. 1953 .

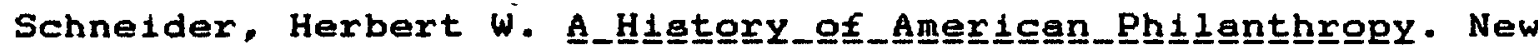
York: Columbia University Press, 1946.

Sears, Jesse Brundage. Phhil Education. Washington D.C.: Government Printing Office, 1922.

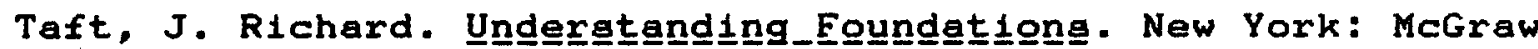
Hill, 1967. 


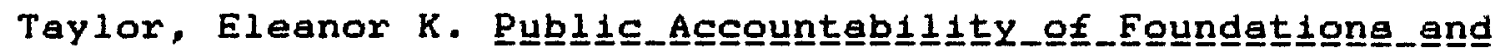

Char 1 table_Truagtg. New York: Russeli Sage Foundation, 1953 .

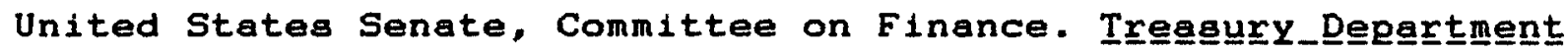

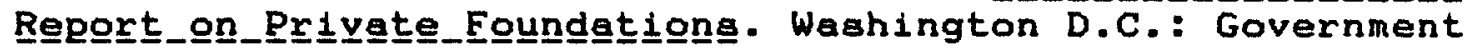
Printing office, 1965 .

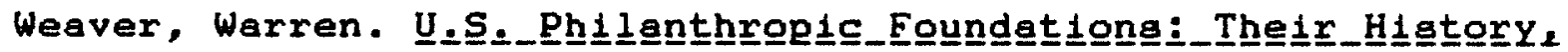
Stxㅡ느느늘﹎.Management_and_Record. New York: Harper \& Row. 1967 .

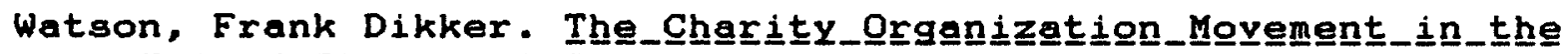

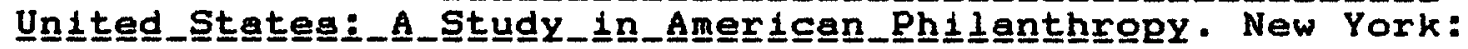
Mackilian, 1922 .

Whitaker, Ben. The_Eoung Bodíes. Revised edition. London: Penguin, 1979.

\section{General and Theoretical Worka:}

While childhood history has alowly gained credibility over the past twenty years little critical scholarly attention has been paid to the ldeological impact of the mental health movement. There is a paucity of work on mental hygiene organizations or research in either the United Statea or Canada. Similarly, the critical and authoritative study of philanthropy in the twentieth century while growing, is atill an underdeveloped area of research. In the absence of a body of secondary literature which crosses the questions asked in this study, the theoretical and conceptual perspectives necessary to put children, mental hygiene and philanthropy in perspective was gained from a variety of general works. Many of the monographs and articles cited from the $1960 \mathrm{~g}$ and $1970 \mathrm{~g}$ contributed to the opening up of research on topics such as children and philanthropy and public policy. The questions which guided this research and analysis were informed by issues raised by these scholars about authority, democratic atructurea and social change including the relationship between ideologies and elites. Some of the most fundamental contributions were provided by cultural and social histories of the United States and Canada. The sociology of knowledge provided a major theoretical orientation. Since part of the objective was to integrate levels of data and analysis I found authoritative diacuasions on hiatoriographical and methodological issues especially informative.

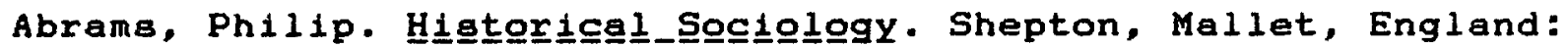
Open Books, 1982.

Allen, Richard. The_Social_Pagsion._Religioug_and_Social_Reform

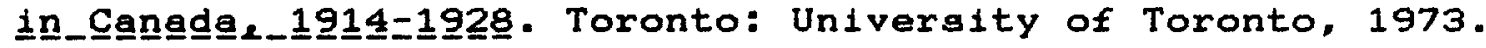


Axelrod, Paul. "Business Men and the Building of Canadian Universities: A Case Study." Canadilan_His흐or LXII, 2(June 1982): 19 .

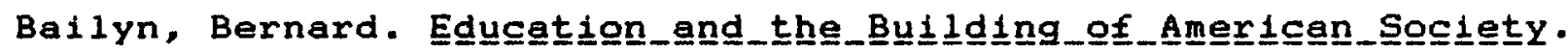
New York: $w . w$. Norton, 1960.

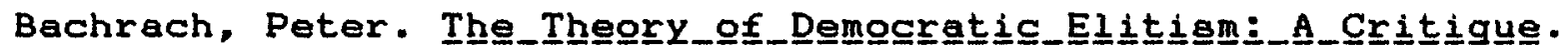
Boston: Little Brown, 1964.

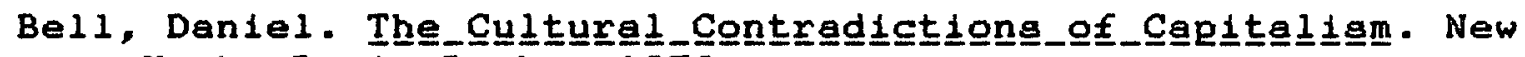
York: Basic Books, 1976.

Ben-David, Joseph, and Clark, Texry Nichols. Cيultuㅡㄹㅡ_eng-_It으

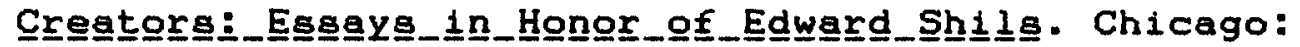
University of Chicago.

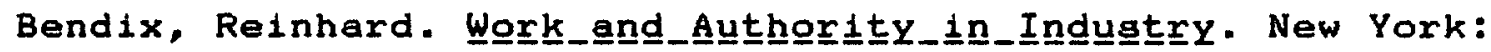
wiley, 1956, repring Berkeley: University of California Press, 1974.

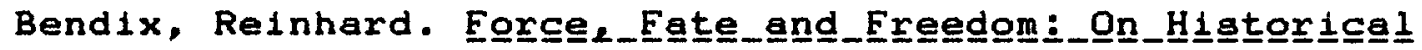
Socilology. Berkeley: University of California Press, 1984.

Bercuson, David J. Ego이므_and_wi one_Big_Union. Toronto: McGraw Hill Ryerson, 1978 .

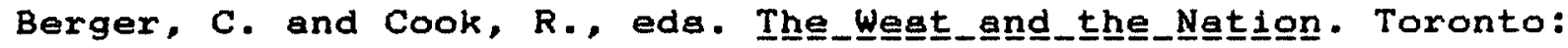
McClelland Stewart, 1976.

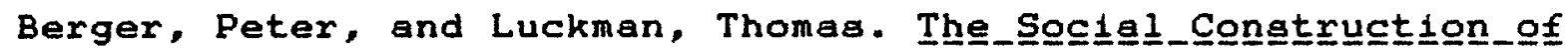

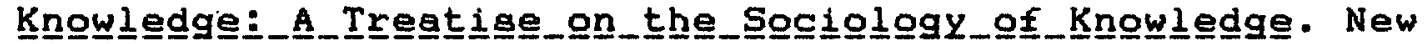
York: Doubleday, 1967.

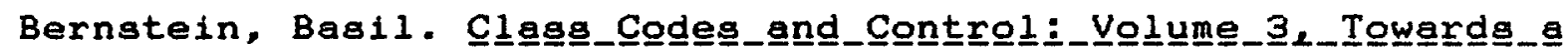

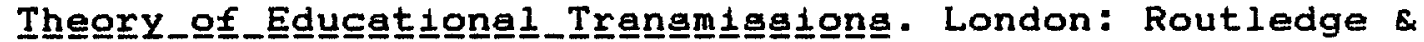
Kegan Paul. 1977.

Bernstein, Basil. "On Pedagogic Discourse." in Richardson, John

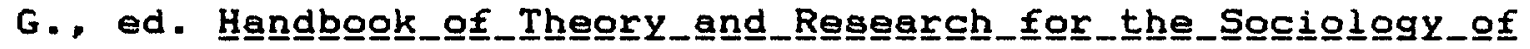
Educㅡ느으. Westport, Conn.: Greenwood Press, 1986, pp. $205-$ 40.

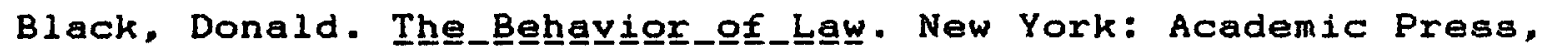
1976.

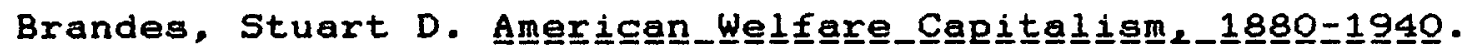
Chicago: Univeraity of Chicago, 1970.

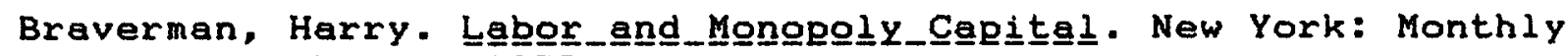
Review Press. 1975. 


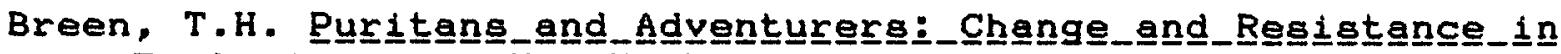

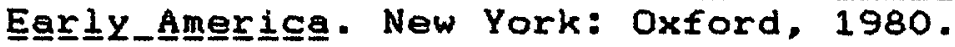

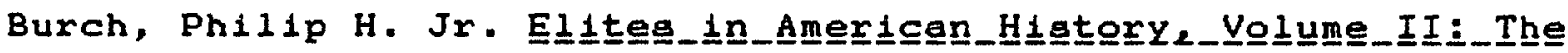

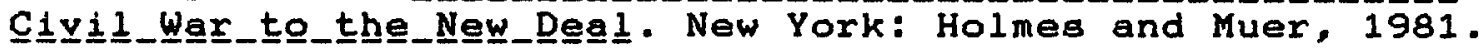

Clark, Burton R. Eduçating_thhe_Expent__Society. San Francisco: Chandler, 1962.

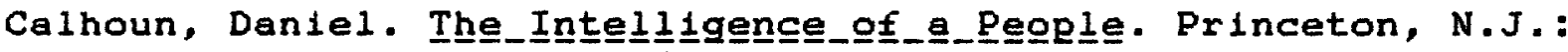
Princeton University Press, 1973.

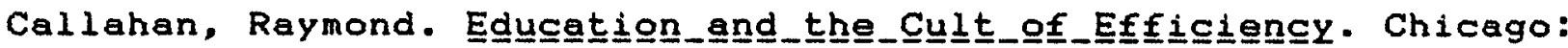
University of Chicago Press, 1962.

Careless, J.M.S. "Frontierism, Metropolitanism and Canadian

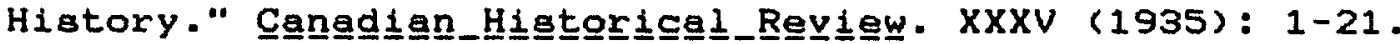

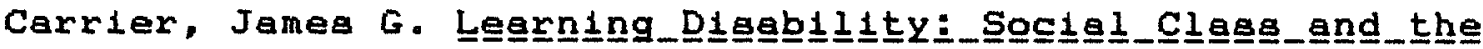

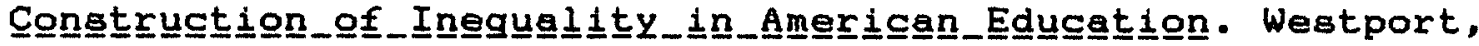
Conn.: Greenwood Press, 1986.

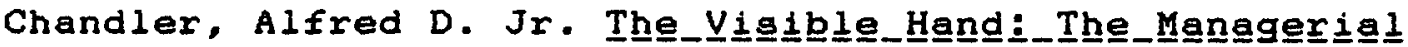

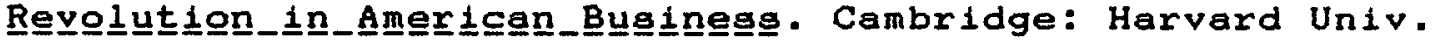
Press, 1977.

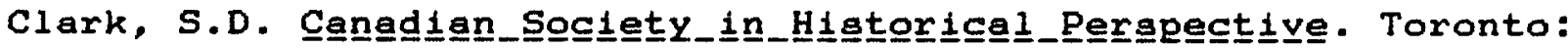
University of Toronto Press, 1976.

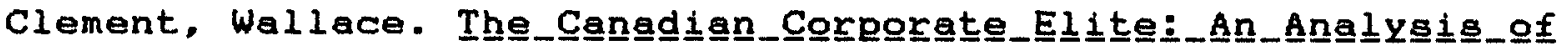
Economic_power. With a Foreward by John Porter. Toronto: McClelland \& Stewart, 1975.

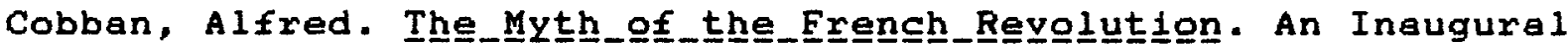
Lecture Presided Over By His Excellency The French Ambassador, University College, London, 6 May 1954. Arden Library London: H.K. Lewia Co. 1955, reprint 1978.

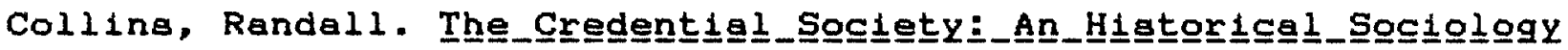

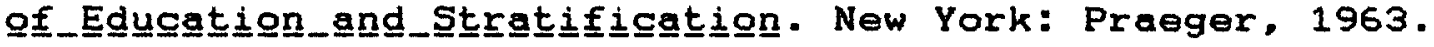

Conkin, Paul K. "Intellectual History." in Cartwright, William H., and Wataon, Richard $L$. Jr., eda. The_Reintererereteteton_of

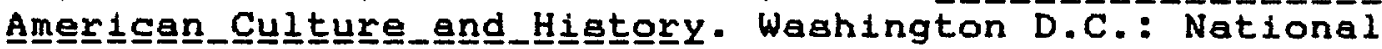
Council for Social Studies, 1973.

Coser, Lewis A. Men_of Free Press, 1965, reprint 1970.

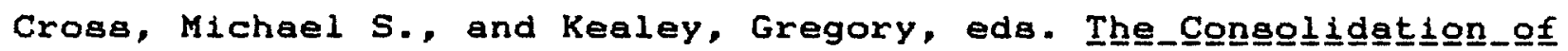

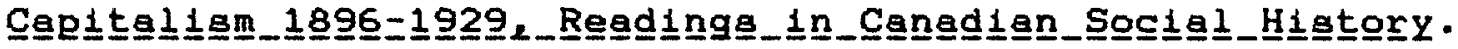


Toronto: McClelland Stewart, 1983.

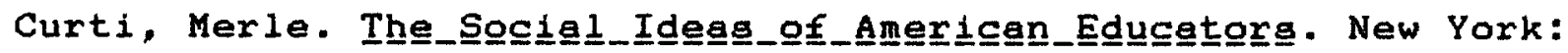
Charles Scribner's Sons, 1935, reprint Totowa, N.J.: Littlefield Adams, 1966.

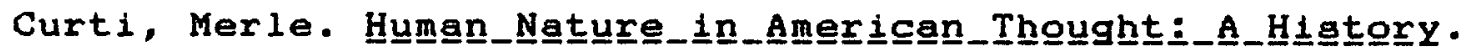
Madison: University of Wisconsin, 1980.

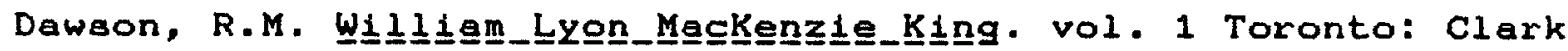
Unwin, 1943, reprint 1958 .

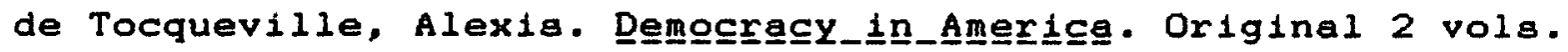
1835, 1840. Edited and Abridged by Richard D. Heffner. New American Library. New York: Mentor Books, 1956.

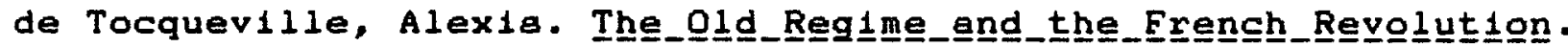
Original 1856. Transiated by Stuart Gilbert. New York:

Doubleday Anchor, 1955.

Digging, John Patrick. "The Soclalization of Authority and the

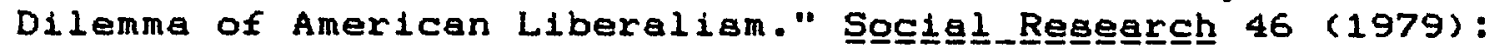
456-86.

Duby, Georges. The_Three_orderg:_Feudalal_Society_Imaginged. Translated by Arthur Goldhammer with a Foreward by Thomas N. Bisson. Chicago: University of Chicago, 1978.

Elias, Norbert. "Introduction: Soclology and History." in Ihe Courㅡ﹎.So도트y New York: Basil Blackwell, 1983.

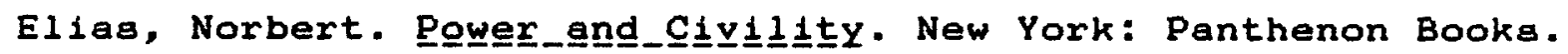
1982.

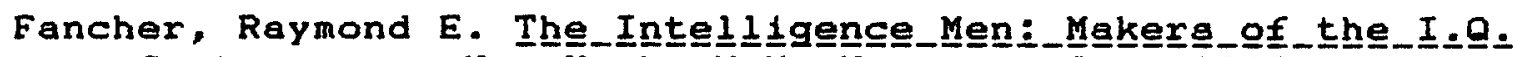
Contrrougergy. New York: w.W. Norton \& Co., 1985 .

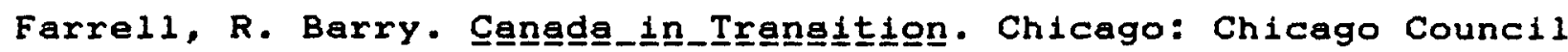
on Foreign Relations, 1984.

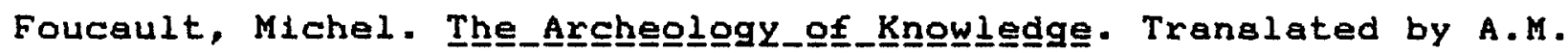
Sheridan Smith. London: Travistock, 1967, reprint 1982.

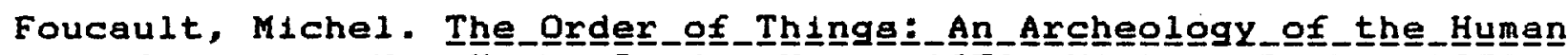
Scliencees. New York: Random House 1970, Vintage Books, 1973 .

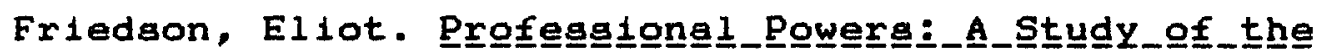

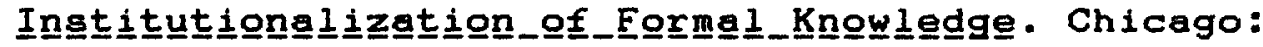
University of Chicago, 1986.

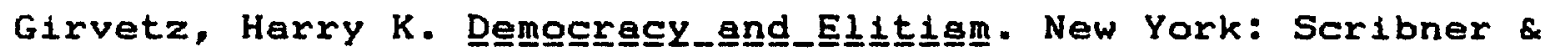
Sons, 1967. 


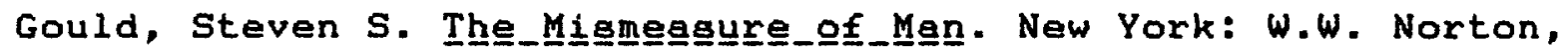
1981 .

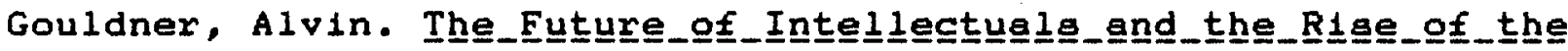
New_C lags.s. New York: Seabury, 1979 .

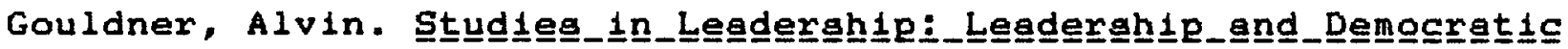
Actílon. New York: Russel1 Sage, 1965 .

Ha11, Peter Dobkins. The_organizention_of Amer

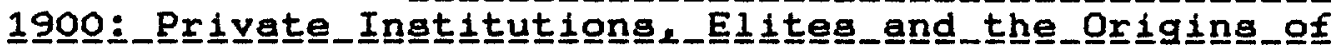

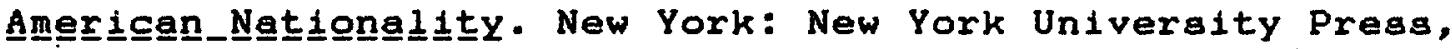
1982 .

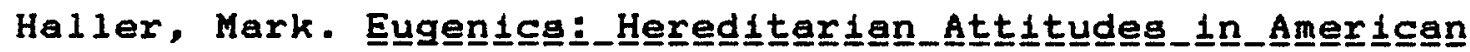

Thoughhㅡ. New Brunswick: Rutgers University Press, 1963.

Hareven, Tamara. "An Ambiguous Allience: Some Aspects of American Influences on Canadian Social Welfare." 보스느으므

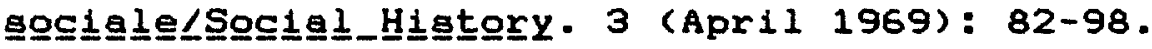

Hartz, Lou1s., ed. The트ogunding Harcourt Brace \& World, 1964.

Haya, Samuel P. Congervation_and_the_Gogpel_of_Efficienchcy:_The

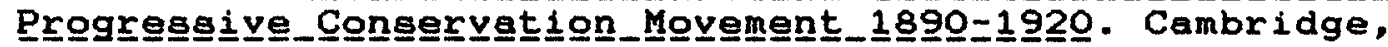
Mass.: Harvard University Press, 1959.

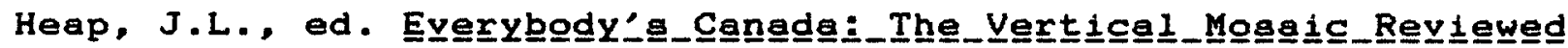
and_Re=examinged. Toronto: Burns and MacEachern, 1974.

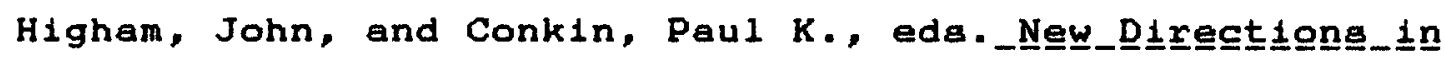

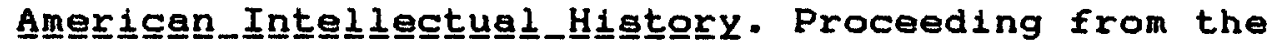
Wingapread Conference, Racine, Wisconsin, 1978. Baltimore: Johns Hopkins University Press, 1979.

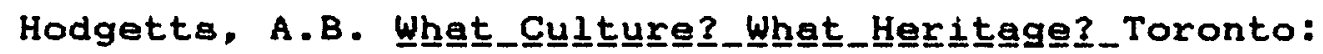
OISE/National History Project, 1968.

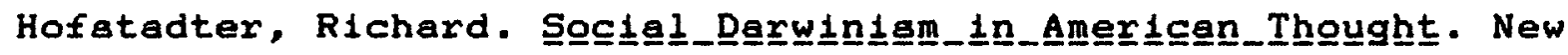
York: George Braziller, 1969.

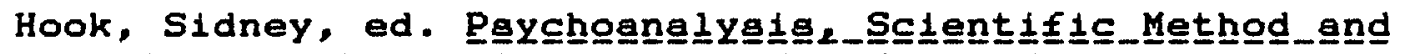

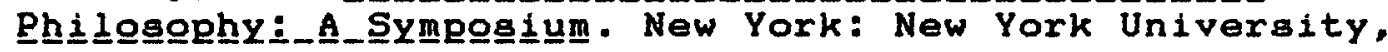
1959.

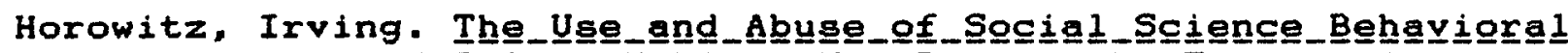
Regegarch_and_políly_Making. New Brunswick: Transaction Books, 1975. 


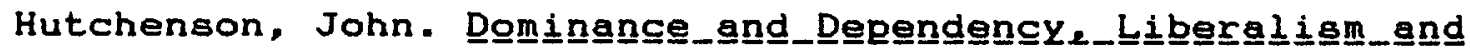
Nataiongl_Poli McClelland \& Stewart, 1978.

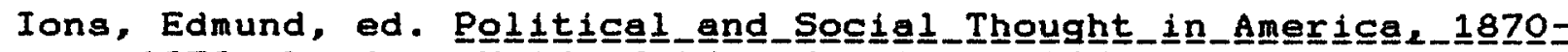
1979. London: Weidenfeld \& Nicolson, 1970 .

Karl, Barry D. "Philanthropy: Policy Planning and the Bureaucratization of the Democratic Ideal." Daegdelㅡㅁㅡ. 105 (1976): 129-49.

Katz, Michael B. "Origina of the Institutional State." Marx任

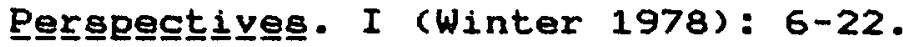

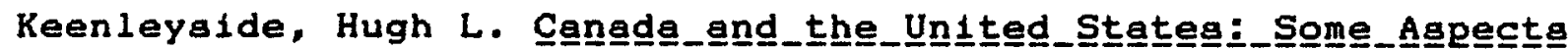

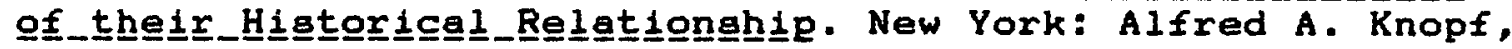
1929, revised and enlarged with Gerald S. Brown 1953.

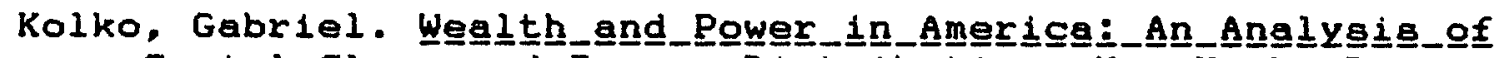

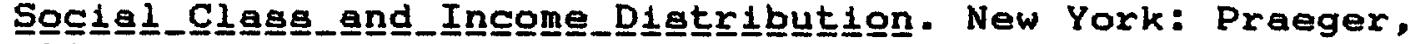
1964 .

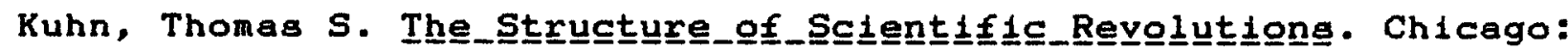
University of Chicago Press, 1962 .

Larson, Margli Sarfatt1. The_Rige_of_Profogegsionglisgm:_A

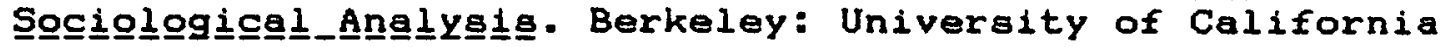
Press, 1977 .

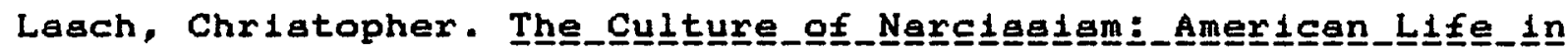

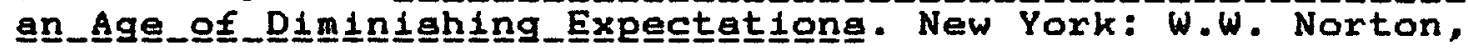
1979 .

Lindblom, Charles E., and Cohen, David K. Uge日eble_Knowledge,

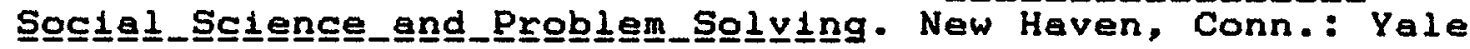
University Press, 1979.

Lichthe1m, George, The_Concept_of_Idegloggy_and_other_Ege日eyg. New York: Vintage Books, 1967.

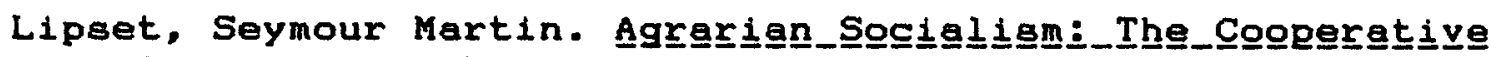

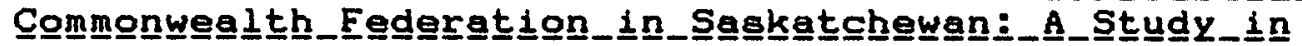

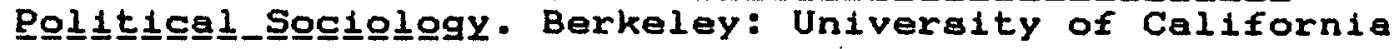
Press, 1950.

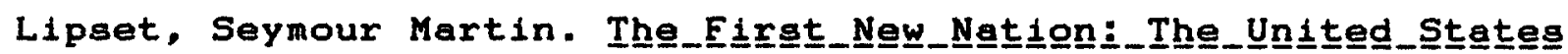

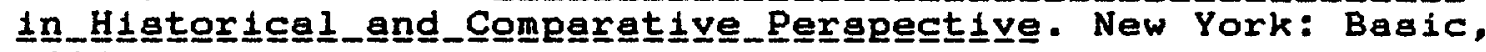
1963.

Lipset, Seymour Martin. "Canada and the United States: a

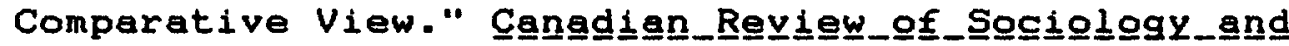

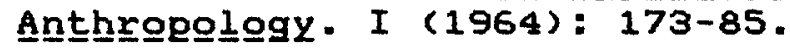


Lipset, Seymour Martin. "Historical Traditions and National Character: A Comparative Analysis of Canada and the United

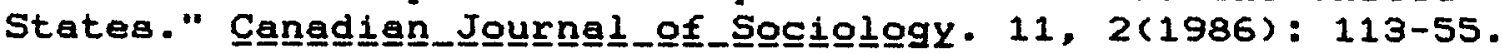

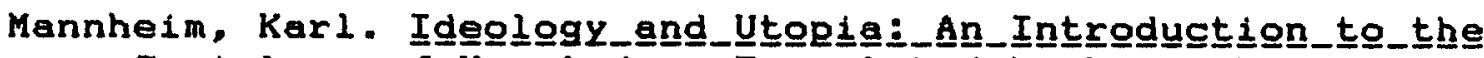
Sociㅇㅇ은 으_Knnowledge. Translated by Louis Wirth and Edward Shils. New York: Harcourt Brace Jovanovich, 1936.

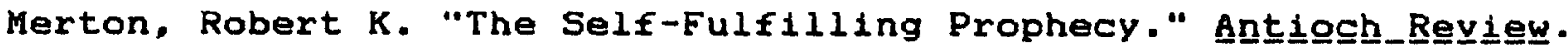
$8(1948): 193-210$.

Merton, Robert K. The_Soclology_of_Science: Theoretićal_and Emperícal_Inyegtigatílong. Edited by Norman $W$. Storer. Chicago: University of Chicago, 1974.

Morton, W.L. The Wisconsin, 1962, 2nd edition 1972.

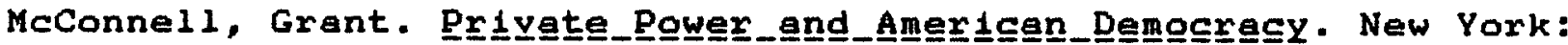
Alfred A. Knopf., 1966.

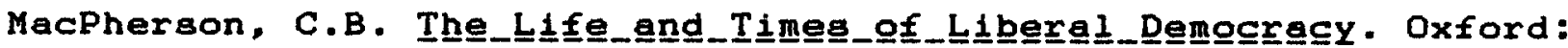
Oxford University Press, 1977.

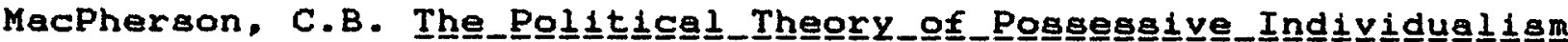
Hobblegs_to﹎Locke. Oxford: Oxford University Press, 1962.

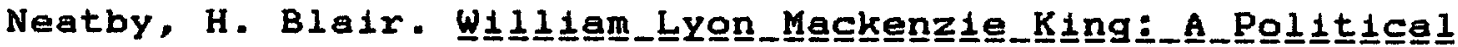
Bilogrephy. vol. 2. Toronto: University of Toronto, 1958 , reprint 1963.

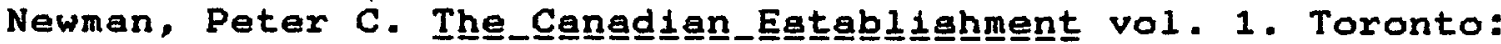
McClelland \& Stewart, 1975.

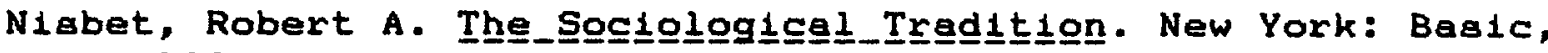
1966.

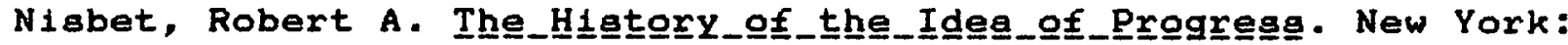
Basic, 1980.

Oleson, Alexandra., and Voss, John, eds. The_organiziztílon_of

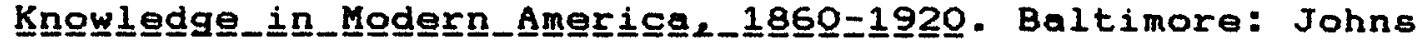
Hopking Univ. Press., 1979.

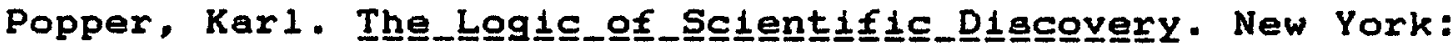
Torchbooks, 1934, reprint 1968 .

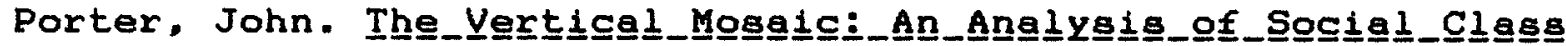
and_Power 1 므_Cengede. Toronto: University of Toronto, 1965 , reprint 1981 . 


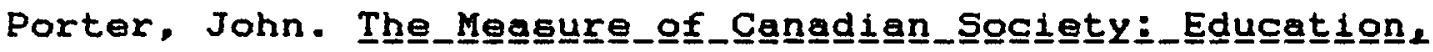

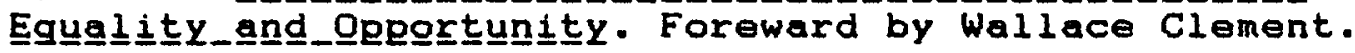
Toronto: Gage, 1979.

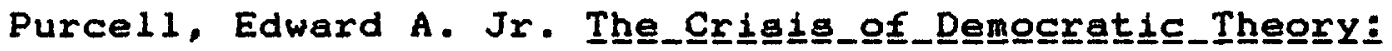

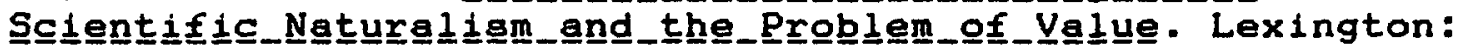
Univ. Press of Kentucky, 1973.

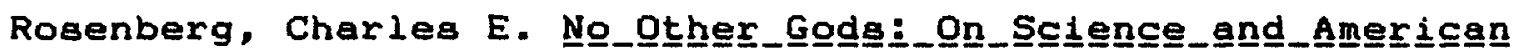
Sociㄹㄴ.Thought. Baltimore: Johns Hopkins Univ. Press, 1976.

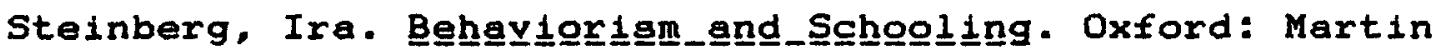
Robertson, 1980.

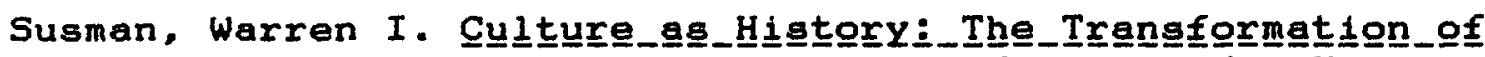
Americican_Socilety_in_the_Twentieth_c_entuuy. New York: Pantheon Books, 1974, reprint 1984 .

Toby, Ronald C. The_Amer 1930. Pittaburg: University of Pittsburg, 1971 .

Tylor, Peter $L$, and Bell, Leland V. Caring

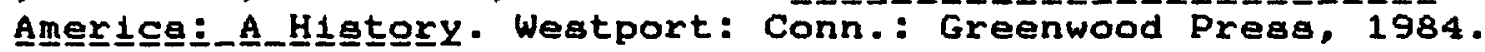

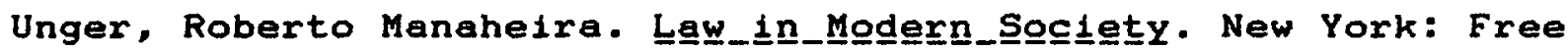
Press, 1976.

Urban, Wayne. "Some Historiographical Issues in Revisionist

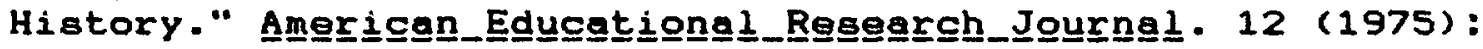
348-9.

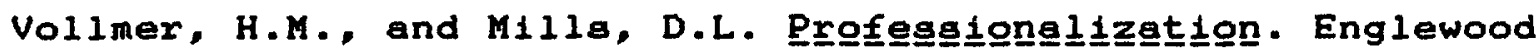
Cliffs, N.J.: Prentice Hall, 1966.

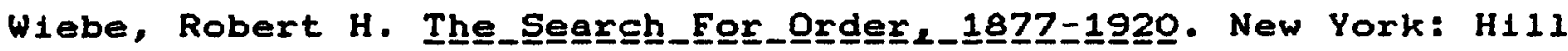
and Wang, 1967 .

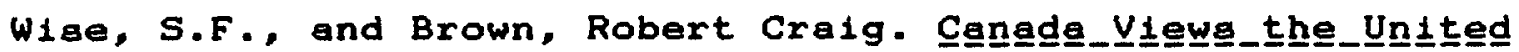

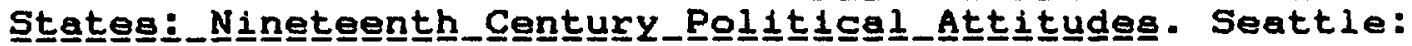
University of Washington Press, 1967.

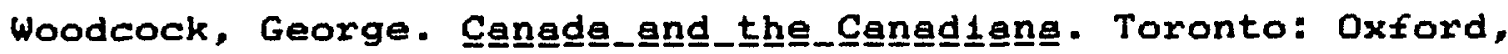
1970 .

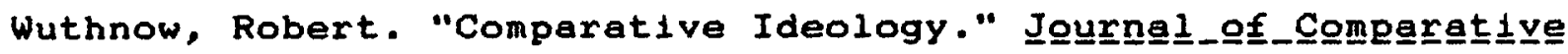
So오으으으. XXII, 3(1981): 121-40. 